\title{
Autoren in religiösen literarischen Texten der späthellenistischen und der frühkaiserzeitlichen Welt
}

\author{
Herausgegeben von \\ EVE-MARIE BECKER \\ und JÖRG RÜPKE
}

Culture, Religion, and Politics in the Greco-Roman World 3

Mohr Siebeck 


\title{
Culture, Religion, and Politics in the Greco-Roman World
}

\author{
Herausgeber
}

Kendra Eshleman (Boston College), Teresa Morgan (University of Oxford), Laura Nasrallah (Harvard University), Maren R. Niehoff (The Hebrew University of Jerusalem), and Peter Van Nuffelen (Ghent University)

\section{Beirat}

Milette Gaifman (Yale University), Martha Himmelfarb (Princeton University), Hayim Lapin (University of Maryland), Duncan MacRae (University of California, Berkeley), Jörg Rüpke (Universität Erfurt), Lieve Van Hoof (Ghent University) 



\title{
Autoren in religiösen \\ literarischen Texten \\ der späthellenistischen und \\ der frühkaiserzeitlichen Welt
}

\author{
Zwölf Fallstudien
}

herausgegeben von

Eve-Marie Becker und Jörg Rüpke

Mohr Siebeck 
Eve-Marie Becker, geboren 1972; 2006-18 Professorin für neutestamentliche Exegese an der Universität Aarhus, Dänemark; 2014 Research Fellow am Max-Weber-Kolleg in Erfurt; 2016-17 Distinguished Visiting Professor of New Testament an der Candler School of Theology, Emory University Atlanta, USA; 2017-18 Research Fellow am Israel Institute for Advanced Studies in Jerusalem, Israel; seit 2018 Professorin für Neues Testament an der Universität Münster. orcid.org/0000-0002-0398-6448

Jörg Rüpke, ist Fellow für Religionswissenschaft und stellvertretender Direktor des MaxWeber-Kollegs für kultur- und sozialwissenschaftliche Studien der Universität Erfurt. orcid.org/0000-0002-4173-9587

ISBN 978-3-16-156111-5 / eISBN 978-3-16-156138-2

DOI 10.1628/978-3-16-156138-2

ISSN 2510-0785 / eISSN 2568-6623

(Culture, Religion, and Politics in the Greco-Roman World)

Die Deutsche Nationalbibliothek verzeichnet diese Publikation in der Deutschen Nationalbibliographie; detaillierte bibliographische Daten sind im Internet über bttp://dnb.dnb.de abrufbar.

(C) 2018 Mohr Siebeck Tübingen. www.mohrsiebeck.com

Das Werk einschließlich aller seiner Teile ist urheberrechtlich geschützt. Jede Verwertung außerhalb der engen Grenzen des Urheberrechtsgesetzes ist ohne Zustimmung des Verlags unzulässig und strafbar. Das gilt insbesondere für die Verbreitung, Vervielfältigung, Übersetzung und die Einspeicherung und Verarbeitung in elektronischen Systemen.

Das Buch wurde von Martin Fischer in Tübingen gesetzt, von Gulde Druck in Tübingen auf alterungsbeständiges Werkdruckpapier gedruckt und von der Buchbinderei Spinner in Ottersweier gebunden.

Printed in Germany. 


\section{Inhaltsverzeichnis}

Eve-Marie Becker und Jörg Rüpke

Autor, Autorschaft und Autorrolle in religiösen literarischen Texten.

Zur Betrachtung antiker Autorkonzeptionen - zugleich eine Einleitung

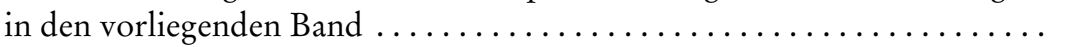

Oda Wischmeyer

Jesus ben Sira als erster frühjüdischer Autor $\ldots \ldots \ldots \ldots \ldots \ldots \ldots \ldots$

Gesine Manuwald

Die ,religiöse Stimme ${ }^{\prime}$ Ciceros . . . . . . . . . . . . . . . . . 39

Ulrike Egelhaaf-Gaiser

Im Schutz der Musen und des Bacchus. Die biographische Gottesnähe

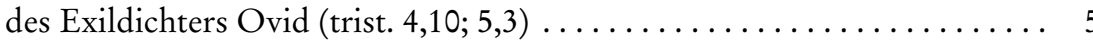

Maren R. Nieboff

Philo and Josephus fashion themselves as religious Authors in Rome ....

Eve-Marie Becker

Paulus als doulos in Röm 1,1 und Phil 1,1.

Die epistolare Selbstbezeichnung als Argument ................ 105

Jan Willem van Henten

Josephus as Narrator . . . . . . . . . . . . . . . . . . . . . . . 12

Jan Dochhorn

Die Konstruktion von Autorschaft in der Apokalypse - mit einem

Seitenblick auf das Corpus Johanneum . . . . . . . . . . . . . . . . 151

Jörg Rüpke

Der Hirte des Hermas: Autorenprofil und Textstrategien eines Visionärs des zweiten Jahrhunderts n. Chr. . . . . . . . . . . . . . . . . . . . . . . . . . 181 


\section{Georgia Petridon}

The curios case of Aelius Aristides. The Author as sufferer and illness as individualizing motif

Dorothee Elm von der Osten

Die Masken des Lukian. Auf der Suche nach der (religiösen) Stimme des Autors

Markus Vinzent

Tertullian. The Rhetor's Voice in his Prefaces

Barbara Aland

Der gnostische Mythos, seine Vorlagen und seine Wirkungen.

Autorkonzepte in Beziehung

Stellenregister

Sach-, Personen und Ortsregister 


\title{
Autor, Autorschaft und Autorrolle in religiösen literarischen Texten
}

\author{
Zur Betrachtung antiker Autorkonzeptionen - zugleich \\ eine Einleitung in den vorliegenden Band
}

\section{Eve-Marie Becker und Jörg Rüpke}

\section{Die „Rückkehr des Autors“ und ihre Folgen für die Frage nach der Autorschaft in antiken religiösen Texten}

In den textbasierten Altertumswissenschaften, also in Klassischer Philologie, Religionsgeschichte, Alter Geschichte und Ancient Judaism und den ihr benachbarten theologischen Teildisziplinen - hier besonders der neutestamentlichen Wissenschaft und der älteren Kirchengeschichte - hat die zunächst literaturwissenschaftlich getragene Autorforschung mit ihrem Interesse an der „Rückkehr des Autors " 1 in jüngster Zeit vermehrt an Bedeutung gewonnen. ${ }^{2}$ Während die Literaturwissenschaft Autorforschung wesentlich im Sinne der Autorschaftstheoriebildung betreibt, geht es den auf die Interpretation literarischer Texte aus der antiken Welt bezogenen Fächern vor allem darum, antike Texte in ihrer Bindung an Autoren und Autorkonzepte zu sehen und die „authorial voices“ als Konstituenten der Textinterpretation zu würdigen.

Hinter dem Interesse an Konzeptionen von Autorschaft steht die Einsicht, dass eminente Texte der antiken literarischen kanones durch ihre Verfasser, die auctores, nicht nur historisch und literarisch „autorisiert“ sind, $^{3}$ sondern dass das jeweilige Konzept von Autorschaft auf die Produktion und Rezeption eines Textes direkt einwirkt. Die Autorschaft ist somit nicht allein in Hinsicht auf die Untersuchung von literarischen Autorisierungsstrategien ein wichtiger Faktor. Vielmehr wirkt die Autorkonzeption - ähnlich dem literarischen Genre - als

\footnotetext{
${ }^{1}$ Vgl. dazu verschiedene Beiträge, in: Jannidis et al. (Hgg.) 1999; Jannidis et al. (Hgg.) 2000; Detering (Hg.) 2002; Schaffrick/Willand (Hgg.) 2014.

${ }^{2}$ Vgl. dazu verschiedene Beiträge, in: Taub/Doody (edd.) 2009; Marmodoro/Hill (edd.) 2013; Becker / Pilhofer (Hgg.) 2005/2009; vgl. auch: Becker/Mortensen (edd.) 2018.

${ }^{3}$ Vgl. Becker/Scholz (Hgg.) 2012; Plotke 2012.
} 
eine Art template, das literarische Texte generiert, stilisiert und typologisiert. ${ }^{4}$ Autor, Genre und Leser bzw. Textproduktion, Textform und -gattung und Textrezeption bis hin zur Kanonisierungsgeschichte stehen dabei in einem produktiven Wechselverhältnis. ${ }^{5}$ Der vorliegende Band fokussiert auf literarische Texte, die wir dem weiteren Bereich der religiösen Literatur zuordnen.

Die Betrachtung von Autorkonzeptionen führt über die Frage hinaus, ob und wann wir es bei antiken Texten und Textsammlungen, so etwa im Corpus Paulinum, mit historischen, also authentischen Autorenpersonen oder aber mit Pseudepigraphie, Allonymität, Pseudonymität und Autorfiktion zu tun haben. ${ }^{6}$ In jedem Fall erlaubt die Betrachtung von Autorkonzeptionen den Blick auf das fashioning, die Selbststilisierung eines realen oder eines fiktiven Autors. Die Autorforschung ermöglicht Einblicke in die verschiedenen Autorrollen und die vielen Stimmen (many voices), die ein Verfasser wählt und zum Zwecke der Autorisierung und literarischen Gestaltung seines Schreibens und seiner Person zum Einsatz bringt.

Autorkonzeptionen erweisen sich in diesem Zusammenhang keineswegs als starre oder erstarrte Formate, die kategorisierbar oder systematisierbar wären, sondern sind in ihrer Rückbindung an historisch-reale oder fiktionale Autoren-Personen stetem Wandel und dauernder Veränderung unterworfen. Insofern machen Autorkonzepte ein erhebliches produktives literarisches Potential in der Literaturgeschichte aus: Sie sind ein wesentlicher Faktor der Textproduktion ${ }^{7}-$ das trifft längst nicht nur auf die moderne, sondern bereits auf die antike Literatur zu. Und das gilt - wie dieser Band zeigt - einmal mehr für den Bereich der religiösen Literatur. Die Erforschung von Autorkonzeptionen ist daher auch für die (antike) Religionsgeschichte von erheblicher Bedeutung. Der vorliegende Band leistet mit seinen insgesamt zwölf Fallstudien, die in zeitlicher Erstreckung von Ben Sira im Übergang vom dritten zum zweiten Jahrhundert v. Chr. bis zu den frühchristlichen gnostischen Autoren des zweiten und dritten Jahrhunderts n. Chr. reichen, demnach einen wichtigen Beitrag zur Verbindung literatur- und religionsgeschichtlicher Perspektiven bei der Interpretation antiker Textwelten.

Aus der Sicht der antiken Literaturgeschichte, die in allen Texten, die über eine reine Alltagskommunikation hinausreichen, „literarische Texte“ erkennt, ermöglicht die Autorforschung die Betrachtung individueller Autoren-Personen. Ein Autor ist von seinem je eigenen biographischen und sozio-kulturellen Herkommen geprägt. In autobiographischen oder autobiographisch geprägten Texten wird die individuelle Rolle des Autors bei der Gestaltung seiner Literatur am deutlichsten greifbar. Auch das Element der Autofiktionalität weist auf den Umstand hin, dass antike Literatur von individuellen Autoren-Personen - seien

\footnotetext{
${ }^{4}$ Dazu die oft auf Gattungen bezogenen Beiträge in Marmodoro/Hill (edd.) 2013.

${ }^{5}$ Vgl. etwa Klausnitzer 2014.

${ }^{6}$ Vgl. dazu: Frey et al. (edd.) 2009; speziell: Aune 2009.

${ }^{7}$ Vgl. dazu Becker 2014.
} 
sie historisch real oder literarisch fiktiv und seien sie explizit als Verfasser oder implizit als Erzähler greifbar - getragen, verantwortet und legitimiert wird.

Der individuelle Autor zeichnet sich dadurch aus, dass er bei seiner Textgestaltung literarische Formen und Stilelemente weiterentwickelt, geschichtliche, philosophische, ethische oder religiöse Themen und Diskurse definiert und Raum und Zeit dabei inszeniert oder deutet. Als Textproduzent übernimmt der Autor verschiedene Funktionen: Er agiert als Tradent von bestehenden Überlieferungen sowie als deren Interpret, Hermeneut und Entwickler. Als individuelle Schreiber-Person ${ }^{8}$ tritt der Autor in einen produktiven Wettstreit mit vorausgehenden und zeitgenössischen Autoren, die er nicht nur zu imitieren (mimesis), sondern auch zu überbieten (aemulatio) sucht. Als Person seiner Zeit kann der Autor im reflektierenden Rückblick auf die ihm vorausgehende Geschichte arbeiten und sich dabei selbst inszenieren. Die auf ihn folgende Geschichte ist soweit in seinem Blick, wie er die Nachwelt mehr oder weniger explizit zu adressieren sucht. Den Einfluss auf die lesende Nachwelt kann der Autor in verschiedener Hinsicht zu sichern versuchen. Dabei haben die selbst-autorisierende Rolle als „Autor“ (anctor) und der literarische Gestus, mit dem der Autor Normativität bei seinem Schreiben beansprucht, ebenso Bedeutung wie der Gegenstand und Inhalt seines Werkes: So wie sich die vom Autor gewählte Darstellung und Deutung von Themen der Vergangenheit besonders an dessen moralischer und literarischer Qualität bemessen lässt, unterliegt auch der visionäre oder prophetische Blick des Autors auf die ihm noch entzogene zukünftige Welt und Geschichte der kritischen Bewertung durch seine Leser. Das Konzept der Autorschaft ist dabei keine ahistorische Konstante. Worauf von antiken Verfassern zurückgegriffen wird, ist vielmehr eine Sprecherrolle, eine gesellschaftliche Position, die zunächst an der Performanz als Sänger oder vates oder Dramaturg (im Dramenwettbewerb) hängt und erst allmählich als eine Sprecherrolle in schriftlich verbreiteten Texten etabliert wird. In hellenistischer Zeit wird die Entwicklung von Sprecherrollen durch kritische Texteditionen, Authentizitätsdiskussionen und Autorenbiographien massiv verstärkt, ohne damit die ebenso weit verbreitete anonyme Textproduktion zu verdrängen.

Was verstehen wir unter „religiösen Texten“ - unter einer Sortierung von Texten mit Hilfe eines Begriffes, der in der Antike weder scharf ausgebildet war noch für eine solche Abgrenzung herangezogen wurde? Religiöse Kommunikation allgemein lässt sich zu Vergleichszwecken als eine riskante Kommunikation fassen, die situativ "nicht unbezweifelbar plausible Adressaten“, Götter, Verstorbene, Engel oder Dämonen, ja sogar machtvolle Objekte, einbezieht und nicht von allen Anwesenden als erfolgreich, angemessen oder sinnvoll beurteilt werden muss. ${ }^{9}$ Indem die Sprecher den Adressaten ihres Schreibens Handlungsmacht

\footnotetext{
${ }^{8}$ Vgl. zur Individualität von antiken Autoren: Becker 2017, $21 \mathrm{ff}$.

${ }^{9}$ Rüpke 2015.
} 
und Verantwortung (agency) zuschreiben, verstärken oder verringern sie ihre jeweils eigene. Das gilt auch dort, wo religiöse Kommunikation nicht mehr in rituellen Praktiken in Anwesenheit oder Beteiligung Dritter stattfindet, sondern schriftliche Formen annimmt und damit eine zeitlich wie räumlich zerdehnte Situation schafft, in der die menschliche Kommunikation nicht mehr durch die körperliche Präsenz der Sprecherin oder des Sprechers „autorisiert“ wird. Wo in anderen zerdehnten Kommunikationssituationen, Briefen etwa, Siegel oder begleitende Objekte für glaubwürdige Verweise auf Autoritäten hinter Texten (nicht notwendigerweise die realen Verfasser, aber die logischen Veranlasser) sorgen, greifen andere Sprecher, die sich nicht formalisierter Herrschaftsrollen bedienen können, auf eine Sonderform religiöser Kommunikation zurück. Schon in der Situation wechselseitiger Präsenz richtet sich inspirierte Rede formal nicht mehr an göttliche Adressaten, sondern realisiert deren Präsenz im eigenen Sprechen, das sich nun an menschliche Anwesende als Adressaten richtet.

Diese Form inspirierter Rede, die auch einen Gott zu Wort kommen lässt, steht in Griechenland am Anfang „auktorialen“ Sprechens im anfänglich skizzierten Sinn. Sie beginnt mit Hesiod im späten achten Jahrhundert v. Chr. und steht damit zeitlich parallel zu ähnlichen literarischen Formen in hebräischer Literatur, die sich an mesopotamische wie ägyptische Phänomene anschließen lassen. ${ }^{10}$ Die genannte Form inspirierter Rede verbindet sich dabei mit Formen rhythmischer Gestaltung, die ebenso mündliche Rede wie nicht-alltägliches Sprechen und insbesondere Gesang signalisieren. In dieser Verbindung bleibt inspirierte dichterische Rede in griechischen und lateinischen Texten bis an den Ausgang der Antike und darüber hinaus erhalten. Trotz aller literarischen Standardisierung wird der religiöse Charakter immer wieder, und insbesondere in der römischen Rezeption als vates, ${ }^{11}$ erkennbar. Daraus wird ersichtlich, dass die Klassifizierung als „religiöser Text" vor allem eine rezeptionsgeschichtliche Dimension hat und eine Interpretationsgeschichte voraussetzt, in der seit der Spätantike zentrale religiöse Sprachfiguren als „Kultur“ und „Literatur“, und nicht mehr als „Religion“ klassifiziert wurden. Diese Trennungen sind im vorliegenden Band programmatisch aufgehoben. ${ }^{12}$

Die Sprachform der Prosa macht deutlich, dass in den sie verwendenden Texten andere Strategien auktorialer Beglaubigung dominieren. Ganze Gattungen gerade philosophischer und historiographischer Texte setzen sich im sechsten, fünften und folgenden Jahrhunderten v. Chr. von Redeformen ab, die als „mythologisch“ disqualifiziert werden und denen angeblich universal geltende Argumentation oder Autopsie entgegengestellt werden. ${ }^{13}$ Das schließt nicht aus, dass auch elaborierte schriftliche, ,literarische“ Texte Medien religiöser Kommu-

\footnotetext{
${ }^{10} \mathrm{Zu}$ den Phänomenen Stein 1990 (zu Griechenland); Weippert 1988.

${ }^{11}$ Newman 1969; Bendlin 2002.

${ }^{12} \mathrm{~S}$. den Beitrag von Egelhaaf-Gaiser im vorliegenden Band.

${ }^{13}$ Kurz Rüpke 2011, 15-26; zu historiographischen Strategien ausführlich Becker 2017.
} 
nikation werden können. Für den antiken Raum rund um das Mittelmeer sind hier verschiedene Entwicklungspfade neben Sammlungen poetischer Texte aus rituellen Kontexten - Hymnen, Psalmen - und wohl in kleinerem Kreise konsumierter Offenbarungserzählungen - zum Beispiel der Orphik - zu benennen. Prosaprophetie in der hebräischen Tradition scheint eine erhebliche Institutionalisierung der prophetischen Rolle, die auch den Verzicht auf rhythmisierte Sprache erlaubt, vorauszusetzen. Geographisch verbreitete Netzwerke können sich durch historiographische Schriften als religiöse Gruppen konstituieren, vielleicht ein Prozess, der im frühhellenistischen Judentum zum „biblischen Judentum“ (Kratz) führte. ${ }^{14}$ Etwa zeitgleich lässt sich in Griechenland und im zweiten und vor allem ersten Jahrhundert v. Chr. auch in Rom ein Prozess beobachten, in dem lokale religiöse Praktiken zum Gegenstand schriftlicher Darstellung und Systematisierung gemacht werden. ${ }^{15}$ Daneben treten Kommentierungen von Texten religiöser Inhalte, bei denen sich der Wert und das Ansehen des Kommentars und die Würde des kommentierten Textes wechselseitig konstituieren. Damit kommt es zu Kanonisierungsprozessen, deren Ergebnisse aus historischer Perspektive kontingent erscheinen, weil sie Texte sehr unterschiedlicher religiöser Dichte enthalten können.

In all diesen Fällen wird auch ohne oder weit über Kanones hinaus religiöses Wissen erzeugt, das mit pragmatischem Wissen, wie religiös zu kommunizieren, wie Rituale durchzuführen seien, konkurriert. Die Abgrenzung dieser Wissensbestände als „religiöse“ ist damit zeitgenössisch nur in bestimmten Konkurrenzsituationen, nicht aber grundsätzlich wichtig. „Literarische“ oder rhetorische oder auf einer anderen Ebene philosophische Qualitäten von Literatur spielen in ganz unterschiedlichen Rezeptionszusammenhängen eine Rolle. Damit ist auch die Unterscheidung etwa von „religiösen“ und „literarischen“ Texten letztlich eine Frage der jeweiligen (Rezeptions-)Perspektive. ${ }^{16}$

Die in diesem Band erprobte Autorforschung im Rahmen der Religionsgeschichte, die literarische Texte als "religiöse Texte“ wahrnimmt, ermöglicht wertvolle Einsichten in die Erzeugung von religiösem Wissen und in die individuelle literarische Tätigkeit von „religiösen “ Akteuren. ${ }^{17}$ In der (frühen) Kaiserzeit kommt es zu einer enormen Produktivität, die sich sowohl in einer intensivierten religiösen Kommunikation wie in zahllosen, oft kurzlebigen, aber eben auch langfristig erfolgreichen Gruppenbildungen niederschlägt. Gerade hier, wo Autoren vielfach auch als religiöse „(Klein-)Unternehmer" tätig waren, ist die Frage nach der literarischen Autorschaft von besonderer, auch sozio-politischer Bedeutung: Autorrollen unterstützen nämlich nicht nur das self-fashioning des Autors, sondern autorisieren unter Umständen seine Schrift(en) und seine Per-

\footnotetext{
${ }^{14}$ Siehe Kratz 2013.

${ }^{15}$ Für Rom Rüpke 2014.

${ }^{16}$ Exemplarisch dazu Feeney 1998, 2007a, 2007b.

${ }^{17}$ Vgl. zur Individualität im Bereich von Religionspraxis: Rüpke 2016.
} 
son als Schriftsteller (in leitender Funktion) und leiten dabei - mehr oder weniger intentional - die Prozesse der (Auto-)Kanonisierung literarisch-religiöser Texte ein. ${ }^{18}$

Religiöse Texte machen die Situation literarischer Autorschaft insofern komplizierter, als sie neben den oder dem menschlichen Textproduzenten gerade auch transzendenten Stimmen Platz einräumen. Gottheiten, Engel oder Gestalten der Unterwelt können als „eigentliche“ Autoren hinzutreten. Wenn solche Texte in einem rituellen Kontext zu Gehör gebracht werden, tritt eine weitere Sprecher-Rolle oder voice hinzu: ${ }^{19}$ die Rolle oder Stimme von rituellen Akteuren, seien es religiöse Interpreten oder auch Schauspieler. Bei der mündlichen performance der Texte mag es sich um Rezitationen in kleinen Gemeindeversammlungen oder in großen Auditorien vor offenem Publikum oder um das Verlesen und Interpretieren von Texten in geschlossenen Zirkeln handeln. Einige Autoren und Texte geben selbst Hinweise zu den intendierten Rezeptionsprozessen (vgl. etwa Apc Joh 1,1-8), d.h. zur adressierten audience (einzelne Personen oder Gruppen und Gemeinden: so Phil 1,1; Röm 1,1ff.) und den angestrebten Rezeptionsformen (Lesen, Hören; evtl. liturgische oder kultische Kontexte).

\section{Zum Forschungskontext und Aufriss des vorliegenden Bandes}

Die im vorliegenden Band gesammelten Beiträge resultieren aus einer interdisziplinären und internationalen Tagung zum Thema „Authorial voices“, die im Mai 2015 im Rahmen der von der DFG geförderten Kolleg-Forschergruppe „Religiöse Individualisierung in historischer Perspektive" des Max-Weber-Kollegs im Augustinerkloster in Erfurt stattgefunden hat und dankenswerterweise auch von der Fritz Thyssen-Stiftung und dem Aarhus Universitets Forskningsfond (AUFF) im Rahmen des „Homines novi“-Projektes gefördert worden ist. Den Beiträgen ist die Frage nach den Formen und der Veränderung von Autorkonzepten speziell in religiösen Texten griechisch-römischer, frühjüdischer und frühchristlicher Provenienz im antiken Mittelmeerraum gemein. Dabei spielen Vorstellungen von individueller Produktion und Verantwortung für literarische Texte und die Selbstinszenierung des Verfassers als orthonym, anonym oder pseudepigraph tätigem Autor, der sich zugleich als religiöser Akteur sieht, eine besondere Rolle. Was können wir über einen antiken literarisch wie religiös ambitionierten Autor und sein Selbstverständnis in Erfahrung bringen?

\footnotetext{
${ }^{18}$ Vgl. Becker 2012, $6 \mathrm{ff}$. sowie die Beiträge in Gordon, Petridou, Rüpke 2017.

${ }^{19}$ Vgl. Slater (ed.) 2017.
} 
Bei der Mehrheit der in diesem Band versammelten Beiträge haben wir es mit orthonym schreibenden Autoren zu tun: Über die biographische Identität des Ben Sira, Cicero, Ovid, Philo von Alexandria, Paulus von Tarsus, Flavius Josephus, Aelius Aristides, Lukian von Samosata und Tertullian bestehen keine Zweifel. Im Falle des Apokalyptikers "Johannes“ dauert die Diskussion über eine mögliche historische Autorschaft fort. Unter den Schriften sogenannter gnostischer Autoren dagegen finden sich kaum orthonym, sondern eher anonym oder pseudonym verfasste Texte. Doch gerade hier interagieren Autorrolle, genre und die religiöse Wirkabsicht des Schreibens produktiv. Der „Hirte des Hermas“ ist - als weitgehend anonym und sukzessiv verfasste Schrift - ein Beispiel für geteilte Textproduktion und womöglich die Modifikation von Texten und Verfasserangaben während des andauernd notwendigen $\mathrm{Ab}$ - und Fortschreibens von Texten und/oder während der Performanz solcher Texte.

In dieser vielfältigen Situation von Textproduktion und Textreproduktion, die für die Bildung und Entwicklung einer communal memory entscheidend sind, ${ }^{20}$ wird das explizite oder implizite Bild, das der Text oder der textimmanente antike Erzähler vom Autor entwerfen, selbst zu einer narrativen Strategie, dem Text religiöse Autorität und einen bestimmten literarischen Status zu verleihen: Dabei dient die religiöse Autorisierung der literarischen Stilisierung, und die literarische Stilisierung schärft umgekehrt die religiöse Profilierung. In rhetorisch-stilistischer Hinsicht erhalten die Verfasser daher letztlich eine große Bedeutung für die Wahrheits- und Relevanzansprüche des Textes. Im sozio-kulturellen Sinne wird der Textproduzent zu einem zentralen Akteur in der gesellschaftlichen Wirklichkeit. Ob als religiöser Spezialist oder gar als „,religious entrepreneur" mit einem Interesse an leadership, Gefolgschaft und Lebensunterhalt - betreten Autoren von religiösen Texten das weite Feld von religiösen Diskursen und religiösen Praktiken mit Hilfe literarischer (Selbst-)Inszenierung.

\section{Fragestellungen und Perspektivierungen der in diesem Band versammelten Fallstudien}

Der Band bietet insgesamt zwölf Fallstudien aus der griechischen und lateinischen Literatur, die für die späthellenistische und frühkaiserzeitliche Epoche Autorkonzepte und -profile in - und das ist der besondere Beitrag dieses Bandes in der laufenden Diskussion über "authorial voices“ - religiösen Texten unter der genannten Perspektive analysieren. Ein spezifisches Autorkonzept wurde den Beiträgern und Beiträgerinnen nicht vorgegeben. Vielmehr haben sich die einzelnen Textuntersuchungen an folgenden leitenden, induktiv ausgerichteten Fragestellungen orientiert:

${ }^{20}$ Vgl. dazu noch einmal verschiedene Beiträge in Slater (ed.) 2017. 
- Welche Elemente der literarischen Profilgebung begegnen in den untersuchten Texten?

- Welche Autorkonzepte, Autorrollen, Erzählerfiguren und -positionen werden dadurch im Bereich von religiöser Literatur geschaffen?

- Welcher literarischen Genres bedienen sich die jeweiligen Autoren?

- Stehen Autorkonzeption und literarisches Genre in einem erkennbaren inneren Zusammenhang?

- Findet die Autor-Profilierung innerhalb oder außerhalb (auto-) biographischer Texte beziehungsweise Textteile statt? Wann und warum kommen autofiktionale Elemente zum Einsatz?

- Welche erkennbaren oder verschleierten Intentionen verfolgen die Autoren mit ihrer jeweiligen (literarischen) Profilgebung?

- Geben die Autoren selbst Hinweise auf intendierte Rezeptionsprozesse, etwa Rezeptionsanweisungen - gibt es in einzelnen Texten gegebenenfalls selbst-kanonisierende literarische Elemente?

- Inwieweit tragen die Autoren zu den religiösen und literarischen Diskursen ihrer Zeit bei?

- Was bedeutet Orthonymität bei Ben Sira oder Paulus, und wieweit fallen Philo und Josephus mit ihrem persönlich verantworteten Schreiben literarisch und religiös aus der jüdischen Literatur des ersten Jahrhunderts n. Chr. heraus?

- Woran machen Zeitgenossen religiöse Innovation oder Devianz fest? Tragen Autorprofile und deren mögliche Imitierung zur „religiösen Individualisierung" in der späthellenistischen und frühkaiserzeitlichen antiken Welt bei? ${ }^{21}$

- Welche Rollenmodelle, welche Autoritätsrelationen bieten die religiösen Autoren in literarischen Texten an? Welche Rezeptionsformen und Institutionalisierungen nehmen sie in den Blick?

Der vorliegende Band greift die genannten Fragen in einer literatur- und religionsgeschichtlichen Breite auf, die zeitlich bei dem ersten bekannten frühjüdischen "Autor" (Ben Sira) einsetzt und bis zum Ende des zweiten beziehungsweise bis zum Beginn des dritten Jahrhunderts n. Chr., bis zu Tertullian, reicht und darüber hinaus noch gnostische Autoren des vierten Jahrhunderts n. Chr. miteinbezieht. Die Fallstudien sind räumlich weitgehend auf das Imperium Romanum bezogen. Der Band konzentriert sich auf jene Sprachen und Sprachtraditionen (Griechisch, Latein, mit vereinzelten Seitenblicken auf hebräische und syrische Texttraditionen), die in großem Umfang den Austausch von literarischen Modellen, Institutionen literarischer Kommunikation und schließlich auch - durch Zweisprachigkeit, vor allem aber zahllose Übersetzungen - den Austausch von Textinhalten ermöglichten.

${ }^{21}$ Vgl. auch Rüpke 2013. 
Die hier versammelten Beiträge beschäftigen sich (a) mit grundlegenden Fragestellungen zum kultur- und ideengeschichtlichen Kontext der antiken Autoren und der Autorkonzeptionen. ${ }^{22}$

- Wieweit ist das Autorkonzept ein grundsätzlicher und konstitutiver Teil der griechischen und der lateinischen Kultur- und Literaturgeschichte?

- Wieweit und in welchen kulturellen Zusammenhängen wird dieses Autorkonzept von jüdischen Schriftstellern - jedenfalls bis Flavius Josephus - übernommen, entwickelt und reflektiert?

- Weshalb fehlen Lateinisch schreibende jüdische Literaten?

- Wann und unter welchen Bedingungen verbinden sich aus der Literaturgeschichte übernommene Autor-Konzeptionen in der frühkaiserzeitlichen Welt mit einem dezidiert christlichen Profil?

Die Beiträge bieten (b) konkrete Textinterpretationen unter den oben genannten, induktiv ausgerichteten Frageperspektiven. In der Zusammenschau der hier versammelten Beiträge werden auch komparative Zugänge zu der literaturgeschichtlichen Positionierung eines Autors, der Frage der Textfunktion, der literaturgeschichtlichen Bewertung eines Autors als eher traditionell oder innovativ sowie seiner diskurs- und institutionengeschichtlichen Stellung in den religiösen Transformationsprozessen - besonders in der frühen Kaiserzeit - geboten. Darüber hinaus diskutieren die Beiträge, inwieweit sich in den jeweils untersuchten Texten Elemente einer literarischen Konstruktion von Leserschaft finden, die über die Situativität des Schreibens und die hier adressierten Leser hinausgeht, und wie der Autor selbst die Rezeptionsbedingungen seines Werkes sieht: Nimmt er die „Nachwelt" programmatisch in den Blick?

Die genannten Fragen eröffnen schließlich auch Einsichten in (c) weiterführende literaturtheoretische Diskurse. Der Band möchte einerseits dazu Anregungen geben, „religiöse Autorprofile“ mit Hilfe gegenwärtiger literaturwissenschaftlicher Theoriebildungen innerhalb und außerhalb der Autorforschung zu erheben. Dabei wird diskutiert, welche Methoden der Textinterpretation - wie etwa Semantik, Motivgeschichte, Traditionsgeschichte, Sozialgeschichte, Biographieforschung oder Narratologie - dabei helfen können, antike Konzepte religiös-literarischer Autorschaft aufzuspüren und analytisch zu beschreiben. Andererseits wollen die Beiträge den zumeist literaturwissenschaftlich geleiteten Diskurs über Autorforschung und Autorprofile um letztlich auch literaturtheoretisch relevante Einsichten bereichern, die aus der Untersuchung von antiken Texten resultieren, die im weiteren Sinne der „religiösen Literatur" zugerechnet werden können. Die Betrachtung der „authorial voices“ aus literaturgeschichtlicher und religionsgeschichtlicher Sicht wird so für die allgemeine Autorforschung fruchtbar gemacht.

${ }^{22}$ Vgl. auch Eshleman 2012. 
Die hier versammelten Beiträge wählen jeweils eigenständige Zugänge und Schwerpunktsetzungen bei der Betrachtung der genannten Problemfelder. Die Breite an methodischen Zugängen und Fokussierungen ist nicht nur unvermeidbar, sondern auch notwendig, um einer einseitigen Betrachtung von Autorrollen - als entweder historischem oder literarischem Phänomen - vorzubeugen. Gerade die Tagung, aus der der vorliegende Band resultiert, das heißt: die Diskussion der Vorträge und der hierin präsentierten Konzepte von Autorschaft, hat gezeigt, dass (antike) Autorrollen dann am deutlichsten zu Tage treten, wenn sie literarisch und text-, literatur-, gattungs- und rezeptionsgeschichtlich sowie biographie-, religions-, kultur- und sozialgeschichtlich betrachtet und erforscht werden. Die Vielzahl an methodischen Fragen, die den induktiv ausgerichteten Textuntersuchungen vorgegeben waren, verunklärt die Profilierung von Autorrollen nicht, sondern hilft sie von möglichst vielen Seiten her auszuleuchten. So verstanden ermöglicht die „Rückkehr des Autors“ auch die Wahrnehmung seiner vielfältigen Gesichter und Ausdrucksformen.

\section{Kurze Charakteristik der Einzelbeiträge}

Der Beitrag von Oda Wischmeyer (Erlangen) (Kapitel 2) behandelt mit Jeschua, Sohn Siras, den ersten Autor der hebräischen Literatur, der in eigenem Namen, also orthonym, schreibt. Nicht die Tradition antiker Weisheit und damit die Autorität Salomos, sondern Siras eigene Lehrtätigkeit verleiht dem für die Erziehung junger Männer in Jerusalem konzipierten Text seine Legitimation. Die Analyse der Rezeptionsgeschichte, insbesondere der griechischen Übersetzung durch den anonym bleibenden Enkel, zeigt eine gegenläufige Bewegung. Der Schritt zur Übersetzung und damit zur Verbreitung im Sprach- und Literaturmilieu des hellenistischen Diasporajudentums in Alexandria fand im Zusammenhang mit der Entstehung der Septuaginta statt. In diesem Rahmen erhielt der Text kanonischen Status. Zugleich aber erwies sich die gewählte Autorrolle ben Siras als mehr als graduelle Innovation: Sein eigenes Rollenverständnis wurde als Teil und Motor literarischer Innovationen wahrgenommen und blieb damit kanon- und religionsgeschichtlich nicht unumstritten. So war dem Buch eine anhaltende und nachhaltige innerjüdische Rezeption verwehrt, obwohl Jeschua ben Sira seine eigene literarische Rolle sorgfältig zwischen der persona der Frau Weisheit und seiner auktorialen Person als Weisheitslehrer und religiöser Erzieher ausbalanciert hatte. Diese Form herausgehobener Individualität verbot eine langfristige Übernahme in den hebräischen Kanon des Judentums nach 135 n. Chr. Jeschua ben Sira als orthonymer jüdischer Autor sollte erst im ersten Jahrhundert n. Chr. in der antiken jüdischen Literatur Nachfolger finden, und zwar: in bedeutenden Autoren wie Philon von Alexandria, Josephus und Justus von Tiberias. 
Der Beitrag von Gesine Manuwald (London) (Kapitel 3) bearbeitet eine religionsgeschichtliche Grundfrage, wenn er eine repräsentative Auswahl an Texten untersucht, in denen Cicero sich zum Thema „Religion“ äußert. Es handelt sich dabei um Texte aus verschiedenen Perioden des ciceronischen Schaffens, die zugleich verschiedenen literarischen genres zuzurechnen sind. Manuwald diskutiert die methodischen Schwierigkeiten, die es wahrzunehmen und zu überwinden gilt, wenn „Cicero's own voice“ bei religiösen Fragen erhoben werden soll. Der Beitrag bietet vorläufige Überlegungen dazu, was Cicero selbst über Religionsfragen gedacht haben könnte und warum er in bestimmten Werken jeweils unterschiedliche Meinungen vertreten hat: Cicero scheint je nach Kontext und Situation verschiedene literarische personae adaptiert zu haben. Dahinter wird gleichwohl auch seine persönliche Haltung deutlich: Für Cicero war in erster Linie die Existenz der Götter konstitutiv, so dass er weder dem offiziellen religiösen Kult noch den philosophischen Diskussionen seiner Zeit eine ausschließliche Bedeutung zuerkennen wollte.

Der Beitrag von Ulrike Egelhaaf-Gaiser (Göttingen) (Kapitel 4) geht - aus literaturgeschichtlicher Sicht - der Frage nach, in welcher Weise sich die literarische persona des Autors Ovid in den Exilbriefen des frühen ersten Jahrhunderts n. Chr. präsentiert und welche Rolle der Faktor „Religion“ dabei spielt. Kernthese des Beitrags ist, dass sich der Exildichter nicht nur im Rahmen gemeinschaftlicher Kult- und Festhandlungen, sondern vor allem durch die Inszenierung einer besonderen Gottesnähe profiliert. Dabei wird gezeigt, dass sich Ovid weit stärker und innovativer, als die bisherige Forschung annimmt, an dem Lyriker Horaz orientiert: Während Horaz sein Selbstbild als Schützling des Bacchus und der Musen primär aus seinen poetischen Fähigkeiten und Leistungen begründet hatte, bedient sich Ovid einer biographischen Strategie. Aus dem einschneidenden Ereignis der Verbannung und den dadurch bedingten Bewährungsproben im Exil gewinnt Ovid enge Parallelen zu Bacchus' Vita und leitet einen ganz persönlichen Anspruch auf göttliche Fürsorge und Hilfeleistungen ab. Ovids Innovation gegenüber Horaz zeigt sich in der biographischen Selbstidentifikation und abschließenden Namensnennung. Denn mittels deiktischer Formen der Ich-Prädikation verbindet sich der Autor dauerhaft mit seinen Exilbriefen. In einem performativen Akt der Selbstkanonisierung und der Integration in eine stadtrömische Fest- und Dichtergemeinschaft schreibt sich Ovid einem exklusiven Literatenkreis und dem kollektiven Gedächtnis seiner Leser ein.

Der Beitrag von Maren Niehoff (Jerusalem) (Kapitel 5) untersucht - vor biographiegeschichtlichem Hintergrund - die literarischen Formen, in denen sich Philo von Alexandria in den historischen Traktaten um sein self-fashioning bemüht. Philo verfasste die Traktate nach seiner Ankunft in Rom, wo er als Leiter einer jüdischen Delegation agierte. In dieser Zeit konzipierte er einen neuen Schreibstil, in dem er die literarischen Techniken, die er in seinen früheren Kommentarwerken anwandte, hinter sich ließ. Denn nun tritt Philo (selbst- 
bewusst) in den Vordergrund seines Schreibens. Er teilt mit dem Leser persönliche Erfahrungen und stellt sich programmatisch als religiöse Leitungsperson dar, die sogar ihre Bereitschaft zum Martyrium zu erkennen gibt. Philos Schreibstil ist durch Selbstreflexion geprägt und fordert - in teils ironischer Form - die literarischen Konventionen seiner Zeit heraus. Viele literarische Strategien des self-fashioning, die Philo dabei zur Anwendung bringt, begegnen eine Generation später in den historischen Werken des Josephus wieder. Denn auch Josephus fordert die literarischen Konventionen (frühjüdischen) Schreibens heraus, indem er seine Subjektivität als Historiker hervorhebt, sich in Augenblicken höchst kontroversieller politischer Entscheidungen auf Gott selbst beruft und - jedenfalls theoretisch - das Ideal des Martyriums vor Augen führt.

Der Beitrag von Eve-Marie Becker (Aarhus/Münster) (Kapitel 6) untersucht insbesondere vor dem Hintergrund motivgeschichtlicher Beobachtungen die verschiedenen Autorrollen, die Paulus in seinem wohl letzten brieflichen Schreiben einnimmt. Denn die im Philipperbrief gewählten Autorrollen sind, wie sich zeigt, zunächst situativ bedingt und sachlich-thematisch sowie pragmatisch funktionalisiert. Speziell die Rollenwechsel, die Paulus im Verlauf des Briefs vollzieht, dienen dann aber dazu, Form und Argument des brieflichen Schreibens so $\mathrm{zu}$ konfigurieren, dass eine bestimmte Sprecherrolle dominiert und schließlich selbst zum Argument wird: Wie schon im Präskript des Briefs erkennbar ist (Phil 1,1), geht es Paulus um die literarisch und religiös programmatische Selbstdarstellung als doulos. Der Begriff "Sklave" ruft soziale, religiöse und durch die Septuaginta-Sprache vorgegebene (heils-)geschichtliche Motive assoziativ auf und bündelt diese. Da es Paulus im Philipperbrief - wie schon in Teilen des Römerbriefs (vgl. Röm 1,1), wenn auch unter gänzlich anderen Schreibvoraussetzungen - letztlich angesichts widriger äußerer Umstände als Gefangener um die erfolgreiche Selbstinszenierung als Apostel geht, wird das doulos-Motiv zum leitenden Argument, ja zur Programmatik paulinischen Selbstverständnisses: Als ein nach endgültiger Konformität mit seinem „Herrn“ strebender „Sklave Jesu Christi“" sucht sich Paulus bei seinen Adressaten als ultimatives, und das heißt auch: generationenüberschreitendes Vorbild der Christus-Imitation zu autorisieren.

Jan Willem van Henten (Amsterdam) befasst sich in seinem Beitrag (Kapitel 7) speziell mit Flavius Josephus. Ausgangspunkt sind die Vorworte der historischen Werke, die ihn als erkennbaren („offenen“), akribisch arbeitenden Erzähler präsentieren, der besonders in seinem Zugriff auf Zeitgeschichte die alten Historiographen zu übertreffen sucht. Seine Autorität gegenüber seiner nichtjüdischen intendierten Leserschaft in Rom gewinnt er nicht zuletzt aus seinem biographischen Verweis auf seine priesterliche Herkunft. Inhaltlich erweist sich seine Autorität als Erzähler als eine religiöse, die Gottes Wirken im Lauf der Ereignisse herausarbeitet - diese Erzählhaltung bleibt, wie der Vergleich mit den Erzählungen selbst erweist, über die Vorworte hinaus konsistent. Das gilt 
auch dort, wo er nicht nur Erzähler, sondern auch Protagonist seiner Erzählung im jüdisch-römischen Krieg wird, und zwar über die Kapitulation bei Jotapata/ Yodfat hinaus bis hin zu seinen Weissagungen über Vespasian. Josephus wird gerade auch durch seine eigene Beteiligung wie Expertise für das jüdische Volk zu einer „werbenden Autorstimme“.

Jan Dochhorn (Durham) (Kapitel 8) untersucht das für apokalyptische Texte so ungewöhnliche Phänomen der Orthonymität der „Johannes“-Apokalypse. Von hier her wirft Dochhorn einen Blick auf das Autorprofil des johanneischen Briefcorpus. Letzteres beleuchtet die komplexe Autorkonstruktion der „Offenbarung": Das (nachpaulinische) Konzept von Autorschaft ist vor allem an einen briefeschreibenden und so überörtlich kommunizierenden Autor gebunden, dessen literarisches und religiöses Profil sich allein durch die Selbstvorstellung und das Agieren im Text selbst bestimmen lässt. Entscheidend für die Komplexität des Autorprofils des "Johannes“ ist aber nicht die starke Präsenz des schreibenden Ichs, sondern der häufige Wechsel der Lokalisierung von Autorschaft: von der Niederschrift einer Vision durch den Briefeschreiber über Engel zu Christus und Gott, zu denen Johannes als Knecht Christi oder Gottes nahezu dieselbe Distanz aufweist wie jene Knechte Gottes oder Christi, die er in seinem - in vielen Teilen als Brief stilisierten - Text anspricht.

Der Beitrag von Jörg Rüpke (Erfurt) (Kapitel 9) beschäftigt sich mit einem Text, der sich ebenfalls als Apokalypse versteht, aber gerade in enger Interaktion mit seinem Publikum schichtweise gewachsen ist, dem „Hirten des Hermas“. Die Schrift zeichnet sich ebenfalls durch ein komplexes Modell von Autorschaft aus, das unterschiedliche himmlische Offenbarungsfiguren einführt und gerade durch die offen ausgesprochenen Defizite, ja den expliziten Tadel gegenüber dem Autor sein besonderes Profil gewinnt. Der Blick auf die Rezeptionsgeschichte lässt vermuten, dass gerade so das Autorprofil zu einem Rezeptionsmodell wird, in dem nicht nur die Lektüre des Textes, sondern auch dessen Reproduktion zu einer religiösen Praxis werden.

Der Beitrag von Georgia Petridon (Erfurt) (Kapitel 10) führt in die antike Autobiographie-Forschung und überschreitet dabei klassische Unterscheidungen von historischer Autorschaft und Autorfiktion: Am Beispiel der "Hieroi Logoi“ zeigt Petridou wie sich Aelius Aristides ein self-fashioning verleiht, bei dem die Motive von Leiden und Krankheit grundlegend sind. Aristides gibt sich fortwährend als Leidender zu erkennen und zeichnet Asklepius als den einzigen Arzt, der seine Krankheiten erfolgreich diagnostizieren und behandeln kann. Die Konzeption des Autors als eines Kranken und Leidenden steht in Wechselwirkung mit dem literarischen Genre, das der Verfasser wählt: Die „Hieroi Logoi“ bewegen sich zwischen einer Aretalogie und einer Paradoxographie. Denn indem Aristides sein Leiden und seine Krankheit zum zentralen Motiv macht und Asklepius zugleich zum göttlichen Heiler erklärt, trägt seine Schrift Züge eines Enkomions. Zugleich aber fungiert das Krankheits-Motiv als 
Element von Individuierung und Individualisierung, mit Hilfe dessen der Autor sein spezifisches Autorprofil schärft. Das Ziel dieser „autobiographischen“ Darstellung dürfte weniger in einer historisch zuverlässigen Schilderung von Krankheitsverläufen und Heilungsprozessen als vielmehr darin liegen, sich selbst als einen von Gott beauftragten Autor, gleichsam als einen Chronisten von Leiden und erfahrener Genesung zu zeichnen.

Der Beitrag von Dorothee Elm von der Osten (Berlin) (Kapitel 11) zeigt am Beispiel des Satirikers Lukian zunächst forschungsgeschichtlich auf, in welchem Maße die Rückprojektion von Erzählerfiguren in den unterschiedlichen Werken des Corpus zu einer Charakterisierung einer historischen Autorpersönlichkeit führte, dessen Werk dann wiederum umgekehrt von der so gewonnenen ethnischen Identität (der Syrer) und religiösen Profilierung (der epikureische Eklektiker und Atheist) her interpretiert wurde. Elm von der Osten analysiert in einer kritischen Kehrtwendung die beobachtete Verschmelzung von Erzähler und Autor als performative Leistung der Texte selbst. Die Texte generieren nicht ein statisches Autorprofil, sondern unterminieren eine kohärente Bestimmung von Erzählerrolle und Autoridentität und konfigurieren gerade so eine religiöse Rolle, die sich durch Begriffe wie Pluralität und religiöse Individualität oder „bricolage“ charakterisieren lässt: So begegnet Lukian nicht als Vertreter einer inhaltlichen Position, sondern als literarischer Organisator von religiösem Diskurs.

Markus Vinzent (London/Erfurt) stellt in seinem Beitrag (Kapitel 12) Tertullian, und damit das lateinische Nordafrika im Übergang vom zweiten ins dritte Jahrhundert n. Chr. ins Zentrum seiner Untersuchung. In Anbetracht des großen Euvres Tertullians konzentriert sich Vinzent methodisch auf die Vorworte. Die rationale Schärfe, aber auch die rhetorische Polemik, die die Argumentationen Tertullians charakterisiert, entsteht, wie im Vergleich deutlich wird, nicht durch eine durchgehende Position. Vielfach bringt der Rhetor und Theologe persönliche Erfahrungen anstelle einer Berufung auf eine (festgelegte) göttliche Position in die theologischen Debatten und Auseinandersetzungen mit ein. Die angeführten Erfahrungen führen nicht zur Ausbildung einer einheitlichen Autor-Persönlichkeit, sondern sind in jeweiligen, also „lokalen" Argumentationspositionen von Gewinn, weil sie seine Argumentation als unwiderlegbar erscheinen lassen. Hier ist die rhetorische Durchgängigkeit der Performanz, die „zwingende“ Logik vorführt, wichtiger als die Konsistenz einer inhaltlichen Position.

Autoren gnostischer Texte bilden den Gegenstand der Untersuchung von Barbara Aland (Münster) (Kapitel 13). Kennzeichnend für diese Schriftengruppe ist das Mittel der Anonymität, genauer: der Anonymität jenes Mythos, auf den sich zu beziehen überhaupt erst die Zugehörigkeit zur gnostischen Literatur herstellt. Nicht Orthonymität, die im untersuchten Zeitraum vom zweiten bis zum vierten Jahrhundert n. Chr. gut, wenn nicht sogar inzwischen als „Normalfall“ 
christlicher Autorschaft verbreitet ist, sondern gerade diese Anonymität wird nach Alands Untersuchung zum entscheidenden Werkzeug, dem sprecherlosen Text Autorität zuzuschreiben. Das Konzept der individuellen, anonymisierten Autorschaft begrenzt die Autorität des Schreibens nicht mehr, sondern verleiht den Texten vielmehr einen überindividuellen und vor allem auch religiösen Geltungsanspruch. Das zieht, wie der Blick in die Rezeptionsgeschichte zeigt, erhebliche Polemik an: Nicht Ortho-, sondern Anonymität wird hier zu einem wirksamen Werkzeug von Autorprofilen.

Auch wenn die vorgelegten Analysen keine klare, literaturgeschichtlich progressiv fortschreitende Entwicklungslinie bei der antiken Konzeption von Autorschaft erkennen lassen, so zeigen sie doch, wie gerade in religiös zunehmend komplexen Situationen auktoriale Profile eigene Positionen literarisch vermittelter religiöser Autorisierung und Individualisierung vorantreiben. Die geschaffenen Autorprofile werden so selbst zu religionsgeschichtlichen Fakten, zu Positionen, ja zu Institutionen in der Welt und Umwelt zeitgenössischer oder nachfolgender religiöser Akteurinnen und Akteure. Die Autorrollen stoßen auf Kritik oder Nachahmung, sie werden als deviant verworfen ${ }^{23}$ oder als Traditionskern verstanden.

Insbesondere die letzten beiden Kapitel in diesem Band zeigen, wie weit sich das Instrumentarium an Autorfiktionen im Untersuchungszeitraum entwickelt hat: Es umfasst die fast bis zur Konturlosigkeit reichende Einzelproblem-bezogene Positionierung eines facettenreichen, an sich orthonymen Verfassers wie die strategische Anonymisierung im literarischen Umgang mit religiösem Mythos. Doch auch hier gilt: Literarische Kommunikation gewinnt in dieser Epoche mediterraner Religionsgeschichte in erheblichem Maße neue "authorial voices“ und „faces“ hinzu. ${ }^{24}$

\section{Literaturverzeichnis}

Aune, D.E. (2009). „Reconceptualizing the Phenomenon of Ancient Pseudepigraphy,“ in: J. Frey et al., Hgg., Pseudepigraphie und Verfasserfiktion in frühchristlichen Briefen. Tübingen (WUNT 246). 789-824.

Becker, E.-M.; Pilhofer, P. (2005/2009), Hgg., Biographie und Persönlichkeit des Paulus. Tübingen (WUNT 187).

Becker, E.-M.; Scholz, S. (2012), Hgg., Kanon in Konstruktion und Dekonstruktion. Kanonisierungsprozesse religiöser Texte von der Antike bis zur Gegenwart. Ein Handbuch. Berlin/Boston.

Becker, E.-M. (2012). „Antike Textsammlungen in Konstruktion und Dekonstruktion. Eine Darstellung aus neutestamentlicher Sicht,“ in: dies.; S. Scholz, Hgg., Kanon in

\footnotetext{
${ }^{23}$ Dazu Rüpke 2011/2016.

${ }^{24}$ In weiterem Rahmen Rüpke 2016/2017.
} 
Konstruktion und Dekonstruktion. Kanonisierungsprozesse religiöser Texte von der Antike bis zur Gegenwart. Ein Handbuch. Berlin/Boston. 1-29.

Becker, E.-M. (2014). „Von der Rezeption zur Produktion. Über Kategorien des Verstehens, “ in: dies.; S. Scholz, Hgg., Auf dem Weg zurneutestamentlichen Hermeneutik. Oda Wischmeyer zum 70. Geburtstag. Tübingen. 113-120.

Becker, E.-M. (2017). The Birth of Christian History. Memory and Time from Mark to Luke-Acts. New Haven (Anchor Yale Bible Reference Library).

Becker, E.-M.; Mortensen, J. (2018), edd., Paul as homo novus: Authorial strategies of self-fashioning in light of a Ciceronian term. Göttingen (SANt 6).

Bendlin, A. (2002). „Vates, “ in: Neuer Pauly 12/1. 1150-1151.

Detering, H. (2002), Hgg., Autorschaft. Positionen und Revisionen. Stuttgart.

Eshleman, K. (2012). The Social World of Intellectuals in the Roman Empire: Sophists, Philosophers, and Christians. Cambridge.

Feeney, D. (1998). Literature and Religion at Rome: Cultures, Contexts, and Beliefs. Cambridge.

Feeney, D. (2007a). „The History of Roman Religion in Roman Historiography and Epic“, in: J. Rüpke, ed., A Companion to Roman Religion. Oxford. 129-142.

Feeney, D. (2007b). „On not Forgetting the 'Literatur' in 'Literatur und Religion': Representing the Mythic and the Divine in Roman Historiography," in: A. Bierl; R. Lämmle; K. Wesselmann, Hgg., Literatur und Religion 2: Wege zu einer mythisch-rituellen Poetik bei den Griechen. Berlin. 173-202.

Frey, J. et al. (2009), edd., Pseudepigraphie und Verfasserfiktion in frübchristlichen Briefen. Tübingen (WUNT 246).

Gordon, R.; Petridou, G.; Rüpke, J. (2017), edd., Beyond Priesthood: Religious Entrepreneurs and Innovators in the Roman Empire. Berlin (Religionsgeschichtliche Versuche und Vorarbeiten 66).

Jannidis, F. et al (1999), Hgg., Rückkehr des Autors. Zur Erneuerung eines umstrittenen Begriffs. Tübingen.

Jannidis, F. et al. (2000), Hgg., Texte zur Theorie der Autorschaft. Stuttgart.

Klausnitzer, R. (2014). „Autorschaft und Gattungswissen, “ in: M. Schaffrick; M. Willand, Hgg., Theorien und Praktiken der Autorschaft. Berlin/Boston (Spectrum Literaturwissenschaft 47). 197-234.

Kratz, R. G. (2013). Historisches und biblisches Israel: Drei Überblicke zum Alten Testament. Tübingen.

Marmodoro, A./Hill, J. (2013), edd., The Author's Voice in Classical and Late Antiquity. Oxford.

Newman, J.K. (1969). The Concept of vates in Augustan Poetry. Bruxelles (Collection Latomus 89).

Plotke, S. (2012). „Autorschaft durch Autorisierung. Bearbeitung des Alexanderstoffs als Modelfall differenter Verfasserkonzeptionen,“ in: Beiträge zur Geschichte der deutschen Sprache und Literatur 134. 344-364.

Rüpke, J. (2011/2016). Aberglaube oder Individualität? Religiöse Abweichung im römischen Reich. Tübingen. Engl.: Religious Deviance in the Roman World: Superstition or Individuality?. Cambridge.

Rüpke, J. (2013), ed., The Individual in the Religions of the Ancient Mediterranean. Oxford.

Rüpke, J. (2014). Römische Religion in republikanischer Zeit: Rationalisierung und ritueller Wandel. Darmstadt. 
Rüpke, J. (2015). „Religious Agency, Identity, and Communication: Reflecting on History and Theory of Religion“, in: Religion 45. 344-366.

Rüpke, J. (2016/2017). Pantheon: Geschichte der antiken Religionen. München. Engl.: Pantheon. Princeton.

Rüpke, J. (2016). On Roman Religion. Lived Religion and the Individual in Ancient Rome. Ithaca (Townsend Lectures).

Schaffrick, M.; Willand, M. (2014), Hgg., Theorien und Praktiken der Autorschaft. Berlin/ Boston (Spectrum Literaturwissenschaft 47).

Slater, N. W. (2017), ed., Voice and Voices in Antiquity. Orality and Literacy in the Ancient World. Leiden/Boston.

Stein, E. (1990). Autorbewußtsein in der frühen griechischen Literatur. Tübingen (ScriptOralia 19).

Taub, L.; Doody, A. (2009), edd., Authorial Voices in Greco-Roman Technical Writing. Trier (AKAN-Einzelschriften 7).

Weippert, M. (1988). „Aspekte israelitischer Prophetie im Lichte verwandter Erscheinungen des Alten Orients“, in: G. Mauer; U. Magen, Hgg., Ad bene et fideliter seminandum: Festgabe für Karlbeinz Deller zum 21. Februar 1987. Kevelaer/Neukirchen-Vluyn. 287-319. 



\title{
Jesus ben Sira als erster frühjüdischer Autor
}

\author{
Oda Wischmeyer
}

Autorforschung liegt anders als Gattungsforschung nicht im Zentrum der Wissenschaft vom antiken Judentum. Die frühjüdische kanonische, deuterokanonische beziehungsweise apokryphe und nichtkanonische Literatur ist großenteils pseudonyme oder anonyme Literatur ohne Hinweise auf real-historische Autorenschaft - mit der Ausnahme der beiden großen Schriftsteller Philon von Alexandria und Josephus, die im alexandrinischen beziehungsweise römischen Literaturbetrieb und deren Autorbegriff verortet sind. ${ }^{1}$ Die Autorfrage im Sirachbuch wird dementsprechend eher selten ${ }^{2}$ und wenn, dann vor allem unter kompositionsgeschichtlichen Aspekten von Einheit oder möglicher „Fortschreibung“ in jüngeren Textversionen und Anhängen besonders des griechischen Textes behandelt. ${ }^{3}$ Ben Sira als real-historischer Autor wird aber kaum bestritten. ${ }^{4}$ Der vorliegende Beitrag versteht Ben Sira als real-historischen Autor und untersucht sein literarisches self-fashioning in der Spannung zwischen dem Weisheitslehrer in der Tradition Salomos, der persona der Frau Weisheit mit

\footnotetext{
${ }^{1}$ Beide Schriftsteller haben eine eigene gelehrte Literatur nach sich gezogen: vgl. Siegert 2016, 7, der sie weitgehend von der sie umgebenden Literatur abkoppelt.

${ }^{2}$ Vgl. aber die klare Ansage bei Sauer 2000, 20: „Es verdient hierbei folgende Tatsache eine besondere Betonung: Der Verfasser und Sammler der in diesem Buch anzutreffenden Weisheitstexte bekennt sich selbst zu seinem literarischen Werk und offenbart auch seinen Namen als Autor. Dies ist ein vollkommen neuer Wesenszug der Schriften dieser Zeit ... [Es] tritt ein Mensch mit seinem eigenen Namen in das Licht der literarischen Öffentlichkeit“. Ganz knapp nur zum Namen: Siegert 2016, 147.

${ }^{3}$ Vgl. zuletzt: Witte 2015a, 1-20. Zu Fortschreibungen u. ä. Witte S. 8f. (Lit.). Zu den Einleitungsfragen: Siegert 2016,140-156. Zu weiteren (nur in Zitaten überlieferten oder verlorenen) Autorenwerken der hellenistisch-jüdischen Literatur vgl. Siegert 2016, 390-464, dort S. 390 Grundsätzliches zum Unterschied zwischen der Praxis der Autorennennung in der jüdisch-hellenistischen („Einer ungeschriebenen Zitierregel folgend nennt kein hellenistisch-jüdischer Autor den anderen“) und der rabbinischen Literatur. Zum Thema: Wischmeyer 2017.

${ }^{4}$ Siegert 2016, 147 zum Namen. Siegert scheint eine Familientradition für die Entstehung des Werkes anzunehmen, siehe auch S. 16. Festzuhalten ist aber, dass es hier zwar um Sammlung von Traditionen bzw. kleineren Textpartien im Lehrhaus Ben Siras gehen kann, nicht aber über einen längeren (möglicherweise über Jahrhunderte sich hinziehenden) Textentwicklungsprozess. Das ist sowohl durch die Übersetzung des Enkels als auch durch die hebräischen Textfunde ausgeschlossen.
} 
ihrer himmlischen Autorität und dem orthonymen Autor, der ein Lehrhaus in Jerusalem unterhält und mit seinem Werk für diesen Lehrbetrieb wirbt. Letzteres wird durch den Prolog seines Enkels, der das hebräische Werk ins Griechische übersetzt hat, nachhaltig unterstrichen.

\section{Das Buch Ben Sira/Jesus Sirach}

Das Sirachbuch liegt nur zu circa zwei Dritteln auf Hebräisch vor. Der defizitäre Überlieferungsstand erklärt sich daraus, dass das Werk nicht Teil des hebräischen Tanak wurde und seine direkte Überlieferung im Judentum spätestens seit dem Mittelalter abgerissen ist. Vollständig erhalten ist dagegen die griechische Übersetzung als Teil der Septuaginta, der heiligen Schrift des griechischsprachigen Judentums. ${ }^{5}$ Der hebräische Text ist noch nicht kritisch ediert. Für eine solche Edition müssen die Ergebnisse der Textsicherung der in der Kairoer Geniza, ${ }^{6}$ in Qumran und in Masada gefundenen Fragmente zusammengestellt werden. ${ }^{7}$ Durch den Platz in der Septuaginta geriet das Sirachbuch in den großen Strom antiker christlicher Bibelübersetzungen, von denen besonders die syrische und die lateinische Übersetzung für die Textrekonstruktion von Bedeutung sind. ${ }^{8}$

Das Buch stellt sich als Weisheitswerk vor $(1,1)$ und gibt in 51 Kapiteln „Lehren, die das Leben des einzelnen in Familie und Ehe betreffen“ (Kap. 2-23), weiterhin Lehren zum „Verhalten im öffentlichen Leben, in der ... Gemeinde und im religiös-kultischen Bereich" (Kap. 25-50). ${ }^{9}$ Eingeschoben sind Gebete, Texte zum Weisheitslob, größere und kleinere thematische Texteinheiten sowie ein großer Rückblick auf die Geschichte Israels, der in Kapitel 50 mit einem Lob des Hohenpriesters Simon II. schließt, eines Zeitgenossen des Verfassers (Kap. 42-50). Kapitel 51 enthält verschiedene Zusätze, darunter das Akrostichon 51,13-30ab, ein Lehrgedicht über die Weisheit, in dem Ben Sira abschließend für sein Lehrhaus wirbt $(51,29) .{ }^{10}$

${ }^{5} \mathrm{Zu}$ den Handschriften vgl. Ziegler 2016. Vgl. weiter die Einführung in die Handschriften bei Sauer 1981, 483-487. Neue Lit. bei Witte 2015a, 3-5. Der griechische Text liegt in einer kürzeren und einer längeren Version vor: G-I und G-II. Dazu neue Literatur bei Witte 2015a, 5 .

${ }^{6} \mathrm{Zu}$ den Handschriftfunden der Geniza vgl. vor allem die Forschungseinrichtungen in Oxford und Cambridge: http://genizah.bodleian.ox.ac.uk; URL http://www.lib.cam.ac.uk/ Taylor-Schechter/Collection.

${ }^{7}$ Dazu Sauer 2000, 24-26, ergänzend Witte 2015, 3. Vgl. den diplomatischen Text von Beentjes 1997. Vgl. auch die Texte bei: http://www.bensira.org/.

${ }^{8}$ Dazu Witte 2015a, 3-7.

${ }^{9}$ Sauer 2000, 35.

${ }^{10}$ Zum Text Sauer 2000, 348-351. Zu vorsichtig 350: „Darin könnte ein Selbstbekenntnis Ben Siras gesehen werden“. 
Wer war der Autor dieses umfangreichsten jüdischen Weisheitswerkes der Antike? ${ }^{11}$ Simon, Sohn Jeschuas, Sohn Eleasars, Sohn Siras (Sir 50,27. 30), oder: Simon, Sohn Jeschuas, der Sohn Siras genannt wird (51,30), oder: Jeschua/Iēsous (Vorrede 7) ist der erste uns überkommene Schriftsteller in der antiken hebräischen Literatur, der in seinem eigenen Namen schreibt und seine Person deutlich zeigt. Er verfasste sein umfangreiches Werk über die Weisheit ${ }^{12}$ gegen Ende der Ptolemäerherrschaft über Ägypten-Palästina in Jerusalem (ca. 190-175 v. Chr.). Sein Enkel, der den Namen seines Großvaters in der griechischen Kurzfassung "Jesus" nennt, seinen eigenen Namen aber verschweigt, ${ }^{13}$ übersetzt das Werk zwischen 132 und 117 v. Chr. in Alexandria ins Griechische. ${ }^{14}$ In seinem Prolog beschreibt er die Mühen und die Absicht seiner Übersetzungsarbeit.

Der Großvater Ben Sira, um die häufig in der Literatur genannte Kurzfassung seines hebräischen Namens zu verwenden, schreibt in dem klassischen hebräischen Genre der Weisheitsschrift auf der Basis des kurzen Parallelsatzes, dessen Verfasser sich üblicherweise durch das Pseudonym König Salomos autorisieren. Ben Sira verfolgt demgegenüber den innovativen Ansatz, seine Schrift als Verschriftlichung seiner eigenen Lehrvorträge und damit zugleich als Produkt seiner Tätigkeit als Erzieher junger Männer in Jerusalem zu konzipieren. Er stellt damit sein „Lehrhaus“ $(51,29)$ als unabhängige literarische Institution in Jerusalem dar. Die im Ansatz traditionale, nicht zeitgebundene Weisheitsliteratur wird dadurch zur pädagogischen Gegenwartsliteratur. Die Rezeption des siracidischen Werkes erfolgt aber weniger in Jerusalem - obgleich es auch eine spätantike und mittelalterliche Rezeptionsgeschichte des hebräischen Sirachbuches gibt ${ }^{15}$ - als viel mehr in der griechischsprachigen Diaspora in Alexandria: In seiner griechischen Übersetzung wird das Buch Teil der Septuaginta, der griechischen Übersetzung des Tanak, und erhält für das griechischsprachige Judentum kurzzeitig kanonischen Status. Damit kommt das Sirachbuch in den Kreis jener hauptsächlich griechischsprachigen Schriften des hellenistischen Judentums, die entweder durch ihre Septuagintazugehörigkeit bald Teil der christlichen Bibel wurden oder aber von christlichen Schriftstellern geschätzt und zitiert und so vor dem

${ }^{11}$ Vgl. die sogfältige Textanalyse anhand von 51,13-30 (schwierige Textüberlieferung) und 39,1-11 zur Frage nach der Person Ben Sira bei Ueberschaer 2007, 322-337. Das Ergebnis bleibt sehr blass: ein frommer Weisheitslehrer.

${ }^{12} \mathrm{Zu}$ den Titeln vgl. Siegert 2016, 21-25 (wichtige allgemeine Definitionen) und $145 \mathrm{zu}$ Sirach.

${ }^{13}$ Prolog 27-36: Im achtunddreißigsten Jahr des Königs Euergetes / kam ich nach Ägypten und verbrachte dort einige Zeit / und fand Vergleichbares von nicht geringer Bildung. / Dringlichst nahm ich mir vor, auch selbst ein gewisses (Maß) an Eifer / und Mühe aufzubringen, dieses Buch zu übersetzen, / und ich brachte viele schlaflose Nächte und Sachverstand / in der Zwischenzeit/ (dafür) auf, das Buch zu Ende zu bringen und herauszugeben, / und (so auch) für die (etwas zu leisten), die in der Fremde begierig sind zu lernen, / dass sie sich (ihre) Gesinnung (so) zurichten lassen, / gesetzestreu zu leben. Übersetzung: Kraus/Karrer (2009).

${ }^{14}$ Prolog 28.

${ }^{15}$ Zur Rezeptionsgeschichte vgl. Siegert 2016, 155 f. 
endgültigen Vergessen bewahrt blieben, das ihnen in der nachantiken Kultur des Judentums widerfuhr. Seit der Wiederentdeckung von ca. zwei Dritteln des hebräischen Sirachtextes existieren - wieder - zwei Fassungen des Sirachbuches. ${ }^{16}$

Über den Enkel wissen wir außer den Nachrichten, die er den Lesern selbst im Prolog gibt, nichts. Wahrscheinlich übersetzte er das Werk des Großvaters zwischen 132 und 117 v. Chr. ${ }^{17}$ Wenig beachtet ${ }^{18}$ wird Zweierlei. Erstens: Der Enkel kam - wohl als junger Mann - aus Jerusalem. Er musste dort schon gute Griechischkenntnisse erworben haben ${ }^{19}$ um das viel Zeit verschlingende Übersetzungswerk in Alexandria ausführen zu können. Zweitens: Der Enkel war - wie in gewisser Hinsicht schon sein Großvater - ein Modernist und ein Konservativer zugleich, nämlich jemand, der einem fast noch zeitgenössischen und orthonymen Werk zu mindestens teilweise kanonischem Status verhalf und es ,in die Septuaginta brachte“ (Sauer). ${ }^{20}$ Der Enkel war selbst ein großer Übersetzer, ein sprachlich wie literarisch außerordentlich begabter Mann - wie sein Großvater - und verdient seiner Übersetzungstheorie wegen einen eigenen Platz in der Geschichte der frühjüdischen Literatur. ${ }^{21}$

Die komplexe Geschichte des Ausgangstextes: hebräischer Ben Sira, griechischer Sirach der Septuaginta in der jüdischen Diaspora, griechischer und lateinischer Sirach des antiken Christentums in Septuaginta und Vulgata (und anderen Versionen) sowie syrischer Sirach der jüdischen Diaspora und des syrischen Christentums (Peschitta), zeugt von dem innovativen Potential und der Durchsetzungskraft der Weisheitsschrift Sirachs. Sie ist die einzige orthonyme Schrift der Septuaginta, die zwei Generationen nach ihrer Entstehung in ihrer griechischen Übersetzung kanonisch wurde und deren reale Entstehungsbedingungen ${ }^{22}$ zudem im Prolog der Schrift aufgedeckt werden. Zugleich ist die Übersetzung aber auch ein Ausdruck der traditionalen Kräfte des alexandrinischen Judentums: Der Enkel bleibt anonym und schafft die Voraussetzungen dafür, dass das aktuelle Werk seines Großvaters nicht nur den Status des literarischen Klassikers, sondern darüber hinaus den der religiösen Autorität erhält und seine zeitbedingten Entstehungsumstände abstreift. ${ }^{23}$

${ }^{16}$ Zum hebräischen Text und den antiken Übersetzungen und deren unterschiedlichem Umfang vgl. die ausführliche und zuverlässige Einführung bei Skehan/di Lella1987, 51-62.

${ }_{17}$ Skehan/di Lella 1987, 135.

${ }^{18}$ Vgl. die zu kurze Charakteristik bei Siegert 2016, 147.

${ }^{19}$ Wie die siebzig Übersetzer der Tora aus Jerusalem, von denen der Aristeasbrief spricht (Pelletier 1962).

${ }^{20}$ Wie dies tatsächlich ausgesehen hat, wissen wir nicht. Vgl. Sauer 2000, S. 18; Witte, „Der „Kanon' heiliger Schriften des antiken Judentums“, in: Witte 2015a, 39-58, $57 \mathrm{f}$.

${ }^{21}$ Bei Siegert 2016 nicht eigens erwähnt. Der Enkel ist der einzige historisch greifbare Übersetzer in dem großen Übersetzungswerk der Septuaginta.

${ }^{22}$ Im Prolog 20-26 thematisiert der Enkel die Übersetzungsprobleme.

${ }^{23}$ Das unterscheidet das Sirachbuch von den meisten frühjüdischen Schriften. 


\section{Autoren- und Autorisierungskonzepte in der kanonischen und außerkanonischen Literatur Israels}

Die althebräische Literatur kommt bekanntlich ohne real-historische Verfasserangaben aus. Wir kennen die realen Autoren der alttestamentlichen Schriften nicht. Andererseits finden sich überall in den Schriften der Bibel Israels fiktive oder besser historisch-traditionale Verfassernamen, die der Autorisierung der Schriften dienen. ${ }^{24}$ Für unsere Fragestellung ist dabei weder das Phänomen einer Autorisierung durch „falsche“ Zuschreibung (Pseudepigraphie) ${ }^{25}$ interessant das Sirachbuch ist nicht pseudepigraph - noch die traditions- und redaktionsgeschichtliche Perspektive der "geschichteten Texte“ (J.A. Loader ${ }^{26}$ ) des Alten Testaments - das Sirachbuch ist im großen und ganzen einheitlich. ${ }^{27}$ Es geht vielmehr um das Zusammenspiel von Autorisierung beziehungsweise Legitimierung und author-fashioning der hebräischen Literatur, die Ben Sira vorlag. ${ }^{28}$ Diese „klassischen“ hebräischen Autorenkonzepte sind die Basis seines eigenen Autorverständnisses, das zwischen Innovation und Klassizismus changiert.

Werfen wir zunächst einen kurzen Blick auf David und Salomo. David wird in 1 Sam 16 und an anderen Stellen mit Musik zusammengebracht, in 2Sam 22 und 23 mit Liedern (22,1: „die Worte dieses Liedes“). Dementsprechend autorisieren sich die Psalmen überwiegend mit der Verfasserschaft durch (oder dem Verweis auf) David. ${ }^{29}$ Davids Sohn Salomo erscheint in den alttestamentlichen Ketubim mehrfach als Verfasser: Sprüche 1,1-730; Prediger 1,1 (ohne explizite Namensnennung); Hoheslied 1,1. Salomo ist hier als Weisheitslehrer und als Dichter modelliert. Im frühen Judentum entsteht eine zusätzliche „Salomoliteratur“"31, die zum Teil ihren Weg in die Septuaginta findet und damit im griechischsprachigen Judentum und in der Alten Kirche kanonischen Status erhält, teilweise aber auch extrakanonisch existiert. Salomo ist jetzt ganz weisheitlicher Schriftsteller. Dies

\footnotetext{
${ }^{24}$ Siegert 2016, 16, formuliert einen „weichen“ Autorbegriff, indem er nicht zwischen historischem und implizitem Autor unterscheidet und die Bedeutung Ben Siras als des historischen Autors relativiert.

${ }^{25}$ Dazu für die frühjüdische Literatur Siegert 2016, 2-4. 8 f. („In hebräischer Literatur war Pseudepigraphie bis nahe zur Gegenwart die Regel und nicht die Ausnahme“, S. 3).

${ }^{26}$ Loader 2008, 99-120.

${ }^{27} \mathrm{Zu}$ möglichem „Wachstum“ des Endtextes vgl. Anm. 4.

${ }^{28}$ Zum „Kanon“ Ben Siras vgl. Witte 2015a.

${ }^{29} \mathrm{Zu}$ David als Verfasser und Adressat von Psalmen vgl. einführend: Witte 2009. Witte 419 kommentiert rezeptionsgeschichtlich: „David sollte als Identifikationsfigur für den einzelnen Beter vorgestellt werden“. Ebenso wichtig ist aber der produktionsgeschichtliche Aspekt. Zur Gestalt Davids im Frühjudentum vgl. Pomykala 2004 sowie Miura 2007.

${ }^{30}$ In der hebräischen Fassung des Sprüchebuches sind in Kap. 30-33 Sprüche anderer Könige gesammelt. Die LXX lässt das gesamte Sprüchebuch von Salomo stammen: ein Indiz für die zunehmende Bedeutung der Vorstellung von Salomo als Weisheitslehrer. Umso wichtiger ist der Verzicht Ben Siras auf diese Autorenzuschreibung.

${ }^{31}$ Vgl. Weisheit Salomos, Testament Salomos, Psalmen Salomos. Zur Bedeutung Salomos im Frühjudentum: Torijano 2002.
} 
Bild geht vor allem auf die Darstellung der Kapitel 3 (besonders V. 12), 5 und 10 des 1. Königsbuches zurück, in denen Salomos Weisheit und seine literarische Produktion beschrieben werden:

5,9 Und Gott gab Salomo sehr große Weisheit und Verstand und einen Geist, so weit, wie Sand am Ufer des Meeres liegt,

10 dass die Weisheit Salomos größer war als die Weisheit von allen, die im Osten wohnen, und als die Weisheit der Ägypter.

11 Und er war weiser als alle Menschen ... und war berühmt unter allen Völkern ringsum.

12 Und er dichtete dreitausend Sprüche und tausendundfünf Lieder.

13 Er dichtete von den Bäumen, von der Zeder an auf dem Libanon bis zum Ysop, der aus der Wand wächst. Auch dichtete er von den Tieren des Landes, von Vögeln, vom Gewürm und von Fischen.

Besonders deutlich ist dann das author-fashioning in Pred 12,9f.:

12,9 Es bleibt noch übrig zu sagen: Der Prediger war ein Weiser und lehrte auch das Volk gute Lehre, und er erwog und forschte und dichtete viele Sprüche.

10 Er suchte, dass er fände angenehme Worte und schriebe recht die Worte der Wahrheit.

Deutlich ist auch die unterschiedliche Akzentuierung zwischen beiden Texten: In 1 Kön geht es neben der Weisheit um Spruch- und Lieddichtung, besonders mit enzyklopädischem Charakter, im Prediger kommen der ethische und der ästhetische Aspekt der Weisheitslehre hinzu. Literaturgeschichtlich dürfte die Zuschreibung des Hohenliedes zu Salomo besonders interessant sein. Hier liegt keine Weisheitsliteratur vor, die sich auf Salomo als weisen König zurückbeziehen könnte, sondern eine Überarbeitung älterer hebräischer Liebeslieder, die wohl aufgrund der Überlieferung von Salomos exzessivem Liebesleben mit Salomos Namen und seiner Autorität in Verbindung gebracht wurden. Die Salomoszene in Hoheslied 3,6-11 bot die Textgrundlage für eine Anknüpfung an Salomo als Verfasser. ${ }^{32}$ Datiert man die vorliegende Fassung des Hohenliedes etwa mit Hans-Peter Müller in das Jerusalem des dritten Jahrhunderts v. Chr. und stellt eine deutliche Nähe zur zeitgenössischen griechischen Liebeslyrik her, ${ }^{33}$ dann wird der Unterschied zu Sirach besonders augenfällig: im Hohenlied die traditionale Einkleidung und die Anknüpfung an Salomo, bei Ben Sira - ein oder zwei Generationen später - die selbstbewusste Orthonymie. Schon hier sei darauf hingewiesen, dass das hebräische Hohelied Teil der hebräischen Bibel wurde, während das hebräische Sirachbuch diese Stellung nicht erreichte. $\mathrm{Ob}$ Ben Sira dies allerdings überhaupt intendierte, wenn er nicht mit der Autorität Salomos schrieb, muss noch gefragt werden.

Dass wichtige Teile der Literatur des Alten Israel den großen Königen David und Salomo zugeschrieben werden, hat ebenso Auswirkungen auf das Königsbild Israels wie auf die uns hier interessierende Frage nach der Autorisierung

\footnotetext{
${ }^{32}$ Insgesamt begegnet Salomo 1,1.5; 3,7.9.11; 8,11-12.

${ }^{33}$ Müller 2000.
} 
von Schriften, die durch diese Zuschreibung kanonisch werden sollten: Beide Größen autorisieren sich im Sinne der Zuschreibungen gegenseitig. Der Königspalast und die königliche Kanzlei werden als Plätze der Literaturproduktion, ja als wesentliche Zentren des „Literaturbetriebs“ vorgestellt. Wenn die Psalmen überwiegend als „königliche Literatur“ eingekleidet werden, wird zugleich das enge Bündnis zwischen Königtum und Tempel und, im weiteren Sinne, zwischen Staat und Religion demonstriert. Ben Sira führt genau diese Verbindung in Kapitel 50 mit seinem Preislied auf den Hohenpriester Simon II. (219-196 v. Chr.) unter den politisch sehr anderen Bedingungen der Ptolemäerherrschaft fort. Traditionell eng und wieder durch die Gestalt Salomos vermittelt ist auch das Verhältnis von Weisheit und Königtum. Die vorsiracidische Weisheitslehre und -literatur stellt sich selbst also hauptsächlich als höfische Literatur vor, was für die ältere Weisheitsliteratur wohl auch weitgehend der Realität entspricht. Die uns nicht bekannten real-historischen Autoren schreiben im Mantel der großen Könige Israels.

$M_{o s e}{ }^{34}$ ist in der jüdischen und christlichen Tradition der wichtigste Autor der hebräischen Bibel. Das gilt aber nicht für die Tora selbst. In Dtn 31,9. 22. 24 wird nur berichtet, Mose habe vor seinem Tod „das Gesetz“, „das Lied“35 und „das Buch dieses Gesetzes“ aufgeschrieben und neben die Bundeslade legen lassen $(31,26)$, das heißt, das Deuteronomium erklärt sich selbst in mehreren, nicht klar aufeinander abgestimmten Anläufen zu einem „Mosebuch“ im Sinne der Verschriftlichung von Gottesrede. Eckart Otto hat besonders darauf hingewiesen, dass nach der Darstellung im Pentateuch selbst Mose lediglich die Gesetze verschriftlicht habe, in der jüdischen Auslegungstradition dann aber Mose zum Verfasser des gesamten Pentateuchs wurde. ${ }^{36} \mathrm{Um}$ Otto zu zitieren: „Die Karriere des M[ose] als lit[erarische] Gestalt beginnt im 7. Jh. und lässt ihn in bab[ylonischer] und pers[ischer] Zeit zur Zentralgestalt des Pentateuch werden. ${ }^{{ }^{37}}$ Die damit entstehenden literaturgeschichtlichen und theologischen Aporien sind bekannt. Der Ausdruck „literarische Gestalt“ von Otto - im Sinne von „Autorengestalt“ zu verstehen - weist einerseits zurecht auf die langsame Stilisierung des Mose als eines Schreibers und Schriftstellers hin, ohne aber zu verdecken, dass es sich im Sinne von Dtn 31 - und auch im Sinne aller späteren Ausweitungen der literarischen Tätigkeit des Mose - stets nur um protokollartige Niederschriften göttlicher Gesetze handelt. Mose schreibt nieder, was er gehört hat. Und er schreibt stets „im Auftrag von ..." Das bedeutet: Mose ist gerade nicht als Autor imaginiert. Die Gesetzestexte des Pentateuch sind vielmehr auf "Gott als Autor" zurückzuführen - eine theologische Denkfigur, die nicht erst Teil der lutherischen Orthodoxie, sondern - wie erwähnt - bereits

\footnotetext{
${ }^{34}$ Vgl. Feldman 1992, 1993 sowie Robertson 2007 sowie Römer 2007 und Witte 2015b.

${ }^{35}$ Dtn 32,1-43.

${ }^{36}$ Otto, E. 2001.

${ }^{37}$ So zusammenfassend und thetisch Otto 2002, 1534-1538; Zitat S. 1538.
} 
Grundlage jüdischer ${ }^{38}$ und altchristlicher Schriftauslegung war und als solche auch gegenwärtig in den verschiedenen konfessionellen und religionsbasierten Hermeneutiken Verwendung findet. ${ }^{39}$

Eine eigentümliche Zwischenposition zwischen Gesetzgeber, Schreiber und Schriftsteller nimmt der Priester Esra ein. ${ }^{40}$ Interessanterweise ist ein Teil des Esrabuches von Esr 7,27 bis 9,15 als Ich-Bericht geschrieben. Dabei wird in der Forschung diskutiert, ob es sich bei dieser Textpassage um die Umarbeitung einer ursprünglichen Denkschrift Esras handelt (K. Koch) oder um eine historische Erzählung (A. Gunneweg). ${ }^{41}$ Wie dies auch sei - Esra wird von der alttestamentlichen Wissenschaft nicht als realer Autor des Esrabuches angenommen, auch wenn Vieles dafür spricht, dass er eine historische Person war. ${ }^{42}$ In jedem Fall wurde er zu einer religiös-literarischen Autorisierungsgestalt für verschiedene nicht kanonisierte Esraschriften. In der wichtigsten Schrift der Esraliteratur, dem 4. Esrabuch ${ }^{43}$, wird Esra nicht als Priester, „Schreiber“ oder Chronist, sondern als apokalyptischer Prophet von höchst anspruchsvollem literarisch-theologisch-philosophischem Niveau entworfen. ${ }^{44}$

Die Frage der Autorisierung der Propheten lässt sich einerseits sehr einfach beantworten: Sie geben „Sprüche des Herrn“ („so spricht der Herr ...“) wieder und sind dadurch direkt autorisiert, wenn auch um die Legitimität dieser Autorisierung in Israel heftig gestritten wurde. Die Sprüche gehen, wie die Bücher der Schriftpropheten darstellen, zu einem gewissen Teil auf historische Gestalten wie Jesaja zurück, deren Biographie ebenfalls mindestens bruchstückhaft erzählt wird, während die jeweiligen Prophetenbücher das Ergebnis von Wachstums- und Redaktionsprozessen wohl aus den Prophetenschulen sind. ${ }^{45}$ Allerdings sind in der Prophetenforschung nicht nur die historische Gestalt und das religionsgeschichtliche Profil der Propheten, sondern auch die traditionsund redaktionsgeschichtliche Analyse und die Literaturgeschichte der einzelnen Prophetenbücher so umstritten, dass hier allgemeine Aussagen kaum gemacht werden können. In unserem Zusammenhang bleibt aber festzuhalten, dass auch die Propheten als historische und literarisch tätige Personen dargestellt werden und die Prophetenbücher nicht anonym überliefert sind oder als reine Gottesrede gefasst werden. Autorenliteratur im Sinne des real-historischen Autorbegriffs sind diese Bücher aber nicht.

\footnotetext{
${ }^{38}$ Das gilt auch für Paulus.

${ }^{39}$ Dazu: Bayer 1999.

${ }^{40}$ Vgl. den Überblicksartikel Esra/Esrabücher von Koch 1999.

${ }^{41}$ Gunneweg 1985.

${ }^{42}$ Vgl. Witte in: Gertz 2009, 518.

${ }^{43}$ Maßgeblicher Kommentar: Stone 1990.

${ }^{44} \mathrm{Zu}$ der umfangreichen und unübersichtlichen Literatur unter dem Namen Esras vgl. die Tabelle bei Koch 1999, 1582.

${ }^{45}$ Einführung in die sehr kontroverse literaturgeschichtliche Forschungslage bei Schmid 2009, 313-324 sowie Gertz 2009, dort S. 335 f. einführend zum „Problem des historischen Jesaja“.
} 
Ben Sira ist der erste Schriftsteller in Israel, der im letzten Teil seines Weisheitsbuches auf die gesamte Geschichte, wie sie in der hebräischen Bibel enthalten ist, zurückblickt: von Henoch bis zu Serubbabel. ${ }^{46}$ Er führt diesen Überblick bis zu seinem Zeitgenossen, dem Hohenpriester Simon II. (218-192 v. Chr.), weiter: ein Beleg dafür, dass für Ben Sira die Geschichte Israels eine Einheit darstellt, literarisch entworfen als ununterbrochene Kette führender Männer. ${ }^{47}$ Wie ist nun Sirachs eigene Sicht auf die großen Männer Israels und ihr Verhältnis zur Literatur? Was nimmt er von dem eben beschriebenen author-fashioning in Israel wahr? Ben Sira bestätigt sehr konventionell den ersten Teil des Bildes, das ich gerade gezeichnet habe: David ist für ihn der Liederdichter und Mäzen der Tempelmusik (47,9f.), Salomo der Weisheitsdichter (47,14. 17). Weder Mose noch die Propheten kleidet Sirach in das Gewand des Autors. Alle sind sie „begnadete Männer" 48 und Israels Väter $(44,1)$, alle sind sie bedeutend, weise und voll prophetischer Kraft (44,3 f.), niemals Schriftsteller. Auffallend ist aber, dass Ben Sira in der Eingangsstrophe seines Enkomions (44,1-15) nicht nur ihr Herrschertum hervorhebt, sondern auch ihr Verhältnis zur Sprache und Literatur:

4 Fürsten von Völkern in ihren Erwägungen

Und Herrscher in ihren Entscheidungen, weise Denker in ihrer Treue zur Überlieferung,

5 die da erforschen Lieder nach ihrer Regel, die da Sprüche vortragen nach schriftlicher Überlieferung,

6 charaktervolle Männer, die sich auf ihre Stärke stützen

Und denen ein ruhiges Wohnen in ihren Besitzungen vergönnt ist.

In den Versen 4c, 5 und 6 sehen wir nicht die Heroen Israels, sondern Ben Sira selbst nach dem Vorbild der Könige David und Salomo vor uns. Der weise Literat schreibt hier sein eigenes Profil in den Katalog der Väter Israels ein, die er im Übrigen eher konventionell darstellt.

Wenn wir versuchen, von diesem skizzenhaften Tableau zu Einsichten zum Autorenbegriff der Literatur des Alten Israel zu kommen, zeichnen sich zwei Ergebnisse ab. Erstens versteht sich diese Literatur bei aller traditions- und redaktionsgeschichtlichen Entwicklung durchaus nicht in toto als anonym, etwa als Zusammenstellung von Volkssagen, Volksliedern, Volksweisheit, mündlichen Geschichtsüberlieferungen und Gesetzen, sondern zum größeren Teil als Literatur prominenter Autoren. Es sind Könige und Propheten, Weise und Priester, denen die Rolle von Autoren beigelegt wird. Gerade die Einleitung in das Lob der Väter bei Ben Sira macht diese Perspektive ganz deutlich: Die „Männer der Vorzeit“ sind Helden, Fürsten, Weise und Propheten, die jeweils als eminente Individuen gedacht sind, nicht als „Stimme des Volkes“. Zweitens muss zwischen Mose und den Propheten einerseits und David und Salomo

\footnotetext{
${ }^{46}$ Sir 44,1-50,24.

${ }^{47} \mathrm{Vgl}$. Maertens 1956.

${ }^{48}$ Übersetzung nach: Sauer 2000.
} 
andererseits unterschieden werden. Ich habe darauf hingewiesen, dass sowohl Mose als auch die Propheten Gottessprüche und -gesetze empfingen. Insoweit wurden sie als authentische und autorisierte Schreiber, nicht als autarke Autoren modelliert. Die Legitimität ihrer Schriften war Offenbarungslegitimität. Anders steht es mit David und Salomo: Die Könige wurden in den Psalmen und Weisheitsschriften durchaus als selbstverantwortete Dichter und Schriftsteller dargestellt. Historisch-reale Autoren im literaturwissenschaftlichen Sinne waren sie nicht. In den Zuschreibungen konnte sich aber das überaus starke Interesse des Alten Israel an Dichtung (Psalter, Hoheslied, Hiob, Königsgeschichten) und ihre Hochschätzung in einer der Religion und der Identität des „Volkes Israel“ angemessenen Weise äußern. Die „Nationalliteratur“ des Alten Israel ${ }^{49}$ - sit venia verbo - wurde in einer zentripetalen Bewegung an führende Personen der Geschichte Israels gebunden und durch die schrittweise Kanonisierung ebenso bewahrt wie religiös ausgezeichnet. Damit ist die Basis für das Autorverständnis, auf dem Sirach aufbaute und das er um seine eigene Konzeption bereicherte, skizziert.

\section{Beziehungen zwischen Autorenkonzept, Gattung, Textproduktion und -rezeption bei Sirach}

Das Autorkonzept Ben Siras ist vor allem Teil seines Bildes vom „Weisen“ bzw. Gelehrten (38,24): das längst eingeführte Konzept (Spr 1,1-6; Pred 1,1) des weisen, vielerfahrenen $(34,9)$ Ratgebers, Forschers und Lehrers, der seine Lehrvorträge auch schriftlich festhält. Dabei ist Salomo nicht der gedachte Verfasser des Sirachbuches, wohl aber das literarische Vorbild Sirachs. Sirach schreibt über Salomo:

47,17 Durch Lied, Spruch, Rätsel und Spottgedicht setztest du Völker in Erstaunen.

Eben dies tut Sirach nun aber nicht mehr unter der Autorität - so das Sprüchebuch - oder in der literarischen Rolle oder persona - so mindestens Teile des Hohenliedes - des Salomo, sondern unter seiner eigenen Autorität als Jerusalemer Weisheitslehrer, der für sich in Anspruch nimmt, die wohlsituierten jungen Männer Jerusalems zu erziehen. Der Lehrvortrag 38,24 bis 39,35 ist als Aretalogie des Weisen konzipiert, dessen Profil durch die Kontrastierung mit anderen „Berufen“ - Bauern und Handwerker - geschärft wird. In diesem Lehrgedicht finden wir Sirachs Selbstverständnis als Weisheitslehrer kunstvoll in der dritten Person expliziert. Vom „Weisen“ gilt: Er kennt und interpretiert die weisheit-

${ }^{49}$ Vgl. die Überlegungen bei Siegert 2016, 230, zur Septuaginta als „Beginn einer jüdischgriechischen Nationalliteratur“. 
liche und prophetische Literatur Israels (39,1-3). Er ist Fürstenratgeber $(39,4)$ und sammelt Erfahrungen auf Reisen $(39,4)$. Er betreibt Theologie $(39,5)^{50}$ und betet in gehobener und vorbildlicher literarischer Weise - daher die relativ häufigen und gewichtigen Gebete im Sirachbuch ${ }^{51}$ - und wird inspiriert $(39,6)$. Er fungiert als allgemeiner Ratgeber und Lehrer $(39,8)$. Wichtig ist die Kompetenz des Weisheitslehrers im „Gesetz des Bundes“ (39,8). Ben Sira ist der frühjüdische Theologe, der Weisheit und Tora zusammengedacht $t^{52}$ und damit den Weisen zu einer Art von jüdischem Universaltheologen gemacht hat. Die Aretalogie schließt mit der Verherrlichung des Ruhmes und des späteren Gedenkens des Weisen, der eine öffentliche nationale und internationale Rolle spielt und in die memoria Israels eingeht (39,9-11). Als Autor zu fungieren, gehört nicht explizit zu diesem Konzept, das ganz traditionell auf Mündlichkeit und politischer sowie pädagogischer Kommunikation beruht. Aber 39,1-3 zeigen doch, dass der Weise als Kenner der nationalen Literatur verstanden wird und diese selbst weiter fördert. Die philologisch-literarische Kompetenz - wenn man das so nennen soll - des Weisen wird in 44,4f. nochmals angesprochen:

44,1 Ich will nun preisen begnadete Männer unsere Väter in ihren Geschlechtern ...

44,4b weise Denker in ihren Schriftkenntnissen Und Spruchdichter in ihrer Treue zur Überlieferung.

44,5 Die da erforschen Lieder nach ihren Regeln, die da Sprüche vortragen nach schriftlicher Überlieferung.

Am Ende von Kap. 50 findet sich eine erste rückblickende Zusammenfassung des Werkes, die deutlich macht, was Sirach besonders wichtig ist: die Verbindung seiner Erziehungstätigkeit mit seiner Spruchdichtung, deren charismatischer Charakter und ihre gesellschaftliche Wirkung:

50,27 Erziehung, Einsicht und Spruchdichtung der (verschiedenen) Lebenslagen

von Simon, dem Sohn des Jeschua, dem Sohn des Eleasar, dem Sohn des Sira, die hervorströmten aus der Erforschung seines Herzens, und die er hervorströmen ließ in Einsicht.

28 Wohl dem Manne, der über sie nachsinnt, und wer sie sich zu Herzen nimmt, wird weise werden.

Wenn Sirach im Schlusslied 51,13-30 noch einmal die Relevanz seiner Lehre $(51,28)$ betont und auf das Weiterbestehen seines „Lehrhauses“ hinweist ${ }^{53}$, konkretisiert er seine Rolle als Weisheitslehrer und weisheitlicher Schriftsteller.

50 „Seinen Sinn richtet er darauf, zu erklären / vor dem Herrn, der ihn erschaffen hat, / und vor dem Höchsten betet er" (Übersetzung Sauer 2000, 268). Theologie, d.h. Nachdenken über Gott, die Schöpfung und besonders den Menschen, ist stets mit Frömmigkeitspraxis verbunden.

${ }^{51}$ Dazu Wischmeyer 1995, 267-270; Urbanz 2009.

${ }^{52}$ Grundlegend: Marböck 1999.

${ }^{53}$ 51,23: „Wendet euch zu mir, ihr Ungebildeten, und ruht im Haus meiner Lehre“ (Sauer 2000, 349). Zu den Übersetzungsmöglichkeiten von bebet midrashi vgl. Skehan/di Lella 1987, 
Dass Ben Sira sich nicht nur als als konservativer Weisheitsdichter darstellt, sondern auch eine andere Spielart des author-fashioning oder der auktorialen Selbstdarstellung beherrscht, wird deutlich, wenn wir die Gattung seines Buches betrachten. Die Gattungskennzeichen der Weisheitsdichtung in Israel Spruchweisheit in Gnomen (meshalim) oder in kleineren oder größeren Formen, thematischen Abschnitten und/oder Lehrvorträgen - und die Thematik der Weisheitsschriften - Ethik, Lebensklugheit, Beobachtungen zu verschiedenen Lebenssituationen - sind traditionell bestimmt und eng aneinander gebunden, lassen aber auch Raum für Erweiterungen, den Ben Sira ausgiebig nutzt. ${ }^{54}$ So fügt er nicht nur Gebete ein, sondern auch den bereits genannten umfangreichen Schlussvortrag über „die Väter der Vorzeit“ (Kap. $44 \mathrm{ff}$.), der das Thema der Geschichte Israels in die Weisheit integriert, die von Hause aus nicht historisch denkt und fragt. ${ }^{55}$ Ebenso baut Sirach konsequent das Thema der Weisheit als eigener theologischer Größe aus und vertieft seine theologischen Reflexionen über Weisheit und Weisheitslehre. ${ }^{56}$

In diesen Texten begegnen persona-Passagen, in denen der Weisheitslehrer hinter der Weisheit verschwindet, die selbst im Ich-Stil spricht und ihr Wesen offenbart (4,15-19; 24,1-22.23-29), neben Autor-Passagen, die den Weisheitslehrer und -dichter in der dritten oder ersten Person direkt thematisieren $(15,10$; 24,30-34; 39,1-11.12.32; 42,15; 44,1). In den Ich-Passagen, in denen die Weisheit spricht, tritt Sirach seine auktoriale Rolle als Weisheitslehrer an die persona der Weisheit ab. Dies ist die höchste Möglichkeit der Selbstautorisierung seiner Schrift. Diese - literarisch besonders sorgfältig gearbeiteten - Passagen gehören zu dem mythologischen Deutungskonzept der „Frau Weisheit“ ${ }^{57}$, die in einer theologisch ungeklärten Weise an der Schöpfung beteiligt und durch die Geschichte hindurch Israel-Jerusalem verbunden war. 24,3-22 ist weisheitliche Selbstoffenbarungsrede, 24,23-29 ein kommentierendes Lob des Gesetzes, und in 24,30-34 hören wir wieder das Ich des real-historischen Autors, des Weisheitslehrers, der sich metaphorisch als Wasserleitung der Bildung bezeichnet. Das Ich des Lehrers Ben Sira - und damit auch des real-historischen Verfassers - hören wir vor allem in $24,30-34^{58}$ und besonders deutlich in 51,28. In 51,28 fehlt die weisheitliche Einkleidung, die wir vorher in dem abschließenden Loblied auf die

578. Der Wendung lässt sich nicht eindeutig entnehmen, ob Sirach schon so etwas wie ein institutionalisiertes „Lehrhaus" betrieb oder ob die Wendung mindestens halb metaphorisch zu verstehen ist. Deutlich ist aber, dass Sirach jungen Männern in Jersusalem „Weisheitsunterricht" gab und seine Lehren schriftlich niederlegte. Zum Thema Schule/Lehrhaus grundlegend: Lemaire 1981; Wischmeyer 1995, 175-177 (ältere Lit.); Ueberschaer 2007, 60-134.

${ }^{54}$ Vgl. Witte, Texte, 7-9 zur Lit.

${ }^{55}$ Zur Geschichte bei Ben Sira vgl. meine Bemerkungen: Wischmeyer 1995, 273-278.

56 4,11-19; 14,20-15,10; 18,27-29; 19,18-20; 24,1-34; 38,24-39,11; 39,12-35; 50,27-29; 51, $13-50$.

${ }^{57}$ Einführend: Witte in: Gertz 2009, 449.

${ }^{58}$ Zum Text: Ueberschaer 2007, 301-305. 
Weisheit (51,13-30) antreffen. Letzterer Text ist von besonderem Interesse, weil hier weisheitliches Autor-fashioning und reales Autoren-Ich kombiniert sind. Sirach schreibt einen autobiographischen Rückblick über seine Begegnung mit der Weisheit seit seiner Kindheit:

13 Ein Knabe war ich früher, da irrte ich umher, da hatte ich Gefallen an ihr und suchte sie.

14 Sie kam zu mir in Schönheit, und bis zu ihrem Ende will ich sie suchen ...

17 Eine Amme war sie mir, meinem Lehrer erstatte ich meinen Dank ...

19 Ich brenne nach ihr, und mein Angesicht wende ich nicht ab ...

20 Mein Inneres ist erregt wie ein Ofen, sie zu schauen, weil dies so ist, erwerbe ich sie als einen guten Besitz ...

Die Weisheit wird als schöne junge Frau (im Sinne der Brautmetapher) und gleich darauf in typischer Metaphernhäufung als Amme, aber auch als „Besitz“ angesprochen: verschiedene Möglichkeiten und Stadien des Verhältnisses eines Mannes zur Frau. In den folgenden Versen 23-30 wendet sich Ben Sira zum letzten Mal werbend an sein Hörer- beziehungsweise Lesepublikum und stellt noch einmal eine Beziehung zum Publikum her:

23 Wendet euch mir zu, ihr Ungebildeten, und ruht im Haus meiner Lehre ...

28 Viele waren es, die gehört haben meine Lehre in meiner Jugend.

Ben Sira verbindet sein Leben und seine Existenz aufs Engste mit der Weisheit und mit seinem Lehrhaus $(51,23)$, in dem er Bildung vermittelt. Dabei denkt er immer zunächst an den mündlichen Vortrag. Die Selbstcharakterisierung:

51,25 Meinen Mund tat ich auf und redete von ihr

bestätigt das orale Grundmodell und ist gleichzeitig ein klassisches Kolophon am Ende des Sirachbuches:

51,30 Bis hierher reichen die Worte Simons, des Sohnes Jeschuas, der genannt ist Ben Sira.

Die Weisheit Simons, des Sohnes Jeschuas, des Sohnes Eleasars, des Sohnes Siras. Es sei der Name des Herrn gepriesen von jetzt an bis in Ewigkeit.

Orales Modell mündlicher Unterweisung und Verschriftlichung stehen also nicht gegeneinander, sondern in einem Folgeverhältnis.

Es ist die Gattung der Weisheitsschrift, die es dem Autor Ben Sira erlaubt, mit verschiedenen Autorkonzepten zu spielen und sein persönliches „modernes“ Konzept des Weisheitslehrers, der ein Buch schreibt, in die klassischen Konzepte des Weisheitslehrers in der Tradition Salomos und des zwischen Mythos und Metapher changierenden Konzepts der Frau Weisheit als der höchsten Autorisierungsinstanz einzuzeichnen. Der häufige Wechsel des „Ich“, die many 
voices des real-historischen Autors Ben Sira werden durch die dichterische Unschärfe der Weisheitsgestalt und der Weisheitstheologie ermöglicht.

Für die Buchproduktion ist 39,32 besonders wichtig, weil Sirach hier als realer Autor von seiner schriftstellerischen Tätigkeit spricht:

Darum habe ich mich von Anfang an fest daran gehalten, habe es sorgfältig bedacht und legte es in einem Buche nieder.

Damit sind wir bei der Textproduktion, über die wir ehrlicherweise nur Vermutungen anstellen können. Ben Sira hat getan, was er in 41,14b einmal explizit macht:

Unterricht über die Scham vernehmt, Unterricht über die Scham!

Unterricht über die Scham vernehmt, ihr Söhne!

Er hat Lehrvorträge zu bestimmten Themen zusammengestellt wie zum Beispiel "Zucht des Mundes“ $(23,7-15)^{59}$, Belehrung über das Gastmahl $(31,12-32,13)^{60}$, über Frauen (25,13-26,27), über Krankheit, Gesundheit und den Arzt und das Sterben $(37,29-38,23)$. Für diese, aber auch für die spezifisch der Weisheit gewidmeten Passagen, für die Gebete und für den Rückblick auf die großen Männer Israels gilt Zweierlei: Einerseits bleibt Ben Sira bei dem literarischen Grundmuster des zweizeiligen, oft antithetisch strukturierten und gnomisch formulierenden Einzelspruches, wie es der Weisheitstradition Israels entspricht. Oft geht es um glückliche Einzelformulierungen, die eine Einsicht mit einem Rat und einem Hinweis auf Erfolg oder Misserfolg verbinden und durchaus als zu memorierender Einzelspruch im Sinne eines Sprichwortes entstanden sind. Solche Sprüche können zu thematischen Lehreinheiten zusammengestellt werden. Einige dieser thematischen Einheiten, besonders solche, die klassischen Themen wie Frauen, Kinder, Gesinde gelten, werden weiter ausgedehnt zu kleinen Traktaten (so besonders die Lehre über das Gastmahl, aber auch theologische Themen wie „Was ist der Mensch“? 33,7-18), die auch eine bestimmte Form der Argumentation und der Entwicklung eines Gedankenganges ermöglichen. Was davon zunächst mündlich vorgetragen wurde und was erst bei der Niederschrift entstand, lässt sich nicht sagen. Sicher ist, dass das Sirachbuch in seiner Endgestalt bereits von Ben Sira und nicht von dem Enkel als Buch konzipiert und - wie man sich dies auch vorstellen mag - herausgegeben worden ist, und zwar nicht am Ende seines Lebens, sondern während seiner Lehrtätigkeit. Die Groß-Komposition ist klar strukturiert: Ben Sira beginnt mit einem umfangreichen Lob der Weisheit in Kap. 1, fügt eine Zäsur nach dem Schöpfungslob in 42,15-43,33 ein, schließt das Lob der Väter der Vorzeit an und führt das Buch bis in seine direkte Gegenwart fort. Der erste Schluss findet sich in 50,27-29.

\footnotetext{
${ }^{59}$ Diese Überschrift entstammt dem griechischen Text.

${ }^{60}$ Die Überschrift „Lehre über Brot und Wein gleichzeitig“ stammt aus der hebräischen Überlieferung $\left(\mathrm{H}^{\mathrm{B}}\right)$.
} 
Kapitel 51 enthält einen kompliziert gebauten Psalm und die schon erwähnte autobiographische Retrospektive und Selbstvorstellung und -empfehlung des Verfassers - beides auch schon in der Übersetzung des Enkels vorhanden. Ben Sira hat damit einerseits an den traditionellen Vorgaben weisheitlicher Dichtung festgehalten, die verschiedene Stoffe und Themen in kleinen Einheiten reihend nebeneinanderstellen, andererseits sowohl bei den Einzelteilen als auch in der Gesamtkonzeption ein bestimmtes Ziel verfolgt und ein eigenständiges weisheitliches Literaturwerk, ein Weisheitslebrbuch, verfasst.

Die Textrezeption ist im Fall des Sirachbuches besonders interessant, da wir es hier mit einem literarisch-kanonischen Hybrid zu tun haben. Sirach gehört, legen wir die christliche Bibel als Maßstab an, zu der kleinen Gruppe sog. deuterokanonischer (katholischer terminus technicus) oder apokrypher (protestantischer terminus technicus) Literatur des Alten Testaments. Aus der Perspektive der hebräischen Bibel handelt es sich schlicht um außerkanonische hebräische Literatur, deren Status aber diskutiert wurde. Aus der Septuagintaperspektive, die die Position der griechischsprachigen Juden war und bis heute die offizielle Perspektive der orthodoxen Kirchen und in der lateinischen Übersetzung der Vulgata auch der katholischen Kirche ist, ist das Sirachbuch ebenso schlicht kanonisch. Wir fragen hier im Zusammenhang der Autorenproblematik nach dem Verhältnis von realem Autor, Legitimierungsstrategien und Kanonisierungsansätzen. Aus dem Gesagten geht bereits hervor, dass der reale Verfasser Jesus Ben Sira einerseits darauf verzichtete, die Autorengestalt Salomos für die mögliche Kanonisierung seines Werkes zu instrumentalisieren, und stattdessen sein Buch unter seinem eigenen Namen herausbrachte. Unter Umständen schadete dieser Verzicht auf königliche Legitimierung dem Kannisierungsprozess seiner Schrift. Andererseits betrieb er durchaus Autor-fashioning, vor allem in seinem autobiographischen Schlusstext, in dem er reale Biographie mit klassischen Metaphern aus der "Salomodichtung“ mischt.

Gab Ben Sira selbst Rezeptions- oder sogar Kanonisierungsanweisungen? Diese Frage wird, soweit ich sehe, kaum gestellt. Sicher ist es, dass Sirach Eigenwerbung betreibt und häufig auf die Vorteile hinweist, die die Lektüre seines Buches bringt. Aber wichtiger ist ihm, dass sein Lebrbetrieb "funktioniert" (51,23-29). Daraus geht hervor, dass Sirach selbst sein Werk „publiziert“ haben muss, und zwar nicht am Ende seines Lebens, sondern während des Lehrbetriebs, und dass er mit dem gesamten Werk für sein Lehrhaus wirbt und am Ende explizite Reklame betreibt. In die Nähe solch aktueller Selbstwerbung kann man auch den schon erwähnten Lobpreis auf den Hohepriester Simon II. zählen. Ben Sira stellt sich ganz deutlich in die Nähe dieses höchsten Religionsfunktionärs in Jerusalem. Von einer Kanonisierungsabsicht ist dagegen nichts zu spüren. Das „Lehrhaus“ wird in der Literatur gern als eine dem Kepos oder der Akademie vergleichbare lockere Bildungs- und Diskussionsstätte auf privater Basis entworfen. Allerdings ist der Schulcharakter in Sirachs Lehrhaus doch 
deutlicher. Die Jünglinge Jerusalems sollen lernen, nicht diskutieren oder ein gemeinsames Leben mit Sirach führen. Wichtig ist aber die literarische Komponente des Schulbetriebes. Da Sirach die Weisheitslehre bei aller Innovation doch stets in Analogie zu Salomo entwirft und sich im Genre der in Israel geübten Weisheitsdichtung bewegt, werden die Jünglinge zwar nicht philosophisch, ${ }^{61}$ wohl aber literarisch erzogen:

32,4 Beim Gelage sollst du keine Gedanken vortragen, sondern Lieder.

Sirach setzt voraus, dass zur Kultur, wie er sie lehrt, nicht nur Weisheitsvorträge - ob beim Gelage oder im Lehrhaus - gehören, sondern auch schöne Lieder (32,3-6). Ihm ist sehr bewusst, dass er selbst als Weisheitsdichter tätig ist und seine Dichtung verschriftlicht und zur Weisheitsliteratur macht.

\section{Der Prolog: die Leistung und Bedeutung des Sirachbuches und der Übersetzung}

Die stupende Arbeit der Übersetzung des Sirachbuches ins Griechische durch eine Person, den Enkel des Verfassers, habe ich bereits als eigene literaturgeschichtliche Leistung gewürdigt. ${ }^{62}$ Der Prolog zeigt - ganz anders als die vollständig unrealistische Übersetzungslegende im Aristeasbrief ${ }^{63}$-, wie sehr der Enkel mit dem Übersetzungsproblem ringen musste. Immerhin konnte er auf die Übersetzungsarbeit jüdischer Philologen in Alexandria zurückgreifen, die bereits die Tora und die Propheten und andere „Schriften“, das heißt die älteren Weisheitsbücher, übertragen hatten (Prolog 24-26). Für unsere Thematik ist entscheidend, wie der Enkel das Werk des Großvaters präsentiert. Mehrere Punkte sind dabei wichtig. Erstens: Die Literatur Israels wird im Ganzen als „Bücher der Väter" bezeichnet (10), die zunächst denjenigen zur Verfügung stehen, die lesen können (4). Sie enthält paideia kai sophia (3), wird also in toto (auch Tora und Propheten) mit weisheitlichen Kategorien beschrieben. Zweitens: Der Großvater war in den Schriften Israels gut bewandert: Er las „die Bücher der Väter“ - er hörte sie nicht nur. Drittens: Auf dieser Basis unternahm es Sirach, „auch selbst (autos) etwas zu schreiben, was sich mit Erziehung und Weisheit befasst" (8). Hier wird die historische bzw. individuelle Autorenrolle des Großvaters am deutlichsten ausgesprochen. Viertens: Das eigene Buch Ben Siras ist, zumindest in den Augen des Enkels - derselben Thematik gewidmet wie die bereits vorhandenen Schriften. Fünftens: Seine Intention war es, als jemand, der selbst

${ }^{61}$ Dazu Wischmeyer 1995, 174-200.

${ }^{62}$ S.o. Anm. 22. Zum Problem antiker Übersetzungstätigkeit vgl. Dochhorn 2009, 623.

${ }^{63}$ Aristeasbrief 301-307.310. 
die Schriften Israels lesen konnte (auf Hebräisch), „denen, die außen sind“, 64 nützliche Weisheitsbildung durch Worte - mündliche Lehre - und Schrift zu vermitteln (4-6). Das heißt, der Enkel versteht das Werk des Großvaters als zusätzliche weisheitliche Lehre, ohne deutlich zu machen, wie sich der Status des neuen Werkes zu den vorhandenen Werken Israels verhalte.

\section{Kanonischer Status}

Nirgends tritt das Verständnis Ben Siras als eines Autors deutlicher in Erscheinung als in der Wendung des Enkels, der Großvater habe „auch selbst etwas niederschreiben wollen“. Ob hier das alexandrinische Autorenverständnis mitwirkt, lässt sich schwer sagen. Jedenfalls scheint der Enkel die Intention des Großvaters genau zu treffen. Ben Sira selbst führt sein „Lob der Väter“ bis in seine Gegenwart fort und macht auch nicht deutlich, dass er auf einen abgeschlossenen religiös-literarischen Kanon Israels zurückblicke. Ist damit eine Tendenz zur Selbstkanonisierung verbunden? Oder mindestens eine Kanonisierung des großväterlichen Werkes durch den Enkel vorbereitet? Hier ist Vorsicht geboten. Dass Ben Sira die Schriften vorliegen hatte, die den hebräischen Kanon ausmachen, geht aus seinem „Lob der Väter" hervor. Aber las er die hebräischen Bücher als Kanon? Oder aber als "Gesetz, Propheten und andere Schriften“ Israels, das heißt: gleichsam als Nationalbibliothek? Der Enkel jedenfalls fasst die kanonischen Schriften unter dem Oberbegriff „Lehre und Weisheit“ zusammen und rückt sie in die Perspektive einer Nationalliteratur, in deren Reihe er auch das Werk seines Großvaters stellen will. Wie nahe der Enkel damit an der Vorstellung des Aristeasbriefes von der Einordnung der Tora Israels als „der jüdischen Gesetze" (nomima Ioudaiōn) in die alexandrinische Bibliothek ist, mag hier als Frage gestellt werden. ${ }^{65}$ Allerdings macht gerade der Aristeasbrief deutlich, dass man sich vor einer einseitigen Option für Kanon heiliger Schriften versus Nationalliteratur hüten muss. Kaum eine andere frühjüdische Schrift hat ein so normatives Konzept von Kanon wie der Aristeasbrief. ${ }^{66}$ Auf jeden Fall hat der Enkel mit seiner Übersetzung dem Sirachbuch zu seiner kanonischen Stellung in der Septuaginta verholfen, obgleich er die reale Verfasserschaft durch seinen Großvater und die historischen Entstehungsbedingungen seiner Übersetzung (27-36) im Prolog darlegt.

\footnotetext{
${ }^{64}$ Das scheint sich auf die Verbindung von griechischer Sprache und Diasporasituation in Ägypten zu beziehen.

${ }_{65}^{6}$ Aristeasbrief 10.

${ }^{66}$ Auf den literarischen Aspekt des Kanonverständnisses des Aristeasbriefes weist hin: Irrgang 2012.
} 


\section{Das autobiographische und das literarische Ich bei Ben Sira und (religiöse?) Individualisierungstendenzen}

Dass es sowohl ein historisch-autobiographisches als auch ein literarisch modelliertes Ich bei Ben Sira gibt, ist bereits deutlich geworden, auch dass beide gerade in Kapitel 51 sehr bewusst und kunstvoll miteinander verbunden sind. Andererseits muss noch einmal betont werden, dass wir eine derart eindeutige und bewusst gesetzte Stimme eines autobiographischen Ich in der kanonisierten Literatur Israels vor und nach Ben Sira nicht kennen. Immerhin gehört aber auch sein Enkel mit seiner historischen Selbsteinordnung zu den ersten Zeugen einer Individualisierung jüdischer Autoren der Antike. Ohne Zweifel ist das autobiographische Ich des realen Autors Ausdruck seines Selbstverständnisses als eines eigenständigen Weisen, Lehrers und Schriftstellers. Gerade der autobiographische Text zeigt, wie weit sich Sirach seiner eigenen Person und seiner eigenen Tätigkeit sowie seiner individuellen Erfahrungen bewusst ist und wie er sie literarisch einsetzt. Auf der anderen Seite haben wir auch gesehen, wie nahe er seine Person an Salomo heranrückt, sich die Maske der Frau Weisheit vorhalten kann und sich literarisch im Bereich von Tradition, weisheitlicher Gattung, Weisheitsthematik und -metaphorik bewegt. Auch hier haben wir es mit einem Hybrid zu tun. Wie grundlegend und zukunftweisend aber die Individualisierungstendenz des Großvaters ist, zeigt zunächst der Enkel. Dann geht die Linie zu dem großen Exegeten Philon von Alexandria und seiner Legatio ad Gaium, zu den autobiographischen Einlassungen des Paulus und zu dem Historiker Josephus, der die erste jüdische Autobiographie schreibt.

Wie weit die Individuierung bei Ben Sira religiös beeinflusst ist, lässt sich kaum sagen. Ben Sira ist Teil und Träger der Religion Israels. Ein „Außerhalb“ dieser Religion gibt es nicht. ${ }^{67}$ Das alte "Ich“ der Frau Weisheit ist ein literarischer Stilzug der Offenbarungsliteratur. Wenn die ursprünglich ganz profane Weisheitsliteratur diesen Stilzug schon seit Spr 1;8 und 9 anwendet, um ihre Offenbarungsqualität zu betonen, drängt sie in die religiöse Literatur Israels hinein - mit Erfolg, wie eben schon das Sprüchebuch zeigt. Sirach denkt, lehrt und schreibt in dieser Tradition. Er setzt dies Ich häufig, und zwar ebenso mit der Intention religiöser Legitimierung. Aber daneben steht sein reales Ich, das er zwar als fromm und weise, nicht aber als spezifisch religiös im Sinne jüdischer religiöser Funktionäre entwirft. Die eigentlich religiös-funktionale Sphäre behält er seinem Zeitgenossen, dem Hohepriester Simon II. vor, dessen Lob am Ende des Väterlobes in Kap. 50 steht. Der Hohepriester wird aber nicht mit der Literatur Israels in Verbindung gebracht: Das Tempelopfer und der Gottesdienst sind der Inbegriff der Religion Israels, wie Sirach sie versteht. Daneben kultiviert

${ }^{67}$ Das gilt trotz der kulturellen Selbständigkeit des Weisheitslehrers, vgl. Wischmeyer 1995, zusammenfassend 294-297. 
Sirach die Erziehung der jungen Männer Jerusalems und entwirft seine eigene „pädagogische Provinz“. ${ }^{6}$

Der Weise und Lehrer Jesus Sirach steht neben dem Hohepriester und erhebt seinen eigenen literarischen Anspruch - selbstverständlich fromm im Sinne der Religion und Kultur Israels, aber eben ein Lehrer und selbständiger Schriftsteller seiner Zeit. Dass seine Religion zur Entwicklung seiner Individualität beigetragen haben könnte, lässt sich seinem Werk kaum entnehmen. Eher müsste man das Gegenteil annehmen: dass nämlich seine Pädagogik zu seiner Individualität als Weisheitslehrer beigetragen habe. Aber auch hier gilt: Ein scharfes Entweder Oder entspricht nicht der religiös-kulturellen Situation im Jerusalem der späten Ptolemäerzeit.

\section{Literaturverzeichnis}

Bayer, O. (1999). Gott als Autor. Zu einer poietologischen Theologie. Tübingen: Mohr Siebeck.

Beentjes, P.C. (1997). The Book of Ben Sira in Hebrew. A Text Edition of All Extant Hebrew Manuscripts and a Synopsis of All Hebrew Ben Sira Texts (Vetus Testamentum Suppl 68). Leiden: Brill.

Dochhorn, J. (2009). „Übersetzung V. Altphilologisch“, in: Wischmeyer, O., Lexikon der Bibelhermeneutik. Berlin: de Gruyter. 623-624.

Feldmann, L. (1992, 1993). „Josephus' Portrait of Moses, “ in: JQR 82, 1992, 285-328; JQR $83,1993,7-50.301-330$.

Gertz, J.H. (2009). Grundinformation Altes Testament (UTB 2745). Göttingen: Vandenhoeck \& Ruprecht.

Gunneweg, A.H.J. (1985). Esra (KAT 19,1). Gütersloh: Mohn.

Irrgang, N. (2012). „Eine Bibliothek als Kanon. Der Aristeasbrief und der hellenistische Literaturbetrieb Alexandriens,“ in: Becker, E.-M.; Scholz, S., Hgg., Kanon in Konstruktion und Dekonstruktion. Kanonisierungsprozesse religiöser Texte von der Antike bis zur Gegenwart. Ein Handbuch. Berlin/Boston: de Gruyter. 257-292.

Koch, K. et al. (1999). „Art. Esra/Esrabücher,“ in: $R G G^{4}$ 2, Tübingen: Mohr Siebeck. 1581-1589.

Kraus, W.; Karrer, M. (2009), Hgg., Septuaginta Deutsch. Das griechische Alte Testament in deutscher Übersetzung. Stuttgart: Deutsche Bibelgesellschaft.

Lemaire, A. (1981). Les écoles et la formation de la Bible dans l'ancien Israël (OBO 39). Fribourg: Universitaires/Vandenhoeck \& Ruprecht.

Loader, J. A. (2008). „Intertextualität in geschichteten Texten des Alten Testaments, “ in: Wischmeyer, O.; Scholz, S., Hgg., Die Bibel als Text. Beiträge zu einer textbezogenen Bibelhermeneutik (NET 14). Tübingen: Francke, 99-119.

Maertens, Th. (1956). L'Éloge des Pères. Ecclesiastique XLIV-L. Bruges: Editions de l'Abbaye de Saint-Andre, Collection Lumière et Vie 5.

${ }^{68}$ Dazu Wischmeyer 1995, 287-302. 
Marböck, J. (1999). Weisheit im Wandel. Untersuchungen zur Weisheitstheologie bei Ben Sira (BZAW 272). Berlin/New York: de Gruyter, [Erstauflage 1971: (BBB 37), Bonn: Peter Hanstein].

Miura, Y. (2007). David in Luke-Acts: His Portrayal in the Light of Early Judaism. Tübingen: Mohr Siebeck.

Müller, H.P. (2000). „Hohes Lied,“ in: $R G G^{4} 2$ Tübingen: Mohr Siebeck. 1838-1840.

Otto, E. (2001). Die Tora des Mose. Die Geschichte der literarischen Vermittlung von Recht, Religion und Politik durch die Mosegestalt, Göttingen: Vandenhoeck \& Ruprecht.

Otto, E. (2002). „Mose I. Altes Testament,“ in: $R G G^{4}$ 5. Tübingen: Mohr Siebeck. 15341538.

Pelletier, A. (1962). Lettre d'Aristée à Philocrate. Introduction, texte critique, traduction et notes (SC 89). Paris: Éditions du Cerf.

Pomykala, K.E. (2004). „Images of David in Early Judaism,“ in: Evans, C. A., Of Scribes and Sages: Early Jewish Interpretation and Transmission of Scripture, vol. 1. London: T\&T Clark. 33-46.

Robertson, S. D. (2007). Philo's portrayal of Moses in the Context of Ancient Judaism. Notre Dame: University of Notre Dame Press.

Römer, Th. (2007). La construction de la figure de Moïse. The construction of the figure of Moïse (Transeuphratène Suppl 13). Paris: Gabalda.

Sauer, G. (1981). Jesus Sirach (JSHRZ III,5). Gütersloh: Mohn.

Sauer, G. (2000). Sirach/Ben Sira (ATD Apokryphen Bd. 1). Göttingen: Vandenhoeck \& Ruprecht.

Schmid, K. (2009). „II. Hintere Propheten (Nebiim),“ in: Gertz, J.H., Grundinformation Altes Testament (UTB 2745). Göttingen: Vandenhoeck \& Ruprecht. 313-324.

Siegert, F. (2016). Einleitung in die hellenistisch-jüdische Literatur. Berlin/Boston: de Gruyter.

Skehan, P. W.; di Lella, A. A. (1987). The Wisdom of Ben Sira (The Anchor Bible 39). New York: Doubleday.

Stone, M. (1990). Fourth Ezra (Hermeneia). Minneapolis: Fortress Press.

Torijano, P. A. (2002). Solomon the Esoteric King: From King to Magus, Development of a Tradition. Leiden: Brill.

Ueberschaer, F. (2007). Weisheit aus der Begegnung. Bildung nach dem Buch Ben Sira (BZAW 379). Berlin: de Gruyter.

Urbanz, W. (2009). Gebet im Sirachbuch. Zur Terminologie von Klage und Lob in der griechischen Texttradition (HBS 60). Freiburg: Herder.

Wischmeyer, O. (1995). Die Kultur des Buches Jesus Sirach (BZNW 77). Berlin: de Gruyter.

Wischmeyer, O. (2017). „Die Konstruktion von Kultur im Sirachbuch,“ in: Karner, G.; Ueberschaer, F.; Zapff, B., Hgg., Texts and Contexts of the Book of Sirach / Texte und Kontexte des Sirachbuches. Atlanta: SBL Press. 71-98.

Witte, M. (2009). „III. Schriften [Ketubim], “ in: Gertz, J.H., Hg., Grundinformation Altes Testament (UTB 2745). Göttingen: Vandenhoeck \& Ruprecht. 414-586.

Witte, M. (2015a). „Wege der Sirachforschung, “ in: ders., Texte und Kontexte des Sirachbuchs. Gesammelte Studien zu Ben Sira und zur frübjüdischen Weisheit (Forschungen zum Alten Testament 98). Tübingen: Mohr Siebeck. 1-20.

Witte, M. (2015b). „Mose, sein Andenken sei zum Segen“ (Sir 45,1), in: ders., Texte und Kontexte des Sirachbuchs. 123-150.

Ziegler, J. (2016). Septuaginta 12,2, Sapientia Jesu, filii Sirach. Göttingen: Vandenhoeck \& Ruprecht. 


\title{
Die ,religiöse Stimme`Ciceros
}

\author{
Gesine Manuwald
}

\section{Einleitung}

Die Entdeckung der Sammlung von Briefen, die Marcus Tullius Cicero (106-43 v. Chr.) an seinen Freund Atticus gerichtet hat, in einer Bibliothek in Verona im Jahr 1345 hat Francesco Petrarcas (1304-1374) Einstellung zu Cicero grundlegend verändert. Das macht Petrarca in einigen Briefen seiner von Ciceros Episteln inspirierten Sammlung Familiarium rerum libri deutlich (fam. 24.2-4): Anhand der persönlichen, an den engen Freund gesandten Briefe Ciceros erkannte Petrarca, dass zur Gestalt Cicero nicht nur das zu Petrarcas Zeit bewunderte öffentliche Auftreten gehört, wie es in den politischen und gerichtlichen Reden sowie den rhetorischen und philosophischen Schriften zum Ausdruck kommt, sondern auch eine ,normale Menschlichkeit', die Charakteristika wie Unsicherheit oder Streitsüchtigkeit aufweist. Daraufhin kam Petrarca zu dem Schluss, dass man nur dann ein faires und abgewogenes Urteil über Cicero abgeben könne, wenn man das gesamte Quellenmaterial gelesen habe, und dass die Beurteilung zweigeteilt ausfallen werde, da man manche Aspekte von Ciceros Verhalten schätze und andere kritisiere. Diese Entdeckungsgeschichte zeigt exemplarisch die Wirkung, die ein eingehenderes Kennenlernen der Persönlichkeit eines Schriftstellers auf einen Leser haben kann, und veranschaulicht zugleich die Auffassung, dass diese bei ausreichendem Material aus den erhaltenen Schriften ermittelt werden könne.

Das Interesse an Ciceros Persönlichkeit besteht ungebrochen fort: In jüngster Zeit etwa beginnt der britische Schriftsteller Robert Harris (*1957) seinen erfolgreichen Roman Imperium (zuerst publiziert 2006), Teil einer Trilogie, in der Ciceros Leben von dessen Sekretär Tiro erzählt wird, folgendermaßen (S. 3-4): „In the decades after his [i.e. Cicero's] death, I [i. e. Tiro] was often asked, usually in whispers, what Cicero was really like, but always I held my silence. How was I to know who was a government spy and who was not? At any moment I expected to be purged. But since my life is almost over, and since I have no fear of anything any more - not even torture, for I would not last an instant at the hands of the carnifex or his assistants - I have decided to offer 
this work as my answer. I shall base it on my memory, and on the documents entrusted to my care."

Abgesehen von einer allgemeinen Neugier in Bezug auf Gestalten der Antike ist es kein Wunder, dass sich sowohl das reale Erlebnis Petrarcas als auch die fiktive Erzählung ,Tiros‘ bei Harris auf Cicero beziehen: Cicero ist einer der wenigen Autoren der Antike, von dem man in seinem umfangreichen erhaltenen Cuvre eine große Zahl von Selbstzeugnissen hat und der als politisch Agierender auch Gegenstand der Aussagen anderer war. Diese Quellenlage macht jedoch (im Gegensatz zu Petrarcas Annahme) Schlussfolgerungen über die Person Cicero nicht einfacher. Denn bei Ciceros eigenen Äußerungen finden sich sowohl Veränderungen im Laufe seines Lebens als auch Unterschiede in der Präsentation, je nach Gattung der jeweiligen Schrift: Jedes einzelne Werk ist zu einer bestimmten Zeit für ein bestimmtes Publikum mit einem bestimmten Zweck verfasst. Da Cicero also jeweils ein (nicht immer identisches) Ziel verfolgte und dafür jeweils ein spezifisches Bild von seiner Person zeichnen wollte, können nicht alle Aussagen wörtlich genommen werden. Das gilt besonders bei den für eine weitere Öffentlichkeit gedachten Reden und philosophischen Schriften. Bei den Briefen, die als Sammlung erst nach Ciceros Tod herausgegeben wurden, ${ }^{1}$ geht man in der Regel davon aus, dass sie Ciceros tatsächlichen Auffassungen näherstehen. Aber auch da kann man nicht in jedem Fall damit rechnen, dass Cicero seine wahren Überzeugungen offenbart: Die Briefe dienen ebenfalls spezifischen Absichten, und es ist möglich, dass manche Briefe vor der Veröffentlichung, an die Cicero zumindest am Ende seines Lebens dachte (Cic. Att. 16,5,5 [9. Juli 44 v. Chr.]; fam. 7,25,1 [ca. 24. August 45 v. Chr.]), überarbeitet wurden oder von vornherein für mehr Leser als den genannten Adressaten gedacht waren. Weil nicht für alle Perioden von Ciceros Leben Material aus allen Gattungen vorliegt, ist es schwierig, der Frage nach der wirklichen Position Ciceros bzw. ihrer chronologischen Entwicklung unabhängig von den Bedingungen der zur Verfügung stehenden Textgrundlage nachzugehen.

Die Sachlage, dass Cicero sich in verschiedenen Werken zu demselben Gegenstand unterschiedlich äußert, und die sich daraus ergebende Unklarheit, ob sich irgendwo seine wahre Überzeugung finden lässt, liegen auch in Bezug auf seine Haltung zur Religion vor. ${ }^{2}$ Man kann daher nicht einfach eine oder mehrere Stel-

\footnotetext{
${ }^{1}$ Vgl. z. B. Hutchinson 1998, 3, 4 mit Anm. 4.

${ }^{2} \mathrm{Zu}$ Cicero und Religion vgl. Hooper 1917; Burriss 1924; 1926; Gueuning 1925; 1926; 1929; van den Bruwaene 1937; Defourny 1954; Ferguson 1962; Heibges 1969a; 1969b; Ben Mansour 1970; Goar 1972; André 1975; Guillén 1976; Mandel 1983-1984; Troiani 1984; Tarán 1987; Guillén Cabañero 1999; Stroh 2010; Short 2012 (mir nicht zugänglich); Görler 2015; vgl. auch die bibliographischen Hinweise bei Gawlick / Görler 1994, 1145-1147. - Einige dieser Arbeiten versuchen, aus Ciceros Schriften Informationen über Religionspraktiken und Ansichten der Römer zu Ciceros Zeit zu entnehmen, andere geben einen Überblick über Aussagen zur Religion in Ciceros Euvre, weitere befassen sich mit dem Verhältnis von Religion und Philosophie in seinen Werken bzw. seiner Einstellung zur Staatsreligion und mehr philosophischen Positio-
} 
len für die ,religiöse Stimme‘ Ciceros zitieren. ${ }^{3}$ Deswegen soll zunächst genauer geprüft werden, in welchen Werken je nach Gattung mögliche Zeugnisse für Ciceros Ansichten über die Religion zu finden sein könnten. ${ }^{4}$

\section{2. ,Stimme des Autors' in Ciceros Werken?}

Unter den vorliegenden Aussageformen Ciceros werden die Äußerungen in den Briefen in der Regel als diejenigen betrachtet, anhand derer man seiner Persönlichkeit am nächsten kommen könne. ${ }^{5}$ In der Tat spricht Cicero in Briefen an Familienmitglieder oder Freunde über Details seines persönlichen Lebens wie Gesundheitszustand, Reisepläne, finanzielle Position, Kinder und Neffen, berührt also Themen, die er in der Öffentlichkeit nicht behandelt, schon gar nicht in einer persönlich engagierten Weise. ${ }^{6}$ Die Briefe unterscheiden sich außerdem in stilistischer Hinsicht von anderen Werken, da sie, zumindest die privaten Brie-

nen. Etliche berühren die Frage nach Ciceros eigener Auffassung, ohne jedoch in der Regel die zugrunde liegenden methodischen Probleme explizit anzusprechen. Dabei sind die Ansichten über Ciceros Position divers (vgl. Tarán 1987, 1: „Cicero’s religious conceptions - including his attitude toward the Roman state religion, whether or not a supreme being (or beings) controls and guides the universe, and the question of the immortality of the soul - have received divergent interpretations at least since the days of the Latin Christian apologists. Some have taken him to be sincere in his views on theological matters; others have maintained that for reasons of political expediency and / or fear he in fact tried to conceal his unbelief; and still others have accused him of inconsistency or worse.").

${ }^{3}$ Grundsätzlich zum Verhältnis von Literatur und Religion im antiken Rom vgl. Feeney 1998. - Feeney (1998, 140-142) weist unter anderem darauf hin, dass das römische religiöse System nicht ein monolithisches gewesen sei, sondern aus den verschiedensten Formen religiösen Wissens bestanden und sich ständig weiterentwickelt habe, auch und gerade in Auseinandersetzung mit Literatur.

${ }^{4}$ Troiani (1984) ist im Zweifel darüber, ob man Ciceros wahre Haltung ermitteln könne (bes. Troiani 1984, 933). - Alle Arbeiten, die Ciceros Werke als Quellengrundlage auswerten, müssen sich mit dem Problem auseinandersetzen, inwiefern diese Texte als faktische Aussagen, Ciceros persönliche Meinungen oder durch die Situation bestimmte Argumente zu verstehen sind; allerdings wird dieser Themenkomplex selten explizit angesprochen. Einige Überlegungen bietet Kurczyk (2006), die eine Reihe von Werken Ciceros im Hinblick auf ihren autobiographischen Status analysiert und dafür methodisch relevante Fragen aufgreift. Dabei geht es dem generischen Ansatzpunkt entsprechend hauptsächlich um die öffentliche und retrospektive Selbstdarstellung Ciceros. Dass Cicero ständig darauf bedacht sei, ein bestimmtes Bild von sich selbst zu zeichnen (,self-fashioning '), hebt in Bezug auf Ciceros rhetorische Schriften und einige der Reden Dugan (2005) hervor. In beiden Studien wird jedoch nicht ausdrücklich die weitere Frage gestellt, was eine solche Zielsetzung für die Aussagekraft der Werke als potentielle Dokumente für Ciceros persönliche Meinungen bedeutet.

${ }^{5}$ Vgl. z. B. Fuhrmann 1990, 9. - Van den Bruwaene $(1937,43)$ betrachtet die Briefe als genuine Äußerungen der eigenen Meinung des Autors.

${ }^{6}$ Vgl. z. B. die Zusammenstellung von Aussagen zu verschiedenen Aspekten des privaten Lebens bei Carcopino (1951), wobei einzelne Bemerkungen gelegentlich recht wörtlich genommen sind. Aspekte wie ,Religion` oder ,Verhältnis zu den Göttern' sind in Carcopinos Übersicht nicht aufgenommen. 
fe, kürzere Sätze, mehr griechische Wörter und einen weniger ausgefeilten Aufbau, also insgesamt einen weniger formalen und mehr kolloquialen Stil aufweisen (z.B. Cic. fam. 9,21,1). ${ }^{7}$ Dennoch ist nicht zu erweisen, dass Cicero in solchen Kontexten immer völlig seine wahre Überzeugung zum Ausdruck bringt. Daher kann man nicht ohne Weiteres annehmen, dass diese Texte den, echten' Cicero zeigen. Zwar sagt Cicero in einem Brief, dass man anders schreibe je nachdem, ob man sich an einen bestimmten Adressaten oder an viele Leser richte (Cic. fam. 15,21,4 [Dez. 46 v. Chr. (?)]). Das ,Briefgeheimnis‘ war jedoch offenbar kein absoluter Wert: So kritisiert Cicero in der Auseinandersetzung mit Marcus Antonius diesen, weil er in seiner Unwissenheit über das angemessene Benehmen einen Brief Ciceros an ihn in der Öffentlichkeit vorgelesen habe (Cic. Phil. 2,7 [Okt. 44 v. Chr.]). Dasselbe tut Cicero jedoch wenig später in einer weiteren Rede aus demselben Kontext, wenn er einen Brief von Antonius an Octavian und den Konsul Hirtius Stück für Stück vorliest und kommentiert (Cic. Phil. 13,22-48 [20. März 43 v. Chr.]).

Weitere Äußerungen in Ciceros Briefen zeigen, dass Cicero häufig Abschriften von Briefen anderer an ihn oder seine eigenen Briefe an andere weiterleitete oder Abschriften von Briefen an andere Leute erhielt (z. B. Cic. Att. 1,17,1 [5. Dez. 61 v. Chr.]; 15,6 [2. (?) Juni 44 v. Chr.]; 15,14 [28. Juni 44 v. Chr.]; 15,29 [6. Juli 44 v. Chr.]). In Bezug auf den Brief an L. Lucceius, in dem Cicero diesen zu einer historiographischen Darstellung seines Konsulats zu bewegen suchte (Cic. fam. 5,12 [April 55 v. Chr.]), forderte er Atticus ausdrücklich auf, sich von Lucceius davon eine Kopie zu besorgen; denn er hielt diesen Brief für, sehr hübsch (valde bella) (Cic. Att. 4,6,4 [April / Mai 55 v. Chr.]). Fast alle diese weitergeleiteten Briefe betreffen öffentliche bzw. offizielle Angelegenheiten. Wenn Cicero über persönliche Dinge und Befindlichkeiten schreibt, kann man eher den Eindruck von Unmittelbarkeit gewinnen; jedoch war er sich, wie Äußerungen gegenüber Briefpartnern belegen, bewusst, dass es verschiedene Formen der brieflichen Kommunikation und anlassbedingte Stilhöhen gebe (Cic. fam. 2,4 [53 v. Chr.]; 4,13,1 [Aug. (?) 46 v. Chr.]; 6,10b [Sept. (?) 46 v. Chr.]). Entsprechend kann man sich nicht sicher sein, wie weit die Stilisierung auch in persönlicheren Briefen geht.

Wie Briefe geben sich Reden als direkte persönliche Äußerungen des Sprechers, sind aber von vornherein, bereits beim ursprünglichen mündlichen Vortrag und später bei der schriftlichen Veröffentlichung, für ein größeres Publikum konzipiert, eingeschränkter in der Themenwahl und dienen offensichtlich einem klar definierten Ziel. ${ }^{8}$ In Ciceros Schriften wird an verschiedenen Stellen deutlich, dass er davon ausgeht, dass Reden nicht unbedingt die Meinung des

\footnotetext{
${ }^{7}$ Vgl. z. B. Hutchinson 1998, 3-4, 9-16.

${ }^{8}$ Vgl. auch Leonhardt 1999, 68, der betont, dass Reden „nicht unmittelbar als persönliche Äußerungen Ciceros gewertet werden“ dürften (ähnlich Brunt 1989, 198, in Bezug auf Religion, während Goar 1972, 110-111, etwas zuversichtlicher ist).
} 
Sprechers wiedergeben müssen, dass ihr Inhalt und die Argumentation vielmehr der jeweiligen Situation geschuldet und auf die Überzeugung des Publikums ausgerichtet seien (Cic. de orat. 2,30; Cluent. 139; vgl. auch Quint. inst. 2,17,20-21).

Gleichzeitig kann die Tatsache, dass Reden Äußerungen eines individuellen Sprechers sind, Teil der Überredungsstrategie sein; denn der Redner hat die Möglichkeit, seine Persönlichkeit einzubringen und so die Wirkung der Rede zu steigern. Das tut Cicero beispielsweise in seiner Antrittsrede als Konsul vor dem Volk in den ersten Januartagen des Jahres 63 v. Chr., in der er sich auch gegen die von einem Volkstribunen eingebrachte Vorlage eines Agrargesetzes wendet (Cic. leg. agr. 2). Cicero beginnt die Rede, indem er feststellt, dass er im Unterschied zu fast allen anderen Konsuln ein homo novus sei und daher nicht auf die Unterstützung von Vorfahren bauen könne. Er betont dem Volk gegenüber, dass er einer der Ihren sei und sich deshalb in der Position, zu der sie ihn dankenswerterweise gewählt hätten, für ihre Belange einsetzen werde (leg. agr. 2,1-7). Auf dieser Basis interpretiert Cicero seinen Widerstand gegen das von dem Volkstribunen eingebrachte Agrargesetz als ein Vorgehen zum Wohl des Volks. Ob Cicero wirklich glaubte, dass die geplanten Maßnahmen für das Volk schädlich seien, oder ob er die Gesetzesvorlage ablehnte, weil er sie für politisch riskant hielt, ist nicht mit Sicherheit festzustellen. Trotz der deutlichen Profilierung einer spezifischen Darstellung seiner Persönlichkeit ist also nicht zu erkennen, was Cicero wirklich meint.

In philosophischen und rhetorischen Schriften tritt der Autor, abgesehen von persönlichen Einleitungen, naturgemäß mehr zurück, zumal Cicero für fast alle diese Werke die Form des philosophischen Dialogs wählte. Auf diese Weise lassen sich verschiedene Meinungen, die den Dialogfiguren (etwa Vertretern unterschiedlicher philosophischer Richtungen) in den Mund gelegt werden, nebeneinander stellen, ohne dass sich der Autor wertend dazu äußern muss (Cic. fin. 1,12). In den Tusculanae disputationes bemerkt Cicero, dass er hier und auch sonst öfter der sokratischen Methode gefolgt sei, die eigene Ansicht verborgen zu halten (Cic. Tusc. 5,11). Als Autor kann er jedoch sein Verhältnis zu den im Dialog vorgetragenen Meinungen auch auf indirekte Weise deutlich machen oder selbst als Dialogfigur auftreten. Dadurch ergibt sich für die Interpretation das Problem, wie das literarische Abbild zum historischen Autor steht, wobei dieses Verhältnis nicht in allen Dialogen gleich sein muss. Da Cicero die Dialogpartner bewusst auswählte (Cic. Att. 13,19,3-5 [29. Juni 45 v. Chr.) und sich selbst nicht an jedem Dialog teilnehmen lässt, kann man vielleicht davon ausgehen, dass die jeweilige Zusammenstellung der Sprecher - in Verbindung mit den Dialog einleitenden Äußerungen des Autors in den Proömien - bedeutungsvoll ist. ${ }^{9}$

\footnotetext{
${ }^{9}$ Schofield (2008, bes. 81-83) meint, dass Cicero als Akademiker zwar in unterschiedlichen Werken verschiedene Ansichten zeigen könne (Cic. Tusc. 5,32-33), es jedoch keine Hinweise gebe, dass ,Cicero' als Dialogfigur bestimmte Meinungen lediglich um der Argumentation willen vertrete oder der Leser generell zwischen dem Autor Cicero und dem Sprecher Cicero zu
} 
So bringt Cicero im Dialog Laelius über die Freundschaft (44 v. Chr.) seine eigene Person mit ein, indem er sich auf ein Ereignis in seiner Jugend bezieht, als er Q. Mucius Scaevola eine Unterhaltung referieren gehört habe, die C. Laelius mit seinen beiden Schwiegersöhnen geführt habe (Cic. Lael. 3). Cicero gibt vor, diese Unterhaltung aus dem Gedächtnis aufgezeichnet zu haben, als Antwort auf Atticus' Bitte um ein Werk über die Freundschaft, und zwar weil ihm Laelius wegen seiner Freundschaft zu Scipio für das Thema eine besondere Autorität $\mathrm{zu}$ besitzen scheine. Aus stilistischen Gründen lasse er die Unterredner selbst auftreten, und er bittet Atticus, ihn für eine Weile zu vergessen und zu glauben, dass Laelius selbst spreche (Cic. Lael. 4-5).

Entsprechend legt Cicero in dem (ebenfalls Atticus gewidmeten) Dialog Cato über das Greisenalter (44 v. Chr.) die Argumentation dem alten Cato (im Gespräch mit Laelius und Scipio) in den Mund, weil dieser ihm für die Erörterung dieses Themas besonders geeignet scheine. Andererseits lässt Cicero erkennen, dass diese Figur eine literarische Fiktion sei, wodurch die Darstellung mehr Autorität gewinnen solle (Cic. Cato 3). Das bedeutet, dass Cicero historische Figuren unter Umständen so konzipiert, dass ihre Äußerungen mit seinen eigenen Auffassungen identifiziert werden können. Cicero erliegt dabei, wie er in der Einleitung zum Laelius sagt, sogar selbst der Faszination der von ihm geschaffenen Gespräche bedeutender Persönlichkeiten (Cic. Lael. 4): ${ }^{10}$ „Deshalb werde ich selbst, wenn ich meine Werke lese, manchmal in eine solche Stimmung versetzt, dass ich glaube, Cato und nicht ich spräche.“

\section{Ciceros ,religiöse Stimme‘}

Angesichts der spezifischen Problematik in Bezug auf die Authentizität, die Fülle des Materials und die chronologisch und gattungsbedingte Varianz stellt sich die Frage, wie sich aus den erhaltenen Texten die ,religiöse Stimme' Ciceros ermitteln lässt. ${ }^{11}$ Immerhin ergeben sich einige für eine Antwort relevante Aspekte, wenn man aussagekräftige Stellen aus gattungstypologisch verbundenen Schriften zusammenstellt und analysiert. Dabei ist die Berücksichtigung der gattungsbedingten Sprechsituation entscheidend, da in den Reden die Person des Sprechers und die Erzeugung einer bestimmten Vorstellung von dessen Einstellung zu religiösen Fragen Teil der Darstellungs- und Überzeugungsstrategie

unterscheiden habe (während ,Quintus‘ sich explizit zu seinen persönlichen Ansichten äußere, Cic. div. 2,100).

${ }^{10}$ Cic. Lael. 4: ...; itaque ipse mea legens sic afficior interdum, ut Catonem, non me loqui existimem.

${ }^{11}$ Für eine Art „Definition` von religio vgl. Cic. inv. 2,65-66; 2,161. - Hier soll es in erster Linie um Ciceros Aussagen zur Religion überhaupt gehen; die Frage, ob sich bei Cicero eher ein Mono- oder ein Polytheismus zeigt (dazu Görler 2015), wird dagegen weitgehend ausgespart. 
sind, während der Autor in den Dialogen zurücktreten und allenfalls als Vermittler auftreten kann, wobei er seine eigene Position lediglich durch die Auswahl der vorgestellten Themen und die Art von deren Präsentation zu erkennen gibt und der Adressatenkreis von vornherein offener gefasst ist und weniger explizite Rezeptionsanweisungen vorliegen.

In seinen Reden zeigt sich Cicero als frommer Anhänger der römischen Staatsreligion, und zwar sowohl unmittelbar in eigener Sache als auch bei der Durchsetzung seiner Politik oder der Charakterisierung von Gegnern. ${ }^{12}$ Zum Beispiel fügt Cicero manchmal in die peroratio, also an emphatischer Stelle, Anrufungen an Götter ein, vor allem in Reden, bei denen es wegen deren Thematik inhaltlich passt (z. B. Cic. Verr. 2,5,184-189; dom. 144-145). Bezeichnend ist die ausführliche Anrufung der nacheinander genannten Götter Jupiter, Juno, Minerva, der Penaten und Vesta am Ende der Rede De domo sua (57 v. Chr.). Mit dieser Rede versuchte Cicero, vor dem Priesterkollegium darzulegen, dass die Weihung eines Teils seines Grundstücks an die Göttin der Freiheit (Libertas), auf Initiative seines Gegners Clodius während Ciceros Exil (58-57 v. Chr.), ungültig sei, und er das Grundstück also nach seiner Rückkehr zurückerhalten könne. Cicero hebt bei der Götteranrufung sowohl die allgemeine Bedeutung dieser Götter für die Stadt (etwa bei Jupiter und den Penaten) als auch deren besondere Gewogenheit ihm gegenüber (bei Minerva) hervor. Im Verlauf der Götteranrufung verschiebt sich die Akzentsetzung, indem Cicero seine Rettungsleistung gegenüber den Penaten und Vesta, die er mit der Niederschlagung der Catilinarischen Verschwörung vollbracht habe, in den Mittelpunkt rückt. So erscheint er zwar als demütig Bittender, aber auch als einer, der es gerade wegen seiner Verdienste gegenüber den Göttern verdient, vom Priesterkollegium mit Wohlwollen bedacht zu werden.

In einer der Catilinarischen Reden, gehalten während seines Konsulatsjahrs, machte Cicero sich die Tatsache zunutze, dass eine vor zwei Jahren auf Anweisung der Opferschauer in Auftrag gegebene Jupiter-Statue just an dem Tag am Ende des Jahres 63 v. Chr. aufgestellt wurde, an dem die (nach seiner Darstellung wesentlich durch seine Aktivitäten) ertappten und gefangen genommen Verschwörer und die Zeugen gegen sie zur Senatsverhandlung gebracht wurden (Cic. Cat. 3,19-20). ${ }^{13}$ In dieser Rede, in der er den Ablauf der jüngsten Ereignisse für das Volk zusammenfasst, legt Cicero dar, dass, sobald diese Statue aufgestellt und zum Senat gewandt war, alle verschwörerischen Pläne aufgedeckt worden seien. Daraus leitet Cicero ab, dass nicht er, sondern Jupiter selbst den Verschwörern Widerstand geleistet und das römische Volk gerettet und er selbst also lediglich unter Leitung der Götter gehandelt habe. Folglich sei ein Dankfest an

\footnotetext{
${ }^{12}$ Heibges (1969b, 848) weist darauf hin, dass es unmöglich sei, aus Ciceros Reden ein kohärentes theologisches System zu ermitteln.

${ }^{13}$ Zur Argumentation mit Religiösem in der Ersten Catilinarischen Rede vgl. Sauer 2013.
} 
allen Göttersitzen beschlossen worden (Cic. Cat. 3,21-23). Moderne Interpreten haben sich gefragt, ob es sich wirklich um einen glücklichen Zufall handelt oder ob Cicero für die Terminierung verantwortlich ist. ${ }^{14}$ In jedem Fall nutzt Cicero die Situation elegant rhetorisch aus in einer Rede vor einem Publikum, bei dem er offensichtlich der Meinung ist, dass es auf derartige Dinge Wert lege. Der spätere Rhetoriklehrer Quintilian sieht diese Passage als ein Beispiel für die rhetorische Argumentation mit Übernatürlichem (Quint. inst. 5,11,42).

Für eine rhetorische Instrumentalisierung könnte sprechen, dass Cicero an anderen Stellen (wo ein anderes Argumentationsziel verfolgt wird) nicht zögert, sich selbst eine größere Rolle bei der Niederschlagung der Verschwörung zuzuschreiben (z. B. Cic. Pis. 5-7 [55 v. Chr.]), während er in dieser Rede vor der Volksversammlung den ,Zufall' herausstellt und die erfolgreiche Bekämpfung der Verschwörung dem Einfluss einer höheren Macht zuweist. ${ }^{15}$ Jedenfalls lässt sich aus dieser Rede nicht auf die wahre religiöse Überzeugung Ciceros zurückschließen, zumal seine Anrufungen der traditionellen Götter in den in der Volksversammlung gehaltenen Reden generell häufiger und emphatischer sind als in den im Senat vorgetragenen. Man kann lediglich feststellen, dass Cicero offenbar der Meinung war, dass die Religion beim Publikum einen so hohen Stellenwert hat, dass sich erfolgreich damit argumentieren lässt.

Wenn Cicero Götterfiguren in seinen Texten gattungsgemäß und zweckgebunden einsetzt bzw. von ihrer göttlichen Wirkung ausgeht, ist er möglicherweise beeinflusst von dem Schema der dreigeteilten Theologie, wie sie sich bei seinem Zeitgenossen Varro findet, wonach Götter des öffentlichen Kults von denen in der Literatur zu unterscheiden seien $(A R D$ fr. 7 Cardauns = Aug. civ. 6,5). Jedenfalls lässt sich eine solche Vorgehensweise auch aus den (zumindest geplanten) Epen über sein Konsulat (De consulatu suo) und sein darauffolgendes Exil (De temporibus meis) erschließen: In diesen (heute nicht oder nur fragmentarisch erhaltenen) Werken bezeichnete Cicero die Göttin Minerva, der er sich in der Rede De domo sua als Helferin und Begleiterin bei seinen Plänen und Maßnahmen verbunden zeigt (Cic. dom. 144), offenbar als seine Lehrmeisterin, die ihn die Künste gelehrt habe, und stellte sich als einer Götterversammlung beiwohnend und in göttlichem Auftrag die Stadt Rom beschützend dar ([Sall.] in Cic. 3; 7; Quint. inst. 11,1,23-24). Ciceros Epen wurden bereits in der Antike mit Spott bedacht. Es ist jedoch nicht klar, ob sich diese Reaktion im Wesentlichen auf seine glorifizierende Selbstdarstellung bezieht oder ob die hier entworfene Rolle der Götter dabei von Bedeutung war. ${ }^{16}$

${ }^{14}$ Vgl. Dyck 2008, 197, mit Verweis auf Berry 2006, 312 vs. Butler 2002, 97 (vgl. auch Heibges 1969b, 844), die gegenteilige Ansichten vertreten. - Vgl. auch Cic. div. 2,46.

${ }^{15}$ Auch in anderen Reden behauptet Cicero göttliche Unterstützung für sein Konsulat (z. B. Cic. Mur. 82).

${ }^{16}$ Zur Selbstdarstellung Ciceros in den Epen im Vergleich zu der in den Reden vgl. auch Kurczyk 2006, 93-115. 
Für die Betrachtung von Ciceros öffentlichen Stellungnahmen zu seiner Einstellung gegenüber den Göttern ist die erwähnte Situation, dass Cicero nach seiner Rückkehr aus dem Exil in der Verhandlung vor dem Priesterkollegium gegenüber dem Einspruch des Clodius seinen Besitz wieder erstreiten musste, besonders ergiebig. ${ }^{17}$ Mit der Rede De domo sua (57 v. Chr.) erreichte Cicero, dass er sein in seiner Abwesenheit zerstörtes Haus auf dem zugehörigen Grundstück wieder aufbauen durfte. In dieser Rede gibt sich Cicero als Laie in technischen Fragen der Religion und als jemand, der sich der Autorität des Priesterkollegiums beuge (Cic. dom. 32-33). Ein Jahr später wurde ein Erdgrollen in Latium beobachtet, für die Römer ein beunruhigendes Götterzeichen. Das daraufhin eingeholte Gutachten der Opferschauer (haruspices) enthielt als Begründung für den Götterzorn unter anderem die Angabe, dass heilige Orte als profan behandelt worden seien (Cic. har. resp. 9; 20; 62). Diese Verursachung bezog Clodius auf Cicero und dessen Haus, so dass Cicero sich erneut genötigt sah, seine Position in der Rede De haruspicum responsis (56 v. Chr.) zu erläutern. Bevor Cicero mit der Argumentation im Einzelnen beginnt, legt er seine allgemeine Einstellung zur römischen Staatsreligion dar, gewissermaßen um klarzumachen, dass er das gesamte Verfahren ernst nehme. Insofern ist diese Aussage Ciceros, die manchmal als eine grundsätzliche Stellungnahme gesehen wird, auf ein dem eigenen Interesse dienendes Ziel gerichtet, ist jedoch nichtsdestoweniger aufschlussreich (Cic. har. resp. 18-19): ${ }^{18}$

sed quoniam mea causa expedita est, videamus nunc quid haruspices dicant. ego enim fateor me et magnitudine ostenti et gravitate responsi et una atque constanti haruspicum voce vehementer esse commotum; neque is sum qui, si cui forte videor plus quam ceteri qui aeque atque ego sunt occupati versari in studio litterarum, his delecter aut utar omnino litteris quae nostros animos deterrent atque avocant a religione. ego vero primum habeo auctores ac magistros religionum colendarum maiores nostros, quorum mihi tanta fuisse sapientia videtur ut satis superque prudentes sint qui illorum prudentiam non dicam adsequi, sed quanta fuerit perspicere possint; qui statas sollemnisque caerimonias pontificatu, rerum bene gerundarum auctoritates augurio, fatorum veteres praedictiones Apollinis vatum libris, portentorum expiationes Etruscorum disciplina contineri putaverunt; quae quidem tanta est ut nostra memoria primum Italici belli funesta illa principia, post Sullani Cinnanique temporis extremum paene discrimen, tum hanc recentem urbis inflammandae delendique imperi coniurationem non obscure nobis paulo ante praedixerint. [19] deinde, si quid habui oti, etiam cognovi multa homines doctos sapientisque et dixisse et scripta de deorum immortalium numine reliquisse; quae quamquam divinitus perscripta video, tamen eius modi sunt ut ea maiores nostri docuisse illos, non ab illis didicisse videantur. etenim quis est tam vaecors qui aut, cum suspexit in caelum, deos esse non sentiat, et ea quae tanta mente fiunt ut vix quisquam arte ulla ordinem rerum ac necessitudinem persequi possit casu fieri putet, aut, cum deos esse intellexerit, non intellegat eorum numine hoc tantum imperium esse natum et auctum et retentum? quam volumus licet, patres conscrip-

${ }^{17} \mathrm{Zu}$ diesen Äußerungen Ciceros vgl. auch Stroh 2010.

${ }^{18} \mathrm{Zu}$ dieser Stelle vgl. auch Goar 1972, 60-62. 
ti, ipsi nos amemus, tamen nec numero Hispanos nec robore Gallos nec calliditate Poenos nec artibus Graecos nec denique hoc ipso huius gentis ac terrae domestico nativoque sensu Italos ipsos ac Latinos, sed pietate ac religione atque hac una sapientia, quod deorum numine omnia regi gubernarique perspeximus, omnis gentis nationesque superavimus.

Soviel zu meiner persönlichen Angelegenheit. Sehen wir jetzt, was die Haruspices sagen! Ich gestehe, daß ich tief beeindruckt bin von der Bedeutung des Wunderzeichens, dem Gewicht des Gutachtens und der einmütigen, unbeirrbaren Auskunft der Haruspices. Wenn etwa jemand glaubt, ich beschäftigte mich eingehender als andere, die ebenso stark in Anspruch genommen sind wie ich, mit der Philosophie, so bin ich nicht der Mann, der daran Freude hätte oder überhaupt diese Literaturgattung pflegte, die uns von der Religion abführt und abschreckt. Nein! Zunächst einmal sehe ich in unsern Vorfahren die Vorbilder und Lehrer in der Pflege der Religion; ihre Weisheit scheint mir so groß gewesen zu sein, daß mir derjenige in höchstem Maße verständig erscheint, der - ich will nicht sagen: ihrer Weisheit gleichkommen kann, aber jedenfalls ihre Größe zu erkennen vermag. Ihrer Ansicht nach war die Wahrnehmung der bestehenden feierlichen Zeremonien Sache der Pontifices, die Gutachten, ob etwas mit Aussicht auf Erfolg geschehen solle, Sache der Augurn, die alten Schicksalsprophezeiungen Sache der Wahrsagebücher des Apollo, die Sühnung von Wunderzeichen Sache der Disziplin der Etrusker. Letztere ist so bedeutsam, daß sie zu unsern Lebzeiten jene unheilvollen Anfänge des Italischen Krieges, sodann die beinahe tödlichen Gefahren der Zeiten Sullas und Cinnas und schließlich jetzt die jüngste Verschwörung zur Inbrandsetzung der Stadt und zur Vernichtung des Reiches uns kurz vorher deutlich genug vorausgesagt haben. [19] Sodann: wenn ich wirklich einmal Muße gehabt habe, dann habe ich auch die Erfahrung gemacht, daß kluge, gelehrte Männer mancherlei über das Walten der unsterblichen Götter gesagt und schriftlich niedergelegt haben. Was sie zu sagen wissen, ist gewiß vortrefflich; indessen sieht man doch, daß sie es offenbar von unsern Vorfahren gelernt haben, und nicht diese von ihnen. Wer ist denn so wahnwitzig, daß er nicht das Walten der Götter fühlte, wenn er gen Himmel blickt, oder meinte, was so planmäßig geschieht, daß kaum jemand imstande ist, mit all seiner Kunstfertigkeit die unwandelbaren Gesetze der Weltordnung zu begreifen, geschehe zufällig, oder, wenn er begriffen hat, daß es Götter gibt, nicht zu der Überzeugung käme, daß durch ihr Walten unser großes Reich entstanden und gewachsen ist und erhalten wird? Mag unsere Eigenliebe noch so stark sein, Patres Conscripti, so übertreffen wir doch weder die Spanier an Zahl, noch die Gallier an Stärke, noch die Punier an Verschlagenheit, noch die Griechen an Kunstfertigkeit, noch schließlich selbst die Italiker und Latiner an der unserer Rasse und unserm Lande angeborenen und von Hause aus mitgegebenen Wesensart; nur durch unsere Frömmigkeit, durch unsere Religiosität und diese eine Weisheit, daß wir erkannt haben, wie alles durch das Walten der Götter gelenkt und gesteuert wird, sind wir allen Völkern und Rassen überlegen gewesen. [übers. H. Kasten]

Hier bemüht sich Cicero, dessen Interesse an der Philosophie in Rom bekannt gewesen sein muss, darzulegen, dass er die Religion mehr als die Philosophie schätze. Er leugnet sogar zunächst, sich damit zu beschäftigen, da diese Literaturgattung von der Religion abführe, während er in seinem Werk De natura deorum (Cic. nat. deor. 1,6) behauptet, sich von Jugend an mit Philosophie befasst zu haben. An dieser Stelle in der Rede beruft er sich jedoch auf die Vorfahren als Lehrer der Gottesverehrung und auf die von diesen etablierten Rituale. Interessanterweise stilisiert Cicero die traditionelle Religion als Grundlage der Stellung Roms, 
so dass er mit seiner Argumentation von seiner eigenen Person (und möglichen Widersprüchen) ablenkt und sich im Konsens mit seinen Gegnern befindet. Was Cicero über die Staatsreligion wirklich denkt, ist nicht eindeutig festzustellen. ${ }^{19}$ Es ergibt sich jedoch wiederum, dass er eine Vorstellung von den jeweiligen Ansichten seiner Hörerschaft hat und seine eigene Position entsprechend darstellt.

Als Cicero sich in der zweiten Phase seines Rückzugs aus dem politischen Leben literarisch mit religiösen Fragen beschäftigte, tat er es in philosophischem Kontext, vor allem in den Schriften De natura deorum und De divinatione (44 v. Chr.). ${ }^{20}$ Im persönlichen Vorwort zu De natura deorum bezeichnet er die für die Religion wichtige Frage nach dem Wesen der Götter als besonders schwierig und schwer zu durchschauen (Cic. nat. deor. 1,1). Zu dieser Frage lägen verschiedene und sich widersprechende gelehrte Meinungen vor, die meisten stimmten immerhin darin überein, dass es Götter gebe. Dass Cicero den nicht-notwendigen Kommentar , was sehr wahrscheinlich ist' (quod maxime veri simile est) und die Bemerkung, dass man von der Natur zu einer solchen Auffassung geführt werde, hinzufügt (Cic. nat. deor. 1,1-2; vgl. auch 1,62; 3,7), macht plausibel, dass er tatsächlich der Auffassung von der Existenz von Göttern zuneigte und im persönlichen Vorwort einer philosophischen Schrift den Ort sieht, wo das verhalten zum Ausdruck gebracht werden kann. Diese Annahme zu Ciceros Position wird dadurch gestützt, dass Cicero sich hier nicht für die verschiedenen Vorstellungen von den Einzelheiten des Lebens der Götter interessiert, sondern als zentrale Frage die Auseinandersetzung mit Philosophen bestimmt, die meinten, dass sich die Götter nicht um die Angelegenheiten der Menschen kümmerten (Cic. nat. deor. 1,3). Götterverehrung (pietas, sanctitas, religio) habe nur dann einen Sinn, wenn sich die Götter um die Menschen kümmerten, und bei der genannten Auffassung einiger Philosophen werde dem gesamten Götterkult die Basis entzogen. Das scheint Cicero nicht akzeptieren zu wollen: Wenn es keine religio gäbe, geriete das menschliche Leben in Unordnung, und es gäbe keine Gerechtigkeit mehr (Cic. nat. deor. 1,3-4).

Im Hauptteil des Werks lässt Cicero verschiedene Redner die Ansichten der drei Philosophenschulen (Epikureer, Stoiker, Akademiker) ausführen, und zwar fiktiv in einem Gespräch über das Wesen der Götter im Haus seines Freundes, des Akademikers C. Cotta, zu dem Cicero selbst als Zuhörer hinzukommt (Cic. nat. deor. 1,15). Dieses literarische Konzept entspricht der Überzeugung, die Cicero am Anfang von De natura deorum zum Ausdruck bringt, dass die Neu-

${ }^{19}$ Das Verhältnis von Philosophie und Religion in der späten Republik diskutiert Brunt (1989); er weist darauf hin, dass die philosophischen Vorstellungen offenbar lediglich eine geringe Wirkung auf die religiöse Praxis hatten. Das scheint besonders für die Divination zu gelten (vgl. Ciafardone 2013; in Bezug auf Aberglauben vgl. auch Mandel 1983-1984).

${ }^{20} \mathrm{Zu}$ Ciceros Ansichten zu Theologie und Divination anhand der philosophischen Schriften vgl. Leonhardt 1999, 61-66, 66-73. - Zu der Schwierigkeit, aus Ciceros philosophischen Werken seine Auffassungen zur Religion zu entnehmen, vgl. auch Ferguson 1962, 89. 
gierde der Leute, die sich nach seiner eigenen Meinung zu den in den Schriften diskutierten Problemen erkundigten, größer als nötig sei, da es nicht um die Autorität einer Person, sondern um die Diskussion von Argumenten und Sachverhalten gehe (Cic. nat. deor. 1,6; 1,10). Nach dem Epikureer C. Velleius lässt Cicero im zweiten Buch Q. Lucilius Balbus die stoische Sicht erläutern, wobei dieser unter anderem erklärt, dass es Götter gebe und sie sich um die Angelegenheiten der Menschen kümmerten (Cic. nat. deor. 2,3). Auch wenn ,Cicero' an diesem Dialog als Zuhörer und nicht als Vertreter eines festgelegten Standpunkts teilnimmt und sogar betont, dass er unvoreingenommen zuhören werde (Cic. nat. deor. 1,17), sagt er am Ende in eigener Person, dass ihm die Rede des Balbus der Wahrheit näherzukommen scheine (Cic. nat. deor. 3,95). In guter akademischer Tradition, zu der Cicero sich bekennt (Cic. nat. deor. 1,12), legt er sich allerdings nicht darauf fest, dass das tatsächlich die Wahrheit sei. Trotz aller akademischen Skepsis ist jedoch erkennbar, dass Cicero in diesem Werk durchblicken lässt, dass er wohl von der Existenz von Göttern ausgeht und glaubt, dass diese sich für die Menschen interessierten und leitend eingriffen. ${ }^{21}$ Durch diese Andeutungen des Autors erhält die Darstellung der unterschiedlichen Positionen im Dialog einige Signale zur Leserlenkung.

Im Unterschied zu dieser verhaltenen Positionierung Ciceros in De natura deorum gibt es an anderen Stellen Festlegungen des Sprechers, Cicero' zur Divination, und sie scheinen sich auf den ersten Blick zu widersprechen, besonders die in De legibus (ca. 52 v. Chr.) und De divinatione (44 v. Chr.): In De legibus betont der Dialogpartner ,Marcus', dass Divination grundsätzlich möglich sei. Denn wenn man annehme, dass es Götter gebe, sie sich um die Belange der Menschen kümmerten und diesen in die Zukunft weisende Zeichen geben könnten, dann sehe er nicht, warum es Divination nicht geben solle. Dafür nennt er Beispiele aus der römischen Geschichte und von außerhalb Roms. Allerdings sei die Divination zweifellos in der gegenwärtigen Zeit wegen ihres Alters und aus Vernachlässigung verschwunden (bes. Cic. leg. 2,32-33). In De divinatione, einem Gespräch zwischen ,Cicero' und seinem Bruder,Quintus', widerlegt, Cicero' die von seinem Bruder vorgebrachten Argumente für die Wahrsagekunst, die als sinnentleert erscheine: Es überwiegt also der skeptische Zweifel. ${ }^{22}$ Möglicherweise handelt es sich um eine Akzentverschiebung, die auch mit dem Charakter der Werke zu tun haben mag: De legibus ist ein staatstheoretischer Dialog, in dem Cicero sich eher abwägend äußert, und De divinatione besteht in einer kritischen Diskussion der verschiedenen Formen der Wahrsagung, die ,Quintus' auf der Grundlage stoischer Doktrin verteidigt, während ,Cicero' sie aus akademischer Perspektive widerlegt, ohne dass ausdrücklich eine positive Lösung formuliert

\footnotetext{
${ }^{21}$ Zur Deutung des umstrittenen Schlusses von De natura deorum (mit weiterer Literatur) vgl. Tarán 1987; Leonhardt 1999, 61-66; Görler 2015, 406-408.

${ }^{22}$ Vgl. Leonhardt 1999, 73; Stroh 2010.
} 
wird..$^{23}$ Offenkundig beantwortet Cicero auch eine derartige, die persönliche Religiosität berührende Frage nicht mit absoluter, gleichbleibender Gewissheit; vielmehr äußert er Urteile nach der jeweiligen Betrachtungsperspektive. ${ }^{24}$

Wenn man davon ausgehen kann, dass Cicero zumindest die Existenz von Göttern annahm und der Ansicht war, dass religiöses Verhalten ,echt' sein solle, ist es nicht verwunderlich, dass er in Briefen an Einzelpersonen gelegentlich die Hoffnung auf die Hilfe der Götter zur Erreichung ihm wichtiger Ziele ausspricht. Wirken die Bemerkungen auch in manchen Fällen wie konventionelle Floskeln (z.B. Cic. fam. 10,3,3; 10,5,3; 10,22,1), könnte in anderen Zusammenhängen, in Briefen an Vertraute, wenn ein Bezug auf Ciceros eigenes Schicksal oder die schwierige Lage des Staats vorliegt, eine tatsächliche verhaltene Hoffnung auf eine fast unmöglich erscheinende Besserung einer nahezu aussichtslosen Situation dahinterstecken (z. B. Cic. fam. 16,12,1 [27. Jan. 49 v. Chr.]). In einem Brief an seine Frau Terentia aus dem Exil bemerkt Cicero allerdings, dass sie ihre Hoffnung auf Götter und er auf Menschen gesetzt habe (Cic. fam. 14,4,1 [29. April 58 v. Chr.]). Das muss jedoch nicht bedeuten, dass Cicero auf ein geschlechtsspezifisches Verhalten hinweisen wollte. Eher ist diese Einschätzung auf eine realistische Einstellung gegenüber den politischen Verhältnissen in Rom oder eine resignative Stimmung angesichts der Situation im Exil zurückzuführen. Jedenfalls schreibt Cicero in derselben Zeit seinem Bruder, dass die Götter aufgehört hätten, auf seine Gebete zu hören (Cic. ad Q. fr. 1,3,9 [13. Juni 58 v. Chr.]). Jedoch implizieren solche Bemerkungen sowohl den Glauben an die Existenz der Götter als auch daran, dass sie prinzipiell in das Leben der Menschen eingreifen können. Die Tatsache, dass Cicero in einem Brief an Atticus Zweifel daran äußert, ob ein fürsorglicher Gott existiere (Cic. Att. 4,10,1 [22. April 55 v. Chr.), steht nicht unbedingt in Widerspruch zu dem, was sich anhand anderer Stellen als Ciceros Ansicht ermitteln lässt, sondern könnte als ein Eingehen auf die epikureischen Neigungen und Gottesvorstellungen des Adressaten zu verstehen sein. Man muss daher konstatieren, dass auch aus Briefzeugnissen aus dem engsten Familienund Freundeskreis keine sicheren Hinweise zu Ciceros religiöser Einstellung zu gewinnen sind, da wiederum die Positionierung des Autors im Verhältnis zum anvisierten Leserkreis die Aussagen zu religiösen Fragen bestimmt.

\section{Schlussfolgerungen}

Am Ende dieses selektiven Überblicks über die ,Stimme Ciceros in Bezug auf die bzw. seine Religion ergibt sich, dass Cicero wegen seiner adressaten- und zweckbezogenen Darstellungsweise in den wenigsten Fällen seine eigene Mei-

\footnotetext{
${ }^{23}$ Vgl. Wardle 2006, 8-17 (mit Verweis auf weitere Literatur).

${ }^{24}$ Vgl. auch Leonhardt 1999, 80-81.
} 
nung direkt zu erkennen gibt und auch die häufigen Äußerungen in der ersten Person nicht von vornherein als Ausdruck der eigenen Überzeugung angesehen werden können. ${ }^{25}$ Stattdessen nimmt Cicero je nach Situation jeweils eine andere persona an. ${ }^{26}$ Dieser Proteus-hafte Charakter des Autors Cicero war vermutlich in der damaligen Einzelsituation der jeweiligen Äußerung für zeitgenössische Adressaten weniger ein Problem, weil sie nicht, wie moderne Forscher, die Absicht hatten, Aussagen Ciceros in verschiedenen Schriften und zu verschiedenen Zeiten miteinander zu verbinden und zu vergleichen, sondern eher auf die jeweilige Äußerung eingingen und natürlich auch Kenntnis der historischen Person Cicero hatten. Möglicherweise gab es schon in der Antike Leser, die das Bedürfnis hatten, Ciceros eigene dezidierte Meinung zu erfahren, wenn man seine Bemerkungen in De natura deorum (Cic. nat. deor. 1,6; 1,10) über die allzu große Neugier der Leute so deuten kann. Moderne Forscher können lediglich versuchen, aus den erhaltenen Zeugnissen gewisse Auffassungen für Cicero zu ermitteln. ${ }^{27}$ Dieser Befund zeigt auch, dass die Person des Autors oder ein Bezug zu den Ansichten des Autors für die Vermittlung von Aussagen zu religiösen Themen für Cicero nicht immer im Vordergrund steht: In den Reden geht er auf religiöse Fragen ein, wie er glaubt, dass es den Vorstellungen der Zuhörerschaft entspricht; das gilt auch für die Briefe zu einem gewissen Grade, auch wenn hier gelegentlich persönliche Haltungen durchscheinen; in den Dialogen finden sich neben der Vorstellung verschiedener Ansichten gelegentlich verhaltene Kommentare des Autors.

Cicero hat sich als politisch aktives Mitglied der römischen Gesellschaft und als Privatmann, der sich mit Philosophie beschäftigte, über religiöse Fragen geäußert. Religion als Element des römischen Staatskults sowie als Problemkomplex auf philosophischer Ebene bedeutete für ihn nicht, dass die eine Perspektive die andere ausschloss. ${ }^{28}$ Als Grundlage des Staats, d.h. als Erfüllung der

${ }^{25}$ Auch wenn man Ciceros Einstellung zu einem einzelnen Gott zu ermitteln versucht, lässt sich seine Haltung nicht eindeutig bestimmen (zu Cicero und Dionysus / Bacchus / Liber vgl. Manuwald 2019).

${ }^{26}$ Die verschiedenartigen Facetten der Äußerungen Ciceros hat aus anderer Perspektive auch Steel (2005) festgestellt; vgl. bes. 48: „Different forms of writing are, for Cicero, about multiplying possibilities for conveying a particular message: whatever his circumstances, there is always a type of writing that is available. He moves with enormous freedom among them because he lacks inhibition about his capacities to tackle a particular type of writing, and because his ultimate concern is not to be an epic poet, or a philosopher, or even a great orator, but to subsume and incorporate all these textual presences into a permanent record of 'Cicero'."

${ }^{27}$ Gawlick/Görler (1994, 1099-1116) gehen davon aus, dass sich in Ciceros Werken jeweils zwei unterschiedliche Auffassungen finden lassen, eine eher rational begründete und eine eher auf dem Glauben beruhende, die jeweils in verschiedener Weise zum Tragen kommen.

${ }^{28}$ In Auseinandersetzung mit Ansichten früherer Forscher, die zum Teil Cicero als scheinheilig betrachten, argumentiert Heibges (1969a), dass zwischen Reden und philosophischen Schriften eine geringere Diskrepanz bestehe als oft angenommen und Cicero in beiden Fällen die offizielle Staatsreligion und philosophische Argumente einsetze, wie es ihm passe. Troiani (1984, 951-952) meint, dass die Religion für Cicero die Staatsreligion gewesen sei und seine 
Pflichten gegenüber den Göttern, hat Cicero offenbar die Religion nicht in Zweifel gezogen; schließlich war er selbst Augur. ${ }^{29}$ So enthalten die Reden eigentlich keine Äußerungen, die auf eine von der damals üblichen abweichende Religiosität oder auf Zweifel daran hindeuten. Die ,religiöse Stimme' Ciceros ist in solchen Fällen traditionell, oder sie instrumentalisiert traditionelle Vorstellungen. Anscheinend war Cicero der Ansicht, dass die Mehrheit der Zeitgenossen den Staatskult ernst nehme, so dass er Verweise auf Priesteraussagen oder auf die Einwirkung von Göttern in einer politischen Rede als wirkungsvolle Elemente ansehen und einsetzen konnte. Eine solche Strategie gilt vermutlich ebenso für Ciceros Dichtungen: Auch wenn Cicero ein gewisses Maß an Selbstüberhebung oder literarischer Ehrgeiz bestimmt haben mögen, gehört wohl eine gewisse Distanz zu den Göttern dazu, um sich selbst im Rahmen einer Götterversammlung darzustellen. Umgekehrt kann man nicht mit Sicherheit sagen, dass Cicero einen philosophisch geprägten Gottesbegriff gehabt habe. Allerdings ist, während Cicero die verschiedenen philosophischen Ansichten über die Götter in den Dialogen gleichrangig zu Wort kommen lässt, zu erkennen, dass er nicht vollkommen neutral informiert, sondern, trotz einer generell skeptischen Haltung, dennoch von der Existenz der Götter als einer lenkenden Gewalt ausgegangen zu sein scheint. ${ }^{30}$ Vielleicht sind die Äußerungen in persönlichen Briefen ebenfalls in diesem Sinne zu deuten, und ist auch die Identifikation der Minerva als seiner besonderen Schutzgöttin mehr als eine Geste gegenüber der Öffentlichkeit (z. B. Cic. dom. 144; fam. 12,25,1; leg. 2,42).

Natürlich ist es bei einem Autor der Vergangenheit, von dem keine Tagebücher oder andere persönliche Dokumente vorliegen, immer schwierig, die wahren Überzeugungen, gerade was Glaubensfragen angeht, genau zu ermitteln. Jedoch ist angesichts der Fülle des Materials, das man über oder von Cicero hat, der diffuse Befund in Bezug auf seine religiösen Ansichten einigermaßen überraschend. Jedenfalls, was auch immer Cicero gedacht haben mag, der Einfluss

wahren Überzeugungen eher in seinem Umgang mit der Philosophie zu finden seien (siehe auch oben Anm. 19).

${ }^{29}$ Vgl. auch Ben Mansour 1970, 373.

${ }^{30}$ Vgl. auch Leonhardt 1999, 61-62: „Ciceros sonstige Äußerungen zur Religion und zu den Göttern legen aber doch, so schwierig sie insgesamt zu deuten sind, eher nahe, dass Cicero im allgemeinsten Sinn nicht Agnostiker war, sondern an das Wirken des Göttlichen in der Welt glaubte.“; Görler 2015, 420: „Ob der Nachweis gelungen ist, dass Cicero zum Monotheismus tendierte, vielleicht sogar stark tendierte? Ihn gläubig zu nennen ginge zu weit. Er war zum Skeptiker geboren, er konnte nie alle Zweifel überwinden. ... Aber er war kein negativer, kein destruktiver Skeptiker wie seine griechischen Vorbilder Arkesilaos und Karneades. Er war auch nicht neutral und kühl distanziert. Nein, er neigte zu positiven Annahmen; er fühlte sich hingezogen zum Glauben an ein Leben nach dem Tode, an die Selbstgenügsamkeit eines tugendhaften Lebens - und zum Glauben an einen allmächtigen Gott, der sich um die Welt und um die Menschen kümmert.“; ferner Ferguson 1962, 92; André 1975, 21. Nach van den Bruwaene $(1937,245)$ kann man bei Cicero von „sincerité et ... conviction religieuses“, aber nicht von „mentalité religieuse“ sprechen. 
seiner Äußerungen zu religiösen Fragen, besonders derjenigen in den philosophischen Schriften, ist für die europäische Geistesgeschichte nicht zu überschätzen, da sich die Kirchenväter intensiv mit ihnen auseinandergesetzt haben, wobei mehr die Aussagen als solche denn ihr Verhältnis zur persönlichen Sichtweise des Autors eine Rolle spielten. ${ }^{31}$

\section{Literaturverzeichnis}

André, Jean-Marie (1975). „La philosophie religieuse de Cicéron: dualisme académique et tripartition varronienne, " in: Alain Michel; Raoul Verdière, edd., Ciceroniana. Hommages à Kazimierz Kumaniecki. Leiden. 11-21.

Ben Mansour, Abd El Hadi (1970). „Aspects de la religion de Cicéron.“ Bulletin de l'Association Guillaume Budé 29: 359-373.

Berry, Dominic H., trans. (2006). Cicero. Political Speeches. Translated with Introductions and Notes. Oxford (Oxford World's Classics).

Brunt, P.A. (1989). „Philosophy and Religion in the Late Republic,“ in: Miriam Griffin; Jonathan Barnes, edd., Philosophia Togata. Essays on Philosophy and Roman Society. Oxford. 174-198.

van den Bruwaene, Martin (1937). La théologie de Cicéron. Louvain (Université de Louvain, Recueil de travaux publiés par les membres des Conférences d'Histoire et de Philologie, $2^{\mathrm{e}}$ Série, $42^{\mathrm{e}}$ Fascicule).

Burriss, Eli Edward (1924). „Cicero’s religious unbelief.“ Classical Weekly 17: 101-103.

Burriss, Eli Edward (1926). "Cicero and the Religion of His Day.“ Classical Journal 21: 524-532.

Butler, Shane 2002. The hand of Cicero. London/New York.

Carcopino, Jérôme (1951). Cicero. The secrets of his correspondence. 2 vols. London (Orig.: Les secrets de la correspondance de Cicéron. Paris 1947).

Ciafardone, Giuseppe (2013). „Il conservatorismo politico di Cicerone nel De divinatione." Euphrosyne 41: 333-342.

Defourny, Pierre (1954). „Les fondements de la religion d'après Cicéron.“ Les études classiques 22: 241-253, 366-378.

Dugan, John (2005). Making a new man. Self-fashioning in the rhetorical works. Oxford/ New York.

Dyck, Andrew R. (2008). Cicero. Catilinarians. Cambridge (Cambridge Greek and Latin Classics).

Feeney, Denis (1998). Literature and religion at Rome. Cultures, contexts, and beliefs. Cambridge (Roman Literature and its Contexts).

Ferguson, John (1962). „The religion of Cicero,“ in: John Ferguson; L. A. Thompson; A. R. Hands; W. A. Laidlaw, Studies in Cicero. Rom (Collana di Studi Ciceroniani II). 81-96.

Fuhrmann, Manfred (1990). Cicero und die römische Republik. Eine Biographie. 2., durchges. Auflage. München/Zürich.

Gawlick, Günter; Görler, Woldemar (1994). „Sechstes Kapitel. Cicero,“ in: Hellmut Flashar, ed., Die Philosophie der Antike. Band 4. Die Hellenistische Philosophie. Basel

${ }^{31}$ Zur Nachwirkung von De natura deorum bei den Kirchenvätern vgl. z. B. Opelt 1966. 
(Grundriss der Geschichte der Philosophie, Begründet von Friedrich Ueberweg, Völlig neubearbeitete Ausgabe). 991-1168.

Goar, R.J. (1972). Cicero and the State Religion. Amsterdam.

Görler, Woldemar (2015). „Ciceros Religion - Polytheismus oder Monotheismus?“ in: Christoph Kugelmeier, Hg., Translatio humanitatis. Festschrift zum 60. Geburtstag von Peter Riemer. St. Ingbert. 405-426.

Gueuning, L. (1925/1926/1929). „Les idées religieuses de Cicéron.“ Nova et Vetera 7: 233-246, 324-343 / 9: 1-22 / 11: 24-38.

Guillén, J. (1976). „Introducción a la teología de Cicéron.“ Helmantica 27: 193-259.

Guillén Cabañero, J. (1999). Teología de Cicerón. Salamanca (Bibliotheca Salmanticensis, Estudios 212).

Heibges, Ursula (1969a). „Cicero, a hypocrite in religion?“ American Journal of Philology 90: 304-312.

Heibges, Ursula (1969b). „Religion and Rhetoric in Cicero's Speeches.“ Latomus 28.4: 833-849.

Hooper, W.D. (1917). „Cicero’s Religious Beliefs.“ Classical Journal 13: 88-95.

Hutchinson, Gregory O. (1998). Cicero's Correspondence. A Literary Study. Oxford.

Kurczyk, Stephanie (2006). Cicero und die Inszenierung der eigenen Vergangenheit. Autobiographisches Schreiben in der späten Römischen Republik. Köln/Weimar/Wien.

Leonhardt, Jürgen (1999). Ciceros Kritik der Philosophenschulen. München (Zetemata 103).

Mandel, Joshua (1983-1984). „State religion and superstition in Cicero's philosophical works." Euphrosyne 12: 79-110.

Manuwald, Gesine (2019). „Dionysus / Bacchus / Liber in Cicero, “ in: Fiachra Mac Góráin, ed., Dionysus and Rome. Oxford (im Druck).

Opelt, Ilona (1966). „Ciceros Schrift De natura deorum bei den lateinischen Kirchenvätern." Antike E Abendland 12: 141-155.

Sauer, Vera (2013). Religiöses in der politischen Argumentation der späten römischen Republik. Ciceros Erste Catilinarische Rede - eine Fallstudie. Stuttgart (Potsdamer Altertumswissenschaftliche Beiträge 42).

Schofield, Malcolm (2008). „Ciceronian dialogue,“ in: Simon Goldhill, ed., The end of dialogue in antiquity. Cambridge. 63-84.

Short, Richard Graham (2012). Religion in Cicero. Diss. Harvard University (http://nrs. harvard.edu/urn-3:HUL.InstRepos:10381393).

Steel, Catherine (2005). Reading Cicero. Genre and Performance in Late Republican Rome. London (Duckworth Classical Essays).

Stroh, Wilfried (2010). „Cicero und die römische Religion“ (http://stroh.userweb.mwn. de/schriften/cic_religion.pdf).

Tarán, Leonardo (1987). „Cicero's Attitude Towards Stoicism and Skepticism in the De natura deorum, " in: Karl-Ludwig Selig; Robert Somerville, edd., Florilegium Columbianum. Essays in Honor of Paul Oskar Kristeller. New York. 1-22; wieder abgedr. in: Leonardo Tarán, Collected Papers (1962-1999). Leiden/Boston/Köln 2001: 455-478.

Troiani, Lucio (1984). „La religione e Cicerone.“ Rivista storica italiana 96: 920-952.

Wardle, David (2006). Cicero on Divination. De Divinatione. Book 1. Translated with Introduction and Historical Commentary. Oxford (Clarendon Ancient History Series). 



\title{
Im Schutz der Musen und des Bacchus
}

\author{
Die biographische Gottesnähe des Exildichters Ovid (trist. 4,10; 5,3)
}

\section{Ulrike Egelhaaf-Gaiser}

\section{Thema und Fragestellung ${ }^{1}$}

Für eine auktoriale Untersuchung scheint Ovid geradezu prädestiniert: Er ist der einzige Dichter klassischer Zeit, der seine Biographie in einer stolzen Länge von 130 Versen beschreibt. Diese Sphragis, mit der Ovid das vierte Buch seiner Tristien beschließt, ${ }^{2}$ übertrifft die literarischen Siegel eines Properz, Horaz und Vergil ${ }^{3}$ etwa um das Zehnfache; und sie wird durch biographische Selbstaussagen in anderen Schriften nochmals erweitert und ergänzt. ${ }^{4}$

Ein weiteres Spezifikum unter den augusteischen Dichtern liegt in Ovids Produktion von neun Büchern Exilbriefen, die beide Briefbücher des Horaz nicht nur an Umfang weit überbieten, sondern auch eine ganz neue Intensität der autobiographischen Selbstinszenierung erreichen. ${ }^{5}$ Die Tristien und Epistulae ex Ponto verleihen nicht nur dem - seinerseits erst 20 Jahre alten - Genre des poetischen Briefs ${ }^{6}$ eine neue, elegische Facette, ${ }^{7}$ sondern fordern zudem durch die überbordende Fülle ihrer Selbstaussagen den Leser zu einer differenzierten Auseinandersetzung mit der allgegenwärtigen persona des klagenden Ichs heraus.

\footnotetext{
${ }^{1}$ Herzlich gedankt sei Meike Rühl (Osnabrück/Wuppertal) für hilfreiche Literaturhinweise und konstruktive Gespräche.

${ }^{2}$ Generell zu Form und Funktion antiker Sphragides Kranz 1961.

${ }^{3}$ Prop. 1,22; Hor. c. 2,20 und c. 3,30; Hor. epist. 1,20,19-28; Verg. georg. 4,559-566.

${ }^{4} \mathrm{Zu}$ denken ist dabei an das auktoriale Siegel der Amores $(3,15)$ oder an diverse Einsprengsel in Ovids Fasten (fast. 1,540: Verbannung; fast. 4,79-84: Herkunft aus Sulmo; fast. 4,303-304: decemvir stlitibus iudicandis). Zu Ovids Informationsfreudigkeit siehe Knox 2009, 4: „Ovid is himself the source for most of what we know about his life; indeed, he provides more informations about himself than most ancient poets."

${ }^{5}$ Zum autobiographischen Charakter und Stellenwert der Exilbriefe im Gesamtwerk Korenjak 2005, 52 f.; Korenjak 2007, 241-248.

${ }^{6}$ Wulfram 2008.

${ }^{7}$ Zur gattungsgeschichtlichen Tradition der ovidischen Exildichtung Stroh 1981, 2640-2644.
} 
Der vorliegende Beitrag sucht daher zu präzisieren, welchen literarischen Vorbildern Ovids auktoriale Selbstaussagen in den Exilbriefen verpflichtet sind, in welchem sozialen und literarischen Umfeld sich das Ich dabei verortet und welche Dichtungsgottheiten ihm in seiner Existenz als vates $\mathrm{zu}$ einem ganz persönlichen Profil verhelfen.

Als Bezugspunkte wurden mit trist. 4,10 und trist. 5,3 zwei Briefe ausgewählt, die mehrere thematische und generische Schnittmengen aufweisen: Beide sind autobiographisch geprägt, wobei der Sprecher sich hierfür verschiedene Rollen wählt. So sieht sich das Ich in trist. 4,10 retrospektiv zuerst und vor allem als Dichter; in trist. 5,3 kombiniert der Sprecher diese poetische Existenz mit der eines cultor Bacchi, dessen Vita der des Gottes in frappierender Weise vergleichbar sei.

In beiden Fällen sucht sich das briefliche Ich in soziale Netzwerke des augusteischen Literaturbetriebs zu integrieren: In trist. 4,10 nutzt es hierzu die Patronagezirkel eines Messalla und Maecenas, in trist. 5,3 dagegen ein dionysisches Dichtercollegium, das den gemeinsamen Schutzgott am jährlichen Festtag hymnisch ehrt. Der in trist. 4,10 etablierte Literatenkreis wird somit in trist. 5,3 mit einer anonymen Kultgemeinschaft überlagert, in deren Mitte sich der abwesende Exildichter einschreibt. Gleichzeitig - und mit diesen Inklusionsinteressen konkurrierend - sucht sich das Ich ganz individuell zu profilieren. Dabei greift es auf das Konzept der Theophilie zurück, ${ }^{8}$ das seit Hesiods Musenhymnus literarisch etabliert ist ${ }^{9}$ und in der Odendichtung des Horaz eine ebenso innovative wie programmatische Aktualisierung erfahren hat. ${ }^{10} \mathrm{Im}$ Rahmen einer literarisch imaginierten Kulthandlung konstruiert der Sprecher der Tristie 5,3 nun seinerseits eine Dichterbiographie, die ihn eng an den virtus-Träger und olympischen Aufsteiger Bacchus annähert.

Ich möchte in meinem Beitrag zeigen, wie das briefliche Ich sein bereits in den Fasten angedeutetes Selbstverständnis als Liebling der Götter ${ }^{11}$ in beiden Briefen ausbaut und weiterentwickelt. Meine These ist, dass Ovids poetisches Selbstbild, wie er es in der Exildichtung propagiert, ganz maßgeblich von der Lyrik des Horaz inspiriert ist. Indem sich der Exildichter an Kerngedanken der

${ }^{8}$ Der Begriff beschreibt laut Krasser 1995, 30 „die freundschaftlich fürsorgliche Hinwendung einzelner Götter zu besonders ausgezeichneten Menschen“; zur Entwicklung dieses Motivs ebenda 37-51.

${ }^{9}$ Hes. theog. 94-103.

10 Pointiert inszeniert sich Horaz als Liebling der Götter in c. 1,17,13-14: di me tuentur, dis pietas mea / et musa cordi est; ähnlich Hor. c. 1,26,1: Musis amicus tristitiam et metus / tradam protervis in mare Creticum; zur göttlichen Errettung des Dichters aus Gefahr Hor. c. 1,22,9-12; c. 2,7,13-16; c. 3,4,9-20. Zur Neufassung des Theophiliemotivs bei Horaz und zur Funktionalisierung des Bacchus als persönlicher Lehrer und treibende Kraft des Dichters umfassend Krasser 1995; zu Horaz' Selbstinszenierung als beschützter Dichter siehe auch Harrison 2007, 22-24.

${ }^{11}$ Ov. fast. 6,7-8: fas mibi praecipue vultus vidisse deorum, / vel quia sum vates, vel quia sacra cano. 
Horazischen Poetik abarbeitet, adaptiert er diese auf die spezifischen Bedürfnisse seiner Person und seine neue Lebenssituation im Exil. Dabei betreibt er eine lebensweltliche Erdung der bei Horaz raum-zeitlos gehaltenen Denkfiguren: Die Sonderstellung und persönliche Götternähe, die Horaz teils aus seiner moralischen Integrität, vor allem aber aus seinem lyrischen Können ableitet, ${ }^{12}$ beansprucht der verbannte Ovid nun für seine aktuelle Duldungsfähigkeit in einer romfernen und literaturfeindlichen Umwelt. Eine besondere ästhetische Qualität spricht er seiner Exildichtung explizit ab, da sein poetisches Können unter dem Einfluss seines barbarischen Aufenthaltortes empfindlich gelitten habe. ${ }^{13}$ Trotz dieses demonstrativ herabsetzenden Grundtenors schwingt nun aber in beiden zu behandelnden Tristien ein hoher Stolz auf die Exildichtung mit. Dieser offene Widerspruch lässt sich meiner Meinung nach nicht nur mit Claassen durch eine mythisch überhöhte Selbststilisierung zum poeta exsul und vates, ${ }^{14}$ sondern auch aus einer gezielten Aneignung des horazischen Theophiliemotivs erklären.

Sollte sich diese Vermutung erhärten lassen, so bestünde zwischen beiden Dichtern ein weit engeres Verhältnis als bisher von der Forschung eingeräumt wird: $\mathrm{Zu}$ einzelnen, eher punktuellen Textreferenzen ${ }^{15}$ und einer makrostrukturell analogen Werksequenz (Jugenddichtung - lyrisches / episches Hauptwerk biographische Altersbriefe ${ }^{16}$ käme dann eine poetologische Nahbeziehung, die sich auf eine besondere Nähe nicht nur zu den Musen, sondern auch zu Bacchus stützt. Denn kein vorgängiger Dichter hat so dezidiert wie Horaz die Figur des Bacchus genutzt, um poetologische und persönliche Selbstaussagen zu vermitteln. ${ }^{17}$ Wenn Horaz dabei Bacchus nicht nur als seinen Inspirationsgott beschreibt, sondern mit weiteren Konnotationen (v.a. des virtus-Trägers und selbstverdienten Aufsteigers in den Olymp, ${ }^{18}$ aber auch des Vertreters friedvoller und musischer Künste und des Gegenpols zum augustusnahen Apoll ${ }^{19}$ ) aus-

${ }^{12}$ Zur Verschmelzung beider Bereiche siehe c. 1,17,13f.: di me tuentur, dis pietas mea / et mus a cordi est und 1,17,21 f.: hic innocentis proelia Lesbii / duces sub umbra; 1,22,1: integer vitae scelerisque purus und 1,22,10: dum meam canto Lalagen). Allein auf seine poetische Leistung beruft sich dagegen Horaz im c. 3,30.

${ }^{13}$ Zahlreiche Gedichte suggerieren eine schlechte Qualität der Exildichtung, so etwa trist. 3,1,17f.; 4,1,1-4; 5,1,69-72. Zu Recht weist Claassen 1988, 164 darauf hin, dass diese Selbsterniedrigung Teil des poetischen Rollenspiels ist und sich weder sprachlich noch stilistisch bestätigen lässt.

${ }^{14}$ Siehe Claassen 1988, 169: „The creation of the myth of exile is a poetic triumph. Ovid the man has responded uniquely to totaltarian oppression. Ovid the poet has presented the world with a stylized picture of the heroic fortitude of a creative genius in extreme conditions. $\mathrm{He}$ offers a view of reality which may possible derivate froom literal fact, but transcends it by the truth of its depiction of suffering and survival."

${ }^{15}$ Zingerle 1967 III; Korenjak 2007, 240 Anm. 4.

${ }^{16}$ Korenjak 2005 passim und 2007, 243-248.

${ }^{17}$ Krasser 1995 passim, besonders 92-99; 127-141; $150 f$.

${ }^{18}$ Hor. c. $2,19,13-32$; c. 3,3,13-16.

${ }^{19}$ Zum Konzept des Liber modicus Hor. c. 1,18; Krasser 1995, 102-108; zur Inspiration durch Bacchus als Alternative zum augusteischen Apoll Hor. c. 3,25. 
stattet, so scheint mir dies ein gewichtiges Argument für eine gezielte Adaption der horazischen Bacchusoden seitens Ovid zu sein. Wenn der Exildichter nun seine Biographie mit der des Bacchus parallelisiert, so sucht er damit explizit eine quasi dionysische, Wiedergeburt' seiner Person zu erwirken: wenn nicht in Form einer Begnadigung seitens des Princeps, so doch in der Zuerkennung literarischer Unsterblichkeit durch den Leser.

Bevor wir uns aber den Textbeispielen zuwenden, ist ein Blick auf den Forschungsstand angebracht, um über begriffliche und methodische Grundsatzfragen Klarheit zu gewinnen: Mit welchem Recht können wir überhaupt die Artikulation einer ,Stimme des Autors' im Text voraussetzen? Wie ist ein solcher Ansatz mit dem Postulat der Literaturwissenschaft vereinbar, nach dem eine hermetische Grenze zwischen dem historischen Autor und dem textinternen Ich besteht?

\section{Ille ego qui: Diskussionen um die auktoriale persona}

Die Vita keines anderen Augusteers wurde so heftig und kontrovers diskutiert wie diejenige Ovids: Weder Vergils mögliche Landenteignung ${ }^{20}$ noch Horaz' politische Radikalwende nach Philippi ${ }^{21}$ haben die Gemüter auch nur annähernd so sehr erhitzt wie die Frage nach der Authentizität von Ovids Verbannung und deren mögliche Hintergründe. ${ }^{22}$ Angesichts der hohen Wellen, die der alte Streit um ,Dichtung und Wahrheit' von Ovids Exil geschlagen hat, kann leicht übersehen werden, dass sich in den letzten Jahren eine neue und nicht weniger brisante Grundsatzfrage in den Vordergrund gespielt hat: Die neuere Forschung erörtert die persona Ovids unter literaturwissenschaftlichen Prämissen, nach denen grundsätzlich von einer kategorialen Scheidung zwischen historischem Autor und elegischem Ich auszugehen ist: Kann und darf diesem Ich im Euvre Ovids also überhaupt eine auktoriale Qualität zugeschrieben werden ${ }^{23}$

Gegen diese generelle Skepsis lässt sich einwenden: Selbst wenn die methodische Trennung von historischem Autor und literarischem Ich heute Gemeingut

\footnotetext{
${ }^{20}$ Abgeleitet aus Verg. ecl. 1 und 9; in kritischer Auseinandersetzung mit derart biographisierenden Lesungen Korenjak 2003, 69; Holzberg 2006, $15 \mathrm{f}$.

${ }^{21}$ Hor. sat. 1,6,47 f.; c. 2,7,9-12; epist. 2,2,46-54; zum horazischen Selbstbild als Kämpfer im Bürgerkrieg Harrison 2007, 24-26.

${ }^{22}$ Zusammenfassend zur älteren Forschung v.a. der achtziger Jahre um eine mögliche Fiktionalität des Exils Wulfram 2008, $219 \mathrm{f}$. mit Anm. 19; siehe auch Williams 2002, $337 \mathrm{f}$.; Watson 2002, 154-157; White 2002, 16 f.

${ }^{23}$ Die von mir vertretene Auffassung, wonach sich die aktuelle Forschung der literaturwissenschaftlichen Problematik bewusst sein muss, aber die moderne Scheidung nicht unreflektiert auf antike Texte übertragen darf, folgt der Linie von Korenjak 2003, Mayer 2003 und Wulfram 2008, $93 \mathrm{f}$. und berücksichtigt zusätzlich die hilfreichen Beobachtungen von Volk 2005.
} 
der Forschung ist, kann der Autor natürlich die Stimme des Erzählers in eine beliebige, auch autobiographische Nähe zu sich rücken. Zudem ist unser heutiges Verständnis des literarischen Icherzählers nicht selbstverständlich mit dem des antiken Rezipienten gleichzusetzen. Denn einerseits weiß die Antike - und allen voran Ovid - sehr wohl zwischen den Ichaussagen fiktiver personae im Rahmen einer Ethopoiie (vgl. etwa die Heroides) und den selbstreflexiven Aussagen eines Liebeslehrers oder Kalenderdichters zu scheiden, der seine Stimme nicht nur, aber besonders deutlich in Proömien und auktorialen Siegeln zu Gehör bringt. ${ }^{24}$ Mit gleichem Recht haben andererseits Korenjak 2003 und Mayer 2003 auf die antike Praxis biographisierender Werkdeutungen verwiesen: Ein antiker Leser ging offenkundig davon aus, dass der Autor in der Aussage einer fiktiven Person - ob diese nun Tityrus (Verg. ecl. 1) oder Ofellus (Hor. sat. 2,2) heißt - seine eigene Meinung offenbare, die auktoriale Stimme sich also durch die Maske einer fremden persona zu Gehör bringe.

Ungeachtet ihrer verschiedenen Positionen sind sich weiterhin Volk 2005 und Korenjak 2005 darin einig, dass die Exildichtung ganz unstrittig eine größere auktoriale Qualität als alle früheren Werke Ovids besitzt. ${ }^{25}$ Dies gilt insbesondere für den Fall, dass zumindest ein Teil der Exilbriefe tatsächlich an reale Adressaten versandt und als Werbung in eigener Sache eingesetzt wurde. Denn dann besitzen die Exilbriefe in der Tat eine grundlegend andere, historisch gebundene Authentizität. ${ }^{26}$

Unabhängig von der Historizität der Verbannung setzt die von Ovid neu geschaffene Subgattung des poetischen Exilbriefs die Atmosphäre einer schriftlichen Kommunikation unter ortsfernen Freunden voraus. Die räumliche Distanz von Adressant und Adressat hat dabei Folgen für die sprachliche Gestaltung des Texts: Wie sich an Ovids Exildichtung vielfach beobachten lässt, sucht sich das briefliche Ich seinem Gegenüber möglichst unmittelbar präsent zu machen, ja sich dem transportablen Brief geradezu körperlich ,einzuschreiben ${ }^{6}{ }^{27}$ Dies geht so weit, dass einerseits die Buchrolle in ihrem (angeblichen) Erscheinungsbild (ihrer von Tränen verwaschenen Schrift und ihrem ungeglätteten Papyrus) das traurige Leben und den Gemütszustand des Verbannten dem Leser haptisch vor Augen führt. ${ }^{28}$ Zugleich wirkt das Lebensumfeld derart auf den Briefschreiber ein, dass dieser sich nur noch klagend äußern kann: Das Exil liefert nicht nur den exklusiven Stoff der Briefe, sondern wird zu deren Inspirationsinstanz erhoben. ${ }^{29}$

\footnotetext{
${ }^{24}$ Hierzu Volk 2005, 87-92.

${ }^{25}$ So betont bereits Korenjak 2005, 53 Anm. 23 den strikt autobiographischen Charakter der Exildichtung.

${ }^{26}$ Volk 2005, 92.

${ }^{27}$ Rühl 2011, 2-7.

${ }^{28}$ Siehe trist. 1,1,1-24 und 3,1,1-24. Martelli 2013, 171-174.

${ }^{29}$ Die Identität von Dichter und Werk, das dessen Lebensumstände geradezu eins zu eins abbildet, ist besonders deutlich in trist. 5,1,3-5: hic (libellus) quoque talis erit, qualis fortuna
} 
Für uns ist wichtig, dass sich hier ein Ich nicht nur im literarischen Raum des Briefs um eine greifbare Gestalt bemüht, sondern sich dabei auch explizit als Autor präsentiert. ${ }^{30}$ Tatsächlich sagt der (implizite) Autor Ovid nirgends so oft ,ich“ wie in den Exilbriefen: Den Amores, der Ars, den Remedia und den Fasten mit jeweils maximal 4 Belegen ${ }^{31}$ stehen die Tristien mit $15^{32}$ und die epistulae ex Ponto mit stolzen 38 Belegen $^{33}$ gegenüber. Bemerkenswert ist weiterhin, dass dieses auktoriale Ich seinem Leser zwei konkurrierende Signale sendet. Denn während die namentliche Werk- oder Briefsignierung mit ,Naso ${ }^{34}$ auf die Identität von literarischem Ich und Autor abhebt, ${ }^{35}$ changiert die Formel ille ego (qui $)^{36}$ zwischen einer betonten Kontinuität und einem markierten Abstand des einstigen vom heutigen Ich. ${ }^{37}$

Schließlich ist der einheitlich klagende Duktus der Briefe als Argument für eine auktoriale Qualität des Ichs ins Feld zu führen. Denn er zielt ebenso wie die breit entfaltete Lebens- und Gefühlswelt des elegischen Sprechers auf eine positive Vereinnahmung des Rezipienten; und er wirbt nicht nur für die literarische persona des exsul, sondern ganz ausdrücklich auch für das dem ,geneigten Leser (trist. 4,10,132: candide lector) vorliegende Briefcorpus. ${ }^{38}$

So vielfältig nun die Indizien auf die Gegenwart einer auktorialen Stimme in der Exildichtung sein mögen, warnt uns doch andererseits die ausgeprägte Stilisierung der dichterischen persona vor einer vereinfachenden Gleichsetzung des werkinternen poeta exsul mit dem historischen Autor: ${ }^{39}$ Wie Claassen 1988 überzeugend zeigt, hat Ovid die bisherige Tradition der Exilliteratur grundlegend durch die Erzeugung eines Exilmythos revolutioniert, den er immer neu variiert und anreichert. ${ }^{40}$ Gemeint ist damit nicht, dass Ovids Verbannung per se eine literarische Fiktion sei, sondern vielmehr, dass der Verfasser der Briefe seine persona und Lebenswelt konsequent in mythischen Bildern überhöht und damit

poetae:/ invenies toto carmine dulce nibil. / flebilis ut noster status est, ita flebile carmen, / materiae scripto carmine dulce nibil; zum Exil als Inspirationsquelle trist. 5,1,27f.: non haec ingenio, non haec componimus arte: / materia est propriis ingeniosa malis; grundlegend zu trist. 5,1 Stroh 1981, 2667 f. Ähnlich etwa Ov. trist. 3,1,9f.; Pont. 3,9,35-38.

${ }^{30}$ Trist. 5,1,35-47.

${ }^{31}$ Ov. am. 1 ep. $1 ; 1,11,27 ; 2,1,2 ; 2,13,25$; ars 2,744; 3,812; rem. 71 f.; 558; fast. 5,377.

${ }^{32}$ Exemplarisch Ov. trist. 1,7,10; 2,1,119; 3,3,74-76; 3,4,45; 3,10,1; 3,12,51; 4,4,86; 5,1,35.

${ }^{33}$ Ov. Pont. $1,1,1 ; 1,3,1 ; 1,5,2 ; 1,7,4 ; 1,7,69$ und weitere.

${ }^{34}$ So in Ov. trist. 3,10,1; 5,4,1; 5,13,1 und vielfach.

${ }^{35}$ Zur Identitätsfunktion des römischen Namens grundlegend Kunst 1999. Siehe auch unten Kapitel 4 und 5.

${ }^{36}$ So Ov. am. 2,1,2; trist. 3,3,74; Pont. 4,3,10 und öfter.

${ }^{37}$ Volk 2005, 86. Zur sprachlichen Assimilation an Grabinschriften siehe Fairweather 1987, 186f.; King 1998, $102 \mathrm{f}$. und 106-109; Martelli 2013, $173 \mathrm{f}$.

${ }^{38}$ Trist. 3,1,81-82; trist. 4,10,1-2 und 131-132; trist. 5,1,1-2.

${ }^{39}$ Zur konsequenten Stilisierung der Exilwelt Williams 2002.

${ }^{40}$ Vgl. auch Claassen 1999, 185-204; Claassen 2008, 180-183 zur Heroisierung des Dichters und Claassen 1999, 238-241 zur Bildersprache des Exils. Zur Fortführung von Claassens Ansatz siehe Wasyl 2003. 
die elegischen Gattungsgrenzen überschreitet. ${ }^{41}$ So gleicht er sich epischen exempla an - vorzugsweise den heimatverlustigen Irrfahrern Odysseus und Aeneas. ${ }^{42}$ Der heroisierte poeta exsul lebt einsam in einer schlichten Hütte und befragt zufällig anlandende Seefahrer nach der fernen Heimat; ${ }^{43}$ er sieht sich von einer zürnenden Gottheit gestraft ${ }^{44}$ und nimmt sein Exil als Todeserfahrung wahr; ${ }^{45}$ er bewährt seine virtus im Kampf gegen feindliche Barbaren und im tapferen Ertragen seines Schicksals. ${ }^{46}$

Zugleich weicht die von Ovid konstruierte persona des exsul aber demonstrativ von ihren epischen Vorbildern ab, insofern sie als poeta und vates gezeichnet wird. ${ }^{47}$ Dieses literarisch erzeugte Dichterbild ist durchaus widersprüchlich: Zwar ist es einerseits so sehr in sein Schicksal verstrickt, dass es keine Dichtung mehr schreiben kann, seine Sprache im Barbarenland verlernt hat ${ }^{48}$ und seine Schriften im Feuer verbrennt. ${ }^{49}$ Jedoch weiß es seiner Muse andererseits dafür Dank, dass sie ihm mit Hilfe der klagenden Dichtung die sprachliche Artikulation seines Leids eröffnet. ${ }^{50}$ Die vorgebliche Sprachlosigkeit des Ichs gehört demnach ebenso zur auktorialen Rollenkonstruktion wie das selbstbewusste Porträt als ein besonders geliebter Schützling der Götter.

Angesichts der skizzierten Argumente empfehlen sich die Exilbriefe als ein besonders geeignetes Textcorpus, um nach der Stimme des Dichters Ovid zu suchen. Wie sieht es dort nun aber mit dem religiösen Profil des Autors aus? Wären hierfür nicht die Fasten weit besser geeignet, in denen das elegische Ich an exponierter Stelle (so v. a. in den Proömien des 2. und 4. Buchs) seinem eigenen Staunen über den vollzogenen Wandel vom jugendlichen amator zum kaiserlichen Festsänger Ausdruck verleiht ${ }^{21}$ Was haben die Exilbriefe, in denen Religion und Kult nur eine Nebenrolle spielen, ${ }^{52}$ sechs Büchern aitiologischer Kult- und Festerzählungen entgegenzusetzen?

${ }^{41}$ Zur persona des Ichs zwischen poeta, exsul und vates Claassen 2008, 8-10; 40-51. Zur Personenzeichnung in der Exildichtung summarisch Wulfram 2008, 219.

${ }^{42}$ So in trist. 4,10,102-110; trist. 5,3,12. Zum homerischen Odysseus in der Exildichtung McGowan 2009, 169-201. Zur epischen Färbung der Exilbriefe auch Williams 2002, 350-352.

${ }^{43}$ Ov. trist. 3,12,31-44.

${ }^{44}$ Ov. trist. 2,27-40; 4,10,97f.; 5,3,29f.

${ }^{45}$ Ov. trist. 3,3,53 f.; Pont. 3,4,75 f.

${ }^{46}$ Ov. trist. 4,1,69-84; 4,10,105f.

${ }^{47}$ Claassen 1988, 169; Claassen 2009, 182.

${ }^{48}$ Ov. trist. $3,1,17 \mathrm{f}$.

${ }^{49}$ Ov. trist. 4,1,99-102.

${ }^{50}$ Ov. trist. 4,1,49-52; 4,10,115-122. Zu den verschiedenen Facetten im Konzept der tröstenden Musen Stroh 1981, 2658-2669.

${ }^{51}$ Fast. 2,5-8; fast. 4,7-12.

${ }^{52}$ Immer wieder finden sich Gebetsanklänge, so etwa trist. 1,9,,1-4; trist. 2,155-178 oder Pont. 2,8; hinzu kommt die Erwähnung einzelner Kultrealia, so z. B. das nach Minerva benannte Schiff, das den Dichter nach Tomi bringt in trist. 1,10,1-2, oder die Kaiserbilder in Pont. 2,8; desgleichen begegnen öffentliche wie private Rituale, z. B. Triumphschilderungen in trist. 4,2 


\section{Im Schutz der Götter: Religiöser Rollenwechsel im Spätwerk Ovids}

Der zunächst unmittelbar einleuchtende Einwand lässt sich entkräften: $Z_{w a r}$ inszeniert sich das elegische Ich der Fasten im Rahmen der üblichen Exordialtopik als inspirierter vates, der sich demonstrativ von seiner jugendlichen Liebesdichtung abwendet ${ }^{53}$ und sich dank seiner sakralen Themen einer besonderen Nähe zu seinen Göttern gewiss ist. ${ }^{54}$ Und ebenso zweifellos tritt er seinen göttlichen Auskunftsgebern als ein belesener Dialogpartner auf Augenhöhe gegenüber; im gelehrten Gespräch erweist er sich als ein kompetenter Forscher und Dichter, der selbstbewusst in Kallimachos' Fußstapfen tritt. ${ }^{55}$ Gelegentlich nimmt das elegische Ich auch die Rolle eines Festordners ein, der das Kultgeschehen aus der Sicht eines Augenzeugen verfolgt und kundig kommentiert, ${ }^{56}$ desgleichen adressiert er in der Rolle des inspirierten vates immer wieder im hymnischen Gebetsstil eine Gottheit. ${ }^{57}$ Nirgendwo in den Fasten agiert der Erzähler jedoch als ein privater Kultanhänger, der an eine bestimmte Gottheit in persönlicher Sache oder gar in Stellvertretung des Autors herantritt. Die Spurensuche nach einer auktorialen Individualreligion scheint daher bei den Fasten fehl am Platz.

Bestätigung findet diese Beobachtung im direkten Abgleich, wie die Musen und Bacchus / Liber in den Fasten und in der Exilliteratur jeweils funktionalisiert werden: Bezeichnenderweise sind die Musen in der Kalenderdichtung als die tradierten Inspirationsinstanzen ihres Amtes entthront. An ihre Stelle tritt nun nämlich programmatisch der Kaiser, dessen Altäre und Tage besungen werden und dem das Werk daher zugeeignet ist. ${ }^{58}$ Auch in den Folgeproömien greift das elegische Ich nicht auf die Inspirationskraft der Musen, sondern der ihm gattungsbedingt besonders nahestehenden Venus zurück, die sein poetisches Schaffen kontinuierlich begleitet hat. ${ }^{59}$

oder das Bacchusfest in trist. 5,3. Insgesamt aber bleiben die erwähnten Kultbezüge eng überschaubar.

${ }^{53}$ Fast. 2,3-8; zur literarischen Pose der Abwendung und zur Kontinuität von Liesdichtung und Fasten Miller 1991, 21-34.

${ }^{54}$ Fast. 3,1-18; fast. 6,7f.: fas mibi praecipue vultus vidisse deorum, / vel quia sum vates, vel quia sacra cano. Zur Inspirationstopik Miller 1991, 35-43.

${ }_{55}$ Miller 1982, 400-413; Barchiesi 1997, passim, besonders 51-3.

${ }^{56}$ Fast. 1,709-722; 4,133-140. Zu solchen Fastenpartien und ihrer hellenistischen Tradition Miller 1980; zu den variablen personae des elegischen Ich in den Fasten Miller 1991, $72 \mathrm{f}$.

${ }^{57}$ Z. B. fast. 2,641-644; 5,663-672.

${ }^{58}$ Fast. 1,15-26. Vgl. fast. 2,15-18.

${ }^{59} \mathrm{Im}$ Proöm des vierten Fastenbuchs nimmt das elegische Ich emphatisch auf seine Stellung als treuer ,Gefolgsmann der Venus' Bezug (fast. 4,7-8: saucius an sanus numquid tua signa reliqui? / tu mibi propositum, tu mibi semper opus). Venus gilt daher nicht nur des Dichters Musenanruf, weil ihr der Monat April gehört; denn im Unterschied zu allen anderen Monatsgöttern bleibt es ihr allein vorbehalten, die erbetene Inspiration mit einer Dichterweihe zu verknüpfen (fast. 4,15-17). Zu Venus' dominierender Rolle als Inspirationsinstanz in den Fasten Barchiesi 1997, 53-60. 
Erst im fünften Proöm werden die Musen hinzugebeten. Doch auch dort werden sie nicht als Inspirationsgottheiten, sondern als Ritualexpertinnen bemüht. Sie unterscheiden sich demnach in nichts von allen anderen göttlichen Auskunftgebern, die das elegische Ich andernorts befragt. Und damit noch nicht genug: Die Musen können sich über die Namensgebung des Monats Mai nicht endgültig einig werden. Sie sind demnach als mißstimmig (fast 5,9: dissensere deae) und nur bedingt hilfreich gezeichnet. ${ }^{60}$ Auch innerhalb der einzelnen Bücher bleiben die Musen unauffällig: Nur zweimal werden sie zur Beantwortung kultpraktischer Fragen angerufen. ${ }^{61}$

Ganz anders in der Exildichtung: Hier avancieren die Musen zu persönlichen Wegbegleiterinnen, die dem auktorialen Ich seit dessen Kindesbeinen besonders zugewandt sind und ihm nun auch fern von der Heimat in all seinem Kummer und Leid geradezu seelsorgerlich zur Seite stehen: Zu Recht hat Wilfried Stroh auf Ovids innovatives Konzept der ,tröstenden Musen“ verwiesen, die dem poeta exsul durch seine eigene Dichtung zur Selbsttröstung und quasi therapeutischen Selbstbefreiung vom aktuellen Leid verhelfen. ${ }^{62}$ Wenn allerdings Stroh die programmatische Stoßrichtung dieses neuen Typus von Poesie in ihrem ,völligen Ichbezug' sieht, ${ }^{63}$ so ist dieses Postulat angesichts der oben skizzierten Rolleninszenierung des auktorialen Ich zu relativieren: Neben die dem Dichter geltende Trostwirkung tritt die poetische Selbstprofilierung, die sich dezidiert nach außen richtet und auf die mitfühlende Teilnahme und Bewunderung einer offenen Leserschaft zielt: Im Fall der unten zu besprechenden trist. 4,10 verbindet sich das Konzept der tröstenden Muse programmatisch mit dem der Theophilie und mündet letztlich in einer triumphalen Selbstapotheose des Dichters.

Ein ähnlicher Funktionswandel lässt sich für Bacchus konstatieren: In den Fasten wird ihm anlässlich der Liberalia ein Kalendereintrag von knapp 80 Versen gewidmet, dessen aitiologische Kleinerzählung von der aktuellen Praxis gespendeter Opferkuchen (liba, etymologisch abgeleitet von Liber) ihren Ausgangspunkt nimmt und dann um einen lose verknüpften Nachtrag zur Togaübergabe an diesem Festtag erweitert wird (fast. 3,713-790).

$\mathrm{Zu}$ Bacchus tritt das elegische Ich dabei ausschließlich auf professioneller Ebene in Bezug, indem es sich eingangs explizit als vates autorisiert und den Gott um seine Gunst anruft, solange es dessen Fest besinge (fast. 3,714: Bacche, fave vati, dum tua festa cano!). Es zeigt sich damit zwar durchaus seines poetischen Schaffens und des daraus entstehenden Werks bewusst, nimmt aber dafür

\footnotetext{
${ }^{60}$ Ov. fast. 5,108: quid faciam? turbae pars habet omnis idem. / gratia Pieridum nobis aequaliter adsit, / nullaque landetur plusve minusve mibi. Zur Stelle Newlands 1995, 73-76; Barchiesi 1991. Generell zur Ambivalenz der göttlichen Informanten, die einerseits als Garanten der Wahrheit auftreten, andererseits ihre eigenen Aussagen unterlaufen, Barchiesi 1997, 181-203.

${ }^{61}$ Ov. fast. 2,271-282 zu den Lupercalia sowie Ov. fast. 6,799f. zum Hercules Musarum.

${ }^{62}$ Stroh 1981.

${ }^{63}$ Stroh 1981, 2659.
} 
keine individuelle Gottesnähe in Anspruch, die über die situationsgebundene Inspiration hinausginge. Vielmehr profiliert sich die persona des Erzählers auf der Folie der üblichen Kultpraxis und der Masse der Kultteilnehmer als antiquarischer Gelehrter: Die Popularität des Fests (fast. 3,713: lux celeberrima) kommt ihm gerade recht, um seine aitiologische Erzählung von der Konkurrenz religiöser Hymnendichtung abzugrenzen und damit zugleich ein Signal der auf Belesenheit beruhenden Distinktion zu setzen: Wie das Ich ausdrücklich betont, wolle es nicht nochmals die altbekannten Bacchusmythen (vom Tod der Semele und der wunderbaren Geburt durch Iuppiter über den Triumphzug nach Indien bis zur mirakulösen Bestrafung der Frevler Pentheus, Lykurg und der tyrrhenischen Schiffer) würdigen; stattdessen werde es sich ganz auf die aitiologische Klärung des rätselhaften Kuchenverkaufs durch eine arme alte Frau (fast. 3,726: vilis anus) - also einen literarisch noch unbearbeiteten Aspekt des römischen Bacchuskultes - fokussieren.

$\mathrm{Zu}$ diesem Zweck greift der Erzähler dann, wie Cancik und Cancik-Lindemaier zu Recht anmerken, ${ }^{64}$ trotz seiner demonstrativen Absage an die hymnischen Bacchuserzählungen doch wieder auf den Mythos zurück: Zur Erklärung des weiblichen Geschlechts dienen die Mänaden, für die Greisin wird die besondere Vorliebe alter Menschen für Wein angeführt und für ihre Bekränzung mit Efeu die Nymphen von Nysa, die den göttlichen Säugling zum Schutz vor Iuno unter Efeulaub versteckt hätten (fast. 3,763-770). In seinem myth-historischen Aition sucht demnach der Erzähler die Liberalia in den hauptstädtischen Festkalender zu integrieren, diesen Festtag des jungen, hellenistisch geprägten Bacchus gegenüber den anderen populären, durchweg Iuppiter geweihten Weinfesten ${ }^{65}$ aufzuwerten und nicht zuletzt erzählerisch mit ehrwürdig-römischen Kulttraditionen zu verschmelzen. ${ }^{66}$

In der Tristie 5,3 wandelt sich der kalendarische Festgott zum inspirierenden Schutzherr der Dichter. In dieser Rolle wird er zum fürsorglichen Nothelfer und persönlichen Fürsprecher Ovids, der sich seinerseits nun in eine ganz besondere, biographisch begründete Nähe zu Bacchus rückt. ${ }^{67}$ Selbst wenn sich das brieflich imaginierte Jahresfest nicht zwingend mit den Liberalia gleichsetzen lässt,

${ }^{64}$ Cancik; Cancik-Lindemaier 2003, 153.

${ }^{65}$ Vinalia priora am 23. April (siehe fast. 4,863-900); Vinalia rustica am 15. August; Meditrinalia am 11. Oktober.

${ }^{66}$ Es dürfte kein Zufall sein, dass die vilis anus, deren Kuchenverkauf an den Liberalia den Impuls für die aitiologische Erzähleinlage gibt, unverkennbar an die unmittelbar vorausgehende Kleinerzählung der Anna von Bovillae erinnert, die gleichfalls als arme alte Frau geschildert wird (fast. 3,668: pauper, sed multae sedulitatis anus) und das römische Volk im Zuge von dessen Auszug auf den Heiligen Berg mit ihren bäuerlichen Kuchen gespeist habe. Abgesehen von der motivischen Verknüpfung verleiht die Anna von Bovillae ihrem Perndant bei den Liberalia einen ehrwürdigen Anstrich.

${ }^{67}$ Bereits trist. 1,7,1-4 stellt eine enge Beziehung des Exildichters zu Bacchus her, indem es ein mit einem Efeukranz geziertes Dichterbildnis imaginiert. Die Tristie 5,3 buchstabiert dieses Motiv nun in voller Breite aus. 
besteht ein unverkennbares Referenzsystem zwischen beiden Texten. Dieses stützt sich sowohl auf die gemeinsame Praxis gesungener Kulthymnen zu Ehren des Gottes als auch auf deren komplementäre Inhalte. Denn in der Tristie greift das auktoriale Ich genau auf die Momente der göttlichen Vita zurück, die es in den Fasten noch ausdrücklich zurückgewiesen hatte. Ein Teil der Bachusmythologie - der Tod der Semele durch Iuppiters Blitz, die Rettung des ungeborenen Kindes und die Heimatferne des weit nach Osten ziehenden Bacchus - wird nun als Analogie für den Sturz und Quasi-Tod des vom ,Blitz' des Princeps getroffenen Dichters und für sein anschließendes Exil gedeutet, um daraus ein Argument für eine entsprechende Errettung des Verbannten zu gewinnen. Die Bestrafung des Pentheus und Lykurgus wird ihrerseits Teil einer hymnischen Aretalogie, mit welcher der verbannte Dichter seinen Schutzgott für die anschließende Bitte um Hilfe gnädig stimmen will.

Formal lässt sich diese thematische Variation des Bacchusfests, der dazu versammelten Festgemeinschaft und der von ihr besungenen Göttervita mit den für Ovid typischen Techniken des literarischen Selbstzitats und des Erzählens auf Lücke erklären. ${ }^{68}$ Die Umfunktionalisierung der Bacchuserzählungen lässt sich dabei bereits aus der unterschiedlichen Gattungsbindung beider Texte begründen: Der öffentlichen, sachorientierten und (vorgeblich) göttlich autorisierten Belehrung der Leserschaft in den Fasten steht die betont private, freundschaftliche und hoch emotionale Aussprache unter gleichberechtigten Briefpartnern gegenüber. Beeinflusst ist die jeweilige Stimme des elegischen Ichs aber natürlich auch durch die imaginierte Situation und die gewählte Perspektive auf den gemeinsamen Gegenstand: Obwohl beide Werke nahezu zeitgleich und damit unter ähnlichen Exilbedingungen entstanden sind (oder, im Fall der Fasten, dort zumindest überarbeitet wurden), ${ }^{69}$ verortet sich der implizite Autor des Kalendergedichts inmitten der stadtrömischen Kultlandschaft und ihres aktuellen Festgeschehens; dagegen sieht sich der Verfasser der Tristien von seiner vertrauten Lebenswelt räumlich wie zeitlich isoliert. Er kann sich daher lediglich seine einstige Kultgemeinschaft mit freundschaftlich verbundenen Dichtern sehnsuchtsvoll ins Gedächtnis rufen.

Es wäre demnach zu vereinfacht gedacht, wollte man das denkbar unterschiedlich konstruierte Verhältnis des auktorialen Ichs zu den Musen wie zu Bacchus und den zumal in den Tristien zu beobachtenden Anspruch einer ganz persönlichen Gottesnähe ausschließlich biographisch erklären. Ein Aspekt wurde zu-

${ }^{68}$ Dies gilt umso mehr, als weitere Episoden der Bacchusvita, die nur in einem der beiden Texte erwähnt werden - so die in fast. 3,723 f. genannten tyrrhenischen Schiffer und die in trist. 5,3,40f. gerühmte Verstirnung der Ariadne - ihrerseits in anderen Werkpartien auserzählt werden: erstere Episode in fast. 3,459-516, letztere in met. 3,597-691. Allgemein zum ovidischen Selbstzitat Frings 2005.

${ }^{69}$ Die fünf Bücher der Tristien werden üblicherweise in die Jahre 8-12 n. Chr. datiert: Williams 2002, 338; Claassen 2009, 174. Zur Forschungsdebatte um die Entstehungszeit der Fasten und deren Überarbeitung in der Verbannung Newlands 1995, 3-6; Holzberg 1997a, 45 f. 
dem bisher komplett ausgeblendet, nämlich der von mir postulierte Einfluss der horazischen Lyrik auf Ovids Neukonzeption der Theophilie. Dieser Punkt wird in der zweiten Hälfte meines Beitrags eine zentrale Rolle spielen: Hier sollen zunächst die bereits erzielten Forschungserkenntnisse zur Sphragis 4,10 rekapituliert und um eigene Thesen ergänzt werden. Im direkten Vergleich werde ich dann die trist. 5,3 unter ähnlichen Fragestellungen in den Blick nehmen.

\section{Gratia, Musa, tibi: Ein Leben in der Gunst der Musen (trist. 4,10)}

Da die Tristie 4,10 zu den meistbehandelten Exilgedichten Ovids gehört, ${ }^{70}$ wird hier auf eine ausführliche Interpretation verzichtet. Die für uns wichtigen Aspekte lassen sich stattdessen schlaglichtartig umreißen und sind nach wachsender Bedeutsamkeit für meine Fragestellung geordnet:

1. Der autobiographische Charakter: Von einer Biographie grenzt sich die Textform der Sphragis durch ihre auktoriale Selbstbezüglichkeit ab. Die autobiographische Rückschau ist stets innerhalb des eigenen Lebenszeitraums an einem bestimmten Zeitpunkt verfasst und daher aus der aktuellen Umgebung und Situation motiviert. Dementsprechend finden kaum zufällige, sondern vorrangig, wenn nicht ausschließlich existentielle Ereignisse Erwähnung. Die Lebensschilderung ist weder objektiv noch vollständig; sie wählt aus, setzt Akzente und setzt eine sorgfältig geformte persona in Szene. ${ }^{71}$ Die Interaktion zwischen Vergangenheit und Gegenwart nimmt dabei einen großen Stellenwert ein: In unserem Fall erfolgt die erzählende Deutung des eigenen Lebens konsequent aus der Perspektive des Exils. ${ }^{72}$ Dieser Umstand führt zu einer strikten Dichotomie der Vita in die Zeitphasen vor und nach dem kaiserlichen Relegationsurteil. Die Verbannung aus Rom ist - weit über die Tristie 4,10 hinausgreifend - für die gesamte Exildichtung prägend. Insofern spiegelt die Erzählstruktur im literarischen Siegel die maßgebliche Zäsur im Leben des Autors und in seinem literarischen Wirken.

2. Eine stilisierte Dichtervita: Die Sphragis konzentriert den Blick ganz auf den Dichter. Von dessen poetischem Impetus werden alle weiteren Aspekte seiner persona - Geburtsort und Standeszugehörigkeit, Rhetorikunterricht und Ansätze zum konventionellen cursus honorum, mehrfache Heirat und Verlust

${ }^{70}$ Angelehnt sind die folgenden Punkte vor allem an Fredericks 1976, punktuell ergänzt durch Beobachtungen von Holzberg 1997a und Fairweather 1987; siehe weiterhin D’Agostino 1969; Paratore 1958; King 1998 (zu diversen Bezügen zum Totenkult); Martelli 2013, 164-171 (zum Aspekt der literarischen Unsterblichkeit).

${ }^{71}$ Fredericks 1987, 141 f.; Holzberg 1997a, 34 f.

${ }^{72}$ Fredericks 1976, 142; allgemein zur Retrospektive auf das eigene Leben vor der Verbannung in Ovids Exilgedichten Claassen 1999, 173-181. 
beider Eltern - zurückgedrängt. So werden der Kreis und Stammbaum der Familie, die zunächst Normen und Werte des kindlichen und jugendlichen Ichs bestimmen (V 5-36), alsbald von rein literarischen Gruppierungen - den augusteischen Patronagezirkeln und der Generationenfolge berühmter Dichter - abgelöst (V 41-58), so wie dann später der Tod beider Eltern (V 77-84) die symbolische Todeserfahrung des exilierten Dichters vorwegnimmt. ${ }^{73}$

Im Ringen um seine ganz persönliche Lebensform erhebt der auktoriale Erzähler zudem seinen Bruder zum alter ego. Des Bruders standeskonforme Laufbahn bietet ihm eine ideale Folie, vor der er seine musischen Neigungen entfalten kann. Sein Tod setzt prompt dem inneren Konflikt des Elegikers ein Ende, der sich ständig zwischen musischer und militärischer Lebensform hin- und hergerissen sah. ${ }^{74}$ Aus der Gattungswahl sieht das auktoriale Ich aber nicht nur seine damalige Lebenswahl motiviert. Vielmehr stellt es seine Person und Identität bereits mit der deiktischen Selbsteinführung im ersten Vers (ille ego qui fuerim tenerorum lusor amorum) ganz dezidiert unter elegische Vorzeichen und schreibt den Amores seine allseitige Bekanntheit in der Hauptstadt zu (V 57-60). Maßgebliche Wendepunkte im Leben des auktorialen Ichs stehen demnach in direktem Bezug zu seinem Dichten.

3. Formen der Selbstkanonisierung: Im Dienste der literarischen Selbstverortung greift der Dichter auf verschiedene Verweistechniken und -ebenen zurück. So reiht er sich im Mittelteil der Sphragis zunächst selbstbewusst in den Kreis erstrangiger Zeitgenossen ein. ${ }^{75}$ Der Katalog spannt namhafte Autoren verschiedener Groß- (Macer: Lehrdichtung, Ponticus, Vergil: Epos, V 41-44, 47 und 51) und Kleingattungen (Bassus: Iambik, Horaz: Lyrik, Properz: Elegie, V 45-50) zusammen. Erst in einer zweiten Runde wird dieser transgenerische Kanon auf den engen Kreis der augusteischen Elegiker begrenzt. In ihre chronologische Folge (Gallus - Tibull - Properz), schreibt sich Ovid an vierter Stelle ein (V 52-56) und konstruiert sich damit analog zu seiner familiären Abstammung eine literarische Ahnentafel. ${ }^{76}$

Der expliziten und namentlichen Kanonisierung stehen implizite Motivreferenzen gegenüber. Diese betreffen zum einen die mythisch-epischen exempla des Aeneas und Odysseus, die durch die Selbstbezeichnung des poeta exsul als eines Vieldulders zu Land und zur See (V 107: totque tuli terra pelagoque) evoziert sind. Zudem sieht sich der Leser durch die Einwirkung der Musen und

${ }^{73}$ Fredericks 1976, 145. Zur wiederkehrend eingesetzten Todesmetapher in der Exildichtung ebenda 143 mit Fußnote 14. Zur rituellen Erinnerungspflege durch Kultcollegien und möglichen Assoziationen mit trist. 4,10 King 1998, 104-112.

${ }^{74}$ Fredericks 1976, 146-148.

${ }^{75}$ Zum Passus Knox 2009, 3 f. mit Verweis auf die hier vorgenommene Selbstkanonisierung. Suerbaum 2012, 181 bezeichnet die elegische Katalogbildung als „wirkungsvollste Art der Selbstkanonisierung “, und stellt die dafür einschlägigen Textabschnitte zusammen.

${ }^{76}$ Wie Suerbaum 2012, 181 zu Recht betont, ist mit der Selbststilisierung als Liebeselegiker eine keineswegs selbstverständliche Einschränkung der Gattung impliziert. 
durch die Erwähnung des Helikon (V 19-26 und V 119-120) gleich an zwei verwandte Vorbilder erinnert, nämlich die Dichterweihe des Hesiod und die Traumreise des Kallimachos auf den Musenberg. ${ }^{77}$ Die Echos mythischer Heroen und literarischer Klassiker werden schließlich in einem finalen Cluster von Horazreferenzen nochmals intensiviert und überboten: Wie die Forschung längst erkannt hat, enthält die hymnische Danksagung des auktorialen Ichs an seine tröstende Muse (V 115-132) wörtliche Anklänge sowohl an die horazische Musenode 4,3 $3^{78}$ als auch an die triumphale Selbstapotheose des Lyrikers in seiner Sphragis der ersten Odensammlung $(3,30){ }^{79}$

Über diese konkreten Horazbezüge hinausgreifend sucht Ovids hymnische Schlussfanfare offenkundig ganz allgemein den Anschluss an den gehobenen Tenor der Horazoden. Die Vermutung einer programmatischen und umfassenden Horazassimilation in Ovids Sphragis lässt sich anhand der letzten beiden Tristienverse weiter erhärten: Dort wird der pathetische Dank an die Muse in leicht variierender Wiederaufnahme durch einen Dank an den Leser ersetzt. ${ }^{80}$ Ovids lector candidus, auf dessen Gunst der unsterbliche Ruhm des Exildichters gründet, tritt somit an die Stelle des horazischen Ideallesers und Widmungsträgers Maecenas: Dessen Anerkennung setzt das lyrische Ich in den beiden Schlussversen der ersten Ode als Bedingung für seine eigene Apotheose voraus. ${ }^{81}$ Die wohlwollende Aufnahme seitens des Lesers wird ihrerseits wiede-

${ }^{77}$ Hes. theog. 22-34; Call. ait. Frg. 3-4 Asper.

${ }^{78}$ So bereits Zingerle 1967 III, 10; Luck 1977, 275; Stroh 1981, 2646; Korenjak 2007, 240 Anm. 4.

${ }^{79}$ Auf die Horazode an Melpomene verweist neben allgemeinen Parallelen in Thema und Sprechhaltung (direkte Anrede und pathetische Danksagung an die Muse, Unsterblichkeit der eigenen Dichtung) das abwandelnde Zitat in trist. 4,10,115 f.: ergo quod vivo durisque laboribus obsto ... gratia, Musa, tibi: nam tu solacia praebes; vgl. Hor. c. 4,3,21-24: totum muneris hoc tui est, / quod monstror digito praetereuntium / Romanae fidicen lyrae; quod spiro et placeo, / si placeo, tuum est. Der nagende Zahn der kallimacheisch gefärbten Neider in trist. 4,10,123 f.: nec, qui detrectat praesentia, Livor iniquo / ullum de nostris dente momordit opus deutet auf Hor. c. 4,3,16: et iam dente minus mordeor invido; eine enge motivische Überbietung bietet schließlich Ovids Reflexion über seine weltweite Leserschaft (trist. 4,10,121-132), die auf die von Horaz proklamierte Aufnahme in den Kreis der Dichter seitens der stadtrömischen Jugend (c.4,3,13-15) referiert. - Parallelen zu Horaz' Schlussgedicht c. 3,30 legt bereits die literarische Form der Sphragis nahe. Aus Horaz entlehnt Ovid das Motiv der literarischen Erhöhung trotz niederer Herkunft (Hor. c. 3,30.,12: ex humili potens) für seinen eigenen Aufstieg von der Donau zum Helikon (trist. 4,10,119f.: tu nos abducis ab Histro, / in medioque mibi das Helicone locum); vor allem aber gibt die ovidische Selbstapotheose (trist. 4,10,130: protinus ut moriar, non ero, terra, tuus) ihre intertextuelle Abhängigkeit zu erkennen (c. 3,30,6f.: non omnis moriar multaeque pars mei / vitabit Libitinam). Momente der motivischen Kontrastimitation und demonstrativen Überbietung des lyrischen Vorbilds (zeitlich konstant wachsender Ruhm bei Horaz gegenüber Ovids räumlicher Ausdehnung der Leserschaft auf den ganzen Erdkreis) treten stützend hinzu. Motivische wie sprachliche Echos lassen schließlich auch an die große Musenode des Horaz denken (Hor. c. 3,4,21 f.: vester, Camenae, vester in arduos / tollor Sabinos).

${ }^{80}$ Trist. 4,10,117: gratia, Musa, tibi; trist. 4,10,132: iure tibi grates, candide lector, ago.

${ }^{81}$ Hor. c. 1,1,35f.: quodsi me lyricis vatibus inseres, / sublimi feriam sidera vertice. Zugegebenermaßen liegt hier keine wörtliche Intertextualitätsmarkierung vor; dennoch scheint mir 
rum bei beiden Autoren programmatisch an ihre literarischen Eigenverdienste geknüpft. ${ }^{82}$ Mit seinem finalen Musenhymnus beansprucht das auktoriale Ich der Tristien demnach dezidiert, in die Fußstapfen des Lyrikers Horaz zu treten und einen ähnlich kanonischen Rang einzunehmen.

4. Literarische Profilierung und umgeformte Theophilie: Als ein neuer, der spezifischen Exilsituation geschuldeter Zusatz in Ovids Reflexion über das Verhältnis von Autor und Leser ist die Dynamik hervorzuheben, die sich im Spannungsfeld der Verse 123-132 ergibt: Zunächst vollzieht sich das elegische Klagelied noch in vollständiger Isolation; es dient demnach ausschließlich der ichbezogenen Selbsttröstung. ${ }^{83}$ Derselbe Sprecher behauptet aber nur 15 Verse später triumphierend, unter den zeitgenössischen Dichtern ,am häufigsten auf der ganzen Welt' gelesen zu werden. ${ }^{84}$ Die fehlenden Hörer im Exil werden also durch eine weltweite Leserschaft kompensiert, die dem Exildichter Ovid gegenüber allen anderen Literaten den Vorzug gibt. Schmerz und Trauer des klagenden Heimatverbannten erleben somit einen ungeahnten Siegeszug in Rom: Die neue Gattungskombination von Exildichtung und Brief hat letztlich doch ihr Publikum gefunden. ${ }^{85}$

Ermöglicht wird dieser grandiose Publikumserfolg durch eine schrittweise Transformation des Nahverhältnisses von Dichter und Muse (V 117-122): So ist der Dank des auktorialen Ichs zunächst ausschließlich an die trostspendende Muse geknüpft, die damit die therapeutische Befreiung von Kummer ermöglicht. Wenn diese nun im nächsten Vers als Führerin und Gefährtin gepriesen wird, so eröffnet dies den gleitenden Übergang zur Entführung des Dichters von seinem kummererfüllten Exilort in die göttliche Sphäre des Helikon. ${ }^{86}$ Aus

ein bewusster Bezug auf diese Horazverse angesichts der analogen Schlussposition im jeweiligen Gedicht und dank der thematischen Nähe (Darstellung der poetischen Lebensform, Vorwegnahme der eigenen Apotheose) wahrscheinlich. Siehe dazu auch unten Anm. 86.

${ }^{82}$ Hor. c. 1,1,29f.: me doctarum hederae praemia frontium / dis miscent superis; der Aspekt der poetischen Leistung, die Ruhm verdient, ist hier in den Worten doctus und praemia ausgedrückt. Ov. trist. 4,10,131 formuliert das Zusammenspiel von poetischer Leistung und Publikumsgunst dagegen als Alternative, innerhalb derer das zweite Glied deutlich mehr Gewicht erhält: sive favore tuli, sive hanc ego carmine famam.

${ }^{83}$ Trist. 4,10,113 f.: quod quamvis nemo est, cuius referatur ad aures, / sic tamen absumo decipioque diem.

${ }^{84}$ Trist. 4,10,127f.: cumque ego praeponam multos mibi, non minor illis / dicor et in toto plurimus orbe legor.

${ }^{85}$ Zum Innovationscharakter der ovidischen Exildichtung Claassen 1988, 169; Williams 2002, 338f.

${ }^{86}$ Die räumliche Versetzung von Tomi an den Helikon verweist m.E. nicht nur auf Kallimachos' Traumprolog, sondern modifiziert auch Horaz' Konzept einer in göttliche Sphären entrückten Lebensform, mittels derer sich das lyrische ,Ich' in der Eröffnung des ersten Odenbuchs demonstrativ von allen anderen im Vorfeld entworfenen Lebensformen abgrenzt (Hor. c. 1,1,29-34). Der kühle Hain, der bei Horaz von Nymphen, Satyrn und zwei lyriknahen Musen (Polyhymnia: lesbische Leier, Euterpe: Flöte) bevölkert wird, bietet ein dionysisch gefärbtes Äquivalent zum von den Musen bewohnten Helikon, der seit Hesiod als locus amoenus gezeichnet wird. Mit ihrer komplexen Verknüpfung der Leitmotive ,Dichterlandschaft', ,Über- 
dieser besonderen Auszeichnung, die nur ganz auserwählten Dichtern (Hesiod, Kallimachos, Horaz) zuteilwird, lässt sich dann wiederum das seltene Musengeschenk eines Dichterruhms zu Lebzeiten begründen. ${ }^{87}$ Aus der ichbezogenen Selbsttröstung als der zentralen Thematik und dem Grundtenor der Tristien entwächst also letztlich mithilfe der Muse die Möglichkeit zur literarischen Apotheose und weltweiten Erinnerung.

Unter unserer Fragestellung ist abschließend bemerkenswert, dass das auktoriale Ich seinen Ruhmgewinn mit der Verleihung eines, stolzen Namens' (sublime dedisti nomen) verbindet. Erst die Muse gibt dem Dichter demnach seine eigentliche Identität: ${ }^{88}$ Der Verweis auf den anonymen lusor amorum im ersten Vers wird somit zu einem unverwechselbaren Namenszug unter dem Gedicht auch wenn die erwartete Selbstbezeichnung ,Naso' bis zuletzt unterbleibt. Die namentliche Identität des elegischen Ich wird auch in unserem zweiten Fallbeispiel eine wichtige Rolle spielen. Ihm wollen wir uns nun in einem letzten Kapitel zuwenden.

\section{E sacris hederae cultoribus unum: In Bacchus' Gefolgschaft zur Unsterblichkeit (trist. 5,3)}

Anders als die Sphragis des vierten Tristienbuchs hat die Tristie 5,3 in der Ovidforschung bisher kaum Beachtung gefunden. ${ }^{89}$ Für unsere Fragestellung scheint es hilfreich, den Text unter ähnlichen Aspekten wie die Tristie 4,10 auszuleuchten, um so Schnittmengen und grundlegende Abweichungen herauszuarbeiten.

1. Der religiöse Anlass: Ein erster Unterschied liegt in der Erzählsituation und, dadurch bedingt, der Sprechhaltung des elegischen Ich. Das Primärziel der Tristie 4,10 war ja die retrospektive Lebensschilderung des Dichters, innerhalb derer lediglich der abschließende Dankeshymnus an die Muse den autobio-

höhung/ Abgrenzung vom Volk', ,Gottesnähe‘ und ,Dichterruhm/ Apotheose` eröffnet die Horazode ein umfassendes Bezugsfeld für Ovids literarisches Siegel. Der Rückbezug gewinnt durch die exponierte Stellung beider Texte (Eröffnung der ersten Odensammlung, Schluss des vierten Tristienbuchs) eine zusätzliche Plausiblität und programmatische Stoßkraft.

${ }^{87}$ Trist. 4,10,117-122: gratia, Musa, tibi: nam tu solacia praebes, / tu curae requies, tu medicina venis, / tu dux et comes es, tu nos abducis ab Histro, / in medioque mihi das Helicone locum; / tu mihi quod rarum est, vivo sublime dedisti / nomen, ab exsequiis quod dare fama solet.

${ }^{88}$ Zur Identitätsstiftung mittels des Namens und der Namensweitergabe Kunst 1999, 158168.

${ }^{89}$ Streiflichtartig erwähnt wird das Gedicht bei Cancik; Cancik-Lindemaier 2003, 158 f. im Rahmen einer gesamtheitlichen Besprechung ovidischer Bacchusfeste; Swoboda 1978, $78 \mathrm{f}$. führt die Tristie als Beispiel für die literarische Verarbeitung von Gedankengut aus orphischen Hymnentexten an; Bretzigheimer 1991, 73-75 vermutet in der Assimilation an Bacchus eine antiaugusteische Stoßrichtung, da sich der Princeps bekanntlich vorrangig mit Apoll identifiziert; Amann 2006, $224 \mathrm{f}$. konstatiert das Fehlen komischer Momente. 
graphischen Rahmen sprengte. Die Tristie 5,3 verschreibt sich dagegen dezidiert im Eröffnungsvers (V1 f.: illa dies haec est, qua te celebrare poetae ..., Bacche, solent) der Schilderung eines Bacchusfests. Sie greift dabei auf ein ganz ähnliches Zeigemoment wie die Tristie 4,10 zurück (4,10,1: ille ego qui fuerim). Doch tritt nun an die Stelle des Bezugs auf die eigene Vergangenheit das aktuelle Festereignis. Dabei wird statt des Ichs das Du in Form der namentlich adressierten Gottheit, welcher der Tag zugeeignet ist, hervorgehoben.

Weit stärker als die Tristie 4,10, die sich ja mit ihrem literarischen Siegel an eine zeitlose Nachwelt und offene Leserschaft des ovidischen Exilwerks wendet (trist. 4,10,2: quem legis, ut noris, accipe posteritas), betont die Tristie 5,3 ihre enge Situationsbindung: Zugespitzt gesagt, wäre das Gedicht ohne die aktuelle Festsituation (und sei sie imaginär) gar nicht denkbar. Seine literarisch konstruierte Erstleserschaft ist daher nicht nur ganz allgemein der lector candidus; vielmehr sind es nun die stadtrömischen Dichterkollegen, die sich zu Bacchus' Verehrung versammelt haben. Ein gewisser zeitlicher Spielraum wird nun allerdings dadurch eröffnet, dass das Fest nicht näher spezifiziert wird und sich der Sprecher zudem über das exakte Datum verunsichert sieht (V 2: si modo non fallunt tempora). Damit lanciert das elegische Ich erstmals seine prekäre Exilsituation. Da der poeta exsul von der realen Kult- und Dichtergemeinschaft ausgeschlossen ist, muss er vor seinem (und des Lesers) inneren Auge die stadtrömische Festsituation erzeugen, an der er einstmals Anteil hatte.

2. Der verbannte Dichter in der Kultgemeinschaft: In der Tristie 4,10 suchte sich das auktoriale Ich konsequent durch seine musische Affinität zu exponieren und von seinem familiären wie literarischen Umfeld abzugrenzen. Dagegen tritt in der Tristie 5,3 die persona des elegischen Ichs zunächst (!) ganz demonstrativ in die Anonymität einer Gruppe zurück. Diese wird in den ersten beiden Versen über ihre doppelte Tätigkeit als Dichter und Verehrer des Bacchus spezifiziert. Auch im weiteren Gedichtverlauf gibt sich der elegische Sprecher vorgeblich ganz bescheiden: Erbittet er sich von ,seinem' Gott doch lediglich, in der einstigen Festgemeinschaft erneut willkommen zu sein und seine Stimme mit allen anderen zu einem kollektiven Bacchuslob vereinen zu dürfen.

Auf den ersten Blick scheint sich das auktoriale Ich demnach in der Tristie 5,3 mit der Vision einer künftigen Reintegration in die Kreise seiner stadtrömischen Dichterkollegen zu begnügen. Bei näherer Betrachtung fällt jedoch auf, dass der Elegiker seiner persona mit Macht ein individuelles Profil zu verleihen sucht auch wenn dieses über weite Teile des Gedichts namenlos bleibt. Zunächst scheint die auktoriale Selbstcharakterisierung nur als eine plausible Strategie, um Bacchus von der Notwendigkeit einer direkten Intervention zugunsten des Verbannten zu überzeugen. Zu diesem Zweck wird die anfängliche Vergegenwärtigung einstiger Festtage mit der appellativen Erinnerung verknüpft, dass die aktuelle Kult- und Dichtergemeinschaft seit dem vernichtenden Schicksalsschlag, der das auktoriale Ich seiner musischen Lebensform entfremdet hat, eine 
schmerzliche Lücke aufweist. Dass ausgerechnet im privilegierten Kreis seiner professionellen Hymnensänger einer fehlt, muss einem Inspirationsgott wie Bacchus, dem alle Dichter besonders lieb sind - so legt der elegische Sprecher geradezu beschwörend nahe - als allererstem auffallen. Darauf, dass sich der Dichtergott nun aber nicht nur diffus durch die Absenz eines unbestimmten aliquis und eines namenlosen unus irritiert sieht, arbeitet das auktoriale Ich mit allen Mitteln der Redekunst hin: Gleich dreimal erzeugt es in der imaginierten Festgemeinschaft spezifische Gelegenheiten, die Bacchus auf die Leerstelle im Kreis seiner privilegierten cultores aufmerksam machen sollen. ${ }^{90}$

Die dreifache Variation steigert nicht nur die Intensität der Bitte um schnellstmögliche Hilfe, sondern lässt zudem vermuten, dass Bacchus weniger einen quantitativen als einen qualitativen Verlust empfinden soll: So gibt denn auch das elegische Ich unmittelbar nach einem ersten Hilferuf eine hymnische Kostprobe seines Könnens (V 35-44), das es natürlich - dies der unterschwellige Anreiz nach seiner Rückkehr aus dem Exil voll und ganz in den Dienst seines Retters stellen würde. Implizit lockt es seinen potentiellen Fürsprecher Bacchus mit der Aussicht, welche gesteigerte Attraktivität dessen tradierter Leistungskanon gewönne, wenn er um eine so neue, unerhörte Rettungstat wie die erfolgreiche Fürsprache beim Princeps erweitert würde.

3. Biographische Theophilie: Dass nun wiederum gerade Bacchus zum Schutzanwalt des verbannten Dichters prädestiniert ist, macht das elegische Ich anhand von Bacchus' Vita deutlich, wobei es die konventionelle Gebetsform der Götteraretalogie innovativ abwandelt. Denn der Sprecher trifft aus der reichen Fülle bacchischer Verdienste um Götter und Menschen eine gezielte Auswahl, die ihm als Argument besonders gelegen kommt. Aus der hymnischen Überhöhung formt er so eine Überzeugungsrede nach allen Regeln der Kunst. Dabei spitzt er die Bacchustaten so zu, dass er sie mit Ereignissen seines eigenen Lebens konsequent gleichsetzen kann. Aus dem konventionellen, rein göttlichen Leistungskanon wird so unversehens eine doppelte Aretalogie, die Bacchus und den Exildichter in ein bestmögliches Licht zu setzen sucht. Durch die analoge Biographie wird der Sprecher in seinem Anspruch bestätigt, ein ganz besonderer cultor Bacchi zu sein: Mittels seiner biographischen Theophilie schreibt er sich eine Sonderstellung zu, die ihn innerhalb der Dichtergemeinschaft auszeichnet.

Mit der biographischen Selbstangleichung an Bacchus ist erneut ein auktoriales Moment in der Tristie greifbar. Diese geht zudem deutlich über das übliche Konzept der Theophilie hinaus: ${ }^{91}$ Zwar haben sich bereits hellenistische Herrscher

90 Trist. 5,3,15 f.: tu tamen e sacris hederae cultoribus unum / numine debueras sustinuisse tuo; trist. 5,3,33 f.: et potes aspiciens circum tua sacra poetas /,nescioquis nostri 'dicere ,cultor abest'; trist. 5,3,43f.: huc ades et causas relevens pulcherrime, nostros, / unum de numero me memor esse tuo.

${ }^{91}$ Pace Amann 2006, 224f., demzufolge „die Angleichung der eigenen Erlebnisse an jene einer Gottheit keine derart unerhörte Begebenheit darstellt“, sondern sich „im Rahmen dessen, 
(und römische Feldherrn hellenistischer Prägung, allen voran Marcus Antonius) als alter Dionysos inszeniert. ${ }^{92}$ Desgleichen erhält die Theophilie in hellenistischen Dichterviten wichtige Impulse dadurch, dass diese Texte häufig Wunder- und Rettungsgeschichten erzählen, mittels derer die besondere Gottesnähe veranschaulicht wird..$^{93}$ Aber in beiden Traditionen werden nur ganz ausgesuchte und vereinzelte Komponenten (etwa wundersame Geburtsumstände, Rettung aus Gefahren, Feldzüge) zur Assimilation herangezogen; eine Analogiebildung, die anhand von exemplarischen Lebensstationen (Schwangerschaft/Geburt, Exil/Todeszustand, verdiente Rettung/Wiedergeburt/Apotheose) immer neue Parallelen zwischen Dichter und Gott aufdeckt (der schicksalhaft Geborene, der Heimatferne/Verbannte, der heroische Dulder, der moralische virtus-Träger, der verdient Erhöhte/Vergöttlichte), ist meines Wissens singulär. ${ }^{94}$ Die neue Qualität der Theophilie bezieht sich sowohl auf das Spektrum der Vergleichsmomente als auch auf die Tatsache, dass der Dichter hierbei weit weniger auf seine poetische Leistung als auf seine moralische Integrität und Tugendbewährung in einem ähnlich schwierigen Lebensverlauf wie dem des verehrten Gottes pocht. ${ }^{95}$

Ovids Neuformung der Theophilie in trist. 5,3 könnte - zumal in ihrer erklärten Bindung an Bacchus und nicht mehr an die Musen wie noch in trist 4,10 durch die Wirkmacht der Horazoden beeinflusst sein. Zugegebenermaßen fehlen zur Stützung dieser Vermutung wörtliche Intertextualitätsbezüge. Doch ist bereits eine poetische Anrufung von Bacchus als Schutzgott mitnichten selbstverständlich; dies gilt umso mehr, wenn der Gott eben nicht nur (wie bei Tibull und

was man hat erwarten können“, bewegt. Bretzigheimer 1991, 73 findet die Theophilie an sich nicht bemerkenswert, sondern lediglich ihren Bezug auf den Gott Bacchus.

${ }^{92}$ Hunter 2006, 48-50.

${ }^{93}$ Krasser 1995, 48-53.

${ }^{94}$ Als Analogie gedeutet werden im Einzelnen das musische Leben im Chor der Pieriden (V 5-6, V 10); der ,Blitzschlag' des von Octavian verhängten Relegationsurteils und der von Zeus' Blitz verursachte Tod der Semele (V $31 \mathrm{f}$.); die wundersame Doppelgeburt des Bacchus aus dem Bauch der toten Mutter und dem Schenkel des Zeus (angedeutet im zweifachen Parzengesang, V 25 f.), die eine ähnliche, Wiedergeburt' des exilierten Dichters und Wendung seines misslichen, von den Parzen bestimmten Schicksals (V 144) impliziert; der Aufenthalt fern von der Heimat, sei es am Schwarzen Meer (V 11 f.) oder bei den Geten, Persern und Indern (V 21-24); die Zeichnung als heroische Dulderfigur (V11f., im unverkennbaren Anklang an Odysseus/ Aeneas; V 28) und als exemplarischer virtus-Träger; die daraus abgeleiteten Verdienste, die im Fall des Dionysos eine Erhebung zum olympischen Gott gerechtfertigt haben und daher für den Dichter eine ähnliche Rettung erwarten lassen (V 19, V 32-35).

${ }^{95}$ Richtungsweisend v. a. die Verse $27 \mathrm{f} .:$ me quoque, si fas est exemplis ire deorum, / ferrea sors vitae difficilisque premit. Das quoque erinnert an dasselbe Wort, mit dem wenige Verse zuvor Bacchus' mühe- wie verdienstvoller Aufstieg zum Olymp eingeleitet wurde, V $19 \mathrm{f}$.: ipse quoque aetherias meritis invectus es arces, / quo non exiguo facta labores via est. Die Wortwiederholung suggeriert, dass der Dichter nicht nur das schwierige Leben und die Mühen seines Gottes wiederholt, sondern damit auch rechtmäßigen Anspruch auf eine ähnlich heroische Leistungsbewährung erheben und sich im Gegenzug eine der Apotheose vergleichbare Belohnung erhoffen darf. 
Properz) als Inspirationsinstanz, als Kulturstifter und Eroberer, ${ }^{96}$ sondern als ein vielfältiger und dem Dichter persönlich besonders nahe stehender Leistungsträger bemüht wird. Ovids Fokussierung auf Bacchus in einem Exilgedicht, das derart biographische und auktoriale Züge trägt, ist somit bemerkenswert und daher poetologisch wie intertextuell, verdächtig'.

Horaz hatte seinerseits neue Wege beschritten, indem er sich wiederholt und programmatisch zu Bacchus als seinem Dichtergott bekannte. Diese persönliche Nahbeziehung erklärte der Lyriker in einem Ensemble von Bacchusoden ${ }^{97}$ bald aus seinen musischen Neigungen (c. 1,1,29-34), bald aus seiner moralischen Integrität und seinem maßvollen Leben (c. 1,18; 2,19,25-28), bald aus seiner herausragenden Leistung als Dichter, die er als gleichwertige Entsprechung zu Bacchus' Taten und Tugenden deutete (c. 2,19,9-32; c. 3,3,13-15; 3,25,17-20). Zentrale Bedeutung kommt dabei der Koppelung von großer, selbst vollbrachter Leistung und verdienter Unsterblichkeit zu. ${ }^{98}$ Die horazische Lyrik könnte zudem insofern wegbereitend für Ovid sein, als das lyrische Ich dort selbstbewusst seine Versetzung in einen dionysischen Musenhain und damit eine dauerhafte Existenz in göttlicher Sphäre ankündigt. ${ }^{99}$ Ein letzter, nicht minder wichtiger Aspekt liegt in der Vorstellung, dass Bacchus nach seiner endgültigen Etablierung im Olymp nun selbst in der Lage ist, andere schutzbedürftige Menschen zu retten und ihnen die verdiente Unsterblichkeit zu schenken: Diesen Gedanken führt Horaz exemplarisch in der Schlussstrophe des c. 2,18 vor, in welcher sich Bacchus sogar in die Unterwelt wagt, um seine Mutter Semele von dort empor $\mathrm{zu}$ holen und in den Kreis der Götter zu versetzen. ${ }^{100}$

${ }^{96} \mathrm{Zu}$ Bacchus als Inspirationsinstanz auch und gerade in der augusteischen Dichtung Hunter 2006, 42-80; Hunter betont dabei völlig zu Recht das Identifikationspotenzial des Gottes als Kulturstifter und Eroberer, das die Elegiker Tibull $(1,7)$ und Properz $(3,17)$ stark machen. Doch auch wenn sich hier gewisse Schnittmengen zum horazischen Gottesbild ausmachen lassen, bleibt die Intensität und Programmatik, mit der Horaz seine Assimilation an Bacchus betreibt, einzigartig und unerreicht.

${ }^{97}$ Die Gedichte stehen zum Teil ganz, teils anteilig im Zeichen des Bacchus. In allen Fällen kommt Bacchus aber eine wichtige Bedeutung zu, siehe: c. 1,1,29-34; 1,18; 2,19; 3,3,1-16; 3,25; einen gewichtigen Schlussvers im Zeichen des Bacchus hat zudem c. 4,8. Eingehende Interpretationen bietet Krasser 1995, 92-149.

${ }^{98}$ So namentlich in dem Katalog vergöttlichter Heroen in Hor. c. 3,3,1-16, siehe Krasser $1995,127-130$.

${ }^{99}$ Hor. c. 1,1,29-34, siehe Krasser 1995, 100-108.

${ }^{100}$ Hor. c. 2,18,29-32: te vidit insons Cerberus aureo / cornu decorum leniter atterens / caudam et recedentis trilingui / ore pedes tetigitque crura. Hierzu Krasser 1995, 122f. Vgl. auch den Schlussabschnitt in c. 4,8,28-34, in dem Bacchus im Verbund mit Hercules und den Dioscuren aufgeführt wird - also sämtlich Heroen, die sich selbst den Olymp verdient haben und daher den Schutzbedürftigen auf Erden besonders gewogen sind: dignum laude virum Musa vetat mori. / caelo Musa beat. Sic Iovis interest / optatis epulis inpiger Hercules, / clarum Tyndaridae sidus ab infimis / quassas eripiunt aequoribus ratis, / ornatus viridi tempora pampino / Liber vota bonos ducit ad exitus. 
Wenn daher in der trist. 5,3 das elegische Ich innerhalb seiner selektiven Lebensbeschreibung der fatalen Wirkung des kaiserlichen Blitzes besonders viel Raum gibt und diesen quasi tödlichen Schicksalsschlag dezidiert mit der Erwartung verknüpft, dass sich Bacchus in Erinnerung an seine Mutter auch seiner erbarmen und ihm seine Hilfe nicht verweigern werde, ${ }^{101}$ so scheint mir eine bewusste Wiederaufnahme der bei Horaz formulierten Vorstellungen zumindest naheliegend.

Was gewönne nun aber der Exildichter aus einem horazischen Unterton in seinem eigenen Bacchuslied? Zum einen könnte er seine über den göttlichen Mittelsmann Bacchus an den Princeps herangetragene Bitte von jedem Verdacht der Anmaßung befreien, indem er sich auf die unstrittige literarische Autorität eines Horaz beruft. Wie bereits Korenjak betont hat, bot sich der Rekurs auf Horaz für den Exildichter auch unter biographischen Gesichtspunkten an: Hatte sich doch kein augusteischer Dichter so sehr gewandelt wie Horaz, der in den Jahren nach Philippi eine radikale Wende vom Augustusgegner zum panegyrischen Dichter vollzogen hatte. ${ }^{102}$ Auch jenseits eines Appells an die Milde des Princeps (mit dessen Erfolg der Dichter kaum rechnen konnte) bot eine adaptierende Aneignung der horazischen Bacchus-Theophilie Vorteile. Und diese erschöpfen sich nicht in der von Korenjak postulierten Sympathielenkung im Blick auf eine offene Leserschaft der Tristien. ${ }^{103}$ Denn wenn wir die horazische Kausallogik von herausragender Eigenleistung und Unsterblichkeit auch für Ovid zugrundelegen, hat sich der Dichter unabhängig vom Votum anderer (sei es der Princeps oder der Leser) seine Apotheose bereits durch die vorbildliche Erduldung seines Schicksals im Exil voll verdient.

4. Namentliches Gedenken und auktorialer Dichterrubm: Neue Wege, die offenkundig auf die Exilsituation und auf die damit korrespondierende Briefform und -funktionen (Überwindung von Distanz, Erzeugung von persönlicher Nähe; Überzeugung und Vereinnahmung des Gegenübers, Bestätigung der Freundschaft; Kombination eines modellhaften Erstadressaten mit einer offenen Leserschaft) abgestimmt sind, werden im Schlusspassus der Tristie beschritten. Denn hier wendet sich das auktoriale Ich der ,treuen Schar' (pia turba) seiner stadtrömischen Dichterkollegen zu, die sich zur Feier des Bacchus versammelt haben und nun mit gemeinsam erhobenem Becher in das persönliche Gebet des ortsfernen Ichs einstimmen sollen. Im Zuge dieser Fürbitte möge - so die Wunschvorstellung - jeder einzelne (quisque) des vermissten Exildichters gedenken. Der individuelle und gemeinschaftliche Erinnerungsakt entfaltet dank

${ }^{101}$ Trist. 5,3,29-35: illo (scil. der Stadt- und Himmelsstürmer Kapaneus) nec levius cecidi, quem magna locutum / reppulit a Thebis Iuppiter ipse suo. / ut tamen audisti percussum fulmine vatem, / admonitu matris condoluisse potes, / et potes aspiciens circum tua sacra poetas /, nescioquis nostri' dicere, cultor abest'. I fer, bone Liber, opem.

102 Korenjak 2007, 250-252.

${ }^{103}$ Korenjak 2007, 252-254. 
der expliziten Namensnennung des aus der Gruppe Ausgegrenzten eine geradezu performative Wirkung. Denn er lässt unvermittelt hinter der persona des elegischen Ichs den historischen Autor hervortreten: ${ }^{104}$ Hier erfolgt erstmalig im ganzen Gedicht die namentliche Identifikation des Verbannten. Sie wird dann prompt auf engstem Raum gleich nochmals wiederholt und bestätigt. ${ }^{105}$

Bis zu diesem Schlussmoment seines Gebets hatte der elegische Sprecher zwar immer mehr Aspekte seiner Person und Vita in mythisch verklausulierten Bildern zur Kenntnis gegeben, seine auktoriale Identität aber verdeckt gehalten. Nun sucht er aber sein Gegenüber gezielt zur persönlichen Erinnerungsstiftung $\mathrm{zu}$ aktivieren: In einem emphatischen Aufruf appelliert er ganz explizit nicht nur an die literarische Kompetenz, sondern auch an die moralische Integrität und Loyalität seiner Berufskollegen. Ihnen überträgt er eine ganz besondere Verantwortung: Als exklusive Erstleserschaft seiner Exilbriefe möge sie unter ihresgleichen (V 58: inter vos) Ovids guten Namen wahren, so wie er selbst den alten wie zeitgenössischen Autoren ihre respektvolle Ehrung nicht versagt noch geneidet habe.

Das namentliche Aussprechen (V 49: Nasonis nomine dicto) und das Gedenken (V 58: nomen habere meum) an ,Naso' haben eine ambivalente Funktion: Zielen sie doch gleichermaßen auf die Integration des Abwesenden in das Dichtercollegium und auf die gruppeninterne Distinktion. ${ }^{106}$ In unserem Fall geht die Namensnennung mit einer literarischen (Selbst)kanonisierung einher ein Vorgang, der nicht nur auf die trist. 4,10 zurückverweist, sondern auch ein motivisches Äquivalent in der Horazode 4,3 findet: Dort beruft sich nämlich der betagte Lyriker als Ruhmesgaranten (im impliziten Rekurs auf sein carmen saeculare, das ja von einem Knaben- und Mädchenchor aufgeführt wurde) auf die stadtrömischen Jugend: Diese erachte ihn für wert, in den lieblichen Chor von göttlich inspirierten Sängern eingereiht zu werden. ${ }^{107}$ Der Exildichter Ovid legt diesen Akt der Kanonisierung dagegen in die Hand der stadtrömischen Dichterkollegen und hymnischen Festsänger im Dienste des Bacchus. Er setzt dabei eine letzte Pointe, mittels derer er sich im Kreis berühmter Dichter

104 Trist. 5,3,47-52: vos quoque, consortes studii, pia turba, poetae, / haaec eadem sumpto quisque rogate mero. I atque aliquis vestrum Nasonis nomine dicto, / adponat labris pocula mixta suis, / admonitusque mei, cum circumspexerit omnes, / dicat, ubi est nostri pars modo Naso chori?"

105 Zur Namensnennung als Instrument der Erinnerungsstiftung und Garant des Nachruhms, ja der Unsterblichkeit Kunst 1999, $168 \mathrm{f}$. und $172 \mathrm{f}$.

${ }^{106}$ Beide Funktionen stellt Kunst 1999, 158 generell für den Einsatz römischer Namen fest. King 1998, 104-112 postuliert für trist. 4,10 eine Analogie zum inschriftlich bezeugten Totengedenken in Kultcollegien.

${ }^{107}$ Hor. c. 4,3,13-16: Romae, principis urbium / dignatur suboles inter amabilis / vatum ponere me choros, / et iam dente minus mordeor invido. Dass es sich in der Tristie womöglich nicht nur um eine zufällige, sondern gezielt gesuchte Entsprechung zur Horazode handelt, könnte durch das in beiden Fällen präsente Moment des Dichterchors gestützt werden. 
nochmals eigens auszeichnet und hervorhebt: So bekennt sich das auktoriale Ich zwar demonstrativ zur gebührenden Wertschätzung älterer wie jüngerer Dichtergenerationen, nennt aber (erneut analog zu den zitierten Horazversen) keinen dieser Kollegen beim Namen. Damit bleibt es allein ,Naso' vorbehalten, sich als (in doppeltem Sinne) namhafter Autor im Gedächtnis seiner Leser zu verewigen.

\section{Fazit}

Der vorliegende Beitrag suchte anhand repräsentativer Textbeispiele die literarischen Strategien herauszuarbeiten, mittels derer ein antiker Ovidleser für die Konstruktion einer literarischen persona sensibilisiert und auf auktoriale Aussagen hinter der Maske einer bestimmten Figur verwiesen wurde. Die hohe Präsenz der auktorialen Stimme ließ sich dabei als ein Spezifikum nachweisen, das die briefliche Exildichtung von allen früheren Werken scheidet. Freilich ist dabei stets zu bedenken, dass den Exilbriefen nicht an einer möglichst authentischen Zeichnung des historischen Autors gelegen ist. Vielmehr arbeiten sie mit allen Mitteln der poetischen Kunst an der Mythologisierung des Autors, wobei sie der Figur und Umgebung des poeta exsul quasi heroische Züge verleihen. Intention bei der Erzeugung eines solchen Exilmythos ist die positive Vereinnahmung der Leserschaft, aber auch die Überhöhung des Autors, dessen moralische Integrität und virtus sich auch und gerade angesichts seines schweren Schicksalsschlags der Verbannung in exemplarischer Weise bewähren.

In dieser situations- und gattungsgebundenen Neuschöpfung einer mythisch überhöhten Exilsituation spielen die zeitgenössische Religion und Kultpraxis lediglich eine randständige Rolle. Eine religiöse Selbstprofilierung des Dichters Ovid findet jedoch auf anderer Ebene statt, die an hellenistische Formen des Dichterkultes erinnert. Dabei gewinnt insbesondere das Motiv der Theophilie eine besondere Bedeutung und Innovationskraft: Sie stellt den Exildichter in eine privilegierte Nähe und in den persönlichen Schutz der tröstenden Musen, und sie eröffnet ihm dank seiner Selbststilisierung zum cultor Bacchi und - weit darüber hinausgreifend - aufgrund seiner biographischen Angleichung an Bacchus neue Wege zur Selbstapotheose. Allem Anschein nach hat sich Ovid dabei ganz maßgeblich an dem poetologischen Konzept des nur eine Generation älteren Horaz orientiert. Denn der hatte sich als erster lyrischer Dichter den olympischen Neuaufsteiger zu seinem persönlichen Dichtergott erwählt und die Theophilie in großem Stil zur poetischen Selbststilisierung genutzt.

Bei aller gesuchten Nähe zur horazischen Lyrik geht Ovid im Zuge seiner auktorialen Selbstprofilierung eigene Wege. Diese lassen sich einerseits an einer neuen Funktionalisierung der eigenen Dichterbiographie ablesen: Während Horaz regelmäßig seinen Aufstieg aus niedrigem sozialem Rang infolge eigener 
Leistung betont, ${ }^{108}$ erhebt Ovid seine als göttlicher Blitz stilisierte Verbannung seitens des Princeps zum quasi-religiösen Schlüsselerlebnis, aufgrund dessen er nun in eine exklusive Nähe zu den Musen und Bacchus treten kann. Hinzukommen neue Formen der literarischen Selbstverortung und -kanonisierung. Denn wo sich der Lyriker Horaz demonstrativ von konventionellen Lebensformen distanziert und sich ob seiner poetischen Leistung entweder in einen dionysischen Dichterhain entrücken (c. 1,1) oder von der stadtrömischen Jugend als vates feiern lässt (c. 4,3), nimmt Ovids auktoriales Ich als verdienten Lohn für seine moralische Integrität und virtus-Bewährung im Exil selbstbewusst einen Ehrenplatz im Kreis der stadtrömischen Dichterkollegen in Anspruch, die ihrerseits in festlichem Ambiente als Hymnensänger und cultores Bacchi imaginiert werden. Und wenn sich schließlich der Lyriker Horaz seiner stadtrömischen und reichsweiten Bekanntheit rühmt, ${ }^{109}$ so steht ihm der Exildichter in nichts nach: Sieht er sich doch nicht nur seinen stadtrömischen Dichterkollegen (trist. $5,3)$, sondern weit darüber hinausgreifend einer weltweiten und nicht näher spezifizierten Leserschaft verbunden (trist. 4,10), deren rühmendem Lob er seine literarische Unsterblichkeit vorrangig verdankt sieht.

\section{Literaturverzeichnis}

Amann, M. (2006). Komik in den Tristien Ovids. Schweizerische Beiträge zur Altertumswissenschaft 31 . Basel.

Barchiesi, A. (1991). „Discordant muses.“ Proceedings of the Cambridge Philological Society 37: 1-21.

Barchiesi, A. (1997). The Poet and the Prince: Ovid and Augustan Discourse. Berkeley.

Bömer, F. (1957/1958). P. Ovidius Naso: Die Fasten. Bd. 1: Einleitung, Text und Übersetzung. Bd. 2: Kommentar. Heidelberg.

Bretzigheimer, G. (1991). „Exul ludens: Zur Rolle von relegans und relegatus in Ovids Tristien." Gymnasium 98: 39-76.

Cancik, H.; Cancik-Lindemaier, H. (2003). „Ovids Bacchanal: Ein religionswissenschaftlicher Versuch zu Ovid, Metamorphosen IV 1-415),“ in: H. Cancik. Verse und Sachen: Kulturwissenschaftliche Interpretationen römischer Dichtung, R. Faber; B. von Reibnitz, edd., Würzburg. 142-167.

Claassen, J.-M. (1988). „Ovid's Poems of Exile: The Creation of a Myth and the Triumph of Poetry." Antike und Abendland 34: 158-169.

Claassen, J.-M. (1999). Displaced Persons: The Literature of Exile from Cicero to Boethius. Madison, Wis.

Claassen, J.-M. (2008). Ovid Revisited: The Poet in Exile, London.

${ }^{108}$ Hor. c. 2,20,5-7: non ego pauperum / sanguis parentum, non ego, quem vocas, / dilecte Maecenas, obibo; c. 3,30,12: ex humili potens; vgl. Hor. epist. 1,20,20 f.: me libertino natum patre et in tenui re / maiores pinnas nido extendisse loqueris.

${ }^{109}$ Hor. c. 2,20,14-20; c. 3,30,7-12; c. 4,3,13-16. 
Claassen, J.-M. (2009). „Tristia,“ in: P.E. Knox, ed., A Companion to Ovid. Chichester. 170-183.

Clay, D. (1998). „The Theory of the Literary Persona in Antiquity.“ Materiali e Discussioni per l'analisi dei testi classici 40: 9-40.

D’Agostino, V. (1969). „L'elegia autobiografica di Ovidio (Tristia IV, 10),“ in: J. Bibauw, ed., Hommages à Marcel Renard. Coll. Latomus 101. Bd. 1. Brüssel. 292-302.

Fairweather, J. (1987). „Ovid’s Autobiographical Poem, Tristia 4.10.“ The Classical Quaterly 37: 181-196.

Fredericks, B. R. (1976). „Tristia 4.10: Poet's Autobiography and Poetic Autobiography.“ Transactions of the American Philological Association 106: 139-154.

Frings, I. (2005). Das Spiel mit eigenen Texten: Wiederholung und Selbstzitat bei Ovid. Zetemata 124. München.

Harrison, S. (2007). „Horatian Self-Representations, “ in: S. Harrison, ed., The Cambridge Companion to Horace. Cambridge. 22-35.

Holzberg, N. (1997a). Ovid. Dichter und Werk. München.

Holzberg, N. (1997b). „Ovid's ,Autobiographical References“.“ Lampas 30: 4-19.

Holzberg, N. (2006). Vergil: Der Dichter und sein Werk. München.

Hunter, R. (2006). The Shadow of Callimachus: Studies in the reception of Hellenistic poetry at Rome. Cambridge.

King, R.J. (1998). „Ritual and Autobiography: The Cult of Reading in Ovid“ Tristia 4.10.“ Helios 25: 99-119.

Knox, P.E. (2009). „A Poet’s Life,“ in: P.E. Knox, ed., A Companion to Ovid. Chichester. 3-7.

Korenjak, M. (2003). „Tityri sub persona: Der antike Biographismus und die bukolische Tradition." Antike und Abendland 49: 58-79.

Korenjak, M. (2005). „Abschiedsbriefe: Horaz' und Ovids epistolographisches Spätwerk.“ Mnemosyne 58: 46-61; 218-234.

Korenjak, M. (2007). „Von den Metamorphosen zum Brief des Augustus: Ovids ,horazische Periode, ““ in: M. Janka; U. Schmitzer; H. Seng, Hgg., Ovid: Werk - Kultur - Wirkung, Darmstadt. 239-256.

Kranz, W. (1961). „Sphragis. Ichform und Namensiegel als Eingangs- und Schlußmotiv antiker Dichtung. " Rheinisches Museum für Philologie 104: 3-46 und 97-124.

Krasser, H. (1995). Horazische Denkfiguren: Theophilie und Theophanise als Medium der poetischen Selbstdarstellung des Odendichters. Hypomnemata 106. Göttingen.

Kunst, C. (1999). „Identität und Unsterblichkeit: Zur Bedeutung des römischen Personennamens." Klio 81.1: 156-180.

Luck, G. (1977). P. Ovidius Naso Tristia. Textausgabe, Übersetzung und Kommentar. 2 Bde. Heidelberg.

Martelli, F.K.A. (2013). Ovid's Revisions. The Editor as Author. Cambridge.

Mayer, R. G. (2003). „Persona<l> Problems: The Literary Persona in Antiquity Revisited.“ Materiali e Discussioni per l'analisi dei testi classici 50: 55-80.

McGowan, M.M. (2009). Ovid in Exile: Power and Poetic Redress in the Tristia and Epistulae ex Ponto. Mnemosyne Supplements 309. Leiden.

Miller, J.F. (1980). „Ritual directions in Ovid's Fasti: Dramatic hymns and didactic poetry." The Classical Journal 75: 204-214.

Miller, J. (1982). „Callimachus and the Augustan Aetiological Elegy,“ in: W. Haase, Hg., Aufstieg und Niedergang der Römischen Welt II 30.1. Berlin. 371-417. 
Miller, J.F. (1991). Ovid's Elegiac Festivals. Studien zur Klassischen Philologie 55. Frankfurt.

Newlands, C.E. (1995). Playing with Time: Ovid and the Fasti. Ithaca.

Paratore, E. (1958). „L'elegia autobiografica di Ovidio (Tristia 4,10),“ in: N.L. Herescu, ed., Ovidiana. Paris. 353-378.

Rühl, M. (2011). „Lesen und leben lassen: Ovids corpus der Exildichte,“ unpubl. Vortrag München.

Stroh, W. (1981). „Tröstende Musen: Zur literarhistorischen Stellung und Bedeutung von Ovids Exilgedichten," in: W. Haase, ed., Aufstieg und Niedergang der Römischen Welt II 31.3. Berlin. 2638-2684.

Suerbaum, W. (2012). „Der Anfangsprozess der ,Kanonisierung' Vergils, “ in E. M. Becker; S. Scholz (Hgg.), Kanon in Konstruktion und Dekonstruktion. Kanonisierungsprozesse religiöser Texte von der Antike bis zur Gegenwart. Berlin. 171-219.

Swoboda, M. (1978). „De Ovidii carminum elegicorum fragmentis hymnico-precatoriis.“ Eos 66: 73-90.

Volk, K. (2005). „Ille ego: (Mis)Reading Ovid's Elegiac Persona.“ Antike und Abendland 51: 83-96.

Wasyl, A.M. (2003). „,Ovidius Heros‘. Epic Elements in Ovid’s ,Tristia““, in: J. Styka, ed., The Roman Epic Poetry. Classica Cracoviensia 8. Krakau. 105-128.

Watson, P. (2002). „Praecepta amoris: Ovid’s Didactic Elegy,“ in: B. Weiden Boyd, ed., Brill's Companion to Ovid. Leiden. 141-165.

White, P. (2002). „Ovid and the Augustan Milieu,“ in: B. Weiden Boyd, ed., Brill's Companion to Ovid. Leiden. 91-116.

Williams, G. (2002). „Ovid’s Exilic Poetry: Worlds Apart,“ in B. Weiden Boyd, ed., Brill's Companion to Ovid. Leiden. 337-381.

Wulfram, H. (2008). Das römische Versepistelbuch: Eine Gattungsanalyse, Berlin.

Zingerle, A. (1967). Ovidius und sein Verhältniss zu den Vorgängern und gleichzeitigen römischen Dichtern. Heft I-III. Hildesheim (ND Innsbruck 1869). 


\title{
Philo and Josephus Fashion Themselves as Religious Authors in Rome
}

\author{
Maren R. Niehoff
}

Imperial Rome has recently emerged as a city, which lacked canonical texts in the religious sphere, Augustine being the first Latin author, who constructs his religious identity by reference to reading. ${ }^{1}$ Two Roman philosophers confirm this scholarly insight: Seneca mocks Greek commentary culture, warning his fellow citizens not to waste their time in debating questions such as whether "the Iliad or the Odyssey was written first [or] whether moreover they belonged to the same author" (Brev. Vit. 13.2). Such brooding over texts would make the reader look "rather more annoying" than learned. ${ }^{2}$ The Alexandrian library, the symbol of textual scholarship, amounts in Seneca's view to nothing but "learned luxury" and ostentation, while failing to encourage a personal kind of reading that has a transformative, ethical effect. ${ }^{3}$ In his Epistle "On the God within us" Seneca moreover stresses that the presence of the divine promotes moral development, but should not be sought in temples and rituals. The gods are instead accessed through personal devotion stimulated by the experience of Nature. Finding god within the soul will result in a rational life in accordance with Nature (Ep. 41.1-9). The Roman emperor and Stoic philosopher Marcus Aurelius offers a similar approach to ethics and religion. He declares books to be an obstacle to moral and religious progress, demanding "away with your books!" In his view, too, proximity to the gods is attained through the heart. ${ }^{4}$

Philo and Josephus arrived in first century Rome as a result of political crises: Philo leading the Jewish embassy to Gaius Caligula after the pogrom in Alexandria, Josephus settling in Rome after the defeat of the Jewish revolt in which he had actively participated. ${ }^{5}$ While Josephus is famous for having written most of his treatises in Rome, I have recently made a similar case for the late Philo.

\footnotetext{
${ }^{1}$ Woolf 2012; Rüpke 2001.

${ }^{2}$ Sen., Brev. Vit. 13.2 ("non doctior videaris sed molestior"), Ep. 2.1-6.

${ }^{3}$ Legat. 150; Suet., Claud. 19.3; Sen., Tranquil. 9.4-5.

${ }^{4}$ Marc. Aur., Med. 2.2-3.

${ }^{5}$ For details on the historical background, see Hadas-Lebel 2012, 69-89; Smallwood 1961; van der Horst 2003; Harker 2008; Mason 2016; Cohen 1979; Goodman 1987; Chapman and Rodgers 2016.
} 
I have argued that his embassy to Rome was not only a political event, which transformed him from recluse Bible interpreter to diplomat, but also a platform of intellectual exchange with the Roman elite. As other ambassadors in Rome before and after him, Philo used his years in the capital, when he waited for an audience by Gaius, to write broader treatises as part of his diplomatic mission. Taking into account Philo's literary activity in Rome, we can thus compare his self-fashioning as an author to that of Josephus. Both advocated Judaism in Rome, transforming their religion which was traditionally grounded in the canonical text of the Bible. Given the gap between the Scriptural orientation of ancient Judaism and the dismissal of commentary culture in Rome, Philo and Josephus faced a complex cultural challenge with direct implications for their style of writing. The question of how they fashioned themselves as religious authors in texts addressing a Roman audience thus pertains to broader issues of inter-cultural translation and adaptation. ${ }^{6}$ Did Philo and Josephus present themselves in ways congenial to their Jewish upbringing or did they rather adopt postures resonating with Roman models?

While emerging from very different Jewish communities both Philo and Josephus were involved in Biblical studies before coming to Rome. Philo grew up in the Alexandrian Diaspora on the basis of general Greek learning and the Greek Bible, which he knew by heart, quoting numerous verses from memory and expecting his readers to pick up specific references to Biblical expressions. ${ }^{7}$ His earliest work is a systematic, allegorical commentary on Gen. 2.1-18.2 for the Jewish community of Alexandria. ${ }^{8}$ Scripture serves here as a central source of knowledge about God and as the basis of the Jewish religion. The opening passage of Genesis, for example, suggests to Philo that creating is as much the property of God as burning is the property of fire (All. 1.5). Throughout the Allegorical Commentary Philo as an author remains rather more in the background. The canonical text is physically in the center, being quoted at the beginning of each exegetical section as well as on numerous other occasions. Philo typically speaks about himself as "revealing" and "clarifying" the meaning of

${ }^{6}$ I use the terms "self-fashioning" in the sense coined by Stephen Greenblatt 1980, namely as a reference to the techniques of an author's self-presentation in the text, with special attention to his or her entanglement in contemporary political structures and discourses. Occasionally I will use the term "self-positioning" in a similar sense.

${ }^{7}$ Philo had no sufficient knowledge of Hebrew to read the Scriptures in their original. While Rajak 2009 has argued again for his knowledge of Hebrew on the basis of his Hebrew etymologies, the following considerations mandate against such an assumption: Philo never solves a textual problem in the Bible by recourse to the Hebrew and often offers "Hebrew" etymologies for the Greek rather than the Hebrew form of Biblical names (see e. g. Migr. 165). Philo's exclusive access to the Bible in Greek has been stressed by Katz 1950; Sterling 2010; Sterling 2012.

${ }^{8}$ Philo's commentary on Gen. 18.1-2 is not printed in the standard editions of his work, but is preserved in an Armenian fragment, published by Siegert 1998; regarding the internal Jewish audience of the Allegorical Commentary, see Royse 2009; Birnbaum 1996. Niehoff 2018: 173-191, arguing also for the early date of the Allegorical Commentary. 
the text rather than as expounding his own views or directly positioning himself in the text. ${ }^{9} \mathrm{He}$ often introduces questions that somebody else may raise and presents his own answer in the passive voice ("it must be said"). ${ }^{10}$

Josephus, on the other hand, grew up in Jerusalem in a Hebrew and Aramaic speaking environment. He reached Rome at a much earlier stage in life than Philo. His pre-Roman period was consequently shorter and did not include writing activity, at least not in the form of published treatises. In his autobiography, however, written towards the end of his career, Josephus recalls his early education and first encounters with the intellectual elite of Jerusalem. He significantly portrays himself as studying the Scriptures, being known for his "love of letters" and giving advice at the age of fourteen to the chief-priests and leading men of Jerusalem concerning "a precise detail in our laws". 11

Philo's arrival in Rome had an immediate effect on his choice of literary genre. While composing minute commentaries on the Scriptures back in Alexandria, he began to write in Rome historical and philosophical treatises as well as a general Exposition of Jewish Law. These works no longer address a Jewish, but rather a broad Roman audience. Philo's role as an author in the text has significantly changed, as he abandons the more anonymous style of textual commentary. It is this new authorial voice, which I examine in this paper, comparing his strategies of self-fashioning to those of Josephus, who arrives in Rome one generation later and writes under similar conditions. I will focus on Philo's two extant historical treatises, namely the Embassy and Against Flaccus, both written in a Roman context, and pay special attention to their introductions where Philo defines his role as an author. I will then compare his voice to that of Josephus in the introductions to his two historical works, namely the Jewish War and the Antiquities. I will conclude with a reading of particular scenes where Philo and Josephus describe themselves in religiously significant situations and discuss martyrdom. Given the similar setting of their works, I will ask to what extent their literary strategies converge and vice versa where each of them assumes a distinct posture.

\section{Philo's and Josephus' self-positioning in the Introductions}

Philo offers revealing introductions to his historical treatises, which address the instability of human perspectives, question literary conventions and at the same time convey a strong sense of trust in God and His management of the world. Aware that he is embracing a new style, Philo opens the Embassy with the following sigh: "how long shall we, the aged, be children grown old in our

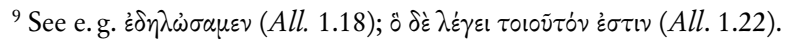

${ }^{10} \lambda \varepsilon \kappa \tau \dot{\text { źov }}$ (All. 1.33-4); see also All. 1.91, 1.101, 2.42, 2.80, 3.4, 3.28, 3.252, Post. 1, 22, 32, 40, 49, Deus 51, Det. 57, Conf. 169, Migr. 169, Gig. 1, Fuga 87.

${ }^{11}$ Jos., Life 9; see also Mason 2003, 12-14; Nakman 2016.
} 
bodies through length of time, but just infants in our souls out of a lack of sense, considering the most incalculable element, fortune, to be the most persistent, but Nature, the firmest element, to be the most unsteady? We change and switch our actions, as if engaged in board games, thinking that fortune's gifts are more stable than Nature's, and Nature's more insecure than fortune's" (Legat. 1). This introduction creates a sense of instability by suggesting that appearances, actions and constructions of the Self are unreliable. The physical signs of old age no longer promise wisdom, thus subverting traditional expectations. Human actions are exposed as inevitably dependent upon context. Rather than adjusting to absolute standards, men tend to change their behavior as they change places. Even more intriguingly, Philo suggests that human beings just play a part "as if engaged in board games". Personal identity is not fixed, but rather determined by the temporary roles we assume, knowing well that they are not real, but only put on for the occasion. In the midst of this instability Philo appeals to his readers with a sense of urgency, stressing that these are times when "many important questions" are being decided - undoubtedly an allusion to the political events he is involved in, namely the diplomatic efforts following the pogrom in Alexandria.

Philo implies himself in a literary "we", appealing to his readers to examine themselves whether they rely on the whims of fortune or recognize the stable features of Nature. His audience is expected to be sufficiently open to consider his work, but not automatically on his side. Philo engages the philosophical inclination of his readers and explains that orienting oneself towards Nature demands exchanging "misleading sense-perception" by "unerring intelligence" (Legat. 2). The readers are encouraged to apply reason and look beyond the concrete reality towards the future and the invisible. Such a perspective will make them aware that the "present time and the many and significant issues that are being decided in it are sufficient to carry conviction, even if some have come to disbelieve that God takes care of men and especially of the suppliant race, which is attached to the Father and King of the universe and the source of all things, and will persuade them as well" (Legat. 3). The suppliant race is, of course, Israel, a name which Philo (wrongly) derives from the etymology "seeing God", suggesting that his people "has perceived of God, being trained to let the soul soar above all created things and behold the uncreated and divine" (Legat. 5). Philo thus defines a specific lesson taught by history. He has in mind recent political developments, especially the assassination of Gaius and the trial of Flaccus, the Roman prefect in Egypt. Both events have internal Roman causes, namely senatorial dissatisfaction with Gaius and Flaccus' failure to keep the province calm. Philo, however, interprets them as expressions of Divine providence, which shows His particular concern for the Jewish people and arranges the course of history accordingly. ${ }^{12}$

${ }^{12}$ Legat. 333-5, Flac. 102, 109, 116-25. 
Philo as an author has left behind his earlier position, when he distinguished himself as an interpreter of the Bible with expertise in the minutiae of the text. In the introduction to the Embassy he has moved into the foreground of the text, positioning himself as a decipherer of political events in a religious spirit, which will guide his readers to recognize God's presence in the world. Philo thus emerges as an author, who is acutely aware of the fragility of life and derives his authority as a narrator from his awareness of Divine providence behind the scene of human action. At this point he does not use his status as an eye-witness to claim greater reliability than others on account of his involvement in the reported affairs or exposure to special sources of information, such as private meetings or personal letters. To be sure, he will later sporadically integrate such evidence in his account, but in the introduction, where he defines his identity, he does not refer to this dimension..$^{13}$ It is rather his particular religious interpretation of known events, which he chooses to foreground and present as a distinct mark of his work.

The treatise Against Flaccus opens with a more impersonal reference to Sejanus' "plot against the Jews" (Flac 1). Philo assumes that his Roman readers will remember Sejanus, the highly influential commander of the praetorian guards, who was elected in $30 \mathrm{CE}$ as consul for the next year together with Tiberius. $\mathrm{He}$ mentions Sejanus also in the Legatio in connection with his "accusations against the Jews of Rome", which were nothing but "false slanders" (Legat. 160). No other ancient author mentions Sejanus' anti-Jewish machinations, including Josephus, who talks about his conspiracy against Tiberius, which Antonia brought to the emperor's attention, thus ushering in his execution in $31 \mathrm{CE} .{ }^{14}$ Philo may well have applied his own theological interpretation to the story of Sejanus' political fall, filling in the details of history and suggesting that his case teaches a lesson in Divine providence. In his view, the Roman prosecution reflects also a grander scheme of Divine retribution according to which anybody maltreating the Jews will be punished by God. It is moreover implied that the foe of the emperor is also an enemy of the Jews and their God. Roman readers, who may well dislike Sejanus for upsetting Tiberius' rule, are encouraged to extend their negative emotions to contemporary opponents of the Alexandrian Jews, such as Flaccus and the city's gymnasiarchs.

Flaccus is then introduced as a Roman politician, who fits the paradigm of sin and punishment. ${ }^{15}$ Philo assumes the role of an omniscient narrator and explains that a tyrannical nature like Flaccus tends to delve into cunning manipulations and cause a lot of damage, even though he was not in a position of highest power

\footnotetext{
${ }^{13}$ For examples of Philo's use of letters and personal experience in the Embassy, see Legat. 179-98, 349-62.

${ }^{14}$ J. A. 18:181-2; see also van der Horst 2003, 89-90. Eus., H. E. 2.5 .7 adopts and expands Philo's account, leading some scholars to assume a lost treatise by Philo on Sejanus.

${ }^{15}$ For an excellent short biography of Flaccus, see van der Horst 2003: 34-38.
} 
(Flac. 1). Philo provides unfamiliar facts about his activities in Alexandria, such as his initial brilliance and fiscal as well as military management, stressing his own expertise in "Egyptian affairs ..., which are complicated and manifold, hardly graspable even for those who have made it their business to examine these matters from their earliest years" (Flac. 3). While not mentioning any of his sources, Philo adopts the language of a historian with privileged access to knowledge. ${ }^{16}$ Roman readers are encouraged to trust him as an Alexandrian author, who is more thoroughly versed than others in the events of his city. The allusion to those "who have made it their business to examine these matters from their earliest years" may well include Apion, the head of the rivaling Egyptian embassy, who had written a history of Egypt with highly negative images of the Jews. ${ }^{17}$ Aware of a competition for Roman sympathies, Philo suggests that his interpretation is more firmly based on the facts and suits imperial policies, which culminated in Flaccus' (and Sejanus') trial. He inscribes himself among the critics of these infamous politicians and supports their downfall from a Jewish perspective.

After describing Flaccus' successful beginning as a prefect, Philo imagines a critical reaction from his readers: "Perhaps someone will say: my dear sir, after having decided to place a charge against the man, you have not gone through the motions of accusation, but put together great praises. Have you struck the wrong note and gone mad?" (Flac. 6). Philo evokes here the atmosphere of a trial by using the verb "to place a charge", which is associated with the court-room and immediately reminds the reader of Flaccus' historical trial in Rome on account of his mismanagement. In that trial, Philo later explains, Lampoo, an Alexandrian gymnasiarch, officially played the role of "accuser", but in reality protected Flaccus. Bribed on a regular basis, Lampoo pretended to write "the minutes of the law-suits", but in reality "deleted some of the evidence and deliberately passed over it". He generally tampered with the documents, "turning the letters upside down". ${ }^{18}$ Philo nicknames Lampoo "letter starer" and parodies the conventional expert of texts, who diligently studies the minutiae of sentences, words and letters in order to establish the original meaning. Lampoo, by contrast, uses his literary skills for his personal profit and "picked up money at every syllable". The pursuit of truth and justice, expected from his role at the court, has obviously been perverted.

Philo, another expert of textual criticism, decides to assume the role of accuser, translating the parodied court room scene into a literary genre. He has internalized Roman court procedures, which serve as a kind of palimpsest for his own writing and convey an ironic perspective on what he sets out to do.

\footnotetext{
${ }^{16}$ For examples of self-positioning in the introductions to historical works, see the contributions on Herodotus, Philostratus and others in Nünlist and Bowie 2004.

${ }^{17}$ For details see Jos., Against Apion; see also Barclay 2007.

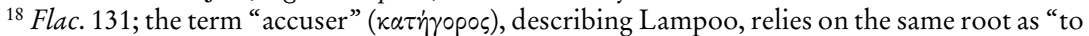

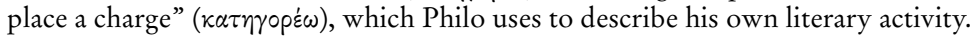


Philo not only plays creatively with court room scenes, but also engages in a sophisticated discussion of literary genres and narrative perspectives. He directly engages the reader, who is introduced as a critical voice, accusing him of "having struck the wrong note and gone mad". This imagined charge of bias in favor of Flaccus turns out to be a clever rhetorical device, which enables Philo to reflect humorously on his own writing and position himself as a violator of literary norms. While not conforming to the rules of an accusation, Philo asserts that he knows "what the sequence of an argument demands" and suggests that he will do better than simply "putting together great praises". He indicates that he will show Flaccus' villainy in a somewhat unexpected manner, namely after enumerating his initial advantages. Philo perplexes his readers and invites them to be involved with his text without knowing precisely which genre it belongs to or which narrative perspective it adopts. The reader is encouraged to listen to the music of Philo's treatise without judging digressions from the known melody as "a wrong note". The deviant tone of Philo's music turns out to be its beauty, ever unexpected and unpredictable, but nevertheless conveying a clear message.

Flaccus is exposed as a prefect, who lost his status when Gaius, his old enemy, replaced Tiberius on the throne. From that moment onwards his power in Egypt was threatened and he associated with faction leaders and anti-Semitic gymnasiarchs. Philo presents himself as privy to a conversation they held with Flaccus alone, saying to him: "lost are your prospects from the boy Tiberius Nero, lost also the hope that you had next to him in your comrade Macro, while your expectations from the present emperor are anything but promising" (Flac. 22). Flaccus gives in to these manipulations, counts on the support of his former adversaries in return for "handing over the Jews" and turns into a puppet on the theatre of Alexandrian politics. Philo eagerly points to the farcical nature of his rule, insisting that his reconciliation with the ring-leaders was nothing but empty words, while he was in reality led like a "dummy on the stage", the title of government inscribed on him merely for show (Flac. 20). Philo emerges once more as an omniscient historian, who reveals the truth behind the bewildering scene of reality, exposing both Flaccus' weakness and the Egyptians' "slanderous nature" (Flac. 29). Ultimately, God intervenes and brings about Flaccus' downfall as a carefully measured punishment for his maltreatment of the Jews (Flac. $102 \mathrm{ff}$.). While Philo adopts a more historical style in the introduction to Against Flaccus than in the Legatio, his profile as a religious author is rather consistent: he uses narrative techniques of irony and subversion of literary conventions in order to create a sense of insecurity and fragmentariness in the reader. Appealing directly to his audience, Philo then invites contemplation of meta-historical structures, which point to Divine providence and justice. While marginally fashioning himself as an eyewitness with special access to information, Philo's main source of authority as a narrator is his religious insight. Rather than presenting a 
consistent, chronological narrative he highlights certain events and explains their theological significance.

Josephus' introduction to his first historical work, the Jewish War, similarly subverts literary conventions. He initially accuses previous historians of not having participated in the events and misrepresenting the facts by relying on hear-say and indulging in rhetoric rather than serious search for the truth $(J$. W. 1.1). Josephus aims at amending this state of affairs by sharing his experience of the war and providing a truthful account. He describes himself as a priest from Jerusalem, a Hebrew by race, who has originally written in his Aramaic mother tongue and now presents a Greek translation of his work to Roman readers $(J$. W. 1.3). His alien origin is a central theme, which he highlights on other occasions in the introduction stressing that he, as a "foreigner" ( $\left.\dot{\alpha} \lambda \dot{o} \phi \nu \lambda \circ \mathrm{s}^{\prime}\right)$ will present a memorial of the achievements of the Greeks and Romans" (J. W. 1.16). More importantly, Josephus provocatively states that his ethnic perspective has led him to subvert historiographical conventions. Confessing to adopt a style "contrary to

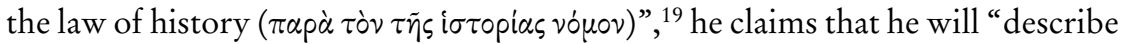
the deeds of both sides [i.e. of the Romans and the Jews] with precision", but "in the interpretation of the facts I impart my disposition, giving in to my own emotions in order to lament my country's misfortunes". ${ }^{20}$ Like Philo, he ironically appeals to his readers' expectations, asking them to trust him, even though he proceeds in an unexpected manner, and insists that this deviation from the literary norms enables him to provide a more accurate picture. Josephus promises a truthful account, because he avoids both hatred of the Jews and flattery of the Romans. His explanations throw light on Philo's self-fashioning. His emphasis on the connection between subverting literary norms and being a foreigner in Rome prompts us to wonder whether Philo, too, felt free to take poetic license, because he knew that his alien status would in any case challenge regular expectations. Moreover, Josephus stresses far more than Philo that he is a reliable eyewitness of the events he reports. We have seen that Philo only briefly points to this aspect in the introduction to Against Flaccus, while generally stressing his theological insights and refraining from a clear distinction between facts and interpretations. Josephus, by contrast, is careful to present himself as a historian, who relates the facts objectively, while offering an emotional interpretation. Theology is not a central concern in this context, instead figuring in the background of the overall narrative in the form of divine providence. While Josephus follows rather closely in the footsteps of Polybius, another Greek historian writing in Rome, Philo only taps into such discourses without fully embracing them. ${ }^{21}$

\footnotetext{
${ }^{19}$ Jos., J. W. 1.11.

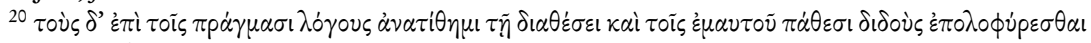

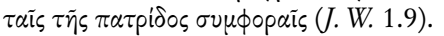

${ }^{21}$ Pol., Hist. 1.1-5; see also Walbank 1972, 1-19.
} 
Josephus inscribes himself into Roman discourses by arguing for a convergence of imperial and Jewish interests. While Philo had referred to the "many important questions" of his time and emphasized Divine providence, but only vaguely alluded to the Roman background of the events, Josephus directly addresses the issues from an internal Roman perspective and identifies concrete points of commonality. Initially, he presents himself as a historian of "the greatest war not only among those of our times, but, as far as we have received report, of all conflicts that ever broke out between cities or nations" (J.W. 1.1). As the Jewish rebels had hoped to involve Jews living in the Euphrates area, the future of the whole Eastern Empire was at stake. By accurately presenting the facts of this enormous event, Josephus claims considerable importance as a Roman historian. ${ }^{22}$ Josephus moreover positions himself by criticizing the approach of his predecessors, who assumed that praising Rome implies deprecating the Jews (J.W. 1.7). In his view, Jewish valor rather enhances Roman reputation, as conquering an insignificant enemy does not bring glory. While Philo had implied that the Roman treatment of Gaius and Flaccus served the Jews and was in fact initiated by their God, Josephus directly praises Titus for his policies: he was reluctant to intervene in internal Jewish matters and destroyed Jerusalem only as a last resort in the guerilla war with the zealots (J.W. 1.10). Roman policies thus converge with enlightened Jewish positions, while Rome's opponents are also sinners in a religious sense.

Josephus uses another strategy of inscribing himself into Roman discourses, which Philo applies in some of his later writings, but not in the introductions to his historical treatises, namely constructing the Greeks as Other. Since late Republican times Rome had entertained an ambivalent attitude towards the Greek heritage: open admiration, on the one hand, competitiveness and dismissal, on the other. Cato became famous for criticizing Greek talkativeness as well as Greek doctors and constructing Roman identity on the basis of practical ethics, in contrast to the Greek ethos. ${ }^{23}$ Philo mentions some of these themes in his description of two groups of Jewish philosophers, the Therapeutae and the Essenes, both of whom he eagerly dissociates from things Greek, arguing instead that they share Roman values. ${ }^{24}$ For Josephus the question of where the Jews belong, either to the Greek East or the Roman West, has become a far more central concern. Already in the introduction to the Jewish War he attacks "eloquent Greeks", who "excel in speech", but lack commitment to the truth and write stories about the war without first-hand knowledge. ${ }^{25}$ The notion of writing history in Greek, while belonging to the Roman side of a deep cultural

\footnotetext{
${ }^{22}$ See also Cohen 1979, 91-93.

${ }^{23}$ Plut., Cic. 2.1-4, 3.1, 4.1-3, 40.1-41.1, Cat. Mai. 2.4, 12.4-5, 22.1-23.2, 24.1; see also Isaac 2004: 381-405.

${ }^{24}$ Philo, Lib. 93-6; for details, see Niehoff 2010.

${ }^{25}$ J. W. 1.13-4; for similar rhetoric see C. Ap. 6-18; see also Barclay 2007: 362-370.
} 
divide, is central to Josephus' identity as a Jewish author, while it is a more marginal aspect for Philo.

In the introduction to the Antiquities Josephus addresses Jewish history from its Biblical beginnings until his own time, thus operating in a much broader intellectual framework than before. In comparison to the War, two new features of self-fashioning are conspicuous: Josephus radiates a new sense of self-confidence and social embeddedness in Rome, while emphasizing the theological message of his historical work. He introduces himself as someone, who has "undertaken the present treatise, assuming that it will appear to all the Greek speakers as worthy of esteem" (J.A. 1.5). Josephus moreover responds to requests by "some who cherished a love for history", especially Epaphroditus, "a man enamored with every kind of learning, taking particular delight in the experience of history" (J.A. 1.8). This man is probably the freedman of Nero, known for his rise to unusual honor and power, but also his subsequent exile and ultimate execution by Domitian. ${ }^{26}$ Josephus identifies with the "multiple turns of fortunes" Epaphroditus experienced, "proving an amazing strength of character" (ibid). He traces his own decision to embark on the preparation of the Antiquities to him and describes how he "yielded to the persuasions of him who ever enthusiastically joins those capable of producing something useful or beautiful, and myself ashamed, if I should seem to take more pleasure in sluggishness than in the work concerned with the most beautiful things" (J.A. 1.9). Steve Mason has made a strong case for arguing that Josephus was not an isolated author, but a well-connected figure in Rome's literary circles, producing his work in conversation with other intellectuals. ${ }^{27}$ Mason bases himself mostly on the War, pointing to such remarks as "I am about to speak to those who know my life" (J.W. 1.22). Following this approach, I would like to point to a significant development in Josephus as an author. While alluding to an intellectual circle in the War, he explicitly presents himself in the Antiquities as surrounded by enthusiastic admirers and points to the social context of his work in Rome. In the time that has elapsed between these two works Josephus has clearly integrated in Rome as a successful author on matters of interest to Roman intellectuals. He shares his ideas in progress, is encouraged to express them and composes his treatises in the comfort of a sympathetic, intellectual circle. Philo understandably never reached that degree of comfort in Rome. Spending only a couple of years in the capital, the circumstances of his writing remain elusive, never permitting us to situate him with the same precision as Josephus.

In theological matters, on the other hand, Josephus increasingly resembles Philo. While theology is marginal in the introduction to the War, Josephus introduces the Antiquities by pointing to Divine providence: "on the whole, anybody

\footnotetext{
${ }^{26}$ See also den Hollander 2014, 280-282.

${ }^{27}$ Mason 2016a, 60-137; Mason 2016b.
} 
who has cared to read my history may learn from it that those who follow God's will and do not dare to transgress the laws excellently laid down, are successful in everything beyond belief and receive happiness as a prize from God" (J.A. 1.14). Josephus even addresses his readers directly and admonishes them "to turn their thoughts towards God", promising that they will recognize His beneficial nature in the narrative of the events. This open promotion of a religious message resembles Philo's approach in the Embassy, which he introduces, as we have seen, by pointing to God's providence behind the scene of human history.

Philo and Josephus have assumed a distinctly Roman posture in their historical works. Refraining from Bible exegesis and assuming familiarity with Roman history, they directly engage with the reader, often introducing a dimension of ironical subversion and taking into account critical views. Both present themselves as eye-witnesses to events which are important for the Roman public, Philo more implicitly, Josephus explicitly and with emphasis on historiographical principles. Historical events serve both authors as a source of theological insight, Philo stressing his role as a religious interpreter of politics, while Josephus increasingly points to Divine providence. For both, writing history involves assuming a religious role in the community and conveying broad insights into God's active involvement in the world.

\section{Philo's and Josephus' self-positioning in key-scenes}

The Embassy provides rich material for Philo's self-fashioning in Rome, as he reflects here on the events through recollection of personal experiences. Philo speaks about "us five ambassadors" and refers to their Egyptian counterpart as "the elders of the Alexandrians", but says nothing about their identity and surprisingly little about their actual activities. ${ }^{28} \mathrm{He}$ writes as if the bare facts of the embassy are known to his audience, his task being to offer a broader interpretation. Philo as a narrator builds his leading role in the Jewish embassy by pointing to his experience and intellectual superiority. His exemplary maturity shows in the first meeting with Gaius, who greeted them in a friendly manner and conveyed the message that he himself will hear the case in due course. While the other ambassadors rejoiced at the emperor's positive response, Philo remains skeptical and is troubled by the following thoughts:

But as I believe to have a greater amount of good sense on account of my age and my good education, I was alarmed by the things which gave joy to them. Bestirring my own thinking power ("logismos"), I said: why, when so many envoys have arrived from almost the whole earth did he say that he would hear only us?

\footnotetext{
${ }^{28}$ Legat. 172, 370; Jos., J. A. 18.257-9, mentions three ambassadors and identifies the grammarian Apion as their head.
} 
What does he want? He cannot have remained ignorant of the fact that we are Jews, for whom it would be a pleasure not to be disadvantaged ... Thus thinking I was deeply disturbed and had no rest by day or night. Yet fainthearted I kept my sorrow secret, since it was not safe to express it, while another very heavy calamity suddenly and unexpectedly fell upon us - a calamity, which brought danger not only to one part of the Jewish citizen-body, but collectively to the whole people (Legat. 182-4)

This is one of the more personal passages in Philo's entire œuvre, when he shares with his readers the thoughts going through his mind. Stressing his own doubts regarding Gaius' sincerity, Philo connects this scene from the initial stage of the embassy with the subsequent news about Gaius' plan to erect his own statue in the Jerusalem Temple. He gives the impression that immediately after the meeting with Gaius, while he was still thinking about its meaning, the bad news about the Temple reached him. According to Philo's own testimony, however, the Jewish ambassadors heard the news at a considerably later stage. In Legat. 185 he mentions the journeys they had in the meantime undertaken to follow Gaius, who was "spending some time round the bay [of Puteoli]". Philo has thus harmonized two events, namely the initial meeting with Gaius in the early part of $39 \mathrm{CE}$ and the subsequent announcement of his plans about the Jerusalem Temple, which most probably dates to the summer of $40 \mathrm{CE} .{ }^{29}$ By fusing the two events Philo gives the impression that human diplomacy was doomed to failure from the beginning, thus preparing for his ultimate message that only God is reliable.

Philo explains his inner thoughts and shows how he relies on his education and logismos in order to judge external appearances more carefully than others. He prides himself in having had the "good sense" of distrusting Gaius rather than accepting his gestures of benevolence. This disclosure of a personal reaction to an external stimulation reflects Stoic philosophy, which is concerned with the individual as embedded in society and reacting to the outside world. While Philo does not use distinctly Stoic terminology, except the rather general notion of logismos, his position is close to that of the Roman philosopher Seneca, who began to publish his first works at the time of Philo's embassy. Seneca similarly treats the individual person with emphasis on his or her reaction to the outside world, often describing how he reacted to specific situations by applying his rational judgment. ${ }^{30}$ Philo's exposition of his prudent behavior seems personal at first sight, but then turns out to be rather more schematic. He doesn't say much about himself other than demonstrating a philosophical truth via his own example. This apparently personal style, which remains peculiarly detached, is also shared by Seneca. Rather than treating ethical questions in the abstract,

\footnotetext{
${ }^{29}$ On the dates, see Smallwood 1961, 256-261; Harker 2008, 11-12.

${ }^{30}$ Sen., Ira 2.1.1-4.1, Ep. 113; see also Sorabji 2000, 17-75; Griffin 2013, 125-148.
} 
Seneca prefers to address friends and discuss specific instances bearing on ethical questions. While often introducing experiences from life, his historical persona remains strangely elusive and detached from identifiable circumstances. In his pioneering treatise On Anger Seneca uses personal language and addresses his brother Novatus, while at the same time turning to a wider audience for whom his experience serves as an exemplar. Both Seneca and Philo project a narrative Self of Stoic complexion in order to demonstrate the concrete truth of their position. Seneca discloses his self in order to show that "everything depends on opinion; ... a man is as wretched as he has convinced himself that he is". Philo tells his readers how he relies on his logismos in order to confront the impression of Gaius' friendly gestures, suggesting that from the beginning this Roman emperor is "our mortal enemy". ${ }^{31}$

Another moment of crisis is described in overtly personal terms, namely the moment when the Jewish ambassadors hear about Gaius' plans to set up his statue in the Jerusalem Temple. We ultimately learn from Philo that Gaius' decision is a reaction to the news of Jews tearing down a pagan altar in Jamneia (in the Land of Israel). Immediately after reading the tax-collector Capito's account of the event, which is according to Philo "highly exaggerated", Gaius decides in the summer or early autumn of $40 \mathrm{CE}$ to punish the Jews by erecting a colossal statue in the main sanctuary. ${ }^{32}$ Philo, however, does not tell this story in its chronological sequence, but rather introduces the Temple issue much earlier. He constructs a dramatic scene in which the Jewish ambassadors receive the bad news from a messenger (Legat. 184-98). Philo recalls a lively exchange between the unsuspecting ambassadors and a messenger, who is too shocked to break the horrifying news and needs to be encouraged to deliver his information piecemeal. He imagines a highly emotional exchange between the two parties. His scene has probably been inspired by Aeschylus' play The Persians and looks like a conscious dramatization of the embassy. ${ }^{33}$ The ambassadors show strong bodily reactions to the threat of a human statue in the Jerusalem Temple: "struck by his words and fixed by consternation, we could not move, but stood speechless and powerless, with our hearts melted and our bodies unnerved, while others appeared bringing the same terrible news. Afterwards we all gathered together in seclusion and bewailed the disaster personal to each and common to all and we recounted in detail such thoughts as the mind suggested, for the unfortunate man talks without end" (Legat. 189-90). In this scene Philo allows himself and the other ambassadors to be appropriately emotional, while also preserving decorum and expressing their plight in seclusion.

\footnotetext{
${ }^{31}$ Sen., Ira 2.1.1-5, Ep. 78.2-4, 78.13; Philo, Legat. 180; see also Edwards 1997; Griffin 1976, 396-397, 43-59.

${ }^{32}$ Legat. 200-3; see also Smallwood 1961, 260-265.

${ }^{33}$ Philo mentions Aeschylus in Prob. 143 and has used scenes from The Persians to interpret the Biblical battle at the Red Sea (for details, see Niehoff 2001, 52-58).
} 
The messenger scene leads immediately to Philo's definition of new priorities. He stresses that the purity of the Temple is an issue of life and death, which requires even martyrdom "in the defense of the laws" (Legat. 192). Philo moreover explains that the embassy must now give priority to the Temple issue rather than negotiate the civic rights of the Alexandrian Jews. This decision is obviously controversial, because Philo makes special efforts to justify it. He initially stresses that the Temple concerns all the Jews, while the question of Jewish rights in Alexandria is more local. Then he asks: "how can it be right and proper to struggle vainly to prove that we are Alexandrians, when over our head hangs the danger threatening the whole of the Jewish commonwealth?” (Legat. 194). Philo must have used the term "Alexandrian" in the technical sense of civic rights, because the dwelling of the Jews in the city was an obvious fact requiring no proof. ${ }^{34}$ When Philo justifies himself for neglecting to "show that we are Alexandrians", he seems to respond to criticism that his embassy is not sufficiently devoted to the civic issue of the Alexandrian Jews. He even confronts harsh questions, such as why he and his ambassadors do not resign from political life and go home (Legat.195). Philo responds to such accusations of incompetence by a strong theological message: "the truly noble are always full of hope and the laws create good hopes for those who study them in depth and do not just pay lip-service. Perhaps these things are a trial of the present generation, to see how inclined it is to virtue and whether it has been trained to bear misfortune with unfaltering reason and without stumbling. All human aid vanishes - let it vanish! But let our hope in God, our Savior, who has often saved our nation from hopeless and impossible situations, remain unshaken in our souls” (Legat. 195-6).

In this highly personal appeal to his readers Philo develops a theology of martyrdom and presents himself as a competent leader in times of suffering. True nobility of mind and real virtue are measured by a person's willingness to endure hardship. Suffering plays a positive role in defining one's identity and prompts a more intense religiosity. The Torah plays a consoling role and inspires hope. Philo uses once more the term logismos, rational thinking, which has already helped him to describe his personal reaction to Gaius. Now the logismos is said to strengthen the mind of those, who have studied and need to be reassured. The narrative about the political struggle for civil rights in Alexandria has been replaced by a theology of consolation. In the process Philo has transformed himself from diplomat to religious leader.

The highlight of Philo's story is the ambassadors' second meeting with Gaius, which enables him not only to describe the climax of the political crisis, but also to define himself as a historical actor and author in the text. His art of self-fashioning is particularly conspicuous in these scenes. Philo initially establishes

${ }^{34}$ On the term "Alexandrian”, see Tcherikover and Fuks 1957, 41, n. 102; Smallwood 1961, 27-31, 255; Collins 2000, 113-122. 
his credentials as an eye-witness, stressing that he will report what "we have seen and heard" (Legat. 349). As he recalls it, the situation was lost from the beginning: "entering [Gaius' presence], we immediately realized from his look and movements that we had come not to a judge, but an accuser of those more hostile than our enemy" (Legat. 349). While Philo is eager to present Gaius as a "ruthless tyrant" on the grotesque stage of history, the worst he can say about him is that he poked fun at Jewish customs. There is an obvious tension between Philo's claim that the emperor was madly obsessed with enforcing his own worship and the relatively harmless treatment he gives to the Jews, who refuse to address him as a god. Instead of forcing them to show him Divine honors, Gaius simply says that the Jews strike him as "unfortunate rather than wicked" and leaves the room..$^{35}$

Philo further dramatizes the scene and uses the encounter with Gaius for his own theological purposes. Stressing that he and his fellow ambassadors are "seized by a profound terror" and "helpless under such befooling and reviling", Philo stages a clash of civilizations. While the issue of Alexandrian citizenship is no longer discussed, Gaius shows interest in the Jews' peculiar customs and opens the meeting by a sneering question: "are you the god haters, who do not believe me to be a god?" Philo stresses the Jews' Otherness by introducing the perspective of the Egyptian embassy, which is said to rejoice at this opening and, dancing about, invokes blessings on Gaius. Philo further writes that the emperor poked fun at Jewish food customs, asking: "why do you refuse to eat pork?" This question, too, is enthusiastically greeted by the Egyptians, who thus confirm Judaism's unique nature and clash with Egyptian values. This image of the Egyptians reflects the historical fact that Apion, the head of the rivaling embassy, denounced the Jews both on account of their "atheism" and their abstention from pork. ${ }^{36}$ Philo significantly addresses only the religious, but not the political points of dispute with the Egyptian diplomat, ignoring his claims about the civic status of the Alexandrian Jews.

In Philo's narrative the Jewish ambassadors focus on religion and explain to the emperor that "different people have different customs" (Legat. 362). The meeting between Gaius and the Jewish ambassadors is presented as a stage for constructing Jewish difference. This scenario fits neither the context of the civic dispute in Alexandria nor the threat of a statue in the Jerusalem Temple. Neither Gaius nor the ambassadors mention these topics. Most strikingly, the issue of Gaius' deification is not connected to the prospect of his statue in the Jerusalem Temple; and the subject of Jewish customs does not lead to a discussion of Alexandrian citizenship. Philo's scene is historically unlikely and primarily serves his overall theological purposes. The pillars of Jewish Otherness, which

\footnotetext{
${ }^{35}$ Legat. 367; see also Bilde 1978, 72-74; Gruen 2012.

${ }^{36}$ Legat. 353-63; see also Jos., C. A. 2.66-7, 2.137.
} 
he highlights, namely monotheism, special food laws and inherent opposition to Egyptian values, resurface in his Exposition. Philo declares essential features of Judaism, as he never did before in his earlier Alexandrian writings. It is under a critical gaze from the centre of Roman power that Philo formulates his particular ethnic identity. ${ }^{37}$

Philo compares the embassy's meeting with Gaius to "mimes in theatres" (is

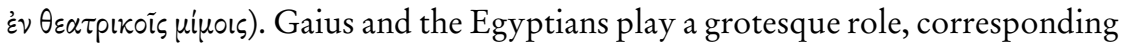
to the emperor's imitations of the gods. As Philo recalls in other passages of the Embassy, Gaius not only slipped on the stage and joined in the dancing, but also, "as in a theatre", put on the insignia of the various gods, expecting to receive the reverence due to them. ${ }^{38}$ Philo thus unmasks Rome as a grand stage, where even the emperor is nothing but an actor playing different parts in a mime. His own performance as an author, accentuated in his self-reflective introductions and dramatic style throughout his report, turns out to be a part played on the Roman scene. Philo not only experiences Rome as a theatrical farce, but inscribes himself as an author in dramatic discourses.

Philo's notion of martyrdom in a theatrical context anticipates significant pagan and Christian voices. Seneca distinguishes himself from other Stoics by emphasizing noble suffering. While his predecessors identified the goal of ethics as the "good which is unalloyed, peaceful and beyond the reach of trouble", he considers brave endurance under torture and even death as desirable, because they bring out the virtues more than the "dead sea" of fortune. Socrates is admired not so much for his philosophy, but for his willingness to meet death and drink the cup of poison (Ep. 67.5-10,13.14-5). The author of Luke-Acts similarly stresses martyrdom by reinterpreting the Gospel of Mark with emphasis on Jesus' noble suffering and imagining Paul's trial before the Roman emperor. ${ }^{39}$ In the second century martyrdom becomes a central theme in Christian discourses, ranging from Ignatius' Letters to the Martyrdom of Polycarp and the Passion of Perpetua. Of particular interest is Justin Martyr, because he also integrates martyrological motifs in a philosophical interpretation of religion. In his view, proper Christianity is distinguished from "Gnosticism" by its readiness for martyrdom. Justin tells the story of his conversion as a reaction to the sight of Christian martyrs and introduces himself as someone, who expects "to be fixed to the stake", perhaps by Cresence, "a lover of bravado and boasting". Interpreting Christianity in a Platonic and Stoic mode, Justin highlights the similarity between Jesus and Socrates, both of whom died a martyr's death. Justin concludes his Second Apology

${ }^{37}$ See also the collection of articles assembled by Whitmarsh 2010, which deals with similar issues of identity in a pagan context.

${ }^{38}$ Legat. 359, 45-6, 79. Suetonius and Dio also mention Gaius' performing in the theatre (Suet., Cal. 11, 54.1-2; Dio 59.5.4-5); see also Calabi 2003, 111-3; Edwards 1994.

${ }^{39}$ Lk 22.43-4, 23.46 (cf. Mk 14.32-42, 15.34); see also Ehrman 1997, 109-111; Harrill 2012, $1-12,97-101$. 
by a vivid address to the Romans, anticipating that his appeal to martyrdom will be to their taste. ${ }^{40}$ Writing a century earlier in the context of the Jewish embassy to Gaius, Philo is already sensitive to the dramatic potential of suffering and explores it by appealing to Roman conventions. Anticipating subsequent Christian authors, he inscribes the history of his people into contemporary Roman discourses and constructs himself as a dramatic author on the verge of martyrdom for the Jewish cause.

Josephus is famous for highlighting the spirit of Jewish martyrdom under Roman conquest. He describes the siege of Masada and transmits the speech of the rebel leader Eleazar, who enjoins his comrades to "die nobly and in freedom" rather than accept Roman rule..$^{41}$ Eleazar moreover suggests that the Jews' readiness to die for their freedom and customs is part of Jewish education and theology. It is God's will "that we depart from life, if we are not likely to make use of it according to custom" (J.W. 7.359). Josephus endorses this perspective in his apologetic work Against Apion, where he praises the Jews for their serious commitment to their Scriptures and heritage, while the Greeks neglect their records, indulge in rhetoric and incline to ever new fashions. The Jews, he stresses, are willing to give up their lives for their values and "die gladly". ${ }^{42}$

Josephus is equally famous for his avoidance of implementing these values in his own case, when besieged by the Romans and facing a choice between suicide and surrender. After recommending martyrdom to his fellow rebels and prompting them to kill each other as a last resort, Josephus engages critical views in a clever rhetorical move. He quotes his fellow rebels, who understood that he will surrender to the Romans, as shouting to him (í $\beta$ 'ow): "God will be dumbfounded out of grief, as he gave the Jews souls scorning death! Is life so dear to you, Josephus, that you stay alive to see the light as a slave?!" (J. W. 3.356). Josephus uses this criticism as a spring-board to construct himself as a victim of the Jewish zealots. "Fearing an attack" and "considering it treason of God's commands to die before delivering the message", ${ }^{43}$ he appeals to their reason and tries to convince them of the advantages of cooperation with Rome. Josephus speaks about religious treason as an alternative to political treason, of which he

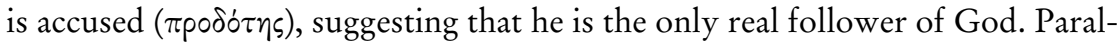
lel to Philo, he claims special religious insight, precisely when his decisions are most controversial. Appeal to religious authority thus covers a personal plight and allows him to fashion himself in a new role as author. Josephus stresses his priestly lineage, which offers him privileged access to Biblical prophecies and prophetic dreams (J.W. 3.351). Priesthood and divination were privileged as-

\footnotetext{
${ }^{40}$ Just., 2 Apol. 12.1, 3.1, 9.1-1-5, 14.1-15.5; see also Perkins 1995; King 2013; Coleman 1990; Nasrallah 2006.

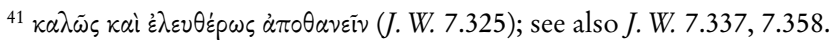

${ }^{42} \theta \nu \eta \dot{\sigma \kappa \varepsilon l v} \dot{\eta} \delta \varepsilon \dot{\omega} \omega$ (Ag.Ap. 1.42); see also Ag. Ap. 2.218.

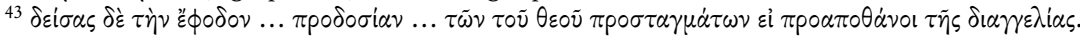


pects of religion in Rome and Josephus can count on their appeal to his readers. They support his argument that God has instructed him about the destinies of the Jews and the Romans, letting him know in advance what the outcome of the war will be. Moreover, Vespasian's accession to the throne has been signaled to him, predestining him to announce the good news and become a protégé of the future Roman emperor.

Josephus moreover presents himself as a philosopher arguing with his critics in the cave before surrendering to the Romans. Like Philo, he is familiar with Stoic ideas, using them to justify his decision. Stressing that he "philosophizes", he appeals to Stoic notions of Nature. Man, he explains, is created by God in a particular manner and should not interfere with the Divine scheme. The soul should thus not be detached from the body and the anticipated span of life not be shortened. Suicide, he concludes, is an "act of impiety against God" as well as a violation of the law of Nature, seeing that no animal ever puts an end to its life and disregards the gift of the creator (J.W. 3.370). In his own case, Josephus thus employs philosophy to the opposite ends as Eleazar, who referred to Platonic notions of the soul's immortality in order to encourage suicide as a transition to another life. Josephus' appeal to Stoic notions of nature as well as his political decision will have resonated with his audience, which seems to have been Roman rather than Jewish. Josephus insists that he has not changed, as "the Romans know" - a clear hint to his readers, who will appreciate that he has remained committed to Jewish causes. Josephus makes a final appeal to his readers: "it is well to adopt a righteous frame of mind and not add to our human calamities impiety towards our creator" (3.379). Theology and philosophy converge to make an argument for Josephus' political step. This posture significantly resembles that of Philo, who also fashions himself as a religious author with privileged insight in controversial political situations. Both authors moreover theoretically embrace martyrdom, Philo not having to prove himself, while Josephus makes a case for his own exception.

Both Philo and Josephus thus engage Roman discourses in order to fashion themselves as religious authors in their historical works. Leaving behind exegetical models of defining their religion, they appeal to historical events as a key to understand God and Divine providence. Both claim special insights, Philo on account of his philosophical acumen, Josephus on account of his priestly heritage. Both also position themselves vis-à-vis other Jewish groups, appealing to the Romans to side with their particular interpretation of things. Their ironical subversion of literary conventions may reflect their awareness of ultimately being strangers in Rome, thus anticipating Lucian, who fully developed satire out of an acute awareness of belonging to no particular fatherland or society. 


\section{Bibliography}

Barclay, John M. G. (2007). Flavius Josephus. Against Apion. Translation and Commentary. Leiden: Brill.

Bilde, Per (1978). “The Roman Emperor Gaius's Attempt to Erect His Statue in the Temple of Jerusalem.” Studia Theologica 32: 67-93 [reiussed, in: P. Bilde, Collected Studies on Philo and Josephus, ed. by E.-M. Becker et al., Göttingen: Vandenhoeck \& Ruprecht 2016, SANt 7, 11-34.]

Birnbaum, Ellen (1996). The Place of Judaism in Philo's Thought. Atlanta: Scholars Press.

Calabi, Francesca (2003). “Theatrical Language in Philo’s In Flaccum,” in: Italian Studies on Philo of Alexandria, ed. by Francesca Calabi, 91-116. Boston/Leiden: Brill.

Chapman, Honora Howell; Rodgers, Zuleika (2016). A Companion to Josephus. Oxford: Wiley Blackwell.

Cohen, Shaye J. D (1979). Josephus in Galilee and Rome. Leiden: Brill.

Coleman, K.M. (1990). "Fatal Charades: Roman Executions as Mythological Enactments." JRS 80: 44-73.

Collins, Jophn J. (2000). Between Athens and Jerusalem (2 ${ }^{\text {nd }}$ ed.). Grand Rapids: Eerdman's.

Darshan, Guy (2012). "The Twenty - Four Books of the Hebrew Bible and Alexandrian Scribal Methods," in: Maren R. Niehoff, ed., Homer and the Bible in the Eyes of Ancient Interpreters, 221-244. Leiden: Brill.

Den Hollander, William (2014). Josephus, the Emperors, and the City of Rome. Leiden: Brill.

Edwards, Catherine (1994). "Beware of Imitations: Theatre and the Subversion of Imperial Identity,” in: Jaś Elsner and Jamie Masters, edd., Reflections of Nero: Culture, History, and Representation, 83-97. Chapel Hill: University of North Carolina Press.

Edwards, Catherine (1997). "Self-Scrutiny and Self-Transformation in Seneca's Letters." Greece and Rome 44: 23-38.

Ehrman, Bart D. (1997). The New Testament. New York/Oxford: Oxford University Press.

Goodman, Martin (1987). The Ruling Class of Judea: the Origins of the Jewish Revolt against Rome A. D. 66-70. Cambridge: Cambridge University Press.

Greenblatt, Stephen (1980). Renaissance Self-Fashioning. Chicago: University of Chicago Press.

Griffin, Miriam T. (1976). Seneca: A Philosopher in Politics. Oxford: Clarendon.

Griffin, Miriam T. (2013). Seneca on Society. Oxford: Oxford University Press.

Gruen, Erich (2012). “Caligula, the Imperial Cult, and Philo’s Legatio.” SPhA 24: 135-47.

Hadas-Lebel, Mireille (2012). Philo of Alexandria. A Thinker in the Jewish Diaspora. Leiden: Brill.

Harker, Andrew (2008). Loyalty and Dissidence in Roman Egypt. Cambridge: Cambridge University Press.

Harrill, J. Albert (2012). Paul the Apostle. Cambridge: Cambridge University Press.

Isaac, Benjamin (2004). The Invention of Racism in Classical Antiquity. Princeton: Princeton University Press.

Katz, Peter (1950). Philo's Bible. Cambridge: Cambridge University Press.

King, Karen L. (2013). "Willing to Die for God: Individualization and Instrumental Agency in Ancient Christian Martyr Literature," in: Jörg Rüpke, ed., The Individual in the Religions of the Ancient Mediterranean. Oxford: Oxford University Press. 
Mason, Steve (2003). Flavius Josephus. Life of Josephus. Translation and Commentary. Leiden: Brill.

Mason, Steve (2016a). The History of the Jewish War, A. D. 66-74. New York: Cambridge University Press.

Mason, Steve (2016b). “Josephus as a Roman Historian,”, in: Chapman and Rodgers 2016: 89-107.

Nakman, David (2016). “Josephus and Halacha," in: Chapman and Rodgers 2016: 282292.

Nasrallah, Laura (2006). "The Rhetoric of Conversion and the Construction of Experience: the Case of Justin Martyr." SP 40: 467-474.

Niehoff, Maren R. (2001). Philo on Jewish Identity and Culture. Tübingen: Mohr Siebeck.

Niehoff, Maren R. (2010). “The Symposium of Philo's Therapeutae: Displaying Jewish Identity in an increasingly Roman World." Greek, Roman and Byzantine Studies 50: 95-117.

Niehoff, Maren R. (2011a). Jewish Exegesis and Homeric Scholarship in Alexandria. Cambridge: Cambridge University Press.

Niehoff, Maren R. (2011b). "Philo's Expositio in A Roman Context." Studia Philonica Annual 23:1-21.

Niehoff, Maren R. (2017b). "Parodies of Educational Journeys in Josephus Flavius, Justin Martyr and Lucian of Samosata," in: ead., ed., Journeys in the Roman East: Imagined and Real. Tübingen: Mohr Siebeck.

Niehoff, Maren R. (2018). Philo of Alexandria. An Intellectual Biography. New Haven: Yale University Press.

Nünlist, René; Bowie, Angus (2004). Narrators, Narratees, and Narratives in Ancient Greek Literature. Leiden: Brill.

Perkins, Judith (1995). The Suffering Self: Pain and Narrative Representation in the Early Christian Era. London: Routledge.

Rajak, Tessa (2009). Translation and Survival. Oxford: Oxford University Press.

Royse, James R. (2009). “The Works of Philo," in: Adam Kamesar, ed., The Cambridge Companion to Philo, 32-64. Cambridge: Cambridge University Press, 2009.

Rüpke, Jörg (2001). Die Religion der Römer. München: C. H. Beck.

Siegert, Folger (1998). “The Philonian Fragment De Deo.” SPhA 10:1-33.

Smallwood, E. Mary (1961). Philonis Alexandrini Legatio ad Gaium. Leiden: Brill.

Sorabji, Richard (2000). Emotion and Peace of Mind. Oxford: Oxford University Press.

Sterling, Gregory (2010). "Philo," in: John J. Collins and Daniel Harlow, edd., The Eerdmans Dictionary of Early Judaism, 1063-1070. Grand Rapids: Eerdmans.

Sterling, Gregory (2012). "The Interpreter of Moses: Philo of Alexandria and the Biblical Text," in: Matthias Henze, ed., A Companion to Biblical Interpretation in Early Judaism, 415-434. Grand Rapids: Eerdmans.

Tcherikover, Victor A.; Fuks, Alexander (1957). Corpus Papyrorum Judaicorum, vol. 1. Cambridge: Harvard University Press.

van der Horst, Pieter (2003). Philo's Flaccus. The First Pogrom. Leiden: Brill.

Walbank, F. W. (1972). Polybios. Berkeley: University of California Press.

Whitmarsh, Tim (2001). Greek Literature and the Roman Empire. The Politics of Imitation. Oxford: Oxford University Press.

Whitmarsh, Tim (2010). Local Knowledge and Microidentities in the Imperial Greek World. Cambridge: Cambridge University Press. 
Woolf, Greg (2012). "Reading and Religion in Rome,” in: Jörg Rüpke and Wolfgang Spickermann, edd., Reflections on Religious Individuality. Greco-Roman and JudaeoChristian Texts and Practices, 193-208. Berlin: de Gruyter.

Wright, Benjamin G. (2015). The Letter of Aristeas. Berlin: de Gruyter. 



\title{
Paulus als doulos in Röm 1,1 und Phil 1,1
}

\author{
Die epistolare Selbstbezeichnung als Argument
}

\author{
Eve-Marie Becker
}

\section{Vorüberlegung}

In Entsprechung zu dem Tagungsthema, das die Anregung zu dem folgenden Beitrag gab, ${ }^{1}$ werde ich mit einführenden Überlegungen zur Erforschung antiker Autoren und Autorrollen beginnen: Wie die gegenwärtige antike Autorforschung herausstellt, haben antike Autoren many voices, mit denen sie sich an ihre lesende oder zuhörende audience wenden. Das Phänomen der many voices ist nicht psycho-pathologisch signifikant, sondern ergibt sich aus dem literarischen Zusammenspiel von Form und Argument. Dorothea Frede (2013) ${ }^{2}$ hat zuletzt die drei Stimmen, besser: Autorrollen untersucht, mit denen Aristoteles in seiner „Nikomachischen Ethik“ auftritt. Sie wählt mit Aristoteles einen Autor, der bei der Frage, wieweit die literarische Gestaltung eines Textes (im jeweiligen literarischen genre und innerhalb des genres) und der philosophische Gehalt miteinander verbunden sind, bisher eher ausgeblendet wurde. ${ }^{3}$ Frede unterscheidet drei verschiedene Autorrollen in der Nikomachischen Ethik: Aristoteles wird hier als systematischer Philosoph, als Forscher und Pädagoge greifbar. An jede Autorrolle ist eine spezifische Thematik und Sprechabsicht geknüpft. ${ }^{4}$ Aristoteles gibt zumeist nicht explizit zu erkennen, ${ }^{5}$ mit welchem Rollenmodell er jeweils operiert. Vielmehr erschließt sich das aristotelische Rollenkonzept darin, mit welchen literarischen Formen der Autor seine Argumente präsentiert und wel-

\footnotetext{
${ }^{1}$ Der vorliegende Beitrag führt dabei zugleich einige Beobachtungen zur paulinischen Semantik der „Demut“ im Philipperbrief aus, die ich im Blick auf die Begriffs- und Motivgeschichte der $\tau \alpha \pi \varepsilon เ v \circ \phi \rho \sigma$ vं $\eta$ in Phil 2,3 gesondert dargestellt habe: Becker 2015.

${ }^{2}$ Frede 2013, 215-237.

${ }^{3}$ Vgl. auch Rapp 2010, 283.

${ }^{4}$ „There is Aristotle the systematic philosopher, who determines the subject matter, its principles, and the appropriate method(s). Then there is Aristotle, the researcher working out the substantive details by applying those method(s). And finally, there is Aristotle the pedagogue, the teacher of the subject-matter, trying to convince his audience of the appropriateness of his investigation and its results“, Frede 2013, 216.

${ }^{5}$ Ausnahmen könnten die direkten Anreden an die audience sein, z. B.: Eth Nic 1,3,1095a2ff.
} 
che Methoden der Untersuchung und Darstellung er dabei nutzt. ${ }^{6}$ Die Analyse der many voices des Aristoteles kann, wie ich im Folgenden in weiterführender Übertragung auf Paulus zeigen werde, auch für die Analyse des Philipperbriefs methodisch anregend und fruchtbar sein. Im Unterschied zu Aristoteles legt Paulus jedoch, wie wir sehen werden, vielfach die von ihm gewählten Autorrollen offensiv offen.

\section{Die Funktion der Autorrollen bei Paulus}

Paulus wählt in seinen Briefen verschiedene Sprecher- oder Autorrollen, die er zumeist explizit macht. Diese Autorrollen erfüllen im Blick auf die Wirkabsicht seiner brieflichen Schreiben insgesamt drei Funktion: Sie dienen erstens der Autorisierung der Sprechabsicht, zweitens der Unterstützung oder Formulierung eines Arguments und drittens dem self-fashioning der Person (Stephen Greenblatt), das letztlich über die konkrete Briefsituation hinausweist. ${ }^{7}$ Diese drei Funktionen lassen sich jedoch nur in einem ersten Schritt gesondert betrachten, denn sie wirken zum Zwecke der Konfigurierung des sachlichen Arguments letztlich zusammen. Die Selbstbezeichnung des Paulus als doulos in Röm 1,1 und Phil 1,1 bringt dieses Zusammenwirken von Autorrolle und Argument pointiert zum Ausdruck.

Im Einzelnen: Die explizite Verwendung der Autorrollen ermöglicht es Paulus erstens, die jeweilige Sprechabsicht darzulegen und diese mit dem Ziel der Autorisierung seiner Rede zum Einsatz zu bringen. So spricht Paulus in unterschiedlichen brieflichen Zusammenhängen als berufener Apostel (Röm 1), Gemeindegründer (1 Kor 1 ff.), Schriftausleger (Röm 9-11), Kontrahent (Gal; 2 Kor 10-13), Apokalyptiker (1 Kor 15; 2 Kor 12), Ratgeber (1 Kor 7), Gefangener (Phil 1), Briefeschreiber ( 2 Kor 2 f.7), intimer Freund (Phlm) - um nur einige der many voices, die Paulus selbst wählt, offenlegt und gestaltet, zu nennen. Diese Rollen sind situativ bedingt (historischer Kontext des Briefeschreibers und der Adressaten) und sachlich-thematisch (Fragen- und Problemstellungen) sowie pragmatisch (Wirkabsicht bei den Adressaten) definiert und funktionalisiert. Doch auch innerhalb eines Briefs oder Briefteiles kann es zu einem Rollenwechsel kommen. Wir werden das gleich in Phil 1-2 sehen. Meine These ist, dass die Rollenwechsel, die speziell im Philipperbrief zu beobachten sind, dazu dienen, Form und Argument so zu konfigurieren, dass eine bestimmte Sprecherrolle selbst zum Argument

\footnotetext{
${ }^{6}$ So dient die „endoxic method“ der Präsentation als Philosoph: Die endoxische Methode ist von der induktiven Methode („'what is [better] known to us"“) zu unterscheiden: „The endoxic method is ... a procedure that uses 'reputable' or 'common opinions' as its starting point“, Frede 2013, 223.

${ }^{7}$ Vgl. allgemein zum Begriff und Konzept: Greenblatt 1980.
} 
wird, das zugleich auf die literarische und religiöse Selbstdarstellung des Paulus als doulos zurückwirkt.

Denn in Phil 1-2 wird zweitens die Rolle des doulos zu einem theologischen und ethischen Argument des Textes: Es dient der näheren Darstellung und Exemplifizierung dessen, was Paulus mit ,Niedrig-Gesinnung' bzw. Demut

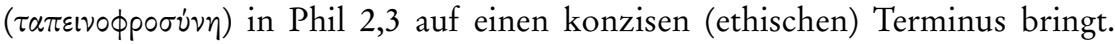
Der Begriff doulos ist zugleich ein verkürzender Ausdruck für die narrative Identität, die Paulus sich in seinem Briefeschreiben verschiedentlich gibt (vgl.

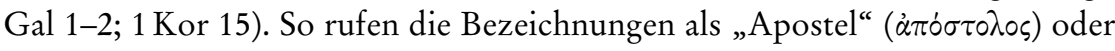
eben als "Sklave“ ( $\delta \circ \tilde{\lambda} \lambda \circ \varsigma)$, die besonders in den brieflichen superscriptiones begegnen, wahlweise die spezielle narrative Identität des Gesandten oder des Untergeordneten auf, die Paulus in seinem Briefeschreiben an anderen Stellen ausführlicher narrativ ausgestaltet. ${ }^{8}$ Umgekehrt führen die Verwendung des Begriffs doulos in Phil 1-2 und seine dortige kontextuelle Prägung dazu, dass das Lexem neue semantische Merkmale hinzugewinnt: So wirken die $\tau \alpha \pi \varepsilon v v \circ \phi \rho \circ \sigma \dot{v} \nu \eta$ sowie die historische Situation, unter deren Eindruck Paulus Phil 1-2 schreibt, und die pragmatische Funktion des gegenwärtigen Schreibens ihrerseits semantisch auf die Wortbedeutung von doulos zurück. Semantik, Form und Argument korrelieren.

Paulus nutzt die Selbststilisierung als doulos (Phil 1,1) drittens zum aktiven Zwecke des self-fashioning. Paulus erstrebt die unmittelbare Konformität mit dem Kyrios Christus (Phil 2,6-11) und ordnet diesem Streben die brieflich-literarische Beschreibung seiner apostolischen (und persönlichen) Existenz (Phil 3,10f. 21) zu. Paulus schreibt sich sukzessive in die Konformität mit Christus hinein. ${ }^{9}$ So bringt die literarische wie religiöse ,Selbststilisierung ' des Paulus als doulos in grundlegender Weise das Selbstverständnis des Apostels, der nach Christus-Konformität sucht, zum Ausdruck. Die Selbstbezeichnung als doulos wird sogar zu einem Personenmerkmal, ${ }^{10}$ das zugleich für die sachlich-theologische Deutung wichtiger Paulusbriefe (Philipper- und Römerbrief, aber auch die korinthische Korrespondenz und Galaterbrief) konstitutiv ist. Umso erstaunlicher ist, dass gegenwärtige Paulus-Darstellungen diesem grundlegenden

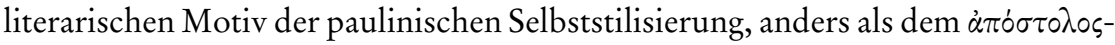
Titel, ${ }^{11}$ zumeist wenig oder gar keine gesonderte Aufmerksamkeit schenken ${ }^{12}$

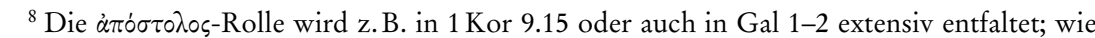
die $\delta \circ \tilde{\nu} \lambda \circ \varsigma$-Rolle der Argumentation des Römer- und Philipperbriefs unterliegt, skizziere ich in dem folgenden Beitrag (s. u.).

${ }^{9}$ Vgl. dazu auch Becker 2015, 137.

${ }^{10}$ Hierbei auch weiter auszuarbeiten, vgl.: Becker 2013 a.

${ }^{11}$ Vgl. dazu etwa: Frey 2005/2009.

${ }^{12}$ In gegenwärtigen Paulus-Darstellungen wird das doulos-Motiv - besonders im Blick auf das Selbstverständnis (self-understanding) des Paulus - nicht weiter problematisiert, vgl. z.B. dazu: Wolter 2011; Schnelle 2014, 158 ff.; Wright 2013. Eine mangelnde motivische und sozialhistorische Ausleuchtung des Ausdrucks begegnet auch etwa in: Byron 2003a, der die Analyse 
oder es vorschnell einer verkürzenden Deutung unterziehen. So wird das doulos-Motiv etwa als religiöser Ausdruck der „Erkenntnis des Auferstandenen als des Kyrios" ${ }^{13}$ als allgemeine Replik auf das Selbstverständnis der Propheten als ,Knechte Gottes ${ }^{14}$ oder als eine spezielle Form der Rezeption von (Deutero-) Jesaja verstanden, die mit der Identifikation des Paulus mit dem Gottesknecht (bes. Jes 49,1 ff.) in Zusammenhang gebracht wird. ${ }^{15}$ Elias J. Bickerman versteht die doulos-Bezeichnung vor dem Hintergrund der altorientalischen Bedeutung von ebed als "title of honor". ${ }^{16}$ Oder: „Paulus stellt seine Position als Mittler nach dem Modell jener Menschen dar, die Gott in den Dienst nimmt, um durch sie an seinem Volk zu handeln ". ${ }^{17}$ Gerhard Sass (1941) hatte der Untersuchung

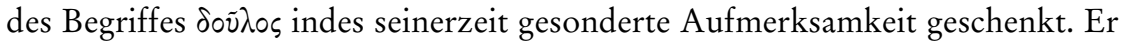
schlug vor, die Verwendung von doulos in Phil 1,1, Röm 1,1 und Gal 1,10 als "Amtsbegriff“ zu verstehen, der sich nur in Teilen aus der hebräischen Vorstellungswelt herleiten lässt. ${ }^{18}$ Auch Robert Jewett (2007) spricht im Anschluss

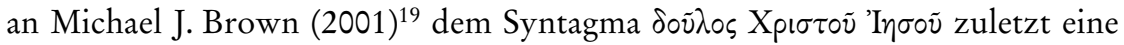
eigenständige epistolographische Funktion zu. Er schlägt bei der Analyse der paulinischen Selbststilisierung in Röm 1,1 vor, diese als Auseinandersetzung des Paulus mit der römischen Machtpolitik zu verstehen. ${ }^{20}$ Allerdings lässt Jewett bei seiner Deutung Phil 1,1 weitgehend außer Acht.

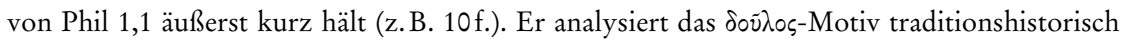
und deutet die paulinische Verwendung dann wie folgt als theologisches Konzept: „... When Paul used the expression to refer to himself or to others, he was declaring his association with the figure of Christ, his release from sin through the Christ event, his enslavement to God and his obedience to God through the imitation of the paradigmatic slave of God, Christ", 263. Vgl. zur paulinischen Sklaven-Metaphorik auch Byron 2008.

${ }^{13}$ Kraus 2013, 233 - mit Hinweis auf Blank 1968, 203 ff. und Zeller 2010, 301.

${ }^{14}$ So etwa Lohse 1996, $121 \mathrm{f}$.

${ }^{15}$ Vgl. Kraus 2013, 233 f. - mit Hinweis auf Wilk 1998, z. B. 367 ff., aber auch 287 ff.. Nach Wilk reflektiert das Jesajabuch in paradigmatischer Weise das „Ereignis seiner (= der paulinischen) Berufung“; ferner „gibt das Jesajabuch Auskunft über das Wesen der paulinischen Verkündigung“; „Einsatzpunkt der Anwendung von Jesajaworten auf die eigene Person ist für Paulus die Offenbarung Jesu Christi“ (367f.). Die Frage nach der konkreten Identifizierung des sog. Gottesknechtes in Jes $42 \mathrm{ff}$. bei Paulus lässt Wilk jedoch offen; wieweit Phil 1,1 und Röm 1,1 durch implizite Jesaja-Motivik inspiriert sein können, wird ebenfalls nicht weiter untersucht. Wilk sieht allerdings grundsätzlich im Philipperbrief Jesaja-Rezeption vorliegen, so z. B. hinter Phil 2,15f. Jes 49,4 durchscheinen (301f.).

${ }^{16}$ Bickerman 1986, 148. - Ich verdanke diesen speziellen Literaturhinweis Albert I. Baumgarten (Bar-Ilan University).

17 Wolter 2014, 80.

${ }^{18}$ Sass 1941, 32.

${ }^{19}$ Vgl. Brown 2001, 737: Das Syntagma ,is a technical term alluding to the Familia Caesaris“.

20 „Paul is ... introducing his 'persona' with proper credentials as an agent of Christ Jesus, using the technical term for a 'king's official' or an imperial bureaucrat ... The proximity between 'slave of Caesar' and 'slave of Jesus Christ' sets an agenda pursued throughout the letter concerning whose power is ultimate, whose gospel is efficacious, and whose program for global pacification and unification is finally viable“: Jewett 2007, $100 \mathrm{f}$. - unter Hinweis auf: Hester $2004,85 \mathrm{ff}$. 
Um der genannten komplexen Funktionalität der Autorrollen und speziell der Stilisierung des Paulus als doulos genauer auf die Spur zu kommen, betrachten wir zunächst die Rollenwechsel, die Paulus in Phil 1-2 vollzieht (3.), und gehen dann der Frage nach, welche literarische und religiöse Funktion speziell der paulinischen Selbststilisierung als doulos im Philipperbrief (und darüber hinaus) angesichts der antiken Wortbedeutung als sozialer und/oder religiöser Begriff (4.) zukommen kann (5.). Ich meine, in der doulos-Rolle letztlich einen übergeordneten Aspekt des paulinischen Selbstverständnisses erkennen zu können, dem Paulus nicht zufällig im Philipperbrief die deutlichsten Konturen verleiht.

\section{Rollenwechsel in Phil 1-2}

Im Präskript des Philipperbriefs bezeichnen Paulus und sein Mitarbeiter Ti-

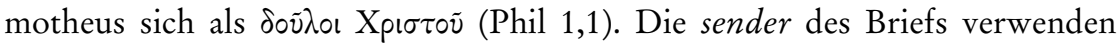
eine Selbstbezeichnung, die Teil eines größeren semantischen Feldes ist, das im Brief mehrfach begegnet: ${ }^{21}$ In Phil 2,22 wird Timotheus als jemand bezeichnet, der im Dienst für das Evangelium steht ( $(\hat{\varepsilon} \delta \circ \dot{\lambda} \lambda \varepsilon v \sigma \varepsilon v . .$.$) . Im Blick auf seine eige-$ ne Situation in Gefängnishaft $(1,12 \mathrm{ff}$.) und den missionarischen Einsatz seines Mitarbeiters Epaphroditus $(1,30)$ entfaltet Paulus darüber hinaus narrativ, was

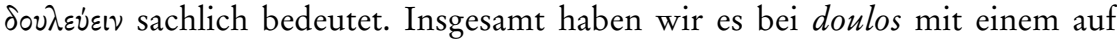
einen Begriff gebrachten self-fashioning des Paulus zu tun, das die Argumentation des Philipperbriefs leitet. Die Rolle des Paulus als doulos wird zum textübergreifenden Argument hinter den wechselnden Autorrollen, die der Apostel besonders in den beiden ersten Kapiteln des Philipperbriefs wählt.

In 1,3-11, literarisch-formal gesprochen: der Danksagung des Briefs, stellt sich Paulus, der nun in der ersten Person Singular schreibt, als Beter in Gefangenschaft dar, der um das Wohl der Gemeinschaft besorgt ist. Paulus befindet sich in der religiösen Rolle des Beters vor Gott. In 1,12-26 lässt Paulus die Adressaten am Status seiner Gefangenschaft, das heißt besonders an den äußeren und inneren Bedingungen seiner Haft teilhaben. Er stellt die Ungewissheit seiner persönlichen Situation und den offenen Ausgang des Prozesses in den Vordergrund seiner Darstellung. Paulus spricht als Gefangener, der ein Prozessurteil zu erwarten hat. Bei der Beschreibung seiner äußeren und inneren Situation spielt Paulus auf die Niedrigkeit seines gegenwärtigen Aufenthaltsortes an. Von 1,27 an - vielleicht bis 2,18 - präsentiert sich Paulus dann als ethischer Lehrer der ekklesialen Gemeinschaft, der das rechte $\pi \circ \lambda \imath \theta \varepsilon \dot{v} \varepsilon \sigma \theta \alpha \iota$ der Adressaten zum Thema macht und, um die einheitliche Gesinnung der Gemeinde zu stärken, für das Ethos der ,Niedrig-Gesinnung' wirbt, das er an der Beispiel-Erzählung über den freiwilligen Statusverzicht Jesu exemplifiziert (2,6-11). Gerade das Verhalten

${ }^{21}$ Vgl. zum Folgenden auch: Becker 2015, $120 \mathrm{ff}$. 
des Paulus unter den Bedingungen der Haft soll vorbildhaft erscheinen, weil der Apostel eine von ihm selbst gewählte Haltung der Niedrig-Gesinnung übt. Er ist bereit, seine Fürsorge für die Philipper permanent in den Vordergrund seiner Lebenshaltung zu stellen und seine eigenen persönlichen Wünsche diesem Vorhaben unterzuordnen $\left(1,22 \mathrm{ff}\right.$.). ${ }^{22}$

Die verschiedenen Sprecherperspektiven konvergieren sachlich in der im Präskript schon programmatisch eingeführten Rolle des Paulus als doulos. Paulus zeigt mit dieser Rollenbeschreibung an, dass er sich dem göttlichen Handeln unterordnet. In Phil 1-2 legt er im Einzelnen dar, wie er diese Unterordnung konkret leistet. Er ist äußerlich unfrei, sorgt für die Gemeinde und bringt in eindrücklicher Weise die Niedrigkeit seiner Lebensumstände zum Ausdruck. Im Lichte des Christus-exemplum (2,6-11) betrachtet, bringt die äußere Situation Paulus allerdings nur noch nachdrücklicher auf den von ihm selbst gewünschten Weg der Christus-Konformität (3,10f.).

Wie Paulus diese Rolle als doulos im Sinne metaphorischer Sprache deutet und sie letztlich sogar zum leitenden sachlichen und literarischen Argument seines Schreibens macht, soll gleich umfassend und über Phil 1-2 hinaus erläutert

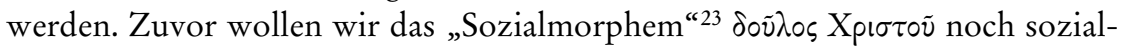
historisch und motivgeschichtlich betrachten, um seine semantischen Konnotationen, die dem metaphorischen Sprachgebrauch zugrunde liegen, beschreiben zu können.

\section{Doulos sozialhistorisch und motivgeschichtlich betrachtet}

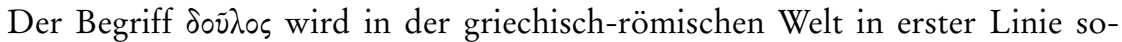
zio-kulturell verwendet, begegnet aber auch als literarischer Topos. ${ }^{24}$ Doulos ruft zunächst gemein-antike Assoziationen von dem unfreien, tendenziell niedrigen sozialen Status der Sklaven auf (vgl. auch 1 Kor 12,13; Gal 3,28). ${ }^{25}$ Der Begriff wird nicht religiös verwendet, sondern dient primär der Abgrenzung „des grie-

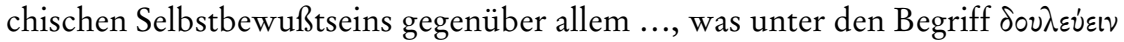
fällt". ${ }^{26}$ Das gilt für die griechisch-hellenistische wie auch für die römische Sprach- und Denkwelt (vgl. Stoiker), sogar für die des Philo. ${ }^{27}$ Warum und wie aber macht sich Paulus die Bezeichnung als doulos bei seinem self-fashioning in Phil 1 zu Eigen? Wir haben mit einer synthetisierenden Adaption verschiedener

${ }^{22}$ Vgl. dazu: Becker 2013b.

${ }^{23}$ Baltzer 2000, 1224.

${ }^{24}$ Vgl. Dinter 2013, 177-193. - Zur frühchristlichen Bedeutung (besonders bei Paulus) vgl. Martin 1990; ders. 1991; Byron 2003a; Turner 2013.

${ }^{25}$ Vgl. Alföldy 2011, $179 \mathrm{ff}$.; Ebel 2013, $80 \mathrm{ff}$.

${ }^{26}$ Rengstorf 1935, 264.

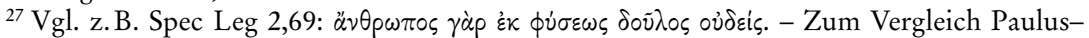
Seneca, vgl. Brookins 2017. 
Motivbereiche zu rechnen, die sozialhistorisch (griechisch-römische und frühjüdische Welt) und traditionsgeschichtlich (vor allem Septuaginta-Rezeption) determiniert sind.

(a) Grundsätzlich findet sich im paulinischen Sprachgebrauch eine eigentliche Verwendung des Begriffs, die mit dem griechisch-römischen Sprachgebrauch vertraut ist und auch in der hellenistisch-jüdischen Welt begegnet. ${ }^{28}$ Die eigentliche Verwendung des Begriffes wird gerade im Philipperbrief verschiedentlich konkretisiert. Im brieflichen Proömium (1,3ff.) schildert Paulus seine gegenwärtige Situation „in Fesseln“ (1,7; vgl. auch 1,13f.17). Mit dieser Situationsbeschreibung stellt Paulus den ihn in seinem selbständigen Handeln einschränkenden Freiheitsentzug und den allgemein bekannten (vgl. Epiktet, Diss 2,6,25 ff.) negativen Status des Ortes heraus, an dem der Apostel „zur Apologie des Evangeliums liegt ${ }^{\text {" }}(1,16) .{ }^{29}$ Die hierbei aufgerufenen Vorstellungen von der Rolle des Sklaven entsprechen auch über die aktuelle Situation der Gefängnishaft hinaus, in der sich Paulus befindet, der konkreten Lebenswirklichkeit des Apostels in der sozio-kulturellen Welt der frühen Kaiserzeit.

Eben dieser Aspekt des paulinischen Sprachgebrauchs von doulos wird in der gegenwärtigen Paulus-Forschung durchaus gerne als Beitrag zur sozialhistorischen Rekonstruktion der paulinischen Gemeinden in den Vordergrund gestellt, ${ }^{30}$ dabei aber äußerst unterschiedlich gedeutet und bewertet, ${ }^{31}$ gerade auch, was die Frage der Freilassung von Sklaven betrifft. ${ }^{32}$ Unumstritten ist: Sklaven zählten vielfach zu den Mitgliedern der paulinischen Gemeinden. ${ }^{33}$ In verschiedenen Briefen kommt Paulus auf sie zu sprechen. So nimmt er auf die soziale Stellung der Sklaven Bezug (z.B. 1 Kor 7,21; zu Phlm s.u.) und greift die Sklaverei als ein zeitgeschichtliches Phänomen auf. Dabei werden unterschiedliche paulinische Haltungen erkennbar. Einerseits deutet der Apostel die Rolle der Sklaven im Rahmen seiner ekklesialen Lehre und Ermahnung neu. Denn selbst derjenige, der Sklave ist, wird in der Gemeinschaft mit Christus frei

${ }^{28}$ Vgl. dazu Hezser 2005.

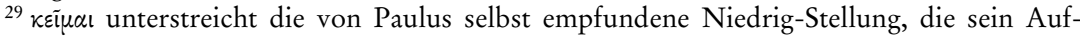
enthaltsort mit sich bringt. Wieweit die Beschreibung des inneren Empfindens den äußeren Umständen der Haft historisch tatsächlich entspricht, ist in diesem Zusammenhang von untergeordneter Bedeutung.

${ }^{30}$ Vgl. Lampe 2013, bes. 179 f.; Theissen 2011, 253 ff.; ders. 1989, bes. 68 ff. bereits kritisch über die forschungsgeschichtlichen - teils marxistisch geprägten - Interessen, die im Hintergrund der sozialgeschichtlichen Erforschung des „Urchristentums“ standen. Vgl. zur Sklaverei als klassischer Fragestellung griechisch-römischer Wirtschafts- und Sozialgeschichte: Štaerman 1981, 307-335; Alföldy 1981, 336-371. - Vollenweider 2013, 10 ff.; Wright 2013, 12.

${ }^{31}$ Vgl. etwa Marchial 2011, 749-770, der die möglichen sexual-historischen Kontexte, in denen sich der Philemonbrief bewegt, in den Vordergrund stellt.

${ }^{32} \mathrm{Vgl}$. Harrill 1995.

${ }^{33}$ Vgl. Koch 2014, 267: „Haus- oder auch Gemeindesklaven, Sklaven aus Bergwerken oder Latifundien dagegen nicht ...“. 
(1 Kor 7,22; Gal 3,28). ${ }^{34}$ Soziale und religiöse Rollen interagieren so als Paradoxon. Rollenwechsel und Rollenstabilität werden gleichzeitig vollzogen und gefordert. Gerade wegen ihrer deutlichen Anlehnung an die konkrete soziale Wirklichkeit antiken Sklavendienstes lässt sich die paulinische Sklaven-Metaphorik nicht als möglicher Ausdruck eines schon umgedeuteten Konzeptes von Macht oder frühchristlicher leadership verstehen. ${ }^{35}$

Das scheint der Beobachtung zu entsprechen, dass andererseits die paulinische Haltung zum Sklavendienst als überaus konventionell erscheint - jedenfalls auf den ersten Blick. Den entlaufenen Sklaven Onesimus hat Paulus offenbar schon ermahnt, zu seinem ,Herrn' zurückzukehren (Phlm 13 ff.). Die häusliche Ordnung soll somit gewahrt bleiben. Gleichzeitig wird Philemon dazu angehalten, Onesimus mit Respekt und Freundschaft, ja als „geliebten Bruder“ (Phlm 16) wieder in sein Haus aufzunehmen (Phlm $8 \mathrm{ff}$.). Die diesen Weisungen unterliegende ethische Argumentationsstruktur des Paulus ist nicht ungewöhnlich. Denn ähnlich wie in anderen Feldern ethischen Diskurses - etwa in der Diskussion über Ehe, Scheidung oder Unverheiratetsein (z. B. 1 Kor 7) - geht es Paulus auch im Falle des entlaufenen Sklaven Onesimus wohl in erster Linie um die Aufrechterhaltung und -sicherung von bereits etablierten Lebensformen. Gleichwohl werden diese unter den Bedingungen kommunitären Lebens in der geschwisterlichen Agape neu beschrieben (z. B. Phlm 16ff.), bewertet und begründet. In Phlm $8 \mathrm{ff}$. bedient sich Paulus dabei sogar in eindrücklicher Weise emotionaler Sprache. ${ }^{36}$ Es lässt sich also durchaus diskutieren, wieweit das Ersuchen des Paulus gegenüber Philemon im Ergebnis nicht sogar radikaler ist, als es eine mögliche Bitte um Freilassung des Sklaven wäre. ${ }^{37}$ Wieweit aber können wir die bis hierhin skizzierte sozialhistorische Betrachtung des $\delta \circ \tilde{\lambda} \lambda \circ \varsigma_{-}$ Begriffes im Zusammenhang mit ihrer motivgeschichtlichen Prägung durch die

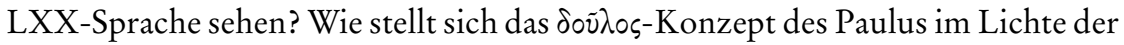
Motiv- und Traditionsgeschichte dar?

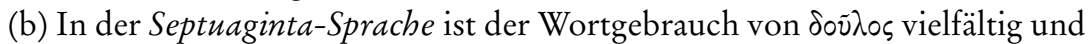
weit gefächert. ${ }^{38}$ Der Begriff wird zumeist nicht absolut gebraucht, sondern re-

${ }^{34}$ Lampe 2013, 180: „Sklavenemanzipatorisch sind Paulus` Texte (nur) im Blick auf den sozialen Raum der Gemeinde“. - Auf die hier zu beobachtende Vergleichbarkeit der paulinischen Vorstellungen von Emanzipation mit denen Epiktets hat bereits Zahn 1894, 18 und 25 (unter Verweis auf z. B. Epiktet, Diss 1,19,8; 2,16,41; 4,7,17) aufmerksam gemacht.

${ }^{35}$ Vgl. dazu Martin 1990. - Zur Kritik an Martin vgl. auch Byron 2003b, $180 \mathrm{ff}$.

${ }^{36}$ Vgl. dazu ausführlich: Wischmeyer 2015, bes. $145 \mathrm{f}$. Phlm 8-17 sind zugleich vielleicht sogar „die persönlichsten Sätze des Paulus zur $\alpha \gamma \alpha \dot{\alpha} \pi \eta$. Die Wendung ,auf ewig“ und ,Bruder im Fleisch' gehören zu jener Sprache der Liebe als großer Emotion, die in den neutestamentlichen Schriften sehr selten ist. Paulus verbindet mit einzelnen Gemeindegliedern nicht nur eine ethische und geistliche, sondern auch eine tiefe persönliche Beziehung ...".

${ }^{37}$ Vgl. dazu: de Vos 2001, 104: „What he (= Paul) expected effectively undermined the collectivist, authoritarian and patriarchal values of Graeco-Roman society".

${ }^{38}$ Rengstorf 1935, $268 \mathrm{ff}$. unterscheidet im Sprachgebrauch der LXX: 1. den sozialen Wortgebrauch („Bezeichnung des Sklaven und seines Standes und der Beschreibung seiner Lage“), 2. 
lational konstruiert, er bezeichnet im Allgemeinen das nationale Verhältnis Israels zu Gott. Das Volk Israel wird als Knecht (עִבֶד) verstanden, das seinem Herrn zu dienen hat (z.B. Jes 48,20; 49,3 ff.). Vielfältige intertextuelle Verbindungen etwa zu den Königserzählungen (1 Kön 3,9/3 Kg 3,9LXX) ${ }^{39}$ oder auch der Exodus-Geschichte ${ }^{40}$ lassen sich herstellen. Eine besondere Bedeutung

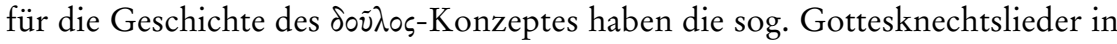
Deutero-Jesaja. ${ }^{41}$ Schon im zweiten Gottesknechtslied (Jes 49,1-6*) begegnen in Form der Ich-Rede intensivierende Züge von Individuierung:42 Die nationale Bedeutung des Gottesknechtes wird von einer einzelnen, gleichwohl schwer zu identifizierenden, selbstsprechenden Person her (zum Beispiel Mose, dem König oder dem wie Jeremia leidenden Propheten $)^{43}$ bestimmt und abgeleitet. Die im Gottesknechtslied sprechende Einzelperson steht pars pro toto für Israel, denn sie hat die Aufgabe, ganz Israel in die Gottesknechtschaft zu führen - eine Aufgabe, die schon seit der Zeit des Perserkönigs Kyros an universaler politischer und religiöser Bedeutung gewonnen hatte. Der Gottesknecht agiert als eine ,individuelle' Größe, auch wenn es bei dem Einzelnen nicht um die Person als solche, sondern „um ihr Amt, um ihren Dienst, um ihr Knecht-Sein“ geht. ${ }^{44}$

Die deutero-jesajanischen Gottesknechtsvorstellungen sind allgemein im frühen Judentum, ${ }^{45}$ so auch Paulus bekannt und vertraut - in einigen Teilen des Römer- und Philipperbriefs lassen sie sich wiederfinden und nachweisen. ${ }^{46} \mathrm{Im}$ Fokus der Paulusexegese steht gemeinhin das sogenannte vierte Gottesknechts-

den politischen Wortgebrauch („Form zur Bestimmung des Verhältnisses der Untertanen zum König in der despotischen Monarchie des vorderen Orients“), 3. den ,zeremoniellen 'Wortgebrauch - es geht darum, „das Abhängigkeits- und Dienstverhältnis zu beschreiben, in dem der Mensch zu Gott steht" und 4. den gottesdienstlichen Gebrauch - in diesem Zusammenhang ist auch die Kyrios-Akklamation zu sehen.

${ }^{39} \mathrm{Vgl}$. Becker 2015, 100.

${ }^{40}$ Vgl. dazu Zetterholm 2017.

${ }^{41}$ Jes 42,1-9; 48,16-49,12; 50,2-51,16; 52,13-53,12. Baltzer, 2000, 1226 weist allerdings darauf

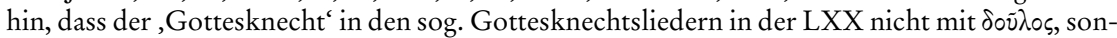
dern mit $\pi \alpha i \check{\iota}$ übersetzt wird - das trifft allerdings für Jes 49,1ff. nicht zu. Die LXX-Übersetzung ist also nicht konkordant.

${ }^{42}$ Vgl. dazu auch Westermann 1986, 171.

${ }^{43}$ Vgl. dazu die literarkritisch geleitete Analyse von Merendino 1980. Hermissson 2003, $331 \mathrm{f}$., sieht in Jes 49,1-6 in erster Linie „Formanalogien“ zum Danklied des Einzelnen, zu prophetischen Berufungsberichten (Jer 1,6; Ex 4,10) und zu Ps 2, d.h. zur Proklamation des Königs als Weltherrscher.

${ }^{44}$ Westermann 1986, 171.

${ }^{45}$ Vgl. z.B. Page 1985, 481-497; Hengel 1996, 49-91.

${ }^{46}$ Vgl. noch einmal generell zur Verwendung des Jesajabuches bei Paulus: Wilk 1998, 444 (tabellarische Übersicht über Anklänge an Jes 42-53). In den „Loci citati vel allegatio“ (Nestle-Aland ${ }^{28}$, 859f.) werden folgende Stellen als mögliche Zitate oder Anspielungen in den authentischen Paulusbriefen ausgewiesen: Jes 49,1 (Gal 1,15); 49,3 (Gal 1,24); 49,4 (Phil 2,16); 49,8 (2 Kor 6,2); 50,8 (Röm 8,33); 51,1 (Röm 9,31); $51,5.8$ (Röm 1,17; 3,21); 52,15 (Röm 15,21; 1 Kor 2,9); 53,1 (Röm 10,16); 53,3 (Phil 2,7); 53,5.8 (1 Kor 15,3); 53,11 (Röm 5,15.19; Phil 2,7); 53,12 (Röm 4,25; 1 Kor 15,3). 
lied (Jes 52,13-53,12), ${ }^{47}$ das „Leben, Tod und Erhöhung“ des Gottesknechts thematisiert. ${ }^{48}$ Ist speziell dieser Text im Hintergrund von Phil 2,6-11 zu vermuten, wie in der Exegese verschiedentlich vorgeschlagen wurde? ${ }^{49}$ Paulus bezieht in der Tat den Begriff des doulos auch in konzeptioneller Hinsicht in seine christologische Deutung des Lebens und Sterbens Jesu mit ein. In Phil 2,7b wird Chris-

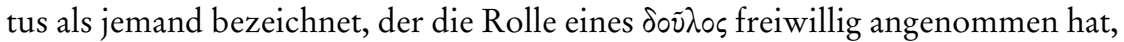
indem er seinen gott-gleichen Status aufgegeben und die Haltung des $\tau \alpha \pi \varepsilon v v^{\prime} \varsigma$ gezeigt hat. ${ }^{50}$ Auch darüber hinaus wird einzelne Motivik aus Deutero-Jesaja in Phil 2 erkennbar: Phil 2,10f. gilt als Rezeption von Jes 45,23. ${ }^{51}$ Allerdings: Eine direkte motivische oder literarische Anlehnung von Phil 2,6-11 speziell an das vierte Gottesknechtslied ist nicht nachweisbar. ${ }^{52}$ So sachlich, motivisch und literarisch vielfältig Deutero-Jesaja als Buch und die darin enthaltenen verschiedenen Vorstellungen von Verkündigung, Rechtsverzicht oder Leiden innerhalb und außerhalb der Gottesknechtslieder sind, ist auch die Aufnahme, Deutung und Weiterbearbeitung dieses Traditions- und Motivbereichs bei Paulus äußerst uneindeutig und komplex.

Für unsere Fragestellung ist also besonders die Beobachtung relevant, dass Paulus keine kohärente sachliche Beschreibung des doulos in möglicher direkter motivischer Anlehnung an die Gottesknechtslieder vornimmt. Hiermit jedoch schließt der Apostel in einem konzeptionellen Sinne genau an die oszillierende Beschreibung des "Gottesknechts“ in Jes 42-53 an, die dessen genaue Identifikation vor dem Hintergrund des Jesaja-Buches so schwierig macht, wie schon Bernhard Duhm konstatiert hatte. ${ }^{53}$ Hat vielleicht sogar erst die mangelnde Kohärenz des Vorstellungsbereiches die breite Rezeption des (Deutero-) Jesaja-Buches im antiken Judentum ermöglicht? Im Lichte der vielgestaltigen Knechts-Motivik, die Deutero-Jesaja innerhalb und außerhalb der sog. Gottesknechtslieder bietet, wird jedenfalls das paulinische Verständnis der doulos-Rolle gerade in seiner semantischen Polyvalenz plausibel. Es ist nämlich gleichermaßen durch den auszuübenden prophetischen Verkündigungsauftrag, die damit verbundene Mittlerschaft „von Recht und Heil“ sowie Lehre, Leiden und Tod bestimmt. ${ }^{54}$ So stellt sich (Deutero-)Jesaja für Paulus als vielgestaltiger und gerade deswegen äußerst produktiver, bestens geeigneter Intertext dar.

Der vielgestaltige Rückbezug auf Deutero-Jesaja als Intertext bei den paulinischen doulos-Vorstellungen wirft ein wichtiges Licht auf die textlichen $\mathrm{Zu}$ -

\footnotetext{
${ }^{47}$ Vgl. etwa Hofius 1993, 414-437; Janowski/Stuhlmacher 1996.

${ }^{48}$ Baltzer 2000, 1225.

${ }^{49}$ Vgl. z. B. Talbert 1967, 153; Hofius 1993, 426.

50 Tugendähnliche Haltungen zeichnen sich besonders dadurch aus, dass sie in Freiwilligkeit geübt werden.

${ }^{51}$ Vgl. Wilk 1998, $322 \mathrm{ff}$.

52 Vgl. dazu Becker 2015, $100 \mathrm{ff}$.

${ }^{53}$ Vgl. die entsprechenden Hinweise auf B. Duhm bei Baltzer 2000, 1225.

${ }^{54}$ So die inhaltliche Beschreibung der Gottesknechtslieder bei: Baltzer 2000, $1225 \mathrm{f}$.
} 
sammenhänge in Phil 1-2. So treten Phil 1,1 und 2,6-11 als an einander gebundene Texte zu Tage - sie werden zu gegenseitigen Intertexten. Denn das eingangs qualifizierte Selbstverständnis des Paulus als doulos wird besonders durch die Beschreibung des Schicksals Jesu determiniert. Umgekehrt erfährt die im exemplum erzählte Geschichte vom Statusverzicht Jesu in Phil 2,6-11 in der Selbstbezeichnung des Paulus als doulos an personaler Aktualisierung. Dass Pau-

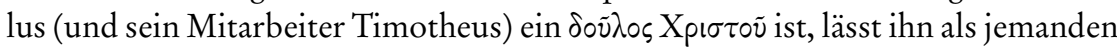
erscheinen, der am Schicksal Jesu partizipiert. In der Logik des Briefeschreibers Paulus bedeutet diese an Christus orientierte Rolle keine Schande, sondern ermöglicht die Autorisierung und Verifizierung des Apostels auf dem erstrebten Weg der Christus-Konformität.

Indem sich Paulus fortlaufend nicht als „Knecht Gottes“, sondern als „Knecht Christi“ bezeichnet (beide Titel begegnen nebeneinander in Jak 1,1), macht er zudem deutlich, dass er seine Unterordnung als eine religiöse Unterordnung unter den Kyrios Christos (Phil 2,11) und so auch als Möglichkeit der Teilhabe am eschatologischen Geschick des Gottessohnes versteht. In die Selbststilisierung des Paulus als doulos fließen also gleichermaßen die verschiedenen sozialgeschichtlichen Implikationen und die vielgestaltigen, gerade auch durch Deutero-Jesaja produktiv entwickelten motivgeschichtlichen Prägungen des Begriffs ein, die bis hierher angedeutet wurden.

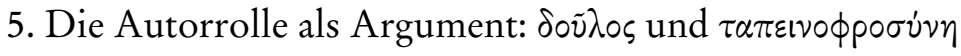

Welche Funktion beim literarischen self-fashioning des Paulus kommt nun der epistolaren Stilisierung als doulos zu? Bis hierher sahen wir: In Phil 1,1 wie auch in Röm 1,1 (vgl. ähnlich, aber nicht im Präskript: Gal 1,10) bezeichnet sich Pau-

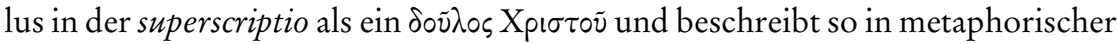
Form seine Unterordnung unter den Kyrios. An den Status als doulos sind hohe eschatologische Erwartungen geknüpft. Denn Christus selbst wurde erst in seiner Kyriotes akklamativ bestätigt, nachdem er zuvor die Rolle eines Sklaven frei gewählt hatte (Phil 2,7b). ${ }^{55}$ Es handelt sich bei der paulinischen Bezeichnung als

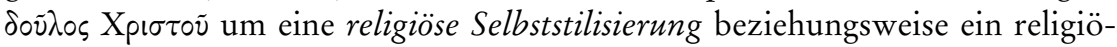
ses self-fashioning, ${ }^{56}$ das an christologische Sprache anschließt und nun in den Rahmen autobiographischer Rede tritt. Paulus bringt damit sein ,öffentliches Selbstbewusstsein' als Apostel zum Ausdruck. ${ }^{57}$

\footnotetext{
${ }^{55}$ Auch in der nachpaulinischen Literatur werden Selbsterniedrigung und Erhöhung in einem Wirkzusammenhang gesehen vgl. etwa 1 Petr 5,6.

${ }^{56}$ Vgl. dazu auch Wischmeyer 2014, 136. In Phlm, wo Paulus das soziale Geschick des Sklaven Onesimus thematisiert (V. 16), bezeichnet sich Paulus selbst gerade nicht als $\delta \circ \tilde{u} \lambda$ os.

${ }^{57}$ Vgl. dazu ausführlich - auch für das weitere: Becker 2015, $130 \mathrm{ff}$.
} 


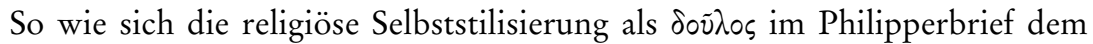
weiteren semantischen Feld der ,Niedrigkeit' zuordnen lässt (A. Bonhöffer), ${ }^{58}$ ist sie vom Präskript an Teil eines umfassenden ethischen Konzepts, das Paulus als Person in seiner Gefängnishaft exemplifiziert und verifiziert. Paulus präsentiert und beweist sich als Vorbild an ,Niedrigkeit' und kann so auch von den Philippern eine religiöse, am Vorbild Christi und Pauli orientierte und somit ethisch aktualisierte und erweiterte Haltung und Übung der Demut fordern. Die Selbstbezeichnung als „Sklave“ in Phil 1,1 ist also weit mehr als eine rein formale beziehungsweise epistolare Selbststilisierung im Präskript. Vielmehr exemplifiziert Paulus besonders gerade mit Hilfe der Rollenwechsel, die er in Phil 1-2 vollzieht, wie er selbst sich in verschiedenen Haltungen in die ,Niedrig-Gesinnung' einübt, die das Konzept der $\tau \alpha \pi \varepsilon เ v \circ \phi p \circ \sigma \nu \dot{v \eta}$ (Phil 2,3) impliziert. So erhält das paulinische Vorbild für die Philipper eine paradigmatische Funktion. Die Orientierung an Paulus aktualisiert und erweitert die Orientierung an Christus. Zugleich wird die von den Philippern praktizierte Niedrig-Gesinnung das Beispiel des Paulus wiederum verifizieren und seinen Status als doulos Christi so bestätigen.

Die briefliche Selbstinszenierung des Paulus als Sklave sagt demnach Wesentliches über den literarischen und theologischen Charakter des Philipperbriefs aus. Das wird besonders im Vergleich mit den vorhergehenden paulinischen Briefen deutlich: In der korinthischen Korrespondenz begegnet (noch) keine

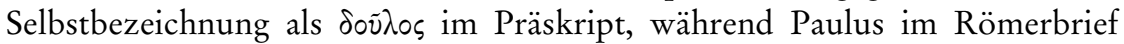
bereits einleitend mit der „Sklaven“-Rolle befasst ist. Haben wir es hier mit unterschiedlichen brieflich-formalen Nuancierungen zu tun, oder lassen die variierenden Formen der Selbstbezeichnung auf unterschiedliche Diskurse zurückschließen, in denen Paulus jeweils als Briefeschreiber agiert?

Wie ich an anderer Stelle ausführlich gezeigt habe, deutet Paulus in der korinthischen Korrespondenz seine Arbeit als Apostel und Gemeindeleiter „in einer stetigen Paradoxie von Freiheit und Knechtschaft" (z.B. 1 Kor 9,1.19: $\dot{\lambda} \lambda \varepsilon \dot{\theta} \theta \varepsilon p \circ \varsigma$, $\dot{\varepsilon} \delta \circ \dot{\lambda} \lambda \omega \sigma \alpha) .{ }^{59}$ Anders stellt sich die Situation offenbar im Römerbrief dar, wo sich

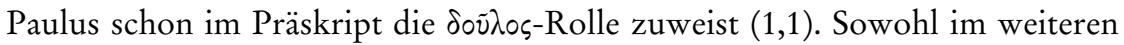
Verlauf des Präskriptes (bes. 1,5-7) als auch in Röm 6 und 12-14 setzt sich Paulus offensiv mit der rechten Haltung des $\delta \circ \nu \lambda \varepsilon v ่ \varepsilon เ v$ auseinander. Er wirbt für den Dienst in der Gerechtigkeit $(6,19)$ und ermahnt zu einer Gemeinschaft, die sich am Dienst für den Kyrios orientiert $(12,11)$ und sich dabei Christus selbst zum Vorbild nimmt $(15,1 \mathrm{ff}$.). Die daraus erwachsende Gemeindeethik und -paränese

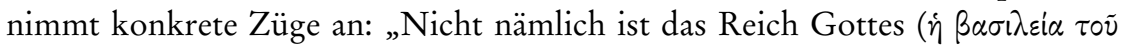
$\theta \varepsilon \circ \tilde{v})$ Essen und Trinken, sondern Gerechtigkeit und Friede und Freude im Hei-

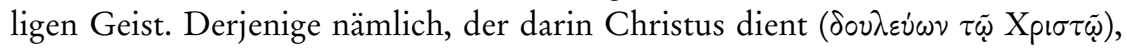

\footnotetext{
${ }^{58}$ Vgl. Bonhöffer 1911, 65; Becker 2015, 120 ff.

${ }^{59}$ Becker 2015, 133. - Zur Funktion paradoxer Rede und dem rhetorischen Umgang mit geschwächter Glaubwürdigkeit: Lausberg 1990, $\$ 37$.
} 


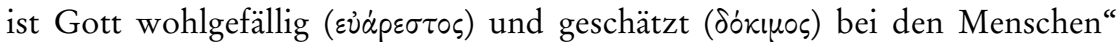
$(14,17 \mathrm{f} .)^{60}$

Obgleich sich Röm 12-15 und Phil 1-2 hinsichtlich der narrativen Form und der textlichen Pragmatik deutlich unterscheiden - Paulus bereitet hier seinen Besuch in der caput mundi vor und erläutert in diesem Zusammenhang sein Missionsverständnis und -programm, während er dort, in Phil 1-2, persönliche und ethische ultima verba aus seiner Gefangenschaft formuliert -, stehen sich beide Brief(teil)e erstaunlich nahe. In beiden Texten nämlich entwickelt Paulus „den motivischen Zusammenhang von Unterordnung unter Christus, der Übung von Niedrig-Gesinnung, die jeweils am Vorbild expliziert wird, und dem Bemühen um die ekklesiale Gerechtigkeit“ ". ${ }^{61}$

Lässt sich womöglich gerade im oben skizzierten programmatischen Umgang des Paulus mit dem semantischen Feld der Niedrigkeit ( $\delta \circ v \lambda-, \tau \alpha \pi \varepsilon v-)$ eine ,Entwicklung im paulinischen Denken` erkennen, die von der korinthischen Korrespondenz zum Römer- und Philipperbrief führt? Wir können diese Frage hier nicht weiter vertiefen, wohl aber konstatieren, dass die Selbstbezeichnung des

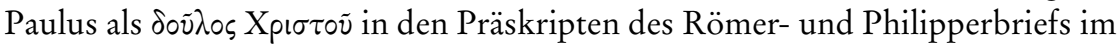
Unterschied zur korinthischen Korrespondenz, wo sich Paulus ja gerade nicht mit Hilfe dieses Syntagmas stilisiert, ${ }^{62}$ der übrigen Konzeption von Sklavendient und Niedrig-Gesinnung in beiden Briefen korrespondiert. Die Selbststilisierung des Paulus als doulos im brieflichen Präskript ist also nicht zufällig, sondern intentional gewählt. Mit dieser Selbstbeschreibung fasst Paulus sein apostolisches Selbstverständnis, das sein Briefeschreiben nach Rom und Philippi leitet, programmatisch zusammen. Er schreibt sich so eine durch Sklavendienst und Niedrigkeit bestimmte Autorrolle zu, die er in den Dienst der Verkündigung und Gemeindeleitung, der mitunter leidvollen Arbeit am Evangelium stellt. Die teils implizite (Wechsel von Autorrollen), teils explizite (besonders Phil 2,6-11 als Intertext zu Phil 1,1) theologische und ethische Entfaltung des doulos-Konzeptes in weiten Teilen des Philipper-, aber auch des Römerbriefs autorisiert die eingangs gewählte Selbstbezeichnung, so wie diese umgekehrt auf die folgenden Abschnitte des Briefeschreibens sachlich bereits vorverweist und einwirkt.

Die in Phil 1,1 und Röm 1,1 gewählte epistolare Selbststilisierung des Paulus bietet daher nicht weniger als eine vorweggenommene oder komprimierte $\mathrm{Zu}$ sammenfassung paulinischer Argumentation. Die von Paulus angenommene Autorrolle korrespondiert einem wichtigen brieflichen Argument: dem rechten

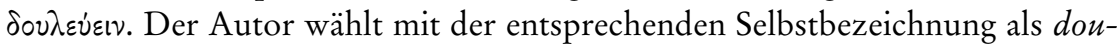

${ }^{60}$ Vgl. hierzu noch einmal: Becker 2015, bes. 134-136.

${ }^{61}$ Becker 2015, 136.

62 In den von Kraus 2013, 233 genannten Stellen - 2 Kor 4,5 und 1 Kor 9,19 - verwendet

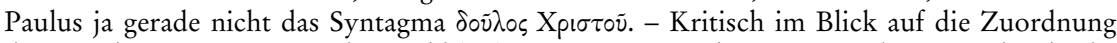

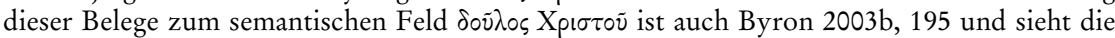
genannten Belege im Lichte des philosophischen Diskurses über die „obligation of obedience“. 
los für sich eine Rolle, die er sachlich an das Handeln Christi rückbindet und den Gemeinden theologisch und ethisch als dauerhaft nötigen Maßstab ihres Denkens und Handelns vor Augen stellt. So wird die gewählte Autorrolle zum brieflichen Argument, und Paulus selbst, nicht Christus allein, wird zum rechten, literarisch konfigurierten und so generationenüberschreitenden Vorbild für die Einübung in die frei gewählte $\tau \alpha \pi \varepsilon v \nu \circ \phi \rho \circ \sigma \dot{v} \eta$.

\section{Literaturverzeichnis}

Alföldy, G. (1981). „Die Freilassung von Sklaven und die Struktur der Sklaverei in der römischen Kaiserzeit," in: H. Schneider, Hg., Sozial- und Wirtschaftsgeschichte der römischen Kaiserzeit. Darmstadt (WdF 552). 336-371.

Alföldy, G. (2011). Römische Sozialgeschichte. Stuttgart.

Baltzer, K. (2000). „Art. Gottesknecht,“ in: $R G G 3,1224-1226$.

Becker, E.-M. (2013a). „Die Person des Paulus,“ in: F. W. Horn, Hg., Paulus Handbuch. Tübingen. 128-134.

Becker, E.-M. (2013b). „Die Person als Paradigma politisch-ethischen Handelns: Kriton 50a und Phil 1,23 f. im Vergleich, “ in: P-G. Klumbies; D. S. du Toit, Hgg., Paulus - Werk und Wirkung: FS für Andreas Lindemann zum 70. Geburtstag. Tübingen. 129-148.

Becker, E.-M. (2015). Der Begriff der Demut bei Paulus. Tübingen.

Bickerman, E.J. (1986). Studies in Jewish and Christian History. Part Three. Leiden (AGAJU 9).

Blank, J. (1968). Paulus und Jesus. München (StANT 18).

Bonhöffer, A. (1911). Epiktet und das Neue Testament. Gießen (RGVV 10).

Brookings, T. (2017). „(Dis)correspondence of Paul and Seneca on Slavery,“ in: J. Dodson; D. Briones, ed., Paul and Seneca in Dialogue. Ancient Philosophy \& Religion 2. Leiden. 179-207.

Brown, M.J. (2001). „Paul's Use of DOULOS XRISTOU IHSOU in Romans 1:1,“ in: JBL 120.723-737.

Byron, J. (2003a). Slavery Metaphors in Early Judaism and Pauline Christianity: A Traditio-Historical and Exegetical Examination. Tübingen (WUNT 2.162).

Byron, J. (2003b). „Slave of Christ or Willing Servant? Paul's Self-Description in I Corinthians 4:1-2 and 9:16-18,“ in: Neot. 37, 179-198.

Byron, J. (2008). Recent Research on Paul and Slavery. Sheffield.

Dinter, M.T. (2013). „Slavery in Flavian Epic,“ in: G. Manuwald; A. Voigt, edd., Flavian Epic Interactions. Berlin/Boston (Trends in Classic 21). 177-193.

Ebel, E. (2013). „Ein ehemaliger Sklave spricht über Sklaverei und Freilassung. Zum sozialgeschichtlichen Hintergrund von Epiktets Diatribe über die Freiheit,“ in: S. Vollenweider et al., Hgg., Epiktet, Was ist wabre Freibeit? Diatribe IV,1 eingeleitet, übersetzt und mit interpretierenden Essays versehen von S. Vollenweider et al. Tübingen (SAPERE 22). 79-96.

Frede, D. (2013). „Form and Argument in Aristotle’s Nicomachean Ethics: Some Observations, “ in: M. Erler; J. E. Heßler (Hgg.), Argument und literarische Form in antiker Philosophie. Akten des 3. Kongresses der Gesellschaft für antike Philosophie 2010. Berlin/Boston (Beiträge zur Altertumskunde 320). 215-237. 
Frey, J. (2005/2009). „Paulus und die Apostel. Zur Entwicklung des paulinischen Apostelbegriffs und zum Verhältnis des Heidenapostels zu seinen ,Kollegen““ in: E.-M. Becker; P. Pilhofer, Hgg., Biographie und Persönlichkeit des Paulus. Tübingen (WUNT 187). 192-227.

Greenblatt, S. (1980). Renaissance Self-Fashioning: From More to Shakespeare. Chicago.

Harrill, J.A. (1995). The Manumission of Slaves in Early Christianity. Tübingen (HUTh 32).

Hengel, M. (1996). „Zur Wirkungsgeschichte von Jes 53 in vorchristlicher Zeit,“ in: B. Janowski; P. Stuhlmacher, Hgg., Der leidende Gottesknecht. Jesaja 53 und seine Wirkungsgeschichte mit einer Bibliographie zu Jes 53. Tübingen (FAT 14). 49-91.

Hermissson, H.-J. (2003). Deuterojesaja. 2. Teilband Jesaja 45,8-49,13. Neukirchen-Vluyn (BKANT XI/2).

Hester, J. D. (2004). „The Rhetoric of Persona in Romans: Re-reading Romans 1:1-12,“ in: S.E. McGinn, ed., Celebrating Romans: Template for Pauline Theology: Essays in Honor of R. Jewett. Grand Rapids. 83-105.

Hezser, C. (2005). Jewish Slavery in Antiquity. Oxford/New York.

Hofius, O. (1993). „Das vierte Gottesknechtslied in den Briefen des Neuen Testaments,“ in: NTS 39: 414-437.

Janowski, B.; Stuhlmacher, P. (1996) (Hgg.). Der leidende Gottesknecht. Jesaja 53 und seine Wirkungsgeschichte mit einer Bibliographie zu Jes 53. Tübingen (FAT 14).

Jewett, R. (2007). Romans: A Commentary. Minneapolis (Hermeneia).

Koch, D.-A. (2014). Geschichte des Urchristentums. Ein Lebrbuch. Göttingen.

Kraus, W. (2013). „Die Anfänge der Mission und das Selbstverständnis des Paulus als Apostel der Heiden, “ in: F. W. Horn, Hg., Paulus Handbuch. Tübingen. 227-237.

Lampe, P. (2013). „Erster Korintherbrief,“ in: F. W. Horn, Hg., Paulus Handbuch. Tübingen. 172-185.

Lausberg, H. (1990). Elemente der literarischen Rhetorik. Eine Einfübrung für Studierende der klassischen, romanischen, englischen und deutschen Philologie. Ismaning.

Lohse, E. (1996). Paulus. Eine Biographie. München.

Marchial, J.A. (2011). „The Usefulness of an Onesimus: The Sexual Use of Slaves and Paul's Letter to Philemon, “ in: JBL 130: 749-770.

Martin, D. B. (1990). Slavery as Salvation: The Metaphor of Slavery in Pauline Christianity. New Haven/London.

Martin, D. B. (1991). Slave of Christ, Slave of All: Paul's Metaphor of Slavery and 1 Corinthians 9. Ann Arbor.

Merendino, R. P. (1980). „Jes 49 1-6: ein Gottesknechtslied?,“ in: ZAW 92: 236-248.

Page, S.H.T. (1985). „The Suffering Servant Between the Testaments,“ in: NTS 31: 481497.

Rapp, C. (2013). „Sprachliche Gestaltung und philosophische Klarheit bei Aristoteles, “ in: M. Erler; J. E. Heßler, Hgg., Argument und literarische Form in antiker Philosophie. Akten des 3. Kongresses der Gesellschaft für antike Philosophie 2010. Berlin/Boston (Beiträge zur Altertumskunde 320). 283-303.

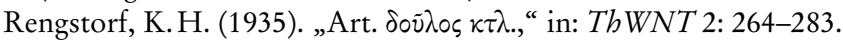

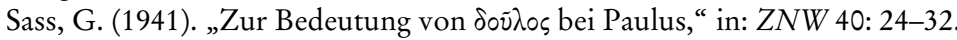

Schnelle, U. (2014). Paulus. Leben und Denken. Berlin/Boston (de Gruyter Studium).

Štaerman, E. M. (1981). „Der Klassenkampf der Sklaven zur Zeit des römischen Kaiserreiches, " in: H. Schneider, Hg., Sozial- und Wirtschaftsgeschichte der römischen Kaiserzeit. Darmstadt (WdF 552). 307-335. 
Talbert, C.H. (1967). „The Problem of Pre-Existence in Philippians 2 6-11, “ in: JBL 86: 141-153.

Theissen, G. (1989). „Theoretische Probleme religionssoziologischer Forschung und die Analyse des Urchristentums, “ in: ders., Studien zur Soziologie des Urchristentums. Tübingen (WUNT 19). 55-76.

Theissen, G. (2011). „The Social Setting of Pauline Communities, “in: S. Westerholm, ed., The Blackwell Companion to Paul. Malden/Oxford. 248-267.

Turner, G. (2013). „The Christian Life as Slavery: Paul’s Subversive Metaphor,“ in: The Heythrop Journal 54: 1-12.

Vollenweider, S. (2013). „Toren als Weise. Berührungen zwischen dem Äsoproman und dem 1. Korintherbrief,“ in: P.-G. Klumbies, D.S. du Toit, edd., Paulus - Werk und Wirkung. FS A. Lindemann zum 70. Geburtstag, Tübingen. 3-20.

Vos, C. de (2001). „Once a Slave, Always a Slave? Slavery, Manumission and Relational Patterns in Paul's Letter to Philemon,“ in: JSNT 82: 89-105.

Westermann, C. (1986). Das Buch Jesaja. Kapitel 40-66. Göttingen/Zürich (ATD 19).

Wilk, F. (1998). Die Bedeutung des Jesajabuches für Paulus. Göttingen (FRLANT 179).

Wischmeyer, O. (2015). Liebe als Agape. Das frübchristliche Konzept und der moderne Diskurs. Tübingen.

Wischmeyer, O. (2014). „Romans 1:1-7 and Mark 1:1-3 in Comparison. Two Opening Texts at the Beginning of Early Christian Literature," in: E.-M. Becker; T. Engberg-Pedersen; M. Müller, edd., Mark and Paul, Comparative Essays Part II: For and Against Pauline Influence on Mark. Berlin/Boston (BZNW 199). 121-146.

Wolter, M. (2011). Paulus. Ein Grundriss seiner Theologie. Neukirchen-Vluyn.

Wolter, M. (2014). Der Brief an die Römer. Teilband 1: Röm 1-8. Neukirchen-Vluyn (EKK 6/1).

Wright, N.T. (2013). Paul and the Faithfulness of God: Parts I-IV (2 vols.). London.

Zahn, T. (1894). Der Stoiker Epiktet und sein Verbältnis zum Christentum. Rede beim Antritt des Prorektorats der Königlich Bayerischen Friedrich-Alexander-Universität Erlangen am 3. November 1894 gehalten. Erlangen.

Zeller, D. (2010). Der erste Brief an die Korinther. Göttingen (KEK 5).

Zetterholm, M. (2017). „Slave and Free: Hermeneutical Reflections on Paul's Use of the Slave-Master Metaphor, “ in: E.-M. Becker; K. Mtata, edd., Pauline Hermeneutics: Exploring the „Power of the Gospel“. Leipzig. 47-59. 


\title{
Josephus as Narrator
}

\author{
Jan Willem van Henten
}

This contribution focuses upon the self-presentation of the Jewish historian Joseph ben Matityahu-commonly known as Flavius Josephus-as narrator. I will discuss Josephus' profile as historian and narrator in the introductions to his writings as well as in selected passages of the main body of his works. Josephus adopts a classical authorial profile by building on Thucydidean ideals, but he articulates it in connection with his role as a Jewish historian in Rome with a specific mission. He writes from his own experience, identifies with the Jewish people and laments the calamities that befell his nation. In Antiquities he emphasizes the moral implications of the divine laws revealed by Moses and highlights that God punishes or rewards the follow-up of these laws accordingly. Josephus also claims to have the expert knowledge of a Jewish priest, which lends authority to his interpretation of the events as well as his role as a historian.

\section{Introduction}

Flavius Josephus, born as Joseph ben Matityahu in $37 \mathrm{CE}$, was a Jewish priest who acted as one of the commanders of Galilee during the Jewish rebellion against Rome (66-70 CE) until his arrest at Jotapata/Yodfat in 67. After his prediction that the Roman commander Vespasian would become emperor materialized, he was rewarded by the new emperor and spent the rest of his life in Rome as a historian. ${ }^{1} \mathrm{He}$ wrote four works: a history of the armed conflict between the Jews and Rome (The Jewish War), a history of the Jewish people starting from the creation of the world up to Josephus' own time (The Jewish Antiquities), an autobiographical work that demonstrates his credentials (The Life) and, finally, an apologetic work called Against Apion. ${ }^{2}$ Josephus presents himself explicitly as a Jewish historian: he is a prominent member of the Jewish people, which history he writes (e. g. Ant 1.4), and he is keen on explaining Jewish practices for non-Jews and pointing out that the God of Israel determines what happens to

\footnotetext{
${ }^{1}$ Rajak 1983, 1-45; 144-222; Bilde 1988, 13-60; Den Hollander 2014.

${ }^{2}$ Bilde 1988, 61-122.
} 
Jews and non-Jews. Without Josephus we would know hardly anything about the history of the Jews from the mid-Hasmonean period until the destruction of Jerusalem (ca. 125 BCE-70 CE) - the period that saw both the rise and fall of Jewish statehood and the emergence of Christianity.

As discussed below, Josephus aimed for elitist non-Jewish and Jewish readers in Rome, but there is not much evidence of a Jewish reception, whether in Greek or Hebrew, of Josephus' writings in antiquity. Passages in Greco-Roman writings show that several pagan authors were familiar with at least sections of Josephus' works. ${ }^{3}$ Josephus' works have, however, been preserved and transmitted by the Christians, among whom he was extremely popular. An important reason for the early Christians to read Josephus' works was, of course, their content. Josephus is the most important external source for the origins of Christianity. He briefly mentions John the Baptist and Jesus' brother James, and even includes a passage about Jesus as the Messiah, the so-called Testimonium Flavianum (Ant 18.63-64). ${ }^{4}$ As a matter of fact, the early Christians found confirmation in Josephus for many other important issues of the New Testament message, including the prediction that the Jerusalem Temple had to be destroyed. From the third century CE onward many Christian authors refer to Josephus and several of them paraphrase or quote him, sometimes extensively and systematically. ${ }^{5}$ His role as external source that confirms the truth of the New Testament message ultimately led to his characterization as fifth evangelist by Christian scholars in the early modern period. ${ }^{6}$ The Church father Eusebius praises the accurateness of his report (Hist. Eccl. 3.5.4). His elaborate quotations from The Jewish War, especially dramatic descriptions, may imply that the literary quality of Josephus' work was a second reason for the early Christians to study him. The Christian authors from the third and fourth century were often highly educated-which is not always acknowledged-and they greatly appreciated the literary quality of books that matched the standards of classical literature. Jerome's characterization of Josephus as the "Greek Livy" (Graecus Livius; Ep. 22.35) supports this observation. Jerome also notes in his summary of Josephus' works that he was found worthy of a statue in Rome because of his splendid talents. ${ }^{7}$

Scholars have long considered Josephus a mere copyist, who passed on materials transmitted to him without changing much. Recently, methodological

\footnotetext{
${ }^{3}$ See esp. Tacitus, Hist. 5.13; Suetonius, Vesp. 5,6, Cassius Dio 66.4 and the Epitome of Aelius Herodian.

${ }^{4}$ Carleton Paget 2001; Whealey 2003.

${ }^{5}$ Survey in Schreckenberg 1972. See also Hardwick 1989; Inowlocki 2006.

${ }^{6}$ Berggren 1862, xii; Keim 1878, 1; Schreckenberg 1980, 179; Meijer 2016, 17. The Dutch translator of Josephus Lambert van den Bos compares Josephus already to an evangelist in his preface (p. 2) to the reader ("dat hy ... byna een slagh van een evangelist moet zijn ...") from 1665, van den Bos 1679.

7 ... et ob ingenii gloriam statuam quoque Romae mervit, De viris illustribus $13 ;$ PL 23.662-3.
} 
debates and literary analysis have revealed that Josephus was a historian with a complex agenda of his own. ${ }^{8}$ He was a Jewish author who had contemporary interests, both personal and collective. The local elite in Flavian Rome interested in Jewish culture must have been prominent among his targeted readers, including the group of the wealthy freedman Epaphroditus, who was his literary patron. ${ }^{9}$ Some of his Roman readers may have been Jews, especially those members of the Herodian family living in Rome and those connected with them. ${ }^{10}$ Hippolytus of Rome (died 235 CE) was the first Christian author living in Rome who seems to have been familiar with Josephus' works. ${ }^{11}$

Narratology offers a fresh perspective on noteworthy difficult passages and helps to articulate Josephus' role as narrator. The more we read Josephus from a literary perspective and compare him with other Greek narrative texts, the more we may tend, with good reason, to appreciate his own contribution as author, i. e. the way he tells his story, and his interpretation of the war against Rome, which is strongly determined by his religious and political views. Narratological analysis shows that Josephus is an overt narrator with a mission. ${ }^{12} \mathrm{He}$ claims special knowledge of the war between the Jews and the Romans in 66-70 CE, which ultimately led to the destruction of the Jerusalem Temple. He also claims to know that the course of events had God's approval and that the Jews, therefore, had to accept Roman rule. The dramatic story of the defence and capture of the city of Jotapata/Yodfat (reported in book 3 of the Jerwish War), during which Josephus surrendered to the Romans, proves this point. Josephus attests as a character in the story that the Romans had to win the war because God supported them. His surrender proved that he was a servant of God and not a traitor (Bell 3.354). In this way Josephus the narrator also offers a divine legitimation for the behaviour of Josephus the general (see also below).

In the following pages I will focus on Josephus as narrator. To put it very simply: my focus will be not so much on what Josephus tells us, but on bow he tells his story, i.e. his style of writing and the narrative techniques he uses. ${ }^{13}$ In this contribution I will focus on the question how Josephus as narrator manifests himself in his narrative. Narratologists distinguish between several types of narrators: 1) external narrators 2) secondary narrators, i. e. characters telling stories, and 3) instances of metalepsis, where the world of the narrator and characters

\footnotetext{
${ }^{8}$ See especially Mason 2011.

${ }^{9}$ Mason 1998; 2003; 2005; den Hollander 2014.

${ }^{10}$ Goodman 1994, 329-38; Mason 2000, xix-xx, xxiv; 2005, 84-90; den Hollander 2014, 263-79; cf. Price 2005; Curran 2011.

${ }^{11}$ Schreckenberg 1972, 72-3.

12 Landau 2006.

${ }^{13}$ My methodology is based on narratological theories and insights which have become classics (e.g. Genette 1980; Bal 1997) and have also been implemented in the Studies in Ancient Greek Narrative project: de Jong, Nünlist, Bowie 2004; De Jong, Nünlist, 2007; de Jong 2012.
} 
merge. ${ }^{14}$ Josephus' way of presenting the story is fascinating, because he is a participant in some of the events he recounts, but in the wake of Thucydides and Caesar he also adopts the role of an external narrator. I will take the prologues of all four of Josephus' writings as starting point for my analysis and then continue with an eclectic discussion of passages from the main body of his writings in order to see how they relate to Josephus' remarks in the introduction to his works. One may expect that an overt external narrator is explicit about his aims and that his explanation of these aims in the introductory passages are matched by the main narratives, but it has been observed already that this is not always the case in Josephus. ${ }^{15}$ In a final section I will discuss the results of my analysis from the perspective of the main questions that underlie the present volume.

\section{Self-presentation in Josephus' introductions}

In the prologue to The Jewish War, the history of the first Jewish revolt against Rome presented as the biggest war ever (Bell 1.1), ${ }^{16}$ Josephus the narrator puts his cards clearly on the table. ${ }^{17}$ "First revolt" is hardly an appropriate phrase for the conflict Josephus describes, because the themes and key words introduced in the prologue indicate that apart from rebellion banditry and internal corruption are recurring issues already in the pre-history of the war narrated in books 1 and 2. Josephus first introduces the kind of history he aims to present to his narratees, by contrasting it with the work of other authors who were not present during the events (1.1) as well as those who were present but distort the truth by either flattering the Romans too much or depicting the Jews too negatively out of hatred of them (1.2; also 1.6-9). ${ }^{18}$ Instead, Josephus aims at a precise report ( $\tau$ ò

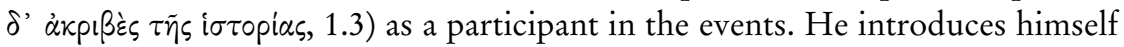
by emphasising his position as "a Hebrew by birth and a priest from Jerusalem" and by referring to his expert knowledge as one who "at the opening of the war myself fought against the Romans and in the sequel was perforce an onlooker"

\footnotetext{
${ }^{14}$ See de Jong 2014, 17-45 for an overview and bibliography; also de Jong, Nuenlist, Bowie 2004, esp. pp. 1-10. Josephus is not discussed in this volume.

${ }^{15}$ E. g. Bilde 1988, 108; Mason 2005, 96, who indicates that the War's prologue focuses strongly on Roman history and Roman protagonists, which is not matched by the main narrative.

${ }^{16}$ This remark implies already that Josephus is following the footsteps of Thucydides (1.1), who makes a similar claim (Marincola 1997, 17; 198-99; Rajak 1998, 223). See also Polybius 1.63 on the First Punic War and 2.31, 35 on the War against the Celts (Bilde 1998, 203).

${ }^{17}$ Bilde 1988, 74. About prologues in ancient Greek historiography, see Lieberich 1899; Earl 1972.

${ }^{18}$ Mader 2000, 153, argues that by focusing on the subjects of the Roman empire Josephus aims at neutralizing "potential anti-Jewish sentiment in the post-war years". Tacitus, Hist. 1.1.1-3, also comments that other historians have distorted the truth because of hatred or flattery, Swoboda 2014, 197.
} 
(Bell 1.3). ${ }^{19}$ In this way Josephus flags his work right at the start by two key points of ancient historiography: autopsy (also 1.15-16, 18; Apion 1.55$)^{20}$ and the Thucydidean ideal of ákpißsı (also 1.6, 9, 26; 7.454-5; Ant 3.230; 8.56; 9.208). ${ }^{21}$ One of the ways in which Josephus obtains this $\alpha$ xpi $\beta \varepsilon ı \alpha$ is by choosing a subject from the recent period and not from the more remote past, just like, as he himself emphasises, the Greek historians had done (Bell 1.13). This remark can be taken as a veiled reference to Thucydides, who had rebuked Herodotus for choosing such a remote subject. ${ }^{22}$

While briefly indicating the context and the protagonists of the war (Bell 1.4-9), Josephus adds a dimension to his own role as a participant: he points to his personal sufferings and announces that he will lament the calamities that be-

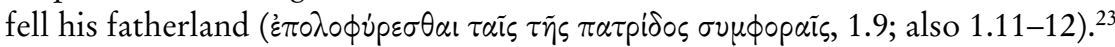
This turn, which creates a tension with the ideal of factual accuracy, ${ }^{24}$ forms at the same time the transition to the central themes of the history of the Jewish War. Josephus' prologue already implies that the intervention of the Romans, with its devastating outcome, was brought about by internal conflicts and the tyrannical behaviour of Jewish leaders. "Sedition" or "internal war" $(\sigma \tau \dot{\alpha} \sigma \iota \varsigma)$ is mentioned several times in the prologue as a prominent theme $(1.10,25,27) .{ }^{25}$ Tyranny is a second central theme, highlighted by several anonymous references to Jewish tyrants ( $\tau$ ípavvol, 1.10, 11, 24, 27-28). ${ }^{26}$ Thirdly, the Jewish rebels are associated

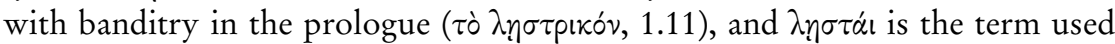

${ }^{19}$ Chapman 2005: 290. Josephus not only points to autopsy but also to his own practical experiences, which is an important motif in Polybius, Marincola 1997, 134-36.

${ }^{20}$ Rajak 1983, 75-76; Marincola 1997, 63-86; 90; 145.

${ }^{21}$ Van Henten and Huitink 2007, 213-14. Of course, the two points strengthen each other

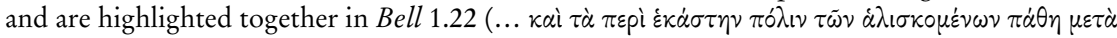

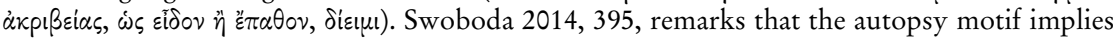
that Josephus' autobiographical sections are truthful. See also Schwartz 1989-1990, 128, and cf. Apion 1.50-52. In 1.30 Josephus highlights $\alpha \lambda \eta^{\prime} \theta \varepsilon \iota \alpha$ "truth" as another key phrase, which is connected with áxpißzı (Lindner 1972, 135; Mader 2000, 152-57; Price 2005, 110).

${ }^{22}$ Thucydides 1.20-2 and Hornblower 1991 ad 1.20.3; 1.21.1; 1.22.4. About Thucydides as the first writer of contemporary history, see Marincola 2001, 63-65.

${ }^{23}$ An important aim of Josephus is, therefore, to evoke compassion among Greek and Roman readers, Swoboda 2014, 238; 417-426. See also Lindner 1972, 132-41; Mader 2000, 2-4; Price

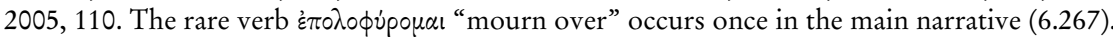
Landau 2005, 176 fn. 48, notes that Josephus explicitly includes emotions in his history, which she sees as a unique feature (i. e., the explicit appeal to emotions).

${ }^{24}$ Mader 2000, 2-3. Both aims are in contrast with each other in Bell 5.20.

${ }^{25}$ Josephus further highlights this theme by making $\sigma \tau \dot{\alpha} \sigma \varsigma s$ the first word of the subsequent narrative (1.31). The theme is often associated with Thucydides' histories (especially his report about the civil war at Corcyra): Rajak 1983, 91-94; Mason 2005, 97-99; Price 2001, 11-78. Cf. Brighton 2009, 24-28. Mader 2000, 55-103 argues for an ongoing intertextual interplay between Bell 4.121-282 and Thucydides.

${ }^{26}$ This motif links up with Josephus' depiction of the rebel leaders as tyrants in the main narrative: Menahem, the son of Judas from Galilee, and Simon bar Giora (Bell 2.442, 652; 4.508; cf. $2.275 ; 4.165-166,172,178,208,258,397,508 ; 7.261$. Brighton 2009, 78-83; 86. 
most commonly for the rebels in The War's main narrative. ${ }^{27}$ The introduction of these themes implies that Josephus conveys already in the prologue a message that the Jews themselves were to blame for their defeat by the Romans, which, as he explains later on, happened in line with the divine scenario. ${ }^{28}$

In the remaining paragraphs of the prologue (Bell 1.19-30) Josephus gives a summary of the events told in the main narrative, whereby he indicates that he will be short about the pre-history of the war (1.18). ${ }^{29}$ In this summary he repeats points made earlier on, but he also signals a new feature, namely that the narrative will be focused on Jerusalem with the Temple as central location. Antiochus IV's capture of Jerusalem as first event mentioned (1.19) highlights Jerusalem as focal point of the conflict and the geographical information later on culminates in Jerusalem with its defence systems and the Temple as its most prominent building (1.25-26; see also 1.27-28). This focus matches the centrality of the Temple in the main narrative $\mathrm{e}^{30}$ and is at the same time closely connected with Jerusalem as Josephus' place of origin and his being a priest mentioned already in 1.3, which strengthens the motifs of Josephus' personal involvement and his religious authority.

In the prologue to the Jewish Antiquities Josephus refers to his previous work (Ant 1.6), the Jewish War, and he once again adheres to Thucydidean ideals ( $\dot{\lambda} \lambda \dot{\eta} \theta \varepsilon 1 \alpha$ in $1.4 ; \dot{\alpha} x p i \beta \varepsilon 1 \alpha$ hinted at in 1.17). ${ }^{31}$ However, his presentation of this work at the start is considerably different from the prologue of the War. Josephus first indicates that there are several motives for writing an elaborate history (1.1-5). He mentions in passing his own involvement ("I learned from experience", $\pi \varepsilon i p \alpha \mu \alpha \theta \omega \dot{\omega}, 1.4)$ and criticizes competitors who distort the truth (1.4). In his first factual information about the current work (1.5) he quickly makes four points, which are all taken up again further on in the prologue: (1) it is aimed at all the Greeks (i. e., non-Jews? see also 1.9), ${ }^{32}$ (2) it concerns "our entire ancient

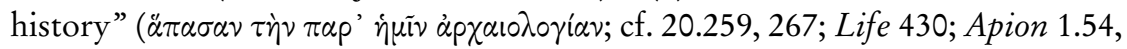

${ }^{27}$ Steve Mason and Mark Brighton convincingly argue that the semantic fields connected with $\sigma \tau \dot{\alpha} \sigma i \varsigma, \lambda \eta \sigma \tau \eta^{\prime} \varsigma, \tau \dot{p} p \alpha v v o \varsigma$ and related words cohere closely, which implies that Josephus' interpretation of the conflict with the Romans highlights the role of internal dissension and tyrannical behaviour of Jewish leaders (Mason 2005; Brighton 2009, 7; 60-2; 75-87; 86-92; 101-03).

${ }^{28}$ See, e. g., Bell 6.110, 250, 288.

${ }^{29}$ The pre-history is narrated in books 1 and 2 (2.1-292). Mason 2005, 95, characterizes the summary as a "Polybian-style table of contents" shaped "to appeal to Roman interests." See also Eckstein 1990.

${ }^{30}$ With Tuval 2013, 128.

${ }^{31}$ Swoboda 2014, 467. Antiquities is usually dated in 93-94 CE, based on Josephus' reference in Ant 20.267 to the present time as the 13th year of Domitian, which equals Josephus' 56th year. Discussion in Mason 2001, xv-xvi with fn. 1.

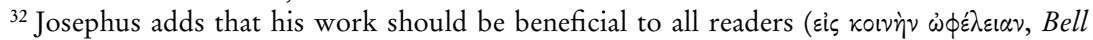
1.3), Swoboda 2014, 450. 
$127 ; 2.136,287),{ }^{33}$ and (3) the arrangement of the Jews' political constitution ( $\tau \dot{\eta} \nu \delta เ \alpha \dot{\alpha} \alpha \xi \iota \nu \tau \sigma \tilde{v} \pi \circ \lambda เ \tau \varepsilon \dot{v} \mu \alpha \tau \circ \varsigma)$, and that (4) in the form of a translation from the Hebrew Scriptures. ${ }^{34}$

The first issue concerns the audience aimed for in the Antiquities. The ongoing debate about this tends to lead to a consensus that this audience consisted primarily of the contemporary cultural elite in Rome (above). The word "E $\lambda \eta \eta v \varepsilon s$ has several connotations, including persons who speak Greek or are ethnic

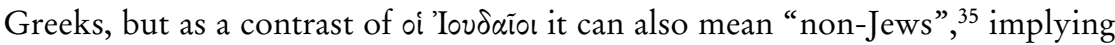
that the elite of literati at Rome that was aimed for was multi-ethnic and multilingual. The reference to the local wealthy freedman Epaphroditus as Josephus' patron (1.8-9; also Vita 430; Apion 1.1; 2.1,296), who is characterized as a lover of every kind of culture ( $\pi \alpha i \delta \varepsilon i \alpha, 1.8)$, supports this configuration of Josephus' main audience. ${ }^{36}$ Josephus hopes to produce a "useful and beautiful work" (1.9) for non-Jews: "I have taken in hand this present task thinking that it will appear to all

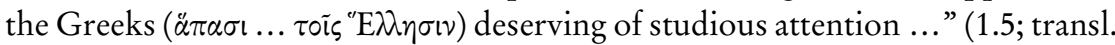
Feldman).${ }^{37}$ Josephus is confident about the non-Jewish interest in his enterprise, because he can point to a previous case that he considers to be a persuasive analogy with his own work (1.9-13). He first states: "Moreover, besides these considerations that I have stated, I took into account, not incidentally, both whether our ancestors were willing to transmit and whether some of the Greeks themselves were eager to know about our affairs" (1.9; transl. Feldman, my italics). Next he points at the Greek translation of the Jewish ("our”) books of the law produced at the invitation of King Ptolemy II with the permission of the Jewish high priest Eleazar. Finally he indicates self-confidently in this brief but telling passage that his own work will even surpass this translation, because he will transmit all of Jewish Holy Scripture (1.12-13). ${ }^{38}$

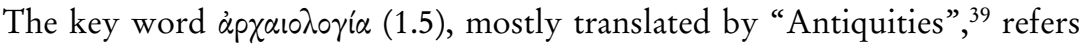
here to the history of the Jews from ancient times onward. The prologue (1.21,

${ }^{33}$ The Jewish laws and constitution are central topics in this history, Swoboda 2014, 469-470. history and constitution. On Josephus' pragmatic approach to history (cf. Ant 1.5: $\pi p \alpha \gamma \mu \alpha \tau \varepsilon i \alpha$ ), see Swoboda 2014, 472.

${ }^{34}$ In the reference to the Antiquities in the prologue of Against Apion (below) Josephus presents the content of Antiquities slightly differently: it is based on the Sacred Scriptures of the Jews and concerns the origin of the Jewish people, its orginal composition and the land possessed currently, and comprising a history of 5000 years (Apion 1.1; cf. the brief summary in Ant 20.259-261).

${ }^{35}$ Bauer and Aland 1988, 507; Windisch 1964, 507-511.

${ }^{36}$ So far, there has not been a conclusive identification of this Epaphroditus, see for a recent survey den Hollander 2014, 279-86.

${ }^{37}$ Sterling 1992 argues that Josephus aims at establishing Jewish group identity and presenting an exposé of Jewish history and culture for a non-Jewish audience. Mason 2000, xix, concludes that Josephus "expects gentile readers who are deeply interested in Judean culture".

${ }^{38}$ Krieger 2000, 259-61. Also: Swoboda 2014, 450-01; 467.

${ }^{39}$ Rajak 1982: “Archaeology”; Mason 2000, xxiii: "Judean Ancient Lore”. 
26) as well as the actual beginning of the main narrative (1.27) indicate that this history starts right at the beginning of humankind with the creation of the world, which implies that the history of the Jews is as old as the history of humankind.

The third point mentioned in 1.5 concerns the political organization or constitution of the Jews, which is further on connected with the divine laws revealed by Moses, which are briefly explained in 1.18-26. ${ }^{40}$ These laws are contrasted with legal systems based on myths or mythologies current among other people $(1.15,22)$. They have moral implications, which explains that

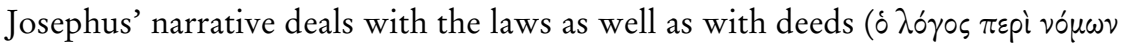
кai $\pi p \alpha \dot{\xi} \xi \varepsilon \omega \nu$ है $\chi \omega \nu$...). Josephus connects this with the philosophy of nature (the constitution reflects natural law; 1.18, 24-25) ${ }^{41}$ and the nature of God, who serves as the perfect model for humans $(1.19,23)$ and punishes and rewards humans on the basis of their deeds (1.20; also 1.14). ${ }^{42}$

The fourth point, that the ancient history of the Jews is based on Josephus'

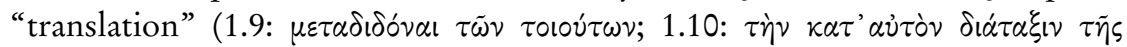

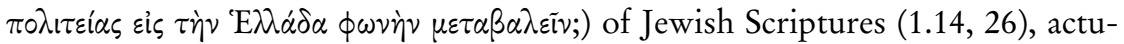
ally a paraphrase and not a translation, is explained in 1.10-17. This section of the prologue implies that Josephus' history highlights a moral message, as the following paragraphs about the laws indicate (1.18-26, above):

On the whole, one who would wish to read through it would especially learn from this history that those who comply with the will of God ( and do not venture to transgress laws that have been well enacted succeed in all things

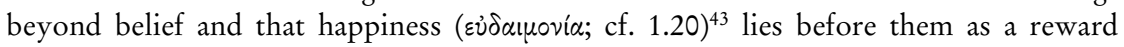
from God. But to the extent that they dissociate themselves from the scrupulous observance of these laws the practicable things become impracticable, and whatever seemingly good thing they pursue with zeal turns into irremediable misfortunes. (Ant 1.14; transl. L.H. Feldman, BJP)

The four points highlighted in the prologue of Antiquities imply that God's watchful care ${ }^{44}$ over all humans, Jews and non-Jews, is a leitmotiv in the narrative and a pivotal point in the moral lessons taught in the history. ${ }^{45} \mathrm{It}$ is significant

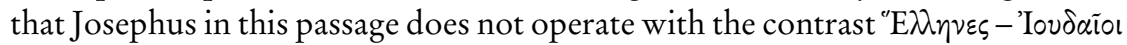
("non-Jews" - "Jews", cf. above). From his perspective the lessons to be learnt

${ }^{40}$ Schwartz 1983-1984; Feldman 1998: 144-48. Josephus sometimes characterizes the Jewish constitution as an ג̇ also Bell 1.170; 2.205). In Against Apion he also uses the term Orokpatía (2.165; Mason 2000: xxvi-xxvii).

${ }^{41}$ Hayes and Israel-Vleeschhouwer 2014.

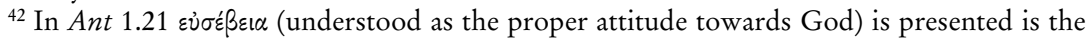
key virtue for humans.

${ }^{43}$ Mason 2000, xxix-xxxii, argues that Josephus also aims at presenting a Judean philosophy as an alternative for non-Judean (or non-Jewish) philosophies.

${ }^{44}$ Frequently indicated by the word $\pi$ póvol $\alpha$, but not in the prologue, Attridge 1976, 71-107.

45 Attridge 1976, 41-70; Feldman 1998, 74-5; Mason 2000, xvi, xxxii-xxxiii. 
from the history contained in Jewish scripture are relevant for all humans. By way of analogy this pragmatic approach to history implies that Jewish as well as non-Jewish readers would benefit from Josephus' own history, because by applying his "lessons" they could also be awarded with happiness, in line with the examples from Scripture. ${ }^{46}$

Josephus' third work, the Life (with the Antiquities, to which it is connected, usually dated in 93-94 CE), ${ }^{47}$ lacks an explicit prologue. Josephus' begins this work in the "I-form" with his very distinguished ancestry ( $\gamma \varepsilon$ v $\vee \varsigma)$, descending not only from a priestly family but also from the royal house of the Hasmoneans (Life 1-2). ${ }^{48}$ The implication of this ancestry is that as far as his descent concerned he was on a par with the highest political figures in Rome. The beginning of Life (1-12) points to a self-portrait of Josephus as a public figure, which focuses on his ancestry and education $\left(\pi \alpha i \delta \varepsilon^{\prime} \alpha\right)$. The work continues with Josephus' character $(\tilde{\eta} \theta \varsigma)$ as reflected in his public performance (12-413). It ends with a report about domestic affairs in Alexandria, the area of Jerusalem and Rome. ${ }^{49}$ The short epilogue (Life 430) confirms the impression evoked by the beginning of the work that it concerns the autobiography of Josephus, although the events narrated mainly concern a period of less than half a year (December 66-May $67)$, i. e., Josephus' active period as a leader and military commander. ${ }^{50}$ It gives a brief summary of the work and highlights Josephus' character once again, and it also mentions Epaphroditus as patron (above):

These, then, are the things that occurred throughout my entire life ( $\tau \dot{\alpha} \pi \varepsilon \pi p \alpha \gamma \mu \varepsilon \dot{\varepsilon} \alpha \mu \circ \mathrm{ol} \dot{\alpha} \dot{\alpha}$

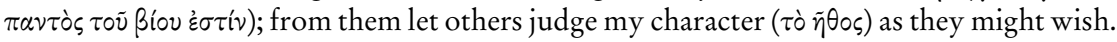
Having repaid you, Epaphroditus most excellent of men, the entire record of the Antiq-

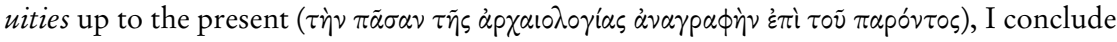
the narrative here. (430; transl. Mason)

The phrase "the entire record of the Antiquities up to the present" implies that the Life and the Antiquities are connected somehow. The Life may have functioning as an appendix to the major work of the Antiquities, as several scholars have argued (cf. Ant 1.5; 20.259, 267). ${ }^{51}$ Steve Mason goes one step further: by building on the work of David Barish he argues that Life is fully part of the Antiquities and that Antiquities 20.262-266, which reads as the conclusion of this

\footnotetext{
${ }^{46}$ Villalba i Varneda 1986, 254-255; 274.

${ }^{47}$ See footnote 31 .

${ }^{48}$ The entire work is consistently written as a first-person report. Discussions of previous scholarship into the Life: Bilde 1988, 104-113, and Mason 2001, xxvii-xxxiv.

${ }^{49}$ Mason 2001, xxi-xxiii. For other self-introductions in Josephus, see Bell 1.3 and Apion $1.54-55$.

${ }^{50}$ Bilde 1988, 107; Schreckenberg 1998, 762-770; Levick 1999, 40-41; Mason 2001, xxi; cf. Kokkinos 1998, 387-395.

${ }^{51}$ Bilde 1988, 104-105; Mason 1998; 2001, 173; Siegert, Schreckenberg, Vogel 2001, 1; 23 fn. 1; Schwartz 2007, 3-4.
} 
elaborate work (explicit in 20.267), also functions as the surrogate introduction to Life. ${ }^{52}$ One paragraph of this conclusion is closely connected with Life indeed:

Perhaps it will not be a provocation to jealousy, or strike ordinary folks as gauche, if I review briefly both my own ancestry and the events of my life while there are still those living who can offer refutation or corroboration. (Ant 20.266; transl. Mason).

This sentence indicates that Josephus intends to boast about his ancestry ( $\pi \varepsilon p i$

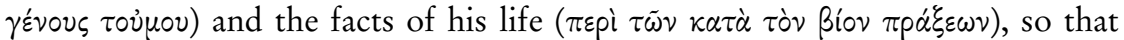
others can confirm or refute them. This matches the content and aim of Life and it can function as the introduction to this work, but this is not the only interpretation possible. It can also be a cross-reference to a work that Josephus still intends to write, as he notes in passing in Ant 20.267 and also does in the prologue of Antiquities (1.25). ${ }^{53}$ Daniel Schwartz acknowledges that Life and Antiquities are connected, but he argues that both works could also have been circulated independently and points to a parallel in Xenophon's related works Oeconomicus and Memorabilia. ${ }^{54}$

Two points still have to be mentioned. Steve Mason argues persuasively that the Life is an autobiography along the lines of certain Greek and especially Roman traditions, which implies that it is focused upon the aristocracy as a short and rather free self-portrait that presents the author's character and virtues during his public performance as a model for others who have to fulfil public duties. ${ }^{55}$ Sallust and Cicero offer similar autobiographies. Sallust includes a short autobiography at the beginning of his Catilinarian War (Bell. Cat. 3-4). Cicero ends his Brutus with a report about his own early life and training (Brut. 88.301-97.333). Another example concerns Nikolaos of Damascus, who probably started his universal history with his autobiography. ${ }^{56}$ Josephus' focus on his own role as a model commander and statesman implies that the Life shares with the Antiquities a practical focus on moral lessons (cf. Ant 1.14 above). Josephus' continuous references to his deeds and rewards drives this point home, because his acts were ultimately successful and rewarded by God (15-16; 83;

52 Barish 1978; Mason 2001, xiv-xv; 173. Similarly Swoboda 2014, 444 with fn 274. Previously, several scholars argued for two editions of Antiquities, the second one including Life, which would be reflected in a double ending (20.259-266 and 20.267-268): Laqueur 1920, 1-6; Thackeray 1929, 16-19; Gelzer 1952, 67-90; cf. Kokkinos 1998, 396.

${ }^{53}$ Ant 1.25 refers to a work about Customs and Causes, which most probably was never completed and is in any case unknown (see also Ant 4.198).

${ }^{54}$ Schwartz 2007, 3-4. The fact that Life follows in many of the Josephan manuscripts after the War and not after the Antiquities (Siegert, Schreckenber, Vogel 2001, $1 \mathrm{fn} .1$ ) may also indicate that Life circulated independently from Antiquities.

${ }_{55}$ Mason 1998; 2001: xxxiv-l; also Siegert, Schreckenberg, Vogel 2001, 3; 183-84.

${ }^{56}$ FGrH 2.90 F 131-139; Misch 1950, 307-315; Wacholder 1962, 37-51; Scardigli, Affortunati 1987, Mason 2001, xlii-xliii. 
208-209; 425), while his enemies failed and were appropriately punished (332; $372 ; 390-393) .{ }^{57}$

Josephus' final work, known as Contra Apionem (between 94 and ca. 105 CE), starts with a brief prologue (Apion 1.1-5; cf. also 1.58-59). ${ }^{58}$ Josephus presents this writing as a sequel to the Jewish Antiquities (Apion 1.1-2). The work was prompted because:

... a considerable number of people pay attention to the slanders spread by some out of malice, and disbelieve what I have written on ancient history ( $\tau \dot{\eta} \nu \alpha \dot{p} \chi \alpha 10 \lambda \circ \gamma$ í $\alpha \nu)$, but believe

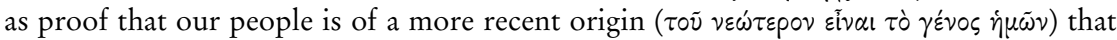
it was not thought worthy of any mention by the most renowned historians (Apion 1.2; transl. Barclay).

Josephus' aim in this writing, therefore, seems to be the refutation of these slanders about the Jews and the lies about their origin as well a presentation of the correct view of this ancient origin (see also Apion 1.3-4, 59). ${ }^{59}$ This purpose explains why some of the early readers of this work refer to it as On the Antiquity of the Jews [or: Judeans]. ${ }^{60}$ The audience aimed for according to Apion 1.2-3 concerns all those who want to learn the truth about the origin of the Jewish people, which implies mainly a non-Jewish audience because the Jews are obviously aware of this origin. Epaphroditus, Josephus' patron, characterized as a lover of truth (Apion 2.296), is part of this declared audience. ${ }^{61}$ Josephus announces that he will execute the task aimed for by offering (1) a report of other witnesses [probably non-Greek reports, cf. Apion 1.58-59] about the origin of the Jews that the Greeks consider most trustworthy, (2) a refutation of the slanders by demonstrating that they contradict themselves (Apion 1.4), and (3) an explanation why not many Greeks mention the Jews in their history as well as an attempt to inform those persons who are or feign to be ignorant of this history through the work of those who have not neglected it (Apion 1.5; cf. 1.3). The main topics of the work as highlighted by its prologue are, therefore, the evidence for the ancient origin of the Jews and the refutation of the accusations against the Jews. ${ }^{62}$ This is not the place to discuss the interconnections between the prologue and the remaining part of Against Apion in detail, ${ }^{63}$ but two issues should be briefly mentioned: (1) the content of book 1 relates less closely to the prologue than that of book 2 , and (2) the rhetorical type of the writing is debated. ${ }^{64}$ The second

\footnotetext{
${ }^{57}$ Mason 2001, xlix.

${ }^{58}$ Barclay 2007, 1-8; 41-42.

${ }^{59}$ Droge 1996, 125.

${ }^{60}$ Origen, C. Celsum 1.16; Hist. Eccl. 3.9.4, Mason 2000, xxiii.

${ }^{61}$ Barclay 2007, xlvi-xlvii. See also above p. 127 with fn. 34.

${ }^{62}$ With Barclay 2007, xvii.

${ }^{63}$ See Bilde 1988, 113-122; Barclay 2007, xvii-lxxii.

${ }^{64}$ I.e., does it belong to the dicanic or epideictic type of speech? Discussion in Kasher 1996; van Henten and Abusch 1996; Mason 1996, who argues that Apion is a logos protreptikos; Gerber 1997, 67-99; Barclay 1998; 2007, xxx-xxxvi.
} 
point is connected with a very significant transition in Apion 2.144-145 from an apologetic and polemical discourse focused on accusations against the Jews to a positive exposition of the illustrious Mosaic laws and Jewish religious practices. ${ }^{65}$

\section{Interconnections of prologues and main narratives}

Above I have characterized Josephus as an overt narrator who puts his cards clearly on the table. The introductory sections discussed confirm this observation and the main bodies of Josephus works indicate several techniques employed to articulate the voice of the narrator.

These include narratorial analepsis and prolepsis, which are frequent in the introductions and conclusions of books, the use of space and characterizations as well the habit to comment upon events or persons during or after narrating them. Here I can only elaborate some examples mainly taken from my earlier research into these phenomena.

Narratorial prolepsis often highlights important motifs in the narrative. As indicated above, rebellion ( $\sigma \tau \dot{\alpha} \sigma \iota \varsigma)$ is a leitmotiv in Josephus' narratives of both The War and The Antiquities. It is prominent in War's prologue (above) and re-occurs frequently in the story of the war. It is also prominent in Antiquities; the first major rebellion in this work, that of Korah against Moses, is announced in a prolepsis (Ant 4.11-13), which highlights the dreadful consequences of rebellion together with Moses' powerful and rescuing leadership in strongly rhetorical terms. This passage provides a universal blueprint, as it were, of the internal rebellion theme in the entire work of the Antiquities. The particularities of Korah's rebellion and Moses' counteractions are related further on ${ }^{66}$ Another important case in Josephus' narratorial announcements of future events linked with major themes in the story concerns the fall of Jerusalem and especially the destruction of the Temple narrated in book 6 of The War. Most events in The War lead up to this fall, and book 7 essentially functions as an epilogue to the destruction. We have seen already that the prologue of War's points to the destruction of the Temple in the summary of the events by means of an explicit announcement (1.28). When Josephus starts his actual narrative with the desecration of the Temple by Antiochus IV Epiphanes (Bell 1.31-33), he puts the Temple right in the centre of attention. By placing this brief episode at the beginning of the main narrative, Josephus is demonstrating that the Temple is not invulnerable to attack, thereby signalling its destruction as a theme. This theme is taken up also in the prelude to the history of the war, with a similar function

\footnotetext{
${ }^{65}$ Bilde 1988, 118; van Henten and Abusch 1996, 303; Barclay 2007, xix-xx.

${ }^{66}$ Ant 4.14-66; van Henten and Huitink 2007, 217.
} 
(Bell 1.148, 179). ${ }^{67}$ Narratorial prolepsis also highlights God's intervention time and again. One example concerns Herod the Great's disastrous relationship with his sons, which ends in the execution of three of the sons. A prolepsis indicates the involvement of the Deity called Tyche (Fortune) here, at the moment when the relationship deteriorates even further:

The affairs in his [Herod's] family were greatly troubled and the situation with his sons was much worse in this period. For, on the whole, in the earlier period, it had been quite easy to perceive how the greatest and most troublesome events that happen to humans were threatening the kingdom through Fortune, but they steadily increased and then got even a greater impact for the following reason ... (Ant 16.300; my translation).

Completing analepses in Josephus sometimes provide the narratees with essential background information on certain characters or events, as and when the information is needed. For example, when after a previous reference in Bell 2.575, Josephus' personal enemy John of Gischala enters the stage as actor, his previous career is briefly outlined in an analepsis (Bell 2.585-594). This analepsis also serves as a character-sketch, in which the narrator puts John in a bad light. ${ }^{68}$ Such analepses are often completing, but may also be repeating, in which case they serve to refresh the narratees' memory about a certain character when he or she is about to play an important role in the narrative once again. The frequent addition of a formula like "as I said (before)" marks such analepses explicitly as repeating. ${ }^{69}$ Short analepses also appear in a different context, namely when important characters "leave the stage", that is, when they die. In such brief "obituaries" the character's actions are recalled, often with some qualifying comments by the narrator. In connection with the death of Niger the Peraean (Bell 4.359), for example, Josephus remarks that this man had been "the bravest" in the war with the Romans. He reminds the narratees of the valour he had shown in conflicts narrated as far back as Bell 2.520 and 3.11-28. ${ }^{70}$ Such analepses as well as prolepses obviously overlap with characterization, because Josephus often passes judgment on his characters with the help of this device. As an overt narrator he reveals, for example, Samson's unfaithfulness to the ancestral customs because of the judge's lust for the Philistine hetaere Delilah, which was "the beginning of his ruin" (see Ant 5.306 in the larger framework of 5.285-317). Such pro-and analepses stand out, because Josephus' default mode is telling his story in its chronological order.

\footnotetext{
${ }^{67}$ Van Henten and Huitink 2007, 217; Tuval 2013; van Henten 2017.

${ }^{68}$ Most analepses that inform the narratees about certain characters' previous actions are not so elaborate, they merely consist of a single sentence or clause, frequently a relative or garclause. Short narratorial analepses: e. g. Bell 2.183, 224, 249; Ant 2.70; 7.34, 67; 17.34 .

${ }^{69}$ Van Henten and Huitink 2007, 221-222. Explicit analepses: e.g. Bell 4.208; 5.61; Ant 13.320; 20.101, 102.

${ }^{70}$ Cf. Bell 4.319-325.
} 
The prologue of The Antiquities and the set-up of The Life indicate that Josephus intends to tell his narratees a moral message (e.g. Ant 1.14), which is illustrated by the statements and deeds of the characters in the story, including himself. Characterization is one way of articulating this message. The most common type of direct characterization in Josephus' historical works concerns brief notes by the narrator when he introduces a character or short flashbacks when someone dies or combinations of both. In Antiquities 1-11 this is a common feature in the sections on the biblical patriarchs and matriarchs, the judges as well as the kings of Israel and Judah. In the later books of Antiquities it occurs frequently in the section about the Hasmonean and Herodian rulers (Ant 12-17). This form of characterization is also found in Josephus' other writings, although Against Apion mostly offers brief characterizations of targeted authors or opponents of Josephus when they are introduced. The characterization of Josephus' opponents occurs also in Life, next to Josephus' characterization of himself in this work (above).

Korah, who rebelled against Moses (above), is characterized as follows at the beginning of the narrative about his rebellion:

Kores [Greek version of the Hebrew name Korah], a certain one of the Hebrews who

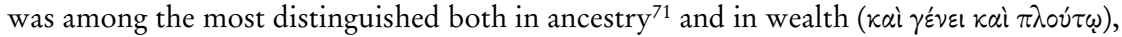
an able speaker (íavòs $\delta$ ' $\varepsilon i \pi \varepsilon i v)$ and most persuasive in dealing with crowds, seeing that Moyses was established in extraordinary honor, was hostile through envy (i்ì $\phi \theta o ́ v o v)$, for he happened to be his fellow tribesman and kinsman, and was embittered because he was more deserving to enjoy this glory by virtue of his being wealthier and not inferior in ancestry. (Ant 4.14; trans. Feldman)

The character sketch of Korah is selective. Josephus emphasizes Korah's ancestry and wealth, and he highlights his eloquence and success in manipulating crowds, a trait that is matched by Josephus himself in his Life (e.g. 22-23;30-31;102-103; $141-144 ; 244 ; 262 ; 264-266 ; 305-308 ; 377-380 ; 385-388)$. This characterization helps the narratees to understand why Korah poses a serious threat to Moses' leadership. The characterization indicates at the same time that Korah uses his abilities out of questionable motives: like most emotions in Josephus, jealousy and anger are negative traits. Being led by his emotions Korah fails to appreciate the fact that Moses is rightly more honoured than he is. Moses is the leader of the Jewish people because of the special favour in which God holds him. At the end of the story the impression about Korah's moral character that the narratees received at his introduction is confirmed: Korah and his fellows are consumed by a God-sent fire (Ant 4.54-56).

The story about King David includes several brief characterizations by

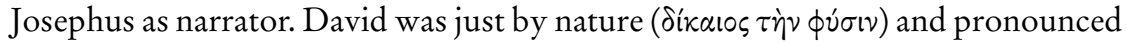

${ }^{71}$ Descent and education are often mentioned in Josephus' introductions of characters, and sometimes in passing. 
judgment with an eye to the truth (Ant 7.110). He put his confidence in God and the justice of the war that he was about to make (7.119). He was by nature

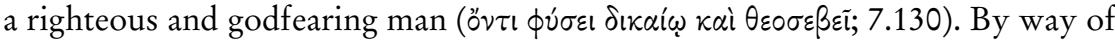
exception he forgot Moses' commandments when he decided to start a census, but he changed his mind after he realized that he had offended against God (7.118-329). Josephus' characterizations focus much more on types than on individuality, because they mostly concern virtues and deeds-with an emphasis on the attitude towards God-and the ways in which a character fits in with his scheme of virtues. This results in types like the good or the bad ruler, with

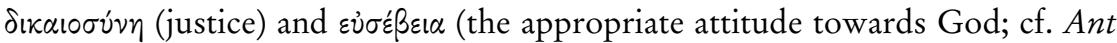
$7.269 ; 15.267 ; 16.92,169)$ or their opposites as most important traits. ${ }^{72}$ King Herod the Great is Josephus' most elaborate character. The extensive reports about him in War 1 and Antiquities 14-17 function in the broader context as a negative guideline for the interpretation of the subsequent war against Rome and the monarchy as the rejected type of leadership of the Jews. ${ }^{73}$

Josephus applies various ways of characterization to Herod, and Herod becomes a much more wicked character in Antiquities than in War. Herod is characterized by virtues and vices as well as deeds. Important virtues of Herod

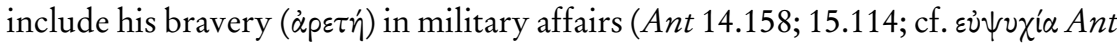
$14.355)$ and his magnanimity ( $\mu \varepsilon \gamma \alpha \lambda \circ \psi \nu \chi_{i}(\alpha)$, which may refer to his generous treatment of non-Jews, including his Roman patrons (Ant 15.48, 196; 16.140141) or activities like his care for subjects in need (15.316) or the construction of splendid buildings (Bell 1.554). Vices include his suspicion of relatives and persons at the court (Ant 15.42, 183, 210, 258; 16.90, 108, 119, 223, 324, 334), his jealousy (Bell 1.463, 633-634; Ant 15.50, 66-67, 82, 16.248) and his violent attitude (Ant 14.165; 15.321). The episode about Manaemus/Menahem the Essene (Ant 15.373-379; absent in the War), who predicted that Herod would

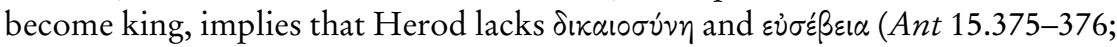
differently: Bell 1.400), the two main virtues that indicate whether someone is a good ruler or not. In Antiquities especially Herod's deeds articulate Herod's complex but mostly negative character: his innovations time and again violate the Jewish laws and at the end of his life the king reveals his true nature: he appears to be a tyrant. ${ }^{74}$ He makes his point that Herod is a tyrant by applying the technique of gradual character revelation. He feeds the narratees with observations by others in the story that point to the king's tyrannical character (Ant 14.165; 15.70, 222, 321, 353; 16.1-5). After reporting Herod's first deed, the elimination of Ezekias' gang of robbers, Josephus notes already that prominent Jews became afraid of him: "But the chief Jews were in great fear when they saw

\footnotetext{
${ }^{72}$ Van Henten 2014, 189.

${ }^{73}$ Van Henten 2011a.

${ }^{74}$ Van Henten 2011b; also 2008a; 2008b.
} 


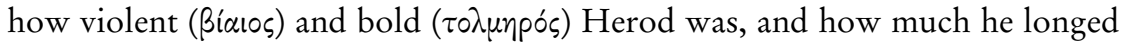

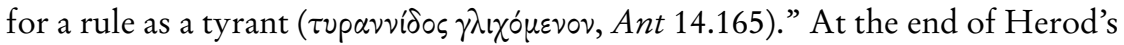
career Josephus presents us with the full picture of Herod as a tyrant in his story about the golden eagle episode (Ant 17.148-164): tyrannical traits such as rage, pure anger, bitterness and cruelty characterize Herod's behaviour, as well as his conviction that the Jewish people despised $\operatorname{him}(17.148,164)$. The flashback by Jewish delegates before Augustus after Herod's death, finally, connects Herod's tyrannical deeds with his character:

When the delegates of the Jews, who were eagerly looking forward to arguing for the dissolution of the kingdom, were permitted to speak, they turned to accuse Herod of lawless acts ( $\left.\pi \alpha \alpha^{2} \nu \rho \mu i \omega v\right)$. They declared him a king only in name and claimed that he had agreed to take upon himself the ruinous task, like

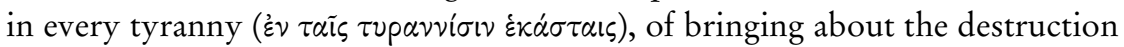
of the Jews. He did not depart from inventing all kinds of new measures that

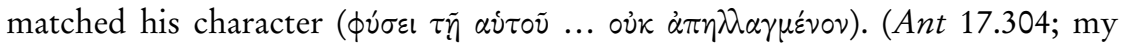
translation)

Comments are a third technique that shows the explicit engagement of Josephus as narrator, who passes judgment on others as God's mouthpiece, although he does not say so explicitly. One example forms his conclusion of the report about the dreams of Archelaus and Glaphyra (Ant 17.343-353), a section that concludes the narrative of book 17 of the Antiquities. The two dreams characterize both Archelaus and Glaphyra as negative characters. In the light of Josephus' moral message and his emphasis on God's involvement in the story it does not surprise us that both royal figures come to no good end: Archelaus looses his territory and is expelled to Gaul (17.355) and Glaphyra dies a few days after her dream was revealed to her (17.353). ${ }^{75}$ Josephus' comments on these events echo his remarks in the prologue of Antiquities about the moral implications of his history:

I think ( $\dot{\xi} \gamma \dot{\omega} \delta \dot{\varepsilon} \ldots$ vopi $\sigma \alpha \varsigma)$ that these dreams are not strange in connection to my history ( $\tau \tilde{\omega} \delta \varepsilon \tau \tilde{\omega} \lambda \lambda{ }^{\prime} \gamma \omega$; cf. Ant 15.372), because they concern royal persons. They also demonstrate that something that resembles immortality is part of the soul and that the divine provi-

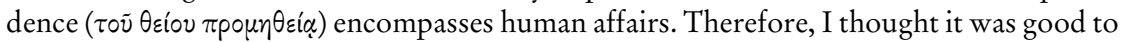
speak about such things. Let anyone for whom these things are unbelievable $(\dot{\alpha} \pi 1 \sigma \tau \varepsilon i \tau \alpha \iota ~ \tau \dot{\alpha}$ $\tau o(\alpha ́ \delta \varepsilon ;$ cf. Ant 15.379) benefit from his own view, but let there be no hindrance to anybody

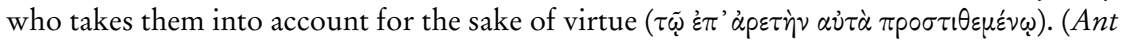
17.354, my transl.)

Josephus emphasizes in this comment that the dreams concern royal persons, probably because kings and queens function as models in his story. Archelaus and Glaphyra's dreams point to God's involvement in their rule, which connects them with other dream reports about rulers in Josephus' writings, such as those

\footnotetext{
${ }^{75}$ Van Henten 2003.
} 
of Pharaoh (Ant 2.75-86; cf. Gen. 41) ${ }^{76}$ and Nebuchadnezzar (Ant 10.194-217; cf. Dan. 2 and 4). ${ }^{77}$ Most of these dreams concern major events in the future of the respective kingdoms. The dreams of Pharaoh stand out as a parallel to Ant 17.343-53 because of the correspondence between the content of the dreams (ears of grain symbolizing years/cows-oxen) and the formal similarity that the dreams occur in pairs, which may emphasize their importance. Josephus also refers to immortality in his brief reflection about the dreams in Antiquities 17.354, which may reflect on Glaphyra's former husband Alexander re-appearing from the dead in her dream (17.351-353). The comment ties in with the general aim of Josephus' history as indicated in the prologue: Josephus is keen on teaching moral lessons and showing how the God of Israel works in history. The readers should benefit from his history and live in line with Jewish practices resulting in a morally good life and the proper attitude (eusebeia) towards God, because this could lead them to immortality or happiness as a reward (also above). Archelaus and Glaphyra function as negative models, they demonstrate the exact opposite of the appropriate way of life. From this perspective one understands why Josephus connects the dreams in his comments in 17.354 with God's providence and a virtuous life (cf. Ant 1.20). In the prologue Josephus indicates that God responds to human decisions and acts by rewarding or punishing humans accordingly (1.14). In other dream reports Josephus points out that God was not only the origin of the dream but determined the events announced in it as well. ${ }^{78}$ Reading Archelaus' and Glaphyra's dreams through this lens implies that the royal couple not only got what it deserved, but also that it was God's doing. The narratees should be aware of this and behave accordingly.

Another example of a comment that strongly guides Josephus' narratees concerns the oracle about a leader of the world in book 6 of the War, where Josephus "corrects" the interpretation of the Jewish sages. It is important also because it reflects Josephus' view about the events narrated in the War. In books 5 and 6 Josephus describes the Roman siege and capture of Jerusalem step by step. When the Sanctuary (vaós, 6.316) of the Temple and its surrounding buildings were on fire because individual Roman soldiers raised fire without being ordered to do so (6.249-284), ${ }^{79}$ Josephus interrupts his report with the description of a series of prophecies and portents (6.285-315): first rather brief references to false prophecies, which misled the people (6.285-288), and then a series of prodigies and

${ }^{76}$ Franxman 1979, 240-244.

77 Gnuse 1996.

78 Bell 3.351-354; Ant 1.208-209, 278-284, 331-334, 341-342; 2.10-17, 63-73, 75-86, 171176, 212-217; 5.215-221, 277-278, 348-350; 6.37-40; 7.92-93, 147; 8.22-25, 125-129; 10.194211; 11.326-328, 11.333-335; 13.322; Franxman 1979, 217; Gnuse 1996, 154.

${ }^{79}$ Josephus gives mixed signals about who was responsible for the fire. He sometimes blames the Jews for the fire or states that they were looking at it with enthusiasm (Bell 5.445; 6.167, 216, 251, 364), but he also reports that Titus was responsible for it (Bell 6.228; Ant 20.250). 
prophecies that were warnings from God (6.288-315; see esp. 6.288, 295, 310).80 These prodigies indicate the upcoming destruction (6.288), but the Jews ignored them according to Josephus. Most of these prodigies are mentioned in passing. Josephus pays most attention to a prophet of doom, Jesus, Son of Ananias, who prophesied the destruction of Jerusalem for seven years and five months, until his death, which he also foresaw (6.300-309).

The portents mentioned so far function as a lens for Josephus' interpretation

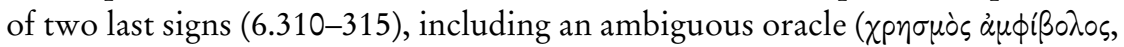
6.312). Referring to the previous portents ("When one considers these things ..."), Josephus notes the discrepancy between God's providence and warning of humans ( $\tau \dot{\partial} \nu \mu \dot{\varepsilon} \nu \theta \varepsilon \dot{\nu} \nu \dot{\alpha} \nu \theta \rho \dot{\omega} \pi \omega \nu$ ) and their self-destruction out of folly and by their evil deeds (6.310). He mentions as a recent example of this human stupidity the attempt of the Jews to make the Temple quadrangular through the destruction of the Antonia fortress, although God had indicated that when such a thing would happen the city and the sanctuary would be captured (6.311). The second sign concerns the ambiguous oracle, which apparently likewise functioned as a motive for starting the rebellion against the Romans: "What incited them most

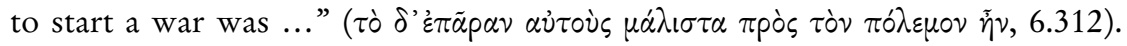
Josephus indicates that the content of the oracle is "found in their holy writings ..." (6.312), but as a matter of fact it is difficult to connect a biblical passage with the actual oracle: ${ }^{81}$

What incited them [i.e., the Jews] most to start a war was an ambiguous oracle, likewise found in their holy writings, that at about that time someone from their country would

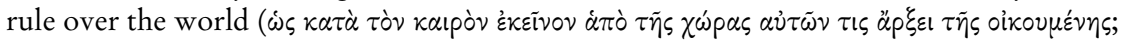
Bell 6.312).

Josephus immediately adds his own interpretation of this oracle:

They [i. e., the Jews] interpreted that [the oracle] was referring to their own people [ís oiksiov] and many of the sages were mistaken in their judgment. But the saying obviously predicts the rule of Vespasian, who was acclaimed emperor in Judea (6.313).

Josephus' report obviously implies that there were two interpretations of the oracle, which were worlds apart. The context indicates that for the Jews, including many sages, the oracle predicted their deliverance, brought about by a

${ }^{80}$ Michel and Bauernfeind 1962-69, 3.178-92; Lindner 1972, 125-132; Rajak 1983, 191-194; Becker 2006, 304-316; Gussmann 2008, 357-363.

${ }^{81}$ Scholars who opt for a specific biblical passage mostly argue for Numb. 24:17 (Hahn 1963, 167-191; Hengel 1976, 244-246; Koch 1997, 115-16;) or a Danielic passage (7:3-8: Mason 1992, 46-48; 1994, 176; 185-87, 189-190; 7:13-14: Beckwith 1979-1981, 532-535; 9:24-27: Bruce 1965; Gaston 1970, 459-461; Tomasino 2008, 96-108; den Hollander 2014, 95). For older references, see Hengel 1976, $244 \mathrm{fn}$. 3. Shochat 1960 argues for a rabbinic re-interpretation of Isaiah 10:33-34 (bGit. 56ab). Evans 1995, 56-58, mentions Gen 49:10 and Numb 24:17 as possible sources; Goodman 2007, 152 fn. 19, Numb. 24:17 and Dan. 7:13. Jonquière 2011, 222, points to Isaiah 41 and Sibylline Oracles 3.652-656. 
new Jewish ruler, who would in a Jewish framework plausibly be a Messianic figure. ${ }^{82}$ If we presuppose a Messianic scenario for the oracle, which is plausible in the context because Josephus reports that the oracle motivated the Jews to rebel, "that time" would probably refer to the end-time during which the Messiah would act. Strikingly, Josephus does not even give his narratees a hint that the oracle was interpreted in a Messianic way. There is, however, a plausible explanation for Josephus' ignoring the Messianic associations connected with the oracle: he thought very little of messianic figures ${ }^{83}$ From Josephus' perspective the oracle presents another negative example that proves his argument about the deep contrast between God's providence and human folly. He flatly rejects the interpretation that the oracle concerns a Jewish ruler and corrects it by pointing out not only that it refers to Vespasian but also that it became true (6.313). Thus, Josephus indicates that his interpretation is corroborated by the facts, which is, as a matter of fact, supported by other sources. Prompted by Tiberius Alexander the legions acclaimed Vespasian emperor in Alexandra on July 1 ${ }^{\text {st }}$ 69. The Roman army in Judea acknowledged Vespasian as emperor two days later (Tacitus, Hist. 2.49-51). ${ }^{84}$ In line with Josephus' own comments and the broader context, the implication of the oracle is that Jewish Scripture prophesied that Vespasian would become world leader, i. e., emperor. This became true, which implies that Vespasian was divinely sanctioned as emperor.

\section{The profile and authority of the narrator Josephus}

What does my analysis so far yield from the perspective of the leading questions of this volume? The first observation corroborated by Josephus' prologues and the genres of his writings is that he positions himself within a group of historians, Jewish as well as non-Jewish, and that he adopts a "classical authorial profile". In the prologues of War and Antiquities Josephus connects his books with the works of other historians, including historians about the war between the Romans and the Jews, but unfortunately he doesn't mentioned their name (contrast the explicit criticism of Justus of Tiberias in Vita 336-339). Josephus disqualifies these anonymous historians because they distorted the truth (Ant 1.4; cf. Vita 338 about Justus), flattered the Romans and hated the Jews too much, or because they were not present during the events themselves (Bell 1-2). These points not only elucidate Josephus' own profile-he was obviously present and he claims for himself the ideal middle position concerning the assessment of the role of

\footnotetext{
82 With Windisch 1929, 66-69; Hospers-Jansen 1949, 162; Hahn 1963; Abel 1969, 247-252; Gaston 1970, 459; Stern 1974-1984, 2.61; Hengel 1976, 244-246; Evans 1995, 56-58; Koch 1997, 115-116; Goodman 2007, 151-54.

${ }^{83}$ Spilsbury 2003, 18; Goodman 2007, 153.

${ }^{84}$ Kienast 1996, 108.
} 
Romans and Jews-, but he also builds on historiographical tropes known from the times of Herodotus and Thucydides onward. The way he does that implies that "classical authorial profile" should be nuanced. Josephus obviously applies the classical genres of historiography, autobiography (Vita) and either dicanic or epideictic speech (Apion), but he does that in an early imperial Roman context. ${ }^{85}$ Moreover, he criticizes some of the Greek historians (Bell 1.13, above; Apion 1.19-21, 24-25), highlights specific tropes like autopsy (Bell 1.3, 15-16, 18; Apion $1.55)$, and emphasizes points that are peculiar for his own works. The prologues of War and Antiquities especially echo motifs important in Thucydides (accuracy, truth, focus on recent history, theme of stasis, above), ${ }^{86}$ but he articulates them in his own way. He re-interprets the stasis motif, for example, in the framework of a narrative strategy that points out that the Jews themselves were to blame for their defeat, which was God's punishment for their dissension, robbery and profanation of the area of the Temple. Peculiar for all of Josephus' works is that he identifies himself with the Jewish people and points out that he suffered together with it. ${ }^{87}$ This motif is particularly important in War, the prologue of War emphatically announces that Josephus laments the dramatic fate of the Jewish people in this work (Bell 1.9, 11-12). In Antiquities the moral implications of its history stand out in the prologue (above) as well as Josephus' comments and characterizations of the main characters, which imply rather boldly, for Jews and non-Jews alike, that a decent life in line with justice and the proper attitude to the God of the Jews (eusebeia) will be rewarded by this God with happiness but that wickedness will be punished.

The Vita doesn't deal with Josephus' role as narrator or author. It is an autobiography along the lines of Greek as well as Roman traditions that focuses on Josephus' character and virtues during his public performance as a model for others who have public duties as a commander and statesman. Its opening section (1-12) focusing upon Josephus' ancestry (priestly as well as royal) and education implies that Josephus in his Roman context claimed for himself the status of a statesman as well. ${ }^{88}$

An important point of Josephus' profile concerns his capacity as a Jewish priest, which is highlighted at the beginning of War and Life (Bell 1.3; Vita 1-2). This remains very relevant despite the destruction of the Jerusalem Temple,

${ }^{85}$ Mason 2016 argues that Josephus should be considered a Roman historian, because he wrote primarily for an aristocratic local context and shares several characteristics with Roman historians, such as a strong focus upon individual characters and their moral assessment. Also Niehoff 2016, 136-41.

${ }^{86}$ Other passages imply that Josephus also builds on other authors, including Herodotus and Polybius, Villalba i Varneda 1986; Eckstein 1990; Mader 2000.

${ }^{87}$ Niehoff 2016, 140.

${ }^{88}$ Josephus' changed views about the Temple in Antiquities and Against Apion may be understood in the framework of his argument that the priests are the obvious leaders of the Jewish people, van Henten 2017. 
because Josephus' priesthood not only points to his aristocratic descent but also implies expert knowledge, on which he builds in certain sections of his historical works as well as in Against Apion. His priestly knowledge is used as part of a narrative strategy, because it enables him to interpret and explain passages of the sacred scripture of the Jews as well as dreams (cf. his comments on the dreams of Archelaus and Glaphyra in Ant 17.354). They imply divine revelation, as the Jotapata/Yodfat episode indicates (below), and require Josephus' explanation. Josephus' priesthood, therefore, provides him with a special religious authority. This explains why Josephus refutes so easily the interpretation of the Jewish sages of the oracle about a new world leader coming from the country of the Jews and argues-without offering much evidence-that the oracle refers to Vespasian (Bell 6.312-313, above). Josephus' remark that the oracle can be found in the sacred writings of the Jews (6.312) may be a hint at his priestly capacity as an expert interpreter of these writings. The correctness of his interpretation was, in his opinion, corroborated by the facts. Josephus' expert interpretation of sacred scripture, dreams and oracles, together with the moral appeal implied by his writings, underline his strategy to point out how divine providence operates in human history. The famous crucial Jotapata/Yodfat episode in $\operatorname{War} 3$ is a key passage in which this strategy becomes obvious.

The Jotapata/Yodfat episode, which contributed a lot to Josephus' image as a traitor of the Jewish people, depicts why and how Josephus surrendered to the Romans (Bell 3.340-392). Josephus himself is the main character in this story, which continues with his prediction about Vespasian becoming emperor (Bell 3.399-408). Because of its relevance for our topic it is worthwhile to look at it in detail. Josephus' dramatic report of the Roman siege of Jotapata led by Vespasian (67 C. E.) and leading up to Josephus' surrender (Bell 3.141-392) highlights his own role as a brave and shrewd leader of the Jewish defenders of the city (Bell 3.145-288, 316-339). It also indicates that the course of events had God's approval. ${ }^{89}$ The Romans succeeded in capturing Jotapata after 47 days, but Josephus and 40 prominent men managed to find refuge in a cave that was connected with a cistern (3.340-44). Josephus adds that this escape was enabled by a divine power (3.341). A woman betrayed the hiding place to Vespasian, which created a hopeless situation for the persons in the cave. They didn't want to surrender to the Romans and intended to commit suicide as a group. As is well-known, Josephus did his utmost to persuade them to surrender, but his elaborate speech to achieve that was unsuccessful (3.361-382). Josephus shrewdly managed to stay alive by agreeing that lots would determine one by one who would be killed by whom in order to prevent suicide (3.387-390). ${ }^{90}$ Josephus apparently knew that he would survive the procedure with the lots, which he did together with one other person,

\footnotetext{
${ }^{89}$ Lindner 1972, 49-68; Cohen 1979, 94-100; Jonquière 2011.

${ }^{90}$ Cf. the use of lots for arranging the collective killing at the Masada episode (Bell 7.395-397).
} 
whom he persuaded to surrender together to the Romans (3.391). Although Josephus leaves it to the reader to conclude whether his survival and surrender were due to co-incidence ( $\tau \dot{x} \chi \eta)$ or God's providence (זpóvola, 3.391), his own view clearly matches the second option. ${ }^{91}$ This ambiguity may be explained by the observation that Josephus sometimes provides two perspectives from which an event may be interpreted but also indicates his own preference for one of these.

Josephus' explanation why he had to surrender to the Romans is significant. He does this by making an appeal to his divine inspiration through dreams and his role as interpreter of God's statements, which were of crucial importance for the future (3.350-354)..$^{92} \mathrm{He}$ may hint here at his later role as help and stay of Vespasian and Titus, which starts with his famous prediction that Vespasian would become emperor (3.399-408). His appeal to a divine revelation underpins his repeated suggestion that the Roman victory and political takeover did occur with God's consent. In this passage about the dreams that Josephus recalled at the moment when his group was trapped in the cave Josephus refers once

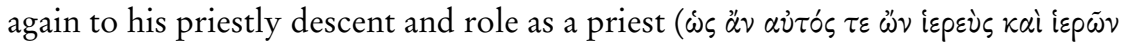
हैyovos), ${ }^{93}$ implying that he is the expert in the prophecies of the sacred scriptures (3.352). This boils down to the claim that Josephus had the authority of being an interpreter of God's will. During the dramatic situation in the cave Josephus "is

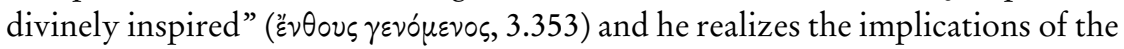
dreams he had seen before. He formulates their implications in a prayer before God in direct speech:

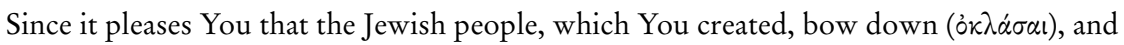
since all their good fortune ( $\dot{\eta} \tau \dot{v} \chi \eta \pi \tilde{\alpha} \sigma \alpha)$ has gone over to the Romans, and since You have elected my person ( $\tau \dot{\eta} \nu \bar{\xi} \mu \dot{\eta} \nu \psi \psi v \chi \dot{\eta} \eta$ ) to tell what is to come to pass hereafter, I willingly surrender myself to the Romans and will live. I solemnly affirm (or: call You to witness) ${ }^{94}$ that I do this not as a traitor of the Jews, but as a servant of You. (3.353-354; my transl.)

Josephus as a character in the story conveys a major message of Josephus the narrator here: the Romans had to win the war because God supported them. This implies not only a radical re-interpretation of his own role as a commander of the Jews, but also that Josephus himself had become the medium and the message for the right interpretation of the events. The divine revelation to which he has access and which only he can explain as a priestly expert implies that his surrender to the Romans was the proper thing to do, because by surrendering Josephus could act as a servant of God. His expert knowledge as a priest of the divine will (3.352), as revealed in Jewish Scripture, is crucial, because it legitimates his de-

\footnotetext{
${ }^{91}$ Cf. Vit 83, where Josephus attributes his deliverance from his opponents to God.

${ }^{92}$ Ladouceur 1980, 248-49; Gray 1993, 35-52; Kelley 2004, 260-63; 272.

${ }^{93}$ Cf. Bell 1.3; Life 1.1-2; Apion 1.54.

${ }^{94}$ Michel and Bauernfeind 1962-1969, 1.371.
} 
cision and lends authority to his further role as a mediator between the Romans and the Jews and a historian.

In Antiquities there is an additional element that contributes to Josephus' profile as author and further enhances his authority as a historian who is at the same time a priestly expert. In the prologue of this work he constructs an analogy between Antiquities and the Septuagint translation of the Jewish Law for Ptolemy II Philadelphus (1.9-17, 26, above), which was granted to the king by the high priest Eleazar (1.11). This law was revealed by God as the lawgiver of the Jews (1.15), which implies a huge authority for the Septuagint. The analogy presupposes a similar status for Josephus' work, but Josephus even goes a step further by arguing that Antiquities even surpasses the Septuagint, because it renders the entire set of Jewish sacred scriptures (1.12-13), "neither adding nor omitting anything" (1.17). ${ }^{95}$ The fact that Antiquities is supposed to be a fully complete rendering of Jewish sacred scripture, which starts with the story about the creation, the first humans and Abraham as ancestor of the Jews, ties in with two points of Josephus' narrative strategy in Antiquities and Against Apion, as discussed above in connection with their prologues: (1) the very ancient origin of the Jewish people, which is almost as old as the first humans (cf. Ant 1.5, 21, 26-27; Apion 1.3-4, 59), and (2) the political organization of the Jews, which is an ideal model, because it is based on the laws revealed by God to Moses and not on myth (Ant 1.15, 22; Apion 2.145-219).

\section{Conclusion}

Josephus writes mainly for non-Jewish and Jewish literati at Rome. He aims for akribeia in line with the Thucydidean ideal and claims that he delivers that because he first was a participant in the conflict between the Jews and the Romans and next an observer, which means that the well-known criterion of autopsy is matched as well by his histories. Again in line with Thucydides Josephus also highlights that he writes about recent history, which implies criticism of Greek historians (Bell 1.13). Josephus' profile as a historian implies that he writes from his own experience (Ant 1.4), which allows him to add a special dimension to his work (esp. in War): he identifies with the Jewish people and indicates not only his own personal sufferings but he laments as a member of this people the great calamities that befell his nation (Bell 1.9, 11-12). In Antiquities Josephus emphasizes the moral implications of the divine laws revealed by Moses (Ant 1.5, 18-26) and he highlights that God punishes or rewards the follow-up of these

\footnotetext{
${ }^{95}$ Rajak 1982, 472 argues that this formula here emphasizes the completeness of Josephus' rendering of scripture and not its faithfulness, as Greek and Roman parallels imply, van Unnik 1978.
} 
laws accordingly $(1.14,18-20,23-25)$. The assessment of the characters in the main body of Antiquities corroborates this important point, as Josephus' own public performance does in the Life (esp. 430). Josephus' role as a model commander and prudent statesman implies that the Life shares with the Antiquities a focus on moral lessons for the readers. Being an overt external narrator Josephus makes God's involvement in history explicit, he shows how God is closely involved in the events described, which ties in with the moral message Josephus conveys: the readers should benefit from his history and opt for the appropriate way of life in line with the laws of Moses. Part of the articulation of his role as a Jewish historian in Rome is Josephus' claim to the expert knowledge of a Jewish priest, he emphasizes that he is a priest born in Jerusalem (Bell 1.3; Life 1-2; Apion 1.54; Bell 3.352). His geographical origin and priestly background not only means that he knows what he is talking about when he deals with Jerusalem and the Temple, the main battleground of the Jewish War, but also that he has insider knowledge of Jewish sacred scripture, which lends authority to his interpretation of the events as well as his own role as a historian, as the famous Yodfat/Jotapata episode in book 3 of War implies. In the Jerwish Antiquities, which is partly based on Jewish scripture, Josephus enhances this authority by constructing an analogy with the divinely sanctioned Septuagint Translation (Ant 1.9-17, 26).

\section{Bibliography}

Abel, Ernest L. 1969. 'Jesus and the Cause of Jewish National Independence', REJ 128. 247-252.

Attridge, Harold W. 1976. The Interpretation of Biblical History in the Antiquitates Judaicae of Flavius Josephus. HDR 7. Missoula, Mont.: Scholars Press.

Bal, Mieke 1997. Narratology. Introduction to the Theory of Narrative. First edition 1985. Toronto: University of Toronto Press.

Barclay, John M. G. 2007. Against Apion: Translation and Commentary. Flavius Josephus: Translation and Commentary 10. Leiden: Brill.

Barish, David A. 1978. 'The Autobiography of Josephus and the Hypothesis of a Second Edition of his Antiquities', HTR 71. 61-75.

Bauer, Walter; Aland, Barbara 1988. Wörterbuch zum Neuen Testament. 6th edn. Berlin: de Gruyter.

Becker, Eve-Marie 2006. Das Markus-Evangelium im Rabmen der antiken Historiographie. WUNT 194. Tübingen: Mohr-Siebeck.

Beckwith, Roger T. 1979-1981. 'Daniel 9 and the Date of Messiah's Coming in Essene, Hellenistic, Pharisaic, Zealot and Early Christian Computation', RQ 10. 521-542.

Berggren, Jakob 1862. Bibel und Josephus über Jerusalem und das Heilige Grab wider Robinson und neuere Sionspilger als Anhang zu Reisen im Morgenlande. Lund: Berlingsche Buchdruckerei.

Bilde, Per 1988. Flavius Josephus between Jerusalem and Rome: His Life, his Works and their Importance. JSPSup 2. Sheffield: JSOT Press. 
Brighton, Mark A. 2009. The Sicarii in Josephus's Judean War: Rhetorical Analysis and Historical Observations. SBLEJL 27. Atlanta, Georgia: Society of Biblical Literature.

Bruce, Frederick F. 1965. 'Josephus and Daniel'. Annual of the Swedish Theological Institute 4. 148-162.

Carleton Paget, James 2001. 'Some Observations on Josephus and Christianity', JTS 52. 539-624.

Chapman, Honora H. 2005. 'Spectacle in Josephus' Jewish War'. In Flavius Josephus and Flavian Rome, ed. Jonathan Edmondson, Steve Mason, James B. Rives. Oxford: Oxford University Press, 289-313.

Cohen, Shaye J.D. 1979. Josephus in Galilee and Rome: His Vita and Development as a Historian. Columbia Studies in the Classical Tradition 8. Leiden: Brill.

Curran, John 2011. 'Flavius Josephus in Rome'. In Flavius Josephus: Interpretation and History, ed. Jack Pastor, Pnina Stern and Menachem Mor, JSJSup 146, Leiden: Brill, 65-86.

Den Hollander, William 2014. Josephus, the Emperors, and the City of Rome: From Hostage to Historian. AGJU 86. Leiden: Brill.

Droge, Arthur J. 1996. 'Josephus Between Greeks and Barbarians'. In Josephus' Contra Apionem: Studies in its Character and Context with a Latin Concordance to the Portion Missing in Greek, ed. Louis H. Feldman and John R. Levison. AGJU 34. Leiden: Brill.

Earl, Donald C. 1972. 'Prologue-Form in Ancient Historiography', ANRW 1.2. 842-856.

Eckstein, Arthur M. 1990. 'Josephus and Polybius: A Reconsideration', Classical Antiquity 9. 175-208.

Evans, Craig A. 1995. Jesus and his Contemporaries: Comparative Studies. AGJU 25. Leiden: Brill.

Feldman, Louis H. 1998. Josephus' Interpretation of the Bible. Berkeley: University of California Press.

Franxman, Thomas W. 1979. Genesis and the "Jewish Antiquities" of Flavius Josephus. Biblica et Orientalia 35. Rome: Biblical Institute Press.

Gaston, Lloyd 1970. No Stone on Another: Studies in the Significance of the Fall of Jerusalem in the Synoptic Gospels. Leiden: Brill.

Gelzer, Matthias 1952. 'Die Vita des Josephos', Hermes 80. 67-90.

Genette, Gérard 1980. Narrative Discourse. An Essay in Method. Ithaca, N. Y.: Cornell University Press.

Gerber, Christine 1997. Ein Bild des Judentums für Nichtjuden von Flavius Josephus: Untersuchungen zu seiner Schrift Contra Apionem. AGJU 40. Leiden: Brill.

Gnuse, Robert K. 1996. Dreams and Dream Reports in the Writings of Josephus: A Tradition-Historical Analysis. AGJU 36. Leiden: Brill.

Goodman, Martin 1994. 'Josephus as Roman Citizen'. In Josephus and the History of the Greco-Roman Period, ed. F. Parente and J. Sievers. Leiden: Brill.

Goodman, Martin 2007. 'Messianism and Politics in the Land of Israel, 66-135 C. E.' In Redemption and Resistance: The Messianic Hopes of Jews and Christians in Antiquity, ed. Marcus Bockmuehl and James Carleton Paget. Edinburgh: T \& T Clark, 149-157.

Gray, Rebecca 1993. Prophetic Figures in Late Second Temple Jewish Palestine: The Evidence from Josephus. New York: Oxford University Press.

Gussmann, Olivier 2008. Das Priesterverständnis des Flavius Josephus. TSAJ 124. Tübingen: Mohr Siebeck.

Hahn, István 1963. 'Josephus und die Eschatologie von Qumran'. In Qumran-Probleme: Vorträge des Leipziger Symposions über Qumran-Probleme vom 9. bis 14. Okt. 1961, 
ed. Hans Bardtke. Schriften der Sektion für Altertumswissenschaft. Berlin: Akademie Verlag.

Hardwick, Michael E., 1989. Josephus as an Historical source in Patristic Literature through Eusebius. Brown Judaic Studies 128. Atlanta, GA: Scholars Press.

Hayes, Christine E., Israel-Vleeschhouwer, Amos 2014. Jewish Law and its Interaction with Other Legal Systems. Liverpool: Deborah Charles Publications.

Hengel, Martin 1976. Die Zeloten. Untersuchungen zur jüdischen Freibeitsbewegung in der Zeit von Herodes I. bis 70 n. Chr. 2nd. Ed. Leiden: Brill.

Hornblower, Simon 1991. A Commentary on Thucydides. Vol. 1. Oxford: Clarendon Press.

Hospers-Jansen, Anna M.A. 1949. Tacitus over de Joden: Hist. 5, 2-13. Groningen/Batavia: J.B. Wolters.

Inowlocki, Sabrina 2006. Eusebius and the Jewish Authors: His Citation Technique in an Apologetic Context. AGJU 64. Leiden: Brill.

de Jong, Irene J.F. 2007. 'Narratological Theory on Time’. In Time in Ancient Greek Literature, ed. Irene J. F. de Jong and René Nünlist. Studies in Ancient Greek Narrative 2. Mnemosyne Supplements 291. Leiden: Brill.

de Jong, Irene J.F. 2012. Space in Ancient Greek Literature. Studies in Ancient Greek Narrative 3. Mnemosyne Supplements 339, Leiden: Brill.

de Jong, Irene J.F. 2014. Narratology and Classics: A Practical Guide. Oxford: Oxford University Press.

de Jong, Irene J. F., Nünlist, René, Bowie, Angus, 2004. Narrators, Narratees and Narratives in Ancient Greek Literature. Studies in Ancient Greek Narrative 1. Mnemosyne Supplements 257. Leiden: Brill.

Jonquière, Tessel M. 2011. 'Josephus at Jotapata: Why Josephus Wrote What he Wrote'. In Flavius Josephus: Interpretation and History, ed. Jack Pastor, Pnina Stern, Menachem Mor. JSJSup 146. Leiden: Brill, 217-225.

Kasher, Aryeh 1996. 'Polemic and Apologetic Methods of Writing in Contra Apionem'. In Josephus' Contra Apionem: Studies in its Character and Context with a Latin Concordance to the Portion Missing in Greek, ed. Louis H. Feldman and John R. Levison. Leiden: Brill, 143-186.

Keim, Theodor 1878. Aus dem Urchristentum. Geschichtliche Untersuchungen in zwangloser Folge I . Zürich: O. Füssli \& Co.

Kelley, Nicole 2004. 'The Cosmopolitan Expression of Josephus' Prophetic Perspective in the Jewish War', HTR 97. 257-274.

Kienast, Dietmar 1996. Römische Kaisertabelle: Grundzüge einer römischen Kaiserchronologie. Darmstadt: Wissenschaftliche Buchgesellschaft.

Koch, Klaus 1997. 'Spätisraelitisch-jüdische und urchristliche Danielrezeption vor und nach der Zerstörung des zweiten Tempels'. In Rezeption und Auslegung im Alten Testament und in seinem Umfeld: Ein Symposion aus Anlass des 60. Geburtstages von O. H. Steck, ed. Rainer G. Kratz and Thomas Krüger. Freiburg/Göttingen: Universitätsverlag, 93-123.

Kokkinos, Nikos 1998. The Herodian Dynasty: Origins, Role in Society and Eclipse. JSPSup 30. Sheffield: Sheffield Academic Press.

Krieger, Klaus-Stefan 2000. 'Die Funktionen der Septuaginta-Legende in Flavius Josephus' Werken Antiquitates Judaicae und Contra Apionem'. In Internationales Josephus-Kolloquium Aarbus 1999, ed. Jürgen U. Kalms. MJSt 6. Münster: Lit, 246-261. 
Ladouceur, David J. 1980. 'Masada: A Consideration of the Literary Evidence', GRBS 21. 245-260.

Landau, Tamar 2005. 'Power and Pity: the Image of Herod in Josephus' Bellum Judaicum'. In Josephus and Jewish History in Flavian Rome and Beyond, ed. Joseph Sievers and Gaia Lembi. JSJSup 104. Leiden: Brill, 159-181.

Landau, Tamar 2006. Out-Heroding Herod: Josephus, Rhetoric, and the Herod Narratives. AGJU 63. Leiden: Brill.

Laqueur, Richard 1920. Der jüdische Historiker Flavius Josephus: ein biographischer Versuch auf neuer quellenkritischer Grundlage. Giessen: von Münchow.

Levick, Barbara 1999. Vespasian. London: Routledge.

Lieberich, Heinrich 1899. Studien zu den Proömien in der griechischen und byzantinischen Geschichtsschreibung. I: Die griechischen Geschichtsschreiber. Munich: J. G. Weiss.

Lindner, Helgo 1972. Die Geschichtsauffassung des Flavius Josephus im Bellum Judaicum: Gleichzeitig ein Beitrag zur Quellenfrage. AGJU 12. Leiden: Brill.

Mader, Gottfried 2000. Josephus and the Politics of Historiography: Apologetic and Impression Management in the Bellum Judaicum. Mnemosyne Supplements 205. Leiden: Brill.

Marincola, John 1997. Authority and Tradition in Ancient Historiography. Cambridge: Cambridge University Press.

Marincola, John 2001. Greek Historians. Oxford: Oxford University Press.

Mason, Steve 1992. Josephus and the New Testament. Hendrickson, Peabody.

Mason, Steve 1994. 'Josephus, Daniel and the Flavian House'. In Josephus and the History of the Greco-Roman Period: Essays in Memory of Morton Smith, ed. Fausto Parente and Joseph Sievers. SPB 41. Leiden: Brill, 161-191.

Mason, Steve 1996. 'The Contra Apionem in Social and Literary Context: an Invitation to Judean Philosophy'. In Josephus' Contra Apionem: Studies in its Character and Context with a Latin Concordance to the Portion Missing in Greek, ed. Louis H. Feldman and John R. Levison. Leiden: Brill, 187-228.

Mason, Steve 1998. 'An Essay in Character: the Aim and Audience of Josephus's Vita'. In Internationales Josephus Kolloquium Münster 1997, ed. Jürgen U. Kalms and Folker Siegert. MJSt 2. Münster: Lit, 31-77.

Mason, Steve 2000. 'Introduction to the Judean Antiquities'. In Judean Antiquities 1-4: Translation and Commentary. Flavius Josephus: Translation and Commentary 3. Leiden Brill, xiii-xxxvi.

Mason, Steve 2001. Life of Josephus: Translation and Commentary. Flavius Josephus: Translation and Commentary 9. Leiden: Brill.

Mason, Steve 2003. 'Flavius Josephus in Flavian Rome: Reading on and Between the Lines'. In Flavian Rome: Culture, Image, Text, ed. Anthony J. Boyle and William J. Dominik. Leiden: Brill, 559-590.

Mason, Steve 2005. 'Of Audience and Meaning: Reading Josephus' Bellum Judaicum in the Context of a Flavian Audience'. In Josephus and Jewish History in Flavian Rome and Beyond, ed. Joseph Sievers and Gaia Lembi. JSJSup 104. Leiden: Brill, 71-100.

Mason, Steve 2011.'What Is History? Using Josephus for the Judaean-Roman War'. In The Jewish Revolt against Rome: Interdisciplinary Perspectives, ed. Mladen Popović. JSJSup 154. Leiden: Brill, 155-240.

Mason, Steve 2016. 'Josephus as a Roman Historian'. In A Companion to Josephus, ed. H.H. Chapman and Z. Rodgers. Blackwell Companions to the Ancient World 110. Chichester: Wiley-Blackwell, 89-107.

Meijer, Fik 2016. Jezus E de vijfde evangelist. Amsterdam: Athenaeum. 
Michel, Otto, Bauernfeind, Otto 1962-1969. Flavius Josephus: De bello judaico, der jüdische Krieg: Griechisch und Deutsch. 3 vols. in 4. Munich: Kösel.

Misch, Georg 1950. A History of Autobiography in Antiquity. 2 vols. London: Routledge and Kegan Paul.

Niehoff, Maren R. 2016. 'Josephus and Philo in Rome'. In A Companion to Josephus, ed. H.H. Chapman and Z. Rodgers. Blackwell Companions to the Ancient World 110. Chichester: Wiley-Blackwell, 135-146.

Price, Jonathan J. 2001. Thucydides and Internal War. Cambridge: Cambridge University Press.

Price, Jonathan J. 2005. 'The Provincial Historian in Rome'. In Josephus and Jewish History in Flavian Rome and Beyond, ed. Joseph Sievers and Gaia Lembi. Leiden: Brill, 101-118.

Rajak, Tessa 1982. 'Josephus and the "Archaeology” of the Jews', JJS 33. 465-477.

Rajak, Tessa 1983. Josephus: The Historian and his Society. London: Duckworth.

Rajak, Tessa 1998. 'The Against Apion and the Continuities in Josephus' Political Thought'. Understanding Josephus: Seven Perspectives, ed. Steve Mason. JSPSup 32. Sheffield: Sheffield Academic Press, 222-46.

Scardigli, Barbara, Affortunati, Monica 1987. 'Considerazioni sull' autobiografia di Nicolao di Damasco (FGrHist 136-138)', Annali della Facoltà di Lettere e Filosofia dell' Università di Siena 8. 389-401.

Schreckenberg, Heinz 1972. Die Flavius-Josephus-Tradition in Antike und Mittelalter. Leiden: Brill.

Schreckenberg, Heinz 1980. 'Flavius Josephus und die lukanische Schriften'. In Wort in der Zeit: Neutestamentliche Studien, Festgabe für K. H. Rengstorf zum 75, Geburtstag, ed. Wilfrid Haubeck and Michael Bachmann. Leiden: Brill, 179-209.

Schreckenberg, Heinz 1998. 'Josephus', RAC 18. 761-801.

Schwartz, Daniel R. 1983-1984. 'Josephus on Jewish Constitutions and Community'. SCI 7. 30-52.

Schwartz, Daniel R. 1989/1990. 'On Drama and Authenticity in Philo and Josephus', SCI 10. 113-29.

Schwartz, Daniel R. 2007. Flavius Josephus, Vita: Introduction, Hebrew Translation, and Commentary. [Hebrew] Jerusalem: Yad Ben-Zvi Press.

Shochat, Azriel 1960. 'On the Ambiguous Oracle in the Words of Josephus'. In Sefer Yosef Shiloh, ed. Michael Händel. [Hebrew] Tel Aviv, 163-165.

Siegert, Folker, Schreckenberg, Heinz, Vogel, Manuel 2001. Flavius Josephus Aus meinem Leben (Vita): Kritische Ausgabe, Übersetzung und Kommentar. Tübingen: MohrSiebeck.

Spilsbury, Paul 2003. 'Flavius Josephus on the Rise and Fall of the Roman Empire', JThS 54. 1-24.

Sterling, Gregory E. 1992. Historiography and Self-definition: Josephos, Luke-Acts, and apologetic Historiography. Leiden: Brill.

Stern, Menachem 1974-1984. Greek and Latin Authors on Jews and Judaism. 3 vols. Publications of the Israel Academy of Sciences and Humanities: Section of Humanities. Jerusalem: Israel Academy of Sciences and Humanities.

Swoboda, Sören 2014. Tod und Sterben im Krieg bei Josephus. Die Intentionen von Bellum und Antiquitates im Kontext griechisch-römischer Historiographie. TSAJ 158. Tübingen: Mohr Siebeck. 
Thackeray, Henry S. John 1929. Josephus: the Man and the Historian. New York: Jewish Institute of Religion Press.

Tomasino, Anthony J. 2008. 'Oracles of Insurrection: the Great Catalyst of the Great Revolt', JJS 59. 87-111.

Tuval, Michael 2013. From Jerusalem Priest to Roman Jew: on Josephus and the Paradigms of Ancient Judaism. WUNT 2, Series 357. Tübingen: Mohr Siebeck.

Van den Bos, Lambrecht, Flavii Josephi Des wijdt-vermaerden Joodschen historie-schrijvers boecken: te weten, twintigh van de oude geschiedenissen der Joden, en een van sijn eygen leven: noch seven van de Joodsche oorlogen, en de verwoestinge Jerusalems. mitsgaders twee van de Joodsche oudtheyt, tegens Apionem den letter-konstenaer: en ten laetsten een van de heerschappij des vernufts, en het lijden en doot der Machabeen nu op nieures uyt de Grieksche en Latijnsche sprake vertaelt. Amsterdam: Steven Swart and Hendrick Wetstein, 1679.

van Henten, Jan Willem 2003. 'The Two Dreams at the End of Book 17 of Josephus' Antiquities'. In Internationales Josephus-Kolloquium Dortmund 2002, ed. Jürgen U. Kalms and Folker Siegert. MJSt 14. Münster: Lit, 78-93.

van Henten, Jan Willem 2008a. 'Matthew 2:16 and Josephus' Portrayals of Herod'. In Jesus, Paul, and Early Christianity: Studies in Honour of Henk Jan de Jonge, ed. Rieuwerd Buitenwerf, Harm W. Hollander and Johannes Tromp. NTSup 130. Leiden: Brill, 101-122.

van Henten, Jan Willem 2008b. 'The Panegyris in Jerusalem: Responses to Herod's Initiative (Josephus, Antiquities 15.268-291)'. In Empsychoi Logoi-Religious Innovations in Antiquity: Studies in Honour of Pieter Willem van der Horst, ed. Albertina Houtman, Ab de Jong and Magda Misset-van de Weg. AGJU 73. Leiden: Brill, 2008, 151-173.

van Henten, Jan Willem 2011a. 'Rebellion under Herod the Great and Archelaus'. In The Jewish Revolt: Interdisciplinary Perspectives, ed. Mladen Popovic. JSJSup 154. Leiden: Brill, 241-270.

van Henten, Jan Willem 2011b. 'Constructing Herod as a Tyrant: Assessing Josephus' Parallel Passages'. In Flavius Josephus: Interpretation and History, ed. Jack Pastor, Pnina Stern and Menachem Mor. JSJSup 146. Leiden: Brill, 193-216.

van Henten, Jan Willem 2014. Judean Antiquities 15: Translation and Commentary. Flavius Josephus: Translation and Commentary 7b. Leiden: Brill.

van Henten, Jan Willem 2017. 'Josephus on the Temple from a Post-70 Perspective'. In Jews and Christians in the First and Second Centuries: The Interbellum 701-132 CE, ed. Joshua Schwartz and Peter Tomson. CRINT 15, Leiden: Brill.

van Henten, Jan Willem, Abusch, Ra'anan 1996. 'The Depiction of the Jews as Typhonians and Josephus' Strategy of Refutation in Contra Apionem'. In Josephus' Contra Apionem: Studies in its Character and Context with a Latin Concordance to the Portion Missing in Greek, ed. Louis H. Feldman and John R. Levison. Leiden: Brill, 271-309.

van Henten, Jan Willem, Huitink, Luuk 2007. 'Josephus'. In Time in Ancient Greek Literature: Studies in Ancient Greek Narrative 2, ed. Irene F.J. de Jong and René Nünlist. Mnemomysune Supplements 219. Leiden: Brill, 213-230.

Van Unnik, Willem C. 1978. 'Die Formel “nichts wegnehmen, nichts zufügen”'. In Flavius Josephus als historischer Schriftsteller, ed. W. C. van Unniek. Heidelberg: Lambert Schneider, 26-40.

Villalba i Varneda, Pere 1986. The Historical Method of Flavius Josephus. AGJU 19. Leiden: Brill. 
Whealey, Alice, 2003, Josephus on Jesus: The Testimonium Flavianum Controversy from Late Antiquity to Modern Times, Peter Lang, New York, NY.

Wacholder, Ben Z. 1962. Nicolaus of Damascus. University of California Publications in History 75, Berkeley: University of California Press.

Windisch, Hans 1929. Die Orakel des Hystaspes. Amsterdam: Verhandelingen der Koninklijke Akademie van Wetenschappen NR Letterkunde 28.3.

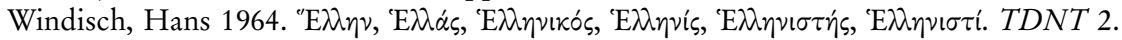
504-516. 


\title{
Die Konstruktion von Autorschaft in der Apokalypse - mit einem Seitenblick auf das Corpus Johanneum
}

\author{
Jan Dochborn

\section{Einleitung}

Dem Bemühen um eine Wiederentdeckung von Autor und Autorschaft kommt die Apokalypse des Johannes entgegen, denn sie ist - zumindest meines Erachtens - ein Stück Autorenliteratur, in dem Autorschaft allerdings auf besonders komplexe Weise konstruiert erscheint. Der folgende Beitrag soll diese Sicht begründen und die Konstruktion von Autorschaft in der Apokalypse näher beschreiben sowie geistesgeschichtlich verorten. Dies wird nicht ohne gattungskritische Überlegungen möglich sein, da Autorschaft etwas mit Textpragmatik zu tun hat und damit dem Dreh- und Angelpunkt der Gattungskritik.

Der Gedankengang dieses Beitrags ist der folgende: Zunächst wird erwiesen werden, dass die Apokalypse als auktoriales Werk eines orthonymen Verfassers wahrgenommen werden will (2). Hierfür wird vorrangig der Proömienapparat der Apokalypse in den Blick zu nehmen sein (die Superscriptio in Apc Joh 1,1-3 und das briefliche Incipit in Apc Joh 1,4-6), der für die Gattungskritik eines Werkes oft und so auch hier entscheidend ist. Als erstes wird die Superscriptio analysiert werden; an ihr wird zu zeigen sein, dass die Apokalypse eine Offenbarungsschrift ist, die als solche einen sekundären Autor - Johannes - in den Hintergrund rückt zugunsten eines eigentlichen Autors, als welcher Jesus fungiert (2.1). Sodann wird primär anhand des nachfolgenden brieflichen Incipit demonstriert, dass die Apokalypse ein Brief ist und in dieser Eigenschaft den uneigentlichen Autor der Superscriptio, Johannes, derart in den Vordergrund rückt, dass dieser nahezu als der eigentliche erscheint (2.2). Anschließend werden eher knapp Momente im Textkorpus besprochen, aufgrund derer deutlich wird, wie die Apokalypse gerade den Autor Johannes inszeniert (2.3). Und schließlich wird hervorzuheben sein, dass die Autorschaft zumindest des Johannes orthonym ist, hier also ein ,echter' Johannes schreibt (2.4). Es folgt ein kurzer Abschnitt, der wesentliche Züge der Autorschaftskonstruktion der Apokalypse 
resümiert sowie die historische und rezeptionsgeschichtliche Bedeutung der Autorschaftskonstruktion der Apokalypse aufzeigt (3). Ein Appendix skizziert eine zur Apokalypse vielfach parallele Entwicklung im Corpus Johanneum (4).

\section{Die Konstruktion von Autorschaft in der Apokalypse}

Der dem Textkorpus der Apokalypse über- und vorgeordnete Kopfteil des Buches, der für unser Thema von entscheidender Bedeutung ist, besteht aus dem

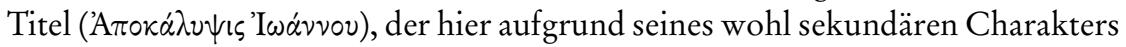
vernachlässigt werden kann (doch vgl. $\$ 3$ ), der Superscriptio, die das Werk als Offenbarungsschrift präsentiert (Apc Joh 1,1-3), und aus dem brieflichen Incipit, die den Briefcharakter der Apokalypse begründet (Apc Joh 1,4-6). Die Doppelung von Anfangsteilen (Superscriptio in 1,1-3; briefliches Incipit in 1,4-6) erscheint ungewöhnlich und aufwendig, findet aber eine Parallele zum Beispiel im Nebeneinander von Superscriptio und Inscriptio bei der Apokalypse des Mose, deren Eingangsteil auch sonst in der Apokalypse des Johannes Entsprechungen findet (s.u.). Es wird nun zunächst die Superscriptio in den Blick genommen werden - im Zusammenhang mit Texteinheiten, die auf sie näher bezogen sind.

\subsection{Die Apokalypse des Johannes als Offenbarungsschrift}

Die Superscriptio führt dem Leser eine Konstellation von Akteuren und Handlungskonstituenten vor Augen, die narratives Gepräge hat - passend zu einem Werk, das überwiegend Erzählung ist, wenngleich Erzählung über die Zukunft. Es sind 6 Einheiten zu unterscheiden, die ich in der Reihenfolge ihrer Erwähnung präsentiere:

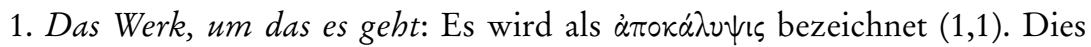
Wort ist als Gattungsbezeichnung in den Incipits mehrerer griechischsprachiger Werke bezeugt (Apocalypsis Esdrae; Legenda Isaiae; 3 Baruch; Protevangelium Jacobi nach Papyrus Bodmer 5). Doch nirgendwo befinden wir uns damit sicher in einer Zeit, die vor der Apc Joh liegt. ${ }^{1}$ Dies gilt auch für das zweite Baruchbuch,

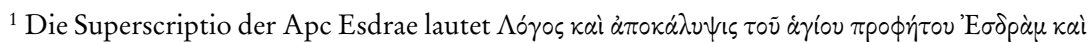
$\dot{\alpha} \gamma \alpha \pi \eta \tau о \tilde{~} \tau о \tilde{v} \theta \varepsilon \circ \tilde{v}$. Sie ist bezeugt durch zwei Codices Parisini graeci aus dem 15. und 16. Jahrhundert, vgl. Wahl 1977, 25 (griechischer Text); 11-12 (Handschriften). Die Legenda Isaiae, eine

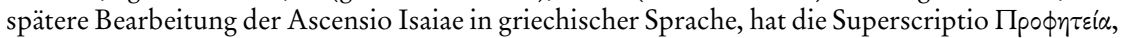

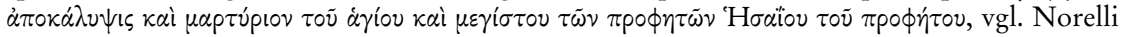
1995, 321-351, speziell 329. In den zwei griechischen Textzeugen des 3 Bar ist die Gattungs-

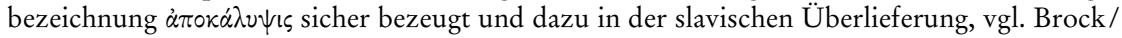
Picard 1967, 81 (griechischer Text); 65-69 (über die zwei griechischen Textzeugen aus dem 15. und 16. Jh.) sowie die (englische) Synopse der griechischen und slavischen Überlieferung bei Kulik 2010, 89. Der Papyrus Bodmer 5 (3. Jahrhundert) bietet für das Protevangelium Jacobi

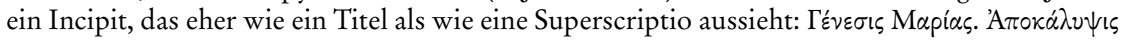
'Iakóßov, vgl. Strycker 1961, 64 (Text); 12-18 (über den Papyrus). - Sicher in der Antike be-
} 
deren syrische Version in der Superscriptio als anylg (geljânâ) bezeichnet wird, was auf griechisch * $\dot{\alpha} \pi \circ \alpha \dot{\lambda} \lambda \nu \psi ı$ z zurückgehen kann, zumal die Superscriptio das 2 Bar als Übersetzung aus dem Griechischen bezeichnet. Mehr als die syrische Version ist uns hier nicht erhalten, und diese auch nur in einer Handschrift aus dem sechsten oder siebten Jahrhundert, womit wir kaum eine sichere Bezeugung

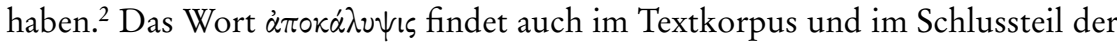
Apc Joh keine Entsprechung (noch nicht einmal das Verb $\alpha \pi \circ \kappa \alpha \lambda v i \tau \varepsilon \sigma \theta \alpha \iota$ begegnet dort), ist also auch nicht unbedingt aus dem Werk heraus zu verstehen. Passend dazu begegnet die nächste Parallele zu diesem Sprachgebrauch in einem anderen Text, und dort gleichfalls in der Superscriptio: Die Apokalypse des Mose (Apc Mos) bezeichnet sich in der Superscriptio als $\dot{\alpha} \pi \circ \kappa \alpha \lambda \nu \phi \theta \varepsilon \tilde{\sigma} \sigma \alpha \pi \alpha \rho \dot{\alpha} \theta \varepsilon \circ \tilde{v}$ („offenbart von Gott“). ${ }^{3}$ Dies ist, wie sich zeigen wird, nicht die einzige Parallele zwischen den Superscriptiones beider Werke.

2. Jesus Christus: Wir haben es mit einer „Apokalypse Jesu Christi“ $(1,1) \mathrm{zu}$ tun, nicht, wie im Titel und schon früh im kirchlichen Sprachgebrauch, mit einer

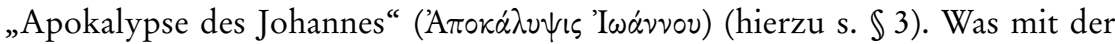
Bezeichnung „Apokalypse Jesu Christi“ gemeint ist, wird im Schlussteil klarer (Apc Joh 22,6-21), wo - vermittelt durch einen Engel - Jesus Christus diese als Buch bezeichnet und autorisiert. Jesus Christus ist der Autor der Apokalypse.

3. Gott: Laut Apc Joh 1,1 hat er Jesus Christus die Apokalypse gegeben. Dementsprechend ist in Apc Joh 1,2 von einem Zeugnis des Johannes über das Wort Gottes die Rede (s.u.). Gott wird als Ausgangspunkt des textgenetischen Geschehens explizit und als aktiv Handelnder vor Augen geführt; das ist untypisch für die Apokalypse, die von Gott sonst eher passivisch redet und gewöhnlich im Modus des Passivum divinum, bei dem nur die Handlung sichtbar ist, nicht aber das logische Subjekt, als welches dann jeweils Gott zu verstehen ist, ohne dass er vor das Auge des Lesers tritt (vgl. etwa Apc Joh 6,2.4.8.11; 9,1.4.5.15; 11,1 etc.). Explizit genannt wird Gott als Ursprungsort des Offenbarungsgeschehens auch

finden wir uns nur mit Prot Ev Jac (gr/pap.bodm), aber das Protevangelium Jacobi wird wohl kaum älter sein als die Apokalypse des Johannes. Auch der Befund in 3 Bar könnte alt sein, aber nicht mit dieser Sicherheit. Ob er auf eine jüdische Grundschicht des 3 Bar zurückgeht, wage ich erst recht nicht zu entscheiden. Die Apc Esdrae und die Leg Isa haben eindeutig ein byzantinisch-christliches Superstrat, dem auch die Superscriptiones entstammen können; die Asc Isa ist ohnehin eine christliche Schrift, die nach der Apc Joh entstanden sein dürfte, vgl. Dochhorn 23-26.

${ }^{2}$ Die Superscriptio von 2 Bar (syr) im Codex Mailand, syr. B 21 inf. (6./7. Jh.) lautet (fol. 257r): כתבא דגלינה דברוך בר נריא דמפק מן יוניא לסורייא (,Schrift“ der Offenbarung des Baruch, des Sohnes von Nerijah, übersetzt von Griechischen ins Syrische). Vgl. Kmosko 1907, 1070. Zur handschriftlichen Überlieferung von 2 Bar vgl. Klijn 1983, 615-616. Die arabische Version des 2 Baruch, 2 Bar (ar), ist am Anfang verstümmelt, vgl. den Text bei Leemhuis/Klijn/Van Gelder 1986, 16-17.

${ }^{3}$ Zum Text vgl. Dochhorn 2005a, 177. Die Superscriptio der Apc Mos ist textkritisch gesichert, da sie sich nach dem gleichen Muster rekonstruieren lässt wie das Textkorpus der Apc Mos und weil es zudem eine Parallele in der Superscriptio des Jubiläenbuches findet, von dem die Apc Mos vielfach abhängt, vgl. ibidem 177-183; 186-188. 
in der Superscriptio der Apokalypse des Mose, aber dort ist von Gott - anders als in der Superscriptio der Apc Joh - passivisch die Rede (vgl. die oben erwähnte Wendung $\dot{\alpha} \pi \circ \kappa \alpha \lambda \nu \phi \theta \varepsilon \tilde{\sigma} \alpha \alpha \alpha \rho \dot{\alpha} \theta \varepsilon \circ \tilde{v}$ in Apc Mos superscr.).

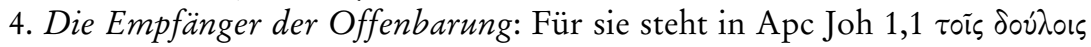

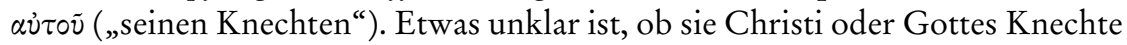
sind; normalerweise sind Knechte in der Apokalypse Gott zugeordnet (Apc Joh 7,3; 10,7; 11,18; 15,3; 19,2.5; 22,3), aber auch Christus (Apc Joh 2,20; vielleicht auch 22,3). Referenz auf Gott ist nicht nur hier genauso möglich wie Referenz auf Christus; auch der offenbarungsmittelende Engel kann Gottes wie Christi Engel sein (s. u.). „Die Knechte“ erhalten die Apokalypse, um über das aufgeklärt zu werden, was „in Kürze“ ( $(\dot{\nu} \tau \dot{\alpha} \chi \varepsilon \varepsilon \iota)$ geschehen wird. Entsprechend werden in Apc Joh 1,3 diejenigen glücklich gepriesen, welche „die Worte dieser Prophetie lesen und hören“; mit ihnen sind wohl auch „die Knechte“ gemeint, die sich hier

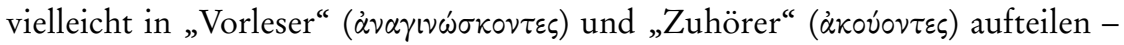
entsprechend einer dementsprechend imaginierten kirchlichen Verlesungspraxis (vgl. 1. Thess 5,27; Kol 4,16).

5. Der Engel: Er ist für die Übermittlung der Apokalypse an Johannes zuständig. Berichtet wird von ihm, dass einer „durch seinen Engel hindurch“ ( Im griechischen Text steht für die Sinnvermittlung das Wort દ̇ $\eta^{\prime} \mu \alpha v \varepsilon v$, dessen genauer Bedeutung hier nicht nachgegangen werden kann. ${ }^{4}$ Subjekt der Sinnvermittlung wird zunächst einmal Gott sein, da dieser das primäre Subjekt des Offenbarungsgeschehens ist (s.o.), und der Engel dürfte damit auch Gottes Engel sein. Dies geht aus dem Anfang des Schlussteils der Apokalypse in 22,6-21 hervor, wo der Engel über sich selbst unter Aufnahme von Wendungen aus der Superscriptio mitteilt: „Und der Herr, der Gott der Geister der Propheten hat seinen Engel ausgesandt, um seinen Knechten zu zeigen, was zu geschehen hat in Kürze“ (22,6). Im gleichen Schlussteil wird aber auch Christus als der Entsender des Engels benannt $(22,16)$. Christus und Gott sind in Apc Joh 22,6-21 partiell funktionsidentisch oder -analog. Dementsprechend wird der Engel auch hier Gottes wie auch Christi Engel sein; das Subjekt von ż $\sigma \dot{\eta} \mu \alpha v \varepsilon v$ bleibt vielleicht mit Absicht offen (Gott ist gleichermaßen denkbar wie Christus). Wie bei diesem Vorgang die Rolle des Engels genau zu denken ist, ergibt sich ebenfalls aus Apc Joh 22,6-21, allerdings nicht explizit: Aus 22,6. 9. 10 geht hervor, dass dort der Engel redet. Das Subjekt mehrerer Ich-Aussagen, die dann folgen, ist allerdings

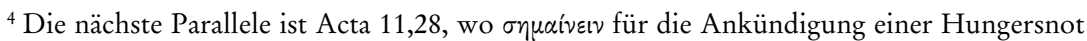
durch den Propheten Agabus steht; weiteres zum Wortgebrauch siehe bei Aune 1997, 15. Zu prüfen ist, ob das Wort in Apc Joh 1,1 in den weiteren Zusammenhang einer Sprachtheorie der Apc Joh 1,1 gehört, derzufolge prophetische Rede anders (eigentlicher) mit Worten umgeht als die gewohnte Rede, vgl. Apc Joh 11,8, wo der Ort der Kreuzigung Jesu „geistlich“ ( Sodom und Ägypten heißt (der Name Jerusalem fällt erst gar nicht und bezieht sich in der Apokalypse durchgehend auf die himmlische Stadt, vgl. Apc Joh 3,12, 21,2.10). 
ein anderer, entweder explizit Jesus (vgl. 22,16) oder implizit Jesus (oder Gott?), vgl. 22,7. 12-13. 18-19. Also redet, wenn der Engel redet, eigentlich nicht der Engel; das Reden geschieht „durch ihn hindurch“ ( $\delta \dot{1}$ - die räumliche Bedeutung dieser Präposition kann mitgedacht werden). Einen Namen führt dieser Engel nirgends, aber er ist laut Apc Joh 21,9 identisch mit einem der sieben Engel, die den letzten Plagenzyklus auslösen, und er fungiert ab Apc Joh 17,1, also im Anschluss an den letzten Plagenzyklus und da, wo es um den Untergang Babylons (= Roms) und die positive Zukunft Zions (= der Christenheit) geht, als Gesprächspartner des Johannes (vgl. Apc Joh 17,1. 7. 15; 19,9-10; 21,9. 15; 22,1). Besonders eng verknüpft erscheint er ansonsten mit der Handlung der Apokalypse nicht; die Visionen der Apokalypse werden anderwärts nicht als durch Engel vermittelt oder gedeutet geschildert, erst recht nicht durch nur einen speziellen Angelus interpres. ${ }^{5}$

Das angelologische Konzept der Superscriptio (und mit ihr der letzten Kapitel der Apokalypse) ist daher wohl weniger von der Apokalypse des Johannes selbst her zu erklären. Passend dazu findet sich wieder eine Parallele in der Superscriptio der Apokalypse des Mose, wo der Erzengel Michael Mose die Offenbarung Gottes vermittelt (für den Vermittlungsvorgang steht dort $\delta_{1} \delta \alpha \chi \theta \varepsilon i \sigma \alpha$ ). Interessanterweise spielt dieser Offenbarungsvorgang im Textkorpus der Apokalypse des Mose sonst keine Rolle, wohl aber tritt Michael im Schlußteil der Apc Mos verstärkt in Erscheinung, so in Apc Mos 38-43 und dann vor allem in Apc Mos 43, wo er halakhisches Offenbarungswissen zu Bestattung und Totentrauer an Seth übergibt. Wie in der Apokalypse des Johannes tritt also der in der Superscriptio als Offenbarungsmittler bezeichnete Engel vor allem am Schluss als jemand auf, der im Auftrag Gottes etwas weiß.

6. Johannes: Er ist genauso wie die Zielgruppe der Apokalypse jemandes

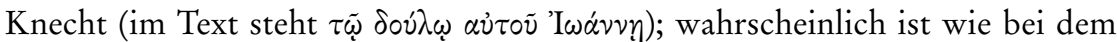
Engel an Gott gleichermaßen wie an Christus zu denken (s.o.). Johannes steht durch den Titel „Knecht“ in einer Reihe mit den anderen Knechten, die Empfänger der „Apokalypse Jesu Christi“ sind; offenbar tendiert er mit Hinblick auf seine Person zur egalitären Titulatur. Dies findet eine Entsprechung im Schlussteil der Apokalypse (vgl. Apc Joh 22,9), wo auch der Engel, der Johannes die Offenbarung vermittelt, in diesen Zusammenhang einbezogen erscheint (er nennt sich dort Mitknecht und will die Proskynese an dieser Stelle allein Gott zukommen lassen). Zu vergleichen ist auch Apc Joh 19,9-10, wo der Engel dasselbe sagt und Johannes als Bruder von mehreren Brüdern anspricht. Die Rolle des Johannes besteht der Superscriptio zufolge darin, dass er das Wort Gottes

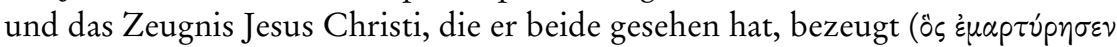

\footnotetext{
${ }^{5}$ In Apc Joh 5,5; 7,13-17 übernimmt allerdings jeweils einer der 24 Presbyter um den Thron Gottes die Aufgabe der Visionsdeutung. Die Presbyter sind meines Erachtens engelaffin; sie entsprechen den Thronen von Kol 1,16, vgl. Dochhorn: Presbyter (erscheint demnächst).
} 


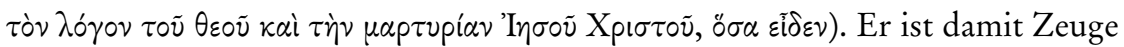
für die von Gott ausgehende Offenbarung Jesu Christi. Im Schlussteil wird dann hervorgehoben, dass er den Inhalt des vorliegenden Buches gehört und gesehen

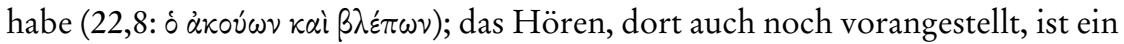
Spezifikum jener Passage.

Dass Johannes die Apokalypse geschrieben habe, wird in der Superscriptio nicht gesagt, auch nicht im brieflichen Incipit (Apc Joh 1,4-6); seine Beteiligung an der Buchentstehung ist dort eher die eines Wahrnehmenden und eines Approbanden. Auch im Schlussteil wird dies nicht ersichtlich, wo allerdings die Apokalypse ausdrücklich als Buch bezeichnet wird (22,18. 19). Deutlich tritt Johannes hingegen als Schriftsteller hervor in Apc Joh 1,11. 19, das allerdings eher in einen Kontext gehört, der die Apokalypse als Brief erscheinen lässt.

Die Konstellation der Akteure und Handlungskonstituenten in der Superscriptio sowie in den mit der Superscriptio assoziierten Texten (vor allem im Schlussteil der Apc Joh) weist das nachfolgende Buch als ein Stück Offenbarungsliteratur aus. Sie hebt dabei vor allem die aktive Seite des Offenbarungsgeschehens hervor und bezeichnet daher nicht Johannes, sondern Jesus Christus als den Autor des Offenbarungswerks (der 'A $\pi \circ$ Ká $\lambda v \psi(\varsigma)$ ), nicht ohne dabei für die Apokalypse des Johannes untypisch deutlich die Herkunft des Offenbarungsgeschehens von Gott vor Augen zu führen. Zugleich erwähnt sie die Vermittlung des Offenbarungsgeschehens durch einen Engel, ein Motiv, das mit dem Textkorpus der Apokalypse zwar vernetzt erscheint, aber in ihm als Ganzem kaum Entsprechung findet. Es hat sich des weiteren angedeutet, dass die marginale Rolle des Johannes als Autor ebenfalls eher ein Spezifikum der Superscriptio und des Schlussteils ist; wir werden sehen, dass es im brieflichen Incipit schon ganz anders aussieht. Insgesamt weist die Superscriptio also Spezifika auf, die sie vom Textkorpus und daneben dem brieflichen Incipit auch konzeptionell absetzen, und passend dazu haben wir ihre engsten Parallelen anderenorts gefunden, nämlich in der Apokalypse des Mose.

Es stellt sich die Frage, ob diese besondere Affinität zur Superscriptio der Apokalypse des Mose mehr zu bedeuten hat. Zunächst einmal: Die Apokalypse des Mose ist etwa um die Zeitenwende entstanden und ist wahrscheinlich schon Paulus bekannt; hierauf deuten mehrere Parallelen zwischen der Apokalypse des Mose und (proto-) paulinischen Briefen. ${ }^{6}$ Sie wird unter Juden und Christen im ersten Jahrhundert n. Chr. durchaus verbreitet gewesen sein, da ihre Traditionen in beiden Religionen schon früh breit gestreut haben (allerdings eher ausgehend von ihrer Ausgabe letzter Hand, der Vita Adae et Evae, in der die Superscriptio der Apc Mos gestrichen wurde; die Apokalypse des Mose ist vor allem in der

\footnotetext{
${ }^{6}$ Vgl. Rm 3,23 // Apc Mos 20,2; 21,6 sowie Rm 7,7-25 // Apc Mos 15-30 und 2 Kor 11,14 // Apc Mos 17,1-2. S. dazu Dochhorn: Adamdiegesen (erscheint demnächst; vorerst einsehbar auf meiner Academia-Seite).
} 
griechischen Kirche erhalten geblieben). ${ }^{7}$ Es ist also durchaus möglich, dass die Apokalypse des Johannes sich mit ihrer Superscriptio an sie anschließt. Vielleicht hat sie es sogar mit der Absicht getan, dass der Leser es merkt. Damit könnte nämlich eine Implikation verbunden sein, die gerade bei der Apokalypse des Johannes hervorragend passen würde und nun - unter ausführlicher Darlegung der in der Superscriptio der Apc Mos zugrundeliegenden Konzeption - zu entfalten ist:

Typisch für die Superscriptio der Apokalypse des Mose ist die Botschaft, dass der Inhalt der Apc Mos, exegetische Narrationen über Adam und Eva und damit exegetische Auslegung von Thora-Texten, Mose beim Empfang der Gesetzestafeln vermittelt wurde, also auf die eine Offenbarungssituation zurückgeht, die für die Thora als ganze stehen kann, wie mehrere jüdische und christliche Belege zeigen. ${ }^{8}$ Gemeint ist mit dieser Botschaft der Superscriptio der Apc Mos: Die in der Apc Mos gebotene (narrative) Exegese ist selbst Offenbarung, Exegese ist Offenbarung. Die Affinität zur rabbinischen Lehre von der mündlichen Thora, die ebenfalls stark auf die Offenbarungssituation auf dem Sinai Bezug nimmt, ist evident; vielleicht gehört die Superscriptio der Apc Mos zu ihrer Vorgeschichte. ${ }^{9}$ Die Superscriptio der Apc Mos ist übrigens nicht der erste Text des frühen Judentums, der eine solche Konzeption entwickelt, denn sie greift selber schon auf die Superscriptio und die Autorschaftskonstruktion des Jubiläenbuches zurück, welches ja seinerseits narrative Exegese zur Thora darstellt (vgl. Anm. 3).

Dass es eher die Superscriptio der Apc Mos als die des Jubiläenbuchs ist, von der her die Apokalypse des Johannes zu verstehen sein wird, ergibt sich aus dem

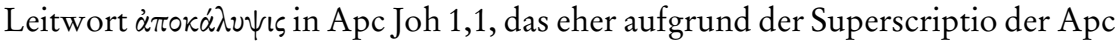
Mos als derjenigen des Jubiläenbuchs erklärt werden kann (vgl. $\dot{\alpha} \pi \circ \kappa \alpha \lambda \nu \phi \theta \varepsilon i \sigma \alpha$ $\pi \alpha \rho \grave{\alpha} \theta \varepsilon o \tilde{~ i n ~ A p c ~ M o s ~ s u p e r s c r .) . ~}$

„Exegese als Offenbarung“ ist auch das Programm der Apokalypse des Johannes. Die Visionen der Apokalypse des Johannes sind - wohl geradezu durchgängig - zu dekodieren, indem man ihre Anspielungen an alttestamentliche Hintergrundtexte richtig identifiziert und damit zu der Entdeckung kommt, dass der Prophet Johannes sieht, was schon die Propheten Israels gesehen haben - mit dem Ergebnis, dass die Apokalypse als prophetische Auslegung alttestament-

${ }^{7}$ Vgl. Dochhorn 2005a, 41-61 über die Vita Adae et Evae als Textzeugen der Apc Mos (und im Zusammenhang damit über die Verbreitung des Textes und einiger Traditionen der Vit Ad in fast allen Sprachen des byzantinischen, westlichen und orientalischen Christentums) sowie Idem: Adamdiegesen (erscheint demnächst), wo unter anderem das Verhältnis zwischen der Apc Mos, der Vit Ad und Paulus zur Sprache kommt. Zur Aufnahme von Traditionen aus der Apc Mos und Vita Ad im rabbinischen Judentum vgl. Dochhorn 2009, 73-77.

${ }^{8}$ Vgl. 1Q 22, Kol. I, 4; 2 Kor 3,13-18; Mischna, Aboth 1,1 sowie Lohse1964, 282-283 über jüdische Vorstellungen zur Sinaioffenbarung (u. a. zur Assoziation von Gesetz und Sinai).

${ }^{9}$ Zum Programm „Exegese ist Offenbarung“ in der Apc Mos vgl. Dochhorn 2005a, 122-124; auf S. 124 (dort Anm. 18) findet sich Material zur Lehre von der mündlichen Thora. 
licher Prophetie verstanden wird. ${ }^{10}$ Die Exegese von Prophetie ist in der Apokalypse des Johannes also selber Prophetie; Exegese ist Offenbarung. Indem die Superscriptio der Apokalypse des Johannes dieses andeutet, ist sie durchaus ein Teil der Apokalypse; sie deutet dies allerdings an durch eine auffällige Nähe zu einem für diese Idee repräsentativen Fremdtext, zur Superscriptio der Apc Mos, und läßt diese Fremdtextnähe wiederum - wie mehrfach erläutert - durch eine eine gewisse Abständigkeit vom Textkorpus des von ihr eingeleiteten Textes erkennen. Es scheint hier ein Lektürewiderstand mit Bedacht gesetzt; diese Technik ist nicht untypisch für die Apc Joh. ${ }^{11}$

\subsection{Die Apokalypse des Johannes als Brief}

Der Briefcharakter der Apokalypse des Johannes und mit ihm die Autorschaft des Johannes tritt deutlich hervor im epistolaren Incipit der Apokalypse (Apc Joh 1,4-6), das auf die Superscriptio folgt. Seine Bauteile sind die folgenden:

1. Als Absender und damit Verfasser fungiert ausschließlich Johannes (Apc Joh 1,4); die Autorschaft Jesu wird nicht noch einmal erwähnt. Darin liegt ein Unterschied zur Superscriptio. Dieser ist aber nicht notwendigerweise auch eine Spannung: Johannes richtet seinen Brief (die Apokalypse) an sieben Gemeinden der Provinz Asia (Apc Joh 1,4), und diese sieben Gemeinden erhalten in Apc Joh 2-3 je einzeln einen speziellen Brief, geschrieben von Johannes, aber diktiert von Jesus (vgl. Apc Joh 1,11. 19). Mit den sieben Sendschreiben in Apc Joh 2-3 ist die Brieflichkeit der Johannesapokalypse besonders nahe assoziiert, durch das Sieben-Gemeinde-Motiv in Apc Joh 1,4 genauso wie durch die kontextuelle Nähe zwischen brieflichem Incipit (Apc Joh 1,4-6) und Sendschreiben (Apc Joh 2-3). Und für die Sendschreiben ist typisch, dass durch Johannes Jesus Christus sich selber mitteilt. Eine Analogie findet sich im Schlussteil der Apokalypse (Apc Joh 22,6-21): Dort redet ein Engel zu Johannes, der sich als der in Apc Joh 1,1 erwähnte vorstellt (vgl. 22,6b), aber es folgen - wohl aus des Engels Munde - Worte Christi. Wenn ein Engel redet, redet Christus, wenn Johannes Briefe schreibt, redet Christus. Vom Textkorpus der Apokalypse her sind die briefliche Autorschaft des Johannes und die Offenbarungsautorschaft Jesu eng miteinander verzahnt.

Johannes stellt sich ohne weiteres Epithet vor; wir werden wohl die Selbstbezeichnung „Knecht Gottes/Christi“ implementieren dürfen, die wir aus Apc Joh 1,1 und indirekt aus Apc Joh 19,10; 22,9 erschließen können und mit der er sich mit den Lesern bzw. Hörern der Apokalypse in eine Reihe stellt, die laut 1,1 ebenfalls Knechte Gottes/Christi sind. Den Hang zur egalitären Selbstbezeichnung teilt die Konstruktion von Autorschaft in der Apokalypse mit der-

\footnotetext{
${ }^{10}$ Vgl. Dochhorn 2010, 64-76.

${ }^{11}$ Lektürewiderständen, auch sprachlichen Härten oder gar Fehlern (Soloezismen), kommt in der Apc Joh vielfach lektürelenkende Wirkung zu, vgl. Beale 1997.
} 
jenigen des ersten Petrusbriefs, wo Petrus zwar im Incipit als Apostel erscheint (1 Petr 1,1), im Textkorpus aber an der einzigen und sehr entscheidenden Stelle, an der er sich selbst zur Sprache bringt, in einer Reihe steht mit den Presbytern, denen er eine Anweisung gibt (1 Petr 5,1). Als Knecht - und zwar des Herrn und Christi - bezeichnet sich sonst noch Jakobus im Incipit des Jakobusbriefs, daneben Judas, der sich im Incipit des Judasbriefs Knecht Jesu Christi und Bruder des Jakobus nennt. Der erste Petrusbrief wie der Jakobusbrief teilen mit der Apokalypse des Johannes wichtige Züge in der Adressatenorientierung (s.u.).

2. Empfänger sind - wie erwähnt - sieben Gemeinden in der Asia. Sie werden

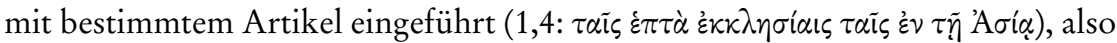
als eine anscheinend schon bekannte Größe. Vielleicht deutet dies auf eine bereits bestehende Beziehung zwischen Johannes und den Gemeinden. An die sieben Gemeinden ergehen dann in Apc Joh 2-3 die sieben Sendschreiben.

Doch sind die sieben Gemeinden nicht nur als Empfänger der Sendschreiben zu denken, sondern der Apokalypse als ganzer, denn in dem Schreibbefehl, der den Sendschreiben vorausgeht (Apc Joh 1,11.19), erhält Johannes die Weisung, das aufzuschreiben, „was er gesehen hat, was ist und was sein wird“ $(1,19)$ : Gesehen hat er die Eingangsvision, was ist, ist die Gegenwart, der die Sendschreiben gelten, und was sein wird, findet sich im Visionsteil, der bis ans Ende des Buches geht (Apc Joh 4 ff). Es ist die Apokalypse als Ganze gemeint, wenn von der Apokalypse als Brief zu reden ist, aber ihre Brieflichkeit konstelliert sich im Zusammenhang mit den Sendschreiben, und dementsprechend ist die Apokalypse nur an die sieben Gemeinden gerichtet, an die auch Sendschreiben gehen.

Viktorinus von Pettau hat die sieben Gemeinden dahingehend gedeutet, dass sie für die Kirche als Ganze stünden, und er findet eine Analogie in den Paulusbriefen, wo sich die Anzahl der von Paulus adressierten Gemeinden auf sieben summiert (Commentarius in Apocalypsin I,7 = CSEL 49,28). Fast die gleiche Idee findet sich im Canon Muratori, der auch gleich Johannes zum Vorgänger des Paulus macht (Can Mur, Z. 39-51) ${ }^{12}$, eine Sicht zur urchristlichen Literaturgeschichte, die sich vielleicht in der von Epiphanius vorgenommenen Datierung der Apokalypse zur Zeit des Claudius wiederspiegelt, vgl. Epiphanius, Panarion 51,33,9 (Holl II,308). Die sieben Gemeinden der Apokalypse wurden in der Alten Kirche anscheinend schon früh als Symbol von Katholizität gedeutet, und es mag sein, dass auch sonst belegte Corpora von sieben Briefen entweder eine Parallele darstellen oder gar unter dem Einfluss dieser Apokalypsedeutung stehen. $\mathrm{Zu}$ denken ist an das Corpus der sieben katholischen Briefe ${ }^{13}$ und die sieben

${ }^{12}$ Vgl. den Text bei Zahn 1901, 74-79, speziell 78.

${ }^{13}$ Die katholischen Briefe sind uns in Handschriften, Kanonverzeichnissen und Kirchen-

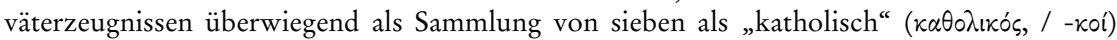
bezeichneten Briefen in der Reihenfolge Jak / 1 Petr / 2 Petr / 1 Joh / 2Joh / 3 Joh / Jud erhalten. Gesichert ist dieser Befund ab dem 4. Jahrhundert, vgl. das Material bei Zahn 1890, 375-380; Preuschen 1910, 36-82; 93. Dieser Befund mag auf eine ältere Sammlung in der ge- 
Gemeindebriefe des Dionysius von Korinth, vgl. Eusebius, Historia Ecclesiastica
IV,23 (Schwartz/Mommsen I,374-379) ${ }^{14}$. Für die Ignatianen als Sammlung kann

nannten Reihenfolge zurückgehen, die unter dem Gesichtspunkt der Siebenzahl als Symbol der Katholizität komponiert wurde - und dies wohl im zweiten Jahrhundert. Folgende Gründe sind dafür zu benennen: 1. In der genannten Reihenfolge ist die Sammlung in unterschiedlichen Quellen des 4. Jh. bezeugt, so bei Athanasius, Festbrief 39, 8 (Preuschen 44); Bibelkanon von Laodicea (Preuschen 71); Cyrill von Jerusalem, Catecheses IV,38 (Preuschen 81-82); diese Streuung wird auf eine ältere Vorlage deuten. 2. Bei Euseb, Hist Eccl II,23,25 (Schwartz/Mommsen

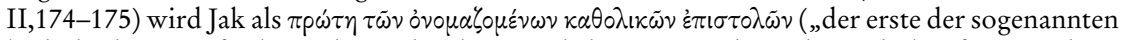
katholischen Briefe) bezeichnet; daneben wird dieser Sammlung der Judasbrief zugeordnet. Euseb scheint ein Wissen um eine Sammlung von sieben katholischen Briefen vorauszusetzen vielleicht in der klassischen Reihenfolge. 3. Ein frühes Zeugnis ist vielleicht Canon Muratori 68-69 (Zahn 1901, 78): Epistola sane Judae et superscriptae Johannis duae in catholica habentur („Der Judasbrief und die zwei als Johannesbriefe betitelten werden natürlich in der „katholischen “ [sc. Sammlung? Kirche?] gehalten”). Das Wort sane könnte andeuten, dass hier nur die umstrittenen Briefe verteidigt werden (womit die Nichterwähnung der anderen erklärt wäre); das Wort catholica kann auf das Korpus der sieben Briefe gehen; vielleicht bezeugt der Canon Muratori indirekt die Schlußstellung von 2 Joh / 3 Joh / Jud, was der klassischen Sammlung entspräche. 4. Ein weiteres frühes Zeugnis ist möglicherweise Clemens, Adumbrationes in Judam 1 (Stählin III, 206), wo es über Judas heißt: Qui catholicam scripsit epistulam („der den / einen katholischen Brief geschrieben hat"). 5. Auf das zweite Jahrhundert deuten die Parallen (sieben Briefe des Dionys; womöglich auch Ignatiusbriefe; s. u.). 6. Mehrere Indizien lassen vermuten, dass der Sammlung Jak / 1-2 Petr / 1-3 Joh / Jud eine kompositorische Strategie zugrundeliegt, bei der dem letzten Glied, dem Judasbrief, eine Schlüsselrolle zufällt: a. Die Reihenfolge Jak / Petr / Joh könnte sich an den drei Säulen in Gal 2,9 orientieren; diese Idee stammt wohl von Leipholdt 1907, 257. Bei Lührmann 1981, 71 findet sich die dazu vielleicht passende Beobachtung, dass im Kanonverzeichnis des Codex Claromontanus (vgl. Preuschen 40-42) die Reihenfolge Petr / Jak / Joh genauso bezeugt ist wie im Text des Codex zu Gal 2,9 (eine typisch westliche Lesart). b. Judas komplettiert die Sammlung im Sinne der Siebenerzahl. c. Mit Judas ergibt sich zugleich eine Inclusio zu Jak, denn Judas bezeichnet sich in Judas 1 als Bruder des Jakobus

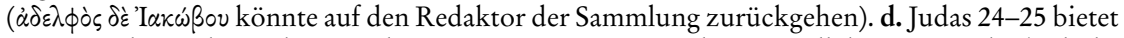
eine Doxologie, die an die Doxologie in Rm 16,25-27 gemahnt; sie soll das Corpus der katholischen Briefe vielleicht genauso abschließen wie Rm 16,25-27 ursprünglich das Corpus Paulinum (vgl. die Finalstellung der Römergemeinde im Can Mur, Z. 53-54). Es könnte eine paulinische Referenz vorliegen - wie schon in dem Bezug auf Gal 2,9. Auch die Doxologie könnte auf den Redaktor der Sammlung zurückgehen. e. Von Judas hängt der 2 Petr ab (vgl. 2 Petr 2,1-22 // Jud 3-16). f. Der 2 Petr wiederum rekurriert explizit auf Paulus, vgl. 2 Petr 3,14-16. g. Paulinische Referenzen in 1 Petr 5,13 // Kol 4,10; Jak 2,20-24 // Rm 4 stabilisieren den Paulusbezug der Sammlung (was nicht heißt, dass sie von ihrem Redaktor geschaffen wären). h. 2 Petr und 1 Joh sind durch antihäretische Rhetorik und das Thema der (dem Häretikertum überlegenenen) Augenzeugenschaft verbunden, vgl. 2 Petr 1,16-21; 1 Joh 1,1-5. i. 1 Petr und Jak sind beide Diasporabriefe (vgl. 1 Petr 1,1; Jak 1,1). j. Das letzte Moment ist wichtig für die Katholizität der Sammlung. Für sich genommen sind manche Briefe dieser Sammlung gar nicht so „katholisch“ (1 Petr geht an eine spezielle Region; 2 Joh an eine Einzelgemeinde, 3 Joh an eine Einzelperson). k. Dies bedeutet: Die Bezeichnung „katholische Briefe“ ist vermutlich der Sammlung von ihrem Redaktor zugewiesen worden. Das Material selbst verhält sich zu der damit zum Ausdruck gebrachten kompositorischen Idee des Redaktors sperrig (wie so oft), lädt auch nicht unbedingt den Leser ein, die Sammlung von sich aus so zu nennen. Die Idee könnte aus der Apokalypse bzw. der Deutung der sieben Sendschreiben im Sinne von Katholizität stammen.

${ }^{14}$ Euseb bezeichnet die Briefe des Dionysius als $\kappa a \theta 0 \lambda \iota \kappa \alpha$, was an die bei ihm geläufige Rede von den sieben katholischen Briefen erinnert (vgl. Anm. 11) und vielleicht durch die Siebenzahl 
Ähnliches gelten, falls Euseb, Hist Eccl III,36 (Schwartz/Mommsen I,274-281), der sieben Ignatianen auflistet und beschreibt (einer von ihnen allerdings an eine Person), Zeuge eines Briefkorpus sein sollte ${ }^{15}$; vielleicht deutet sich auch bei Ignatius selbst ein Verständnis von Briefstellerei im Sinne von Katholizität an, wenn er in Ign, Eph 12,2 schreibt, dass Paulus der Epheser („euer“) in jedem seiner Briefe gedenkt: Anscheinend geht die Epheser mehr als nur ein Paulusbrief an.

Kann es sein, dass schon bei der Apokalypse eine solche Katholizität intendiert ist? Dass die Zahl sieben auf eine Ganzheit deutet, wird man angesichts der Bedeutung von Siebenerzyklen in der Apokalypse wohl von vornherein annehmen dürfen, es gibt aber ein Indiz, das spezifischer ist: Neben den sieben Gemeinden stehen in Apc Joh 1,4 die sieben Geister vor dem Thron Gottes (vgl. dazu Apc Joh 3,1). Der Geist erscheint hier, sieben Gemeinden/Kirchen entsprechend, als ein Kollektiv von sieben Gestalten. Er ist aber in der Apokalypse auch eine Einheit und als solcher mit der einen Kirche assoziiert, wie aus Apc Joh 22,17 hervorgeht, wo der eine Geist neben der Braut (der Kirche) steht. Er scheint dort - als der eine - mit der Kirche als Gesamtheit assoziiert. Geist als Siebenheit und Kirche als Siebenheit, Geist als Einheit und Kirche als Einheit sind in der Apokalypse offenbar Permutationen ein- und desselben Konzepts. Eine Entsprechung findet diese Konstellation in den sieben Sendschreiben: Dort spricht jeweils der eine Geist zu jeder einzelnen der sieben Gemeinden (Apc Joh 2,7. 11. 17. 29; 3,6.13.22), aber er tut es siebenmal - passend zur Siebenzahl der Geister.

Es ist auf der anderen Seite nicht zu übersehen, dass die Sendschreiben sehr konkrete Gemeindesituationen in den Blick nehmen, also nicht einfach in Rom genauso gelten werden wie in Laodizäa (s. 2.3). Mindestens der Apokalypse als ganzer wird indes ein gesamtkirchliches Anliegen unterstellt werden dürfen, allein schon deshalb, weil der Weltuntergang wohl nicht nur ein Problem für die Provinz Asia ist. Ein interessanter außerkleinasiatischer Bezug zeigt sich etwa in Apc Joh 18,4, wo Christen aufgefordert werden, Babylon zu verlassen; Babylon ist Rom (vgl. 1 Petr 5,13). Das ist wohl eine Anweisung, aus Rom herauszuziehen, bevor nur noch rauchende Trümmer übrig bleiben (vgl. Apc Joh 18,9), eine Anweisung, die vielleicht durch den Auszug der Christen aus Jerusalem nach Pella während des jüdischen Krieges angeregt ist ${ }^{16}$ und die nur dann sinn-

der Gemeindebriefe des Dionysius verursacht ist (es tritt ein Personbrief an eine Chrysophora hinzu, vgl. Hist Eccl IV,23,13). Vgl. Harnack 1926, 79 (dort Anm. 2).

${ }^{15}$ In der handschriftlichen Ignatius-Überlieferung gibt es mehrere Korpora, von denen keines Inhalt und Reihenfolge der eusebianischen Zusammenstellung aufweist, vgl. Bihlymeyer 1924, XXXI-XXXVIII. Ein früher Zeuge für die Sammlung von Ignatiusbriefen ist Polykarp, Ad Philippenses 13,2 (zitiert bei Euseb, Hist Eccl III,36,13 [Schwartz/Mommsen I,280-281]).

${ }^{16}$ Zum Auszug der Christen Jerusalems nach Pella vgl. Euseb, Hist Eccl III,5,3 (Schwartz/ Mommsen I, 196-197). Der Gedanke an den Auszug aus Jerusalem würde zur Vorstellungswelt der Apc Joh passen, denn in ihr sind der Kreuzigungsort (in konventioneller Rede: Jerusalem) 
voll erscheint, wenn die Apokalypse auch außerhalb der sieben Gemeinden gelesen werden soll.

Parallelen findet der Adressatenbezug der Apokalypse im ersten Petrusbrief: Auch dieser ist an eine Reihe von Gemeinden gerichtet; das briefliche Incipit nennt fünf anatolische Provinzen. Der Brief ist aber inhaltlich so allgemein (sein Fokus liegt auf dem Umgang mit sozialer Diskriminierung, die Christen widerfährt), dass auch bei ihm wohl ein gesamtkirchlicher Bezug mitzudenken ist.

Eine Affinität des Adressatenbezugs der Apokalypse zum Jakobusbrief ergibt sich daraus, dass dort die Adressaten ganz eindeutig mit einem Symbol für Totalität bezeichnet werden. Der Brief richtet sich laut Jak 1,1 an die zwölf Stämme der Diaspora. Interessanterweise ist auch diese Totalität nicht mit Notwendigkeit die Gesamtheit der Christen. Wenn Jakobus als der Herrenbruder $\mathrm{zu}$ denken und damit vom Leser in Jerusalem zu imaginieren sein sollte ${ }^{17}$, dann ist wohl die Diaspora der Rest der Welt abgesehen von Jerusalem (und vielleicht dem Land); die Christen in Jerusalem und Umgebung sind dann nicht mitgemeint. Gleichwohl werden die Weisheitsworte des Jakobusbriefes, die meist nur wenig situationsbezogen erscheinen, nicht ausgerechnet in Jerusalem oder in Palästina ungültig sein, und dementsprechend kann die Zahl Zwölf dann doch auch wieder das ganze Israel und damit wohl die Kirche auch einschließlich derer in Jerusalem und im Land konnotieren.

3. Die Salutatio steht mit der Formel „Gnade und Friede“ den Paulusbriefen nahe; mit ihnen teilt sie auch das Nebeneinander von Gott und Christus als Quellort von Gnade und Friede, aber diese binitarische Konstruktion scheint hier trinitarisch erweitert, worin sich vielleicht ein fortgeschrittenes Stadium der urchristlichen Briefschriftstellerei erkennen lässt. ${ }^{18}$ Ein Spezifikum der Apokalypse besteht darin, dass für den Geist sieben Geister figurieren, die „vor dem

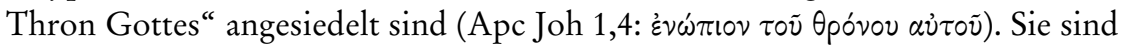
in Korrelation zu den sieben Gemeinden und den sieben Sendschreiben zu sehen (s.o.), doch sind die sieben Geister auch außerhalb der Sendschreiben relevant, vgl. Apc Joh 5,6 und wahrscheinlich Apc Joh 8,2, wo von sieben Engeln die Rede

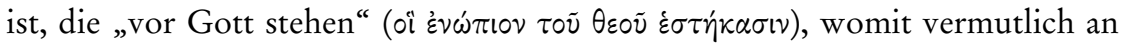
die Erzengel gedacht ist, aber auch an den Geist bzw. die sieben Geister (vgl. die

und Babylon (ansonsten bekannt als: Rom) miteinander assoziiert; beide sind „die große Stadt“, vgl. Apc Joh 11,8; 18,10 .

${ }^{17}$ Nach Popkes 2001, 64 besteht in der Forschung weitgehend Einigkeit darüber, dass der Herrenbruder Jakobus als impliziter Autor zu sehen ist, vgl. dort speziell die Literaturdokumentation in Anm. 467. Im Rahmen der katholischen Briefe hat er ebenfalls als solcher zu gelten, vgl. Anm. 11.

${ }^{18}$ Mit ihrer trinitarischen Salutatio steht die Apokalypse des Johannes im Neuen Testament allein; es lässt sich auch keine Parallele unter den Apostolischen Vätern finden. „Fortgeschritten“ ist hier also im Sinne einer tendenziell sekundären Sonderentwicklung zu verstehen. 
verbalen Anklänge an Apc Joh 1,4). ${ }^{19}$ Spezifisch für die Salutatio der Apokalypse sind auch der Gottestitel in 1,4 (der dreigliedrige Gottesname als Entfaltung der

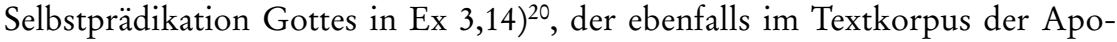
kalypse Entsprechungen findet (Apc Joh 1,8; 4;8; 11,17; 16,5), und die Epitheta für Christus, unter denen etwa „der Erstgeborene von den Toten“ stark an Apc Joh 12,1-6 gemahnt (auch dort gibt es eine Geburt, und zwar die des Auferstandenen). ${ }^{21}$ Das briefliche Incipit der Apokalypse ist gerade durch die Salutatio sehr eng mit dem Textkorpus der Apokalypse vernetzt, mit den Sendschreiben gleichermaßen wie mit den Kapiteln danach. Der Briefcharakter der Apokalypse als Ganzer wird damit umso deutlicher.

Typisch für den Briefcharakter der Apokalypse scheint ein merkwürdiges Nebeneinander von Einzelgemeindenbezug, Bezug auf sieben kleinasiatische Gemeinden und Katholizität zu sein. Dementsprechend ist die Apokalypse Brief, insofern sie die Sendschreiben enthält, aber auch Brief als ganze. Sie ist, was den Adressatenbezug betrifft, auf dem Weg zur Katholizität, kennt aber auch spezifischere Gemeindebezüge, und mit dieser Konstellation findet sie Parallelen vor allem im ersten Petrusbrief. Als Brief, weniger als Offenbarungsschrift, ist die Apokalypse deutlich Werk des Verfassers Johannes, der aber dann, wo er Texte verfasst, deren Brieflichkeit explizit vor Augen geführt wird, nämlich die Sendschreiben, nur ein Diktat Christi wiedergibt. Hier ist er wieder in der Rolle, die er in der Superscriptio innehatte. Er changiert auf interessante Weise zwischen Selbersein und einem Aufgehobensein in Christus; im urchristlichen Milieu hat dies die Bedeutung eines Autors wohl eher erhöht als gemindert, wie sich am Beispiel des gerade im Galaterbrief sehr autoritären Paulus zeigt, der ja gar nicht selber lebt, sondern Christus in ihm (Gal 2,20).

\subsection{Die Inszenierung von Autorschaft im Textkorpus}

Mögen auch die Proömien und die mit ihnen stärker verbundenen Texte besonders deutlich erkennen lassen, wie Autorschaft in der Apokalypse gedacht ist, so wäre das Bild doch unvollständig ohne einen Blick auf das Textkorpus. In diesem ist nämlich vor allem der vom brieflichen Incipit in den Vordergrund gerückte Autor beziehungsweise der Seher Johannes nahezu durchgehend präsent. Das Textkorpus der Apokalypse als ganzer, den Schlussteil inbegriffen, ist eine in der Ich-Perspektive gehaltene Erzählung von Visionen und Auditionen,

${ }^{19}$ Wir haben es in der Apokalypse anscheinend mit einer Engel-Pneumatologie zu tun. Ein traditionsgeschichtlicher Zusammenhang mit den sieben „Ersterschaffenen“ ( $\pi p \omega \tau o ́ k \tau \imath \sigma \tau о \iota)$ bei Clemens von Alexandria ist zu vermuten, vgl. Bucur 2008. Zu den sieben Ersterschaffenen bei Clemens vgl. v. a. den Beleg in Eclogae Propheticae 57 (Stählin/ III,153-154).

${ }^{20} \mathrm{Zu}$ den targumischen Parallelen vgl. Aune 1997, 32-33 (Literatur!).

${ }^{21}$ Zur Deutung der Messiasgeburt in Apc Joh 12,1-6 (speziell 12,5) auf das Ostergeschehen vgl. Dochhorn 2010, 335-342 (dort wird auch die exegetische Arbeit der Apokalypse mit Ps 89 erläutert). 
eine Visionserzählung des Sehers, und dies ab Apc Joh 1,9, wo nach zwei dieser Perspektive enthobenen Prophetenworten (1,7-8) der Seher sich selbst, auf das Briefincipit zurückkomend, vorstellt mit den Worten: „Ich, Johannes“. Diese Ich-Perspektive ist bis zum Schluss durchgehalten, wird aber durchbrochen durch andere Redeformen, etwa das Diktat (an das Ich des Sehers) in den Sendschreiben (Apc Joh 2-3), wo Christus das Ich ist, das redet, womit die aus der Suprerscriptio bekannte Christus-Autorschaft wieder zum Zuge kommt. Vielfach schiebt sich auch, bedingt durch die Fülle des narrativen Materials, eine neutrale Erzählperspektive in den Vordergrund, etwa in Apc Joh 12, wo nur in Apc Joh 12,10 das Ich des Sehers dem Leser vor Augen tritt. Typisch für die Apokalypse erscheint, dass der Ich-Erzähler nicht nur berichtet, sondern in das Geschehen involviert ist. Deutlich wird dies schon in der Eingangsvision (1,9-20): Hier hört und sieht Johannes nicht nur etwas, sondern er nimmt am Visions- und Auditionsgeschehen teil: Er hört am Anfang eine Stimme hinter sich $(1,10)$, er fällt dem, den er sieht, zu Füßen $(1,17)$, aber dieser legt ihm die Hand auf die Schulter (ebenda), und dann soll er schreiben (1,19ff.).

Alles in allem ist der Autor Johannes in der Apokalypse also erstaunlich präsent, aber damit ist sie nicht völlig untypisch für das Neue Testament. Eine Ich-Perspektive, die ein Textkorpus als ganzes umfasst, kann auch für die neutestamentlichen Briefe konstatiert werden, nur dass es sich hier gewöhnlich nicht um eine narrative, sondern um eine diskursive Ich-Perspektive handelt: Es wird aus der Perspektive eines Ichs (oder Wir) argumentiert oder etwa auch Rat und Anweisung gegeben. Sehr deutlich wird dies im Corpus Paulinum, wo Paulus sich in den Textcorpora an insgesamt 16 Stellen namentlich nennt (Deuteropaulinen eingeschlossen); viel häufiger begegnet ein Ich oder Wir, das auf ihn (vielleicht auch seine Mitabsender) verweist. Weniger klar tritt ein diskursives Ich in anderen Briefen hervor, etwa im Jakobusbrief, aber hier ist zu beachten, dass auch schon die Anrede „meine Brüder“ (Jak 2,1) eine Ich-Perspektive konstituiert; eine solche fehlt selbst im Hebräerbrief nicht, der ja bekanntlich kein Präskript hat, also ohne Angabe von Verfasser und Adressat einsetzt (vgl. das - inklusive, nicht auktoriale - Wir in Hebr 1,2; 2,1 und die Anrede „heilige Brüder“ in Hebr 3,1).

Durchaus anders sieht die Situation in den Evangelien aus. Im Markus-Evangelium ist ein Autor als Person nicht erkennbar (vgl. aber die Ansprache des Lesers in Mk 13,13), es sei denn, man sieht den nackten Jüngling in Mk 14,51-52 als eine Autorenreferenz. ${ }^{22}$ Eine solche mag im Matthäusevangelium, dessen

\footnotetext{
${ }^{22}$ Diese Annahme ist gar nicht so weit hergeholt. Die Begebenheit mit dem nackten Jüngling ist erstaunlich unwichtig und entbehrt jeglicher Pointe. Wozu wird sie dann also erzählt? Die Aufforderung an den Leser, sich über die Identität dieses Jünglings Gedanken zu machen, ist doch kaum zu übersehen. Und da fällt auf, dass eigentlich niemand die Begebenheit bezeugen kann außer dem Jüngling selbst. Warum bleibt der Zeuge dann aber anonym, sofern er nicht mit dem Erzähler identisch ist? Über die Echtheit von Geschehen und Autor ist damit noch nicht entschieden; zu bedenken ist aber, dass ein Johannes Markus Jerusalemit war, vgl. Acta 12,12. Vgl. die Überlegungen bei Weiss ${ }^{6} 1878,203$ sowie ${ }^{3} 1906 / 1907$, II,216-7, der auch noch
} 
„Textersteller“ ansonsten ebenso unsichtbar bleibt, mit der Ersetzung des Zöllners Levi durch den Zöllner Matthäus vorliegen (Mt 9,9; vgl. Mk 2,13 // Lk $5,27) .{ }^{23}$ Wie ein Stück Autorenliteratur führt sich das Lukasevangelium und die Apostelgeschichte in den Proömien ein (Lk 1,1-4; Acta 1,1-2), aber der Autor bleibt anonym und tritt in seinem Werk auch danach nicht mehr in Erscheinung - jedenfalls nicht im Evangelium. In der Apostelgeschichte gibt es die vieldiskutierten Wir-Passagen: Mit Acta 16,10 drängt sich ziemlich unvermittelt für einige Textabschnitte ein Wir und damit ein Ich in den Text. Es ist auf jeden Fall ein Erzähler-Ich und soll wohl auch ein Autoren-Ich sein; ob es im Sinne einer Echtheitshypothese so zu verstehen ist (Lukas als Paulusbegleiter) ${ }^{24}$, muss hier nicht diskutiert werden. Interessanter für die Apokalypse ist: Etwas, das der Beteiligung ihres Autors am Geschehen ähnelt, haben wir auch im lukanischen Werk (das im Wir eingeschlossene Ich ist Handlungsteilnehmer). Eine interessante Parallele zu den Wir-Passagen der Apostelgeschichte ist der Lieblingsjünger des Johannesevangeliums: Auch er erscheint eher plötzlich in der Erzählung als gut vorbereitet (vgl. Joh 13,23), bekommt aber mehr Farbe als das Ich im lukanischen Wir. Er wird allerdings mit dem Evangelisten erst vom Nachtrag in Joh 21 identifiziert (vgl. Joh 21,24), den der Evangelist nicht mehr selbst verfasst haben kann, da der Lieblingsjünger laut Joh 21,23 zur Abfassungszeit des Schlusskapitels schon verstorben ist. Vom Johannesevangelium wird noch in einem Appendix die Rede sein.

\subsection{Die Orthonymie der Apokalypse}

Bisher war davon die Rede, wie die Apokalypse Autorschaft konstruiert, und gemeint war Autorschaft, wie die Leser sie sehen sollten, implizite Autorschaft, und zwar dem Gefälle von der Superscriptio zum Incipit und zum Textkorpus entsprechend mehr und mehr die implizite Autorschaft des Johannes. Der implizite Autor kann ein anderer sein als der reale (im Falle von Pseudepigraphie), aber er muss es nicht. Denkbar ist auch der uns aus unserer Lebenswelt viel geläufigere Fall von Orthonymie, also der Autorenechtheit (in welchem Falle freilich immer

die wohl auf Markus bezogenen Worte des Canon Muratori quibus tamen interfuit (, an denen er gleichwohl teilnahm“; Can Mur Z. 1) auf eine partielle Augenzeugenschaft des Markus bezieht, vgl. den Hinweis auf Augenzeugen in Lk 1,2 (als Vorgänger in Sachen Evangelienschriftstellerei?). Vgl. auch Zahn 1899 über die Zionskirche als Ort des Abendmahlssaals, des in Acta 1,13 genannten Versammlungsraumes sowie des Hauses von Johannes Markus. Zu prüfen wird sein, ob der Brückenschlag von den (post-) konstantinischen Traditionen zur Zeit der Urkirche wirklich gelingen kann.

${ }^{23}$ Als Hinweis auf den Evangelisten hat Origenes Mt 9,9 verstanden, vgl. das Exzerpt aus dem ersten Buch des Matthäuskommentar bei Euseb, Hist Eccl VI,25,4-6 (Schwartz / Mommsen II,576-577; Klostermann III/1, 3 [dort Fragment Nr. 1]) und das Fragment zu Mt 9,9 (Nr. 173) bei Klostermann III/1, 84 .

${ }^{24}$ Irenaeus deutet das Wir in den Acta auf den Paulusbegleiter Lukas, vgl. Adversus Haereses III,14,1 (Stieren I, 497-498). 
noch eine Differenz zwischen implizitem und realem Autor besteht, insofern der Autor sich im Werk andersartig darstellen kann, bewusst oder unbewusst, als er in Wirklichkeit ist). Autorenechtheit möchte ich auch für die Apokalypse annehmen: Der Johannes, der hier schreibt - und der soll in dieser Sache vor Allem im Blick sein - ist echt, so echt wie nach der überwältigenden Mehrheitsmeinung der Neutestamentler der Paulus des Galaterbriefes. Ich habe diese Sicht der Dinge anderswo schon begründet ${ }^{25}$, hier reicht die knappe Skizze einer Begründung:

1. Die Apokalypse beleidigt die Laodizener in etwa genauso wie Paulus die Galater: Beide sind des Heils nahezu schon verlustig gegangen (vgl. Apc Joh 3,16 // Gal 5,4). Nehmen wir einmal an, die Situation in Laodizäa sei konstruiert im Sinne pseudepigrapher Schriftstellerei: Dann hätten Christen in Laodizäa bei Erscheinen des Buches wohl gefragt: „Was soll das, sind wir denn so?“ Nehmen wir an, die Situation sei echt gewesen, aber nicht die Apokalypse. Dann hätten sie gefragt: „Wer schreibt uns dies?" Ähnliches beträfe die harsche Kritik an den Nikolaiten und der Prophetin Jezabel: Gab es sie nicht in Pergamon (Apc Joh $2,15)$ bzw. Thyateria $(2,20)$, so war die Apokalypse eine Spiegelfechterei, die wenig überzeugen konnte, gab es sie doch, so konnten sie fragen: „Wer schreibt hier so etwas über uns mit welcher Autorität?". Man vergleiche als Kontrast relativ unzweifelhafte Pseudepigraphen wie etwa den zweiten Petrusbrief: Auch dort werden Christen angegriffen, aber sie werden nicht mit Namen und Adresse genannt (vgl. 2 Petr 2,1 ff.; 3,3-4). Auch der mit dem Galaterbrief thematisch verwandte Kolosserbrief, nach Meinung der meisten Neutestamentler ein Pseudepigraph, schildert zwar verkehrte Ansichten, die der implizite Autor Paulus nicht schätzt, bleibt aber unklar dahingehend, was diese nun direkt in Kolossä angerichtet haben.

2. Die Annahme, dass die Apokalypse des Johannes ein Pseudepigraph sei, wird oft damit begründet, dass Werke der apokalyptischen Literatur des Judentums Pseudepigraphen seien. ${ }^{26}$ Wir lassen jetzt einmal die Frage offen, inwieweit die Apokalypse überhaupt mit der (nach ihr benannten) apokalyptischen Literatur in eine Kategorie gehört (beziehungsweise inwieweit diese Kategorie für Forschungszwecke zu gebrauchen ist). Es sei nur das Folgende angedeutet. Typisch für viele Werke der frühjüdischen Literatur ist die zentrale Stellung (nicht notwendigeweise implizite Autorschaft; s. u.) eines Protagonisten aus der biblischen Erzählwelt (Henoch, Daniel, Baruch, Esra), der sein Wissen - speziell dann, wenn es sich auf die Endzeit bezieht - durch prophetische Geschichtsüberblicke legitimiert, die in Wahrheit Vaticinia ex eventu des (prophetisch meist ausgesprochen unbegabten) realen Verfassers sind. Solche in der Perspektive des realen (und vom realen Autor auch angezielten) Lesers retrospektiven

${ }^{25}$ Dochhorn 2010, 50-52. Als orthonymes Werk sieht die Apc Joh offenbar auch Satake 2008, 32-44.

${ }^{26}$ Vgl. Frey 1993, 425; Strecker 1992, 274. 
Geschichtsüberblicke gibt es aber in der Apokalypse nicht, und ihr Johannes stammt auch nicht aus einer biblischen Erzählwelt, biblisch im Sinne dessen, was damals Schrift war (grosso modo unser Altes Testament). Er verzichtet auf einen Erweis seiner prophetischen Kompetenz - wohl deswegen, weil er nicht erst sicherstellen muss, dass er wirklich der Johannes ist, den man offenbar kennt. Zwischen ihm und den Gemeinden besteht wohl schon eine Beziehung, was vielleicht der bestimmte Artikel bei der Nennung der sieben Gemeinden in Apc Joh 1,4 andeutet (vgl. \$ 2.2) und wohl auch das Lokalkolorit ${ }^{27}$ in den Sendschreiben.

Nur nebenbei sei angedeutet, dass mit dem gattungsbezogenen Pseudepigraphie-Argument schwerwiegende methodische Defizite verbunden sind: Vorausgesetzt wird die Pseudepigraphizität von Werken der jüdischen Offenbarungsliteratur, was keineswegs durchgehend stimmt, denn viele dieser Werke haben einen anonymen narrativen Rahmen (etwa das Danielbuch), durch den sie gerade nicht als Werk eines Autors erscheinen, etwa eines sagenhaften Verfassers aus alter Zeit. Aber selbst, wenn Pseudepigraphizität unfraglich zu konstatieren ist, etwa bei dem vielleicht später als die Apokalypse verfassten vierten Esrabuch, so kann noch nicht geschlossen werden, dass diese jemandem, der selber ein Pseudepigraph schreiben will, zum Vorbild dienen konnte, weil gar nicht so sicher ist, dass dieser sich bewußt sein konnte, es mit mit Pseudepigraphizität zu tun zu haben! Es müsste erst einmal gesichert sein, dass Pseudepigraphizität durchschaubar war, vielleicht auch sein sollte, und damit als Gattungskonvention fungieren konnte. Es gab in der Literatur der Menschheit Pseudepigraphizität, die so funktionierte, etwa in der koptischen Literatur des Mittelalters ${ }^{28}$, aber hier sind wir in einer anderen Zeit und in anderen Milieus. Pseudepigraphie hat viele Gesichter. Und manchmal ist sie auch gar nicht gegeben, so etwa im Falle der Apokalypse des Johannes.

Wer der Apokalypse des Johannes Orthonymie attestiert, sollte theoretisch dazu bereit und in der Lage sein, Auskunft darüber zu erteilen, wer dieser Johannes war. Ich bin dazu bereit, aber gegenwärtig nicht in der Lage. Aufgrund des Autoritätsanspruches der Apokalypse rechne ich mit einem Verfasser, der nicht ganz unbedeutend im christlichen Milieu gewesen sein wird. Als ein solcher kommt der Presbyter Johannes in Frage, den Papias unter anderem als Approbanden des Markusevangeliums erwähnt (vgl. Euseb, Hist Eccl III,39,15 (Schwartz/Mommsen 290-292). Auf ihn dürfte indes eher das Corpus Johanneum zurückgehen ${ }^{29}$, und der Verfasser des Corpus Johanneum muss aus Gründen der Stilkritik ein anderer sein als derjenige der Apokalypse. ${ }^{30}$ Ein anderer

\footnotetext{
${ }^{27}$ Zum Lokalkolorit in den Sendschreiben vgl. Wood 1962 und Hemer 1986.

${ }^{28}$ Vgl. Dochhorn 2014, 51-52; 119-120 (dort Anm. 8d).

${ }^{29}$ Vgl. Hengel 1993.

${ }^{30}$ Nach wie vor bin ich überzeugt durch Frey 1993, da er auch auf Unterschiede im Sprachgebrauch abhebt, die weniger Ausdruck eines unterschiedlichen Stilwillens sind, der auch bei einem Autor wechseln kann, als vielmehr von Prägung.
} 
Johannes, der prominent war, ist der Zebedaide, den schon Justin als Verfasser der Apokalypse ansieht. ${ }^{31}$ Von diesem sagen etwas unsichere Papiastraditionen allerdings, dass er genauso wie Jakobus von den Juden umgebracht worden sei, freilich ohne notwendigerweise auf eine Gleichzeitigkeit des Martyriums hinzudeuten (die ausweislich Acta 12,1 und Gal 2,9 auch ausgeschlossen ist), so dass Johannes dies Martyrium, wenn es denn geschehen ist, auch im hohen Alter widerfahren sein kann. ${ }^{32} \mathrm{Mk}$ 10,35-40 ist kein Argument für einen frühen (vormarkinischen) Tod des Zebedaiden, der ihn als Verfasser der Apokalypse ausschließen würde: Die Ankündigung Jesu, dass die Zebedaiden seinen Becher trinken und seine Taufe empfangen würden, ist wohl kaum ein Vaticinium ex eventu $^{33}$ als vielmehr eine Ankündigung von Leidensnachfolge, bei der man nicht unbedingt ums Leben kommen muß (vgl. die Worte von der Kreuzesnachfolge in Mk 8,34-38, die zu Mk 10,35-40 eine kompositorische Parallele bilden, insofern beide Texte auf eine Leidensweissagung folgen, vgl. Mk 8,31-33 // 10,32-34).

Der Zebedaide ist also noch nicht ausgeschlossen, aber damit haben wir wohl noch nicht genug in der Hand, ihn als Verfasser zu sichern. Es bleibt immer $\mathrm{zu}$ beachten, dass die Apokalypse nicht gerade am Anfang der urchristlichen Literaturproduktion steht und christliche Traditionsbildung in starkem Maße voraussetzt, was sich gerade auch in diesem Beitrag zeigt. Allerdings wird auch nur eine sehr schematische Betrachtung von Geschichte einem Christen der ersten Generation verwehren, zum ersten ein höheres Lebensalter zu erreichen und zum zweiten ein Spätwerk zu verfassen bzw. ein Werk, das auf der Synthese von mehreren Jahrzehnten Christentumsgeschichte beruht. Ein alter Mensch ist selten darauf beschränkt, der Botschafter der Ideen und Erlebnisse seiner Jugend zu sein, und wenn er ist, dann ist er zumeist unbedeutend.

${ }^{31}$ Justin erwähnt in Dialogus cum Tryphone 81,4 (Goodspeed 193-194) „einen Mann mit Namen Johannes, einer der Apostel des Christus“ als Verfasser der Apokalypse; die Bezeichnung „Apostel“ deutet auf den Zwölferkreis, vgl. Dial 42,1 (Goodspeed 138-139); vgl. Dochhorn 2010, 47-48.

${ }^{32}$ Vgl. Papias, Fragment Nr. 10 nach Körtner 1998, 62-63. Dieses Fragment findet sich in einer Sammlung von Euseb-Exzerpten im Codex Oxford, Baroccianus 142, stammt aber nicht aus Euseb und wurde in der Forschung (auch bei Körtner) fälschlich Philipp von Side zugeordnet, vgl. Michael Oberweis: Das Papias-Zeugnis vom Tode des Johannes Zebedäi, New Testament Studies 38 (1996), 277-295, speziell 281-283. Es enthält mehrere Papiasnotizen,

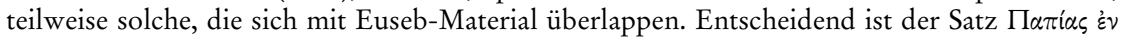

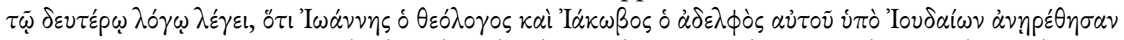
(„Papias sagt im zweiten Buch, dass der Theologe Johannes und sein Bruder von den Juden getötet worden seien“). Vgl. auch Fragment Nr 17 bei Körtner 68-69, ein Konvolut von Informationen über Johannes (Rückkehr aus Patmos unter Nerva; Abfassung des Evangeliums; Tötung durch die Juden laut dem zweiten Buch des Papias; Beweis aus dem Jesuslogion Mk 10,38-39 // Mt 20,23). Dem Kontext nach fand das Martyrium des Johannes im hohen Lebensalter statt, aber der Kontext ist nicht papianisch. Das Fragment Nr. 17 stammt aus einem Textzeugen des Georgius Monachus (Paris, Coislianus 305), vgl. Oberweis (wie oben), 279-280.

${ }_{33}$ Als Vaticinium ex eventu, das auf einen Märtyrertod des Johannes Zebedäus vor Abfassung des Markusevangeliums deutet, wird Mk 10,35-40 verstanden bei Kraft 1974, 10. 


\section{Zur historischen Bedeutung der Autorschaftskonstruktion der Apokalypse des Johannes}

Wie aus dem bisher Erörterten hervorgegangen sein dürfte, ist die Apokalypse des Johannes ein eher spätes Werk urchristlicher Literaturproduktion, in dem neben der Autorschaft Christi als des Offenbarers die Person eines - orthonymen - Autors namens Johannes sehr deutlich vor Augen tritt, deutlicher als in den narrativen Werken des Urchristentums und etwa so klar in der Ich-Perspektivierung wie bei den Briefen des Paulus. Als Hintergrund dieser Autorschaftskonstruktion ist zum einen die neutestamentliche Briefliteratur identifiziert worden und zum anderen die Autorschaftskonstruktion eines Mose-Pseudepigraphs, der Apokalypse des Mose, die ihrerseits ihr Vorbild hatte in der Autorschaftskonstruktion eines anderen Mose-Pseudepigraphs, des Jubiläenbuchs. Es sind also eine typisch frühchristliche Traditionslinie und eine bereits im frühen Judentum etablierte Tradition miteinander kombiniert worden. Das Ergebnis ist eine Autorschaft, der einerseits die persönliche Greifbarkeit des Briefautors eignet und die andererseits so abgeleitet erscheint wie bei dem Offenbarungsempfänger Moses, so dass hinter dieser Autorschaft eine weitere aufscheint, die nicht nur irdischer Natur ist. Der Autor Johannes erscheint mit dieser Konstruktion nicht geschwächt, im Gegenteil: Er kann auf eine außerhalb seiner selbst befindliche Autorität verweisen, ihm eignet Selbersein gleichermaßen wie Aufgehobensein in einem anderen. Das Aufgehobensein in einem anderen war typisch für die Autorenkonzeption der Moseapokalypse, aber interessanterweise war sie eben auch bei dem Briefautor Paulus zu beobachten (Gal 2,20). Die Amalgamierung der zwei im Hintergrund befindlichen Autorschaftskonzepte erscheint damit prästabilisiert durch Ansätze in diesen Konzepten selbst.

Schwer zu klären bleibt, wie die traditionsgeschichtlichen Prozesse genau abgelaufen sind, die dieser Amalgamierung vorausgegangen sein mögen. Dafür müsste eine Geschichte des neutestamentlichen Briefformulars rekonstruiert werden, was hier kaum geleistet werden kann. Nur die folgenden Bemerkungen seien gewagt:

1. Eine besondere Nähe weist das briefliche Incipit der Apokalypse zu dem echter Paulusbriefe auf. Dies ergibt sich aus dem Nebeneinander von Gnade und Friede in der Grußformel sowie aus dem Nebeneinander von Gott und Christus daselbst, die beide spezifisch paulinisch sind. Die Apokalypse teilt diese Eigenheit mit dem ersten Petrusbrief, mit dem sie auch sonst einiges gemein hat und der im Übrigen eine starke Nähe zur paulinischen Theologie aufweist. ${ }^{34}$

2. Die Gegenprobe: Es fehlen Spezifika der Pastoralbriefe (zusätzliches „Erbarmen“ neben Gnade und Friede in der Salutatio der Timotheusbriefe, der Hin-

${ }^{34}$ Vgl. hierzu Goppelt ${ }^{8} 1978,48-51$. 
weis auf Christus als Retter im Titusbrief). Auch mit den Incipits der zwei kleinen Johannesbriefe hat das briefliche Incipit der Apokalypse nicht viel gemein.

3. Erst recht abständig im Vergleich zur Apokalypse sind das Incipit des Jakobusbriefes und das des Apostelbriefes in Acta 15, das mit dem des Jakobusbriefes die völlige Abhängigkeit von einem vorchristlich-griechischen Briefformular teilt $^{35}$ (zufällig? In Acta 15 ist Jakobus als am Brief beteiligt gedacht; was beide Briefe mit dem historischen Jakobus zu tun haben, kann hier indes nicht geklärt werden).

Es sieht insgesamt so aus, als habe die Apokalypse wie der erste Petrusbrief selbständig auf paulinisches Formular zurückgegriffen. Ob ihr Verfasser Paulusbriefe gelesen hat, ist schwer zu klären; zu beachten ist, dass ausweislich der echten Ignatianen Briefe des Paulus im kleinasiatischen (und antiochenischen Milieu) zumindest kurz nach dem Jahre 100 nicht unbekannt waren (vgl. Ign, Eph 12,2). ${ }^{36}$ Aber gerade Konventionen der Briefstellerei können vielleicht auch ohne direkte literarische Abhängigkeit weitervermittelt werden.

Erstaunlich erscheint auf den ersten Blick der Einfluss eines Mose-Pseudepigraphs aus dem frühjüdischen Milieu. Doch dies liegt historisch näher als man zunächst annehmen mag. Zunächst: Dass es ein Pseudepigraph ist, welches hier einen orthonymen Verfasser für die Konstruktion des Autorenbildes beeinflusst, muss nicht überraschen: Die Pseudepigraphizität der Apokalypse des Mose muss ihm nicht unbedingt bekannt gewesen sein, oder er hat ein Verständnis einer solchen Verfasserschaft, mit dem das betreffende Werk nicht als Fälschung erscheint, wie auch immer dieses Verständnis ausgesehen haben mag. Abgesehen davon: Es erscheint tatsächlich naheliegend, dass es genau dieses Pseudepigraphon war, welches hier im Hintergrund steht. Es war schon aufgezeigt worden, dass die Apokalypse des Mose im frühen Christentum auch sonst Spuren hinterlassen hat; hier bleibt hinzuzufügen, dass gerade Mose-Parabiblica im frühen Christentum und seinem Entstehungsmilieu offenbar eine besondere Rolle spielten: Auch das der Mose-Apokalypse nahestehende Jubiläenbuch ist ein Mose-Parabiblicum. Es war schon im Judentum sehr prominent, und später war es in christlichen Kreisen derart etabliert, dass es zumindest in der äthiopischen Kirche kanonisch werden konnte. ${ }^{37}$ Sein lateinischer Text ist fragmentarisch in einem Mailänder Palimpsest aus dem sechsten Jahrhundert überliefert, in dem es mit der Assumptio Mosis zusammensteht, einem weiteren Mose-Parabiblicum, das von der Apokalypse des Mose abhängig sein dürfte und vom Judasbrief wohl

${ }^{35}$ Unter anderem besteht die Salutatio in beiden Briefen wie gewöhnlich in griechischen

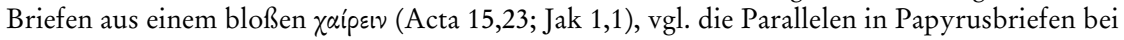
Lietzmann 1934, 4-15.

${ }^{36}$ Zur Rezeption der Paulusbriefe bei Ignatius vgl. Zahn 1889, 816-819.

${ }^{37}$ Das Jubiläenbuch wird im Damaskusdokument zitiert, vgl. CD XVI,3-4 und ist mehrfach in den Qumranfunden bezeugt, vgl. 1Q 18; 2Q 19, 2Q 20; 3Q 5; 4Q 221; 11Q Jub. Zu seiner Verbreitung im Christentum vgl. Rönsch 1874, 251-382. Zum äthiopischen Bibelkanon vgl. Brandt 2000 , 79-115. 
genauso als kanonische Schrift vorausgesetzt wird wie später bei Kirchenschriftstellern des alexandrinischen Christentums (Clemens von Alexandrien, Origenes, Didymus). ${ }^{38}$ Mose-Parabiblica konnten offenbar eine besondere Autorität entfalten im frühen Christentum.

Bei der Konstruktion von Verfasserschaft in der Apokalypse fand also neben einem Rückgriff auf spezifisch Urchristliches (paulinische Briefstellerei) auch die Aufnahme von nichtchristlich-jüdischem Traditionsgut statt. Dies ist gar nicht so untypisch für die Apokalypse: Konstitutiv für ihre Visionen und Auditionen ist einmal der Bezug zu alttestamentlichen Texten und daneben der Einsatz von Traditionswissen, und letzteres kann sowohl spezifisch christlich sein wie dem breiteren Kontext des frühen Judentums entstammen. ${ }^{39}$

Das Autoren-Ich der Apokalypse hat Eindruck bei christlichen Lesern gemacht, und dies schon in ziemlich früher Zeit. Dies gilt zunächst für Justin, der die Apokalypse mit deutlicher Autorenreferenz zitiert, anders als im Falle der Evangelienüberlieferung: Die Evanglienüberlieferung, der man ja einiges an Prominenz zutrauen wird, führt er unter der kollektiven und damit auch anonymisierenden Bezeichnung $\dot{\alpha} \pi \circ \mu \nu \eta \mu \circ v \varepsilon \dot{\mu} \mu \alpha \tau \alpha \tau \tilde{\omega} \nu \dot{\alpha} \pi \circ \sigma \tau \dot{\lambda} \lambda \omega \nu$ („Dokumente der Apostel“) $\mathrm{an}^{40}$, doch den Verfasser der Apokalypse nennt er namentlich: „Ein Mann bei uns mit Namen Johannes, einer der Apostel des Christus" ( $\pi \alpha \rho$ ' $\dot{\eta} \mu \tilde{\nu}$

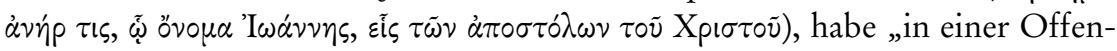

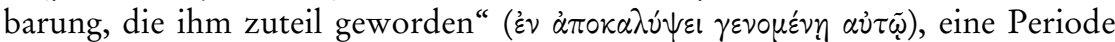
von 1000 Jahren prophezeit, in welcher die Gläubigen vor der Auferstehung der Toten in Jerusalem leben würden. ${ }^{41}$ Hier tritt uns Johannes genauso als Person entgegen wie er als Offenbarungsempfänger ausgewiesen wird, aber der primäre Autor der Offenbarungsmitteilung an Johannes, also Jesus, wird nicht mehr explizit erwähnt. Es passt zu dieser Entwicklung, wenn der Titulus der Apokalypse dann nicht Jesus, sondern Johannes als personales Element mit sich führt, ein Vorgang freilich, der die Evangelien genauso betrifft, deren Tituli ja nicht den allen gemeinsamen Jesusbezug explizit machen, sondern einen unterscheidbaren Evangelistennamen enthalten.

In voller Entfaltung tritt uns ein Bild des Autors der Apokalypse bei Irenäus entgegen. In Adversus Haereses V,30,1 (STIEREN I, 799-801) lehnt Irenäus unter Hinweis auf Augenzeugen, die Johannes von Angesicht zu Angesicht gesehen hätten, eine Textvariante ab, die als Zahl des Tieres 616 liest und nicht 666, und in

\footnotetext{
${ }^{38}$ Vom Codex Ambrosianus C 73 inf (6. Jh.) sind 40 Folien mit dem Jubiläenbuch und 8 Folien mit der Assumptio Mosis in verwirrter Reihenfolge erhalten, vgl. Rönsch 1874, 1-3. Zur Aufnahme der Assumptio Mosis in Judas 9 und bei Kirchenschriftstellern vgl. das Material bei Clemen 1904, 15-16. Ich bereite eine Studie vor, die unter anderem nachweist, dass die Assumptio Mosis von mehreren dieser Kirchenschriftsteller wie wohl auch vom Judasbrief als autoritativ gültiges Schriftzeugnis verstanden wurde.

${ }^{39}$ Vgl. hierzu Dochhorn 2010, 64-76.

${ }^{40}$ Vgl. Apologia Prima 66,3; 67,3; Dialogus cum Tryphone 101,3; 102,5; 103,6.8; 104,1; 106,1,

${ }^{41}$ Vgl. Dialogus cum Tryphone 81,4 (Goodspeed 193-194).
} 
Adv Haer V,30,3 wird dann über den, der die Apokalypse gesehen hat, mitgeteilt, dass dieser das Geheimnis der Zahl 666, den Namen des Antichristen, schon mitgeteilt hätte, wenn dies angemessen gewesen wäre, und dann heißt es schließlich, die Apokalypse sei „beinahe zur Zeit unserer Generation gesehen worden“", nämlich gegen Ende der Regierungszeit Domitians. Hier haben wir einen Autor der Apokalypse, den andere gesehen haben und dessen Zugänglichkeit über Augenzeugenberichte seinen Text gegen Variantenbildung autorisiert. Wie glaubhaft diese Konstruktion immer auch erscheinen mag, wir sollen uns hier als implizite Leser in einer Lage sehen, in der wir uns grosso modo auch bei den Tischgesprächen Luthers wiederfinden, nur dass die Tradenten anonym bleiben.

Ein Moment bleibt hervorzuheben, das auch schon bei den anderen Belegen eine Rolle gespielt hat: Der Autor, der als Person so lebendig vor Augen tritt, wird vorrangig als Seher präsentiert; es scheint, dass ein Seher besonders gute Chancen hat, bei frühchristlichen Rezipienten eine Karriere als Autorenpersönlichkeit zu machen. Eine Parallele hierzu findet sich in einem Buch, das nur kurz nach dem von Irenäus angegebenen Entstehungsdatum der Apokalypse (mag dies nun stimmen oder nicht) entstanden sein soll, und diesmal ist der Gewährsmann Hippolyt. Dieser berichtet in Refutatio IX,13-17 (MArcovich; PTS 25, 357-363) von einem Buch des Elchasai, das für das dritte Jahr des Kaisers Trajan eine allgemeine Gelegenheit zur Buße verkündet (Refutatio IX,13,4) und mit dessen Sieg über die Parther Zukunftsweissagungen assoziiert (Refutatio IX,16,4). Signifikant ist, dass hier sehr klar ein Autor zutagetritt, und dieser wiederum ist ein Seher: Sein Buch sei Elchasai, so Hippolyt, von einem Engel offenbart worden, dessen mehrere Meilen umfassende Leibesgröße ebenso geschildert wird wie die eines ebenso großen weiblichen Engels, der ihn begleitet; die beiden Gestalten werden als der Sohn Gottes und der Heilige Geist identifiziert (vgl. Refutatio IX,13,2-3). Wie im brieflichen Incipit der Apokalypse scheint hier ein Stück christliche Offenbarungsliteratur bemüht, neben Jesus Christus auch dem Heiligen Geist einen gebührenden Ort zuzuweisen. Auch die bei Elchasai stark hervortretende Engelchristologie hat vielleicht Entsprechungen in der Apokalypse, deren Eingangsvision (Apc Joh 1,9-20) sich wohl nicht unbeträchtlich an der Angelophanie in Dan 10,6-11 orientiert. ${ }^{42}$ Vielleicht ist Elchasai abhängig von der Apokalypse, vielleicht hat sie ihn darin bestärkt, sich als Seher-Autor zu präsentieren. ${ }^{43}$

${ }^{42}$ Vgl. Frey 2001, 161-185, speziell 170-173.

${ }^{43}$ Einen Seher-Autor hat auch der Hirt des Hermas, den ich hier aber nicht berücksichtigen kann; zur Autorschaft und Kommunikationsstruktur dieses - wie die Apc Joh orthonymen Werkes vgl. Rüpke 2005 und seinen Beitrag hier im Band. 


\section{Appendix: Eine parallele Entwicklung im Corpus Johanneum}

Die Konstruktion von Autorschaft in der Apokalypse findet Parallelen im Corpus Johanneum. Dort tritt Autorschaft zwar nicht so deutlich vor Augen wie bei der Apokalypse, aber ein Konzept von Autorschaft ist vorhanden, und es beruht wie bei der Apokalypse auf Amalgamierungsprozessen. Es ergibt sich meines Erachtens die folgende Situation, die hier in knapper Form zu umreißen ist: ${ }^{44}$

1. Ausgangspunkt, wenn auch nicht notwendigerweise im Sinne einer zeitlichen Abfolge, sondern im Sinne einer formgeschichtlichen Betrachtung, ist das relativ konventionelle Briefformular der beiden kleinen Johannesbriefe. Ihr Incipit enthält anders als 1 Joh klar erkennbar eine Absenderangabe, eine Angabe zum Adressaten und eine Salutatio; das Explizit enthält Schlussgrüße (2Joh 13; 3 Joh 15). Im zweiten Johannesbrief bietet die Salutatio mit der Formel „Gnade,

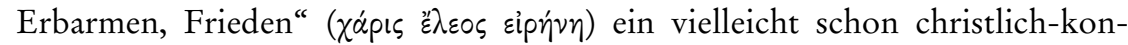
ventionelles Element (2Joh 3; vgl. 1 Tim 1,2; 2 Tim 1,2); im dritten Johannesbrief fällt noch der an das Incipit anschließende Wunsch von Wohlergehen und

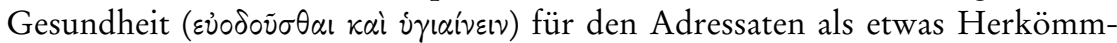
liches ins Auge, das allerdings eher für den nichtchristlichen Kontext typisch sein dürfte (3 Joh 2). ${ }^{45}$ Johanneische Momente sind auch im Formular der kleinen Briefe nicht zu übersehen, etwa das Leitwort „Wahrheit“, das in 3 Joh 1,1 das einzige semantisch tragende Moment der Salutatio ist und das Proöm in 2Joh 1-3 mehrfach bestimmt.

Spezifisch johanneisch ist wohl auch die Absenderbezeichnung im zweiten und dritten Johannesbrief: Der Absender nennt sich „der Alte“ oder „der Ältere“

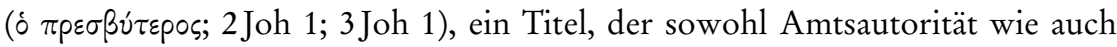
Alter zum Ausdruck bringen kann, gewöhnlich wohl beides, wie die Assoziation von Kirchenleitung und Alter im ersten Petrusbrief und im ersten Clemensbrief andeutet (vgl. 1 Petr 5,1-5; 1 Clem 1,3; 3,3; 21,6). Viele Menschen sind alt, und so stellt sich die Frage, was an diesem Alten so besonderes sein soll. Eine Antwort ergibt sich aus dem Schlussteil des Johannesevangeliums: Der als Autor des Johannesevangeliums dargestellte Jesusjünger (Joh 21,24) wurde ungewöhnlich alt und war damit schon Gegenstand von Legendenbildung; man sagte über ihn, er werde - bis zur Parusie - nicht sterben (Joh 21,20-23): Hier zeigt sich: Diese Person wurde nicht zuletzt aufgrund ihres Alters als wichtig angesehen,

\footnotetext{
${ }^{44}$ Mein Urteil zur Autorschaft des Corpus Johanneum (Joh; 1-3 Joh) ist entscheidend geprägt durch die Studie von Martin Hengel zur johanneischen Frage (1993).

${ }^{45}$ Für Papyrusparallelen speziell zum Wunsch guter Gesundheit vgl. Funk 1967, 424-430.

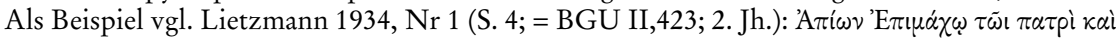

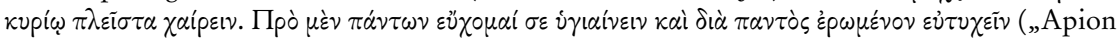
an seinen Vater und Herrn Epimachos, Freude in Fülle! Vor allem bete ich, dass du gesund seiest und es dir kräftiglich gut gehe“).
} 
und so war vermutlich mit seinem Alter auch ein besonderer Anspruch auf Beglaubigung des von ihm vertretenen Standpunktes zum Thema Jesus, wohl auch auf Augenzeugenschaft verbunden, wie ihn das Incipit des ersten Johannesbriefes zeigt (1 Joh 1,1-4). Dementsprechend gibt sich „der Alte“ im zweiten Johannesbrief als Wahrer christologischer Tradition (2Joh 7-11), und auch im dritten Johannesbrief erhebt er mit dem Leitwort „Wahrheit" den Anspruch, über gültiges Wissen zu verfügen (vgl. 3 Joh 1.3.4.8.12).

2. Vom Incipit des ersten Johannesbriefes (1 Joh 1,1-4) war andeutungsweise schon die Rede: Dieses ist geprägt von einem Rückblick auf den Anfang des Christusgeschehens; es wird der Anspruch auf Augenzeugenschaft erhoben, vgl.

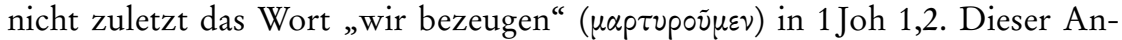
spruch dürfte als funktionales Äquivalent zur Absenderangabe „der Alte“ zu betrachten sein; die Augenzeugenschaft wird passend dazu von einem Autoren-Wir ausgesagt, das allerdings anonym bleibt. Dass dieses Wir für eine Einzelperson steht, ergibt sich etwa aus 1 Joh 2,12.13.14, wo unvermittelt ein singularisches

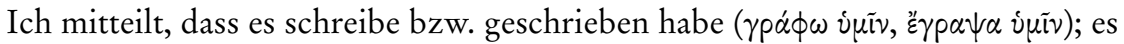
schreibt hier wohl nicht ein anderer als der schon erwähnte "Alte“. Implicit ist damit ein briefliches Moment gegeben, und es gibt deren im Incipit auch mehr: In 1 Joh 1,4 bezeichnet sich das Autoren-Wir als ein solches, das „schreibt“, und als Ziel des Schreibens gibt es an, „dass eure Freude vollkommen sein möge“ (iv $\dot{\eta} \chi \alpha \rho \dot{\alpha} \dot{\eta} \mu \tilde{\omega} \nu \tilde{\eta} \pi \varepsilon \pi \lambda \eta \dot{\eta} \omega \mu \dot{\varepsilon} \nu \eta)$, womit zum einen ein Adressat angedeutet wird und zum anderen wohl auch ein Äquivalent für den Wohlergehenswunsch in 3Joh 2 formuliert ist.

Abschließend bleibt zu erwähnen, dass wahrscheinlich auch das Explicit im ersten Johannesbrief etwas mit Briefkonventionen zu tun hat: Was auch immer der Satz „Kindlein, hütet euch vor den Götzen“ (1 Joh 5,21) bedeuten mag, er ist wie ein Schlussgruß oder ein abschließender Wohlergehenswunsch eine Anrede, die sich vom vorausgehenden Kontext inhaltlich absetzt. Ich kann mir im Übrigen vorstellen, dass er wirklich nicht mehr bedeutet, als er vordergründig sagt. Unter Heiden wünscht man sich Gesundheit (zuweilen am Anfang, oft am Ende $)^{46}$, was selbstverständlich ist, und unter Christen wünscht man sich maximale Distanz zu den Götzen, was ebenfalls selbstverständlich ist, wenn man sich erst einmal an die Religion Israels gewöhnt hat.

3. $\mathrm{Zu}$ vielen der genannten epistolaren Momente gibt es Parallelen im Johannesevangelium: A. Ein Wir, das für autoritatives Wissen und nicht zuletzt Augenzeugenschaft steht, meldet sich auch im Prolog des Johannesevangeliums (Joh 1,14). B. Ein Hinweis auf den Akt des Schreibens und seinen Nutzen für in der zweiten Person angeredete Adressaten findet sich am Ende des Evangelien-Text-

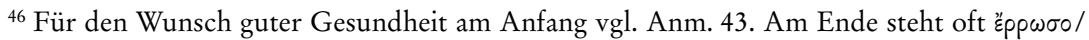
हैрp $\omega \sigma \theta \varepsilon$ („,sei[d] stark “; „leb[t] wohl“), vgl. z. B. Nr. 3 (Pap Oxy II, 292; etwa 25 n. Chr.); 4 (Pap Oxy III, 531; 2. Jh.); 6 (Pap Faj. 112; 99 n. Chr.) bei Lietzmann 1934, 6.6-7.8-9 und dazu Acta 15,29 .
} 
korpus (vor dem Appendix), vgl. Joh 20,31: „Dies ist geschrieben, damit ihr

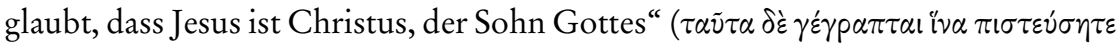

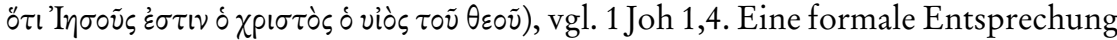
findet Joh 20,31 in Joh 21,24, also am Ende des Evangelien-Appendixes, wo ebenfalls von einem Schreibvorgang die Rede ist und wo als der Schreibende und damit der Evangelienverfasser der Lieblingsjünger (also wohl „der Alte") bezeichnet wird; in diesem Zusammenhang wird seine Zeugenschaft besonders hervorgehoben, die wir schon in 1 Joh 1,2 als ein Motiv epistolarer Rahmung kennengelernt hatten. C. Ein Rekurs auf den Anfang des Christusgeschehens, der dem Titel „der Alte“ implizit und dem Incipit des ersten Johannesbriefes explizit innewohnt, findet sich auch im Incipit des Johannesevangeliums. In der Tat dürfte in 1 Joh 1,1 ff. nicht vorrangig das Schöpfungsgeschehen, sondern das mit Christus verbundene Neuschöpfungsgeschehen im Vordergrund stehen, das durch Schöpfungsreferenzen (1 Joh 1,3) nur typologisch konturiert wird (schon das Erscheinen des Lichts in der Finsternis und das Nichtbegreifen der Finsternis, wie es in 1 Joh 1,5 angesprochen wird, ist eine Referenz auf das Schicksal der Christusoffenbarung unter den Menschen, vgl. Joh 1,10-11; ansonsten wäre hier die Erschaffung des Lichts nach Gen 1,3 im Sinne eines urzeitlich-dualistischer Mächtekampfes verstanden, was im Johannesevangelium ohne Parallele wäre). Die Referenz auf den Anfang dürfte das Johannesevangelium nicht nur aus den Konventionen johanneischer Briefschriftstellerei haben (s. o.), sondern auch aus dem Incipit des Markusevangeliums, dessen Anfangsthematik wohl auch Matthäus in Mt 1,1 mit einer Anspielung an die biblische Schöpfungsgeschichte (Gen 2,4) und Lukas mit dem Hinweis auf die „Augenzeugen von Anfang an“ aufnimmt $(\operatorname{Lk} 1,2)$. Als Gegenprobe mag gelten, dass $\mathrm{Mk} 1,1 \mathrm{am}$ Ende des ursprünglichen Johannesevangeliums fast wörtlich wieder auftaucht; laut Joh 20,31 sollen die Adressaten des Evangeliums glauben, „dass Jesus ist Christus, der Sohn

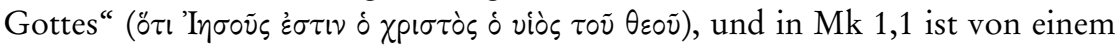

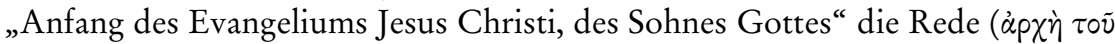

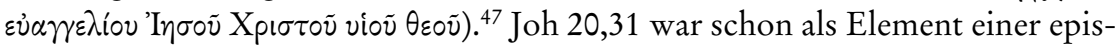
tolaren Kommunikationsstrategie im Johannesevangelium gewertet worden. Wir sehen, wie beim Anfangsmotiv im Johannesevangelium epistolare Tradition und die Tradition der Evangelienschriftstellerei miteinander amalgamiert erscheinen.

4. Zur epistolaren Motivik im Johannesevangelium passt, wenn sich in ihm ein ungewöhnlich starkes Interesse am Verfasser des Evangeliums zeigt, ungewöhn-

\footnotetext{
${ }^{47}$ Vorausgesetzt ist hier für Mk 1,1 der Langtext (mit vioṽ $\left.\theta \varepsilon \circ \tilde{u}\right)$, der durch Makrokontext und Folgekontext (beides Größen, die für die Sicherung einer Lesart als ursprünglich entscheidend ist), bestätigt wird, vgl. Mk 3,11; Mk 15,39. Die Wendung vioũ $\theta$ roṽ kann durch Aberratio oculi ausgefallen sein, die bei den hier fällig werdenden Nomina Sacra-Abbreviaturen besonders

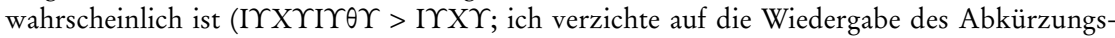
striches). Die Lectio brevior-Regel gilt in solchen Fällen nicht. Nestle-Aland ${ }^{25}$ hatte für den Kurztext optiert; seit Nestle-Aland ${ }^{26}$ ist vioũ $\theta \varepsilon \circ \tilde{~ i m ~ H a u p t t e x t ~ a l s ~ u n s i c h e r ~ m a r k i e r t . ~}$
} 
lich stark im Verhältnis zu den anderen Evangelien: Die Gestalt des Lieblingsjüngers, der in Joh 21,24 mit dem Evangelisten identifiziert wird, gehört zu den prominentesten Spezifika des Johannesevangeliums. Zum Höhepunkt kommt die Präsentation dieser Gestalt innerhalb des Textkorpus in Joh 19,35, wo die Augenzeugenschaft des Lieblingsjüngers für das Hervortreten von Blut und Wasser aus der Seite Jesu hervorgehoben wird, vielleicht nicht zufällig ein Motiv, das am Ende des ersten Johannesbriefes eine imposante Entsprechung findet (1 Joh 5,5-8). Wichtiger aber noch erscheint die starke Affinität dieses Textes zu Joh 21,24; nicht zuletzt dürfte relevant sein, dass die auktoriale Stimme, die im Appendix spricht, sich offenbar auch in Joh 19,35 zu Wort meldet. Es zeigt sich hier eine Affinität der Lieblingsjüngergestalt zum Netzwerk epistolarer Momente im Johannesevangelium, aufgrund derer man konstatieren kann, dass die Autoreninszenierung des vierten Evangeliums etwas mit Traditionen johanneischer Briefstellerei zu tun hat.

Aber auch Evangelienschriftstellerei wird hier im Hintergrund stehen bzw. aufgenommen werden. Es war bereits unter $\$ 2.3$ angedeutet worden, dass sich in den Evangelien des Neuen Testaments bei aller Tendenz zur Anonymität eine Neigung bobachten läßt, den Evangelisten in Andeutungen unterzubringen (vgl. möglicherweise den nackten Jüngling in Mk 14,51-52; Matthäus in Mt 9,9); auch die Wir-Passagen der Apostelgeschichte wurden in diesen Zusammenhang eingeordnet. Die Einbringung des Lieblingsjüngers in die Handlung des Johannesevangeliums kann ebenso in dieser Traditionslinie gesehen werden. Ein rezeptionsgeschichtliches Zeugnis hierzu mag das geheime Markusevangeliuum darstellen, das Züge des johanneischen Lieblingsjüngers auf den nackten Jüngling des Markusevangeliums überträgt (vgl. den Text bei Stählin2 IV, XVII-XVIII).

Frühjüdische Traditionen der Konstruktion von Autorschaft, freilich eher der Autorschaft zentraler Textstücke und nicht so sehr ganzer Schriften, mögen hierbei gleichfalls eine Rolle gespielt haben: Sowohl in der Apokalypse des Mose als auch im Testament Abrahams sind Passagen bezeugt, in denen sich an herausragender Stelle, bei einer theologisch entscheidenden Vision, ohne jegliche Vorbereitung ein Visions-Ich meldet (Abraham, der das Jenseitsgericht schaut, Eva, die das postmortale Ergehen Adams schaut: Apc Mos 33-37; Test Abr $11 \mathrm{ff})$. Auch ein Autoren-Ich kann unvermittelt in eine Handlung eintreten, vgl. Test Hiob 51,1, wo sich Nereus, der Bruder Hiobs, in die Szene von den weissagenden Töchtern Hiobs einschaltet, um dann in Test Hiob 53 als Autor des Buches hervorzutreten. Ebenso unvermittelt meldet sich das Wir in der Apostelgeschichte, übrigens im Anschluss an einen Traum (Acta 16). Und ähnlich unvermittelt kommt auch der Lieblingsjünger in die Handlung des Johannesevangeliums, allerdings an einer Stelle, die mit ihrem Bezug zur Abendmahlsüberlieferung nicht zufällig gewählt wurde (Joh 13,23), denn ein spezifisch sakramentales Interesse ist mit dem Lieblingsjünger dann ja ausweislich von Joh 19,35 verbunden. 
Wir sind mit Joh 19,35 wieder an einer epistolar bestimmten Stelle angelangt. Briefmotivik, Evangelienschriftstellerei und wohl auch frühjüdisches Traditionswissen haben bei der Autorenkonstruktion für den johanneischen Evangelisten zusammengewirkt. Dabei darf nicht übersehen werden, dass dieser Evangelist wie seine Vorgänger nach wie vor anonym bleibt, zumindest auf der Textebene, denn es ist schon aufgrund des puren Vorhandenseins einer Briefkorrespondenz wahrscheinlich, dass „der Alte“ außerhalb der Textwelt nicht gerade anonym war. In seiner Textwelt aber bleibt er es. Und erstaunlicherweise bewahrt er diese Anonymität auch mehr oder minder für die Briefe, in denen er konsequent ohne Rufname bleibt, im ersten Johannesbrief auch ohne Titel. Hier mag umgekehrt Evangelienschriftstellerei auf den Briefschreiber eingewirkt haben: Ein Evangelist ist anonym, und so bleibt es auch der Evangelist, wenn er Briefe schreibt. Ausweislich 1 Joh 1,1-4 und wohl auch des Titels „der Alte“ hat er sich wohl in nicht sehr unbeträchtlichem Maße als jemand verstanden, der Geschichtswissen hat über Jesus, der über ein Evangelium verfügt, das sich als Buch wohl damals noch im Zustand seiner Entstehung befand (aus dem es ausweislich seiner vielen Fehler nie ganz hinausgekommen ist).

\section{Nachwort}

Wir sind am Ende angelangt. Wir haben schwerpunktmäßig die komplexe Konstruktion von Autorschaft der Apokalypse des Johannes in den Blick genommen und etwas knapper die ähnlich komplexe im Corpus Johanneum. In beiden Fällen zeigte sich nicht zuletzt, dass für urchristliche Literatur Autorschaft in Anlehnung an die Gattung Brief als die wohl am meisten kennzeichnende Literaturform des Urchristentums konstruiert wurde: Das Christentum begann als eine Form von Religion, in der mit autoritativem Geltungsanspruch Briefe geschrieben wurden. Am Anfang stand die Distanz überbrückende Kommunikation und damit gerade nicht das, was in der neutestamentlichen Wissenschaft noch immer so beliebt ist: die Einzelgemeinde mit spezifischer Prägung (für die dann ein Evangelist sein Evangelium schreibt). Am Anfang stand Katholizität. Mit ihr entwickelte sich auch die Gestalt der sich autoritativ vermittelten Einzelpersönlichkeit und der durch Christus legitimierte Autor.

\section{Literaturverzeichnis}

Aune, David E. (1997). Revelation 1-5 (Word Biblical Commentary 52). Nashville.

Beale, G. K. (1997). „Solecisms in the Apocalypse as Signals for the Presence of Old Testament Allusions: A Selective Analysis of Revelation 1-22, “in: C. A. Evans / J. A. Sanders (Hrsgg.): Early Christian Interpretations of the Scripture of Israel (Journal for the Study of the New Testament. Supplement Series 148). Sheffield. 421-426. 
Bihlmeyer, Karl (1924). Die Apostolischen Väter. Neubearbeitung der Funkschen Ausgabe (Sammlung ausgewählter kirchen- und dogmengeschichtlicher Quellenschriften, Zweite Reihe 1,1). Tübingen.

Brandt, Peter (2000). „Geflecht aus 81 Büchern. Zur variantenreichen Gestalt des äthiopischen Bibelkanons," Aethiopica 3: 79-115.

Brock, Sebastian P. (1967). Testamentum Iobi; J.-C. Picard: Apocalypsis Baruchi Graece (Pseudepigrapha Veteris Testamenti Graece 2). Leiden.

Bucur, Bogdan G. (2008). „Hierarchy, Prophecy, and the Angelomorphic Spirit: A Contribution to the Study of the Book of Revelation's Wirkungsgeschichte,"Journal of Biblical Literature 127: 173-194.

Clemen, Carl (1904). The Assumptio Mosis (Materials for the Use of Theological Lecturers and Students [= Kleine Texte für Vorlesungen und Übungen] 10). Cambridge.

Dochhorn, Jan (2005a). Die Apokalypse des Mose. Text, Übersetzung, Kommentar (Texte und Studien zum antiken Judentum 106). Tübingen.

Dochhorn, Jan (2005b). „Die Ascensio Isaiae (JSHRZ II,1: Martyrium Jesajas),“ in: G.S. Oegema, Hg.: Unterweisung in erzäblender Form (Jüdische Schriften aus hellenistisch-römischer Zeit VI,1,2). Gütersloh. 1-48.

Dochhorn, Jan (2009). „Röm 7,7 und das zehnte Gebot. Ein Beitrag zur Schriftauslegung und zur jüdischen Vorgeschichte des Paulus,“ Zeitschrift für die neutestamentliche Wissenschaft und die Kunde der älteren Kirche 100: 59-77.

Dochhorn, Jan (2010). Schriftgelehrte Prophetie. Der eschatologische Teufelsfall in Apc Joh 12 und seine Bedeutung für das Verständnis der Jobannesoffenbarung (Wissenschaftliche Untersuchungen zum Neuen Testament 286). Tübingen.

Dochhorn, Jan (2014). Testament Jakobs (Jüdische Schriften aus hellenistisch-römischer Zeit. Neue Folge 1/7). Gütersloh.

Dochhorn, Jan (im Druck). „Die Presbyter in der Johannesoffenbarung: Endzeitlicher Tempelkult im Himmel unter dem Vorzeichen der Gottesherrschaft,“ demnächst veröffentlicht von Jörg Frey.

Dochhorn, Jan (in Vorbereitung). „Die Adamdiegesen und das Neue Testament,“ demnächst in einem vom AELAC (Lausanne) herausgegebenen Tagungsband.

Frey, Jörg (1993). „Erwägungen zum Verhältnis der Johannesapokalypse zu den übrigen Schriften im Corpus Johanneum, “ in: Martin Hengel: Die johanneische Frage. Ein Lösungsversuch (Wissenschaftliche Untersuchungen zum Neuen Testament 67). Tübingen.

Frey, Jörg (2001). „Die Bildersprache der Johannesapokalypse,“ Zeitschrift für Theologie und Kirche 98: 161-185.

Funk, Robert W. (1967). „The Form and Structure of II and III John, “ Journal of Biblical Literature 86: 424-430.

Goppelt, Leonhard (1978). Der Erste Petrusbrief (Kritisch-exegetischer Kommentar über das neue Testament 12/1). Göttingen.

Harnack, Adolf von (1926). Die Briefsammlung des Apostels Paulus und die anderen vorkonstantinischen christlichen Briefsammlungen. Sechs Vorlesungen aus der altkirchlichen Literaturgeschichte. Leipzig.

Hemer, C.J. (1986). The Letters to the Seven Churches of Asia in Their Local Setting (Journal for the Study of the New Testament, Supplement Series 11). Sheffield.

Hengel, Martin (1993). Die johanneische Frage. Ein Lösungsversuch (Wissenschaftliche Untersuchungen zum Neuen Testament 67). Tübingen. 
Klijn, A.F. J. (1983). „2 (Syriac Apocalypse of) Baruch (Early Second Century A.D.), “ in: James H. Charlesworth (ed.): The Old Testament Pseudepigrapha, Volume 1: Apocalyptic Literature and Testaments. New York.

Kmosko, Michael (1907). Liber Apocalypseos Baruch Filii Neriae Translatus de Graeco in Syriacum (Patrologia Syriaca, Pars Prima, Tomus Secundus). Paris. 1057-1306.

Körtner, Ulrich H. J.; Leutzsch, Martin (1998). Papiasfragmente; Hirt des Hermas (Schriften des Urchristentums 3). Darmstadt.

Kraft, Henirch (1974). Die Offenbarung des Johannes (Handbuch zum Neuen Testament 16a). Tübingen.

Kulik, Alexander (2010). 3 Baruch. Greek-Slavonic Apocalypse of Baruch (Commentaries on Early Jewish Literature). Berlin.

Leemhuis, F.; Klijn, A. F.J.; van Gelder, G.J.H. (1986): The Arabic Text of the Apocalypse of Baruch. Edited and Translated with a Parallel Translation of the Syriac Text. Leiden.

Leipoldt, Johannes (1907). Geschichte des neutestamentlichen Kanons, erster Teil: Die Entstehung. Leipzig.

Lietzmann, Hans (1934). Griechische Papyri. Ausgewählt und erklärt (Kleine Texte für Vorlesungen und Übungen 14). Berlin.

Lührmann, Dieter (1981). „Gal 2, und die katholischen Briefe,“ Zeitschrift für die neutestamentliche Wissenschaft 72: 65-87.

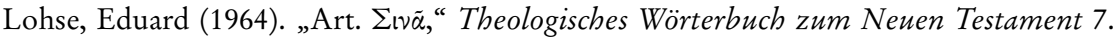
Stuttgart. 281-286.

Norelli, Enrico (1995). „Leggenda Greca di Isaia. Introduzione, editizione et traduzione,“ in: Paulo Bettiolo et al.: Ascensio Isaiae. Textus (Corpus Christianorum. Series Apocryphorum 7). Turnhout.

Oberweis, Michael (1996). „Das Papias-Zeugnis vom Tode des Johannes Zebedäi,“ New Testament Studies 38: 277-295.

Popkes, Wiard (2001). Der Brief des Jakobus (Theologischer Handkommentar zum Neuen Testament 14). Leipzig.

Preuschen, Erwin (1910). Analecta. Kürzere Texte zur Geschichte der Alten Kirche und des Kanons, 2. Teil: Zur Kanonsgeschichte (Sammlung ausgewählter kirchen- und dogmengeschichtlicher Quellenschriften, Erste Reihe 8,2). Tübingen.

Rönsch, Hermann (1874). Das Buch der Jubiläen oder die kleine Genesis. Leipzig.

Rüpke, Jörg (2005). „Der Hirte des Hermas: Plausibilisierungs- und Legitimierungsstrategien imÜbergang von Antike und Christentum,“ Zeitschrift für Antike und Christentum 8: 276-298.

Satake, Akira (2008). Die Offenbarung des Johannes. Redaktionell bearbeitet von Thomas Witulski (Kritisch-exegetischer Kommentar über das Neue Testament 16). Göttingen.

Strecker, Georg (1992). Literaturgeschichte des Neuen Testaments (Uni-Taschenbücher 1682). Göttingen.

Strycker, Émile de (1961). La forme la plus ancienne du Protévangile de Jacques (Subsidia Hagiographica 33). Brüssel.

Wahl, Otto (1977). Apocalypsis Esdrae, Apocalypsis Sedrach, Visio Beati Esdrae (Pseudepigraphi Veteris Testamenti Greaece ediderunt A. M. Denis et M. de Jonge 4). Leiden.

Weiss, Bernhard (1878). Die Evangelien des Markus und Lukas (Kritisch exegetischer Kommentar über das neue Testament 1,2). Göttingen.

Wood, P. (1962). „Local Knowledge in the Letters of the Apocalypse,“ The Expository Times 73: 263-264. 
Zahn, Theodor (1889). Geschichte des Neutestamentlichen Kanons, Erster Band: Das neue Testament vor Origenes, zweite Hälfte. Erlangen/Leipzig.

Zahn, Theodor (1890). Geschichte des Neutestamentlichen Kanons, zweiter Teil: Urkunden und Belege zum ersten und dritten Band, erste Hälfte. Erlangen/Leipzig.

Zahn, Theodor (1899). Die Dormitio Sanctae Virginis und das Haus des Johannes Markus. Separatdruck aus der Neuen Kirchlichen Zeitschrift. Leipzig.

Zahn, Theodor (1901). Grundriss der Geschichte des neutestamtlichen Kanons. Eine Ergänzung zu der Einleitung in das Neue Testament. Leipzig.

Zahn, Theodor (1994). Einleitung in das Neue Testament. Mit einer Einführung von Rainer Riesner. Wuppertal/Zürich (Nachdruck der Ausgabe 1906/1907). 


\title{
Der Hirte des Hermas: Autorenprofil und Textstrategien eines Visionärs des zweiten Jahrhunderts n. Chr.
}

\author{
Jörg Rüpke
}

\section{Vorbemerkung}

Nur wenige antike Texte sind so freigiebig mit der Explizierung des Erzählers wie der „Hirte des Hermas“. Obwohl in der Kapitale des Imperium Romanum geschrieben, in der Antike (und später) weit verbreitet und in verschiedene Sprachen übersetzt und sogar vergleichsweise gut zu datieren, ${ }^{1}$ ist der „Hirte des Hermas" kaum in sozial-, literatur- und religionsgeschichtliche Darstellungen altertumswissenschaftlicher Disziplinen jenseits christlicher Dogmen- und Kirchengeschichte gelangt, obwohl er in einer zentralen Phase religiöser Innovationen im römischen Reich, ${ }^{2}$ im Zentrum, in Rom, einen Blick auf die Interaktion religiöser Strömungen und ihrer sozialen Verortung und so zugleich auf "gelebte antike Religion“ erlaubt. ${ }^{3}$ Die Perspektive, die sich durch den Begriff des Autorenprofils eröffnet, bedarf allerdings in mehrfacher Hinsicht einer Präzisierung. So wird mein Zugriff durch die Begriffe Medialität, Gattung, Text, Autor und Inhalt charakterisiert; synthetisch soll dann der Begriff der „religiösen Praxis" ${ }^{4}$ die Befunde zusammenfassen und auf den Begriff des Autorenprofils zurückführen.

Eine methodische Bemerkung muss vorangeschickt werden. Was wir an Textmaterialien haben, ist ein griechischer Text in Papyrusfragmenten des dritten bis sechsten Jahrhunderts, nahezu vollständig im Codex Sinaiticus, der Bibel-

\footnotetext{
${ }^{1}$ Vgl. aber Gregory 2002 zu einer Öffnung des Zeitraums bis hinunter in die 70er Jahre. Ich danke den Teilnehmerinnen und Teilnehmern der Tagung „Autorenprofile“, aber auch den Seminarteilnehmern in Leuven im März 2016 und den Fellows der Kolleg-Forschergruppe „Religiöse Individualisierung in historischer Perspektive" am Max-Weber-Kolleg für die intensive Diskussion wichtiger Argumente.

${ }^{2}$ Siehe Rüpke 2016, 270-370.

${ }^{3}$ Rüpke 2016, 139-157. Darauf baut die folgende Analyse auf.

${ }^{4}$ Dazu Rüpke 2015. Eine frühere Version des Textes ist erschienen in Entre los mundos: Homenaje a Pedro Barceló, Besançon 2016, 247-260.
} 
handschrift des vierten Jahrhunderts, sowie in einem Codex vom Berg Athos erhalten. Die Korrekturschichten im Sinaiticus, insbesondere jene des fünften oder sechsten Jahrhunderts (Sigle ca), die auf der Kollationierung mit einer anderen kompletten Handschrift beruht, zeigen ein Textinteresse, wie es bei anderen der „Bibel“ zugerechneten Texten besteht. ${ }^{5}$ Darüber hinaus existieren zwei vollständige lateinische Übersetzungen in mittelalterlichen Handschriften, von denen die Palatina sich bis in Manuskripte des achten Jahrhunderts zurückverfolgen lässt, die Vulgata aber noch auf die Lebzeiten des Verfassers zurückgehen könnte. ${ }^{6}$ Um 200 herum zitieren ihn im gallischen Lyon Irenäus, im afrikanischen Karthago Tertullian, im ägyptischen Alexandria Clemens, im palästinensischen Caesarea Origenes. Übersetzungen werden angefertigt in den sahidischen und in den achmimischen Dialekt des Koptischen, ins Äthiopische und ins Mittelpersische. ${ }^{7}$ Dazu kommen wenige kurze Bemerkungen, externe Zeugnisse, aus Texten seit dem Ende des zweiten Jahrhunderts, die den Text dem Bruder eines römischen episcopus Pius im zweiten Viertel des zweiten Jahrhunderts zuweisen. Alles Weitere muss aus dem Text selbst erschlossen werden und Hypothese bleiben - die Existenz eines römischen Bischofs zu dieser Zeit ist dagegen sicher Fiktion. ${ }^{8}$

\section{Selbstpräsentation und Wachstum des Textes}

Die Frage nach den Ursachen der oben umrissenen Popularität der Schrift in der Entstehungs- wie der Folgezeit möchte ich erst am Ende, beim Blick auf den Inhalt, stellen. Der Blick auf die äußere Form beantwortet sie kaum: Die Länge des Textes - in heutigen Ausgaben gut einhundert Druckseiten - übersteigt jeden anderen Text des seit dem Ende des vierten Jahrhunderts geläufigen neutestamentlichen Kanons deutlich. Wäre das ein einheitlicher Text, hätte er von vornherein in Form eines Codex niedergeschrieben werden müssen. Das ist selbst unter Christusverehrern unwahrscheinlich.

Der Text des „Hirten“ weist einen mehrstufigen Entstehungsprozess auf, der zu Textschichten geführt hat, die nicht zuletzt auch unterschiedliche Autorenprofile aufweisen beziehungsweise dasselbe immer weiter modifizieren. Im einzelnen lassen sich unterscheiden:

${ }^{5}$ Batovici 2014, 453 (Datierung nach Amy Myrshall) und 467.

${ }^{6}$ Joly $1958,63$.

7 Joly 1997, 62. Zur reichen ägyptischen Überlieferung.

${ }^{8} \mathrm{~S}$. zu Details und Abweichungen von der communis opinio, die ein Monoepiskopat in Rom erst für das späte 2. Jh. n. Chr. annimmt, Rüpke 1999, 2005, 2013a, b. 


\subsection{Visionenbuch}

Am Anfang der Schrift - zeitlich wie in der heutigen Textgestalt - stand ein heute gut zwanzig Druckseiten umfassendes Visionenbuch. ${ }^{9}$ Verschiedene Offenbarungsgestalten verhelfen dem Icherzähler, der sich ausführlich vorstellt, zu Auditionen wie Wach- und Schlafvisionen bis hin zum Diktat eines himmlischen Buches. Dem Umfang nach ist der Schriftumfang durchaus in Form einer antiken Buchrolle vorstellbar. ${ }^{10}$

\subsection{Gebote}

Eingeleitet durch eine - in einer schon antiken Zählung - fünfte Vision schließen sich zwölf „Gebote“ (entolai, mandata) an: Es handelt sich um eine zweite Textschicht von etwa fünfundzwanzig Druckseiten. ${ }^{11}$ Offenbarungsträger und Dialogpartner ist hier erstmals der namengebende „Hirte“, eine Person im Ziegenfell, die einen Ranzen auf dem Rücken trägt, einen Stab in der Hand hält und sich als zukünftiger Begleiter des - so heißt der Ich-Erzähler nun - „Hermas“ vorstellt. Der Text schließt mit einer Diskussion des Problems falscher Propheten, und macht damit indirekt die Glaubwürdigkeit des Textes selbst zum Thema.

\subsection{Gleichnisse}

In einer Ausweitung der Dialogszene des zwölften Gebotes verwandelt sich der Offenbarungsträger in einen „Engel der Buße“, von dem bislang nicht die Rede war. Als solcher trägt er acht Gleichnisse vor. Wieder handelt es sich um einen Text mit einem Umfang von knapp 25 Druckseiten $^{12}$ - erneut ist eine durchschnittliche antike Buchrolle von 800 bis 1000 Textzeilen vorstellbar, der dritte „Band“ des Werkes, wenn man so sagen will. Diese Gleichnisse werden im Dialog von Hermas und dem Engel ausgelegt. In noch stärkerem Maße ist diese Textschicht politisch interessiert. Sie beginnt nicht nur mit der Frage nach der wahren Stadt-Zugehörigkeit, sondern greift auch in Terminologie und Bildern besonders auf römisch-italische Institutionen und deren Lebenswelt zurück.

\subsection{Turmgleichnis}

Eingeleitet durch den Vermerk der Niederschrift der vorangehenden beiden Textteile bietet der Engel der Buße ein neues Gleichnis, das neunte und umfang-

${ }^{9}$ vis $1-v i s 4$.

${ }^{10}$ Es gibt keinen Grund, für den Text die Form des Kodex anzunehmen; zur Verbreitung dieser Form s. etwa Wallraff 2013; zum Umfang von Buchrollen in Italien s. Suerbaum 1992. Frühe griechische Papyrus-Fragmente lassen sich allerdings einem Codex von $28 \mathrm{~cm}$ Höhe zuordnen: Batovici 2016a. Aus der handschriftlichen Überlieferung, auch nicht Ägyptens, lässt sich kein Argument mehr für die ursprünglich separate Abfassung gewinnen: Batovici 2016b.

11 vis-mand 12.

12 mand $12-\operatorname{sim} 8$. 
reichste. ${ }^{13}$ Es allein erreicht einen Umfang von knapp 25 Druckseiten. Inhaltlich führt es das schon in der Vision 3 vorgestellte Bild des Turmbaus - der Turm steht für die neue ecclesia, die Kirche, die neue Gemeinschaft der Heiligen noch einmal vor. Es schließt mit der Gleichsetzung von Engel und Hirte, wie sie redaktionell jetzt wohl auch in die fünfte Visio, die Eröffnung des zweiten Textteiles, eingetragen wurde. Erneut können wir uns hier eine eigenständige antike Buchrolle vorstellen.

\subsection{Schlussgespräch}

Wiederum durch den Vermerk der Niederschrift des vorangehenden Gleichnisses eingeleitet, spricht nun der Engel ein letztes Mal, ${ }^{14}$ erneut im heimischen Schlafzimmer des Hermas, in dem die Einladung zur 3. Vision und die 5. Vision selbst, das Erscheinen des Hirten, erfolgt waren. Es handelt sich um einen offensichtlich redaktionellen Schluss bei der Zusammenfügung der Texte, selbst nur rund drei Druckseiten lang. Abschließend wird der weitere Beistand des Hirten wie der Jungfrauen zugesagt, jene Tugenden der Ecclesia, die den Turmbau schon in zwei früheren Textpassagen ${ }^{15}$ betrieben hatten.

\subsection{Apokalypse}

Unter der Gruppe von Texten, die auf Christus Bezug nehmen, ist die sich als Brief vorstellende „Offenbarung des Johannes“" ${ }^{16}$ der älteste selbständige apokalyptische Text; hier begegnet auch erstmals der Begriff der apokálypsis als Terminus technicus, allerdings nicht als Gattungsbezeichnung, sondern als titelgebende Inhaltsangabe und Beschreibung der Wissensstruktur. ${ }^{17}$ Von hier aus hat sich der Begriff zur Selbstbezeichnung für die bis ins dritte Jahrhundert hinein zahlreich produzierten griechischsprachigen oder ins Griechische übersetzten Apokalypsen entwickelt.

Eine deutliche Differenz zu vorangehenden, aber auch späteren Apokalypsen ist in der vermutlich fehlenden Pseudonymität der Johannes-Offenbarung zu sehen. ${ }^{18}$ Dem Wortlaut des Textes nach - dem zumindest keine anderen Quellen widersprechen - wird der Text von seinem Verfasser und Visionär, dem schon zuvor als Propheten etablierten Johannes auf Patmos, an die Adressaten, sieben kleinasiatische Gemeinden, versandt. Das geschieht praktisch zeitgleich mit der

\footnotetext{
$13 \sin 9$.

${ }^{14} \operatorname{sim} 10$

15 vis 3 und $\operatorname{sim} 9$.

${ }^{16}$ S. dazu den Beitrag von Jan Dochhorn, Kapitel 9 in diesem Band.

17 Apk 1,1.

${ }^{18}$ Das Folgende nach Rüpke 2005.
} 
Vision, die „am Sonntag“ stattfand, und gerade nicht „zunächst einmal versiegelt" wird. ${ }^{19}$

Anders als bei Johannes, bei dem die detaillierten Umstände - rein schriftliche Produktion für die briefliche Verteilung, die vielleicht die geographische Distanz anstelle der Pseudonymität einsetzt - immerhin schon merkwürdig genug zu sein scheinen, wissen wir von der Entstehung und dem Primärpublikum weiterer apokalyptischer Texte so gut wie nichts. Sicher sagen kann man wohl allein, dass es sich um gruppeninterne Texte, keine missionarischen, primär nach außen gerichteten Werbeschriften handelt - diese Rolle nehmen eher die in Hexametern, also gehobener literarischer Form, abgefassten Sibyllinen wahr.

Hermas kennt apokalyptische Texte, wie das einzige explizite Zitat des Hirtenbuchs aus der apokalyptischen jüdischen Schrift „Eldad und Modat" ausweist. ${ }^{20}$ Bewusste Anspielungen auf weitere Texte lassen sich nicht identifizieren; dass Hermas zentrale Schriften des entstehenden Neuen Testaments und der Septuaginta, des griechischen Tenachs, kannte, legen Formulierungen und Motive nahe; wahrscheinlich waren ihm solche Texte vor allem mündlich, in Form gottesdienstlicher Lesung, bekannt. Das Archiv der römischen Gemeinde hat er sicher nicht benutzt.

Nach der - für das Gesamtwerk etwa einstündigen - Verlesung des Visionenbuches (oder, wohl seltener, nach der Lektüre) musste jeder Zuhörerin und jedem Zuhörer klar sein, dass sie eine Apokalypse vor sich hatten. Formen und Motive apokalyptischer Texte finden sich zahlreich: die Entrückung durch einen Geist; die Visionen himmlischer Offenbarungsgeber, die innerhalb der Vision weitere Visionen eröffnen und erklären; (Johannes vergleichbar) der Auftrag zur Weitergabe, auch zum Versenden des Textes. Um jedes Missverständnis auszuschließen, fallen siebenundzwanzigmal, im Durchschnitt also alle zwei Minuten, die Wörter apokálypsis oder apokalýptein.

Die Fokussierung auf die Apokalypse tritt in den folgenden Schichten aber weitgehend zurück. ${ }^{21}$ Dialoge mit Offenbarungsfiguren werden vorgeführt, nicht berichtet. Insgesamt ist der „Hirte des Hermas“ ein Text eines römischen Juden, der sich um seinen eigenen moralischen Status und den seiner Mit-Glaubenden Sorgen macht. Er versucht Visionen einer idealen Kirche zu kommunizieren, und zwar gegenüber einer stetig wachsenden Gruppe von Juden, für die Christus wichtig geworden ist, die aber voll integriert in einer römischen Gesellschaft leben, die plausible Werte und vielfache Attraktionen bereit hält. Authentische religiöse Erfahrungen verbinden sich mit einem starken Willen zur Kommunikation. ${ }^{22}$

\footnotetext{
${ }^{19}$ Apk 22,10.

${ }^{20} \mathrm{PH} 7,4$.

${ }^{21}$ S.a. die Beobachtungen von Batovici 2015.

22 Zum Problem der Authentizität der Visionen Stone 2003 und Rüpke 2013 a.
} 


\section{Medialität}

Wenn ich von religiöser Erfahrung und vom Text im Singular spreche, mache ich bereits deutlich, dass ich von der Annahme ausgehe, dass es sich um einen einheitlichen Verfasser und nicht nur um einen Schlussredaktor handele, zu dessen Identifikation mit dem Ich-Erzähler der Text einlädt. In jedem Fall bleibt das Autorenprofil über die Textstufen hinweg in seinen Grundstrukturen unverändert. Der Text ist erzählend, aber er wird dominiert, ja, seit der zweiten Textstufe völlig beherrscht durch wörtliche Rede, Dialoge mit zum Teil langen monologischen Passagen. In einem noch stärkeren Maße als in den Narrativen wird die Erzählinstanz so immer weiter und immer detaillierter charakterisiert: in ihren Annahmen, ihren Kenntnissen, ihrem psychologischen und religiösen „Wissen“, in ihrem Ethos. Nach den massiven autobiographischen Informationen der ersten Textstufe wird sie allerdings in ihren äußeren, sozialen Merkmalen nicht mehr in Erinnerung gerufen. Hier öffnet sich eine Identifikationsfigur für die Rezipienten. ${ }^{23}$

Eine schriftliche Offenbarung erfolgt allein in der allerersten Textstufe, in der visio 2. Allerdings erschließt das bloße Kopieren der Buchstaben noch kein Verständnis des Textes; dazu bedarf es vierzehntägigen Fastens und Betens und am Ende einer Zusatzvision mit Textnachträgen. Im Vergleich dazu ist das Medium der (natürlich durch den vorliegenden schriftlichen Text fingierten) Mündlichkeit viel flexibler. Es erlaubt die unmittelbare Nachfrage, erlaubt den Gesprächspartnern sogar das Lesen zwischen den Zeilen.

Dieses Verständnis von mündlicher Kommunikation bildet sich auch in der schriftlichen Fassung des Textes ab. Nachfragen, Interpretation des schon Gesagten, ja Korrektur früherer Verständnisse charakterisieren den Text von der frühesten Textstufe an. ${ }^{24}$ Die Sprecher sind wichtig, ihre Charakterisierung wird zu einem wichtigen Teil des Textes. Gegen die Konventionen der Gattung Apokalypse, die das Visionenbuch bestimmt, spielen autobiographische Angaben wie etwa auch in der wohl etwas älteren Johannes-Apokalypse eine wichtige Rolle. Auch die Offenbarungsträger werden detailreich charakterisiert, ihr Äußeres und gegebenenfalls ihre Begleiter werden nicht weniger eindrücklich geschildert als ihr Gesichtsausdruck und Veränderungen desselben. Das allmähliche Anwachsen des Textes suggeriert einen fortschreitenden Prozess nicht nur schriftlicher, sondern auch mündlicher Kommunikationen: Schrift ist ein Verbreitungsmedium. Aber der Text bildet solche mündliche Kommunikation selbstverständlich nicht nur ab. Auch die neuen Texte - vielleicht erst münd-

\footnotetext{
${ }^{23}$ Für diese Beobachtungen bin ich - wie für die Diskussion weiterer Thesen - den Teilnehmern eines Doktorandenseminars im Collegio Fondazione San Carlo in Modena im April 2015 zu Dank verpflichtet.

${ }^{24}$ Leutzsch 1989, 13-19.
} 
lich, dann in schriftlicher Form - binden sich an die früheren Äußerungen, ${ }^{25}$ bleiben in der Bildsprache, beschränken sich in der Einführung neuen Materials, erhalten - bei aller Entwicklung - das einmal gewonnene Autorenprofil. Der Erzähler ist eine handgreiflich gewordene Person. Die Schriftlichkeit und die Publikation wohl auch einzelner Textstufen ihrerseits erlauben präzise Rückgriffe auf frühere Passagen und eine Länge des Gesamttextes, die für die Re-Oralisierung schon problematisch wäre. Der mündliche Vortrag der Schlussversion nähme weit über vier Stunden ein.

Schriftlichkeit bietet aber für die Kommunikation „an alle Auserwählten“26 zumal in der frühesten Phase des Textwachstums weitere Vorteile. Die Organisation jener griechischsprachigen, „Christus“ in ihr Weltbild einbauenden jüdischen Römer lässt sich in Grundstrukturen dem Visionenbuch entnehmen:

Du sollst nun zwei Abschriften machen und eine dem Clemens, die andere der Grapte schicken. Clemens soll sie an die auswärtigen Städte senden, denn dies ist ihm aufgetragen. Grapte aber wird die Witwen und Waisen daraus lehren. Du selbst magst es in dieser Stadt vorlesen vor den Presbytern, die an der Spitze der Gemeinde stehen. ${ }^{27}$

Nicht näher bestimmte Leitungsfunktionen übt das Kollegium der Presbyter aus. Der Begriff „Presbyter“ scheint synonym mit „Episkopen“ verwendet zu werden. ${ }^{28}$ Dieses Kollegium bildet das Forum, in dem Hermas den ihm geoffenbarten schriftlichen Text selbst vorliest. ${ }^{29}$ Auch hier ist Hermas genau in der Charakterisierung des Status dieses Textes: Es handelt sich in der göttlichen Urschrift um einen Brief, der an Hermas gerichtet ist, seine persönlichen Probleme thematisiert und ihm zugleich Botschaften für Dritte aufträgt. ${ }^{30}$ Die Gemeindeversammlung, die vielleicht in den Anreden „Brüder“ angezielt ist, spielt als Institution explizit keine Rolle. Ob die Verlesung des Schriftstückes vor den Presbytern die Bitte um Erlaubnis, den Text dann unter presbyterialer Aufsicht vor den größeren Kreis zu bringen, impliziert, lässt sich nicht mit Sicherheit ausmachen: Der Verzicht auf schriftliche Verbreitung beließe dem Autoren eine Verfügungsmacht über den Text; während Schriftlichkeit hier Anderen Kontrollmöglichkeiten eröffnen würde. Vor allem aber erlaubt Schriftlichkeit Vervielfältigung, präziser: zwei weitere Abschriften. Sie dienen zum einen dazu, über eine gewisse Graptē die Witwen und Waisen zu erreichen. Die zweite Kopie erlaubt Hermas einen Clemens zu beauftragen, den Text brieflich in anderen Gemeinden zu verbreiten, das heißt weitere Kopien anzufertigen. ${ }^{31}$ Es sei daran erinnert, dass auch die johanneische „Offenbarung“ in Teilen als Brief auftritt.

\footnotetext{
${ }^{25}$ So Osiek 1999, 10. 13.

${ }^{26} \mathrm{PH} 8,3$.

${ }^{27}$ vis $2,4,3=\mathrm{PH} 8,3$.

${ }^{28} \mathrm{Zu}$ den Amtsbezeichnungen im Pastor Hermae s. Maier 1991; kurz Batovici 2011.

${ }^{29} \mathrm{PH} 8,3$.

${ }^{30} \mathrm{PH} 7,1-4$.

${ }^{31} \mathrm{PH} 8,3$.
} 
Am Ende steht in allen diesen Fällen aber die weitere Oralisierung, die allein erlaubt, größere Personenkreise zu erreichen, nachdem die Schrift räumliche oder sozial-geschlechtliche Grenzen zu überschreiten geholfen hat.

\section{Gattung und Autorschaft}

Glaubt man dem vermutlich erst im vierten Jahrhundert geschriebenen Canon Muratori, wäre Hermas der Bruder des römischen Bischofs Pius gewesen. ${ }^{32}$ Diese präzise und aus sachlichen Gründen plausible, in ihrer Herkunft völlig undurchsichtige chronologische Einordnung erlaubt dem Verfasser der Liste dem Hirten die liturgische Verwendbarkeit abzusprechen, da Hermas damit erst der nachapostolischen Zeit angehöre und auch sicher kein Prophet sein könne - diese Liste ist schon lange abgeschlossen.

Auffälligerweise macht der Text des „Hirten“ nicht die geringste Andeutung, dass er sein Glaubwürdigkeitsproblem durch einen solchen Verweis lösen wollte. Denn natürlich hat ein, hat jeder Visionär - und ich setze im folgenden Authentizität visionärer Erfahrung (alle Raffinessen heutigen Verständnisses der Verbalisierung, ja des Konzeptes von „Erfahrung“ eingeschlossen) voraus - ein solches Glaubwürdigkeitsproblem. Dass Visionen in Wach- wie Schlafzuständen glaubwürdige Formen der Kommunikation mit übermenschlichen Instanzen waren, gehörte zu den allgemeinen Überzeugungen, dem Habitus antiker Menschen. Nicht minder gehörte dazu ein kritischer Zugang, der Täuschungen, falsche oder leere Träume als Wasser im Wein aufspürte. Cicero präsentiert die Extrempositionen im Umgang mit Träumen in seinen beiden Büchern „Über die Divination“ in Form zweier Aussagen: Dass gelegentliche falsche Träume korrekte Vorhersagen nicht in Misskredit bringen können, ist die Position des ersten Buches, die der Dialogpartner Quintus Cicero formuliert. ${ }^{33}$ Der Widerpart des Bruders (und Verfassers) Marcus wird im zweiten Buch formuliert, das eine divinationskritische Position vertritt: Angesichts der Menge der Träume sind Zufallstreffer im Sinne korrekter Vorhersage anzunehmen, aber kein Beweis für den divinatorischen Charakter des Traums.

Die von dem Hermas genannten Erzähler gewählte Strategie, ein Profil als Autor, als „Urheber“ zu gewinnen, ist eine doppelte. Die erste besteht in der Erzeugung von Glaubwürdigkeit durch rücksichtslose autobiographische Selbstenthüllung. So lautet der Beginn des Textes:

Mein Besitzer (oder Ziehvater) hatte mich nach Rom an eine Frau namens Rhode verkauft; nach vielen Jahren begegnete ich ihr wieder und begann sie zu lieben wie eine Schwester. Nach einiger Zeit sah ich sie im Tiber baden; ich reichte ihr die Hand und geleitete sie aus

\footnotetext{
${ }^{32}$ Canon Muratori Z. 73-77.

${ }^{33}$ Cic. div. 1,60ff. und 2,121 f. für das Folgende.
} 
dem Fluss heraus. Wie ich nun ihre Schönheit sah, da regte sich in meinem Herzen der Gedanke: Wie glücklich wäre ich, wenn ich solch eine Frau hätte, (so schön) an Gestalt und (so edel) von Art! Nur dies überlegte ich, nichts anderes. ${ }^{34}$

Hermas ist ein Freigelassener, ein gebürtiger Haussklave (verna) oder Findling, der es zu einer eigenen Familie bringt und mit wechselndem Erfolg Geschäfte, wohl Handelsgeschäfte betrieben hatte und erst später zur ehrlicheren Aktivität der Meersalzgewinnung gekommen ist. Gegenüber seiner vormaligeren Besitzerin und Glaubensgenossin Rhode entwickelt er unpassenderweise, wie sich herausstellen wird, erotische Phantasien, als sie nackt aus dem Bade im Tiber entsteigt. Seine eigenen Kinder geraten auf die schiefe Bahn, was er - ganz altrömischer pater familias - auch dem einen Gott der jüdischen Tradition gegenüber mit zu verantworten hat. Der Text, so lautet die Botschaft, hat einen Autor, und dieser Autor ist bekannt (deshalb muss er auch seinen Namen im ersten Buch nicht nennen). Der Autor ist ehrlich und dadurch glaubwürdig. Einmal exponiert, bleibt der Autor nicht nur als Erzähler, sondern auch als Dialogpartner präsent, zeigt Unverständnis, Kleinmut und wird immer wieder getadelt.

Diese erste literarische Strategie scheint wenig zur zweiten zu passen. Hermas verbindet seine Betonung von Mündlichkeit und Authentizität mit der Gattung der „Apokalypse“, um situationsgerecht erfolgreich zu kommunizieren. Im nachexilischen Judentum, verstärkt seit dem zweiten Jahrhundert v. Chr., wurden Texte produziert, die sich als Berichte herausragender biblischer Charaktere ausgaben und in Form von Visionen des Ich-Erzählers Einblicke in die Ereignisse der Endzeit gaben. ${ }^{35}$ Durch die Person des Visionärs war Pseudonymität solcher „apokalyptischer“ Texte vorgegeben: Als Verfasser sollte der in der ersten Person erzählende biblische Seher verstanden werden; die Werktitel weisen das aus. Damit ist Schriftlichkeit ein notwendiges Merkmal: Nur als verschriftlichter Text, als Buch, konnte die Ich-Erzählung für die oft enorme Zeitspanne bis zu ihrer Wiederentdeckung konserviert werden. Diese Notwendigkeit schriftlicher Kommunikation spiegelt sich nun - was seinerseits ja nicht notwendig wäre - regelmäßig im Inhalt der Visionen wider: Die Erkenntnisse des Visionärs entstammen oft himmlischen Büchern, deren Inhalt summarisch, oft aber wortwörtlich dem Visionär in seinen Visionen mitgeteilt wird.

Hermas kannte apokalyptische Texte, wie das einzige explizite Zitat des Hirtenbuchs, nämlich eines aus der apokalyptischen jüdischen Schrift „Eldad und Modat", ausweist. ${ }^{36}$ Und genau in diese Tradition stellte er sich und seine Schrift. Formen und Motive apokalyptischer Texte finden sich zahlreich: die Entrückung durch einen Geist; die Visionen himmlischer Offenbarungsgeber, die innerhalb der Vision weitere Visionen eröffnen und erklären; der Auftrag zur

\footnotetext{
${ }^{34}$ vis $1,1,1-2=\mathrm{PH} 1,1-2$.

${ }^{35}$ Collins 1987; Jones 2011.

${ }^{36} \mathrm{PH} \mathrm{7,4.}$
} 
Weitergabe, auch zum Versenden des Texte. Schließlich fallen siebenundzwanzigmal, im Durchschnitt eines vorstellbaren mündlichen Vortrags des Visionenbuches also etwa alle zwei Minuten, die Wörter apokálypsis oder apokalýptein. ${ }^{37}$

Die Kombination beider literarischer Strategien, die die Textreihe „Apokalypse“ für Hermas' Rezipienten natürlich verändert, bringt den himmlischen Prätext ganz eng in die Gegenwart, kodiert eine gegenwärtige individuell-moralische, nicht eine primär endzeitlich-kosmologische Warnung. Diese Strategie wird in den folgenden Textstufen modifiziert, aber grundsätzlich weiter verfolgt. Nicht das Schlagwort Apokalypse trägt die Fortsetzung, sondern die individuelle Ansprache an den Visionär, seine fortgesetzte Beauftragung zum Schreiben. Noch viel stärker als in der visio 2 wird Hermas zum Primäradressaten aller Offenbarung. Das macht den apokalyptischen Gestus unaufdringlich, aber, wie die Breite der Rezeption zeigt, um so eher generalisierbar.

\section{Inhalt und Strategie}

In klassisch-dogmengeschichtlicher Terminologie geht es im „Hirten des Hermas" um die Möglichkeit einer zweiten Buße nach der Taufe. Die Autoren des dritten Jahrhunderts lasen den Verfasser der Schrift als jemanden, der für schon Gläubige die Möglichkeit einer grundsätzlichen Umkehr annimmt. Aber das ist eine Sicht auf den „Hirten“, die spätere theologische Problemlagen, besonders die Sakramententheologie zum Ausgangspunkt nimmt. Von Taufe und Bußritualen spricht der Text schlechterdings nicht. Ohne diese Brille erscheint der Text in einem anderen Licht.

Vor allem seit der dritten Textstufe stellt sich der Erzähler als jemand dar, der durch sein Interesse für Typologien und Klassifikationen auffällt. Das betrifft Tugenden und Sünden, wie sie etwa schon die "Gebote“ strukturieren. Noch auffälliger, ja zentral ist die Klassifikation von Mitgliedern der ekklêsia, ob sie nun als Steine vorgestellt oder mit Zweigen getestet werden. ${ }^{38} \mathrm{Z}$ wischen verschiedenen Typen und Graden, um nicht zu sagen Prozentsätzen, des guten oder schwachen Glaubens zu unterscheiden, scheint von zentraler Bedeutung zu sein. In Gleichnis 8 führt das zu immerhin achtundzwanzig verschiedenen Typen von Gläubigen. So resultiert das Ausgeben von ellenlangen Weidenzweigen mit grünen Blättern in folgendem Ergebnis:

Von manchen erhielt er Stäbe, die verdorrt waren und zerfressen wie vom Wurm. Der Engel ließ alle, die solche Stäbe abgaben, sich gesondert aufstellen. Andere gaben verdorrte Stäbe, aber sie waren nicht wurmzerfressen; auch diese ließ er sich gesondert aufstellen. Andere gaben halbverdorrte ab; auch sie stellten sich gesondert auf. Andere gaben ihre

\footnotetext{
${ }^{37}$ Dazu Rüpke 2005.

${ }^{38}$ vis $3, \operatorname{sim} 9$ und $\operatorname{sim} 8$ (Zweige).
} 
Stäbe halbverdorrt und mit Rissen ab; auch diese stellten sich gesondert auf. Andere gaben ihre Stäbe grün und mit Rissen $a b$... halb verdorrt und halb grün ... zwei Drittel des Stabes grün, ein Drittel verdorrt ... zwei Drittel verdorrt und ein Drittel grün ... fast ganz grün ... ${ }^{39}$

Hermas ist nicht an den scharfen Grenzen interessiert. Es gibt einen inneren und einen äußeren Bereich von Religionsgenossen; „Völker“ (ethnoi) und „Apostaten“ auf der anderen Seite. ${ }^{40}$ Aber letztere interessieren ihn nicht. Das Problem, das für Hermas zentral ist, liegt im grauen Bereich zwischen den klaren Gruppen. Es ist, folgt man ihm, einfach, zum Glauben zu kommen. Und es ist einfach, dann wieder allmählich aus ihm herauszufallen. Aber es ist schwierig zu wissen, wo ein anderer und man selbst genau stehen. Der Autor fasst das in das Gleichnis der Bäume im Winter: Man sieht die Bäume, aber man sieht nicht, welcher noch lebt: „Denn wie im Winter die Bäume, die ihre Blätter verloren haben, einander gleichen und nicht erkennbar wird, welche verdorrt und welche lebenskräftig sind, so werden auch in dieser Welt Gerechte und Sünder nicht erkennbar, sondern sie gleichen einander alle. “41

Dasselbe Problem lässt sich mit dem Gleichnis vom Turm und Turmbau sagen: Schnell wächst der Turm zu eindrucksvoller Größe heran, aber dann werden Reparaturarbeiten nötig, Steine müssen bearbeitet oder entfernt werden. ${ }^{42}$ Der Turmbau kommt zum Stillstand, die eschatologische Vollendung ist aufgeschoben. Was jetzt fehlt, ist die Klärung der Grenzen. Wer auch immer in der Grauzone ist, muss seinen Sinn ändern, bedarf der metanoia.

Aber was genau ist zu ändern? Hier bleibt Hermas erstaunlich vage. Wenn es um Heirat und Trennung geht, heißt Ehebruch „zu handeln wie die Völker““.43 Sich Rat bei professionellen Wahrsagern zu suchen, ist Idolatrie ${ }^{44}$ - zu beobachten ist das in der eigenen Gruppe. „Die Taten der Völker“ sind der Indikator vollen Abfalls $^{45}$ - aber auch das wir nicht weiter spezifiziert. Offensichtlich gefährdet sind vor allem die Reichen - der einfache Unternehmer wie Hermas ist ihnen bereits zuzurechnen. Öffentliche Wohltaten leisten, Prestige erwerben und so ewigen Ruhm zu ernten, ist ebenso einsichtig wie problematisch.

Aber Hermas geht über Erwartbares hinaus. Natürlich sind Habgier, eine andere Frau, Luxus und Prunkmähler miteinander korreliert. Aber Hermas fokussiert dann auf die gesundheitlichen Folgen übermäßigen Essens, auf den geschäftsbedingten Kontakt mit Heiden, auf das inakzeptable Fernhalten von

\footnotetext{
${ }^{39} \operatorname{sim} 8,1,6-14=$ PH 67,6-14.

${ }^{40} \mathrm{PH} \mathrm{4,2.}$

${ }^{41} \operatorname{sim} 3,3=$ PH 52,3.

${ }^{42} \operatorname{sim} 9,5,2=\mathrm{PH} 82,2 ; \operatorname{sim} 9,6,3-5=\mathrm{PH} 83,3-5$.

${ }^{43}$ mand $4,1,9=$ PH 29,9.

${ }^{44}$ mand $11,1=\mathrm{PH} \mathrm{43,4.}$

${ }^{45} \operatorname{sim} 8,9,3=\mathrm{PH} 75,3$.
} 
Bettlern. Hermas formuliert dafür ein komplexes psychologisches Modell und führt uns zum Gleichnis von den Weidezweigen zurück:

Und die, die ihre Stäbe zu zwei Drittel verdorrt und zu einem Drittel grün abgegeben hatten, das sind die, die zwar Gläubige geworden waren, dann aber reich geworden sind und Ansehen bei den Heiden erlangt haben. Großen Stolz haben sie angenommen und hochmütig sind sie geworden, die Wahrheit haben sie verlassen und haben nicht mit den Gerechten Gemeinschaft gehalten, sondern sie haben mit den Heiden Umgang gehabt, und das erschien ihnen als der angenehmere Weg. Von Gott sind sie nicht abgefallen, vielmehr beharrten sie beim Glauben, taten aber die Werke des Glaubens nicht. Viele von ihnen haben Buße getan und ihre Wohnung im Turm erhalten. Andere aber lebten völlig mit den Heiden zusammen und sind, durch heidnische Ruhmsucht verführt, von Gott abgefallen und haben die Taten der Heiden getan. ... Andere wieder gerieten in Zweifel und verursachten Spaltungen in der Gemeinschaft ... ${ }^{46}$

Für die Reichen sind gerade ökonomische Probleme Zeichen göttlicher Strafe; gerade in diesem Problemkreis geraten sie in die Gefahr der Apostasie. ${ }^{47}$ Der angelos tryphês, der Engel des Luxus, ist zugleich ein Engel der Täuschung; er ist dem aktivistischen und leicht erzürnbaren Charakter des Geschäftsmannes inhärent: Produktives Gewerbe ist daher dem Handel vorzuziehen. Der soziale Aufsteiger Hermas reflektiert hier deutlich seine eigene Situation.

Aber nicht an sozialen Klassenlagen ist Hermas interessiert, sondern am Einzelnen, an der Person, ja an der Psychologie: eupsychos und dipsychos, der Zweifelnde, sind dafür wichtige Begriffe. Umkehr, metanoia, ist als ein individueller biographischer Prozess gedacht. Dieser Prozess bleibt nicht abstrakt, aber wird auch nicht radikal: Der Reiche soll spenden, aber nicht seinen Status aufgeben. ${ }^{48}$ Und auch hier stellt sich das Problem, dass man an der Freigiebigkeit, dem Euergetismus, noch nicht den Gläubigen erkennen kann. Auch zu viel Gebet schadet, es schwächt den Körper. ${ }^{49}$ Fasten ist gut, ein moralisches Leben besser. ${ }^{50}$ Die Ersparnisse kurzzeitigen Fastens kann man den Armen geben. ${ }^{51}$ Wenn man mehr als nötig tut, heißt das Leiturgie. ${ }^{52}$ Und schließlich bleibt noch ein Trost für uns alle - die positive Rolle des Wissens: Hermas selbst muss sich immer wieder für seinen unerschöpflichen Wissensdrang ironisch kritisieren lassen. Nur der Wissende weiß schließlich, ob „Gott ist oder nicht“ ${ }^{53}$ Das ist eine klare religiöse Unterscheidung.

Aber klar ist im Alltag sonst leider wenig. Der Text selbst beginnt mit dem extremen Beispiel einer Gedankensünde: Dass Hermas an Ehebruch denkt, als

\footnotetext{
${ }^{46} \operatorname{sim} 8,9,1-4=$ PH 75,1-4.

${ }^{47}$ vis $3,6,5=\mathrm{PH} 14,5$.

${ }^{48} \operatorname{sim} 1=\mathrm{PH} 50$.

${ }^{49}$ mand $3,10,7=\mathrm{PH} 18,7$.

${ }^{50} \operatorname{sim} 5,1,3-5=$ PH $54,3-5$.

${ }^{51} \operatorname{sim} 5,3,7=$ PH $56,7$.

$52 \operatorname{sim} 5,3,2-3=$ PH 56,2-3.

53 vis $3,4,3=\mathrm{PH} 12,3$.
} 
er Rhode nackt sieht, weiß nicht einmal er selbst: Die himmlische Offenbarungsgestalt muss ihn erst darauf aufmerksam machen. Der einzelne Rezipient beziehungsweise Rezipientin benötigt eine solche Gestalt, benötigt einen „Hirten“, einen „Engel der Gerechtigkeit“, einen „Engel der Buße“, denn er ist auch immer durch „Engel der Bosheit“ und seinesgleichen gefährdet: In seinem Inneren liefern sie sich einen Kampf, den der Einzelne ohne Hilfe nicht bestehen kann. Das Gebot 6 führt das aus:

...,Zwei Engel sind bei dem Menschen, ein (Engel) der Gerechtigkeit und einer der Bosheit.' Ich fragte: ,Herr, wie kann ich ihre Wirkungsweise erkennen, da doch beide Engel bei mir wohnen?' „Höre', sprach er, ,und du wirst sie begreifen! Der Engel der Gerechtigkeit ist zart, bescheiden, sanft und ruhig. Wenn er in dein Herz kommt, dann redet er alsbald mit dir von Gerechtigkeit, Keuschheit, Heiligkeit, Selbstgenügsamkeit und von allerlei gerechten Werken und herrlichen Tugenden. Wenn dies alles in dein Herz kommt, so wisse: der Engel der Gerechtigkeit ist bei dir. ... Schaue nun auch die Werke des Engels der Bosheit! Vor allen Dingen ist er jähzornig und heftig und unverständig; und seine Werke sind böse und verführen die Knechte Gottes. Wenn er in dein Herz kommt, so erkenne ihn an seinen Werken.' Ich antwortete: ,Herr, ich weiß nicht, wie ich ihn erkennen soll.' ,Höre!' sprach er. ,Wenn Jähzorn oder Heftigkeit dich überfällt, so wisse, dass er in dir ist; sodann Verlangen nach vielerlei Geschäften und Luxus in vielen Speisen und Getränken .... ${ }^{54}$

Das ist mehr als eine Botschaft. Der Text führt auch eine Kommunikationsstrategie vor Augen - und ist Teil einer solchen. Die Frage von Gut und Böse ist nicht nur die einer Summenbildung, sondern ist für alle Betroffenen ein biographischer Prozess, der erzählt werden kann. „Umkehr“ ist kein einmaliges, dramatisches Ereignis, sondern ständiger Kampf, ständiges Bemühen. Das führt der Text selbst in seinen immer neuen Ansätzen vor. Wie der visionäre Anstoß für Hermas entscheidend wird, so kann die Darstellung dieses Prozesses zum Anstoß für Hermas’ Adressaten werden.

\section{Text als religiöse Praxis}

In seiner biographischen Dimension, in seiner Bewegung durch Räume, Zeiten und soziale Konstellationen, berichtet der Text von einer religiösen Praxis. Das Rezeptionsangebot dieses Textes formuliert der Text selbst mit seinen mehrfachen Verweisen auf Verbreitung und Niederschrift. Das Verfassen des Textes wird somit als Teil der religiösen Praxis des „Hermas“ genannten Erzählers und Protagonisten beschrieben. Nicht um eine einmalige Handlung geht es dabei. Wie die Übersicht über die Textstufen deutlich gemacht hat, können wir uns die ursprüngliche Entstehung durchaus als ein Verfassen von vier sukzessiven „Büchern“, sprich: Buchrollen, vorstellen, denen mit der letzten Textschicht auf der vierten Buchrolle ein endgültiger Abschluss gegeben wird. Wir haben keine

\footnotetext{
${ }^{54}$ mand 6,2,1-5 = PH 36,1. 5.
} 
Zeugnisse für die Dauer der Arbeit an dem heute vorliegenden Text; innerhalb des Visionenbuches wird eine Zeitangabe geliefert, die ein Jahr übersteigt. ${ }^{55}$ In seinen verschiedenen Stufen, in seinen theologischen Modifikationen, seiner Arbeit an den Bildern und ihren Interpretationen mag der Text gut eine mehrjährige Arbeit in wenigstens vier Anläufen widerspiegeln. Der Erzähler lässt keinen Zweifel daran, dass der Autor immer wieder der Aufforderung bedarf. Schreiben ist Arbeit, ist religiöse Praxis.

Der aus diesen verschiedenen Anläufen und Erweiterungen resultierende Text ist damit in mehrfacher Hinsicht selbst eine Einladung zu religiöser Praxis. Bezeichnenderweise wagt der Canon Muratori nicht, das Buch für die private Lektüre zu verbieten, wenn er auch die Verlesung in gottesdienstlichem Rahmen untersagt. Nicht biblische Traditionen noch Martyriumsgedanken werden im "Hirten“ mobilisiert (für letzteres müssen wir noch auf Ignatius von Antiochia und Polykarp von Smyrna warten $)^{56}$, sondern das Ideal der individuellen moralischen Verantwortlichkeit und die Aufforderung, auf die äußeren, gestalthaften Stimmen des Inneren zu lauschen und dann der richtigen Stimme zu folgen. Für diese Arbeit an sich selbst bietet der Text immer neue Bilder, Gleichnisse und Erkenntnisse an. Die wiederholte lesende Beschäftigung mit dem Text ist religiöse Praxis. Dieser Einladung scheinen viele Leser gefolgt zu sein.

Aber die zu Beginn aufgezeigte enorm schnelle und weite Verbreitung des Textes über geographische, kulturelle und sprachliche Grenzen hinweg ist nicht nur Ergebnis einer großen Nachfrage. In bestimmter Weise spielt auch das Angebot eine Rolle. Zwischen Autor und Leser stehen nämlich noch weitere Individuen: Kopisten und Übersetzer beziehungsweise ihre Auftraggeber und Financiers. Das Angebot wird nicht nur durch die Nachfrage bestimmt, sondern auch durch die Bereitschaft, in eigenem Tun das Angebot des Textes zu verbreiten. Der Text mit seinen vielfachen Aufforderungen, an den Autor zu schreiben, ermöglicht, ja legt nahe, diese Tätigkeit auch als religiöse Praxis zu verstehen, als eine Weise, seine Zeit, seine Mittel mit armen, aber lesekundigen oder hörwilligen Zeitgenossinnen und -genossen zu teilen. Für das zweite Jahrhundert n. Chr., ja für die gesamte Spätantike ergibt sich hier ein mediengeschichtlich wie religionsgeschichtlich wichtiger Befund, der die Bedeutung von Texten nicht nur für die Lebensführung von Angehörigen der Elite, sondern auch für Kommunikationsprozesse und lokale Gruppenbildungen ${ }^{57}$ wie für überregionale Verflechtungen in intensives Licht taucht.

Nicht nur das Übersetzen, sondern auch das Abschreiben stellt sich bei näherer Betrachtung als individueller Aneignungsvorgang dar. Der Text im Codex Sinaiticus des vierten Jahrhunderts war literarisch viel elaborierter als der im

\footnotetext{
55 vis 2,1 .

${ }^{56}$ Frend 1965; Bowersock 1995; Klausner 2005; Waldner 2018.

${ }^{57}$ Dazu Rüpke 2011.
} 
dritten Jahrhundert verfasste Text im Michigan Codex. ${ }^{58}$ Auch die Kopisten und Kopistinnen gewannen ein je eigenes Profil und eine gesellschaftliche Position, deren Geltung sich aus ihrem Anschluss an eine Tradition und deren selbständige Aufnahme speiste. Das gilt für diejenigen, die Epikur in Kampanien in der Villa deipapiri kopierten, wie für diejenigen, die Hermas in Oxyrhynchos abschrieben oder die Bibel in Rom nacherzählten. Sicher unterschieden sich manche Texte in ihrer Reichweite und ihrem Prestige von anderen, wie diese drei Beispiele zeigen. Sie verweisen auch auf je unterschiedliche Autorenprofile. Auf unterschiedliche Buchkulturen verweisen sie dagegen kaum. ${ }^{59}$

\section{Zusammenfassung}

Das Autorenprofil des „Hirten des Hermas“ und die Gattung der Visionsliteratur beziehungsweise „Apokalypse“ stehen in einem erkennbaren Zusammenhang und einer erkennbaren Spannung. Die Konzeption einer im Wesentlichen übermenschlichen Autorenschaft drängt den „Zweitautor“ in eine bestimmte Rolle, die durch die Aufgaben der Textsicherung, Verbreitung und Texterklärung bestimmt ist. Das ist nicht wenig und nicht selbstverständlich. Der Text ist genau in diesen Hinsichten prekär. Die Verschriftlichung der ersten Visionsinhalte muss erst eingefordert werden, erst sie bildet die Grundlage für alles weitere. Auch die Verbreitung ist kein Selbstläufer. Der (Zweit-) Autor muss sich darum gegen institutionelle Widerstände bemühen; die Gelegenheitsstruktur, die diese Institutionen bilden, ist durch hohe Schwellen geschützt. Und schließlich ist der Autor und Icherzähler paradigmatisch „dumm“, stellt all jene Fragen, die auch Zuhörer oder Leserinnen sich stellen mögen. Den Rezeptionserfolg kann das noch nicht erklären. Erst das Zusammenspiel eines kulturüberschreitenden und inhaltlich unterbestimmten Rezipientenmodells, eines sehr schlichten „idealen Lesers", der moralisch nach Idealität erst strebt, und das Angebot eines religiös verdienstvollen Rollenmodells für Schreiber und Übersetzer ${ }^{60}$ mag dafür in einer skriptographischen und vielsprachigen Gesellschaft ausschlaggebend gewesen sein. Zum Texterfolg gehören Produzenten wie Publikum. Erst im Zusammenspiel beider und seiner Rekonstruktion findet der Zugriff über Autorenprofile seinen Ort - und in seiner Ein-Seitigkeit seine Grenzen.

\footnotetext{
${ }^{58}$ Joly 1997, 62.

${ }^{59}$ Gegen Haines-Eitzen 2000, 132.

${ }^{60}$ Zum Begriff der Rolle s. Sundén 1975.
} 


\section{Literaturverzeichnis:}

Batovici, D. (2011). „Contrasting Ecclesial Functions in the Second Century: 'Diakonia', 'Diakonoi', 'Episkopoi', and 'Presbyteroi' in the Shepherd of Hermas and Ignatius of Antioch's Letters.“ Augustinianum 51 (2): 303-314.

Batovici, D. (2014). „Textual Revisions of the Shepherd of Hermas in Codex Sinaiticus.“ Zeitschrift für Antikes Christentum 18 (3): 443-470.

Batovici, D. (2015). „Apocalyptic and Metanoia in the Shepherd of Hermas.“ Apocrypha 26: $151-170$.

Batovici, D. (2016a). „A New Hermas Papyrus Fragment in Paris.“ Archiv für Papyrusforschung 62 (1): 20-36.

Batovici, D. (2016b). „Two Notes on the Papyri of the Shepherd of Hermas.“ Archiv für Papyrusforschung 62 (2): 384-395.

Bowersock, G. W. (1995). Martyrdom and Rome. Cambridge.

Choat, M.; Yuen-Collingridge, R. (2010). „The Egyptian Hermas: The Shepherd in Egypt before Constantine.“ In: T.J. Kraus; T. Nicklas, edd., Early Christian Manuscripts: Examples of Applied Method and Approach. Texts and Editions for New Testmanent Studies 5. Leiden. 191-212.

Collins, J.J. (1987). „Apocalypse: An Overview.“ Encyclopedia of Religion 1: 334-336.

Frend, W.H.C. (1965). Martyrdom and Persecution in the Eary Church: A Study of Conflict from the Maccabees to Donatus. Oxford.

Gregory, A. (2002). „Disturbing Trajectories: 1 Clement, the Shepherd of Hermas and the Development of Early Roman Christianity. “In: P. Oakes, ed., Rome in the Bible and the Early Church. Carlisle. 142-166.

Haines-Eitzen, K. (2000). Guardians of letters: Literacy, power, and the transmitters of early Christian literature. Oxford.

Joly, R. (1958). Hermas, Le Pasteur: Introd., texte critique, trad. et notes. Sources chrétiennes 53. Paris.

Joly, R. (1997). Hermas, Le pasteur. Sources chrétiennes 53 bis. Paris.

Jones, K.R. (2011). Jewish Reactions to the Destruction of Jerusalem in A. D. 70: Apocalypses and Related Pseudepigrapha. Suppl. to the Journal for the Study of Judaism 151. Leiden.

Klausner, S.Z. (2005). „Martyrdom.“ In: L. Jones, ed., Encyclopedia of Religion 8: 57375744.

Leutzsch, M. (1989). Die Wabrnehmung sozialer Wirklichkeit im "Hirten des Hermas". Forschungen zur Religion und Literatur des Alten und Neuen Testaments 150. Göttingen.

Maier, H. O. (1991). The Social Setting of the Ministry as Reflected in the Writings of Hermas, Clement and Ignatius. Studies in Christianity and Judaism 11. Waterloo.

Osiek, C. (1999). Shepherd of Hermas: A Commentary. Hermeneia. Minneapolis.

Rüpke, J. (1999). „Apokalyptische Salzberge: Zum sozialen Ort und zur literarischen Strategie des ,Hirten des Hermas'." Archiv für Religiongeschichte 1: 148-160.

Rüpke, J. (2005). „Der Hirte des Hermas: Plausibilisierungs- und Legitimierungsstrategien im Übergang von Antike und Christentum. “ Zeitschrift für Antikes Christentum 8 (2): 276-298.

Rüpke, J. (2011). Von Jupiter zu Christus: Religionsgeschichte in römischer Zeit. Darmstadt. 
Rüpke, J. (2013a). „Fighting for Differences: Forms and Limits of Religious Individuality in the 'Shepherd of Hermas'. "In: J. Rüpke, ed., The Individual in the Religions of the Ancient Mediterranean. Oxford. 315-341.

Rüpke, J. (2013b). „Two cities and one self: Transformations of Jerusalem and reflexive individuality in the Shepherd of Hermas.“ In: J. Rüpke; G. Woolf, edd., Religious Dimensions of the Self in the Second Century CE. Studien und Texte zu Antike und Christentum 76. Tübingen. 49-65.

Rüpke, J. (2015). „Religious Agency, Identity, and Communication: Reflecting on History and Theory of Religion. “ Religion 45 (3): 344-366.

Rüpke, J. (2016a). On Roman Religion: Lived Religion and the Individual in Ancient Rome. Ithaca.

Rüpke, J. (2016b). Pantheon: Geschichte der antiken Religionen. München.

Stone, M.E. (2003). „A reconsideration of apocalyptic visions.“ Harvard Theological Review 96 (2): 167-180.

Suerbaum, W. (1992). „Zum Umfang der Bücher in der archaischen lateinischen Dichtung. Naevius, Ennius, Lukrez und Livius Andronicus auf Papyrus-Rollen.“ Zeitschrift für Papyrologie und Epigraphik 92: 153-173.

Sundén, H. (1975). Gott erfahren: Das Rollenangebot der Religionen. Aus dem Schwed. übertr. von H. Reller. Gütersloh.

Waldner, K. (2018). Für die Wabrheit sterben: Antike Martyriumserzäblungen zwischen Religion, Politik und Philosophie. Studien zu Antike und Christentum. Tübingen.

Wallraff, M. (2013). Kodex und Kanon: Das Buch im frühen Christentum. Hans-Lietzmann-Vorlesungen 12. Berlin. 



\title{
The Curious Case of Aelius Aristides
}

\author{
The Author as Sufferer and Illness as 'Individualizing Motif'
}

\author{
Georgia Petridou
}

\begin{abstract}
"The final four works in this book are not quite stories. They form a separate unit, one that is autobiographical in feeling, though not, sometimes, entirely so in fact. I believe they are the first and last - and the closest - things I have to say about my own life."

Alice Munro, Dear Life, 255
\end{abstract}

This is how Alice Munro, the Canadian novelist and winner of the 2013 Nobel prize for literature for Dear Life, introduces what she describes as her Finale, the final part of the aforementioned book, which many of her devoted admirers fear may be her last. The bewildering syntactical structure "autobiographical in feeling, though not, sometimes so in fact" along with the fact that the themes of this autobiographical last part of Munro's book are recurrent in the rest of the book and indeed in some of her other books (does that imply that the rest of her short stories are autobiographical too?) brings home the power and the predicaments of the 'I' narratives. The same phrase is telling of any author's (modern or ancient) desire to delimit future receptions of their work and to strike the right balance between lifelike artistry and autobiographical allure.

This seems, then, like an appropriate epigraph for a study on the authorial voice of P. Aelius Aristides Theodoros, as it is both reflected and refracted in his well-known Hieroi Logoi (henceforth $H L$ ). This paper will revisit the $H L$ as a literary work that is both innovative and illustrative of its socio-political milieu. While Aristides rather ingeniously utilises traditional discourses and literary genres attested in both literary sources and epigraphy (aretalogical discourse,

\footnotetext{
${ }^{1}$ My title is a playful take on F. Scott Fitzgerald's The Curious Case of Benjamin Button, a short story originally published in Colliers Magazine (May 27, 1922), and Judith Perkins' wellknown article "The Self as Sufferer". I would like to thank wholeheartedly Eve-Marie Becker and Jörg Rüpke for their pertinent comments on an earlier draft of this chapter and Paul Scade for correcting my English. I am also indebted to Jörg Rüpke and the Max-Weber Kolleg for a generous research fellowship under the auspices of the DFG and FWF-funded International Research Training Group 'Resonant Self-World Relations in Ancient and Modern Socio-Religious Practices' project (shared between the University of Erfurt, Germany and Karl-Franzens-University, Graz, Austria), which allowed me to work on the revisions of this article.
} 
healing pilgrimage narratives, and medical paradoxography), he still succeeds in emphasising his exceptionality both as an author and a sufferer. This paper argues that the means by which this authorial individualisation is achieved is Aristides' insistence on, firstly, the uniqueness of his bodily ailments and, secondly, on the inimitability of Asclepius' 'tailor-made' therapies. ${ }^{2}$ Thus, Aristides succeeds in reinventing not only the literary genres of aretalogy and medical paradoxography, but also himself as an author. ${ }^{3}$

\section{The Hieroi Logoi as autobiography and "fictional autobiography"}

The last decade or so has been exceptionally kind to Aelius Aristides and his $H L$. With an advanced research project in Strasbourg devoted exclusively to producing new critical editions of his work (including the $H L$ ) and a plethora of high-quality publications, both in English and in other European languages, Aristides could hardly complain. ${ }^{4}$ However, it is important to remember that things were not always so. For instance, although the $H L$ may have been warmly received by Philostratus and saluted as divinely inspired in Libanius, ${ }^{5}$ the general reception of Aristides' work from the tenth century onwards has been, with some notable exceptions (on which see below), rather unfavourable. By way of example, this is what Arethas, the well-known Byzantine scholar, scribbled in the margins of one of the manuscripts of the $H L$ : "But why do you have to go on for so long and make such a fuss, Aristides? What's taking you so long? And

\footnotetext{
${ }^{2}$ On the concept of authorial individualization, see Rüpke 2013 and Stefaniw 2012. On individualization and religious rhetoric in the Imperial Anatolia, see Belayche 2013.

${ }^{3}$ Medical paradoxography: Petsalis-Diomidis 2010, 151-167; Petridou 2017; Geus and King 2018. Aretalogy: Martzavou 2012; Jördens 2014.

${ }^{4}$ See, for instance, Horstmanshoff 2004, 325-341; King 2006, 246-263; Pernot 2006, 235-254 and idem 2009; the edited volume by Harris and Holmes; Petsalis-Diomidis 2010; Israelowich 2012; Koúkn 2012; Downie 2013. A new edition of Aristides' HL is currently in preparation by Laurent Pernot and Luana Quattrocelli: Aelius Aristide. Discours Sacrés. Panégyrique sur l'ean de Pergame (orr. XLVII-LIII), Paris: Les Belles Lettres, Collection des Universités de France.

${ }^{5}$ E.g. Libanius, Epistulae 1534.1-5. At this point, I would like to differentiate myself from Downie's reading of the much-discussed passage from Vitae Sophistarum 583. Based on this passage, Downie (2013, viii) argues that in Philostratus' eyes, Aristides was not as valued as the other orators due to his limitations in extempore proclaiming. However, the meaning of this passage is not as unequivocal as Downie makes it sound. The fact that Philostratus chooses to start his account of Aristides and his work by discussing the $H L$ and Aristides' steadfast

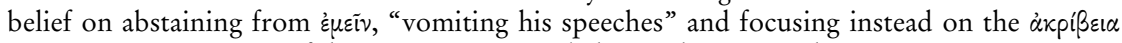
('accuracy', 'precision') of their content counterbalances does not, at least in my view, equate to doubting or rejecting Aristides' self-conscious style of rhetorical delivery. Indeed, it is telling of the popularity of the $H L$. Philostratus starts his account of Aristides' literary vita by mentioning his most well known work.
} 
what's with the fancy dream-delirium?"6 As Luana Quattrocelli remarks, this frosty reception was primarily the byproduct of the clashing self-representation cultures of Byzantium and Graeco-Roman antiquity: Christian humility vs. Graeco-Roman ostententious rhetorical exhibition. L'archiprêtre of unadultered

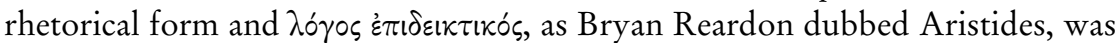
doomed to failure. ${ }^{7}$

Things did not improve dramatically in either the nineteenth or the twentieth centuries. In fact, as has already been noted by Patricia Cox-Miller, scholars were united in proudly exhibiting and variously justifying their deep aversion to Aristides' $H L .{ }^{8}$ One of the many reasons behind such a unanimous scholarly dislike was that the $H L$ was interepreted as a failed antobiography or a failed novel of sorts. This and the following sections will look at the grounds on which modern scholars built these ideas and whether we should indeed take them seriously.

Charles Behr was the first who studied the $H L$ meticulously as a reliable, but not necessarily carefully constructed autobiographical text. He was also the first to comment on the $H L$ as a text of "unbelievable confusion", thus setting it miles apart from the rest of Aristides' other carefully constructed Atticising prose. ${ }^{9}$ In a neat Appendix (A), he painstakingly dated (not always successfully) every single episode narrated in the six books of the $H L$. In his own words, Behr construed the $H L$ as the "voluminous and faithful record of dream world and waking life", which if properly employed could reveal "for the first time unequalled possibilities ... to break the barriers of anonymity which surround the inner life of even the best known figures of antiquity, and without qualification or conjecture, to penetrate to the subconscious level of one of them". ${ }^{10}$ In the same vein, in the second volume of Georg Misch' History of Autobiography in Antiquity (1950, vol. 2, 503), the dubious exercise in psychologising the author and the narrative characters returns with greater vengeance. Once more, the $H L$ is examined as a kind of failed psychological autobiography. Measured against the highly regarded archetypes of narratives that revealed genuine spiritual development and religious confession, such as Augustine's Confessions, the $H L$ simply does not cut it. It falls short both in terms of genuineness and grace, being the literary child of a troubled and boastful author. ${ }^{11}$

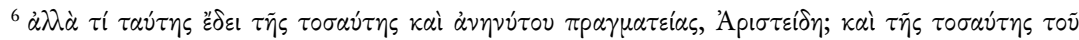

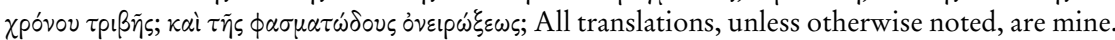
More on Arethas and his critique in Quattrocelli 2008.

${ }^{7}$ Reardon 1971.

${ }^{8}$ Cox-Miller 1994, 193-194.

${ }^{9}$ Behr 1968, 118.

${ }^{10}$ E. g. Behr 1968, xiii; and idem 1994.

${ }^{11}$ Bompaire's analysis (1993) was far more successful in properly contextualising Aristides' $H L$ and setting them next to other first-person narratives of eminent second-century intellectuals like Lucian, Marcus Aurelius and Galen, whose work carried the same alluring autobiographical dimension and centred on rhetoric and the body.
} 
In her seminal monograph on Aristides and his $H L$, Alexia Petsalis-Diomidis discussed extensively these problems with the modern reception of Aristides' work and rightly warned the reader against such "over-realistic readings" of the $H L .^{12}$ Indeed, reading the $H L$ too closely and in a too literal a way raised far too many false hopes and expectations in scholars, who approached this work as a modern kind of autobiographical novel. B. P. Reardon, as a case in point, described the $H L$ as a 'failed novel'. ${ }^{13}$ The autobiographical dimension of the $H L$ - although not completely free from some unnecessary psychologizing - has been explored more fruitfully by Marie-Henriette Quet, Judith Perkins, Helen King, and Patricia Cox-Miller. ${ }^{14}$ The problem of reading the $H L$ too literally has been further exacerbated by the oneiric dimension that some of these narratives have and our modern preconceptions, heavily influenced by Freudian interpretations, of dreams as a window into the subconscious of the dreamer. Taking the cue from Petsalis-Diomidis, Janet Downie was very successful in recognising the self-consciousness of the oneiric narratives in the $H L$. In her recently published monograph, aptly entitled At the Limits of Art, Downie pays close attention to Aristides' rhetorical aspirations and treats these dream narratives not as examples of intentional rhetorical confusion, ${ }^{15}$ but as exhibitions of self-mastery of the literary and linguistic challenge of narrating one's own dreams. ${ }^{16}$

Hand in hand with these "over-realistic readings" and the anachronistic application of modern categories to the study of dreams in the $H L$ went scholarly interpretations of the $H L$ as the narrative keyhole to Aristides' psyche - as if one could possibly get a glimpse into the psyche of any author as self-conscious as Aristides was. Most famously, Eric Dodds construed the HL and Aristides' artful encomium to Asclepius as an earnest plea for a substitute father-figure; ${ }^{17}$ while according to Danielle Gourevitch and William Harries, the $H L$ is an exemplary work of a hysteric and hypochondriac individual. ${ }^{18}$ Finally, according to Christopher Jones, who has produced some of the most thorough and admirable analyses not only of the $H L$ but of most of Aristides's works, the second century rhetorician must have suffered from neurasthenia. ${ }^{19}$ Others focused on Aristides as an individual with severe psychological problems resulting from repressed needs and desires: homoerotic feelings (Gabriel Michenaud and Jean Dierkens); clinical narcissism (Paul Andersson and Bengt-Arne Roos); and grief (Elisavet Kouke). ${ }^{20}$

\footnotetext{
12 Petsalis-Diomidis 2010, 122-124.

${ }^{13}$ Reardon 1971, 255-265 and 263-264.

${ }^{14}$ Cox Miller 1983; Quet 1993; King 1999; and Perkins 1992 and 1995.

${ }^{15}$ For such interpretations, see Korenjak 2005.

${ }^{16}$ Downie 2013, 34.

${ }^{17}$ Dodds 1965, 41-45.

${ }^{18}$ Hysteric: Gourevitch 1968. Hypochondriac: Harris 2009.

${ }^{19}$ Jones 1998, 63-76.

${ }^{20}$ More in Michenaud and Dierkens 1972; and Andersson and Roos 1997.
} 
In the mid-1990s, Simon Swain moved in the right direction, when he cautioned against reading the $H L$ as providing access to the author's innermost thoughts; instead, Swain argued we should always be aware of the fact that this is the literary work of an individual who was very conscious of his public persona. ${ }^{21}$ Swain rightly deemed the $H L$ to be an extremely self-conscious text not only in terms of its content, but also in terms of its very own writing process. ${ }^{22}$ Petsalis-Diomidis drew further attention to the self-reflexivity of this text as sacred narrative and sacred performance. ${ }^{23}$ In her view, Aristides built himself up as a divinely inspired author, who on Asclepius' instigation finally succumbed to chronicling his experiences with illness and sacred healing, not, however, without much protestation and trepidation regarding his rhetorical ability to tell the whole story. ${ }^{24}$ Petsalis-Diomidis was also the first, at least to my knowledge, who properly rehabilitated the text of the $H L$ and set it firmly back into Aristides' rhetorical œuvre: "the $H L$ displays a literary self-consciousness which contradicts interpretations of it as 'unworked jottings' revealing the private thoughts of the author ... this text is not addressed to a select religious group, but engages in mainstream intellectual discourse." 25

To be sure, the two most challenging aspects of the self-reflexive character of the $H L$ for the modern student of Aristides' authorial voice are: a) the constant references to the supplementarity of the $H L$ in relation to the original dream diaries Aristides kept on Asclepius' command, ${ }^{26}$ and b) the repeated references to Aristides as the author who intentionally withholds information from his readers and reveals only part of the truth, especially when it comes to the part of the text where Aristides' initiation into the mysteries of Asclepius is described. ${ }^{27}$ Of course, as Peter van Nuffelen (2007 and 2011) has rightly

\footnotetext{
${ }^{21}$ Swain1996, 255.

${ }^{22}$ Swain 1996, 260-261.

${ }^{23}$ Petsalis-Diomides 2006.

${ }^{24}$ Or. 47.2-3; 48.1,8, 10, 11, 18, 22, 33, 80; 49.6, 17, 30; 50. 15, 38, 70, 80.

${ }^{25}$ Petsalis-Diomidis 2010, 126.

${ }^{26}$ Aristides insists that the $H L$ contained but a fraction of what was originally experienced and written down on the original dream-diaries upon Asclepius' command Or. 48.2. Detailed dream diaries: Or. 48.3, 8; 49.26, 30; 50.25. I have borrowed the term 'supplementarity' from Graf and Johnston $\left(2013^{2}\right)$ and their analysis of the Orphic Texts.

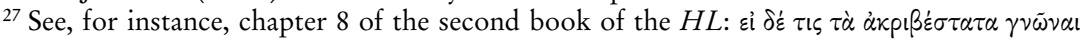

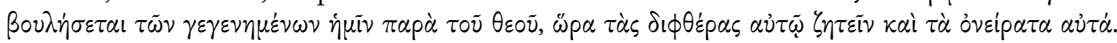

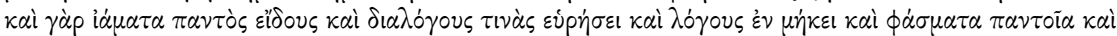

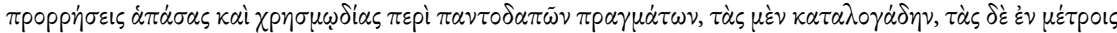

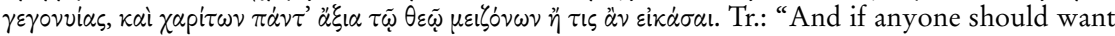
to show most precisely the things which happened to me through the god, he should seek the parchments and the dreams themselves. For he will also find cures of all kinds and some conversations and full-length narratives and all kinds of divine manifestations and all the pronouncements and prophesies of the god about all sorts of things, some written in prose and some in verse, and all worthy of more gratitude to the god than one could imagine." Cf. also Or. $47.71 ; 48.33 ; 49.50$.
} 
argued, aposiopesis was a rhetorical schema popular with many other authors of the second sophistic.

By considering the $H L$ as only one of Aristides' ten other $\lambda o^{\prime}$ o $\mu \alpha v \tau \varepsilon v \tau o$ i, ${ }^{28}$ Janet Downie has asked in her recent monograph how much the $H L$ really differs from the rest of Aristides' orations. Downie firmly embedds the $H L$ into Aristides' rhetorical oeuvre and reads them as an avant-garde rhetorical experiment not at all dissimilar to the rest of his meticulously designed prose hymns and rhetorical declamations. Essentially, Downie answers the all-important question of why Aristides, who was compared to Demosthenes for his stringent Atticising style, chose to preserve for posterity this tantalisingly fragmented first-person narrative which monitors its author's most intimate bodily processes, which is bound together mainly by free association, and, more importantly, "falls far from the polished style of the rest of his literary œuvre". However, and unlike earlier scholars who read the $H L$ as a record of personal anxiety, seeing Aristides as a typical hypochondriac and the embodiment of his contemporary cultural decline (see above), Downie argued compellingly enough that the $H L$ is as craftily contrived as the rest of his literary and rhetorical writings. Indeed, the artfully disarranged narrative stream of the $H L$, as Downie maintains, reveals an author actively engaged in an act of self-representation as a divinely inspired orator. What's more, the $H L$ can be read as Aristides' apologia for his rhetorical vocation (p. viii). Downie fully substantiates her view by comparing the $H L$ to Aristides' other orations, especially to his Against Those Who Burlesque the Mysteries, Or. 34 Keil, in which he also paints oratory as his unique and inescapable divine vocation.

This is not, however, to say that the $H L$ is an autobiography or a kind of "fictional autobiography", that is the kind of ' $\mathrm{I}$ ' narrative in which "the author illusionistically impersonates the narrating character", as Tim Whitmarsh puts it. ${ }^{29}$ Although the $H L$ have been repeatedly compared to other works and authors which fit the brief perfectly, they are only as 'autobiographical' as required by the aretalogical character of the work. One such comparandum was, as expected, Apuleius' last book of the Metamorphoses. Stephen Harrison, in particular, suggested that Apuleius had known and read Aristides' $H L$, and that the $H L$ was indeed the text that Apuleius followed closely and often parodied in the eleventh book of his Metamorphoses, where Lucius' multiple initiations first in the mysteries of Isis and then to those of Osiris are narrated..$^{30}$ As far as the relationship between Lucius and Aristides is concerned, in Harrison's own words, "the gullible and

\footnotetext{
${ }^{28}$ Either his first editor (compiler of the first collection of his works) or Aristides himself puts the $H L$ and ten other orations under the same rubric of $\lambda$ ó $\gamma$ ol $\mu \alpha \nu \tau \varepsilon v \tau o$. Behr 1986 vol. 2, 223 , n. 1 . The meaning of mantento $i$ are that there were prescribed by oracles.

${ }^{29}$ On the concept of fictional autobiography, see Whitmarsh 2013.

${ }^{30}$ Harrison 2001, 245-259.
} 
inexperienced youth is a telling Apuleian comment on the self-important and self-aggrandizing narrative of the middle-aged sophistic superstar. Aristides, it is suggested, may have been deluded in precisely the manner of Lucius". ${ }^{31}$

The connection between the two texts is an easy one to make. Both the $H L$ and the last book of the Metamorphoses are first-person narratives centred on the physical and psychological metamorphosis of an individual. Both metamorphoses have significant religious and socio-political ramifications, and both protagonists recast their experiences in terms of a series of direct and intense encounters with healing deities, Isis in Lucius' case, Asclepius and Sarapis in Aristides, and initiations into the mysteries of the aforementioned deities. ${ }^{32}$

Nevertheless, whereas with Lucius, few would doubt the genuineness of his repeated pathos-filled pleas to be cured from his ass-like physique and ritual ignorance of the Isiac mysteries, in Aristides' curious case a plethora of scholarly commentators have expressed disbelief about the genuineness of his ill health and suffering and his desire to recover. The reader is reminded of the standard accusations, mentioned above, that Aristides' was suffering from hypochondria and emotional dependence on the god..$^{33}$ Are Aristides' claims to ill health part of an elaborate literary stand? Are they essential in his building up his 'authorial profile' as a suffering scriptor (to use a term applied to the modern author by Roland Barthes in an attempt to liberate the text from the tyranny of interpreting the text based on its author) ${ }^{34}$ Or does Aristides simply adhere to literary conventions externally superimposed by the literary genres/discourses he employs and the general intellectual and socio-political milieu of his time?

31 The first who compared the two texts was, of course, André-Jean Festugière 1954, 85-104. Festugière, in his famous Personal Religion among the Greeks, read both the $H L$ and the eleventh book of the Metamorphoses as primary evidence for a kind of intense and more personal religiosity, which could not be fully accommodated within the more formulaic religious systems of Rome.

${ }^{32}$ See, for instance, Met. 11. 21, where the actual act of initiation into the mysteries of Isis is likened to an act of voluntary death, and the initiates as somehow having being reborn by the providence of the goddess who restores their health. It is of great significance that in this particular passage Lucius (or is it Apuleius?) chooses to conclude his description of the expected benefits of the mysteries of Isis by emphasising the medicinal aspect of the cult: the initiates are reborn, because the goddess restores their health. Indeed, the painful journey from the ill and malformed body to restored health (physical and psychological alike) is perhaps the most noteworthy connection between our two narratives and their protagonists.

${ }^{33}$ Festugière $(1954,86)$ describes Aristides as "one of a psychological addiction to illness that has religious ramifications" and "as a paradigmatic instance of Graeco-Roman cultivation of "personal religion".

${ }^{34}$ The Death of the Author (French original: La mort de l'auteur), Manteia 5 (1967). 


\section{Tailor-made therapies and tailor-made therapeiae}

Before answering this question, let us examine chapter 8 of yet another celebratory speech Aristides wrote for Asclepius (Oration 42 in Keil's edition), entitled An Address Regarding Asclepius:

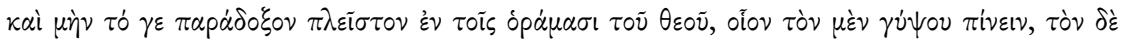

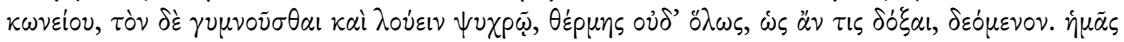

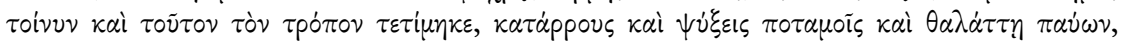

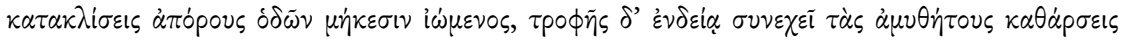

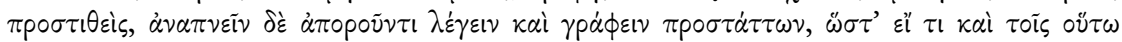

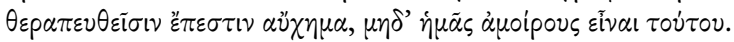

In fact, there is very much that is paradoxical in the remedies of the god, for example one man drinks gypsum, another hemlock, and another undresses and bathes in cold water with no need of warmth, as one would expect. Indeed, he has also honoured us in this way, by stopping catarrhs and colds with baths in rivers and the sea, by curing our inability to lay in bed with long walks, by adding indescribable purgatives to frequent fasting, and by commanding me to speak and write when I found it difficult to breathe, so that if people cured in this way can boast a little bit about it, we have too our share of boasting.

This passage reveals two groups of remedies: on the one hand, we have the prescriptions which candidly contradict contemporary mainstream medical approaches based on the so-called 'humoral medicine' and medical ideas about regulated exercise and dietary control, and which could thus feature easily in medical paradoxographical accounts; and on the other hand, we have the more nuanced rhetorical therapies, which perhaps would better suit an aristocratic man of letters. More importantly, the passage shows how wide-ranging and 'tailor-made' Asclepian therapeiae could be. There was a different therapy not only for different types of diseases, but also for different types of patients, as Galen himself also seems to attest in the following passage from his treatise De Sanitate Tuenda (On Hygiene):

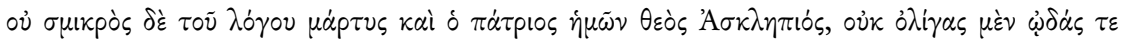

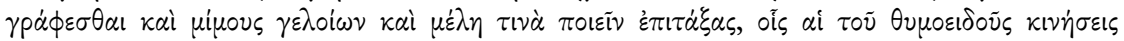

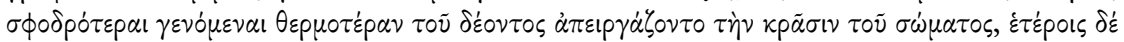
$\tau$ เ

No small witness of this opinion is our ancestral divinity Asclepius, who caused not a few odes to be written and humorous mimes and songs to be composed by those in whom the excessive activity of passion made the constitution of the body hotter than normal. And others, not a few also, he caused to hunt, ride, and exercise in arms. ${ }^{35}$

\footnotetext{
${ }^{35}$ Galen De Sanitate Tuenta 1.8.17-23 Koch $=6.40-42 \mathrm{Kuhn}$. On this passage and analogous 'tailor-made' treatments, see Petridou 2017.
} 
More significantly, Asclepius and other healing deities such as Sarapis seemed to have been in a habit of demanding from their patients a written record of their miraculous recoveries also known as iama or therapeia. See, for instance, how explicitly Marcus Julius Apellas, a member of the Carian socio-political elite and a contemporary of Aristides, on whom more below, was ordered to compose an epigraphic chronicle of his therapeutic encounters with Asclepius (IG IV ${ }^{2} 1.126$,

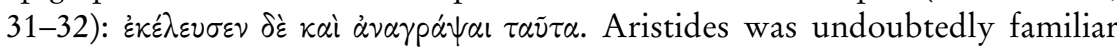
with analogous inscribed ex-votos from the temple of the god in Pergamum. In all likelihood, he also knew of written records of miraculous healings implemented by Sarapis too from his theōria to Egypt. As the much-quoted passage from Strabo's chapter on the Egyptian temple of Sarapis at Canobus shows, the recording of the therapeiae (cures) which the god administered was a common phenomenon; and so was recording the aretas (meaning 'the proven power') of the oracles given at the Serapieion. ${ }^{36}$ The same epigraphic habit was common enough in the temples of Asclepius, as both the surviving epigraphic record and the testimonies of authors like Pausanias and Strabo attest. In this view, Aristides' Hieroi Logoi are far from a whimsical autobiographical take on the chronicling of bodily illness and textual therapies. They are, conversely, the product of a long and persistent cultural tradition of literary activity that was centred on the reiterating of the divine therapeiae.

When Aristides makes use of the first-person narrative, he does not simply apply a veridical veneer to his 'fictional autobiography'. Instead, he simply complies with the mode and registers of the aretalogical discourse, the driving force behind the composition of the hieroi logoi. More to the point, by insisting on the singularity of his illness and his talor-made therapies, Aristides single-handedly reinvents the genre of medical paradoxography (or the discourse of medical paradoxography, if we want to be more accurate) and simultaneously pushes the limits of religious rhetoric to their absolute maximum. By laying emphasis on the complexity and interminable nature of his own illness, he further intensifies the laudatory tone of his own therapeia or iamatic narrative and, by extension, he strengthens his encomium of his divine physician. The next section aims to flesh out this premise by comparing the $H L$ with other literary and epigraphical first-person narratives.

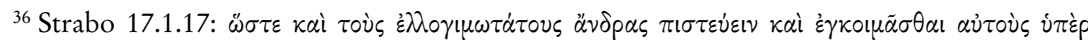

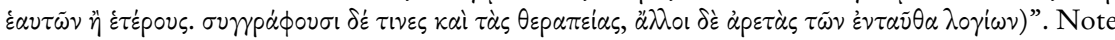
also that arête in the sense of a 'literary recording of the divine therapeia' appears also in the Hellenistic hymn to Issylos (see opening and closing lines with Herzog ad loc and intro p. 50). On the Egyptian deities, in whose honour incubation was practised in the Graeco-Roman world, see the seminal recent work of Renberg 2017 (esp. vol. 1, 329-513). 


\section{The author as sufferer and illness as an "individualising motif"}

Inspired by the work of Susan Sontag and Thomas Couser, Petsalis-Diomidis maintained that in the $H L$, Aristides employs his illness as an "individualising motif" ${ }^{37}$ By this, she means that the famous second century rhetorician focuses specifically on his own ailments rather than those of his community and represents both his illnesses and the cures prescribed by the healing deities he entreats as unique. To provide a vivid example of Aristides' emphasis on himself as an author and a suffering individual, Petsalis-Diomidis reminds us of chapter 9 from the fourth book of the $H L$ (Or.50.9 Keil) where Aristides lightly touches upon the deadly plague of 165 . Although this pandemic killed thousands of people, Aristides lays extra emphasis on his individual suffering and the miraculous and paradoxical cures, which Asclepius prescribed to him alone. ${ }^{38}$ Others may have also received miraculous treatments from the god, as Aristides himself reminds us, but he deems his case as unique by virtue of a) the frequency of these personal correspondences with Asclepius and b) the intensity of the pain he had to endure: ${ }^{39}$

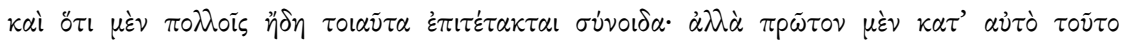

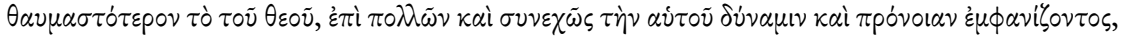

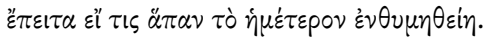

I am aware, of course, that such things have already been prescribed/ordered for many people; but firstly, in itself this activity of the god is more miraculous because he reveals his power and providence on many occasions and constantly, and secondly if one were to recall my overall bad condition.

For the purposes of the present paper, I have embraced the concept of illness as "individualising motif", but I use it in a slightly different way. Aristides does actually convey in detail the suffering of other individuals, and not simply of those individuals who are dear to him (like Zosimus and Philoumene or his foster children). But he does so in ways that can only achieve his main goal, which is the glorification of Asclepius and himself as the god's 'chosen One'. This is not in dissonance with the other epigraphical comparanda we have from this period.

To this end, let us have a quick look at a second-century votive from the Asclepieion of Epidaurus. ${ }^{40}$ The text belongs to Marcus Julius Apellas, who, as

\footnotetext{
${ }^{37}$ Sontag 1991; Couser 1997. See Petsalis-Diomidis 2010, 114, n. 86.

${ }^{38}$ On the plague of 165, see Gilliam 1961. On its impact on Aristides and his elite contemporaries, see Quet 2002.

${ }^{39}$ Or. 48. 55 and Or. 48.47 Keil with Petsalis Diomidis 2010, 145.

${ }^{40} \mathrm{IG} \mathrm{IV}_{2}$ 1.126; Edelstein and Edelstein, 19982, T. 342; Girone 1998, no. 114, 58-70; Prêtre and Charlier 2009, no. 23, 227-232; Petsalis-Diomidis 2010, 110; Steger 20162, 119-125; Renberg 2017, 168-171.

I have opted for this particular inscription not only because of its impressive length, its chronological and thematic affinity to the $H L$, but also because this document seems not to have
} 
mentioned above was a prominent Carian and contemporary of Aristides. The same individual features in a decree from Mylasa, which delineates services to be performed in the shrine of Labraunda by high magistrates and servants. The decree was found at Labraunda (I.Labraunda 58 and 59), where Julius Apellas is

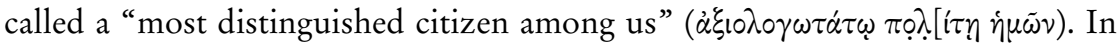
lines $4-5$, we read that while the pilgrim was en route to the Asclepieion, and more specifically, while he was in Aegina, he was advised by the god to keep quiet and avoid unnecessary irritations; while in lines 23-24 an extremely close, even haptic contact with the god is described. However, the most space in this therapeia or iama is taken by the thorough detailing of the god's advice regarding the dietary and bathing habits of his devotee. Further advice on making the necessary payments to the god and his medical attendants, sacrificing to all the right deities, and producing and using pharmaceutical potions and ointments, some of which tie well with ideas we also find in contemporary popular medical like Galen's treatises, are also given extra emphasis in Julius Apellas' account.

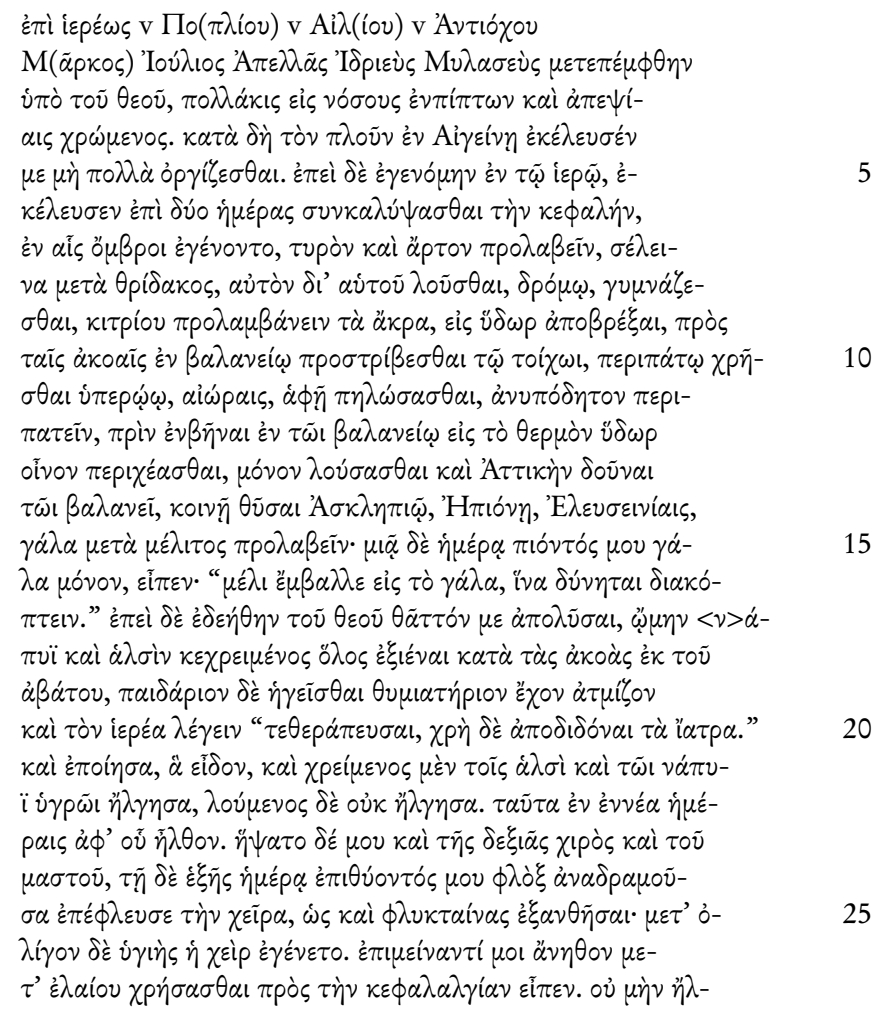

been tempered with by priestly officials, or whosoever was responsible for archiving and editing the records of the patients who took refuge in healing temples. More on this issue in Sineux 2007. 


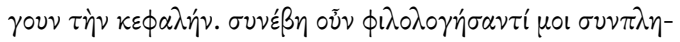

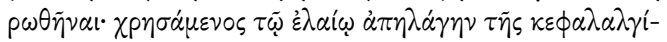

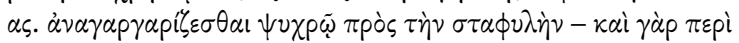

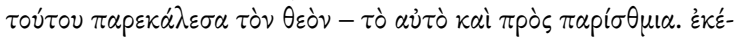

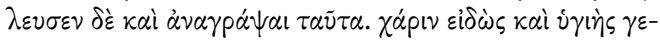

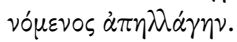

In the priesthood of Publius Aelius Antiochos: I, Marcus Julius Apellas, an Indrian from Mylasa, was sent for by the god, for I was often falling into sickness and was suffering from dyspepsia. In the course of my journey, in Aegina, the god told me not to be so greatly irritated. When I was at the temple (of Asclepius in Epidaurus), he ordered me to keep my head covered for two days, and during those days it rained heavily; to eat cheese and bread, celery with lettuce, to wash myself on my own, to practise running on the track, to take lemon peels, to soak them in water, to rub against the wall in the bath near the (spot of the) akoai, ${ }^{41}$ to take a walk in the upper portico, to take some passive exercise, to smear myself with sand, to walk around barefoot, in the bathroom, before plunging into the hot water, to pour wine over myself, to bathe on my own, and to give an Attic drachma to the bath attendant, to offer sacrifice jointly to Asclepius, Ëpione and the Eleusinian goddesses, and to take milk with honey. When one day I drank milk alone he said, "Add honey in the milk so that it can cut through.” When I asked the god to relieve me more quickly I thought I walked out of the abaton near the (spot of) akoai being anointed all over with mustard and salt, while a small boy was leading me holding a thymiaterion ('censer') that was smoking, and the priest said: "You are cured but you must pay up the iatra ('medical fees')." And I did what I had seen, and when I anointed myself with the salts and the moistened mustard I felt pain, but when I bathed I had no pain. That happened within nine days after I had come. And he (i. e. Asclepius) touched my right hand and also my breast, and on the following day, when I was offering sacrifice the flame leapt up and burnt my hand, so that blisters appeared; yet after a while the hand got healthy. As I stayed on, he (i.e. Asclepius) said I should use dill along with olive oil against headaches. And yet I had no pain in my head. But it happened that after I had studied, my head was congested. After I used the olive oil I got rid of the headache. (Asclepius ordered me) to gargle with a cold gargle for the uvula - since about that too I had entreated the god - and the same also for the tonsils. He bade me also inscribe this. Full of gratitude and having become healthy, I departed.

The long and detailed record of the illnesses and therapies of Marcus Julius Apellas from Mylasa makes for a close parallel to Aristides' personal and pathos-filled attestation to the omnipotence of the Asclepian therapeutics in the HL. A further even closer (at least in terms of geographical proximity) parallel, albeit much briefer, can be found in the testimony of the Rhodian Poplius Aelius Theon.

${ }^{41}$ There is no scholarly consensus about the true meaning of the akoai ('hearing', 'ears') really was. Aristides mentions one more such spot in the Asclepieion of Smyrna in the HL: Or. 47.13. In all likelihood, the akoai was a particular architectural structure or artistic representation that was related to Asclepius' being one of the theoi epekooi, i.e. deities who are listening to people's prayers. More on this issue in Girone 1998, 65-66 and, more recently, Gasparini 2016 and Renberg 2017, 170. 
This second century inscription comes from Pergamum and was unearthed and published in the late 1980s by Helmut Müller:42

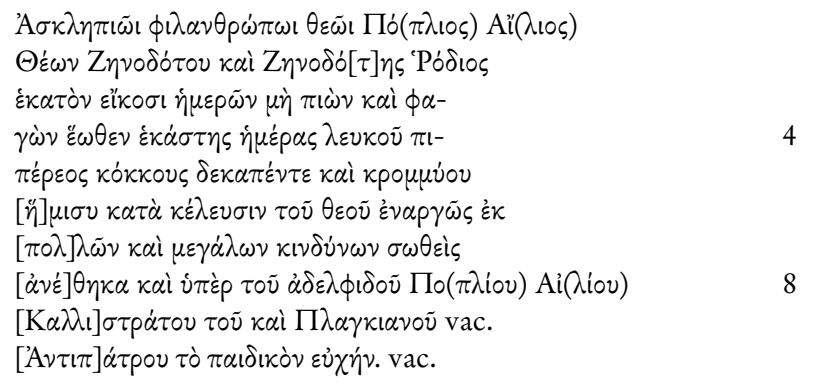

To Asclepius philanthrōpos ('who loves people'), Publius Aelius Theon, son of Zenodotos and Zenodote, a Rhodian, having had nothing to drink for a hundred and twenty days and eaten first thing in the morning each day fifteen grains of white pepper and half an onion by command of the god, having being saved manifestly from many and great perils I dedicated this paidikon ('a statue of Asclepius as a child'?), and also on behalf of my nephew Publius Aelius Kallistratos, also known as Plancianus, son of Antipatros, as an euchē ('vow-fulfilment').

Although we cannot know for sure the exact meaning of the paidikon mentioned in the inscription, we can assume that it depicted an image of Asclepius as a child, an image that would most appropriately commemorate the premature death of Aelius Theon's nephew, Aelius Kallistratos. ${ }^{43}$ We are lucky enough to have one more inscription from the Asclepieion of Pergamum, where the same worshipper, Aelius Theon, dedicates an altar to Eurōstia, the deity who personifies physical strength. ${ }^{44}$ The dedication is said to have been made after a command the dedicant received in his sleep ( $\kappa \alpha \tau^{\prime}$ ovvap).Both inscriptions have one thing in common: by laying emphasis on the broken and dysfunctional body of their dedicants and their miraculous restoration to health by the god, they effectively glorify the medical diversity and omnipotence of Asclepius. Aristides' persistent and exhaustive enumeration of his symptoms, his aches and his triumphant recoveries has the exact same aim. He builds up an elaborate encomium of the divine healer, while simultaneously raising himself as the artful compiler of this composition. Thus he tames religious experience and intimate mortal-immortal contact and puts them into words and raises himself to new heights in the eyes of his peers.

From these and other related literary and epigraphical sources, we learn about the influential role elite patients played in this period in defining and even expe-

\footnotetext{
${ }^{42}$ IvP III 127, SEG 37, 1019; Müller 1987, 193-233; Prêtre and Charlier 2009, no. 20, 210 211; and Steger 20162, 126-131; Renberg 2017, 198-202.

${ }^{43}$ Müller 1987, 209-212; Renberg 217, 198, n. 191.

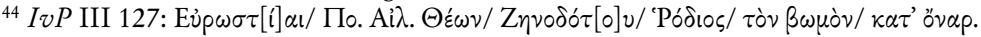


riencing illness and healing. ${ }^{45}$ Within the circles of such elite patients, appealing directly to Asclepius to forego the need for expert analysis of their bodily ailments and regain ownership of their bodily suffering and knowledge was not uncommon. So what makes Aristides so different? Why have he and his claims to ill health been, until very recently, viewed with so much suspicion?

One possible answer to this question is provided by the ways Aristides has been viewed synchronically. Not many ancient authors had the title of "sufferer" written with golden letters in their literary Vitae. Philostratus, for example, introduces Aristides and his work with the following words: "The nature of his disease and the fact that he suffered from palsy in the muscles he tells us himself in his Hieroi Bibloi. These books served him in some sort as a diary (ephemerides), ${ }^{46}$ and such diaries are excellent teachers of the art of speaking well on any subject". ${ }^{47}$ Although many of famous authors of the first and the second centuries (e. g. Marcus Aurelius, and Fronto) did go on to produce detailed accounts of some of their innermost bodily cavities and fluids and include them in the literary production (especially in their epistolary exchange, on which see below) not many had written so extensively about that aspect of their lives. The other side of the same problem is of course, reading too literally Philostratus' notion of ephemeris with modern notions of the personal journal in mind.

The other possible explanation is, of course, that the undeniable religious ramifications of Aristides' illness and, along with it, the genuineness of elite religiosity in the second sophistic has been repeatedly questioned. With the notable exception of Petsalis-Diomidis, the majority of the scholars who work on Aristides have shied away from exploring in depth the esoteric character of the $H L$, its embedded mechanisms of cognitive inclusion and exclusion, and its constant allusion to mysteries of the sort that were extremely popular in the Imperial Era. Ido Israelowich, for instance, in his recent monograph restricts himself to applying lightly to the $H L$ William James' principles about religious signification of painful or traumatic events and simply concludes that "the medical theme in the Sacred Tales is subject to an overall religious meta-narrative". ${ }^{48}$ Even

${ }^{45}$ Petsalis-Diomidis 2010, 221-238; and Várhelyi 2010, 78-90.

${ }^{46} \dot{\varepsilon} \phi \eta \mu \varepsilon p i \varsigma$ is a type of diary, or journal, especially a journal that can be kept in a military campaign, as it was indeed kept by Alexander's staff. See, Ath.10.434b, Plu. Alex.23, Arr. An.7.25.1. Plutarch uses the term to describe Caesar's commentarii in Caes.22. The term can also denote that 'day-book or account-book', as in PCornell 1.2, PCair.Zen.176.357, Plut.2.829c and D. L.6.86.

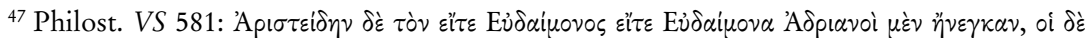

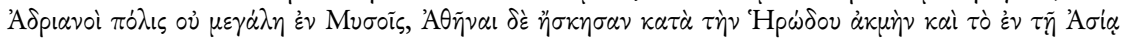

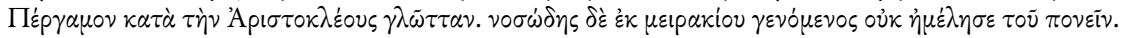

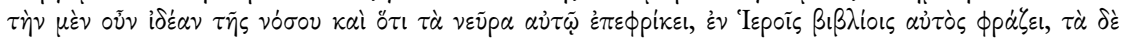

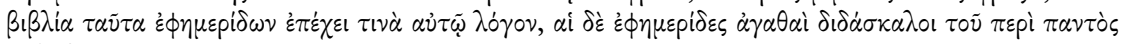
$\varepsilon \tilde{u} \delta\llcorner\alpha \lambda \dot{\varepsilon} \gamma \varepsilon \sigma \theta \alpha \mathrm{l}$.

${ }^{48}$ Israelowich 2012 drawing on James' The Varieties of Religious Experience: A Study in $\mathrm{Hu}$ man Nature, London: Longman, Green and Co, the book that comprises of the edited Gifford 
Israelowich's third chapter, which is entitled 'Reconsidering Private Religions; Religion and Religious Experience in the Sacred Tales', is no more enlightening. It professes to revisit Festugiere's notion of 'private religions', but considers neither bow nor why mystery terminology and imagery frames Aristides' illness experience in the Hieroi Logoi. At the end of the day, the reader leaves with no clearer ideas as to why medicine is conceptualised as a mystery cult in the $H L{ }^{49}$

Israelowich was not alone in noting how inextricably intertwined religion and medicine are in the $H L$. Fitzgerald Johnson was primarily interested in the intersections of medicine and religion when he compared the Life and the Miracles of Thecla to the $H L$. In the process, he offered a valuable service of placing the $H L$ in its right generic contexts. When one compares the $H L$ to Clement's Stromateis or other paradoxographical and miscellanistic writings of the second century AD, Fitzgerald maintains, Aristides' $H L$ stops being a narrative of "unbelievable confusion", to quote Behr, and becomes part of the distinctly imperial tendency of collecting, compiling, preserving and, effectively, appropriating and capitalising on the extraordinary and the miraculous. ${ }^{50}$ The discourses of paradoxography and aretalogy constitute the very action of collecting mirabilia: the first in the fields of medicine and what Petsalis-Diomidis calls "therapeutic competition" among the members of the socio-political and intellectual elite of the second century ${ }^{51}$ the second in the area of enumerating divine epiphanies and intimate contacts of the gods with their devotees. The $H L$ are informed by both of these discourses and simultaneously respond to the widespread current of the popularisation of medicine and the remarkable rise in popularity of healing deities and religions..$^{52}$

It is hardly a coincidence, for instance that medicine is catalogued by Marcus Aurelius among the primary means of communication between the gods and mankind in one of his letters to his dear teacher Fronto. ${ }^{53}$ It is via dreams (somniis), mysteries (mysteriis), medicine (medicina), and finally via oracles (oraculis) that the immortals help and demonstrate their power to the mortals, according to Marcus Aurelius. ${ }^{54}$ The emperor and eminent philosopher, although not an

Lectures on natural theology James delivered at the University of Edinburgh in 1901 and 1902.

${ }^{49}$ Israelowich 2012, 137-188.

${ }^{50}$ Fitzgerald Johnson 2006.

51 Therapeutic competition: Petsalis-Diomidis 2010, 232-233. On paradoxography and the discourse of miracle in both the context of Asclepian healing and second century literary and epigraphical production see ibid, 151-166 and 238-275.

${ }_{52}$ Popularisation of medicine: Nutton 1992 and 1995. See esp. Paz de Hoz 2014, 175-210. Rise of healing religions: Mount 2013, 85-106; Rothschild 2013, 85-106; Bricault 2014; and van Nuffelen 2014.

${ }^{53}$ Marcus Aurelius in Fronto 3.10, p. 43.15 Hout. On Marcus's views about divine healing and Asclepius, see Ep. ad Front. 3.9; Med. 5.8; 4.43. Cf. also Med. 6.33; 10.2 and 36; 3.3 on Marcus' views on the natural sequence between illness and death.

${ }^{54} \mathrm{Cf}$. also Med. 1.17.9, where he thanks Asclepius for remedies prescribed in dreams. More on this in Perkins 1995, 267-272. 
author traditionally associated with illness and divine remedies, was extremely body-conscious and in that respect no different from Aristides and the rest of the Graeco-Roman élite of their time. ${ }^{55}$ Why should one then raise an eyebrow, when Aristides (Or. 51.36) proudly declaims:

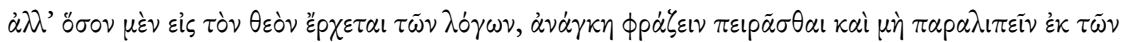

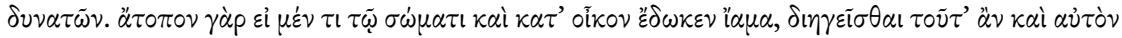

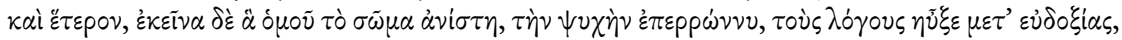

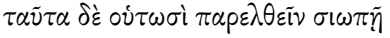

But it is necessary to attempt to put into words all that is concerned with my logoi ('orations/ oratory') which pertain to the god and, as far as it is possible, not to omit anything. For it would be absurd if I recounted in detail every remedy the god prescribed for my body, even when I was at home, and to pass in silence all those other remedies, which simultaneously raised my body, strengthened my soul, and boosted my logoi with good reputation?

\section{Aristides on examining the best physicians}

In a well-known treatise (De Optimo Medico Cognoscendo) that survives only in Arabic translation, Galen delineates the problem of the failed patient-physician relationship in the big metropolis. ${ }^{56}$ First, the wealthy and the powerful do not care enough about their own health; secondly, no proper investigation is carried through when patients die due to lack of proper treatment - the problem being exacerbated by the anonymity of urban health-care providers (De opt. med. cogn. 1. 12-13). Thirdly and more importantly, people simply do not know how to recognise the best physicians.

In Galen's mind, the best physician is the one who excels in prognosis and who inspires confidence in his patients precisely because of his unique ability to prognosticate (De opt. med. cogn. 2.1-3 drawing on [Hipp.] Progn. $1=1$, $78,2-10$ Kühlewein $=11,110,2-9$ L.). The best physician is also someone who "being very learned and wise, trained and skilful"... can cure with drugs diseases that surgeons treat by making incisions (De opt. med. cogn. 10.1). ${ }^{57}$ Indeed, there are a wealth of passages in the $H L$ in which Asclepius employs dietary advice and regimen rather than invasive medical treatments (most notably in Or. 47. 61-68, where Asclepius cures Aristides from a growth, phyma), and the testimonies of Julius Apellas and Aelius Theon discussed above provide further support to this premise. While failing in diagnosis is not even an option for any respectable

${ }^{55}$ Cf. Galen's De Praecognitione, where members of the local socio-political elite have been equally interested in "monitoring and discussing their pulses, their diets, and their medical regimes”, as Cox Miller 1994 rightly notes.

${ }^{56}$ Iskander 1989, with Nutton 1990.

${ }^{57}$ Horstmanshoff 2004. 
physician, the best physician is the one who cures patients with serious and complicated diseases (De opt. med. cogn. 14.3):

For if you find that a physician cures many patients from serious diseases, you will know that he is skilful in therapy; but if you find that he only cures patients with slight and minor ailments you will know he is unskilled.

This is extremely significant for our purposes. If Aristides is writing both in an aretalogical context and follows the trends of medical paradoxography, while simultaneously showing off his knowledge of popularised medical treatises, it is then possible that he has deliberately construed his self-portrait as a someone who suffers from a plethora of serious - notice how often his ailments are described as life-threatening - illnesses with this or an analogous description in mind. In other words, the duration on his illness, the severity of his symptoms and the intensity of their impact on his life and his rhetorical career may have been deliberately intensified to highlight the abundant therapeutic aptitude of his divine physician. I am not quite suggesting that Aristides read this specific treatise, which has been dated to the mid 170s (Iskandar), which nonetheless would have appeared early enough for Aristides to read (d. 181 according to Behr). ${ }^{58}$ This would have made for a very narrow and not particularly fruitful notion of intertextual dependence. What I suggest, however, is that Aristides may have read analogous works, which emphasised the need to judge the medical capacity of a physician against the complexity and seriousness of the ailments he treated. In a highly agonistic environment, where physicians themselves invested highly in competitive demonstrations of both rhetorical ability and anatomic knowledge, it not difficult to imagine that a plethora of treatises and pamphlets with content analogous to that of the On Examining the Best Physicians must have been in circulation..$^{59}$ And there is little doubt that Aristides and his entourage read a lot.

In short, in presenting himself as a sufferer and Asclepius as the only physician who successfully diagnoses and treats his complex and unique ailments, Aristides operates within the generic constraints of the related genres of aretalogy and medical paradoxography. More significantly, when he insists on the difficulty of diagnosing his ailments (this is mainly achieved by emphasising the failure of the earthly doctors to treat him ${ }^{60}$ and the immeasurable suffering he experiences, Aristides takes tradition one-step further. In utilising illness as an individualising motif, he does not simply seek to establish himself as a divinely inspired orator and a distinguished devotee of the god. In building up the complexity and the unusualness of his illness, he builds up simultaneously the encomium of his divine

\footnotetext{
${ }^{58}$ Nutton dates the treatise more precisely to the 178 .

${ }^{59}$ More on this topic in Gleason 1995 and 2009. .

${ }^{60}$ Note here unlike the $H L$ Aristides' view on human physicians in the rest of his work is much more positive. E.g. in his 'To the Rhodians: Concerning Concord, $5(\mathrm{Or} .24 \mathrm{~K})$ and in his 'Against those who burlesque the Mysteries', 53 (Or. $34 \mathrm{~K})$. More on this topic in Petsalis-Diomidis $(2010,146)$.
} 
healer. Aristides, just like J. Apellas and Aelius Theon, received explicit orders from the god to produce a detailed chronicle of his sufferings and the therapies he received; just like Marcus Aurelius spent a fair amount of time contemplating on the intersections between medicine, religion, dreams and mysteries; and finally, just like Galen and Lucian chose to employ the first person narrative to transplant the so-called authoritative gaze into an authoritative voice. ${ }^{61}$ If I were pressed to adjudicate on the autobiographical aspect of Aristides' $H L$, I would be tempted to say that, just like the last part of Alice Munro's Dear Life, the $H L$ are "autobiographical in feeling, though not, sometimes, entirely so in fact".

\section{Bibliography}

Andersson, Paul; Roos, Bengt-Arne (1997). 'On the psychology of Aelius Aristides'. Eranos 95: 26-38.

Barton, Tamsin, S. (1992). Power and Knowledge: Astrology, Physiognomics, and Medicine Under the Roman Empire. Michigan: University of Michigan Press.

Behr, Charles Allison (1968). Aelius Aristides and the Sacred Tales. Amsterdam: A. M. Hakkert.

Behr, Charles Allison (1994). 'Studies on the biography of Aelius Aristides'. ANRW II.34.2: 1140-1233.

Behr, Charles Allison (1981-1986). The Complete works by Aelius Aristides. Brill: Leiden. Belayche, Nicole (2013). 'Individualization and Religious Rhetoric in Imperial Anatolia', in: Jörg Rüpke, ed., The Individual in the Religions of the Ancient Mediterranean. Oxford and New York: Oxford University Press. 433-468.

Bompaire, Jacques (1993). 'Quatre styles d'autobiographie au IIe siecle apres J.-C: Aelius Aristide, Lucien, Marc-Aurele, Galien’, in: Marie-Françoise, Baslez; Phillipe Hoffmann; Laurent Pernot, edd., L'invention de l'autobiographie d'Hésiode à saint Augustin. Paris: Les Belles Lettres. 199-209.

Bowersock, Glen Warren (1969). Greek Sophists in the Roman Empire, Oxford University Press.

Bricault, Laurent (2014). 'Isis, Sarapis, Cyrus and John: Between Healing Gods and Thaumaturgical Saints', in: Luis Arturo Guichard, Juan Luis García Alonso; María Paz de Hoz, edd., The Alexandrian Tradition. Intersections between Science, Religion and Literature. Bern: Peter Lang. 97-114.

${ }^{61}$ Petsalis-Diomidis $(2010,71-73)$ compares the $H L$ with Leukippe and Kleitophon, one of the most celebrated Greek novels, also a first-person narrative populated by dreams, divine epiphanies, statues, images, temples and gazing at the human body, and concludes that it is easy to see how the authoritative, powerful, diagnostic gaze of the first and second centuries AD (expressed in a wide range of scientific texts of the period (such as Polemo's Physiognomy and Galen's medical treatises) was translated on the narrative level to an authoritative, controlling, first-person voice. More on this topic in Barton, 1992, 15-17 and 137-168. If we take this observation in conjunction with the deep and enticingly revelatory character that biography has, one can only image how appealing auto-biography must have been for a second-century author: one still gets to offer and detailed and prima facie personal account of one's life whilst remaining in control of the story's development and quite possibly its reception. See also Cox 1983, xi. 
Couser, Thomas (1997). Recovering Bodies: Illness, Disability, and Life Writing. Madison: University of Wisconsin Press.

Cox Miller, Patricia (1994). Dreams in Late Antiquity: Studies in the Imagination of a Culture. Princeton, NJ: Princeton University Press.

Dodds, Eric R. (1965). Pagan and Christian in an Age of Anxiety. Cambridge: Cambridge University Press. 41-45.

Downie, Janet (2013). At the Limits of Art. A Literay Study of Aelius Aristides' Hieroi Logoi. Oxford University Press.

Edelstein, Emma, J.; Edelstein, Ludwig (1998). Asclepius: Collection and Interpretation of the Testimonies. Baltimore and London: The John Hopkins University Press.

Ehrenheim von, Hedvig (2015). Greek Incubation Rituals in Classical and Hellenistic Times. Kernos. Supplément, 29. Liège: Presses Universitaires de Liège.

Elsner, Jas (1992). 'A Greek Pilgrim in the Roman World'. Past and Present 135: 3-29.

Festugière, André-Jean (1954). Personal religion among the Greeks, Berkeley: University of California Press.

Fitzgerald Johnson, Scott (2006). The Life and Miracles of Thekla: A Literary Study. Hellenic Studies 13. Washington: Harvard University Press.

Gasparini, Valentino (2016). 'Listening stones. Cultural appropriation, resonance and memory in the Isiac cult', in: Vestigia. Miscellanea di Studi Storico-Religiosi in Onore Di Filippo Coarelli Nel Suo 80 Anniversario. Potsdamer Altertumswissenschaftliche Beiträge Band 55. Stuttgart: Franz Steiner Verlag. 555-574.

Girone, Maria (1998). Iamata: guarigioni miracolose di Asclepio in testi epigrafici. Bari: Levante.

Geus, Klaus; King, Colin Guthrie (2018). 'Paradoxography: wonder stories, tall tales, and the limits of reason', in: Paul Keyser, John Scarborough, edd., Oxford Handbook of Science and Medicine in the Classical World. Oxford: Oxford University Press. 431-444.

Gilliam, James Frank (1961). 'The Plague under Marcus Aurelius'. AJP 82: 225-251.

Gourevitch, Danielle (1968). 'Le cas Aelius Aristides ou memoires d'un hysterique au 2e siècle’. Information Psychiatrique 44: 897-902.

Graf, Fritz; Johnston, Sarah Iles (2013). Ritual Texts for the Afterlife: Orpheus and the Bacchic Gold Tablets. London/New York: Routledge.

Harrison, Stephen J. (2001). 'Apuleius, Aelius Aristides and Religious Autobiography'. Ancient Narrative 1. 245-259.

Harris, William Vernon (2009). Dreams and Experience in Classical Antiquity. Cambridge and London: Harvard University Press.

Harrison, Stephen J. (2001). 'Apuleius, Aelius Aristides and Religious Autobiography'. Ancient Narrative 1: 245-259.

Horstmanshoff, H.F.J. (2014). 'Did the god learn medicine? Asclepius and Temple Medicine in Aelius Aristides' Sacred Tales', in: H. F.J. Horstmanshoff; M. Stol, edd., Magic and Rationality in Ancient Near Eastern and Graeco-Roman Medicine. Leiden: Brill. 325-341.

Iskandar, Albert, Z. (1988). Galen, On examination by which the best physicians are recognized, edition of the Arabic version with English translation and commentary, Corpus Medicorum Graecorum Supplementum Orientale IV. Berlin: Akademie Verlag.

Israelowich, Ido (2012). Society, Medicine and Religion in the Sacred Tales of Aelius Aristides. Leiden: Brill.

James, William (1902). The Varieties of Religious Experience: A Study in Human Nature. London: Longman, Green and Co. 
Jones, Christopher P. (1998). 'Aristides and the Asclepieion of Pergamum', in: Helmut Koester, ed., Pergamon: Citadel of the gods; Archaeological record, Literary Description, and Religious Development. Harrisburg: Trinity Press. 63-76.

Jördens, Andrea (2013). 'Aretalogies', in: Eftychia Stavrianopoulou, ed., Shifting Social Imaginaries in the Hellenistic Period. Narrations, Practices, and Images. Leiden: Brill. 143-176.

King, Helen (2006). 'The Origins of Medicine in the Second Century AD', in: Simon Goldhill; Robin Osborne, edd., Rethinking Revolutions Through Ancient Greece. Cambridge: Cambridge University Press. 246-263.

Korenjak, Martin (2005). 'Unbelievable Confusion. Weshalb sind die Hieroi Logoi des Aelius Aristides so wirr?' Hermes 133: 215-234.

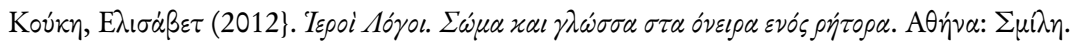

Martzavou, Paraskevi (2012). 'Isis Aretalogies, Initations, and Emotions. The Isis Aretalogies as a Source for the Study of Emotions', in: Angelos Chaniotis, ed., Unveiling Emotions. Sources and Methods for the Study of Emotions in the Greek World. Stuttgart: Frank Steiner. 267-291.

Michenaud, Gabriel; Dierkens, Jean (1972). Les Reves dans les Discours Sacres' d'Aelius Aristide II' siecle ap. J.-C. Essai d'analyse psychologique. Mons.

Mount, Christopher 2013. 'Belief, Gullibility, and the Presence of a God in the Early Roman Empire', in: Tobias Nicklas, Janet E. Spittler, edd., Credible, Incredible. The Miraculous in the Ancient Mediterranean. Tübingen: Mohr Siebeck. 85-106.

Müller, Helmut. (1987). 'Ein Heilungsbericht aus dem Asklepieion von Pergamon'. Chiron 17: 193-233.

Nuffelen van, Peter (2007). 'Words of Truth: Mystical Silence as a Philosophical and Rhetorical Tool in Plutarch.' Hermathena 182: 9 -39.

Nuffelen van, Peter (2011). Rethinking Gods: Philosophical Readings of Religion in the Post Hellenistic Period. Cambridge: Cambridge University Press.

Nuffelen van, Peter (2014). 'Galen, divination, and the status of medicine.' Classical Quarterly 64: 337-352.

Nutton, Vivian (1990). 'The Patients’s Choice: A New Treatise By Galen.' Classical Quarterly 40: 236-257.

Nutton, Vivian (1992). 'Healers in the Medical Market Place: Towards a Social History of Graeco-Roman Medicine’, in: Alison Wear, ed., Medicine in Society: Historical Essays. Cambridge: Cambridge University Press. 15-58.

Nutton, Vivian (1995). 'The Medical Meeting Place', in: Philip van der Eijk et al., edd., Ancient Medicine in Its Socio-Cultural Context. Amsterdam/Atlanta, GA: Rodopi. vol. 1, 3-25.

Paz de Hoz, Maria (2014). 'Lucian’s Podagra, Asclepius and Galen. The popularisation of medicine in the second century AD', in: Luis A. Guichard, Juan L. García Alonso, Maria Paz de Hoz, edd., The Alexandrian Tradition. Interactions between Science, Religion, and Literature. Bern: Peter Lang. 175-210.

Perkins, Judith (1992). 'The Self as Sufferer'. Harvard Theological Review 85: 245-272.

Perkins, Judith (1995). The Suffering Self. Pain and Narrative Representation in the early Christian Era. London: Routledge.

Pernot, Laurent (2006). 'The Rhetoric of Religion'. Rhetorica 24.3: 235-254.

Petridou, Georgia (2017). 'Poésie pour l'esprit, rhétorique pour le corps: Remèdes littéraires et cautions épistolaires dans les Hieroi Logoi d'Aelius Aristide.' Mètis 15: 69-94. 
Petridou, Georgia (2018). “'One has to be so terribly religious to be an artist”: Divine inspiration and theophilia in Aelius Aristides' Hieroi Logoi.' Archiv für Religionsgeschichte 20.1: 253-268.

Petsalis-Diomidis, Alexia (2006). 'Sacred writing, sacred reading: the function of Aelius Aristides' self-presentation as author in the Sacred Tales', in: Brian McGing; Judith Mossman, edd., The Limits of Ancient Biography. Swansea: University of Wales Press. 193-211.

Petsalis-Diomidis, Alexia (2010). Truly Beyond Wonders. Aelius Aristides and the Cult of Asklepios, Oxford: Oxford University Press.

Prêtre, Clarisse; Charlier, Philippe (2009). Maladies humaines, thérapies divines. Analyse épigraphique et paléographique de textes de guérison grecs. Villeneuve d'Ascq.

Quattrocelli, Luana (2008). 'Aelius Aristides' Reception at Byzantium: the case of Arethas', in: William V. Harris; Brooke Holmes, edd., Aelius Aristides between Greece, Rome and the Gods. Columbia Studies in the Classical Tradition 33. Leiden: Brill. 279-293.

Quet, Marie-Henriette (1993). 'Parler de soi pour louer son dieu: le cas d'Aelius Aristide',in: Marie-Françoise Baslez; Philippe Hoffmann; Laurent Pernot, edd., L'invention de l'autobiographie d'Hésiode à saint Augustin. Paris: Presses de l'Ecole Normale Superieure. 211-251.

Quet, Marie-Henriette (2002). 'Éloge par Aelius Aristide des co-empereurs Marc Aurèle et Lucius Verus, à l'issue de la guerre contre les Parthes'. Journal des Savants (janvier-juin 2002). 75-150.

Reardon, Bryan P. (1971). Courants littéraires grecs des IIe et IIIe siècles après J.-C. Paris: Les Belles Lettres.

Renberg, Gil H. (2017). Where Dreams May Come. Incubation Sanctuaries in the Greco-Roman World. 2 vols. Leiden: Brill.

Rothschild, Clare K. (2013). 'Hocus pocus, Galen's On Prognosis and the Gospel of Mark', in: Tobias Nicklas, Janet E. Spittler, edd., Credible, Incredible. The Miraculous in the Ancient Mediterranean. Tübingen: Mohr Siebeck. 107-142.

Rüpke, Jörg (2013). 'Individualization and Indivisuation as Concepts of Historical Research', in: Jörg Rüpke, ed., The Individual in the Religions of the Ancient Mediterranean. Oxford/New York: Oxford University Press. 3-40.

Sineux, Paul (2007). 'Les récits de rêve dans les sanctuaires guérisseurs du monde grec: des textes sous contrôle’. Sociétés E Représentations 23. 45-65

Sontag, Susan (1991). Illness as Metaphor and Aids and Its Metaphors. London: Routledge. Steger, Florian $\left(2016^{2}\right)$. Asklepios. Medizin und Kult. Stuttgart: Frank Steiner.

Stephens, James (2013). The Dreams and Visions of Aelius Aristides. Gorgias Press.

Stefaniw, Blossom (2012). 'Gregory Taught, Gregory Written. The effacement and Individualisation in the Address to Origen and the Life of Gregory the Wonderworker', in: Jörg Rüpke; Wolfgang Spickermann, edd., Reflections on Religious Individuality: Greco-Roman and Judaeo-Christian Texts and Practises. Berlin: De Gruyter. 119-144.

Swain, Simon (1996). Hellenism and Empire: Language, Classicism, and Power in the Greek World, AD 50-250. Oxford: Oxford University Press.

Várhelyi, Zsuzsanna (2010). The Religion of Senators in the Roman Empire. Power and the Beyond. Cambridge: Cambridge University Press.

Whitmarsh, Timothy J. (2013). 'An I for an I: reading fictional autobiography', in: Anna Marmodoro; Jonathan Hill, edd., The Author's Voice in Classical and Late Antiquity. Oxford: Oxford University Press. 233-249. 



\title{
Die Masken des Lukian
}

\author{
Auf der Suche nach der (religiösen) Stimme des Autors
}

\author{
Dorothee Elm von der Osten
}

\section{Einleitung}

Seit der Antike haben die Leser des Lukian die sprechende persona und den Autor der Schriften meist gleichgesetzt und auf dieser Basis in einem nahtlosen Übergang die Biographie Lukians erschaffen, deren Elemente - wie Richter treffend feststellt - über die Jahrhunderte hinweg bemerkenswert konstant geblieben sind. ${ }^{1} \mathrm{Zu}$ diesen konstanten Elementen gehören neben seinem syrischen Geburtsort Samosata ein relativ früher Aufenthalt in Gallien und die Annahme eines Postens in der Provinzialverwaltung Ägyptens in höherem Alter.

Die skizzierte Vorgehensweise ist zum einen auf die Abwesenheit von zeitgenössischen Quellen jenseits des lukianischen Werks zurückzuführen. Lediglich eine in arabischer Übersetzung vorliegende amüsante Anekdote Galens scheint sich auf den Autor Lukian zu beziehen: Dieser habe einmal ein Buch, „in das er dunkle Reden niedergeschrieben hatte, hinter denen sich überhaupt kein Sinn verbarg“, als Werk des Philosophen Heraklit ausgegeben. Ein Philosoph, dem dieses Werk zugänglich gemacht wurde, begann „Deutungen zu jenen Reden beizubringen, wobei er sich selbst äußerst scharfsinnig vorkam, und so blamierte er sich“.2

Die oben genannte Vorgehensweise bei der Rekonstruktion der Biographie des Autors Lukian ist zum anderen auf Lesegewohnheiten zurückzuführen, die erst mit der Entwicklung und Anwendung der Methoden der Narratologie in der zweiten Hälfte des 20. Jahrhunderts eine mangelnde Kompetenz des Lesers zu verraten schienen. Die Erzähltheorie postulierte eine strikte Trennung zwischen dem (realen) Autor und dem Erzähler und verlangte eine entsprechende Kompetenz vom Leser. Der Begriff des impliziten Autors erlaubte zwar die Ein-

\footnotetext{
${ }^{1}$ Ich möchte mich bei Eve-Marie Becker und bei Jörg Rüpke für die Einladung bedanken, meine Gedanken zu Stimme und religiösem Profil des Autors Lukian vorzutragen und zu diskutieren. Konstanz der Biographie: Richter 2005.

${ }^{2}$ Galen zu Hipp. Epid. 2,6,29, Übersetzung Baumbach 2002, 19.
} 
führung einer dritten Instanz zwischen realem Autor und Erzähler, der ein Bild des realen Autors, wie es sich aus dem Text erschließt, bezeichnete: „Es ist dies“, so Genette, „ein induzierter Autor, wie ich ihn aus seinem Text erschließe, ein Bild des Autors, das dessen Text suggeriert". ${ }^{3}$ Dieses Konzept eines impliziten Autors wurde jedoch von Genette selbst kritisch betrachtet, da es von zu geringer methodischer Relevanz sei. ${ }^{4}$

Ein besonderes Merkmal der Schriften des Lukian trägt darüber hinaus dazu bei, dass seine Leser die verschiedenen Stimmen der sprechenden und erzählenden personae meist dem realen Autor zuordneten, nämlich der Umstand, dass Lukians Texte oft in der ersten Person verfasst sind. Auch wenn der Name des Autors Lukian in seinem Werk sehr selten genannt wird - er erscheint z. B. nicht in der scheinbar autobiographisch gefärbten Schrift Somnium -, so wirken andere Figuren, die als Protagonisten in Dialogen und Ich-Erzählungen auftauchen, als stünden sie dem Autor sehr nahe, da sie als gebildete, rhetorisch versierte Syrer auftreten, die die Merkmale griechischer paideia verinnerlicht haben. Sie tragen zudem zum Teil Namen, die nur geringfügig von demjenigen des realen Autors Lukian abweichen. ${ }^{5}$ Oft sind in der Forschung diese Namen daher als Pseudonyme des Lukian gewertet worden - die ihm ähnliche Figur wurde als ein alter ego angesehen. Deren Äußerungen trugen somit zur Zeichnung eines Gesamtbildes des realen Autors bei. ${ }^{6}$

Selbst in denjenigen Forschungsbeiträgen, die zwischen den Stimmen dieser personae sorgfältig differenzieren, ist jedoch eine zentrale Annahme über den realen Autor unbestritten, nämlich der bereits erwähnte Umstand, dass es sich um einen Syrer handelt, der als pepaideumenos mit den Mechanismen der griechischen Bildung im Kontext der Zweiten Sophistik aufs engste vertraut war. ${ }^{7}$

Die Einordnung des so gewonnenen Bildes des Autors bzw., in anderer Terminologie, des Autorkonstrukts ,Lukian' in diskursgeschichtliche $\mathrm{Zu}$ sammenhänge sowie die Beschreibung seiner Position in den religionsgeschichtlichen Transformationsprozessen des zweiten Jahrhunderts n. Chr. werden in der Forschung eng mit der Bewertung seiner Ethnizität verbunden und hängen zum Teil von dieser ab. ${ }^{8}$ Insbesondere die Darstellung des religiösen Profils des Autors ist in einen Zusammenhang mit seiner Herkunft gestellt worden.

${ }^{3}$ Genette 2010, 262.

${ }^{4}$ Genette 2010, 266.

${ }^{5}$ Die den Namen betreffenden Spiele des Lukian („onomastic games“ Ní Mheallaigh 2010, 91) sind unterschiedlich interpretiert worden: als Strategien der Fiktionalisierung des Autors (Dubel 1994), als Teil des Auslotens der kulturellen Identität im Kontext des Römischen Reiches (Goldhill 2002, 66), als performative Veranschaulichung der vergeblichen Suche nach der Wahrheit („recurrent failure of any search for authoritative ,true“ utterances“, Whitmarsh 2001, 252), vgl. Nì Mheallaigh 2010, 91.

${ }^{6}$ Vgl. statt vieler: Goldhill 2002, 66.

${ }^{7}$ Zum Beispiel Goldhill 2002, 66.

${ }^{8}$ Im Folgenden wird also das jeweilige ,Autorkonstrukt ${ }^{`}$ bzw. ,Autorkonzept ${ }^{‘}$ im Vorder- 
Der folgende kurze Blick auf die Forschungsgeschichte berücksichtigt daher zunächst diese beiden Perspektiven - Ethnizität und Religiosität -, um sich dann den Autorkonzepten in der jüngeren Forschungsliteratur zu Lukians Werk zuzuwenden. Daran schließt sich eine Interpretation der Stimme des Autors in der Schrift Alexander oder der Lügenprophet an. In diesem Werk setzt sich der Autor mit zeitgenössischer religiöser Innovation auseinander - hier in Gestalt eines neuen Orakelkultes. Zugleich ist dies eine der wenigen Schriften des Lukian, in der der Ich-Erzähler und Protagonist den Namen des realen Autors trägt. ${ }^{9}$

\section{Forschungsgeschichte}

\subsection{Autorprofil I: Ethnizität}

Lukian wird in der die letzten Jahrzehnte prägenden Forschung zur Bewegung der Zweiten Sophistik zwar häufig als einer ihrer zentralen Vertreter angesehen, aber zugleich auch als ein Autor betrachtet, der das Phänomen der paideia nicht als insider, sondern von außen, von dessen Grenzen her betrachte. ${ }^{10}$ Ein zentrales Argument für diese Auffassung ist die in den Schriften häufig inszenierte syrische Ethnizität der sprechenden oder erzählenden personae. Damit geht die teils implizite Annahme einher, dass der Autor als Syrer Griechisch nicht als Muttersprache sprach und darüber hinaus die Prozesse des becoming Greek, die er in seinen Schriften thematisiere, selbst durchlaufen habe. Die Tatsache, dass die Ambiguitäten hybrider Identitätsbildung in den Schriften des Lukian zum Thema werden, wird also in einen Zusammenhang mit der Ethnizität des impliziten Autors gestellt.

Die Kategorie der Ethnizität und ihr komplexes Verhältnis zur paideia in der Zweiten Sophistik ist zuletzt von Adam Kemezis differenziert beschrieben worden. ${ }^{11}$ So sei zwar, wenn man Ethnizität als ein subjektives, diskursiv hergestelltes Phänomen begreift, paideia das in den Quellen am häufigsten herangezogene Kriterium zur Bestimmung des jeweils vorliegenden Grades an Griechischsein Greekness -, also eine kulturelle Errungenschaft, die bis zu einem gewissen Grad

grund stehen. Vgl. statt vieler zu diesen meist synonym gebrauchten Begriffen Willand 2011: „Sie sind theoriegebunden und beschreiben die Gesamtheit der interpretativen Operationen, mit denen der Autor aufgrund bestimmter theoretischer Prämissen funktionalisiert werden kann. Der Begriff ,Autor' meint dabei nicht die historische Person - dann und nur dann kann von dem realen Autor die Rede sein - sondern trägt immer schon der Tatsache Rechnung, dass es sich um eine geistige Konstruktion des Interpreten handelt."

${ }^{9}$ Zur Bedeutung der Identität zwischen Autor, Erzähler und Protagonist in den Verae Historiae vgl. Nì Mheallaigh 2010 mit weiterer Sekundärliteratur.

${ }^{10}$ Vgl. statt vieler Andrade 2013, 262: ,assuming positions of marginality.“

${ }^{11}$ Kemezis 2014. 
von der Herkunft unabhängig ist. ${ }^{12}$ Es finden sich jedoch auch viele Beispiele, in denen von ,den Griechen' als einer durch Abstammung definierten Gruppe die Rede ist, woraus man schließen kann, dass dem Hellenischen eine auch in diesem Sinne ethnische Dimension zukam. ${ }^{13}$ Kemezis führt ein - besonders bei Lukian häufig anzutreffendes - selbstironisches, spielerisches Moment in den das Griechische betreffenden Diskursen der Zweiten Sophistik auf die unausgesprochene Erkenntnis dieser Widersprüchlichkeit zwischen paideia als einer erworbenen und einer durch Abstammung definierten Kategorie zurück. ${ }^{14}$

Nicht nur in den neueren Forschungsbeiträgen, sondern auch in der Rezeptionsgeschichte des 18. und 19. Jahrhunderts, vor allem in England und Deutschland, ist die Herkunft des Lukian von herausragender Bedeutung für die Bewertung seiner Schriften und der in ihnen vertretenen Ansichten zur Religion. Daniel Richter geht der Rezeptionsgeschichte des Lukian unter dieser Fragestellung nach und kann zwei Phasen voneinander differenzieren. ${ }^{15}$ In der ersten Phase führte eine Verwechslung dazu, dass Lukian als ein (ethnischer) Grieche galt, der lediglich in Syrien geboren wurde. Als sich das Missverständnis auflöste - nämlich die Verschmelzung des Erzählers Lukios von Patras aus der griechischen Version der apuleischen Eselsgeschichte mit dem Autor Lukian -, und zwischen Lukios von Patras und Lukian aus Samosata unterschieden wurde, begann die mangelnde griechische Ethnizität des Autors zu einem Problem zu werden: „The interest of this error, however, lies in its aftermath. Once Lucius of Patras achieves an existence independent from that of Lucian of Samosata, the issue of Lucian's own Greekness becomes fundamentally unstable.... Once the sophist himself becomes unmoored from his Greek ancestry, several of Lucian's readers, Wieland prominent among them, develop other strategies of anchoring Lucian and his texts to the land of Hellas." 16 Wieland tritt in der ausführlichen Einleitung seiner Übersetzung des lukianischen Werkes dafür ein, dass Lukian, nach einem Aufenthalt in Gallien, in Griechenland lebte und hier die wichtigsten seiner Schriften verfasste, solange bis er in Ägypten einen Posten in der

12 Kemezis 2014. Es fällt schwer, im Deutschen eine passende Übersetzung für Greekness, das in solchen Kontexten im Englischen gebraucht wird, zu finden. Im folgenden wird „Hellenisches, Hellenismus, Griechentum, Griechischsein" etc. verwendet.

${ }^{13}$ Kemezis 2014, 393: „In the great majority of our sources from the Second Sophistic, paideia is not opposed to ideas of biological and geographical identity. Discourses explicitly about paideia often still incorporate ideas of descent; conversely, when individuals and communities in the Second Sophistic do identify with descent groups, they still refer to concepts of paideia. Greekness in the Second Sophistic was an acquired class characteristic that had the name of an ethnicity. (...) Paideia was not automatically sufficient for Greekness, since it could be possessed at least in some degree by people (...) who did not self-identify as Greek."

${ }_{14}$ Kemezis 2014, 394: "the self-conscious playfulness of Second Sophistic discourses about Greekness stem largely from an unexpressed recognition of the disconnect between paideia as a learned skill and paideia as an ethnic criterion."

${ }^{15}$ Richter 2005.

${ }^{16}$ Richter 2005, $80 \mathrm{f}$. 
Provinzialverwaltung annahm. Wieland und Pauly betonen die Relevanz des griechischen genius loci für das Werk. Die Biographie des Lukian wird mit dem Bedürfnis geschrieben, ihn so weit wie möglich von seinem Herkunftsland zu distanzieren. ${ }^{17}$

Im Zuge des beginnenden Orientalismusdiskurses im ausgehenden 19. und $\mathrm{zu}$ Beginn des 20. Jahrhunderts wird die Herkunft des Lukian essentialisiert, seinem ,oriental mind' wird schließlich ein Hellenentum weitgehend abgesprochen. So schreibt Eduard Norden vom „Orientalen ohne Tiefe und Charakter ..., der Hohes und Heiliges ins Frivole gezogen hat. "18 Der graduelle Bedeutungsverlust von Lukians Schriften im 19. und 20. Jahrhundert in Europa kann, wie in der Rezeptionsforschung detailliert nachverfolgt wurde, unter anderem auf diese Betrachtungsweise seiner Ethnizität zurückgeführt werden. ${ }^{19}$

In einem engen Zusammenhang mit der oben skizzierten Orientalismusdebatte steht auch die Beurteilung der Authentizität des Werkes De Dea Syria. Ironischerweise wird gerade diesem Werk, in dem sich der Erzähler als Syrer inszeniert, die Authentizität mit dem Argument abgesprochen, dass eine solch ernste Erzählung dem lukianischen Charakter nicht entspräche: „Lucian kann es unmöglich gewesen sein wegen des ernsten Tones (...) in Lucians Leben ist kein Raum für eine derartige Phase gläubiger Gesinnung, wie diese Schrift voraussetzt; man könnte sie nur in die frühe Jugend setzen. “20 Eine Frage des Genres wird hier vor allem zu einer Charakterfrage. In dieser Beurteilung schwingt die Annahme einer mangelnden Tiefe des ,Orientalen' mit.

In der jüngeren, vor allem angelsächsisch geprägten Forschung wird die Ethnizität des Lukian im Kontext des Postkolonialismus diskutiert. Dabei wird die Aufmerksamkeit auf Prozesse hybrider Identitätsbildung gerichtet. In diesem Zusammenhang steht auch die Arbeit von Nathanael Andrade. ${ }^{21}$ Er widmet sich in einer Monographie der syrischen Identität in der griechisch-römischen Welt und stellt diese in den Mittelpunkt seiner Untersuchung der Schriften des Lukian. Er betrachtet ihn unabhängig von seiner ,biographischen`Ethnizität als

\footnotetext{
${ }^{17}$ Richter 2005, $83 \mathrm{f} .:$ „For centuries prior to Wieland, Lucian's readers had chosen to Hellenize the author by conflating Lucian of Samosata with Lucius of Patras. Wieland's essay of 1788 shifts the terms of the conversation about Lucian's Greekness and in doing so, essentially causes the Patrensian Lucian to disappear. Beginning in the late eighteenth century, Lucian's readers came to see the Greekness of Lucian's texts as the necessary consequence of their having been planted, nurtured, and harvested from the soil of Hellas itself."

${ }^{18}$ Das vollständige Zitat lautet: „dem Orientalen ohne Tiefe und Charakter, aber voller Witz

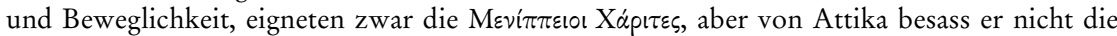

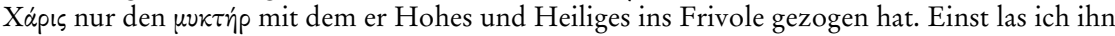
gern wiederholt, jetzt gehe ich nur mit innerem Widerwillen an ihn heran. Er hat keine Seele und würdigt daher trotz aller Virtuosität die seelenvollste Sprache zum $\pi \alpha$ í $\gamma$ viov herab." (Norden 1898/1958 1,394).

${ }^{19}$ Vgl. u. a. Baumbach 2002.

${ }^{20}$ Helm 1912.

${ }^{21}$ Andrade 2013.
} 
einen ,syrischen' Autor, da er in seinem Werk häufig syrische Perspektiven eingenommen oder inszeniert habe. ${ }^{22}$ Ausgangspunkt von Andrades Überlegungen zu Lukian ist die Schrift De Dea Syria. Lukians Text zeige folgendes: „Dynamic and transforming, (As)Syrian culture shares many idioms with Greek culture, and in ways that render incoherent the boundaries of a clear Greek and Assyrian binary. (...) It maps how Syrian culture integrated Greek idioms and intersected with Greek culture“. ${ }^{23}$ Die damit einhergehende Tendenz zu einer Unterminierung eines normativen Hellenismus, die Andrade vor allem anhand der Schrift De Dea syria herausgearbeitet hat, erkennt er auch bei den syrischen Autoren Tatian und Justin, dem Märtyrer: „In fact, while displaying mastery of paideia, ethical self-maintenance, and public performance that characterized Greek sophists, they subjected Hellenism, its origin, and its significance to diverse interpretations " ${ }^{24}$ Römische Syrer repräsentierten nicht ein weniger authentisches Hybrid von Griechischem und lokalen Traditionen, sondern eine neue Ausdrucksweise des Griechischen, eine nicht weniger legitime Tradition als andere im Römischen Reich. Lukian bilde zusammen mit den genannten christlichen syrischen Autoren auf diese Weise eine Form des Hellenismus, der seinen Höhepunkt im Syrien des dritten Jahrhunderts finden sollte, als Palmyra sich mit Zenobia zumindest zeitweise als Zentrum legitimen Griechentums „alongside authentic Romanness" präsentierte. ${ }^{25}$

In der neueren Forschung wird ,Lukian' also in den Diskursen um paideia und Ethnizität insofern als innovativ angesehen, als er - mehr performativ als argumentativ - die Diskrepanz zwischen paideia als erworbener kultureller Errungenschaft und paideia als von griechischer Abstammung abhängig deutlich macht. ${ }^{26}$ Indem er den Anspruch auf Normativität für eine durch (teils erfundene) Traditionen hergestellte Kontinuität mit klassischem Hellenentum unterminiere, könne Hellenismus anders interpretiert werden. Die so ins Spiel gebrachten Arten des Hellenismus erwiesen sich als universalisierungstauglicher, als besser geeignet für die Herausforderungen, die der Kontext des Imperium Romanum stellte.

\subsection{Autorprofil II: Religiosität}

Das Bild von Lukians Verhältnis zur Religion wurde entscheidend von einem Werk geprägt, das in den dreißiger Jahren des 20. Jahrhunderts in Frankreich veröffentlicht wurde und in einer von Croiset am Ende des 19. Jahrhunderts

${ }^{22}$ Andrade 2013, 261.

${ }^{23}$ Andrade 2013, 300; 292. Andrade erinnert seine Leser daran, dass Syrer „realigned and reconstituted what could be experienced as pure or authentic categories", 344 .

${ }^{24}$ Andrade 2013, 262.

${ }^{25}$ Vgl. Andrade 2013, 334-339; Zitat: 337.

${ }^{26}$ Lukians Texte machten folgendes deutlich: „sophists deceptively generated classical models and ,origins' [of Greekness] through their performative acts“" (Andrade 2013, 277). 
begründeten Tradition französischer Studien zu Lukian stand, die in ihm einen Autor von großer sprachlicher Klarheit und stilistischer Eleganz erkannten. ${ }^{27}$ Caster setzte sich mit dieser philologischen, aber auch geistes- und religionsgeschichtlich interessierten Studie mit dem Titel „Lucien et la Pensée religieuse de son Temps" zum Ziel, das über die philosophischen und religiösen Strömungen der antoninischen Zeit in der damaligen Forschung Bekannte mit dem bei Lukian Geschilderten in Beziehung zu setzen. ${ }^{28}$ Er untersuchte in einzelnen Kapiteln die sieben Hauptströmungen der Philosophie, die Vorhersehung, die olympischen Götter, Dämonen, Orakel, Gebete und Opfergebräuche, das Leben nach dem Tod und die Mysterien sowie Magie, neue Kulte und den Synkretismus. Dabei schilderte er zunächst die ,bekannten Fakten' und stellte ihnen daraufhin deren Darstellung und Bewertung bei Lukian gegenüber, der sich seiner Meinung nach überwiegend aus dem Fundus der literarischen Tradition bedienen wollte und auf diese Weise zentrale Elemente der zeitgenössischen Religion unbeachtet gelassen habe. ${ }^{29}$ Casters so gewonnenes Bild von Lukian ist das eines Eklektikers mit starken Anleihen bei den Kynikern und Skeptikern, der jedoch über die Dauer seiner literarischen Tätigkeit hinweg im Grunde Epikureer geblieben sei bzw. deren Position noch radikalisiert habe. Lukians Einstellung zur Religion sei geprägt von seinem Ideal der paideia, die der des Isokrates nahekomme, ein Konzept der perfekten Harmonie und der gedanklichen Schärfe, die einen davon abhalte, sich lächerlich zu machen oder den optimistischen Illusionen der Religiösen anheim zu fallen, die an Opfer, Gebete und das Schicksal, Orakel, Mysterien und das Leben nach dem Tod glauben. Für Caster ist Lukian sogar ein Atheist im modernen Sinne des Wortes. Nur jemand, der ernsthaft areligiös

\footnotetext{
${ }^{27}$ Croiset 1882. Das von Croiset gezeichnete Bild eines mit stilistischen Fragen beschäftigten Schriftstellers, der von den Realitäten des Lebens unbeeindruckt blieb, sollte später sehr einflussreich werden: siehe Bompaire 1958. Maurice Croisets „Essai sur Lucien“ kann als eine für die französische Forschung der Zeit charakteristische Gesamtbetrachtung des Autors angesehen werden. In der Zeit zwischen den beiden Weltkriegen dominierte die Berliner Sicht auf Lukian, im Jahre 1937 erschien jedoch die genannte einflussreiche Studie von Caster, die diese Dominanz der deutschen Forschung modifizieren sollte.

${ }^{28}$ Caster 1937.

${ }^{29}$ Lukians Darstellung der gegenwärtigen Religionen sei unvollständig, er unterlasse es, den Mystizismus der zeitgenössischen Philosophie zu erwähnen, äußere sich nicht über Dämonen, die Kulte des Sarapis, des Asklepios und des Mithras oder den Synkretismus. Er vernachlässige diese Themen aus dem Wunsch heraus, sich vornehmlich aus dem Fundus der reichen literarischen Tradition zu bedienen. Er sei dabei zwar nicht bemüht anachronistisch gewesen, da zum Beispiel seine Kritik an den Orakeln zwar jeweils einer alten Argumentation folgte, aber dennoch genügend Aussagekraft für die gegenwärtige Situation besäße. Sein Material sei jedoch derart eingeschränkt, dass er nicht als ein Zeuge seiner eigenen Zeit bezeichnet werden könne. Für Caster ist Lukian ein um 500 Jahre zu spät geborener Menander. In einer thèse supplémentaire des Autors über die Schrift Alexander oder der Lügenprophet wird ein Lukian gezeigt, der zwar das Interesse und die Gelegenheit hatte, das religiöse Leben seiner Zeit zu beschreiben, aber diese Gelegenheit mit Bestimmtheit nicht ergriffen habe (Caster 1938).
} 
gewesen sei und die Vorstellung eines Göttlichen für abstrus gehalten habe, habe sich so sehr über die Götter mokieren können.

Erst im Jahre 2011 sollte mit der Studie „Götter, Mythen, Philosophen. Lukian und die paganen Göttervorstellungen seiner Zeit" von Fabio Berdozzo wieder eine monographische Abhandlung zu dem Thema innerhalb der Forschung zu Lukian erscheinen. Berdozzo steht in der Tradition Casters, auch wenn er dessen Werk in Teilen zu Recht für methodisch fehlerhaft hält, und untersucht detailliert anhand einer Vielzahl von Werken Lukians Darstellung der traditionellen Götter sowie seine Auseinandersetzung mit dem platonischen und dem stoischen Gottesbild, lässt jedoch z.B. die Schriften Alexander, De Morte Peregrini und De Dea Syria unberücksichtigt. Unter anderem durch einen Vergleich mit den Schriften Galens kommt er zu folgendem Schluss: „Etwas wie ein persönliches religiöses Gefühl des Autors ist an keiner Stelle seines sehr umfangreichen Gesamtœuvres zu belegen, auch indirekt nicht. Vielmehr erscheint ,Religion immer als etwas Negatives, als eine unter den vielen Schwächen, die die menschliche Natur hat. Lukian fehlte im Gegensatz zu seinem Zeitgenossen Galen die Erfahrung des Numinosen, des Heiligen im Sinne Ottos, jener höheren Macht, welche hinter den von den Menschen erfundenen oder manipulierten Riten und Kulten als Substanz immer erhalten bleibt. In den religiösen Phänomenen sah der Samosatenser mit anderen Worten immer nur den menschlichen Teil. Paradoxerweise stand Lukian jedoch der traditionellen griechischen Religion im Prinzip nicht ablehnend gegenüber". .30

Die Schlussfolgerungen von Caster und Berdozzo ähneln den Ergebnissen der älteren Forschungsgeschichte, die unter dem Stichwort der Ethnizität skizziert wurden. Demnach mangelte es Lukian auch aufgrund seines Charakters an der Fähigkeit, das Numinose zu erfahren. Wie in den geschilderten Forschungen wird auch in Berdozzos Untersuchung die Schrift De Dea Syria nicht herangezogen.

Während beispielsweise Dickie, der in einem Aufsatz ebenfalls der religiösen Stimme des Autors bzw. Spuren seiner Theologie anhand eines repräsentativen Ausschnittes des Gesamtwerkes nachgeht, Rechenschaft über seine Konzeption des Autors gibt, beschreibt Berdozzo sein methodisches Verständnis des Autors nicht näher. Das Bild eines Autors und seiner religiösen Erfahrung wird induziert, ohne das Genre der Schriften zu berücksichtigen. ${ }^{31}$

\footnotetext{
${ }^{30}$ Berdozzo 2011, 282 f.; vgl. zu Lukians angeblichem Nihilismus Berdozzo 2011, 288: „Es ist somit nicht korrekt zu behaupten - wie etwa Photios es tut und viele nach ihm getan haben -, dass Lukian an Nichts geglaubt hätte, denn dies kann schlicht und ergreifend auf keine Weise nachgewiesen werden. Richtig ist dagegen zu sagen, dass Lukian keine auctoritas hat gelten lassen. Er entschied sich dafür, sich zu keiner Partei, Schule oder Richtung zu bekennen“. Vgl. auch Whitmarsh 2015, 220-227.

${ }^{31}$ Dickie 2010: „At this point in my argument I abandon caution and try, using both Lucian speaking in his own voice and characters whose standpoint seems to reflect his own, to construct a sketch of Lucian's view of the divine. The dangers in this approach are obvious, but when
} 


\subsection{Autorprofil III: Erzäbltheorie und fiktive Autobiographie}

Die erzähltheoretisch informierte Literatur verfährt anders mit Lukians Schriften als die oben referierten Werke, sie erkennt vielmehr in ihnen selbst bereits Spuren eines Diskurses über Autorkonzepte und eine subtile Warnung vor den Gefahren scheinbar naiver Lesarten. So schreibt zum Beispiel Karen Ní Mheallaig über die Lügengeschichten Verae Historiae, in denen der Erzähler und Protagonist an einer der wenigen Stellen des Gesamtwerks in einer Inschrift mit dem Namen des Autors Lukian („Loukianos“) benannt wird (VH 2,28), Folgendes:

The belated naming of this author-character as "Loukianos" playfully elides the gap between the implied and extra-textual author. In most of Lucian's other works, this gap is preserved by the heteronymity of the authorial personae, obstructing any direct connection to the extra-textual author; Lykinos, for example, is almost, but not quite Loukianos. In contrast, the appearance of the authorial name so prominently in the $V H$ legitimizes at last, it seems, a connection between the extra-textual author and the author in the text. Yet this autograph is embedded in a narrative whose veracity its own author has explicitly denied; as an anti-autobiographical work, the $V H$ ironises the reader's search for the extra-textual author through the text. The splitting and polarisation of the "I" in the $\mathrm{VH}$ along the fault-line of the liar-paradox is an extreme enactment of the fissure that always exists, at least potentially, between the extra-textual author and the implied author or the authorial persona in the text. By compelling the reader, paradoxically, to sever the experiences of the authorial character Lucian from those of the "real" author, the text raises awareness of the ever-potential mediatedness of the authorial ego: even Lucian's supposedly autobiographical inscription is actually authored by Homer. In this way, Lucian exposes the naivety of reading any authorial persona at face value as a conduit to the author outside the text. ${ }^{32}$

In diesem Feld regt sich aber auch Kritik an einer zu großen methodischen Subtilität in der modernen Rezeption antiker Fiktionalität. ${ }^{33}$ Tim Whitmarsh beschäftigt sich mit Lukian im Zusammenhang mit anderen fiktionalen Ich-Erzählungen wie z.B. den Metamorphosen des Apuleius und richtet sein Augenmerk ebenfalls auf den Text Verae Historiae, dessen Genre er als fiktionale Autobiographie bezeichnet. ${ }^{34}$ Mit Rekurs auf die Verschmelzung von Autor

Lucian or sympathetic characters repeatedly appeal to a certain point of view, there is a prima facie case for supposing that this is a position Lucian favours."

${ }^{32}$ Ní Mheallaigh 2009, 22f. vgl. auch ihre Monographie „Reading fiction with Lucian“, Ní Mheallaigh 2014.

${ }^{33}$ Whitmarsh 2013, 66: „The narrator/author divide has become so central to literary criticism that to disturb it seems transgressive, in a way that it clearly was not in premodern times. Narratology is now such a dominant and all-pervasive intellectual idiom that it is easy to forget that antiquity had no dedicated vocabulary to describe the 'narrator' in the strict critical sense of a narrating persona within the textual fiction (as distinct from the 'poet', 'singer', or 'writer'who created it).“ 67: „Too heavy a dependence on modern critical schemes risks inattention to the reading instincts and habits of the ancients themselves."

${ }^{34}$ Whitmarsh 2013, 68: „The idea of a fictional autobiography is a deliberate paradox, since ... the 'autobiographical contract' (whereby author and narrator are assumed to be identical) categorically excludes the 'fictional contract' ... The narratives that we are dealing with, or rath- 
und Ich-Erzähler in der Rezeption der Metamorphosen durch Augustinus unterstreicht er, dass eine strikte Trennung zwischen Erzähler und Autor nicht den Lesegewohnheiten der antiken Leser entsprach. ${ }^{35}$ Texte, die man diesem Genre zuordnen könne, verwischten bewusst die Grenzen zwischen dem Autor und dem Erzähler.

In Genettes Terminologie wird ein solcher Vorgang als Metalepse bezeichnet. Während dies jedoch in Genettes Erzähltheorie einen isolierten, in sich geschlossenen Moment meint, in dem der Text die narrativen Ebenen des Autors und der Fiktion miteinander verschmilzt, sei dieser Vorgang, so Whitmarsh, als ein durchgehender und dynamischer Prozess zu begreifen. Whitmarsh empfindet die narratologische Terminologie als den Lesegewohnheiten der Antike zu wesensfremd und schlägt zur Beschreibung des Verhältnisses von Autor und Autor-personae den Terminus Personifikation oder Verkörperung (impersonation) vor: „The idea of impersonation, it seems to me, better captures the fundamentally nonnarratological approach to the fictional ' $I$ ' that prevailed in the ancient world: like an actor playing a role, the fictional autobiographer created an illusion of identity with the role he played - an illusion that was ever predicated on universal awareness of its unreality. " ${ }^{36}$ Eine Personifikation dieser Art könne man als eine Unterart der Metalepse verstehen und Lukian als einen der in diesem Sinne metaleptischsten Autoren der Antike beschreiben. ${ }^{37}$

Mit Hilfe dieser der Rhetorik und dem Theater entstammenden Terminologie, die die performativen Elemente unterstreicht, könne das illusionistische Element besser verdeutlicht werden, das Oszillieren zwischen dem Erfolg der Illusion und der Demaskierung, das Oszillieren zwischen Nähe und Distanz des Zuschauers bzw. Lesers. Zugleich eröffnet sich damit ein Zugang zur textuellen Inszenierung des Autors, der sich an die bereits im Zuge des performative turn in den Kulturwissenschaften herausgebildete Herangehensweise anlehnt und sich sozial- und theaterwissenschaftliche Methoden zu eigen gemacht hat. ${ }^{38}$

\section{Lukians Alexander oder der Lügenprophet}

Nach dieser notwendigerweise unvollständigen Skizze der Forschungspositionen $\mathrm{zu}$ den Autorkonzepten unter den Stichworten Ethnizität, Religiosität und

er the reading conventions that they imagine, precisely blur (I argue) the boundaries between these categories."

${ }^{35}$ Aug. civ. 18,18.

${ }^{36}$ Whitmarsh 2013, 70.

${ }^{37}$ Whitmarsh 2013, 72: „often manifesting himself in his own works within their fictional texture but under pseudonyms that simultaneously mark nonidentity (Momus, Parrhesiades, Tychiades, and so forth).“

${ }^{38} \mathrm{Vgl}$. dazu und zu Autorfigurationen in wissensvermittelnden lateinischen Texten der Antike: Fuhrer 2012 mit weiterer Literatur. 
Erzähltheorie wird im Folgenden ein Text des Lukian im Vordergrund stehen. Im Sinne der methodischen Transparenz ist dies eine Schrift, in der der Ich-Erzähler bzw. die Autor-persona mit dem Namen des realen Autors benannt wird: Loukianos. Im Gesamtœuvre des Lukian finden sich zwei Schriften, in deren Text der Name des realen Autors im Zusammenhang mit einer Autor-persona genannt wird: Neben den bereits erwähnten Wabren Geschichten ist dies Alexander oder der Lügenprophet - eine Schrift, in deren Zentrum zeitgenössische Religion steht. ${ }^{39}$ Das Genre der Schrift weist darüber hinaus Züge einer fiktionalen Autobiographie im Sinne von Whitmarsh auf.

Aus der Perspektive des zunächst namenlosen Ich-Erzählers, der für sich eine epikureische philosophisch-religiöse Haltung reklamiert, wird die Gründung des Orakel- und Heilkultes des neuen Gottes Glykon in der Region Pontus und die schnelle Erweiterung seiner Einflusssphäre geschildert, die bald bis an den kaiserlichen Hof in Rom reicht. ${ }^{40}$ Nachdem bereits Kritik an dem Propheten von epikureischer und christlicher Seite manifest geworden ist, tritt der bislang extradiegetische Ich-Erzähler als intradiegetischer in Erscheinung. ${ }^{41} \mathrm{Als}$ actor, nun mit dem Namen Lukian, möchte er zwar Alexander als Erfinder des Gottes und seines Kultes entlarven, trägt aber stattdessen zum Erfolg von dessen Inszenierung bei, indem er vor den Augen der Zuschauer als ein ,konvertierter gläubiger Anhänger des Kultes präsentiert wird. ${ }^{42}$ Auf der Weiterreise entgeht er einem von Alexander veranlassten Mordanschlag während einer Schiffsreise und widmet sich fortan dem ,Krieg' gegen Alexander. ${ }^{43}$

Der Ich-Erzähler verkörpert in dieser Schrift also einen epikureischen Kritiker des Orakelkultes, der durch seine Schilderung und durch sein Handeln den Gott Glykon und dessen Kult als menschengemacht und dem Profitstreben seines Gründers und Propheten Alexander geschuldet entlarven möchte. Da dieser Ich-Erzähler als actor den Namen Lukian trägt, könnte man mit Whitmarsh von einer impersonation sprechen: „like an actor playing a role, the fictional autobiographer created an illusion of identity with the role he played“ “. ${ }^{44}$ Das religiöse Profil dieser Rolle des Autobiographen entspräche der Charakterisierung des

${ }^{39}$ Alex. 55; V.H. 2,28. Es finden sich darüber hinaus zwei von der handschriftlichen Überlieferung her sichere Erwähnungen des Namens in Präskripten zu den Briefen De Morte Peregrini und Nigrinus, vgl. Goldhill 2002, 66. Trotz dieses Umstandes bezieht Berdozzo 2011 die Schrift Alexander in seine Untersuchungen nicht ein.

${ }^{40}$ Der Ich-Erzähler präsentiert sich als Anhänger des Epikureismus: Alex. 1,17,25,38,437,61. Schnelle Erweiterung der Einflusssphäre bis hin nach Rom: Alex. 36-37; 48.

${ }^{41}$ Alex. 54.

${ }^{42}$ Der Ich-Erzähler trägt den Namen des realen Autors „Loukianos“: Alex. 55. Er wird als gläubiger Anhänger des Kultes präsentiert: Alex. 55. Ich verwende hier die von Winkler anhand der Metamorphosen des Apuleius entwickelte Terminologie, bei der der Ich-Erzähler zum einen als auctor der Geschichte und zum anderen als actor in der Geschichte bezeichnet wird (Winkler 1985).

${ }^{43}$ Versuchter Mordanschlag: Alex. 56; Kampf gegen Alexander: Alex. 57.

${ }^{44}$ Whitmarsh 2013, 70f. 
realen Autors Lukian wie wir sie z.B. bei Berdozzo finden: „In den religiösen Phänomenen sah der Samosatenser mit anderen Worten immer nur den menscblichen Teil.“45

Van Nuffelen arbeitet heraus, dass die epikureische Erzählerperspektive es zwar ermöglicht, Polemik, die sich gegen diese philosophische Strömung richtete, positiv zu wenden: „The espousal of an apparently Epicurean perspective gives Lucian an excellent vantage point to explore some of the intellectual faultlines of his age: in a reversal of the rejection of Epicureanism by Stoics and Platonists, the narrator of Alexander the False Prophet presents himself as an Epicurean, a doctrine which he consistently associates with truth and common sense in the text, whereas Stoics and Platonists are described as credulous and naïve, and intellectually on the same level as the country bumpkins of Paphlagonia." ${ }^{46}$

Es ist jedoch vielfach hervorgehoben worden, dass in dieser satirischen Schrift durch die Art und Weise, in der die Rolle des epikureischen Kritikers durch die Autor-persona verkörpert wird, nicht nur der Prophet Alexander, sondern auch die Figur seines epikureischen Kritikers unterminiert wird. ${ }^{47}$ So trägt der Ich-Erzähler als actor einerseits mittelbar zum Erfolg des Kultes bei und andererseits in seinem Hass auf Alexander unepikureische Züge. Der Epikureismus, den der Ich-Erzähler verkörpert, entspricht, wie van Nuffelen herausarbeitet, in beunruhigender Weise dem Bild eines Epikureismus wie es sich in anti-epikureischer Polemik abzeichnet - selbst dem Protagonisten Alexander werden Verhaltensweisen zugeschrieben, die man Epikur zum Vorwurf gemacht hat. ${ }^{48}$ Greift man noch einmal die Überlegungen auf, die Whitmarsh im Hinblick auf die Rolle des ,Ich' in der fiktionalen Autobiographie anstellt: „like an actor playing a role, the fictional autobiographer created an illusion of identity with the role he played - an illusion that was ever predicated on universal awareness of its unreality “49, so werden hier literarische Strategien erkennbar, die die Illusion als eine solche kennzeichnen.

Trotz der durch die Namensnennung nahegelegten Identität von Ich-Erzähler, Protagonist und Autor ist die Stimme des Lukian im Alexander nicht diejenige des realen Autors: Dieser lässt sich in seiner Beurteilung zeitgenössischer Religion nicht auf eine (philosophische) Position festlegen, denn auch die von der Figur Lukian im Alexander verkörperte religiöse Skepsis mit ihren dogmatischen Elementen wird ironisiert.

\footnotetext{
${ }^{45}$ Berdozzo 2011, 282.

${ }^{46}$ Van Nuffelen 2011, 186.

${ }^{47}$ Vgl. u. a. Branham 1984; Elm von der Osten 2006 mit weiterer Literatur; van Nuffelen 2011.

${ }^{48}$ Van Nuffelen 2011, 193: „The Epicureanism of the narrator of the Alexander is basically that of anti-Epicurean polemic and Alexander himself is in some aspects disquietingly similar to what some have accused Epicurus of."

${ }^{49}$ Whitmarsh 2013, $70 \mathrm{f}$.
} 
Der implizite Autor schreibt jedoch nicht aus einer Position, die jenseits religiöser Diskurse stünde: „He is writing from within the discourses and capitalising on their polemic and images - and as such he is an interesting source for their popularity “. ${ }^{50}$ Betrachtet man unter dieser Perspektive - mit einem Interesse an zeitgenössischen religiösen Diskursen - weitere wichtige Themen der Schrift Alexander, so lassen sie sich wie folgt umreißen: Religiöser Pluralismus und religiöse Individualität, religiöse Bricolage, erfundene Tradition, religiöses Sehen versus theatralisches Sehen.

Ein Thema, mit dem sich die Schrift und somit ihr impliziter Autor auseinandersetzt, ist die Pluralität religiöser Standpunkte und Praktiken, die über die Pluralität ethnischer Gruppen mit ihrem jeweiligen „ethnic polytheism“ hinausgeht. ${ }^{51}$ Sie setzt somit, wie die den Namen des Autors Lukian im Präskript tragende Schrift De Morte Peregrini die Erkenntnis religiöser Pluralität voraus und gestaltet sie literarisch. Im Alexander werden neupythagoreische Divination, Epikureismus und Christentum miteinander kontrastiert. Durch die Erzählweise werden Zugänge zu Religion individualisiert und einander als Verkörperungen (impersonations) gegenübergestellt.

Alexander beschäftigt sich mit Prozessen religiöser Innovation, die man als eine religiöse bricolage beschrieben hat: als Prozess der Auswahl von Elementen aus verschiedenen Quellen und ihre Rekombination zu einem neuen Ganzen. ${ }^{52}$ Dieses Vorgehen überträgt das Prestige verschiedener bereits existierender Gottheiten und damit ihrer Annahmen über das Universum auf eine neue Gottheit. ${ }^{53}$ Die Ausgestaltung dieses Prozesses von Aneignung und Transformation, von Rekonfiguration und Selektion von Elementen religiöser Tradition ist individuell und hier abhängig von der Individualität des religiösen Spezialisten Alexander, dies wird in der Schrift Alexander im Detail auserzählt. ${ }^{54}$ Der implizite Autor reflektiert somit Prozesse erfolgreicher religiöser Innovation und Individuation.

${ }^{50}$ Van Nuffelen 2011, 198. Bendlin 2006 beschreibt die zeitgenössischen Diskussionen über die religiöse Autorität von Orakeln im Kontext wachsender Konkurrenz zwischen den Eliten kleinasiatischer Poleis.

${ }^{51}$ Vgl. dazu Woolf 2014, 67.

${ }^{52} \mathrm{Zu}$ den klassischen Passagen bei Lévi-Strauss, die den Begriff der bricolage in die Sozialwissenschaften einführten, vgl. die englische Fassung des Textes La Pensée Sauvage: Lévi-Strauss 1966, $19 \mathrm{ff}$. Der Begriff wird unter anderem von Chaniotis 2002 zur Beschreibung des Glykonkultes angewendet.

${ }^{53}$ Vgl. zu diesen Prozessen Woolf 2014, 68.

${ }^{54}$ Ich folge hier den Formulierungen Jörg Rüpkes, der die folgenden Leitfragen für eine Untersuchung von religiöser Individualität nennt (Rüpke 2015b, 2; vgl. auch Rüpke 2015a und die Beiträge in Rüpke, Spickermann 2012): „How can we identify individual appropriation and transformation, or the creative reassembling and consequential selections, of elements of tradition made by individuals? How can we evaluate the impact of such individual modifications on the resulting shape of seemingly stable 'traditions'? Where can we trace the interdependencies of the individual and the social in specific situations?". Richard Gordon $(2013,155-161$, mit weiterer Literatur) arbeitet detailliert die kreativen synthetischen Fähigkeiten („creative, synthetic 
Der Kult des Glykon wird aus der Perspektive des Ich-Erzählers als Erfindung seines Gründers und Propheten Alexander charakterisiert. Damit geht einher, dass auch die hellenischen Abstammungslinien, die für den Gott, seinen Propheten und seine Polis entworfen werden, als lediglich erfundene Traditionen beschrieben werden. Die Schrift thematisiert also indirekt die in den Diskursen der Zweiten Sophistik greifbare Diskrepanz zwischen einer paideia als erworbener kultureller Errungenschaft und paideia als durch griechische Abstammung definiert und durch (erfundene) Traditionen legitimiert. Das Unterminieren einer Form des durch griechische Abstammung gekennzeichneten Hellenismus, die in den Diskursen der Zweiten Sophistik als normativ gesetzt wird, arbeitet Andrade als charakteristisch für die Schrift De Dea Syria heraus. Die Autor-persona präsentiert in ihrer Rolle in De Dea Syria gewissermaßen affirmativ eine syrische Spielart von religiösem Hellenismus, während sie im Alexander einen auf erfundenen hellenischen Abstammungserzählungen gestützten Kult kritisiert. Beide Autorrollen und Haltungen werden performativ jedoch teilweise unterminiert.

Wie auch in der Schrift De Dea Syria werden im Alexander verschiedene Formen des Sehens einander gegenübergestellt und miteinander verschmolzen. Während die Autor-persona Lukian dort die Haltung des herodoteischen, ethnographischen Beobachtens einnimmt, übernimmt er im Alexander die Betrachtungsweise eines Besuchers einer Theateraufführung. ${ }^{55}$ Die Position des unbeteiligten Zuschauers lässt sich aber in beiden Fällen nicht aufrechterhalten, die Grenzen zwischen dem zu betrachtenden religiösen Ritual und dem Betrachter verschmelzen, und der Betrachter wird zum religiösen Akteur: „Despite their external positioning, all spectators, even Herodotean observers, were liable to engage in 'ritual centred' viewing that transformed them from the spectacle's observers into its actors". 56

ability“ 161) heraus, die in der Schrift dem Mystagogen Alexander zugeschrieben werden. Mit deren Hilfe kann dieser sich eine neue religiöse Identität aufbauen, ein „mystagogic self“ (166).

${ }^{55}$ Zur Metaphorik von Theatralität im Alexander (Alex. 5, 12, 60, 19, 25 u. ö.) vgl. u. a. Leyerle 2001, 100: „Lucian of Samosatas' satires on the religious frauds Peregrinus and Alexander prove that the trope of life as a stage was a familiar one in late antiquity. Both of them make sustained use of theatrical metaphors to imply that the success enjoyed by these men resulted from a combination of convincing role playing and the all-too-willing collusion of their audiences." Zum Erzähler in De Dea Syria vgl. Andrade 2013, 304 f.: „the narrator increasingly conflates, descripitive ethnography' with pilgrimage and its ,ritual-centered'viewing, a form of viewing that embeds worshippers in sacred topographies and rites witnessed by gods"; Elm von der Osten 2006; Elm von der Osten 2009 (englisch 2013): zu Rollenspiel und self-fashioning im Alexander.

${ }^{56}$ Andrade 2013, 305. Vgl. zum Verhältnis von Genre und verschiedenen Formen des Sehens bei Lukian auch Elsner 2007, $12 \mathrm{f}$.: „I would argue that the genre chosen for the description of art presupposes a kind of visuality within which images are to be received. Whether a particular form of visuality is one of the reasons a writer chooses a particular narrative style, or whether the form of visuality may be said to arise as a result of the literary genre chosen, matters less (for my purposes here) than the claim that more than one kind of visuality existed in antiquity. 
Auf der Suche nach der Stimme des Lukian und ihrem religiösem Profil zeigt sich also ein (impliziter) Autor, der an den religiösen Diskursen des zweiten Jahrhunderts teilnimmt, darüber hinaus die Unmöglichkeit, gänzlich außerhalb solcher Diskurse zu stehen, thematisiert und die zeitgenössischen Prozesse religiöser Innovation und Individuation im Kontext des Imperium Romanum literarisch inszeniert.

\section{Literaturverzeichnis}

Andrade, N.J. (2013). Syrian Identity in the Greco-Roman World. Greek Culture in the Roman World. Cambridge.

Baumbach, M. (2002). Lukian in Deutschland. Eine forschungs- und rezeptionsgeschichtliche Analyse vom Humanismus bis zur Gegenwart. Beihefte zu Poetica 25. München.

Bendlin, A. (2006). „Vom Nutzen und Nachteil der Mantik. Orakel im Medium von Handlung und Literatur in der Zeit der Zweiten Sophistik, “ in: D. Elm von der Osten; J. Rüpke; K. Waldner, edd., Texte als Medium und Reflexion von Religion im römischen Reich. Potsdamer altertumswissenschaftliche Beiträge 14. Stuttgart, 175-250.

Berdozzo, F. (2011). Götter, Mythen, Philosophen: Lukian und die paganen Göttervorstellungen seiner Zeit. Untersuchungen zur antiken Literatur und Geschichte. Berlin.

Bompaire, J. (1958). Lucien écrivain - Imitation et création. Paris.

Caster, M. (1937). Lucien et la Pensée religieuse de son Temps. Paris.

Caster, M. (1938). Études sur Alexandre ou le faux prophète de Lucien. Paris.

Chaniotis, A. (2002). „Old wine in a new skin: tradition and innovation in the cult foundation of Alexander of Abonuteichos, "in: E. Dabrowa, ed., Tradition and Innovation in the Ancient World. Electrum 6. Krakau. 67-85.

Croiset, M. (1882). Essai sur la vie et les œuvres de Lucien. Paris.

Dickie, M.W. (2010). „Lucian's Gods: Lucian's understanding of the divine,“ in: J. Bremmer; A. Erskine, edd., The Gods of Ancient Greece. Identities and Transformations. Edinburgh Leventis Studies 5. Edinburgh. 384-361.

Dubel, S. (1994). „Dialogue et autoportrait: les masques de Lucien,“ in: A. Billaut; A. Buisson, edd., Lucien de Samosate. Actes du colloque international de Lyon organisé au Centre d'Études Romaines et Gallo-Romaines les 30 septembre - 1er octobre 1993. Lyon. Paris. 19-26.

Elm von der Osten, D. (2006). „Die Inszenierung des Betruges und seiner Entlarvung. Divination und ihre Kritiker in Lukians Schrift ,Alexander oder der Lügenprophet'“" in: D. Elm von der Osten; J. Rüpke; K. Waldner, edd., Texte als Medium und Reflexion von Religion im römischen Reich. Potsdamer altertumswissenschaftliche Beiträge 14. Stuttgart. 141-157.

Here the case of Lucian is significant, since at different times he chose to write in all the genres touched upon here. He was a master of rhetorical ekphrasis (for instance in De Domo or Zeuxis), of outrageous fiction (especially the Verae Historiae), and of religious polemic (Alexander, Peregrinus), but in the De Dea Syria he deliberately chose a different kind of genre - that of the pilgrim's travel book (which many have found uncomfortably sincere within his corpus of writing) - in order to express a form of piety and religious visuality not possible in his more satirical style." 
Elm von der Osten, D. (2009). „Wird auch kahl sein mein Haupt - Alterstopoi in Lukians Alexander oder der Lügenprophet und der Apologie des Apuleius, “ in: D. Elm; Th. Fitzon; S. Liess; S. Linden, edd., Alterstopoi. Das Wissen von den Lebensaltern in Literatur, Kunst und Theologie. Berlin. 71-100.

Elm von der Osten, D. (2013). „Habitus Corporis. Age Topoi in Lucian's Alexander or the False Prophet and The Apology of Apuleius, “ in: J. Rüpke; G. Woolf, edd., Religious Dimensions of the Self in the Second Century CE. Studien und Texte zu Antike und Christentum. Tübingen. 192-220.

Elsner, J. (2007). Roman Eyes: Visuality and Subjectivity in Art and Text. Princeton.

Fuhrer, Th. (2012). „Autor-Figurationen: Literatur als Ort der Inszenierung von Kompetenz, “ in: Th. Fuhrer; A. Renger, edd., Performanz von Wissen. Strategien der Wissensvermittlung in der Vormoderne. Bibliothek der klassischen Altertumswissenschaften. Heidelberg. 129-148.

Genette, G. $\left(2010^{3}\right)$. Die Erzäblung. München.

Goldhill, S. (2002). Who needs Greek? Contests in the Cultural History of Hellenism. Cambridge.

Gordon, R. (2013). „Individuality, Selfhood and Power in the Second Century: The Mystagogue as a Mediator of Religious Options, “ in: J. Rüpke; G. Woolf, edd., Religious Dimensions of the Self in the Second Century CE. Studien und Texte zu Antike und Christentum 76. Tübingen.

Helm, R. (1927). „Lukianos.“ Realencyclopädie der classischen Altertumswissenschaft 13,2, 1725-1777.

Kemezis, A.M. (2014). „Greek Ethnicity and the Second Sophistic,“ in: J. McInerney, ed., A Companion to Ethnicity in the Ancient Mediterranean. Hoboken. 390-404.

Lévi-Strauss, C. (1966). The Savage Mind. Chicago.

Leyerle, B. (2001). Theatrical Shows and Ascetic Lives: John Chrysostom's Attack on Spiritual Marriage. Berkeley.

Ní Mheallaigh, K. (2009). „Monumental Fallacy: The Teleology of Origins in Lucian's Verae Historiae, “ in: A. Bartley, ed., A Lucian for Our Times. Newcastle upon Tyne. 11-28.

Ní Mheallaigh, K. (2010). „The game of the name: onymity and the contract of reading in Lucian, “ in: F. Mestre; P. Gómez, edd., Lucian of Samosata, Greek Writer and Roman Citizen. Barcelona. 83-94.

Ní Mheallaigh, K. (2014). Reading Fiction with Lucian. Fakes, Freaks and Hyperreality. Greek Culture in the Roman World. Cambridge.

Norden, E. (1898/1958). Die antike Kunstprosa 1. Leipzig 1898; Darmstadt $1958^{5}$.

Richter, D. (2005). „Lives and Afterlives of Lucian of Samosata.“ Arion 13,1: 75-100.

Rüpke, J., Spickermann, W., edd. (2012). Reflections on Religious Individuality. Greco-Roman and Judaeo-Christian Texts and Practices. Religionsgeschichtliche Versuche und Vorarbeiten 62. Berlin.

Rüpke, J. (2015). „The 'Connected Reader' as a Window into Lived Ancient Religion: A Case Study of Ovid's Libri fastorum." Religion in the Roman Empire 1. 95-113.

van Nuffelen, P. (2011). Rethinking the Gods: Philosophical Readings of Religion in the Post-Hellenistic Period. Greek Culture in the Roman World. Cambridge.

Whitmarsh, T. (2001). Greek Literature and the Roman Empire: The Politics of Imitation. Oxford.

Whitmarsh, T. (2013). Beyond the Second Sophistic. Adventures in Greek Postclassicism. Berkeley. 
Whitmarsh, T. (2015). Battling the Gods. Atheism in the Ancient World. New York.

Willand, M. (2011). „Autorfunktionen in literaturwissenschaftlicher Theorie und interpretativer Praxis. Eine Gegenüberstellung." Journal of Literary Theory 5,2: 279-302.

Winkler, J.J. (1985). Auctor and Actor. A Narratological Reading of Apuleius' Golden Ass. Berkeley.

Woolf, G. (2014). „Isis and the Evolution of Religions,“ in: L. Bricault; M. John, edd., Power, Politics and the Cults of Isis. Proceedings of the Vth International Conference of Isis Studies, Boulogne-sur-Mer, October 13-15, 2011. Religions in the Graeco-Roman World 186. Leiden. 62-92. 



\title{
Tertullian
}

\author{
The Rhetor's Voice in his Prefaces
}

\section{Markus Vinzent}

Secondary literature has a lot to say about Tertullian and God, as he is one of the crown witnesses for the development of the Trinitarian idea in Christianity, but the question I am looking at here is not how Tertullian conceived of God, but to what extent he makes use of what he believes to be God and whether or not he bases his own authority as an author on this Christian God or rather follows his own intuitions. For this purpose, I am looking more closely at various prefaces of his extant work in the hope of catching a glimpse of his own voice, knowing, for example, that the New Testament literature he saw as authoritative, mostly opens not with an explicit reference to the author's own standing, but to the divine command, Jesus Christ (Matt. 1:1; Mk. 1:1; Acts 1:1; 1 Cor. 1:1; 2 Cor. 1:1; Philem. 1; 1 Tim. 1:1; 2 Tim. 1:1; 1 Peter 1:1; 2 Peter 1:1), the Word (John 1:1; 1 John 1:1; Acts 1:1), God (1 Thess. 1:1; 2 Thess. 1:1; 1 Tim. 1:1; 2 Tim. 1:1; Acts 1:1 ${ }^{1}$ ), truth (2John 1:1), or it places the author as a minister of the Word, Jesus Christ, or God (Lk 1:2; Rom. 1:1; Phil. 1:1; James 1:1; Jude 1:1), or refers to the Church (Tit. 1:1). In fact, just like these New Testament writings, also a number of second century works start similarly (Barn. 1:1: 'In the name of the Lord'; 1 Clem. 1:1: 'The Church of God ...'). One of the most daring openings in this respect is certainly the Gospel of Thomas which claims that 'these are the hidden words that the living Jesus spoke' and that the author was but a scribe, as 'Didymos Judas Thomas wrote them down' (GTh 1). Even without mentioning a scribe, the Epistula Apostolorum begins: 'The book which Jesus Christ revealed unto his disciples' (EpAp 1). In contrast to these, Tertullian, right from the start of his extant works seems to deploy his own, distinct voice, as we see authors introducing themselves such as Flavius Josephus or Hermas. Perhaps, like the latter, Tertullian was no clergy man, but an author of his own standing, a religious entrepreneur who was part of and also targeted head on the 'present time condition' (De praesc. 1:1: 'condicio praesentium temporum') from his own, in-

\footnotetext{
${ }^{1}$ See also Hebr. 1:1, a letter which Tertullian did not believe to be by Paul, but by Paul's companion Barnabas, so in Tert., De pud. XX 2; on this De Boer (2014) and further below.
} 
dividual angle and perspective. And yet, as the intimate writing about the Lord's Prayer will reveal, he does so, not without referring to the divine: 'God's Spirit and God's Word and God's Reason, the Word of the Reason and the Reason of the Word, and both of these Spirit, Jesus Christ our Lord, has marked out for the new disciples of the new covenant a new plan of prayer.' Such a reference, however, is not an invocation, but his individual reasoning about God's reasoning an address that introduces first his Stoic and Phrygian emphasis on God as Spirit, Word and Reason and the novelty of this and his message (new disciples, new covenant, new plan of prayer). Yet, how cautious we have to be with Tertullian's insistence on newness, has been demonstrated by Wolfram Kinzig: Neither age, nor tradition, nor, to a lesser degree even, Scripture are Tertullian's benchmarks for authority, but it is truth and justice, as he understood them. ${ }^{2}$

How do we get to know Tertullian's own voice? Particularly, as his voice is not that of a preacher, not that of a liturgically acting priest, not that of a prophet, perhaps not even that of a teacher, perhaps only that of a philosopher ${ }^{3}$ or a writer?

Unfortunately, as Mortimer J. Adler, noticed, 'titles and prefaces are' often 'ignored by so many readers', because 'they do not think it important to classify the book they are reading', and 'they do not follow' the 'first rule' of analytical reading and 'be grateful to the author for helping them'. ${ }^{4}$ Perhaps too, the reluctance to read prefaces more attentively is due not only to a lack of interest on the part of the reader, but also to the very nature of prefaces. Rather than being intended to assist or support the reader's own intention and interests, as we all know, they are often designed more for the purpose of compelling, reinforcing, of constituting an almost 'contractual force's from which one can hardly distance oneself except by ignoring them.

With the attention to such forceful power, in what follows I will try to sense critically how Tertullian is prefacing his works, recognising his domineering and often perhaps even anxious attempts in reshaping and creatively manipulating the notions and interrelations of exordium, narratio, partitio, and propositio. ${ }^{6}$ From these observations I will move first to the introduction ${ }^{7}$ of his De praescriptione haereticorum, a work, which itself is the preface (in the literal sense of

\footnotetext{
${ }^{2}$ Kinzig (1994), 240-241.

${ }^{3}$ Tertullian seems to have worn a beard, perhaps an indication that he may have fashioned himself a philosopher, see Vinzent (2017), 13.

${ }^{4}$ Adler (1940), 102; White (2011); the present article elaborates on a chapter of my Tertullian's Preface on Marcion's Gospel (2017).

${ }^{5}$ Genette (1997 [1982]), 8; White (2011), 140, 148.

${ }^{6}$ See Sider (1971), 22-24; Dunn (2008), 61-68.

7 Tertullian does not seem to distinguish between prefaces and introductions as Genette (1997 [1987]), 161 does, although even he admits that 'for the most part' the nuances between the different 'cases of co-presence' are 'connotative' (ibid. 162).
} 
praescriptio $^{8}$ ) to further prefaces of anti-heretical and primarily anti-Marcionite works, his De resurrectione carnis, De carne Christi and Adversus Marcionem.

\section{Who's voice is in a preface?}

I have studied them carefully, those smug adult prefaces. With fat smiles of gratitude, fit thanks are given for services rendered and kindnesses bestowed. Long lists of names are cleverly paraded in order to assure you that the author has excellent connections and a loving heart. Let me say at once that in this instance there are none to thank besides myself. I am not thankful to Dr. and Mrs.... [so and so] for moving away the remains. I am not thankful to Aunt Gladys for mislaying eleven chapters. I have always done my own typing myself, using both index fingers, and I have never received any encouragement at all from anyone about anything. And so, in conclusion, I feel that grateful thanks are due to myself, without whose kind encouragement and constant interest I could never have completed my task; to myself, for my valuable assistance in a number of points; to myself, for doing all the dirty work; and above all to myself, whose patience, understanding, and usefulness as a key eye-witness can never be adequately repaid, and who in a typical burst of scrupulousness wish to point out that the 'remains' mentioned above are, of course, literary remains. (Steven Millhause, Edwin Mullhouse: The Life and Death of an American Writer 1943-1954 by Jeffrey Cartwright)

As Kevin Dunn in his Pretexts of Authority: The Rhetoric of Authorship in the Renaissance Preface (1994) has rightly pointed out, this quote makes us face a particular preface, 'Steven Millhauser's parody' of the usual prefatory acknowledgement, itself 'placed within his parody of the literary biography' of literary genius Edwin Mullhouse. ${ }^{9}$ Now, as with every rhetorician, we may ask - who's voice did we hear, did we hear Steven Millhauser's, the voice of his invented protagonist Mullhouse, the invented narrator of Mullhouses' story Jeffrey Cartwright, none at all or all of them?

Prefaces form a specific literary genre, one of the more 'architextual' ones in Genette's sense. ${ }^{10}$ Being pretexts in a variety of ways, they mime authority, pretend to know and dominate what the reader and the listener are going to be subjugated to and yet are still ignorant of. Prefaces often hide the author by way of deflecting, pointing to others, the giants of old and supporters and helpers. More importantly, however, they point to something that is going to follow, the main text itself, as if leading to the self-effacement of the author by replacing him with his voice, or rather his voice through the text, a brutal and radical self-elimination that is so serious that, according to modern historiography, Pseudo-Plato in his second letter denies the authorship of what we today regard as the most

\footnotetext{
${ }^{8}$ On Tertullian's use of praescriptio and praescribo see Allie (1940), 48; Michaélidès (1970), 154-162; Fredouille (1972), 196-134.

${ }^{9}$ (1994), ix.

${ }^{10}$ See the above mentioned Genette (1997 [1982]), 8; see also Genette (1991).
} 
probably authentic dialogues, claiming that these 'derived from Socrates who has only become more beautiful and younger', ${ }^{11}$ an early version of the death of the author. ${ }^{12}$

Fortunately, we may say, here Tertullian differs greatly from others. In his prefaces he comes closer to Steven Millhauser. With only one exception, in the prefaces that have been preserved of his many works he does not thank anybody. Instead, he praises himself and uses prefaces to complain about others who obstruct him in his attempts to get proper information, whom he has to shout down as ignorant, or even as murderers of the truth, and whom he confronts with his own proofs. Fortunately, as we will also see, he does not shy away from admitting his own faults, although he does so not in his prefaces, but rather as a postscript when he calls himself 'Tertullian, the sinner'. ${ }^{13}$ Despite such characteristics and self-affirmation, 'Tertullian's life remains hidden in obscurity.'.14

As one of 'the earliest Christians to write in Latin' he poses 'a special problem' - our first surviving Church historical writings, which are all written in Greek, show 'little interest in the development of Christianity in the western half of the Roman Empire, except when it impinged on the eastern half'. ${ }^{15}$ Timothy D. Barnes reckons only with the very sparse autobiographical information that Tertullian reveals: 1) 'Tertullian was brought up a pagan' (De paen. 1,1); 2) 'on some occasion he sinned egregiously' (De res. 59,3); 3) he 'realized the volatile impatience of his own personality' (De pat. 1,1-2); and 4) he made 'frequent visits to the amphitheatre' (De spect. 19,4). ${ }^{16}$ To this we can add that an admiring

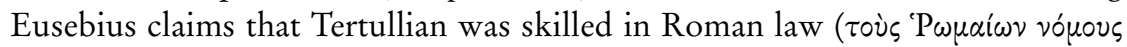
$\eta \dot{\eta} \kappa(\beta \omega \kappa \omega \varsigma),{ }^{17}$ and the even more eager follower Jerome made Tertullian a 'presbyter, a man of the province of Africa and the city of Carthage and the son of a centurio proconsularis,' despite Tertullian himself twice stating to have been a

\footnotetext{
${ }^{11}$ Ep. II 314 c 3-4; see on this Agamben (2013), 19-20.

${ }^{12}$ On the death of the author see Barthes (1968).

${ }^{13}$ So the last words in Tert., De bapt. 20,5: '... cum petitis etiam Tertulliani peccatoris memineritis'.

${ }^{14}$ Dunn (2004), 3.

${ }^{15}$ Barnes (1985; $1^{\text {st }}$ ed. 1971), 5.

${ }^{16}$ Ibid. 246-7.

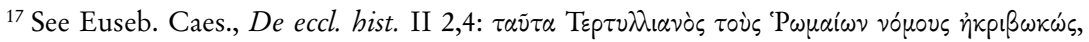

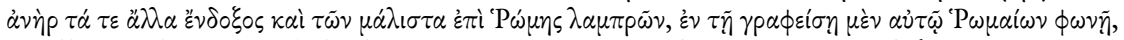

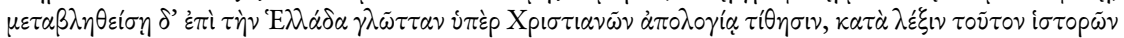

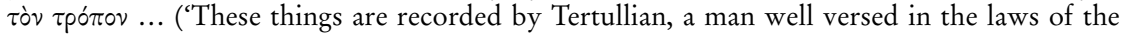
Romans, and in other respects of high repute, and one of those especially distinguished in Rome. In his apology for the Christians, which was written by him in the Latin language, and has been translated into Greek, he writes as follows ...'). Whether Tertullian can be reckoned to have been a jurist (iurisconsultus), or a causidicus (from causas dicere, to plead the cause of others before the courts as an advocate), or whether Tertullian was a rhetorician with some legal knowledge is a question which has been debated for centuries. Hier., De vir. ill. 53.1 does not qualify him with regards to this question, on the question see Vinzent (2017), 12-13.
} 
layman (Exhort. Cast. 7.3; Mon. 12.2). ${ }^{18}$ Barnes, therefore, rightly deconstructed Jerome's and Eusebius' picture of Tertullian. ${ }^{19}$ Nevertheless, Tertullian, who has 'never [been] the subject ... of artistic representation' 'remains a faceless figure', ${ }^{20}$ and yet scholars seem to have known him intimately, calling him 'a polemicist, moralist, theologian', ${ }^{21}$ 'a borderline figure', 'a trenchant yet elusive controversialist', ${ }^{22}$ 'an orator, polemicist, pamphleteer and satirist', ${ }^{23}$ 'a firebrand, a puritan, a misogynist, a rigorist and label him as impatient, uncompromising, fiery, passionate, ardent, harsh, sarcastic and even cruel' and 'it has been said that it is not easy to like Tertullian'. ${ }^{24}$

\section{Philosopher of religion or religious philosopher?}

While we know little more than what was said about his outer appearance, these opinions have been formed from the characteristics that come across strongly through Tertullian's works. As we will see, he is, indeed, tough and uncompromising in his attitude, something he admits to in his Of Patience where he starts with confessing his failure to practice patience: ${ }^{25}$

I fully confess unto the Lord God that it has been rash enough, if not even impudent, in $m e$ to have dared compose [a treatise] Of Patience, for practising which I am all unfit, being a man of no goodness; whereas it would have been a duty that such as have addressed themselves to the demonstration and commendation of some particular thing, should themselves first be conspicuous in the practice of that thing, and should regulate the constancy of their commonishing by the authority of their personal conduct, for fear their words blush at the deficiency of their deeds. ${ }^{26}$

When a rhetor has to 'fully confess unto the Lord God', he seems to benchmark himself against divine laws, and either distrusts his own line of arguments or mistrusts his reader. In this case, however, Tertullian does not deploy the divine authority - God serves him more like a steppingstone to refer to the 'duty' of an author and reflect upon the nature of an account on patience. In highlighting that he was not the ideal author to write about patience, he is clearly putting

\footnotetext{
${ }^{18}$ Jerome, De viris illustribus 53.

${ }^{19}$ Barnes (1985; $1^{\text {st }}$ ed. 1971) with his critical postscript in the second edition (321-335). A summary of his arguments with further lit. is given by Wilhite (2007), 17-27.

${ }^{20}$ Dunn (2004), 6.

${ }^{21}$ Fredouille (1972), 17.

${ }^{22}$ Bray (1979), 1.

${ }^{23}$ Barnes (1985; $1^{\text {st }}$ ed. 1971), vii.

${ }^{24}$ Dunn (2004), 10 with reference to Daly (1993), 3; Raven (2 ${ }^{\text {nd }}$ ed. 1993), 156 . He could have added, for example, Braun (1992), 1-20.

${ }^{25}$ See also On Flight in Time of Persecution 6,3.

${ }^{26}$ Tert., De pat. I 1 (trans. S. Thelwall, ANF, slightly altered). See also De fuga VI 3; on Tertullian and patience see, for example, Fredouille (1972), 361-412.
} 
out more than a captatio benevolentiae, as in his writings he rarely comes across as a tolerant listener. And yet, as he himself distinguishes between practice and theory, and towards the end of the tract between patience and complaisance, ${ }^{27}$ he posts as an extraordinary example of perseverance and persistency not only on a theoretical level. Patience, therefore, seems to be one of the key virtues and skills of a prolific author, something he proved when achieving the detailed criticism of Marcion's texts on which he must have spent months, if not years, given that he had taken it upon himself to do it in three editions. Hence by rhetorically denying himself to be patient, he only makes his achievement even greater in the eyes of his readers, deploying a strategy of contradiction, but without reference to divine authority.

Not only in this preface to Of Patience, but also in others, he puts himself and his personal characteristics, not the divine voice, into the lamplight of his writing. So, for example, in the opening of On Repentance, when he states that he is disgusted with his own pre-Christian past, which he had loved but now sees as a time of blindness: 'Repentance, men understand, so far as nature is able, to be an emotion of the mind arising from disgust at some previously cherished judgement: that kind of men I mean which even we ourselves were in days gone by - blind, without the Lord's light' (De paen. I 1). One wonders, what Tertullian means by 'the Lord's light'. What makes man no longer to be a blind, ignorant stranger, but somebody who can steer through 'the hurricane which is impending over the world' (ibid.)? Tertullian does not refer to Scriptures, to prayers, to the Church, to the Apostles, but to 'the rudder of reason', just as any Stoic would have done. His guiding view of the world is expressed in black or white with very few shades of grey. Yet, the question remains, are these woodcuts of a devotee, or a meer rhetorician or hypersensitive expressions of the inner self of a Stoic artist?

In other prefaces Tertullian expresses strong views about people who produce fables but try to hide them from the eagerly inquisitive author. For example, we find in his Against the Valentinians:

The Valentinians, as everyone knows, are the most commonly encountered sect of heretics - most common because they are mostly apostates from the true religion, tending towards myths, and are not deterred from a strict rule of life. They care about nothing more than to conceal what they teach, if indeed anyone who conceals can be said to teach. Their duty of guardianship is a duty brought on by their consciences. They preach confusion by the way of asserting their piety. ${ }^{28}$

As we can read in this work, Tertullian's record concerning the Valentinians needed an extended preface, as, after some initial information about their diversity, he narrows his aims and limits his exposition 'to the original teachings of their chief teachers; it will not include the high-flying leaders of the mass of

\footnotetext{
${ }^{27}$ See De pat. XVI 3.

${ }^{28}$ Tert., Adv. Val. I 1 (text and trans. Riley, trans. altered).
} 
followers'. And he adds: 'I hope no one will say (because of this limitation) that I have invented this material for the occasion. ${ }^{29}$ Apparently, it was known that as part of such heresiological discourses, forgeries and inventions were used to discredit others. Tertullian, however, shields himself against such accusations by introducing first his reliable and, as he thinks, reputable sources and by explaining his own aspiration as a writer:

Many men who were renowned for their holiness and their leadership, who were not only our predecessors but also contemporaries of those very heresiarchs, have exposed and refuted them in learned volumes. I refer to Justin, philosopher and martyr, Miltiades, that churchly sage, Irenaeus, an eager discoverer of all doctrines, and our own Proculus, the living exemplar of a chaste old age and of Christian eloquence. In their footsteps I might hope to follow in all works of faith, just as I do in this work. ${ }^{30}$

This is no modest programme for a writer, ${ }^{31}$ and it shows Tertullian's ambition to imitate first a philosopher and martyr (Justin), also a sage churchman (Miltiades), a highly interested explorer of all doctrines (Irenaeus) and finally a chaste old experienced Christian rhetor (Proc[u]lus). Tertullian makes no mention of Proculus being, if Eusebius informs us correctly, a 'contender for the Phrygian heresy', ${ }^{32}$ and that he held high the authority of the four prophetesses, the daughters of Philip, whose tomb, together with that of their father, Proc[u]lus knew to have been located 'at Hierapolis in Asia'. ${ }^{33}$ Tertullian insists, based on the 'New Prophecy', that Peter had experienced such 'a great ecstasis, namely out of his mind (amentia)' by the divine Spirit that he was covered with his shadow in the vision of the glory of God. ${ }^{34}$ Unfortunately, Tertullian's long work of seven books De ecstasi, still known to Jerome, has not survived, ${ }^{35}$ but the latter reports that in these books 'against the Church' and 'on behalf of Montanus', the author satirically states that 'he was considered a prophet by many of us'. ${ }^{36}$ The last

\footnotetext{
${ }^{29}$ Tert., Adv. Val. V 1.

${ }^{30}$ Tert., Adv. Val. V 1.

${ }^{31}$ Unfortunately little is known about Tertullian's education, and the exploration of his familiarity with classical literature still 'has scarcely begun', so Bray (1979), 35 .

${ }^{32}$ Euseb. Caes., De eccl. hist. III 31,4; II 25,6; VI 20,3.

${ }^{33}$ See Proclus in Euseb. Caes., De eccl. hist. III 31,4: 'And in the Dialogue of Caius which we mentioned a little above, Proclus, against whom he directed his disputation, in agreement with what has been quoted, speaks thus concerning the death of Philip and his daughters: After him there were four prophetesses, the daughters of Philip, at Hierapolis in Asia. Their tomb

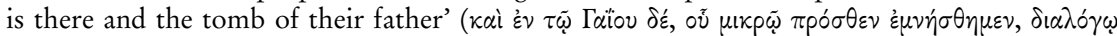

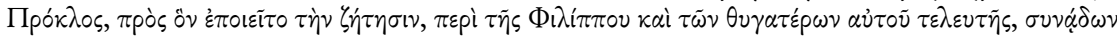

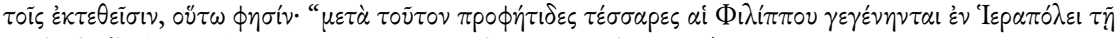

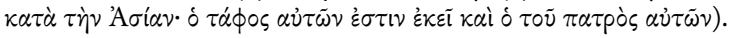

${ }^{34}$ See Tert., $A d v$. Marc. IV 22,4-4.

${ }^{35}$ See Hier., De vir. ill. 24; 40; 53; on this Barnes (1985; $1^{\text {st }}$ ed. 1971), 253-254.

${ }^{36}$ Hier., De vir. ill. 24.
} 
of his seven books was an added volume to refute the defamation of the New Prophecy by Apollonius, who wrote Against Montanus, Prisca and Maximilla. ${ }^{37}$

In his report about his role models Tertullian makes no mention of any institutional careerist, nor of any deacon, priest or bishop, not even a teacher or instructor. Instead, Tertullian seems to aspire to be a scholar through and through. Those people he mentions and regards as 'predecessors' seem also to have been his primary sources, at least in this work against the Valentinians. Without going into further detail, it is noteworthy that in his entire work on Marcion, there is no mention of any of these people, despite the fact that Tertullian is in many places clearly dependent on the writings of at least Justin and Irenaeus, as we can still compare their works with Tertullian's Against Marcion. ${ }^{38}$

\section{The scholar of religion and self-inspection}

Tertullian's aggressive antiheretical style, his shouting at others, is not only apparent in his works against the Valentinians and against Marcion; we also find it in his writings against his contemporary non-Christians, for example, in $O n$ Idolatry where he opens in medias res and explicitly brushes aside the idea of even considering the precise nature and name of this offence, which in his eyes is only disguised by being called 'idolatry':

The principal crime of the human race, the highest guilt charged upon the world, the whole procuring cause of judgment, is idolatry. ... Set aside names, examine works, the idolater is likewise a murderer. Do you inquire whom he has slain? If it contributes ought to the aggravation of the indictment, no stranger nor personal enemy, but his own self. By what snares? Those of his error. ${ }^{39}$

Why such radical prefacing? Why such harsh condemnations? Does Tertullian need such rhetorical bombshelling because he deeply mistrusts not only the pagan human race, but also the Christian addressees of his readership? And who are these addressees? What he does is examining works - the business of a scholar, a scholar of religion rather than a religious scholar in discerning between idolatry or error and true religion or truth. By setting aside names and only focussing on works, he is pushing aside individuals with their institutional contexts, their fame, standing and positions. Yet, as little as these have to contribute to the nature of defences of what Tertullian calls 'idolatry', he sees another form of individualizing nature, namely the religious bond to traditional religion. To him such bondage is based on self-betrayal, the highest form of murder. With idolatry (as with religious allegiance generally for Tertullian), we make a remarkable

\footnotetext{
${ }^{37}$ Hier., De vir. ill. 40.

${ }^{38}$ See Skarsaune (1987), 435-453.

${ }^{39}$ Tert., De idol. 1.
} 
turn towards an individualised understanding of personhood. It is no longer the self which is based on a traditional trajectory of practices, but a highly reflexive distancing of oneself from works, repeated exercises and unquestioned moves, the concepts of which have become fragile and questionable, not because they are suddenly alien, strange or offensive, but because they are intimately threatening the very core of a person, one's 'own self'. In another writing that deals with the non-Christian learned environment, The Soul's Testimony, which contains the famous statement 'for a man becomes a Christian, he is not born one', Tertullian calls upon this simple, untainted and innocent self, which here he calls the soul. With almost self-defeating irony, reminding the modern reader of pious romantic wishes, he writes:

[5] I call in a new testimony, yea, one which is better known than all literature, more debated than all doctrine, more known than all publications, greater than the whole man - I mean all which is man's. Place yourself into the centre, soul, whether you are a divine and eternal thing, as most philosophers believe if it be so, you will be the less likely to lie, - or whether you are the least divine, because indeed a mortal thing, as Epicurus alone thinks - in that case there will be the less temptation for you to speak falsely: whether you are received from heaven, or conceived from earth; whether you are formed of numbers, or of atoms or whether you begin with the body, or after you have put the body on; from whatever source, and in whatever way, you make man a rational being, in the highest degree capable of thought and knowledge.

[6] But I call you not as when, formed in schools, trained in libraries, fed in Attic academies and porticoes, you belchest wisdom. I address you simple, rude, uncultured and untaught, such as they have you who have only you; that very thing of the road, the street, the workshop, wholly. [7] I want your inexperience, since in your small experience no one feels any confidence. I demand of you the things you bring with you into man, which you know either from yourself, or from your author, whoever he may be. You are not, as I well know, Christian; for a man becomes a Christian, he is not born one. Yet Christians earnestly press you for a testimony; they press you, though an alien, to bear witness against your friends, that they may be put to shame before you, for hating and mocking us on account of things which convict you as an accessory. ${ }^{40}$

This self-inspection, self-revelation and fight for self-survival is a response to a world that Tertullian sees as driven by external conventions, a world that cannot be left behind except by looking inwards, leaving one kind of ignorance to pretend another one, attending to knowing oneself, oneself alone. And yet, we are faced not with a mystical self-forgetting, but with a stunning and strong, a fighting self-affirmation that has little left for the old paths of life.

In another preface, that of To the Nationes, Tertullian opens with an attack on his interlocutor, unless it is pure rhetoric, but even then the reader is put into the position of the rhetorical addressee:

\footnotetext{
${ }^{40}$ Tert., De test. anim. I 5-7.
} 
One proof of that ignorance of yours, which condemns whilst it excuses your injustice, is at once apparent in the fact, that all who once shared in your ignorance and hatred (of the Christian religion), as soon as they have come to know it, leave off their hatred when they cease to be ignorant; nay more, they actually themselves become what they had hated, and take to hating what they had once been. ${ }^{41}$

Conversion, according to this passage, is a rational process of insight or knowing, a move out of ignorance, or realizing the truth and starting to embrace what one formerly hated and to hate one's former position. It is not driven by a divine voice, but an apparent and factual turn from injustice to justice. Even when he addresses 'servants of God', as in the opening of On the Shows, he insists on cognition and recognition, on the opposite of ignorance and knowledge. The potential opposition to religion is twofold, first it is placed cognition, in the mind and in conscience, and second it is seen in ethics and piety, keeping in God's honour and reverence:

[1] What state of faith, what argument of truth, what rule of discipline, bar, among other errors of the world, the pleasures also of the public shows, know, servants of God, about to draw near to God, recognise, that you may make solemn consecration of yourselves to Him, so that neither out of ignorance nor of dissimulation sin. [2] For such is the power of pleasure, that, to retain the opportunity of still partaking of them, it contrives to prolong swilling ignorance, and bribes knowledge in dissimulation. [3] To both things, perhaps, some among you are allured by the views of the heathens who in this matter are wont to press us with arguments, such as these: (1) That the exquisite enjoyments of ear and eye we have in things external are not in the least opposed to religion in the mind and conscience; and (2) That surely no offence is offered to God, in any human enjoyment, by any of our pleasures, which it is not sinful to partake of in its own time and place, with all due honour and reverence secured to Him. [4] But this is precisely what we are ready to prove: That these things are not consistent with true religion and true obedience to the true God. ${ }^{42}$

Although he does not fully spell it out, when he talks about retaining 'the opportunity of still partaking of them', it is clear that Tertullian must have loved literature and plays, public shows, even worldly delights, even though he fights against such 'swilling ignorance'. But one can only bribe what is susceptible to the charm of bribery. Even if he blames 'the heathens' for alluring Christians with various arguments that are based on the Stoic concept of adiaphora, Tertullian knows that those supposedly external temptations sit in the core of the Christian self, the reason why he writes his tract to prove the incompatibility of such pleasures 'with true religion' and 'true obedience to the true God'. In order to illustrate proper submission to the true leader and God, in his opening to The Chaplet Tertullian applies a narrative method which, at first sound or sight, must have impressed his audience, so startling is the protagonist's standing against

\footnotetext{
41 Tert., Ad nat. I 1.

42 Tert., De spect. 1,1-4 (trans. S. Thelwall, ANF, altered).
} 
order and expectation; although, on second thoughts, we may start to doubt its power to convince:

[1] Very lately it happened thus: while the bounty of our most excellent emperors was dispensed in the camp, the soldiers, laurel-crowned, were approaching. One of them, more a soldier of God, more steadfast than the rest of his brethren, who had imagined that they could serve two masters, his head alone uncovered, the useless crown in his hand - already even by that peculiarity known to every one as a Christian - was nobly conspicuous. [2] Accordingly, all began to mark him out, jeering him at a distance, gnashing on him near at hand. The murmur is wafted to the tribune, when the person had just left the ranks. The tribune at once puts the question to him: Why are you so different in your attire? He declared that he had no liberty to wear the crown with the rest. Being urgently asked for his reasons, he answered, I am a Christian. O soldier! boasting thyself in God. Then the case was considered and voted on; the matter was remitted to a higher tribunal; the offender was conducted to the prefects. [3] There he put away the heavy cloak, his disburdening commenced; he loosed from his foot the military shoe, beginning to stand upon holy ground; he gave up the sword, which was not necessary either for the protection of our Lord; from his hand likewise dropped the laurel crown; and now, purple-clad with the hope of his own blood, shod with the preparation of the Gospel, girt with the sharper word of God, completely equipped in the Apostles' armour, and crowned more worthily with the white crown of martyrdom, he awaits in prison the largess of Christ. ${ }^{43}$

Only on reflection does one begin to wonder about the story and to question how consistent the narrative is. How, if Christians did not wear the laurel crown, gave up their annual bonus and were known for such resistance as mentioned in the story, hence had given up their aspiration for a military career, could this member of the brethren have appeared amongst the laurel-crowned soldiers? How could he have been 'a soldier of God' while at the same time having successfully served the other master, 'our most excellent emperor'? Rhetoricians like magicians do not always ask us to be too serious, take to things too closely or regard them overly critically; instead they ask us to follow their narrative without adding a pinch of salt.

\section{Tertullian's own voice?}

In some of his prefaces, Tertullian seems to lay down the mask of rhetor and to come closer, to present more of himself, as, for example, in To Scapula:

[1] We are not in any great perturbation or alarm about the persecutions we suffer from ignorant people; for we have attached ourselves to this sect, fully accepting the terms of its covenant, so that, as men whose very lives are not their own, we engage in these conflicts, our desire being to obtain God's promised rewards, and our dread lest the woes with which He threatens an unchristian life should overtake us. [2] Hence we shrink not from the grapple with your utmost rage, coming even forth of our own accord to the contest;

${ }^{43}$ Tert., De cor. 1,1-3 (trans. S. Thelwall, ANF, slightly altered). 
and condemnation gives us more pleasure than acquittal. We have sent, therefore, this small booklet to you in no alarm about ourselves, but in much concern for you and for all our enemies, to say nothing of our friends. [3] For our law commands us to love even our enemies, and to pray for those who persecute us (see Matth. 5:44), aiming at a perfection all its own, and seeking in its disciples something of a higher type than the commonplace goodness of the world. For all love those who love them; it is peculiar to Christians alone to love those that hate them (see Luke 6:27). [4] Therefore mourning over your ignorance, and compassionating human error, and looking on to that future of which every day shows threatening signs, necessity is laid on us to come forth in this way also, that we may set before you the truths you will not listen to openly. ${ }^{44}$

Two elements stand out which made Tertullian placing himself within 'this sect': It is his wish to 'obtain God's promised rewards', and his fear from God's threats. This double nature must have appealed to him to an extent that he was prepared to join those 'men whose very lives are not their own'. And yet, Tertullian's seeming self-effacement only serves his argument that condemnation or even the threat of it does not put its author with his compatriots 'in any great perturbation or alarm'. Still, as before, we are reading literature of a prolific author. He is a writer who relies on martyrs, like Justin, as sources, but he himself does not suffer martyrdom. So, when he boldly states that he does not shrink from the grapple with the rage of his enemies and that 'condemnation gives' him 'more pleasure than acquittal', he knows that he is hiding behind his pen and only sending a 'small booklet ... in no alarm' about himself.

However, there are even more intimate texts which may get us a little closer to our author. One such is his legacy of two books, which he addressed To his Wife:

[1] I have thought it meet, my best beloved fellow-servant in the Lord, even from this early period, to provide for the course which you must pursue after my departure from the world, if I shall be called before you; (and) to entrust to your honour the observance of the provision. [2] For in things worldly we are active enough, and we wish the good of each of us to be consulted. If we draw up wills for such matters, why ought we not much more to take forethought for our posterity in things divine and heavenly, and in a sense to bequeath a legacy to be received before the inheritance be divided, - (the legacy, I mean, of) admonition and demonstration touching those (bequests) which are allotted out of (our) immortal goods, and from the heritage of the heavens? ... [4] The precept, therefore, which I give you is, that, with all the constancy you may, you do, after our departure, renounce nuptials; not that you will on that score confer any benefit on me, except in that you will profit yourself. ... [6] Think not that it is for the sake of preserving to the end for myself the entire devotion of your flesh, that I, suspicious of the pain of (anticipated) slight, am even at this early period instilling into you the counsel of widowhood. There will at that day be no resumption of voluptuous disgrace between us. No such frivolities, no such impurities, does God promise to those who belong to him. ${ }^{45}$

\footnotetext{
${ }^{44}$ Tert., Ad Scap. 1,1-4.

${ }^{45}$ Tert., Ad uxor. I 1-6 (trans. S. Thelwall, ANF, slightly altered).
} 
The tone of this preface is different from all others. It is the only one - except that to Of Patience - which starts with an authorial ' $I$ '. And in it he seems more personal. With his strong admonition to his wife that she should not remarry if he dies before her, he connects the idea that he is thinking only of the spiritual benefits for her, and not of any jealousy or personal interest beyond his death, since there will be no sexual life after death - not a convincing reason, I would have thought, to prevent his wife from remarrying. In addition, he gives potential reasons for her to remarry which, at least partly, may say more about him than about his wife: 'Fleshly concupiscence claims the functions of adult age, craves after beauty's harvest, rejoices in its own shame, pleads the necessity of a husband to the female sex, as a source of authority and of comfort, or to render it safe from evil rumours' ${ }^{46}$ More important, however, is Tertullian's admission that at present he seems to enjoy for himself 'the entire devotion' of his wife's flesh (carnis tuae integritatem), and when he says of the eschaton that this will be a time when there will be 'no resumption of voluptuous disgrace', the reader is left with the view that at present Tertullian does indulge in 'frivolities' (frinola) and 'impurities' (spurca), a view supported by his other confession that despite his declared lack of interest in procreating children ${ }^{47}$ he has committed adultery: 'For myself, I am quite sure that it is in no other flesh than my own that I have committed adultery, nor in any other flesh am I striving after continence. ${ }^{38}$ And although he explicitly denies that he will benefit from his wife's future renunciation of marriage, the way he phrases it allows one to doubt whether the spiritual reasons are all that count. In this passage, as in the opening to Of Patience, the reader may get closer to the author than in most of his prefaces, although that closeness is more to what he would call failures than strengths. Or is it just another rhetorical strategy, as so often appears to be the case when reading Augustine's Confessions, where all these weaknesses are bound up in the captatio to convince the reader of this abundant grace that the author wants him to believe in?

\section{Inconsistencies of a writer who is 'pulling the levers'}

Most of the prefaces of his works show Tertullian fighting off rivals, persecutors, murderers of the truth. He refers to the latter, but rarely to the divine; it sounds as if there were enormous barriers between himself and his opponents, bridged only by the rattling of weapons and armour. For example, the opening of The Soul's Testimony speaks of '... convicting the rivals and persecutors of Christian truth', by making use of 'their own authorities', to highlight 'the crime of at once

\footnotetext{
${ }^{46}$ Tert., $A d$ uxor. IV 3.

${ }^{47}$ Tert., Ad uxor. I 5,1.

${ }^{48}$ Tert., De res. 59,3.
} 
being untrue to themselves and doing injustice to us'. Research into and references to 'the philosophers, or the poets, or other masters of this world's learning and wisdom' are mentioned, to portray himself as 'a most inquisitive spirit, and a still greater memory' to defeat his opponents. And yet, he mentions anonymously 'some' of his own 'people' whom he rather deplores as they

still continued their inquisitive labours in ancient literature, and still occupied memory with it, have published works we have in our hands of this very sort; works in which they relate and attest the nature and origin of their traditions, and the grounds on which opinions rest, and from which it may be seen at once that we have embraced nothing new or monstrous - nothing for which we cannot claim the support of ordinary and well-known writings, whether in ejecting error from our creed, or admitting truth into it. ${ }^{49}$

Strange though it sounds, he castigates his co-fellows for publishing works on 'ancient literature', by which he means pre- or non-Christian literature, but then admits, that he himself has these books in hands. Of course, he intimates, that as a critical scholar he needs to investigate them purely for opposing the views aired in them. In his view, to make use of non-Christian authorities simply reflects 'the unbelieving hardness of the human heart [which] leads them to slight even their own teachers'. As before, we move within a circle of learning, less of devotion. There is talk about the different traditions, the debating of the creed and the admission of the truth, but Tertullian's statement is about the rational level of how to write and talk about God or the gods: 'The poets are fools, when they describe the gods with human passions and stories; the philosophers are without reason, when they knock at the gates of truth', but although he concludes that 'we will have nothing, then, to do with the literature and the teaching, perverted in its best results, which is believed in its errors rather than its truth', Tertullian is doing precisely that - he engages on a literary and apologetical level with these co-fellow Christians, and although he sounds harsh to them, his engagement shows his sympathy for what he pretends to hate.

We hit again that paradox - a highly skilled rhetorician who wants to convince the reader that only the inexperienced, the non-confident, the simple minded, rude, uncultured and untaught is on the way to becoming Christian. ${ }^{50}$

Or to pick up another inconsistency, perhaps slightly more difficult to grasp from his elaborate style, in his famous Apology he attacks the 'Rulers of the Roman Empire':

If, seated for the administration of justice on your lofty tribunal, under the gaze of every eye, and occupying there all but the highest position in the state, you may not openly inquire into and sift before the world the real truth in regard to the charges made against the Christians; if with species alone you are afraid or ashamed to exercise your authority in making public inquiry with the carefulness which becomes justice; if, finally, the extreme

\footnotetext{
${ }^{49}$ Tert., De test. an. 1,2 .

${ }^{50}$ Tert., De test. an. 1,4 .
} 
severities inflicted on our people in recent private judgments stand in the way of our being permitted to defend ourselves before you, you cannot surely forbid the truth to reach your ears by the secret pathway of a noiseless book..$^{51}$

All this sounds as if Tertullian had stood in front of the bench, accusing the Emperor and his authorities on their 'lofty tribunal' of deliberately persecuting innocent Christians, with himself as the defender of the anonymously accused. No wonder that posterity, like Eusebius, made him an expert in Roman law and that later he became identified with a Tertullian known from Justinian's Digest of Roman Law (533 AD). ${ }^{52}$ In our quote, Tertullian speaks of 'recent private judgments', and he makes us believe throughout his work that he is actually engaged in running tribunals and defences. ${ }^{53}$ Yet, as one reads more carefully through the text of the Apology, one will discover that the entire work is the acting of what the Germans would call a 'Schreibtischtäter', the fight of a 'desk criminal', or better somebody who is 'pulling the levers', a pale theoretician compared to his shiny rhetoric who refers, for example, to Pliny's exchange of letters with Trajan and some Christian apologetic works. From Tertullian's referencing it, scholars have drawn the conclusion that the Apology reflects ongoing persecutions of Christians, ${ }^{54}$ although 'the only treatise written in the heat of a persecution and addressed to Christians in prison awaiting trial and martyrdom is the $A d$ martyras'.$^{55}$ Ad martyras, however, is a very strange text which opens with Tertullian's admission that he is not himself one of those embroiled:

[1] Along with the provision, Blessed Martyrs Designate, which our lady mother the Church from her bountiful breasts, and each brother out of his private means, makes for your bodily wants in the prison, accept also from me some contribution to your spiritual sustenance; for it is not good that the flesh be feasted and the spirit starve: nay, if that which is weak be carefully looked to, it is but right that that which is still weaker should not be neglected. [2] Not that I am specially entitled to exhort you; yet not only the trainers and overseers, but even the unskilled, nay, all who choose, without the slightest need for it, are wont to animate from afar by their cries the most accomplished gladiators, and from the mere throng of onlookers useful suggestions have sometimes come. ${ }^{56}$

It is difficult to believe this text to be a writing that was meant to reach martyrs designate, even if they were blessed, catered for with ecclesial 'mother-milk' and 'private means'. Tertullian, himself no martyr and only the clapping and crying onlooker, calls what in dreadful circumstances would normally be life-sustaining support a fattening or feasting (saginari) of the flesh, to which he wants to add

\footnotetext{
${ }^{51}$ Tert., Apology 1,1 (trans. S. Thelwall, ANF, slightly altered).

${ }^{52}$ See the criticism of this opinion by Barnes $\left(1985 ; 1^{\text {st }}\right.$ ed. 1971), chapter 4.

${ }^{53}$ See Steiner (1989), 48.

${ }^{54}$ Pace, for example, Becker, ed. and trans. of Tertullian, Apologeticum (1952), 12; Waltzing, the editor of Tertullien, Apologétique (Paris, 1961), xxxiv-xxxix; Dunn (2004), 29-31.

${ }^{55}$ Rebillard (2012), 43.

${ }^{56}$ Tert., Ad Mart. 1,1-2 (trans. S. Thelwall, ANF, slightly altered).
} 
another booklet of his which he does not see as unfit to nurture and educate the spirit of 'the most accomplished gladiators'. If there is any reality behind this text, Tertullian must have been sitting in one of the last rows of the theatre as a mere spectator, a theoretician, writing for consumption. Or is he the paradoxical rhetorician who with his inconsistencies sounds even more himself than a more perfected Cicero who fought in the courts?

\section{A nuanced author}

Tertullian writes one work On Prayer, a text which we have already referred to, and where one wonders whether in it he relies on Scripture and the authority of the divine Word:

The Spirit of God, and the Word of God, and the Reason of God - Word of Reason, and Reason and Spirit of Word - Jesus Christ our Lord, namely, who is both the one and the other, - has determined for us, the disciples of the New Testament, a new form of prayer; for in this particular also it was needful that new wine should be laid up in new skins, and a new breadth be sewn to a new garment. Besides, whatever had been in bygone days, has either been quite changed, as circumcision; or else supplemented, as the rest of the Law; or else fulfilled, as Prophecy; or else perfected, as faith itself. For the new grace of God has renewed all things from carnal unto spiritual, by superinducing the Gospel, the obliterator of the whole ancient bygone system; in which our Lord Jesus Christ has been approved as the Spirit of God, and the Word of God, and the Reason of God: the Spirit, by which $\mathrm{He}$ was mighty; the Word, by which He taught; the Reason, by which He came. ${ }^{57}$

Tertullian starts, as mentioned, with his Stoic emphasis on 'the Spirit of God', 'the Word of God' and 'the Reason of God' to introduce the 'new form of prayer' which the Lord Jesus Christ has 'determined' for 'the disciples of the New Testament'. Not only does Tertullian stress the notion of 'novelty', he also adds the Biblical reference Luke 5:36 on the new wine and the new skins which, according to Tertullian, was one of the core passages from which Marcion developed his idea of novitas Christiana, and, therefore the distinction between Judaism and what Marcion coined in antithesis to it, Christianity. ${ }^{58}$ Here, however, Tertullian himself adds this passage, though with an important deviation from Marcion, when, similar to Justin, he changes the antithesis for 'change', 'supplement', 'fulfillment' and 'perfection'. 'Christianity', once coined in antithesis to 'Judaism', Tertullian adopts, but he superimposes it onto Judaism which is now regarded no longer (as by Marcion) a self-standing tradition from which Christianity is independent, but a foregoer which is not only old (as old and traditional was rather a positive qualifier), but also carnal, a somehow outdated, bygone system which has been obliterated by the spiritual new one.

\footnotetext{
57 Tert., On Prayer 1.

${ }^{58}$ See Tert., Against Marcion III 16; IV 11.
} 
Strangely enough, for a rhetorician who strives to paint the world in black or white and, therefore, was certainly not only attracted by the Montanist oracles, but also by the antithetical thinker Marcion, where it comes to the relation between the historical past and Christian novelty, Tertullian moves away from the stark contrasts between old and new, between Judaism and Christianity, and becomes a nuanced, though inconsistent interpreter. While he claims that the superinduced Gospel obliterated 'the whole ancient bygone system', he maintains that the prophetism of old and that of the present are the basis, on which the New Testament stands.

If inconsistent and faceless, and with all rhetorical efforts in prefacing his often apologetical works, Tertullian does not seem to be without contours. Perhaps his ambiguities and inconsistencies may even make him more likeable than the contrasts he is often displaying. With regards his self-understanding it should have become clear that he is drawing authority most from where any other Stoic thinker would have taken her or his judgement, namely rational reasoning and justice. At least in his opening prefaces there is hardly anything liturgical, institutional, ritual or even religious, unless one recognizes that for a thorough Stoic (tainted by Plato and Aristotle certainly too) who has become aquainted with the Christian writings and tradition, reason or the logos is the divine instance in man. Of course, Tertullian needs to insist - and the more he does so, the more the modern critical reader becomes suspicious - that his Christian approach is an absolute novelty compared to all former traditions, be it pagan or Jewish.

The power of his prefaces is undeniable, and the weakness of the approach taken here is certainly that we have not compared them to the respective works themselves. ${ }^{59}$ But even without such comparisons, it should have become clear that particularly in the prefaces, Tertullian advances in a great variety his exceptional rhetorical powers, a rhetoric which often seems to be counter-intuitive, as Vincentius of Lérins' in his portrayal of Tertullian in his Remembrancer (Commonitorium) already noticed:

As to his style, who can sufficiently set forth its praise? It was knit together with so much cogency of argument that it compelled assent, even where it failed to persuade. Every word almost was a sentence; every sentence a victory. ${ }^{60}$

Tertullian's rhetoric is a wide net of traps, which for all those who are caught in it will compell assent, but critical readers also wish to be persuaded. If 'every sentence' is 'a victory', the 'almost' (paene) turns his apologetics into a Pyrrhic victory. Too often, however, the net is laid out so hidden, the knots are so well connected and the gaps in between so big that the most critical reader cannot unravel what has been caught by it.

${ }^{59}$ This I have done, at least with regards to Tertullian's De praescriptione in Vinzent (2017).

${ }^{60}$ Vinc., Comm. 18,24(46) (74,9-78,5 Moxon) (trans. C. A. Heurtley, NPNF, altered). 


\section{Bibliography}

Epistula Apostolorum

James, M.R. (1924). The Apocryphal New Testament. Oxford. 485-503

Tertullian

Ad martyras

-. (1954) Qvinti Septimi Florentis Tertulliani Opera. Pars I Opera catholica. Adversus Marcionem, ed. E. Dekkers. CChr.SL 1. Turnhout. 1-8.

Ad nationes libri II

-. (1954). Qvinti Septimi Florentis Tertulliani Opera. Pars I Opera catholica. Adversus Marcionem, ed. J. G. Ph. Borleffs. CChr.SL 1. Turnhout. 9-75.

Ad Scapulam

-. (1954). Qvinti Septimi Florentis Tertulliani Opera. Pars I Opera catholica. Adversus Marcionem, ed. E. Kroymann. CChr.SL 1. Turnhout. 395-436.

-. (1870). The Writings of Tertullian II, tr. P. Holmes. Ante-Nicene Christian Library 15. London. 55-118.

Adversus Marcionem

-. (1972). Tertullian: Adversus Marcionem, ed. and tr. E. Evans. Oxford.

Adversus Valentinianos

-. (1954). Qvinti Septimi Florentis Tertulliani Opera. Pars II. Opera Montanistica, ed. E. Kroymann. CChr.SL 2. Turnhout. 751-778.

-. (1972). Q. S.Fl. Tertulliani Adversus Valentinianos, ed. and tr. M.T. Riley. Ann Arbor. Apologeticum

-. (1954). Qvinti Septimi Florentis Tertulliani Opera. Pars I Opera catholica. Adversus Marcionem, ed. E. Dekkers. CChr.SL 1. Turnhout. 77-171.

-. (1885). Tr. S. Thelwall, ANF 3. 17-55.

De anima

-. (1954). Qvinti Septimi Florentis Tertulliani Opera. Pars II. Opera Montanistica, ed. J.H. Waszink. CChr.SL 2. Turnhout. 779-869.

De baptismo

-. (1954). Qvinti Septimi Florentis Tertulliani Opera. Pars I Opera catholica. Adversus Marcionem, ed. J. G. Ph. Borleffs. CChr.SL 1. Turnhout. 275-295.

De corona

-. (1954). Qvinti Septimi Florentis Tertulliani Opera. Pars II. Opera Montanistica, ed. E. Kroymann. CChr.SL 2. Turnhout. 1037-1065.

De idololatria

-. (1954). Qvinti Septimi Florentis Tertulliani Opera. Pars II. Opera Montanistica, ed. A. Reifferscheid; G. Wissowa. CChr.SL 2. Turnhout. 1099-1124.

De oratione

-. (1954). Qvinti Septimi Florentis Tertulliani Opera. Pars I Opera catholica. Adversus Marcionem, ed. D. F. Diercks. CChr.SL 1. Turnhout. 255-274. 
De paenitentia

-. (1954). Qvinti Septimi Florentis Tertulliani Opera. Pars I Opera catholica. Adversus Marcionem, ed. J. G. Ph. Borleffs. CChr.SL 1. Turnhout. 319-340.

De patientia

-. (1885). Tr. S. Thelwall, ANF 3. 707-717.

-. (1954). Qvinti Septimi Florentis Tertulliani Opera. Pars I Opera catholica. Adversus Marcionem, ed. J. G. Ph. Borleffs. CChr.SL 1. Turnhout. 298-317.

De praescriptione haereticorum

-. (1870). The Writings of Tertullian II, tr. P. Holmes, Ante-Nicene Christian Library 15. London. 1-54.

-. (1954). Qvinti Septimi Florentis Tertulliani Opera. Pars I Opera catholica. Adversus Marcionem, ed. R. Refoulé. CChr.SL 1. Turnhout. 185-224.

De resurrectione carnis

-. (1960). Q. Septimii Florentis Tertulliani De resurrectione carnis liber. Tertullian's Treatise on the Resurrection, ed. and tr. E. Evans. London.

De spectaculis

-. (1954). Qvinti Septimi Florentis Tertulliani Opera. Pars I Opera catholica. Adversus Marcionem, ed. E. Dekkers. CChr.SL 1. Turnhout. 225-253.

De testimonio animae

-. (1954). Qvinti Septimi Florentis Tertulliani Opera. Pars I Opera catholica. Adversus Marcionem, ed. R. Willems. CChr.SL 1. Turnhout. 173-183.

Scorpiace

-. (1954). Qvinti Septimi Florentis Tertulliani Opera. Pars II. Opera Montanistica, ed. A. Re-ifferscheid and G. Wissowa. CChr.SL 2. Turnhout. 1067-1097.

-. (1885). Tr. S. Thelwall, ANF 3. 633-648.

Gospel of Thomas

(1998). Translation by the Berlin Working Group for Coptic Gnostic Writings, taken from Synopsis Quattuor Evangelorium, 2nd corr. 1997, as modified by Stephen J. Patterson; James M. Robinson, in: S.J. Patterson, J.M. Robinson; E. Bethge, The Fifth Gospel. Harrisburg.

Adler, M.J. (1940). How to Read a Book: The Classic Guide to Intelligent Reading. London.

Agamben, G. (2013). Die Macht des Denkens, tr. Francesca Raimondi. Frankfurt.

Allie, J.-L. (1940). L'argument de prescription dans le droit romaine, en apologétique et en théologie dogmatique. Ottawa.

Balfour, I.L.S. (forthcoming). “Tertullian and Roman law - what do we (not) know?", Studia Patristica.

Barnes, T.D. (1985; 1971). Tertullian: A Historical and Literary Study. Oxford.

Barthes, R. (1968). “La mort de l'auteur.” Manteia 5:12-17.

Beck, A. (1930, repr. 1967). Römisches Recht bei Tertullian und Cyprian: Eine Studie zur frühen Kirchenrechtsgeschichte. Halle, repr. Aalen.

Bill, A. (1911). Zur Erklärung und Textkritik des 1. Buches Tertullians „Adversus Marcionem“. TU 3. Leipzig. 
De Boer, E. A. (2014). “Tertullian on 'Barnabas' Letter to the Hebrews' in De pudicitia 20.1-5, Vigiliae Christianae 68: 243-263.

Braun, R. (1962, rev. ed., 1977). Deus Christianorum: Recherches sur le vocabulaire doctrinal de Tertullien. Études Augustiniennes. Paris.

Braun, R. (ed.) (1990). Tertullien: Contre Marcion I. SC 365. Paris.

Braun, R. (1992). “Aux origins de la Chrétienté: un homme de combat, Tertullien,” in: R. Braun, Approches de Tertullien. Collection des Etudes Augustiniennes, Série Antiquité 134. Paris. 1-20.

Bray, G. L. (1979). Holiness and the Will of God: Perspectives on the Theology of Tertullian. London.

Daly, C. (1993). Tertullian the Puritan and His Influence. Dublin.

Dunn, G.D. (2004). Tertullian. London.

Fredouille, J.-C. (1972). Tertullien et la conversion de la culture antique. Études Augustiniennes. Série Antiquité 47. Paris.

Frisius, M.A. (2011). Tertullian's Use of the Pastoral Epistles, Hebrews, James, 1 and 2 Peter, and Jude. Studies in Biblical Literature 143. New York.

Genette, G. (1997 [1982]). Palimpsests: Literature in the Second Degree, trans. C. Newman and C. Doubinsky. Lincoln.

Genette, G. (1997 [1987]). Paratexts: Thresholds of Interpretation, trans. J. E. Lewin. Literature, Culture, Theory 20. Cambridge.

Genette, G. (1991). “Introduction to the Paratext," New Literary History 22: 261-272.

Kinzig, Wolfram (1994). Novitas Christiana. Die Idee des Fortschritts in der Alten Kirche bis Eusebius. Forschungen zur Kirchen- und Dogmengeschichte 58. Göttingen.

Michaélidès, D. (1969). Foi, Écritures et Tradition ou Les 'Praescriptiones' chez Tertullien. Paris.

Michaélidès, D. (1970). Sacramentum chez Tertullien. Paris.

Raven, S. (2 ${ }^{\text {nd }}$ ed. 1993). Rome in Africa. London.

Rebillard, E. (2012). Christians and Their Many Identities in Late Antiquity, North Africa, 200-450 CE. New York.

Sider, R. D. (1971). Ancient Rhetoric and the Art of Tertullian. Oxford.

Sider, R.D. (1990). "Literary Artifice and the Figure of Paul in the Writings of Tertullian," in: William S. Babcock, ed., Paul and the Legacies of Paul. Dallas. 99-120.

Skarsaune, O. (1987). The Proof from Prophecy. Leiden.

Steiner, H. (1989). Das Verbältnis Tertullians zur antiken Paideia. Studien zur Theologie und Geschichte 3. St. Ottilien.

Vinzent, M. (2017). Tertullian's Preface on Marcion's Gospel. Studia Patristica Supplements 5. Leuven.

White, B.L. (2011). "How to Read a Book: Irenaeus and the Pastoral Epistles Reconsidered," Vigiliae Christianae 65: 125-149.

Wilhite, D. A. (2007). Tertullian the African. An Anthropological Reading of Tertullian's Context and Identities. Millenium Studies 14. Berlin. 


\title{
Der gnostische Mythos, seine Vorlagen und seine Wirkungen
}

\author{
Autorkonzepte in Beziehung
}

\author{
Barbara Aland
}

Matthias Baltes zum Gedenken.

Der so genannte gnostische Mythos, ein extrem künstliches Gebilde und noch dazu anonym auftretend, scheint kein geeigneter Gegenstand für eine Fallstudie zur Autorschaft in religiösen Texten zu sein. Aber das täuscht vielleicht. Denn wir haben es - die hier vorliegende Interpretation vorausgesetzt - nicht nur mit dem Text des Mythos (er steht im Mittelpunkt), sondern auch mit seinen Vorlagen und Wirkungen zu tun, einem Textkomplex also, dessen einzelne Texte in enger Beziehung stehen und inhaltlich und formal nur aus diesem engen Bezug aufeinander verstanden werden können. Auch die jeweiligen Autorschaftsmodelle, insbesondere des Mythos, aber auch seiner verschiedenen Rezeptionen, sind nur aus diesem Zusammenhang zu erklären. Es geht also um den Sonderfall "Autorkonzepte in Beziehung“, der seine eigenen Aspekte zur Fragestellung dieses Bandes beitragen kann. Allerdings ist die Beziehung dieser Texte aufeinander nicht selbstverständlich, sondern muss erwiesen werden. Um ein wenig Geduld dafür muss also gebeten werden.

Grundlage der folgenden Studie ist die praktische Interpretation der Texte (Teil 2), d.h. das mittelplatonische Seinsmodell des Numenios als Bezugstext für den gnostischen Mythos, dieser Mythos selbst, für den ich exemplarisch den valentinianischen Mythos auswähle, wie er bei Irenäus, Adversus Haereses 1,1-8, bezeugt ist, sowie die vielfältigen Reaktionen darauf, sei es zustimmend weiterführend in andern gnostischen Mythen, sei es ablehnend kritisch bei Irenäus als Vertreter der christlichen Reaktion wie bei Plotin als Zeuge für die philosophisch-platonische Rezeption. Aufgrund dieser Interpretation erhebe ich die Autorkonzepte der verschiedenen Texte. Diese Konzepte erhärten wiederum die Interpretation und fügen ihr neue Sichtperspektiven hinzu. Um der methodischen Klarheit willen trenne ich die Interpretation (Teil 2) von den darauf ba- 
sierenden literaturtheoretischen Erwägungen zu den Autorkonzepten der Texte (Teil 1). ${ }^{1}$ Beides hat sich im Laufe der Arbeit gegenseitig ergänzt.

\section{Die Autorkonzepte der beteiligten Texte und ihre Funktionen}

Der christlich-valentinianische Mythos ist Begründungs- und Lehrdokument der gnostischen Christen. Gnostiker äußern sich nahezu ausschließlich in mythenartigen Erzählungen und tragen ihre Lehrdifferenzen in Variierungen ihrer "Mythen“ aus. Der valentinianische „Mythos“, dessen Entstehung und Begründung bisher unklar ist, ist kein frei erfundenes Kunstgebilde, sondern das ist die aufgrund der Interpretation in Teil 2 aufgestellte These - orientiert sich an mittelplatonischen Seinsmodellen, die in mythisch-narrative Form mit handelnden personalen Größen umgegossen und an entscheidender Stelle so variiert werden, dass die christlich-gnostische Aussage zum Tragen kommt. Das Konzept der Autorinstanz des Mythos (denn natürlich gibt es einen Autor) ist daher so zu beschreiben:

Der „Autor" knüpft an eine hochangesehene philosophische Vorlage an, die beansprucht, Wahrheit über Gott, Welt und Mensch zu bieten. Er imitiert sie, dadurch den gleichen Anspruch erhebend, und konkurriert mit ihr, indem er sie an entscheidender Stelle abwandelt: Die Seele ist nicht mehr als gestaltendes Element der Körperwelt bleibend göttlich und daher auch Mittler der Erlösung, der Rückkehr zu Gott. Sie ist vielmehr gänzlich gefallen, ohne Befähigung zur Rückkehr, und ein anderer Mittler zu Gott wird notwendig: Christus. Diese neue theologische Sacherkenntnis, die der gnostische „Mythos“ vermitteln will, wird durch die Autorfunktionen von imitatio und variatio zum Ausdruck gebracht.

\footnotetext{
${ }^{1}$ Begrifflich und terminologisch folge ich angesichts der schwierigen Debatte um Autor, Text und Leser den Definitionen, wie sie bei Anz 2007, 133, gegeben sind: „Zu unterscheiden ist zunächst zwischen Autorfunktionen, Autorschaftmodellen und dem realen Autor. Autorfunktionen betreffen den literaturwissenschaftlichen Umgang mit dem Autor in methodischer und theoretischer Ausrichtung sowie in der Interpretationspraxis und fragen nach der Bedeutung, die dem Autor in verschiedenen wissenschaftlichen Ansätzen zugeschrieben wird (vgl. I.5.1). Autorschaftsmodelle stellen dagegen historisch kontingente, literarisch inszenierte und poetologisch konzipierte Konstrukte dar, die je ein bestimmtes ,Bild‘ des Autors im Hinblick auf Absicht, Anspruch und Ursprung seiner literarischen Tätigkeit umreißen (I.5.2). "Noch genauer werden die Begriffe „Autorfunktionen“, daraus sich ergebend „Autorfunktionscluster“, daraus sich ergebend „Autorfiguration/Autorkonzept“, definiert bei Willand, 2011, 279-282. Willand betont, dass der Begriff des Autorkonzeptes sich immer auf das Autorkonzept des Interpreten bezieht, „da er immer vom Interpreten zugeschriebene“ (kursiv Willand) „Funktionen beschreibt“" (280). Beide Arbeiten stützen sich auf den grundlegenden Band von Jannidis, Lauer, Martinez, Winko 1999, und insbesondere die Einleitung der Herausgeber unter dem Titel „Rede über den Autor an die Gebildeten unter seinen Verächtern. Historische Modelle und systematische Perspektiven“" (3-35).
} 
Doch diese neue Grunderkenntnis muss zur Wirkung gebracht und durchgesetzt werden. Das geschieht durch ihre stilistische Gestaltung, ja, Inszenierung ${ }^{2}$ als „Mythos“. Zwar ist die christlich-gnostische Leitidee als Überbietung der platonischen Vorlage durchaus rational und logoshaft gemeint, wird aber stilistisch in einer mythischen Erzählung geboten, die ihrem Genus gemäß logosfremd, nicht diskutierbar und unhinterfragbar ist, die autoritativ religiösen Charakter hat und notwendig anonym bleibt. Diese Anonymität ist eine bewusst gewählte, strategische Anonymität, ${ }^{3}$ die überirdische Autorität vermitteln soll. Letztgültige Wahrheit kann nicht von einem individuellen Autor verantwortet werden. ${ }^{4}$ Auch damit wird die Vorlage übertroffen: Platonische Philosophen beglaubigen ihre Aussagen durch Berufung auf den „göttlichen Platon“. Gnostiker überbieten das durch schlechthinnige Anonymität. ${ }^{5}$ Dieses Autorkonzept von imitatio, variatio und diffiziler Gestaltung steht also hinter dem so genannten gnostischen Mythos, der ein total künstliches Gebilde ohne vergleichbare historische Bezüge ist. Er gleicht weder archetypischen Mythen, noch Mythenallegorien, noch platonischen Mythen im Sinne einer narrativen Ergänzung des Logos.

Schließlich: Diese ungewöhnliche Inszenierung der christlich-gnostischen Grunderkenntnis durch die Autorinstanz des „Mythos“ setzt eine aktuelle Situation voraus, die in der Tat gegeben ist. In der Zeit um 160 bis 180 waren christliche Gnostiker und insbesondere die Valentinianer, in Teilen der christlichen Gemeinden offenbar durchaus erfolgreich. ${ }^{6}$ Zugleich waren sie aber bedroht, denn ihnen wird das Auftreten an wichtigen Kommunikationsorten, den kirch-

\footnotetext{
${ }^{2}$ Kluge Bemerkungen zur „Inszenierung“ einer historischen Persönlichkeit bei Heiser 2012.

${ }^{3}$ Vgl. dazu die Beiträge des Sammelbandes von Pabst 2011, in dem das Thema Anonymität an Texten des Mittelalters und der Neuzeit behandelt wird. Darin s. bes. den einführenden Aufsatz von Pabst, Anonymität und Autorschaft. Ein Problemaufriss, 1-34.

${ }^{4}$ Die anonyme Konzipierung des valentinianischen „Mythos“ ist auch deswegen so auffallend, weil die zeitgenössischen Rezipienten dieses Textes zahlreiche gnostische Lehrer, die auch Texte verfassten, namentlich durchaus kannten und auch selbstverständlich die verschiedenartigen „Mythen“ bestimmten Schulen zuordneten, wie eben den hier behandelten der Schule des Valentinus.

${ }^{5}$ Wenn ausnahmsweise ein Verfasser des Mythos namentlich genannt zu werden scheint, wie in der lateinischen Übersetzung des Referates von Irenäus, Adversus Haereses (AH) 1,8,5 („et Ptolemäus quidem ita“), - so nicht im griechischen Text bei Epiphanius, Pan. 31,27,16 - so ist diese Zuschreibung nicht nur in der Forschung umstritten, sondern war wohl auch, falls überhaupt zutreffend, eher als Zuordnung des „Mythos“ zur Schule eines bekannten valentinianischen Lehrers, nicht als Verfasserangabe gemeint. An Schüler des Ptolemäus als Urheber denkt mit guten Gründen Markschies 2011, $413 \mathrm{f}$ (mit Hinweis auf Markschies 2000). Vgl. aber Rousseau/Doutreleau 1979, 218 zu p. 137, n. 2.

${ }^{6}$ Das geht aus der Praefatio zum 1. Buch von Irenäus' Werk deutlich hervor, in der er im übrigen die listige „Inszenierung“ der gnostische Falschlehre besonders hervorhebt (AH 1, praef. 2: „Der Irrtum ... schmückt sich listigerweise mit einem überzeugenden Kleid und bietet sich als wahrer als die Wahrheit selbst - es ist lächerlich - dar, um als solche Wahrheit durch das äußerliche Aussehen ( $\left.\propto \alpha \nu \tau \alpha \sigma^{\prime} \alpha\right)$ den Unkundigen zu erscheinen.“
} 
lichen Predigtstellen, untersagt. ${ }^{7}$ Sie bedürfen daher der Rechtfertigung ihrer Theologie durch schriftliches Zeugnis, und als solches hat Irenäus den valentinianischen Mythos verstanden, dessen Referat er daher bewusst in voller Länge an den Anfang seines ketzerbekämpfenden Werkes stellt.

Und dieses Konzept des valentinianischen Textes wirkte! Es bewirkte eine gewaltige Rezeption und Reaktion, die breiter und vielfältiger als bei jedem anderen christlichen Text des zweiten Jahrhunderts ist. Uns liegen zustimmende und kritisch ablehnende Reaktionen zeitgenössischer Leser und Rezipienten vor, deren Autorkonzepte in ihren reagierenden Texten jeweils von ihrem Verstehen des gnostischen Textes her bestimmt werden. Zur ersten Gruppe kann die gesamte Fülle der gnostischen Mythendichtung gezählt werden. Zwar gehen die erhaltenen gnostischen Texte selbstverständlich nicht alle auf den hier behandelten valentinianischen Mythos speziell zurück, aber alle weisen doch das gleiche literarische Modell einer anonymen, mythenartigen Erzählung über Gott, Welt und Mensch auf, d.h. auch für sie ist das gleiche Autorkonzept zu rekonstruieren. Die Anonymität der Texte wird zuweilen gesteigert durch autoritative pseudonyme Autorschaften. ${ }^{8}$ Zur zweiten Gruppe gehören die christlichen und platonischen Reaktionen, für die hier stellvertretend Irenäus und Plotin stehen. Für alle reagierenden Texte lässt sich ein Autorkonzept erheben, das sich aus dem jeweiligen Verständnis des vorliegenden mythischen Textes und der Weltanschauung des jeweils rezipierenden Lesers ergibt. Charakteristisch für die ablehnend-kritischen Reaktionen des Irenäus und Plotin ist, dass sie nicht anonym, sondern betont orthonym auftreten. Der Name der Verfasser steht nicht für sie als Individuen, sondern sie äußern sich als autoritative und kompetente Vertreter ihrer jeweiligen Weltanschauung: der Bischof Irenäus von Lyon als kundiger Kenner und Bestreiter der gnostischen Häresie9 und Plotin als maßgeblicher Denker und Sprecher der platonischen Philosophie. Wie das im einzelnen geschieht, zeigt die in Teil 2 gegebene Interpretation. Besonders deutlich ist bei Plotin zu sehen, wie sich das Autorkonzept aus seiner Reaktion auf den vorliegenden gnostischen Text ergibt. Er würdigt seiner kritischen Widerlegung nur die Teile des Mythos, die er als Konkurrenzunternehmung zur platonischen Philosophie ansieht, und tut das stilistisch in einer rein platonischen Diktion, ohne sich auf die Gesamtbedeutung des gnostischen Mythos einzulassen. Seine Polemik ist ausschließlich für Platoniker geschrieben und verweigert sich dem klärenden Gespräch mit den christlich-gnostischen Verfassern.

\footnotetext{
${ }^{7}$ Vgl. Irenäus, AH 3,15,2.

${ }^{8}$ Stellvertretend für pseudonyme gnostische Mythen aus Nag Hammadi sei hier nur das so genannte Ägypterevangelium genannt, das dem "großen Seth“ selbst zugeschrieben wird: „Dieses Buch schrieb der große Seth Buchstabe für Buchstabe in 130 Jahren und legte es auf dem Gebirge nieder, das Charaxio genannt wird ..." (NHC III,2, 68, 10-13, cf. 68,1-5 und NHC IV,2, 80,26, cf. 80, 15-18; Übersetzung Plisch).

${ }_{9}^{9}$ Vgl. zur Herausstellung seiner Kompetenz die Einleitung seines Werkes, AH 1, praef.
} 
Inhaltlich ist wichtiger noch, dass die verschiedenen Reaktionen die gegebene Interpretation des gnostischen Mythos und seiner Autorkonzeption stützen. Denn warum sollte Plotin so heftig reagieren, wenn er nicht verstanden hätte, dass - wie die Interpretation erweist - der valentinianische Mythos konkurrierend an das platonische Seinsmodell anknüpft. Und warum sollten sich alle Gnostiker in „Mythen“ äußern, wenn sie nicht verstanden hätten, - wie die Konstruktion des gnostischen Autorkonzeptes ergab -, dass die mythenartige Ausdrucksweise angemessen für den Anspruch ihres religiösen Anliegens war. Das bestätigt meine These, dass der gnostische Mythos innovative, systematisch-christliche Theologie in Anlehnung und Überbietung platonischer Seinsphilosophie sein will. Sein Autorkonzept entspricht dieser Intention des Textes und befördert ihre Durchsetzung.

\section{Die Interpretation des gnostischen „Mythos“ und seiner Kontexte}

Die Entstehung des gnostischen so genannten Mythos und die Gründe für seine Form und Gestalt sind bisher kaum befriedigend geklärt. Dafür kann auch hier nur ein partikularer Beitrag geleistet werden, indem versucht wird, die Ursachen für die Ausprägung und Gestaltung eines bestimmten relativ frühen, einflussreichen und vollständigen Mythos aufzuzeigen, des christlich-valentinianischen Mythos, wie er vor allem bei Irenäus AH 1,1-8 und ergänzend bei Hippolyt (Ref. 6,29-37) und Klemens von Alexandrien (Exc. Theod. 42,2-65) überliefert ist.

Zunächst zur Bezeichnung „Mythos“ für den gnostischen Grundlagentext: Er ist, wie aus dem bisher Ausgeführten schon hervorgeht, zu eng und sogar irreführend und wird daher im Folgenden nur noch in Anführungszeichen benutzt. Er ist keine Selbstbezeichnung der gnostischen Autoren, sondern stammt aus polemischer Tradition. Irenäus wendet die Bezeichnung fabula/ $\mu \tilde{v} \theta \circ$ s auf die gnostischen Texte im Sinne von „elenden, unhaltbaren Lügengeschichten“ (AH 1,31,3) an, ${ }^{10}$ benutzt also den Terminus in seiner schon lange in der griechischen Literatur eingeführten kritisch-distanzierenden Bedeutung gegenüber den Göttermythen Homers und Hesiods. ${ }^{11}$ Irenäus übernimmt ihn in diesem Sinne aus dem von ihm auch sonst gern zitierten 1. Tim. 4,7 (cf. 6,20), der vor

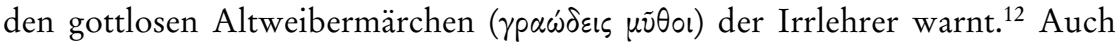
Hippolyt charakterisiert mit diesem Begriff die gnostischen Lehrtexte im Sinne

\footnotetext{
${ }^{10} \mathrm{Vgl}$. AH 4,12,5 und 2,14,1. Im selben Sinne des phantastischen Erfindens von Geschichten wird $\mu \nu \theta_{0} \lambda$ o $\tilde{\varepsilon}^{\prime} \omega$ gebraucht (AH 1,2,3).

${ }^{11}$ Dazu Burkert 1984: „Mythos ist fortan definitorisch die unwahre Erzählung“ (281 mit Belegen).

${ }^{12}$ So AH $1,8,1$ und $1,16,3$.
} 
des lügenhaft und in täuschender Absicht Erfundenen. ${ }^{13}$ Die Gnostiker haben ihre Grundlagentexte kaum als „Mythen“ in Parallele zu griechischen Göttermythen verstanden. Auch die für den gnostischen „Mythos“ üblich gewordene Bezeichnung „Kunstmythos“ ist zwar formal nicht falsch, klärt aber nichts, weil damit nicht gesagt wird, warum und in welcher Absicht die so genannten mythischen Texte ersonnen werden.

Der gnostische „Mythos“ ist auch kein platonischer Mythos zur Ergänzung der im Logos begründet ausgesagten Wahrheit, obwohl er in der Tradition dieser Mythen und ihrer Funktion steht, insofern diese zwar nicht in Logos-gemäßer Begründung wahre Aussagen machen, aber doch in bildhaft narrativer Weise Wahrheit aussagen ${ }^{14}$ und damit den Logos ergänzen. Der gnostische „Mythos“ ist - und das gilt nun insbesondere für den valentinianischen „Mythos“ und ist meine These - eine innovative Neuschöpfung, bei der Logos in mythischer Form ausgesagt wird, eine Art Hybrid von Logos und Mythos. Er bietet Reflexion nach dem Modell mittelplatonischer Metaphysik ${ }^{15}$ in mythischer Darstellungsweise und ist eine Variationsform mittelplatonischer Metaphysik, die trotz ihrer mythischen Aussageform deutlich Systemcharakter aufweist. In ihr werden Terminologie und Reflexionsformen mittelplatonischer Systeme genutzt (und variiert) mit dem Ziel, unter diesen platonischen Voraussetzungen und deren Anspruch die Wahrheit des christlichen Glaubens und die Notwendigkeit Christi begründet zu erweisen. Der valentinianische „Mythos“ ist ohne diese philosophischen Vorlagen nicht zu verstehen. Es handelt sich gemäß seinem Autorkonzept um eine Art besser verstandener und zu seinem eigentlichen Sinn gebrachter Platonismus. Er wird damit freilich - das sei schon hier angemerkt weder christlicher noch platonischer Theologie wirklich gerecht, regt aber die Entwicklung eines angemesseneren christlichen Platonismus an und befördert sie.

Im übrigen war es nicht ungewöhnlich, philosophische Gedanken in mythischer, narrativer Art zu entwickeln. Bei mittelplatonischen Autoren gibt es schon Ansätze dazu. ${ }^{16}$ Die neue religiöse Stilform liegt aber erst im gnostischen „Mythos“ vor, in dem der Charakter der mythisch-narrativen Erzählung vollständig durchgehalten wird, ontologische Größen personifiziert und durch ver-

${ }^{13}$ Hippolyt, Ref.5,23,2. 24,2. 27,5; 6,19,4. 20,4. 42,2. Im Blick auf die alten griechischen Mythen benutzt Hippolyt (wie schon Irenäus AH 2,30,1), den Begriff „Mythos“ sachlich und unpolemisch (Ref. 5,25,4. 26,1), teilweise sogar anerkennend (cf. Ref. 1,1. 8; 5,26,1; 8,17,2: der Mythos im Timaios stamme von Sokrates und sei von Platon besser bearbeitet als von Hermogenes).

${ }^{14}$ Dazu Erler 2007, 89-92.

${ }^{15}$ Die den Valentinianern zeitgenössischen Mittelplatoniker, die ihre direkten Gesprächspartner darstellen, haben die Inhalte insbesondere des Timaios zu einer systematischen Prinzipienlehre zusammengefasst. Dazu vgl. Baltes 1999b, 223-247, bes. 224-234 und 246.

${ }^{16} \mathrm{Vgl}$. etwa die personalisierte Ausdrucksweise in den Fragmenten des Numenios 11-15 (des Places). 
schiedene Namen in ihren jeweils unterschiedlichen Funktionen differenziert werden. Ein und dieselbe Gottheit oder Hypostase kann so ihren verschiedenen Aspekten gemäß verschieden benannt werden. Das erschließt sich, wenn man hinter der gnostischen Mythologie das Modell einer mittelplatonischen Seinslehre erkennt. ${ }^{17}$

Die Beziehungen zwischen Gnosis und Platonismus werden in der neueren Forschung seit den Arbeiten von Hans-Joachim Krämer ${ }^{18}$ diskutiert und heute insbesondere auf der Grundlage von so genannten sethianischen Texten behandelt und bis zu der Vorstellung entwickelt, dass gnostische Autoren einflussreich und belehrend auf neuplatonische Denker, besonders Plotin, gewirkt haben könnten. Ich möchte so weit nicht gehen. Mir scheint die nehmende Rolle der gnostischen und insbesondere der valentinianischen Autoren des zweiten Jahrhunderts ungleich stärker zu sein. Das Verhältnis von Gnosis und Platonismus ist an ihren Texten genauer zu bestimmen als es aufgrund der bekannten platonisierenden spätsethianischen Texte des dritten Jahrhunderts der Fall ist. Eindeutig ist aber, dass eine Beziehung zwischen Platonismus und Gnosis besteht und eine neue Literaturform geschaffen wurde, mit der die valentinianischen Autoren versuchen - unter den Voraussetzungen platonischer Ontologie und Kosmologie und in weitgehender Übernahme von deren Reflexions- und Ausdrucksformen -, christliche Inhalte auszusagen, vor allem die Notwendigkeit Christi zu erweisen, was natürlich nur möglich ist, wenn das platonische Modell an entscheidender Stelle abgewandelt, „korrigiert“ wird. Es entsteht so eine Art häretischer Extremplatonismus, der aber gleichwohl auch in der Platonismusforschung als solcher wahrgenommen werden sollte.

\subsection{Der valentinianische "Mythos" als modifizierende Umformung des mittelplatonischen Modells}

Der Nachweis dieser Annahmen zum Wesen des valentinianischen „Mythos“ kann hier nicht in der gebührenden Ausführlichkeit geführt werden. Ich beschränke mich darauf, die wichtigsten Übereinstimmungen und Abweichungen des valentinianischen Systems mit dem der Seinslehre des pythagoreisierenden Mittelplatonikers Numenios von Apamea, dem die valentinianische Gnosis am nächsten steht, aufzuzeigen. Numenios ist in den zu behandelnden Hauptpunkten seiner Lehre als Vertreter mittelplatonischer Philosophie überhaupt an-

\footnotetext{
${ }^{17}$ Natürlich ist auch zu bedenken, dass die Entwicklung des valentinianischen (wie auch des so genannten sethianischen) „Mythos“ insgesamt nicht ohne den Blick auf die frühen kosmogonisch-mythischen Erzählungen, die einem Simon, Menander, Saturnin und anderen zugeschrieben werden (cf. Irenäus, AH 1,23-26), behandelt werden kann. Dieser Aspekt ist hier aber zu vernachlässigen, weil die Übernahme und Variation der mittelplatonischen Seinslehre ein ganz eigenständiger und neuer Zug der Valentinianer ist und eben darin Gegenstand für die Frage nach der Stimme der „religiösen Autoren“ ist.

${ }^{18} \mathrm{Vgl}$. Krämer 1967.
} 
zusehen. An Plotins Kritik an den Gnostikern, die sich weitgehend auch auf das valentinianische System bezieht, können die Ergebnisse dann verifiziert werden. Dabei wird besonders die von platonischen Termini und Vorstellungen gesättigte Sprache der Gnostiker deutlich.

Beide, Numenios und der valentinianische Lehrtext, der "Mythos“, gehen von einer grundsätzlichen $Z$ weistufigkeit des Göttlichen aus. ${ }^{19}$ Eine erste, transzendente und alles verursachende Gottheit wird abgesetzt von einer zweiten demiurgischen Gottheit. Beide Stufen, insbesondere die zweite, sind jeweils in sich differenziert, werden aber je für sich ausdrücklich als Einheit qualifiziert.

Im Einzelnen ist bei Numenios der so genannte erste Gott bzw. Nus transzendent gegenüber dem geschaffenen Kosmos. Er ist ganz bei sich, einfach, nicht teilbar (Frg.11; Bst. 197.1,1-4), untätig, frei von allen Werken, König (frg.12;

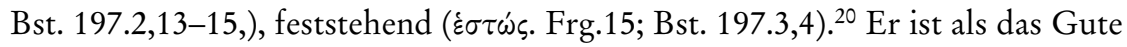

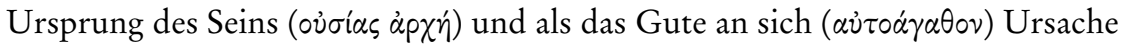

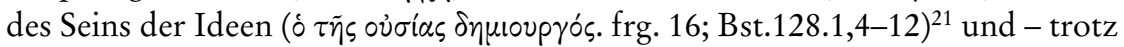
seiner Untätigkeit und Ständigkeit $(\sigma \tau \dot{\sigma} \sigma \iota)$ - „Vater“ des demiurgisch schaffenden zweiten Gottes (frg. 12; Bst. 197.2,1-2 und frg.21; Bst. 197.4,1-4). Seine

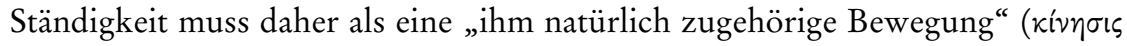

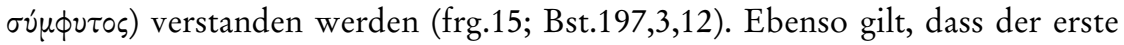
Gott zwar nicht schafft - das ist Aufgabe des zweiten -, aber doch als der Frü-

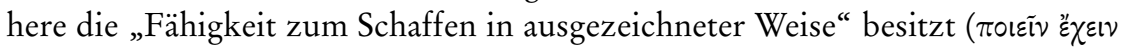

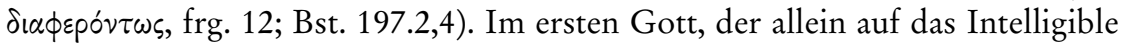
gerichtet ist (frg. 15; Bst. 197.3,6f), werden also zwei Aspekte unterschieden: der

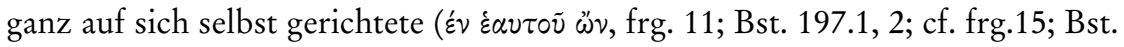
197.3,6) und der die Entstehung alles Weiteren verursachende. Diese Differenzierung der Aspekte des ersten Gottes wird von Numenios besonders betont: „Wundere dich nicht ...“ (über die Unterscheidung der beiden Götter), „du wirst nämlich noch viel Erstaunlicheres hören: ... die dem Ersten zugehörige Ständigkeit $(\sigma \tau \dot{\alpha} \sigma \varsigma \varsigma)$ ist, so sage ich, eine ihm natürlich zugehörige Bewegung. "22 - Die Aspektverschiedenheit ist ihm also wichtig. ${ }^{23}$ Sie wird zum Verständnis der Struktur des valentinianischen Pleromas ebenfalls wichtig werden, denn auch der

${ }^{19}$ Vgl. dazu grundsätzlich Ziebritzki 1994, passim und Pietsch 2008, 324-341 (zu Alkinoos) und 467-472 (zu Numenios), mit Hinweis auf andere Literatur.

${ }^{20}$ Die Abkürzung „Bst.“" steht für „Baustein“ und bezieht sich immer auf das mehrbändige Werk, das zu seinen größten Teilen von Baltes getragen wurde: Dörrie, Baltes 1987-2008. Die folgende Darstellung der Lehre des Numenios ist wesentlich an diesem Werk orientiert. Vgl. auch Baltes 1999a.

${ }^{21}$ Dazu Dörrie, Baltes 1987-2008, Bd. 5, 265-9.

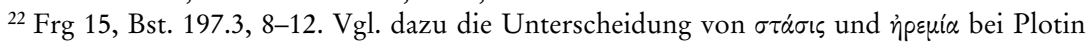
VI 3(44) 27, 1-35

${ }^{23}$ Der Mittelplatoniker Harpokration von Argos benennt in Nachfolge des Numenios die drei Gottheiten und ihre unterschiedlichen Aspekte sogar mit Namen aus der griechischen Mythologie - ein Verfahren, das wir vergleichbar auch im valentinianischen „Mythos“ antreffen, vgl. frg. 14 Dillon, Bst. 197.6,6-12. 
„Mythos“ differenziert verschiedene Aspekte derselben Stufe der Gottheit und benennt sie als solche mit unterschiedlichen Namen.

Zunächst aber zum zweiten Gott des Numenios, der als „Sohn“ des ersten bezeichnet wird und damit auch Nus ist. ${ }^{24} \mathrm{Er}$ ist im Unterschied zum ersten auf das Intelligible und das Sichtbare gerichtet (frg.15, Bst. 197.3,7). Er ist der Schöpfer des Werdens und darin „Nachahmer" ( $\mu \mu \eta \tau \eta \dot{s}$ ) des ersten Gottes, der der Schöpfer des Seins ist; damit ist er der eigentliche Demiurg des Kosmos (frg.16; Bst. 128,1,4-16. frg. 12; Bst. 197.2). ${ }^{25}$ Er ist selbst gut durch seine Teilhabe an der Idee des Guten, dem ersten Gott. ${ }^{26}$ Als Demiurg wendet er sich der Materie zu, einigt $\operatorname{sie}^{27}$, wird aber dabei von ihr, die einen begehrlichen Charakter

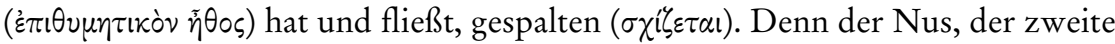
Gott, achtet - während er auf die Hyle schaut und für sie sorgt - nicht mehr auf

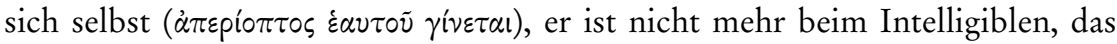
sein eigentliches Selbst ist (frg. 11, Bst. 197.1,11-15). In dieser auf die Materie gerichteten Tätigkeit wird er daher als dritter Gott bezeichnet, der aber mit dem zweiten Gott eine Einheit bildet (frg. 11; Bst. 197.1,5). - Auch bei dieser zweiten Stufe des Göttlichen, dem „Einssein“ des zweiten und dritten Gottes, werden also zwei Aspekte unterschieden: der Aspekt in der Gestalt des nach oben auf den ersten Gott blickenden und von dort seine Inspiration empfangenden Nus und der sich mit der Materie befassende, gleichsam nach unten gerichtete, so genannte dritte Gott. ${ }^{28}$ Dieser wird nach dem Zeugnis des Proklos zugleich als

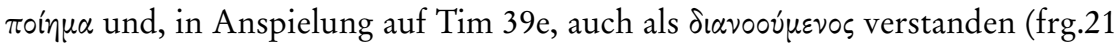
und 22; Bst. 197.4 und 5), das heißt als die Funktion der zweiten Gottheit, in der diese den geordneten Kosmos formt und daher diesen selbst darstellt. Die zweite demiurgische Gottheit des Numenios steht also in der Doppelheit von zweitem und dritten Gott für die platonische Weltseele, insofern diese zur Ideenschau und - damit untrennbar zusammenfallend - zur Gestaltung der Materie in den geordneten Kosmos befähigt ist. ${ }^{29}$ Sie ist daher aber auch nur wirklich bei sich selbst, wenn sie sich dem Intelligiblen zuwendet, denn von ihm kommt ihr ja die weltgestaltende Kraft.

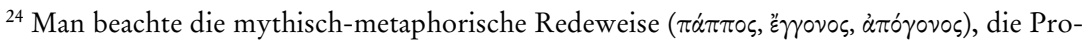
klos „theatralisch“ ( $\pi \rho \circ \sigma \tau \alpha \gamma \omega \delta \tilde{\omega} \nu)$ nennt (frg. 21, Bst. 197.4,10f).

${ }^{25}$ Dazu Baltes in: Dörrie, Baltes 1987-2008, Bd. 7.1, 474.

${ }^{26}$ Frg. 20, Bst. 205.3,11-13. Dazu Baltes in: Dörrie, Baltes 1987-2008, Bd. 7.1, 474.

${ }^{27}$ So gemäß frg.11, Bst.197.1,5-10. Vgl. dazu auch Numenios frg. 18, $8 \mathrm{ff}$ (des Places).

${ }^{28}$ Diesen so genannten dritten Gott bezeichnet Numenios einerseits - in Auslegung von

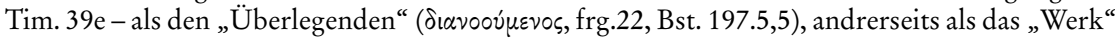
( $\pi \circ i \eta \mu \alpha)$ der zweiten Gottheit (frg.21, Bst. 197.4,4). Das stimmt insofern mit dem oben Gesagten überein, als die „überlegende“, d.h. seelische Funktion der zweiten Gottheit den geschaffenen Kosmos erst zu dem „wahrnehmbaren Gott“, d.h. dem geformten Kosmos macht, der die Welt nach platonischer Ansicht ist (so überzeugend Baltes in Dörrie, Baltes 1987-2008, Bd. 7.1, 476-481).

${ }^{29}$ Dazu Baltes und Pietsch in: Dörrie, Baltes 1987-2008, Bd. 7.1, $475 \mathrm{f}$.
} 
Insgesamt weist also Numenios System folgende Struktur auf: Der erste Gott enthält die Ideen in ungeschiedener Einheit. Er „erschafft“ sie, indem er sein eigenes Sein erfasst. Dadurch erzeugt er den zweiten Gott, den Nus. Dieser entfaltet die Ideen im ersten Gott in ihren Einzelaspekten, indem er sie diskursiv durchläuft. Da er selbst Nus ist, kann er sich der Materie nicht als er selbst und direkt zuwenden. Er bedient sich dazu eines Teilaspektes seiner selbst, des dritten

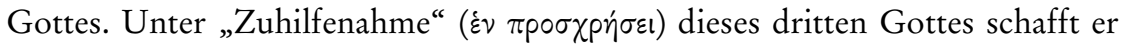
die Welt (frg.22, 197.5,1-5) ${ }^{30}$, so, wie der erste Gott, der als er selbst nicht denkt, unter „Zuhilfenahme“ des zweiten Gottes denkt (ebd.).

Auf diese Differenzierung in beiden Stufen der numenianischen Seinslehre musste besonders aufmerksam gemacht werden, damit sich jetzt die Parallelität dieses platonischen Modells mit der valentinianischen Seinslehre erschließt. Das Pleroma des „Mythos“ umfasst, wie bekannt, die Fülle von dreißig Äonen. Sollten sie wirklich in irgendeiner Weise mit dem soeben vorgestellten Entwurf in Beziehung stehen? Das ist durchaus der Fall, wenn man die deutliche Gliederung im Aufbau des Pleromas wahrnimmt.

Auch in der Geistmetaphysik des valentinianischen „Mythos“31 liegt eine grundsätzliche Zweistufigkeit des göttlichen Seins vor, ${ }^{32}$ deren verschiedene Teilaspekte jeweils mit unterschiedlichen Namen bezeichnet werden. Dem ersten Gott des Numenios entsprechen Bythos und Nus mit ihren jeweils weiblichen Ergänzungen Ennoia und Aletheia einerseits - sie bilden die uranfängliche pythagoreische Vierheit -, dem numenianischen zweiten Gott entsprechen sämtliche Äonen von Logos bis Sophia andrerseits. Die grundsätzliche Unterscheidung beider Gruppen ergibt sich daraus, dass die zweite Gruppe nach Erkenntnis des vorseienden Ursprungs strebt, sie aber nicht besitzt, während die erste uranfängliche Vierheit sich selbst denkend erfasst. ${ }^{33}$ Aus diesem Gegensatz ergibt sich alles Weitere.

Im einzelnen: Der Bythos ist der vollkommene vorseiende ( $\pi \rho \circ \omega$ ) Äon,

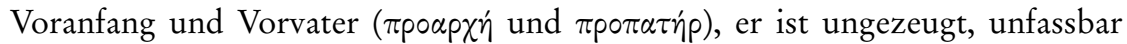

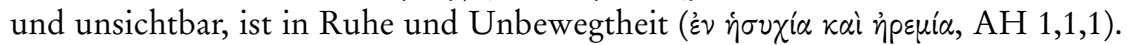
Er bringt die Ideen hervor und erfasst sich selbst. ${ }^{34}$ In der Sprache des „Mythos“

${ }^{30}$ Dazu Baltes in: Dörrie, Baltes 1987-2008, Bd. 7.1, 478 f; Halfwassen 1994, 52 f spricht von einem „kontinuierlichen Entfaltungsprozess“ der drei - nach Tim. 39e-unterschiedenen Stufen des Nus, zwischen denen es „keine strikte Hypostasentrennung“ gibt. Dazu im selben Sinne auch Pietsch, in: Baltes 1987-2008, Bd. 7.1, 467-472.

${ }^{31}$ Vgl. dazu die Graphik zum valentinianischen Äonenschema am Ende dieses Aufsatzes.

${ }^{32}$ Das grundsätzlich zweistufige Modell des Göttlichen findet sich auch bei Alkinoos und andern Mittelplatonikern wieder, vgl. dazu Ziebritzki 1994 und Pietsch 2008. So auch Baltes in: Dörrie, Baltes 1987-2008, Bd. 7.1, 477.

${ }^{33}$ Anders gesagt: der Nus ist der einzige der Äonen, der den vorseienden Vorvater erfasst. Das trennt ihn von den nachfolgenden Äonen.

${ }^{34}$ Vgl. Numenios frg. 16; Bst. 128,1,1 f: Der Nus, d. h. das Gute, ist früher als das Intelligible, d. h. Sein und die Idee, und frg. 11; Bst. 197.1, 1-4: der erste Gott „ruht in sich selbst, ist einfach und ganz auf sich selbst ausgerichtet. 
lautet dieser ontologische Sachverhalt so: Der Bythos als Voranfang und Vorvater hat als seine Syzygos seine Ennoia, sein Denken, mit sich und zeugt mit ihr den Nus, „den Vater und Anfang von allem“, der ihm „ähnlich und gleich“

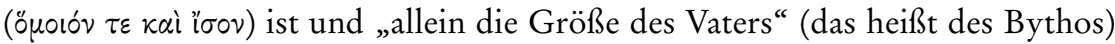

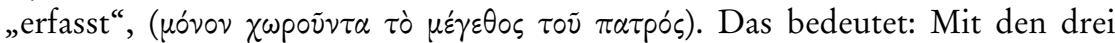
Termini Bythos, Ennoia und Nus (und dessen ihm zugeordneten Partner) ist die erste Gottheit in verschiedenen Aspekten umschrieben, nämlich als Uranfang und Ursache (Bythos, Voranfang etc.), als Sich-selbst-Erfassen (Ennoia und Nus) und damit zugleich als Erschaffen des Seins (der Nus des „Mythos „nimmt wahr, wozu er hervorgebracht ist und bringt Logos und Zoe hervor", die ihrerseits die weiteren Äonen, die Weltseele, erzeugen ${ }^{35}$ ). In allen Aspekten wird eine einheitliche Gottheit beschrieben. Das klingt kompliziert, ja abstrus, bestätigt sich aber im Folgenden:

Auch die Äonen nach dem Nus von Logos und Zoe bis zur Sophia ${ }^{36}$ bilden eine mehrfach in sich differenzierte Einheit, die dadurch zusammengehalten ist, dass sie alle keine direkte Erkenntnis des ersten Gottes haben, wohl aber danach streben (AH 1,2,1 und 5-6). Plotin kritisiert später mit gewissem Recht, dass der Logos, der ja „Vater von allem nach ihm Kommenden“ sein soll, und der parallel zum zur Ideenschau begabten zweiten Nus des Numenios gesehen werden muss, keine unmittelbare Gotteserkenntnis haben soll (II 9 (33) 1,57-63). Es handelt sich aber wohl um einen Fehler in der mythischen Ausdrucksweise des valentinianischen „Mythos“, nicht um einen Denkfehler. Der valentinianische Äon Logos, der unmittelbar vom zum ersten Gott gehörigen Nus als „Vater

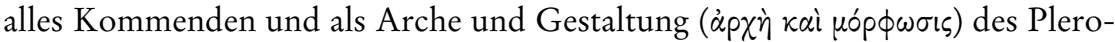
mas" hervorgebracht wird, steht damit natürlich in unmittelbarer erkennender Beziehung zum Nus des Bythos und kann überhaupt nur deshalb selbst hervorbringen. Ich verstehe ihn als das zur Ideenschau befähigte rationale Element der Weltseele.

Die weiter folgenden Äonen sind von absteigender Qualität und stehen insgesamt für den sich der Hyle zuwendenden Aspekt des numenianischen zweiten Gottes. Die Unterschiede zu Numenios halten sich zwar im mittelplatonischen

\footnotetext{
${ }^{35}$ Irenäus, AH 1,1,1 Z. 93-96 Rousseau.

${ }^{36}$ Wegen der Anzahl der Äonen insgesamt gab es nach Hippolyt, Ref. 6,30,6 und 6,31,3, unter den Valentinianern Kontroversen. Einige zählten 28 Äonen, denn der Bythos/Vorvater (mit seiner ihm zugehörigen Ennoia) konnten, weil ungezeugt und vorseiend, nicht zu den Äonen gerechnet werden. Um die erstrebte 30-Zahl voll zu machen (erstrebt wegen der in den Evangelien an hervorgehobener Stelle begegnenden Zahl 30, vgl. Lk 3,23 und Mt 20,1-7 - so nach Irenäus, AH 1,3,1) zählten diese Valentinianer noch die später hervorgebrachten Christus und Heiliger Geist zu den 28 Äonen hinzu (AH 1,2,5) - offensichtlich sekundär. Andere Valentinianer (so Irenäus, AH 1,1,3) kamen auf die gewünschte Zahl 30, weil sie den Bythos/Vorvater (mit seiner Ennoia) zu den Äonen hinzuzählt - wegen des Unterschiedes von „ungezeugt“ und „hervorgebracht“ nicht ganz logisch, aber wohl ursprünglich. Diese innervalentinianische Kontroverse kann als Beispiel für die häufigen innergnostischen Variationen ihrer „Mythen“ stehen.
} 
Denkrahmen, sind aber ganz bewusst beträchtlich. Sie müssen es sein. Denn sie ermöglichen dem valentinianischen Autor die christliche Variation des mittelplatonischen System und bereiten diese vor. Zunächst: Der dem Logos nachgeordnete Anthropos mit seiner Syzygos „Ekklesia“ muss als eine Art Doppelung des Logos verstanden werden. Er bildet zusammen mit Bythos, Nus und Logos und ihren jeweiligen Partnern die Ogdoas, „Wurzel und Grundlegung

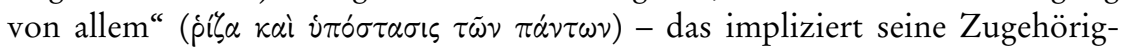
keit zum Logos im Unterschied zu den weiteren Äonen. Geschuldet ist das Äonenpaar Anthropos und Ekklesia offensichtlich der christlichen Intention des Autors, denn mit Nus - der auch Monogenes benannt wird -, Logos und Anthropos wird auf Christus verwiesen, der im weiteren Verlauf des „Mythos“ unter den Namen Monogenes, Stauros, Christus, Soter, Logos, Paraklet, Jesus handelnd und errettend auftritt.

Die übrigen, der Ogdoas nachfolgenden Äonen werden jeweils von Logos oder Anthropos hervorgebracht - eine weitere deutliche Absetzung dieser Äonen von ihren Vorgängern. Der Logos bringt zehn Äonen (eine vollkommene Zahl) hervor, deren Namen sowohl die Zugehörigkeit zu Bythos und Nus als erstem Gott (Bythios, Ageratos, Autophyes etc.) als auch ihre Qualitätsminderung und Gefährdung (Mixis, Hedone,Synkrasis) anzeigt. Der Anthropos bringt zwölf Äonen (eine unvollkommene Zahl) hervor, deren Namen auf den Bezug zum Christuslogos (Parakletos, Patrikos, Metrikos etc.) hindeuten beziehungsweise auf dessen Wirkung (Pistis, Elpis, Agape und so weiter.) anspielen. Der Gehalt dieser Benennungen ist sicherlich im Einzelnen nicht zu tiefsinnig auszudeuten. Zuletzt folgt, wie bekannt, Sophia, mit deren „Fall“ (das heißt dem $\pi \dot{\alpha} \theta_{0}$, , dem sie erliegt) die entscheidende valentinianische Abwandlung vom mittelplatonischen Modell, dem der „Mythos“ bisher der Struktur nachfolgte, einsetzt - eine Abwandlung, die nichtsdestoweniger im Vorstellungsrahmen des platonischen Denkens bleibt: Plotin beschäftigt Abstieg und „Fall“ der Seele oft und dringlich, allerdings mit anderen Konsequenzen.

Im mythischen Lehrtext der Valentinianer wird der Fall der Seele damit begründet, dass Sophia ohne ihren Syzygos ${ }^{37}$ und in frecher Selbstüberhebung

${ }^{37} \mathrm{AH}$ 1,2,2. Nach einer von Irenäus, AH 1,2,3 berichteten Variation dieser Begebenheit, die dem Referat des Hippolyt, Ref. 6,30,7 ähnelt, bringt die Sophia, weil sie sich an ein unmögliches Unternehmen, die auf sich selbst gestützte Suche nach dem Vater, gemacht hat, eine "formlose

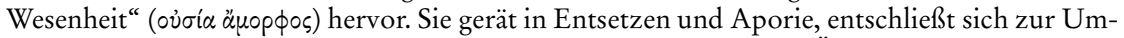

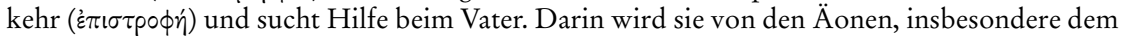
Nus, unterstützt. Von hier aus habe die Hyle ihren Anfang genommen, d.h. aus Unkenntnis, Trauer, Furcht und Erschrecken. - Es handelt sich hierbei um eine sekundäre, verkürzte Variante des valentinianischen Lehrtextes, der die Heilung des $\pi \dot{\alpha} \theta 0 \varsigma$ der Sophia und die Entstehung der Hyle nach AH 1,4,1-5 genauer beschreibt. Danach muss die Variation in AH 1,2,3 sekundär

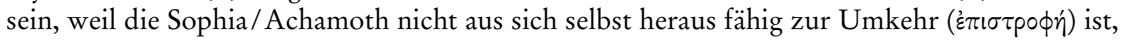
ihr vielmehr vom Nus / Christos geholfen werden muss. 


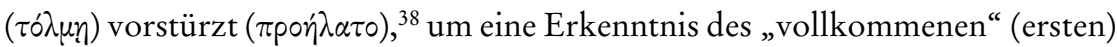
Vaters und eine Gemeinschaft mit ihm zu erzwingen, die der des Nus gleicht. Man bedenke: des Nus, des Teilaspektes des ersten Gottes: sie will den Vater erfassen, wie er sich selbst in seiner eigenen Vernunft erfasst (AH 1,2,2). ${ }^{39}$ Das ist irrwitzig, ist aber nur die höchste Steigerung des Strebens aller Äonen vom Logos an, für die wesenhaft ist, dass sie nach Erkenntnis des Urvater „in einer Art von Ruhe“ (i் $\sigma \nu \tilde{\eta} \pi \omega \varsigma)$ streben, ${ }^{40}$ sie aber - zunächst - nicht erlangen. Das heißt, die Grundannahme dieses Konzeptes ist platonisch. Dort ist die jeweils untere Hypostase aus der oberen hervorgegangen, und sie ist nur und kann nur wirken, weil sie zur Rückwendung zur jeweils oberen befähigt ist und sie vollzieht - das

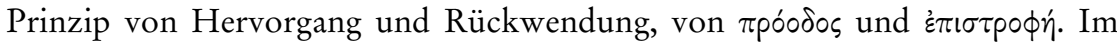
"Mythos" wird dieses - platonische - Prinzip genutzt, um die gesamte Urgeschichte, den gesamten Weltenverlauf zu erklären. Auch hier gilt, dass alles, was aus dem Vater hervorgegangen ist, sein Selbst und seine Vollendung findet, indem es - sich zum Vater zurückwendend - zu ihm zurückkehrt. Das „Unheil“ $(\pi \dot{\alpha} \theta \circ \varsigma)$, der Fall, entsteht, weil die Sophia diese Rückkehr erzwingen will. Ihr Streben nach Erkenntnis ist ungezügelt und regellos. Es wird vorausgesetzt, dass es nicht zum Ziel führen kann. Sophia, d.h. platonisch: die Seele, fällt radikal ohne Möglichkeit der Restitution aus eigener Kraft. Deshalb ist ein Retter, ein die Rückkehr, die für die hervorgebrachten, geschaffenen Wesen angemessene Erkenntnis ermöglichender Erlöser, nötig, um die Gesamtgeschichte zu ihrem Ziel zu bringen. Dieser Erlöser ist Christus in der Gestalt des Gott selbst seienden Nus/Monogenes ebenso wie in der des hervorgebrachten Logos, in der Gestalt des Horos/Stauros, der die Sophia begrenzt und festigt (AH 1,2,2-4), in der des Christus, der die Äonen belehrt (AH 1,2,5), in der der von allen Äonen zum Dank und zur Ehre des Bythos hervorgebrachten Frucht, die Jesus und Soter, Christus und Soter heißt (AH 1,2,6), in der Gestalt des die gefallene, völlig hilflose Enthymesis/Sophia formenden und sie belehrenden Christus und des Parakleten (AH 1,4,1-2 und 5) und so fort, in langer Ausmalung der Aspekte des jeweils rettenden ein und desselben Christus, die schließlich in der Gestalt

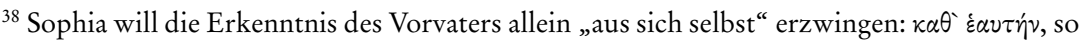
nach Hippolyt, Ref. 6,30,7f. Im Bericht des Hippolyt will die Sophia, - noch selbstbezogener und überheblicher - den Vorvater und Urgrund in seiner Fähigkeit, allein und aus sich zu

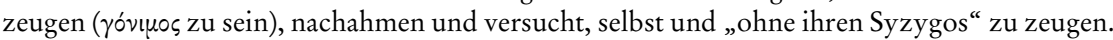

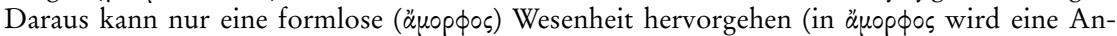
spielung auf Gen. 1,2, den „wüsten“ Zustand der Erde gesehen).

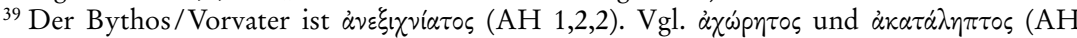
1,1,1.2,1.2,5).

${ }^{40}$ Ausdrücklich heißt es bei Irenäus AH 1,2,2, dass das $\pi \dot{\alpha} \theta \circ$, das die Sophia befiel, bereits „bei denen um den Nus und die Aletheia“ (AH 1,2,2), d. h. beim Logos (und der Zoe) begann verständlicherweise, denn vom Logos an gibt es keine direkte Erkenntnis des Ursprungs (das hat Plotin II 9,1 richtig gesehen und kritisiert), aber es gibt doch eine Suche in gemäßigter Form, einen $\pi \dot{\theta} \theta \circ \zeta \eta \eta \dot{\eta} \sigma \varepsilon \omega \varsigma$ (AH 1,2,1).
} 
des den Menschen belehrenden und ihm damit Rückkehr durch Erkenntnis ermöglichenden Jesus und Soter endet.

Im Unterschied zu Numenios, der hier für den Mittelplatonismus überhaupt steht, wendet sich der zweite, der demiurgische Gott im „Mythos“ also nicht der Hyle zu und gerät wie bei Numenios dabei in Gefahr, sich selbst zu verlieren - eine Gefahr, der er aber niemals erliegt. Der numenianische zweite Gott vermag sich vielmehr - periodisch - zu seinem eigentlichen Selbst zurückwenden und als zur Ideenschau befähigter Demiurg die Hyle zu „einigen“ und den geordneten Kosmos zu formen (Frg.11; Bst. 197.1,5-15). Ganz anders im valentinianischen Lehrmythos: Sophia, d.h. ein Aspekt der Seele, wird zwar zunächst vom Horos/Stauros, einer Kraft außerhalb ihrer selbst, gefestigt, aber ihr leidenschaftliches Verlangen, das ein Teil ihrer selbst ist, eine „pneumatische Wesenheit, aber form- und gestaltlos " ${ }^{41}$ wird aus dem Pleroma, dem Seinsbereich, ausgegrenzt ( $\dot{\alpha} \phi \circ \rho ı \theta \tilde{\eta} v \alpha \iota, A H ~ 1,2,5.4,1)$ und findet sich völlig hilflos

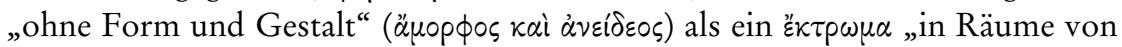
Schatten und Leere geworfen“ (AH 1,4,1), jetzt auch anders, nämlich „Enthymesis" oder "Achamoth" ${ }^{2}$ benannt.

Das ist der Ausgangspunkt für alles weitere Geschehen, es ist die paradigmatische Ursituation des Gefallenen in dieser Welt, es ist die Ursituation auch des Menschen, der erst aus der Folge des Falls entsteht: Er ist unfähig zu jeder Schau des Seienden, unfähig damit seiner Vollendung und seines Glücks. Die platonische Vorstellung, dass Heil nur in der Rückwendung zu Gott und seiner Erkenntnis erfolgen könne, wird also vom christlichen Valentinianismus übernommen. Auch für diesen gilt: Heil, Erlösung und Bewahrung ( $\sigma \omega \tau \eta p i ́ \alpha)$

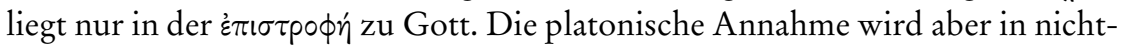
platonischer Weise genutzt und abgewandelt: Nicht die Kraft der Seele ermöglicht dem christlichen Gnostiker Rückkehr, Erkenntnis und Vollendung, so wie sie es für den Platoniker tut. Diese Kraft ist gebrochen. Das Gefallene, der Mensch schlechthin, bedarf vielmehr eines Erretters, der ihm Erkenntnis zusagt und vermittelt. Der gesamte „Mythos“ ist darauf angelegt zu zeigen, dass dies die Ursituation des Menschen ist, aus der ihn nur Gott selbst als Monogenes/ Logos/Christus/Jesus herausführt. In platonischen Bahnen des Denkens wird also versucht, die Notwendigkeit Christi zu erweisen.

Die Konsequenzen dieser folgenreichen modifizierenden Neuinterpretation des platonischen Systems führe ich hier nicht im einzelnen aus. Erwähnt seien nur die sich ergebenden schwerwiegendsten, vom primärplatonischen Modell abweichenden Konsequenzen im valentinianischen „Mythos“:

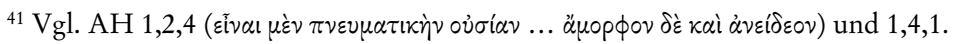

${ }^{42}$ Dieser Name, eine verballhornte Form von semitisch „Weisheit“, zeigt besonders deutlich an, dass es sich dabei um einen Aspekt der Sophia handelt, der von ihr zwar abgetrennt ist, aber dennoch zu ihr gehört. 
Zur Materie: Die Hyle ist nicht mehr Prinzip, ungeordnetes Chaos, zu der sich der zweite Gott hinwenden kann, um sie zur geordneten Welt zu formen, zugleich aber von ihr affiziert werden kann. Im „Mythos“ entsteht die Hyle - sie wird auch hier negativ beurteilt- erst aus der Verzweifelung, der „Unwissenheit, Trauer, Angst und dem Entsetzen“ der gefallenen Sophia (AH 1,2,3) und wird zur geordneten und zum Bau der Welt nutzbaren Materie erst durch den Parakleten/Soter/Christus geformt (AH1,4,5).

Zur Welt und zum Demiurgen: Platonisches und gnostisches System stimmen darin überein, dass die Welt nur durch eine auf das Intelligible gerichtete, zur Ideenschau befähigte Gottheit zustande kommen kann. Das ist bei Numenios und entsprechend bei andern Platonikern der zweite Gott und Nus, der eigentliche Demiurg als Weltseele, bei den Valentinianern der Soter/Christus. ${ }^{43} \mathrm{Als}$ Folge des Falls und des Bruchs zwischen Pleroma und Kenoma hat die Welt aber keinen Hinweischarakter auf Gott mehr, wie es bei den Platonikern für den Kosmos als $\theta$ ròs ai $\sigma \theta \eta \tau^{\prime} \varsigma^{44}$ der Fall ist. Sie ist auch nur durch den psychischen, törichten Demiurgen gestaltet, der von dem eigentlichen Demiurgen Christus angeleitet werden muss. Sie ist zwar bei den Valentinianern - im Unterschied zu den Sethianern - keineswegs gänzlich böse und dämonisch, aber doch nur eine Stätte der Bewährung für das Psychische im Menschen (AH 1,5,1-6). ${ }^{45}$ Bei Numenios dagegen entsteht sie notwendig und unmittelbar - platonisch - aus der harmonischen Entfaltung der Überfülle des ersten Gottes.

Zum Menschen und seinem Ziel: Er ist dementsprechend bei Numenios kraft

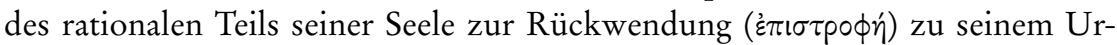
sprung befähigt, was nach dem valentinianischen Lehrmythos nicht der Fall ist. Er bedarf danach zu seiner Rückwendung ( $\dot{\varepsilon} \pi$ für ihn Ziel und Vollendung ist, der offenbarenden Lehrmitteilung durch den Christus, zugänglich hier durch Jesus als Lehrer ${ }^{46}$ oder Jesus als Gleichnis für die Rückkehr und fassbar und lehrbar durch den „Mythos“ (vgl. AH 1,6,1-1,7,5).

Wir fassen zusammen: Der valentinianische „Mythos“ ist in Terminologie und Struktur, in Gehalt und Intention ganz im mittelplatonischen Denkrahmen

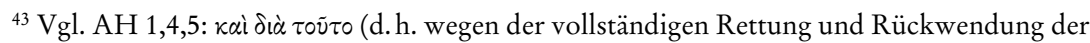
Achamoth, des gefallenen Aspektes der Sophia, und der Formung der „unkörperlichen Materie“

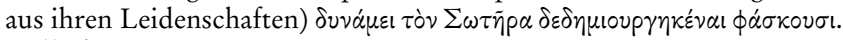

${ }^{44}$ Platon, Timaios 92c 8.

${ }^{45}$ AH 1,6,1: „Deshalb“, d.h. um des Psychischen im Menschen willen, das der Erziehung und Bewährung im Sinnlich-Wahrnehmbaren bedarf, „wurde auch die Welt geschaffen“; $\delta_{i o ̀}$

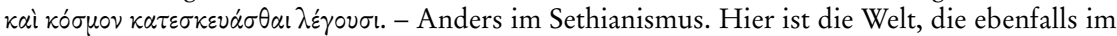
Prozess der Rettung des Gefallenen der Sophia durch Gott entsteht, deutlich negativer und versklavend-dämonischer gezeichnet. D. h., hier wird der bei den Valentinianern nur töricht-unwissende Hersteller-Demiurg als aktiv boshaft beschrieben. Dabei ist zu beachten, dass auch bei den Sethianern der Demiurg seine Befähigung zum aktiven Tun nur durch den „Raub“ einer Kraft von seiner göttlichen Mutter erhält. Vgl. dazu mit Bezug auf das Apokryphon des Johannes B. Aland 2014, 136-141.

${ }^{46} \mathrm{Cf}$. AH $1,25$. 
geschaffen. Er versteht sich geradezu als endgültige Richtigstellung des platonischen Denkansatzes und stellt sich damit in die Tradition der vielfachen Variierungen des Systems durch mittelplatonische Philosophen. Der „Mythos“ kann als grundlegende gnostische Lehrform den Anspruch erheben, Vollendung der platonischen Metaphysik zu sein, weil er sie als Christ von Christus her versteht und damit, wie er meint, deren Wahrheit erst eigentlich aufdeckt. Der christliche Autor des „Mythos“ konkurriert nicht nur mit den Philosophen, sondern will sie übertreffen und damit zugleich für die christliche Philosophie als Übergipfelung aller Philosophie werben. Er tut das, indem er mit dem radikalen Fall der Seele - eine immerhin auch im Platonismus erwogene und teilweise vergleichbar akzeptierte Option ${ }^{47}$ - die Notwendigkeit Christi als eines göttlichen Retters beweisen will. Denn nur durch immer neue Eingriffe des Göttlichen, eben des Christus-Logos, kann das Gefallene auf verschiedenen Seinsstufen gerettet werden. Im Pleroma selbst schon wurde die sich verlierende Sophia durch den Horos/Stauros gefestigt, um dann auf verschiedenen Stufen in immer erneuten

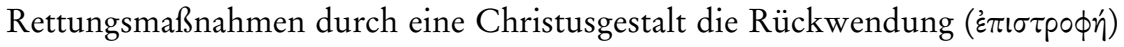
des dazu Unfähigen zu ermöglichen, bis „der gesamte Same vollendet ist“ (AH 1,7,1). Die Weltgeschichte erweist sich so als eine Veranstaltung Gottes zur Rückführung des Gefallenen zu seinem Ursprung. Im einzelnen bedingt der Fall als die entscheidende Veränderung des platonischen Systems auch andere Unterschiede in der Diktion und Vorstellungsweise, die den platonisierenden "Mythos" in Philosophenkreisen kaum empfohlen haben dürften, so die übergroße Differenzierung der göttlichen Seinsstufen durch verschiedene Namen und immer erneute Hervorbringungen von nur scheinbar je neuen göttlichen Wesen, die nur als Teilaspekte von den zwei Hypostasen Nus und Seele zu verstehen sind. ${ }^{48}$

Im Rahmen der Fragestellung dieses Bandes nimmt der gnostische „Mythos“ eine besondere Stellung ein: Da der Text anonym auftritt, der reale Autor unbekannt ist, entfällt jede etwaige Versuchung, den Text des „Mythos“ von der Intention eines individuellen Autors herzuleiten oder sein Anliegen daher zu begründen. Es geht ausschließlich um die Bedeutung und Intention des Textes selbst, der durch seine Anonymität zu verstehen gibt, dass er nicht als Meinungsäußerung eines Individuums gewertet werden will. Auch das Modell eines „impliziten Autors", der für die umfassend verstandene Gesamtbedeutung eines Textes stehen kann, ist hier nicht angebracht, weil damit wieder ein Autor in den Blickpunkt gerät, was aber gerade nicht gemeint ist. Es geht nach dem Text

${ }^{47}$ Zum Fall der Seele bei Plotin s. III 5 (50) 2,28-32; V 1 (10) 1,1-22; IV 8 (6) 1, 1-1; III 7 (45) 11,1-40 und insbesondere die Kommentierung dieser Stellen durch W. Beierwaltes 1981, 244-252. $183 \mathrm{f}$ et passim.

${ }^{48}$ Auch die Kommentierung und Begründung wichtiger Wendepunkte des „Mythos“ durch Bibelstellen empfiehlt diesen bei Philosophen natürlich nicht, vgl. z.B. in AH 1,2,5 die entscheidende Belehrung der Äonen durch Christus, die an Mt. 11,27 ausgerichtet ist. 
ausdrücklich um überindividuelle Sachfragen und Standpunkte. Gleichwohl gibt der Text durch den Bezug auf das platonische Seinsmodell deutliche Hinweise darauf, in welchem Rahmen und mit welchem Anspruch er verstanden und gewichtet sein will: er bindet das Christentum in den bestehenden philosophischen Diskurs ein. ${ }^{49}$ Das geschieht einerseits durch weitgehende Übernahme der platonischen Denkstruktur (Annahme einer höchsten, transzendenten, guten Gottheit als Ursprung von Welt und Mensch, daher Definition des Heils, der Vollendung des Einzelnen als „Rückkehr“ zu Gott) und andrerseits durch die völlig andere, unplatonische Antwort auf die sich aus dieser Denkstruktur ergebende Frage (Wie kann die „Rückkehr“ zu Gott geschehen?). Damit eröffnet der Text des gnostischen „Mythos“ - weit über sich hinausweisend - den Diskurs zwischen Platonismus und Christentum und unterstreicht durch seine eigentümliche Gestalt, Philosophie im mythischen Kleid, seinen Geltungsanspruch darin. ${ }^{50}$

Die tatsächliche Wirkung war enorm, allerdings nicht ganz im Sinne des valentinianischen „Mythos“. Er erreichte seine unmittelbare Wirkabsicht nicht, und das doch wohl mit Recht. Denn weder konnte seine mythisierende Ontologie die Platoniker überzeugen: Der angesetzte Fall durchbricht den Zusammenhang von Sein und Werden mit der Folge, dass die geordnete Welt ihren Hinweischarakter auf ihren Ursprung verliert. Das ist sinnlos, wenn man von der Idee des Guten als der Quelle alles Seins ausgeht und zerstört das System. Noch konnten christliche Denker befriedigt sein. Die Gnostiker wollten platonisch Christus verkündigen. Das ist legitim, wird aber nicht erreicht, wenn man das platonische Denksystem im Kern beschädigt. Nicht nur der Fall, auch die gnostische Konstruktion der Weltseele ist nicht überzeugend. Man kann nicht Christus lehren, wenn man nicht die platonisch gebotenen Denkbahnen durch neue Gesichtspunkte erweitert: vor allem die Inkarnation muss denkend verantwortet werden. Der sich zum Gefallenen hinneigende Didaskalos Christus, wie er im „Mythos“ auftritt (AH 1,4,5), genügt nicht.

\footnotetext{
${ }^{49}$ Vergleichbar ist die Gestalt des Sokrates im Werk Platons. Erler hat eindrücklich darauf aufmerksam gemacht, dass sich in der Gestalt des gottgesandten und -begnadeten Sokrates die „religiöse Stimme“ Platons äußert. Nicht erst für den späten Platonismus sei „a more pessimistic view of human abilities, combined with a growing trust in theology and religious practices" (315) charakteristisch, sondern Platon selbst habe, ausgedrückt in der Person des Sokrates, der er religiöse Aspekte zuschreibt, eine Verbindung zwischen Theologie und Philosophie hergestellt, die über die Person des Sokrates in der Geschichte des Platonismus fortwirkt. Erler fasst zusammen: „Plato also has a kind of doctrine of grace , which points to the need for external help; he too offers a godsent Socrates to stimulate ordinary people to pursue their own investigations and in whom religious and philosophical aspects form an association" (334). Vgl. Erler 2013, 313-339.

${ }^{50}$ Der Mythos passt damit in die Zeit der zweiten Hälfte des zweiten Jahrhunderts, in der ja auch jene andern christlich-apologetischen Theologen wirkten, die ebenfalls mit Hilfe von begrifflichen und terminologischen Anleihen an den Platonismus Wesen und Bedeutung Christi erklären wollten. Auch mit ihnen konkurrieren die christlich-gnostischen Valentinianer.
} 
Die gewaltige Wirkung, die der gnostische „Mythos“ dennoch ausgeübt hat, begegnet uns nicht nur in der wuchernden Fülle der gnostischen Literatur selbst, die variierend, deutend und bis ins Abstruse ausufernd durch die Häresiologen bezeugt und zu erheblichen Teilen belegt ist. Die Rezeption der Gnosis begegnet uns vor allem in den großen kritischen Gegenschriften, die auf christlicher wie nichtchristlicher Seite entstanden sind. Kein anderer christlich-denkerischer Entwurf hat im zweiten und dritten Jahrhundert derart breite Reaktionen erfahren. Im Wesentlichen handelt es sich dabei um widerlegende, polemische Kritik, die aber durchaus auch Züge von lernender Rezeption erkennen lässt. Ich beschränke mich dafür neben einigen grundsätzlichen Stichworten zu Irenäus auf Plotins Kritik an den Gnostikern, soweit sie die oben gegebene Darstellung und Interpretation des valentinianischen „Mythos“ stützen kann.

\subsection{Wirkung und Rezeption des valentinianischen Lebrtextes in der christlichen und nichtchristlichen Welt}

Die Verquickung von platonischer Philosophie und christlich-biblischer Glaubensüberzeugung, die das valentinianische System bot, erregte bei christlichen wie nichtchristlich-philosophischen Zeitgenossen Aufmerksamkeit und Anstoß. Obwohl beide Gruppen den vorgelegten Entwurf des „Mythos“ strikt ablehnen, sind die Autorkonzepte beider Reaktionen in Inhalt und Stil ganz verschieden. Irenäus reagiert als Vertreter einer systematisch-philosophisch noch nicht ausgearbeiteten, noch unfertigen Theologie. Das schlägt sich in der Gestaltung seiner Arbeit nieder. Er ist unsicher, bekämpft den „Mythos“, den er als Beweis seiner Absurdität ausführlich referiert, zunächst vor allem nach seinem Wortlaut, nicht nach seinem Sinngehalt, findet darüber aber fortschreitend zu einer Sachwiderlegung und im Zuge davon in den letzten Büchern seines umfänglichen Werkes zu einem ersten Gesamtentwurf einer systematischen christlichen Theologie von Schöpfung, Rekapitulation und Erlösung. Anders Plotin. Er reagiert als angesehener Vertreter einer hochdifferenzierten Philosophie mit langer respektheischender Tradition. Plotin strebt keineswegs eine wirkliche Auseinandersetzung mit dem gnostischen „Mythos“ an. Sein Konzept geht nur auf Zurückweisung der Sachpunkte, die er als den platonischen Denkansatz korrigierend ansieht (und die er, n.b., der mythischen Erzählung sehr genau zu entnehmen weiß). Die Gestaltung seiner Ausführungen ist bis in den sprachlichen Stil hinein durch ganz und gar überlegenes, nur gelegentlich zornig ausbrechendes Reden aus der Position dessen heraus gekennzeichnet, der sich selbstverständlich als der Stärkere weiß. Aber: Schon dass Plotin überhaupt reagiert, zeigt die Wirkmächtigkeit des „Mythos“. 


\subsubsection{Irenäus}

Für Irenäus, den Bischof, war die Widerlegung der Gnostiker schon deshalb wichtig, weil sie offensichtlich beträchtlichen Zulauf in den christlichen Gemeinden hatten. ${ }^{51}$ Irenäus kritisiert interessanterweise nicht die mythische Darstellungsform des valentinianischen „Mythos“ als solche. Er hält sie - abgesehen von ihrer ausufernden Exuberanz - offenbar für eine prinzipiell mögliche Redeweise, der er widerlegend begegnet, indem er einzelne verwendete Bilder und bildhaft-narrative Passagen aus dem Zusammenhang der mythischen Erzählung willkürlich herausgreift und sie als unsinnig und logisch widersprüchlich brandmarkt. ${ }^{52}$ Wir übergehen Beispiele ${ }^{53}$ für diese rein polemisch-selektive Kritik, halten aber fest, dass Irenäus ungeachtet dieser Art von Polemik den sachlichen Sinn des mythischen Textes durchaus verstanden hat und sich zunehmend darauf konzentriert. ${ }^{54}$

Der theologische Dissens wird an Sachfragen ausgetragen, die der "Mythos“ in seiner Weise behandelt, und die als solche erkannt und gegenübergestellt werden. Das ist an der Beurteilung der Welt und ihres Schöpfers, dem, nach Irenäus, „ersten und wichtigsten Hauptstück“ (AH 2,1,1) christlicher Lehre, zu zeigen.

Für die valentinianische Gnosis ist, wie wir gesehen haben, die Welt eine Station auf dem langen Weg der Rettung des Gefallenen durch den Christus/Soter des Nus. Sie ist

- veranlasst durch den Fall des Äons Sophia, weswegen Irenäus sie „fructus labis“ und „prolatio ignorantiae“, nämlich der Sophia, nennt (AH 2,3,2),

${ }^{51}$ Der Bischof von Lyon muss den Valentinianern das Predigen in der Kirche verbieten, um ihren Einfluss einzudämmen (vgl. AH 3,15,2).

${ }^{52}$ Etwa in dieser Art: Irenäus fragt, wie es außer Gott und seinem göttlichen Pleroma noch ein Kenoma, eine Leere und einen Schatten, geben könne. Von diesem müsste ja angenommen werden, dass es das Pleroma umfasst. Es wäre damit größer als der allmächtige Gott und seine Wirksphäre und würde ihn einschließen und begrenzen (AH 2,1,3. 3,1. 4,2. 5,1 und im ersten Resümee der Widerlegung in AH 2,8,3).

${ }^{53}$ Irenäus behauptet (AH 2,7,1): Wenn das von der Sophia abgetrennte Pathos, die so ge-

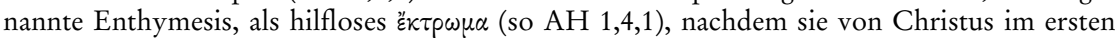
Rettungsakt secundum substantiam ( $\kappa \alpha \tau^{\prime} \circ \sigma^{\sigma} i^{\alpha} \alpha$, AH 1,4,1) geformt worden war, nicht geweint und getrauert hätte (sie hat getrauert, weil sie sich - so geformt - wieder nach Christus sehnen konnte, was sie als hilfloses Ektroma nicht vermochte), dann hätte Christus nicht das „Material“ für die Welt gehabt. Denn die Materie soll ja aus der Trauer und Angst der Enthymesis entstanden sein - ein unberechtigter Vorwurf, denn die Enthymesis erhält unmittelbar nach der ersten Formung durch den Christus die zweite Formung, die $\mu$ óp $\phi \omega \sigma \iota \varsigma$ k $\alpha \tau \dot{\alpha} \gamma \nu \tilde{\omega} \sigma \omega \nu$ durch den Parakleten (AH 1,4,5), was Irenäus hier übergeht. Er bezieht sich selektiv nur auf die erste Formung, nach der Christus sich zurückzieht, um das weitere Rettungswerk dem Parakleten zu überlassen (AH 1,4,1 und 1,4,5). Der valentinianische Christus kann daher auch nicht als causa ignorantiae bezeichnet werden, wie es Irenäus in anderem Zusammenhang versucht (AH $2,5,1 \mathrm{~b})$.

${ }^{54}$ Das ist etwa daran zu sehen, dass er trotz seiner vielfach wiederholten Kritik am unwissenden, psychischen Demiurgen der Gnostiker sehr genau weiß, dass dieser Demiurg nur ausführender Hersteller der Welt ist, der die Anleitung und Vorbilder für sein Tun durch den Logos/Christos erhält (vgl. AH 2.7,1 f). Dieser besitzt allein die eigentliche demiurgische Kraft

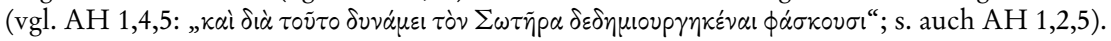


- gemacht aus der durch den Soter zu „unkörperlicher Hyle“ und Psyche geformten Trauer, Angst, Aporie des Gefallenen und seiner Hinwendung zu seinem „Lebendigmacher" (AH 1,4,1 Z. 386 Rousseau. 1,4,2 und 5), und

- hergestellt durch den psychischen Demiurgen mit Hilfe des Soters bzw. seiner Mutter, der pneumatisch gewordenen Achamoth.

Die Welt ist insgesamt eine vorübergehend notwendige Erscheinung im Prozess der

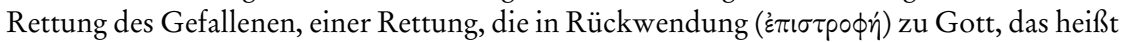
zu seiner Erkenntnis und Schau besteht. Diese Rückwendung und Rettung kann nur durch die Vermittlung des Christus/Monogenes geschehen, wofür an herausgehobener Stelle (AH 1,2,5) Mt 11,2755 angezogen wird: „Niemand ... kennt den Vater als nur der Sohn und wem es der Sohn offenbaren will.“

Für Irenäus dagegen ist die Welt veranlasst, hergestellt und geschaffen allein durch den einzigen und allmächtigen Gott, vermittelt durch Christus, „sein eigenes Wort“ (AH $2,2,5) \cdot{ }^{56}$ Sie ist

- nicht veranlasst durch den Fall eines göttlichen Äons, also nicht die „Frucht eines Fehltritts“ und das „Produkt von Unwissenheit" (labis fructus und ignorantiae productio, AH 2,3,2). ${ }^{57}$ Vielmehr ist das Denken und Schaffen der Welt bei Gott eins. ${ }^{58}$

- Der Schöpfer bedarf deshalb auch keiner „Materialien“ in Form von Hyle und keiner „Werkzeuge“ (AH 2,2,5). Die Welt ist selbstverständlich

- nicht hergestellt durch einen unwissenden Demiurgen oder durch Engel (AH 2,6,1-3). Es ist folglich auch nicht möglich, dass einer die Welt erdacht hat und ein anderer sie gemacht hat. ${ }^{59}$

Aber bei einer solchen Gegenüberstellung sachlicher Dissenspunkte bleibt es nicht. Irenäus sieht sich genötigt, seine sachliche Position zu begründen, der gnostische „Mythos“ erweist sich als anspruchsvolle Herausforderung, und der Bischof Irenäus entwickelt aus dieser Situation heraus - mühsam ${ }^{60}$ und in immer

${ }^{55} \mathrm{Vgl}$. Lk 10,22 und ähnliche Aussagen im Johannesevangelium, bes. Joh 3,35.

${ }^{56}$ Vgl. zum Ganzen besonders AH 2,2,1-3.

${ }^{57}$ Vgl. AH 2,1,1: Sie nennen den Demiurgen der Welt lästerlicherweise eine Frucht des Mangels („blasphemantes extremitatis fructum dicunt.“ Die Welt ist nicht auf ignorantia, passio und labes hin errichtet (AH 2,4,2).

${ }^{58} \mathrm{AH}$ 2,3,2: simul enim ac mente concepit Deus et factum est hoc quod mente conceperat.

${ }^{59} \mathrm{AH}$ 2,3,2: Nec enim possibile erat alium quidem mente concipere, alium vere facere quae ab illo mente concepta fuerant. - Diese Argumentation zeigt deutlich, dass Irenäus trotz seiner scharfen Kritik am gnostischen Demiurgen, bei der er häufig vorgibt, dieser sei der Schöpfer der Welt schlechthin, sehr genau verstanden hat, dass er lediglich ein ausführendes, qualitativ minderes Werkzeug des eigentlichen Schöpfers ist.

${ }^{60}$ Irenäus hat Schwierigkeiten, auf die er nur am Rande, aber deutlich zu sprechen kommt. Die Valentinianer berufen sich, wie erwähnt (AH 1,2,5), für ihre gesamte Deutung auf Mt 11,27: „Niemand ... kennt den Vater als nur der Sohn und wem es der Sohn offenbaren will““. Dieser Vers begründet ihren gesamten Lehrtext, der als strikte, radikale Auslegung dieses Dictums verstanden werden kann. Wenn nur durch den Sohn Gotteserkenntnis - die Heil schlechthin ist - erlangt werden kann, dann kann außer dem Sohn/Nus/Christos niemand, auch die Äonen nicht, diese Erkenntnis von sich aus erlangen oder haben. Es muss ein Fall oder eine Fall-Gefährdung, ein Bruch zwischen Sein und Nicht-Sein angenommen werden, auf den hin der Sohn durch offenbarende Mitteilung den Zugang zur Erkenntnis Gottes eröffnen kann. Der „Mythos“ ist, so gesehen, Deutung des Werkes Christi. 
erneuten Anläufen - einen ersten biblisch und systematisch basierten Gesamtentwurf christlicher Theologie. Dafür steht er namentlich als Vertreter seiner Kirche ein, sein Autorkonzept zielt aber ganz und gar auf die überindividuelle, wirksame Positionierung und Vermittlung des christlichen Glaubens und seiner Antwort auf die von platonischer Philosophie und gnostischem „Mythos“ gestellten Grundfragen menschlicher Existenz.

\subsubsection{Plotin}

Plotins von Porphyrios „Gegen die Gnostiker“ benannte Schrift (II 9 [33]) ist die erstaunlichste Reaktion auf die gnostisch-valentinianische Theologie. ${ }^{61}$ Nur hier wendet sich Plotin in einem langen, zusammenhängenden Text ausschließlich gegen philosophische Gegner. ${ }^{62}$ Als Grund dafür nennt er: Er will Argumentationsmaterial gegen die Gnosis für seine Schüler bieten, die sich nicht von jenen (gnostischen) Leuten belästigen und beirren lassen sollen. ${ }^{63}$ Die Gefahr dazu bestand, weil einige - wohl ehemalige - Freunde ( $\left.\phi \hat{\lambda} \lambda_{\circ}\right)$ Plotins, bevor sie sich ihm anschlossen, mit gnostischen Lehren vertraut waren und dann, als seine

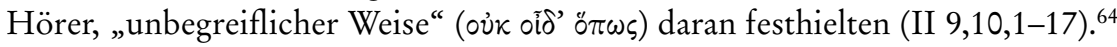
Zweifellos sollen aber nicht nur seine Schüler für etwaige Gespräche gerüstet werden, sondern Plotin selbst ist zornig berührt von der Anmaßung der gnosti-

Irenäus hat das verstanden, aber er sieht sich in Schwierigkeiten gebracht. Da für ihn die Welt, das Schöpfungswerk des einen Gottes, keineswegs unter die Bedingungen des Falls gestellt werden und in seiner Folge entstanden sein kann, muss er mit Mt. 11,27, dem biblischen Hauptund Kronbeweis der Valentinianer, anders fertig werden, und es gelingt ihm nicht völlig überzeugend: „Auch wenn daher ,niemand den Vater erkennt als nur der Sohn und nicht den Sohn als nur der Vater und wem es der Sohn offenbart hat', so erkennen dennoch (tamen) alle eben

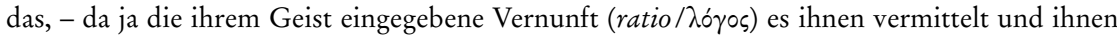
offenbart, - dass ein einziger Gott ist, der Herr aller." Irenäus erklärt mit großem Nachdruck, dass der in seiner Unsichtbarkeit mächtige Gott - ungeachtet von Mt 11,27 - selbstverständlich allen Menschen „tiefes geistiges Verständnis und Gespür für seine starke und allmächtige Größe" verliehen hat (AH 2,6,1). Die Logik dieser Behauptung ist nicht völlig einsichtig. Dem valentinianischen Bestreben, die umfassende und schlechthin alles verändernde Bedeutung Christi (nur er schafft Erkenntnis) auszusagen, wird Irenäus hier kaum gerecht.

${ }^{61}$ Dass die Schrift im wesentlichen gegen die Valentinianer gerichtet ist, zeigt mit guten Gründen K.Alt 1990, 7, 9. Dem folgend so auch J. Halfwassen 2013, 69. Die Schrift Plotins ist aber mit Recht umfassender und allgemeiner „Gegen die Gnostiker" benannt, weil sie die zentralen Hauptpunkte gnostischer Lehre behandelt und widerlegt, in denen Valentinianer und Sethianer durchaus übereinstimmen, wie gezeigt werden kann. Einzelheiten und spezielle gnostische Texte zu widerlegen überließ Plotin seinen Schülern, wie Porphyrios berichtet (VP 16).

${ }^{62} \mathrm{Ob}$ die Schrift, wie meist angenommen (anders Narbonne 2011), zur so genannten Großschrift aus den Schriften III 8, V 8, V 5 und II 9 (30-33) gehört, ist davon unabhängig.

${ }^{63}$ Vgl. dazu die Vita Plotins des Porphyrios 16.

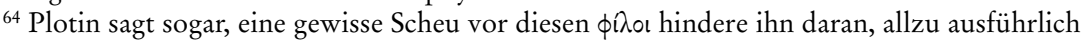
mit seiner Kritik zu werden, was der Leser seiner Schrift kaum bestätigen kann. Sie ist überaus scharf. 
schen Lehren. ${ }^{65}$ Das ist verständlich, denn er hat ihre Nähe wie auch ihre Modifikation platonischer Grundannahmen genau erkannt.

Dass Plotin den gnostisch-valentinianischen Lehrtext als ein „konkurrierendes philosophisches Unternehmen " ${ }^{\text {"6 }}$ behandelt, erklärt auch das gesamte - häufig als "ohne jegliche Systematik“ und „schlecht durchschaubar" bezeichnete ${ }^{67}$ - Wie und Was seiner Kritik, also sein methodisches Vorgehen und die Sachpunkte seiner Kritik..$^{68}$

Zum Wie (und damit zum Konzept seiner Autorschaft): Plotin widerlegt von der platonischen Sache her, nicht von persönlichen Befindlichkeiten aus. Auch er wie schon Irenäus kritisiert die mythische Form nicht als solche, sondern nimmt sie als das, was sie ist, und als was er sie richtig verstanden hat: als philosophische, mittelplatonische Konzeption. Das wirkt sich in seiner Terminologie aus. Er benutzt nicht die Namen und die Begrifflichkeit des gnostisch-valentinianischen Lehrtextes, sondern die entsprechenden des platonischen Modells bzw. seiner eigenen Terminologie. So handelt er nicht vom Fall der Sophia, sondern von dem der Seele - sachgemäß, denn die Sophia entspricht, wie die unteren Äonen, der platonischen Seele. Er spricht nicht vom $\pi \dot{\alpha} \theta 0 s$ und Fall der Seele $e^{69}$, sondern gemäß dem platonischen Phaidros (246 c) - von ihrer Entfiederung oder ihrem Fehltritt $(\sigma \phi \alpha \dot{\lambda} \mu \alpha)^{70}$ oder, wie meistens, von ihrem Sich-Herabneigen, von $v \varepsilon \tilde{v} \sigma \varsigma \varsigma$ oder $v \varepsilon v \varepsilon \varepsilon v{ }^{71}$ den von Plotin häufig für den Abstieg der Seele benutzten Termini ${ }^{72}$

${ }^{65}$ Von den Schriften gegen einzelne gnostische Traktate, zu denen Plotin seine Schüler Amelios und Porphyrios aufforderte, berichtet eben dieser (VP 16, 9-19).

${ }^{66}$ So treffend Ch. Tornau 2001, 394. Man beachte auch die immerhin indirekte „Anerkennung “, die Plotins ausführliche, wenn auch vernichtende Kritik der „Gnostiker“ bedeutet. Ähnliches erfuhren christliche Entwürfe bisher nicht.

${ }^{67}$ So Alt 1990, 11. Frau Alts Gesamtinterpretation der Schrift klärt aber den Aufbau der Schrift in weiterführender Weise.

${ }^{68}$ Plotins Schrift hat in der Forschung außerordentliche verschiedene Deutungen erfahren, und es ist bis heute noch nicht gelungen, ein allgemein anerkanntes Urteil darüber zu fällen. So wurde, um nur einige, insbesondere jüngere Gesamtdeutungen der Schrift zu nennen, mit unterschiedlichen Ergebnissen versucht, die angegriffenen Gnostiker zu identifizieren (so Elsas 1975; Roloff 1970; so auch, aber mit anderem Ergebnis Alt 1990 und Halfwassen 2013). Es wurden die Gnostiker als Gespächspartner Plotins identifiziert, deren Dialog sich nahezu über die gesamte Schaffensperiode Plotins hingezogen habe, so Narbonne 2011. In ähnlicher Weise versteht Spanu die Schrift II 9 nicht als Auseinandersetzung zweier verschiedener „Weltanschauungen“, vielmehr hätten wir es bei den angegriffenen „Gnostikern“ mit „his own disciples with double allegiance“ zu tun, deren Anschauungen lediglich „a different reading of the very same doctrine which Plotinus used to refer to, namely Plato's philosophy" seien, so Spanu 2012, 77-79. Die Arbeiten von Narbonne und Spanu sind aus der amerikanischen Forschungsrichtung erwachsen, die einen ursächlichen und integralen Zusammenhang zwischen Gnosis und Christentum leugnet. Auf Plotins Schrift geht - trotz des Titels seines Werkes - Chiapparini kaum ein, ist aber unbedingt heranzuziehen (Chiapparini 2012).

${ }^{69}$ Er spricht auch nicht von ihrer ignorantia, deminoratio und passio und ihrer dissolutio (cf. Irenäus AH 2,18, 1-5 et passim).

${ }^{70}$ II $9,4,1-3$.

${ }^{71}$ II 9, 4,6f. 10,19-26. 11,1-14. 12, 39-44

${ }^{72}$ Vgl. Sleeman/Pollet, Lexicon Plotinianum s.v. 


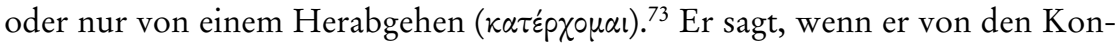
sequenzen des Seelenfalls handelt, nach den Gnostikern erleuchte ( $\dot{\varepsilon} \lambda \dot{\alpha} \alpha \mu \tau \varepsilon v)$ die Seele die Finsternis ${ }^{74}$ und benutzt damit seine eigene Begrifflichkeit und deren Konnotation, die er damit der entsprechenden gnostischen Aussage unterstellt und diese damit schon im Ansatz verfälscht. ${ }^{75}$ Andere Beispiele wären zu nennen. Plotin setzt mit dieser Strategie voraus, dass der gnostische Ansatz, der ja tatsächlich vom platonischen Modell ausgeht, auch dessen authentische Logik verfolgen müsse. Er weigert sich damit grundsätzlich, das Anliegen, das der gnostischen Variierung und Abwandlung des platonischen Vorbildes zugrunde liegt, in irgendeiner Weise zur Kenntnis zu nehmen, geschweige denn, es ernsthaft zu diskutieren. ${ }^{76}$

Dem entspricht weiterhin, dass Plotin vom valentinianischen Lehr- „Mythos“ auslässt, was nicht in die authentische platonische Konzeption passt. So spricht er zwar von Nus und Logos 77 und kritisiert von seiner Sicht aus die Konzeption des Logos, erwähnt aber mit keinem Wort den Äon Anthropos, der doch immerhin dem Logos nahe zugeordnet ist, ${ }^{78}$ noch die im weiteren Verlauf des "Mythos" auftretenden Rettergestalten Christus, heiliges Pneuma, Paraklet, Soter und auch nicht Jesus, obwohl sie alle doch vom Nus hervorgebracht oder veranlasst sind, und damit als Aspekte des Nus fungieren. Er spricht auch nicht

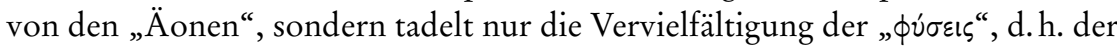
Hypostasen (II 9, 2,1-10). Plotin referiert schließlich den gegnerischen Text

${ }^{73}$ II 9, 10,22-25. 11,1. Plotin behauptet, nach den Gnostikern sei die Seele herabgestiegen und doch wieder nicht herabgestiegen, sondern habe nur die Finsternis erleuchtet. Er verquickt dabei den gefallenen und den geretteten Zustand der Seele.

${ }^{74}$ II $9,10,25 \mathrm{f}$ und $11,1-11$.

75 Plotin benutzt das Bild des „Erleuchtens“ gern, um die stetige erleuchtende Wirkkraft der von oben dauernd erleuchteten Seele in ihrer ununterbrochenen Wirksamkeit auszudrücken (cf.

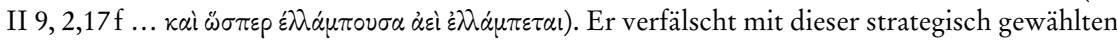
Terminologie die Aussage des gnostischen Textes, der gerade nicht von einer natürlichen, ununterbrochenen Wirkung vom Nus über die Seele zum Kosmos reden will. Schon der Ausdruck des „Erleuchtens“ und seine mitgegebene Bedeutung lässt die gnostische Position also als absurd erscheinen.

${ }^{76}$ Alt hat zuerst gesehen, dass Plotin geneigt ist, „bestimmte Phänomene der fremden Lehre mit Begriffen aus der eigenen Philosophie zu bezeichnen, sie mit deren Inhalten zu identifizieren und von der damit erzielten Basis aus seine Kritik oder Widerlegung durchzuführen." Vgl. Alt 1990, 44. Man kann noch stärker, als es hier geschieht, herausarbeiten, dass Plotins Strategie zeigt, wie genau er einerseits das gnostische Anliegen versteht (Frau Alt zweifelt zuweilen daran), und es andrerseits prinzipiell nicht wahrnehmen will.

${ }^{77}$ Diesen erwähnt er nur, weil es platonisch gedacht unsinnig ist, wenn man „aus dem Nus erst noch den Logos hervorgehen lässt und dann von diesem her einen weiteren Logos von diesem Logos in der Seele entstehen lässt." Denn dann wäre ja, nach Plotin, der Logos zwischen Seele und Nus und beraubte damit die Seele des geistigen Erkennens (voeĩv, II 9,1,57-63). Das entspricht zwar genau dem Aufbau der valentinianischen Ogdoas im Pleroma mit der Äonenreihenfolge Nus, Logos, Anthropos, aber eben nicht dem damit im mythischen Lehrtext Gemeinten.

${ }^{78}$ Vgl. die Graphik zum valentinianischen Äonenschema im Anhang. 
überhaupt nicht, so wie das Irenäus tut, und das liegt nicht nur daran, dass er dessen Kenntnis bei seinen angesprochenen Adressaten voraussetzt, sondern dass er ihn ausschließlich als mögliche platonische Konzeption und Variation nehmen und sie als eine solche kritisieren will. Er verzerrt die Meinung der Gegner dabei nicht unbedingt polemisch böswillig, er betrachtet sie nur extrem selektiv und einseitig. Für den heutigen Interpreten seiner Schrift II 9 macht er damit das Verstehen so besonders schwierig. ${ }^{79}$

Aus dieser Konzeption Plotins ergibt sich nun auch das Was seiner Kritik, die Hauptpunkte seiner Widerlegung. Sie betreffen die Struktur des Pleromas und darin vor allem die Stellung und Funktion des Nus (1), den Fall der Seele als die entscheidende Variation und damit Verkehrung der platonischen Grundüberzeugung (2) und die Konsequenzen des Falls für die Wertung der Welt (3) und des Menschen (4).

Es ist klar, dass der gnostische Fall der Seele (2) im Mittelpunkt der Kritik stehen muss, ${ }^{80}$ denn er bedroht den Kern des platonischen Systems. Für Plotin fällt die „schöpferische Seele“ nicht. Denn fiele sie, so müsste sie das Obere vergessen haben. Hätte sie es aber vergessen, könnte sie nicht Demiurg der Welt sein, was sie aber ist. Denn schaffen kann sie ja nur auf Grund der dort geschauten Paradigmen (II 9, 4, 6-9). Für die Seele gilt vielmehr, dass sie, insofern sie sich der Schau des Oberen hingibt, dem ihr nachgeordneten Unteren spenden kann, kurz:

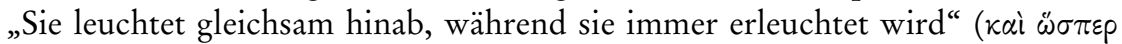

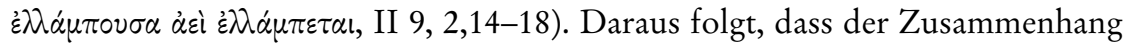
zwischen Geist, Seele und Kosmos / Mensch ununterbrochen ist. Eine Rückkehr

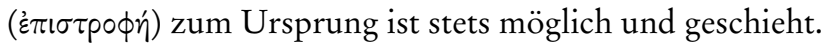

Dieser von den Gnostikern behauptete Fall der Seele, die der dritten Hypostase Plotins entspricht, der eigentliche Anstoß und Zielpunkt seiner Kritik, kann nicht unabhängig von der plotinischen Lehre vom Sein insgesamt behandelt werden, die parallel zu der valentinianischen Lehre von der Entfaltung des Urgrundes zum Äonenpleroma steht (1). Denn die Seele und ihre Funktion ist ja nur Abschluss und Konsequenz dieser Seinslehre bzw. dieser Lehre vom Pleroma. Plotin beginnt seine Schrift daher mit einer Kritik der Entstehung des Pleromas und der darin vorgenommenen Verselbständigung der Teilaspekte der Seinsstufen (II 9,1-3, bes.1). Wir explizieren das ausführlicher am 1. Kapitel der Gnostiker-Schrift, weil daran auch die Eigenart seiner gänzlich nur von seinen platonischen Voraussetzungen ausgehenden Stellungnahme, also der Charakter seines Autorkonzeptes deutlich wird.

Während es für Plotin nur drei Hypostasen geben kann, nämlich neben dem Hen, das für die Valentinianer wie den gesamten Mittelplatonismus noch nicht vorauszusetzen ist,

\footnotetext{
${ }^{79}$ Plotin ist dennoch eine wichtige Quelle für den Valentinianismus und als solche noch zu wenig genutzt.

${ }^{80}$ Darauf weist schon Alt 1990, 44, hin. Vgl. bei Plotin II 9, 2,9f und die Kapitel 4 und 10-12.
} 
nur Nus und Seele, nehmen nach seiner Darstellung die kritisierten Gegner eine Vielzahl von „Wesenheiten“ ( kritischen Argumente, die er anführt, auf die valentinianische Struktur des Pleroma passen und offenbar diese und nicht nur Numenios gemeint sind, wie gesagt wurde. ${ }^{81}$

Im Einzelnen: Die àpxì $\tau \tilde{\omega} \nu \pi \dot{\alpha} \nu \tau \omega \nu$, der Nus (II 9, 1, 20-25; cf. AH 1,1,1, Z. 88 Rous-

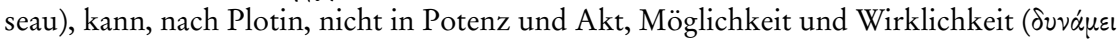

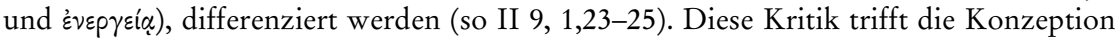

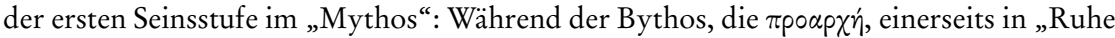
und Ständigkeit“ in „unendlichen Ewigkeiten“ existiert, und mit sich zwar die Ennoia, das heißt den Ideenkosmos hat, aber nicht selbst denkt, also nur potentiell die Proarche von

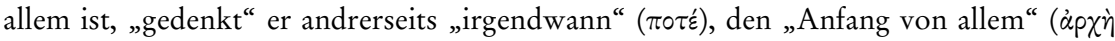
$\tau \tilde{\omega} \nu \pi \dot{\alpha} \nu \tau \omega \nu$ ) hervorzubringen, vorgestellt in einem geschlechtlichen Akt mit der Ennoia, und bringt den Nus hervor. Dieser ist dem Vater „ähnlich und gleich“ und „erfasst allein die Größe des Vaters“, das heißt die Vielheit des Ideenkosmos. Der Nus ist also der Teilaspekt der ersten und einen göttlichen Stufe von Bythos/Nus, der besagt, dass sich diese

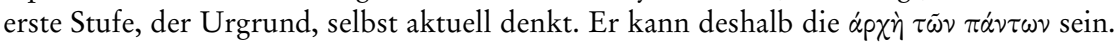
Plotin kritisiert diese Unterscheidung von Potentialität und Aktualität beim Urgrund (in Bythos und Nus) als absurd (Z. 24f).

Aber auch der Nus selbst (für Plotin die Stufe „danach“, das heißt nach dem Urgrund, Z. 25f) wird im valentinianischen „Mythos“ gemäß seinen verschiedenen Funktionen unterteilt. Plotin nimmt darauf Bezug, wenn er kritisiert, man könne nicht einen Nus denken, der „,in Ruhe“ ist und einen anderen, der „sich gleichsam bewegt“, das heißt

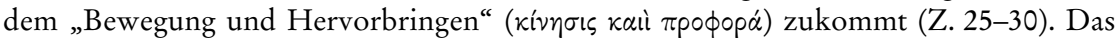
meint natürlich den Nus des „Mythos“, der einerseits den Vater und Ursprung (Bythos) erfasst und damit in Ruhe ist und andrerseits den Nus, insofern er „wahrnimmt, wozu er hervorgebracht ist", und der seinerseits den Logos mit der Zoe hervorbringt, also in Bewegung ist (AH 1,1,1 Z. 93-99 Rousseau). Plotin kritisiert das, weil für ihn der Geist „ist, wie er ist, auf immer identische Weise, daliegend in einer stillestehenden

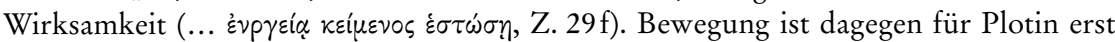
eine Tätigkeit der Stufe nach dem Nus, der Seele als einem „Logos“ (einer „rationalen Struktur“, Tornau), der „vom Nus her in die Seele kommt und sie geisthaft macht“, der Seele, und „nicht einer anderen Wesenheit zwischen Nus und Seele“ (Z. 30-33). Es ist unschwer zu sehen, dass sich Plotin mit dieser später, Z. 57-60, noch einmal erwähnten „Zwischen-Wesenheit“ ( $\mu \varepsilon \tau \alpha \xi u ́)$, die im Sinne des „Mythos“ gar kein „Dazwischen“ ist,

${ }^{81}$ Jens Halfwassen hat ausführlich und eindrücklich gezeigt, inwiefern sich des 1. Kapitel von Plotins Schrift gegen die Gnostiker auf Numenios bezieht (cf. Halfwassen 1994, 34-57). Ich habe daraus gelernt und stimme ihm zu, halte aber seinen nahezu alleinigen Bezug auf Numenios für nicht zutreffend. Die einzige direkte Wendung gegen die Gnostiker (Halfwassen sieht dahinter sicher richtig die Valentinianer), die er Plotins Ausführungen zubilligt, ist neben der von Mittelplatonikern und Gnostikern allseits vorgenommenen Hypostasenvermehrung die Hypostasierung des Logos (s. dazu im Folgenden) durch die Adressaten Plotins, die „eine Entgeistigung der Seele“ mit sich bringe und daher auf den „unbekannten Gott“ der Gnosis verweise (46-48). Das wird aber dem Quellenbefund in der Gnosis nicht gerecht, was Halfwassen allerdings auch nicht beabsichtigt. Die auffällige Übereinstimmung zwischen Plotins Adressaten, den Gnostikern einerseits und gewiss auch Numenios andrerseits, zeigt wieder deren Beziehung untereinander. Es wäre gut, wenn auch die Platonismusforscher sich dessen annähmen - auch wenn gewiss der gnostische Gesprächspartner hier der Nehmende ist. Die Gnosis nimmt auch einen Platz in der Wirkungsgeschichte des Platonismus ein. 
auf den vom Nus hervorgebrachten Logos bezieht. Er ist für den „Mythos“ der „Vater von allem, was nach ihm kommen wird, Anfang und Gestaltgebung des ganzen Pleroma“

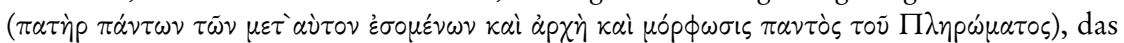
heißt er ist die rationale Spitze der Seele, die auch für Plotin ihre Kraft vom Nus her hat, aber für ihn eben keine Funktion des Nus ist.

Plotin kritisiert die valentinianische Hypostasenvermehrung schließlich in einem erneuten Ansatz, indem er tadelt, man könne nicht einen Nus ansetzten, der denkt, und einen anderen, der denkt, dass er denkt (Z. 33-57). Vielmehr wäre beides ein „einziger Zugriff, dem die Wahrnehmung (oì $\dot{\alpha} \nu \alpha i \sigma \theta \eta \tau \circ \varsigma^{82}$ ) seiner eigenen Aktivitäten nicht fehlt“. Plotin kritisiert also erneut die Unterscheidung zwischen einem Nus, der, zum Bythos mit seiner Ennoia/dem Ideenkosmos gehörig, den Ursprung denkt, und dem Nus als einem

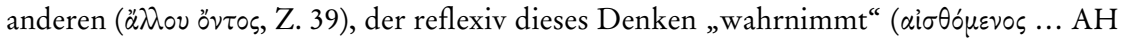
1,1,1 Z. 93 Rousseau) und die Konsequenzen daraus zieht und - den Logos - hervorbringt,

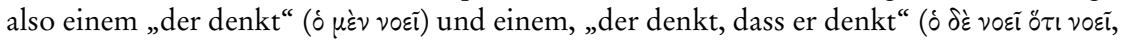
Z. $33 \mathrm{f}) .{ }^{83}$

Plotins Kritik an der valentinianischen Geistmetaphysik endet schließlich mit dem Tadel an der Konzeption dieses Logos, der „Zwischen Seele und Nus“ sei. Dies vorausgesetzt würde nach Plotin die Seele des denkenden Erkennens beraubt, denn sie erhielte

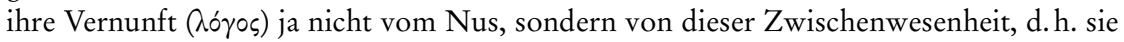
erhielte nur ein Eidolon von Vernunft und könne folglich überhaupt nicht denken und folglich auch nicht demiurgisch tätig sein (Z. 57-63). Jedoch ist nach dem „Mythos“ der Logos bereits die rationale Spitze der Seele, sie erhält ihre rationale Kraft sehr wohl von dem sie hervorbringenden Nus, und der Logos des „Mythos“ kann deswegen der Vater alles Nach-ihm-Kommenden sein. ${ }^{84}$

Im Ergebnis heißt das für unsern Zusammenhang, dass sich alle Punkte der Kritik Plotins an der gnostischen Hypostasenvermehrung auf die valentinianische Konzeption beziehen lassen. Der von Porphyrios gegebene Titel von II 9 „Gegen die Gnostiker“ ist daher schon hier gerechtfertigt. Teile der Kritik Plotins beziehen sich gewiss auch auf Numenios, aber keineswegs nur oder hauptsächlich auf ihn.

Aus dem Gesagten folgt schließlich (3), dass auch die gnostisch-valentinianische Abwertung der Welt und der Tadel ihrer Beschaffenheit für Plotin völlig unangebracht ist (II 9, 13,1f). Für ihn ist der Kosmos wegen seines ewigen Entstehens aus Geist und Seele göttlich, ${ }^{85}$ er ist wegen der ständigen Wirksamkeit des Geis-

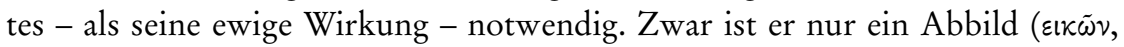
$\mu(\mu \eta \mu \alpha)$ der oberen Welt, weswegen es in ihm auch viel Widriges gibt ( $\pi \circ \lambda \lambda \dot{\alpha} \ldots$ $\delta$ $\sigma \chi \varepsilon p \tilde{\eta}$, II 9, 4,22-26), aber er ist das schönstmögliche Abbild (II 9,8,1-26) und hat Hinweischarakter auf Gott. ${ }^{86}$ Für die Valentinianer ist dagegen die Welt

${ }^{82}$ Vgl. II 9,1,35 f und dazu die sprachliche Parallele in AH 1,1,1 Z. 93 Rousseau: der Nus/

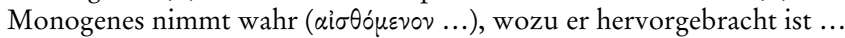

${ }^{83}$ Dazu Halfwassen 1994, 49.

${ }^{84}$ Die Konzeption dieses als Zwischenwesenheit gekennzeichneten Logos, weist sehr deutlich auf den valentinianischen „Mythos“ als Adressaten der Kritik Plotins hin und nicht auf $\mathrm{Nu}$ menios, es sei denn, man wolle dessen dritten Gott parallel zum Logos sehen. Das ist möglich.

${ }^{85}$ II 9, 11,22 f: „Schöpfungsgrund“ (Harder) ist das Denken $\left.\lambda_{\circ} \gamma_{i} \zeta_{\xi} \sigma \theta \alpha \mathrm{l}\right)$.

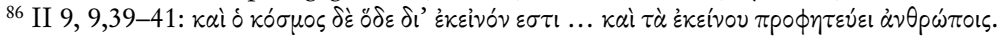


wegen des Falls der Seele notwendig geworden. Sie entsteht als Etappe im Prozess der Formung des Gefallenen ${ }^{87}$ und nicht notwendig aus der Wirksamkeit des Geistigen. Vielmehr ist sie Rettungstat des Nus/Christos. Hergestellt durch den psychischen Demiurgen hat sie keinen direkten Hinweischarakter auf Gott, wenngleich sie nur aufgrund der durch den Nus / Christos / Soter oder die pneumatische Mutter vermittelten Vorbilder hergestellt werden kann. ${ }^{88}$

Am eindrücklichsten schließlich stellt sich in Plotins Schrift der unüberbrückbare Gegensatz zwischen ihm und den christlichen Gnostikern in der Wertung

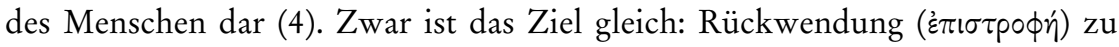
Gott - die Valentinianer haben es in dieser Formulierung dem platonischen Modell entnommen. Der Weg dahin und damit auch die anzustrebende Lebensform ist aber, wie sich aus dem Fall der Seele ergibt, gänzlich verschieden. Nach Plotin ist der Mensch kraft seiner Seele und ihres Anteils am Geist zum Aufstieg befähigt. „Er strebt unablässig nach dem, wonach alles strebt, was dazu fähig ist ... und die es erlangen, sind glückselig “ ${ }^{89}$ Dieses Streben schließt die theoretische Bemühung um das Wesen der Arete und die entsprechende Lebensform mit ein (II 9, 15,21-32). Es umfasst auch die selbstverständliche Anerkennung des Strebens anderer sowie Bescheidenheit und Einsicht in die eigenen Möglichkeiten des Erkennens (II 9, 9,42-52). Sich zu überheben und zu behaupten, höher emporsteigen zu können, als es die menschliche Natur vermag, ist dagegen Zeichen bäuerischen Unverstandes (ả $\gamma p o i k i \alpha$, II 9,9,45f und 26) und frecher Dreistigkeit $(\alpha \dot{\jmath} \theta \dot{\alpha} \delta \varepsilon 1 \alpha){ }^{90}$

Aber gerade dieser Vorwurf anmaßender Einbildung und Überheblichkeit trifft gegenüber den Gnostikern nicht zu. Plotin untermauert diese Anschuldigungen nur mit äußerst schlichten Belegen und Zitaten der Gnostiker: Sie

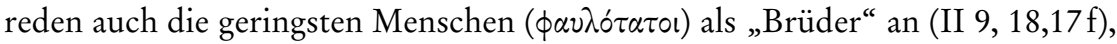

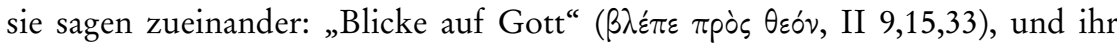

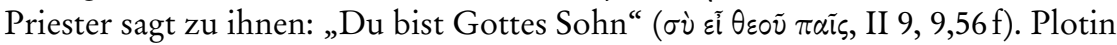
knüpft an diese Aussprüche schwerwiegende Schlussfolgerungen an: Wenn sie Gottes Sohn zu sein meinen, halten sie sich also für besser als die verehrungswürdigsten Menschen in Gegenwart und Vergangenheit, sie halten sich für besser

\footnotetext{
${ }^{87}$ Irenäus, AH 1,6,1,Z. 595-597 Rousseau: diò (weil das Psychische sinnlich wahrnehmbarer

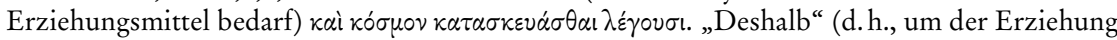
des Psychischen willen) „sei die Welt gemacht worden, sagen sie“, nämlich um dem Psychischen eine Bewährungsstätte zu geben.

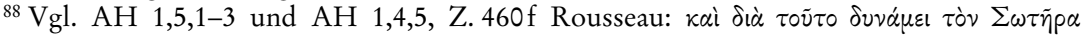

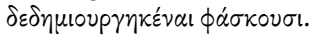

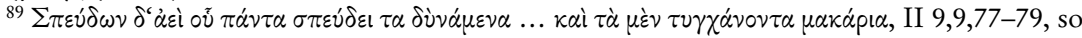
mit Beutler/ Theiler.

${ }^{90}$ II 9, 9,55 und 14,37-43, bes. 40 f. Die Gnostiker behaupten sogar, sie allein seien zur Schau ( $\theta \varepsilon \omega \rho \varepsilon \tilde{v}$ ) befähigt (II 9,18,35f). - Der Weise beansprucht dagegen nach Plotin nicht für sich allein das Vermögen, nach Gott zu streben. Denn „wer sich rühmt zu haben, hat noch nicht, wessen er sich rühmt“" (II 9,9,81-83, Übersetzung Harder).
} 


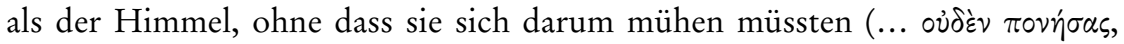
cf. II 9, 9,55-60). Wenn sie sagen „Blicke auf Gott“, so reicht das nicht aus, ohne sich anzustrengen und zu lehren, wie man auf Gott blicken kann (II 9, 15,32-34). Sie berufen sich völlig unsinnig darauf, dass Gottes Pronoia für sie allein sorge ${ }^{91}$ und sie allein schon im Besitz der Erkenntnis seien ( II 9, 15,23). Was geschieht hier? Plotin will nicht verstehen, warum alle diese Konsequenzen der zitierten Aussagen nach valentinianisch-gnostischer Überzeugung tatsächlich zutreffen: Der Mensch ist - dem gnostischen, mythisch verfassten Lehrtext gemäß - aus sich heraus zum Aufstieg nicht fähig, geht vielmehr zurück auf ein hilfloses हैk $\tau$ p $\omega \mu \alpha$, ein aus dem Pleroma ausgestoßenes $\pi \dot{\alpha} \theta 0 \varsigma$,

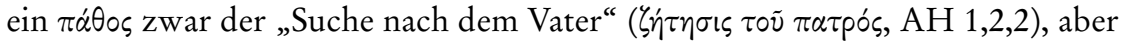
gänzlich ohne Möglichkeit zur Erreichung dieses Ziels. Mühe und Anstrengung verfangen nichts. Allein die Sorge und Zuwendung Gottes zu dem hilflos nach Gott Suchenden führt zur erstrebten Erkenntnis, damit aber tatsächlich zu einer Beschaffenheit, die besser als der Himmel und die besten Menschen ist. Ein Satz wie „Du bist Gottes Sohn“ ist daher die Zusammenfassung für die an den einzelnen Menschen ergehende offenbarende Belehrung über seine Herkunft und Zugehörigkeit - eine Belehrung durch den Christos/Logos/Soter und wie die einzelnen Rettergestalten, die Aspekte des einen Nus/Monogenes, auch immer heißen mögen, eine Belehrung, die ihn, wenn sie angenommen wird, tatsächlich zum „Sohn Gottes“ macht. Alle die Menschen, denen diese Belehrung zugekommen ist, müssen daher tatsächlich als „Brüder“ angesprochen werden, unabhängig von Stand und Ausmaß ihrer Bemühung. Mir scheint, Plotin hat das sehr gut verstanden, hält es aber für so irrwitzig und der platonischen Wahrheit widersprechend, dass er es nur - mit der Stimme des platonisch-philosophischen Autors - als maßlose Selbstüberhebung mit voller Absicht missdeuten kann. Seine Methodik des Argumentierens in der eigenen Begrifflichkeit erreicht hier ihren Höhepunkt.

Als Ergebnis kann festgehalten werden: Alle drei Reaktionen auf den gnostisch-valentinianischen „Mythos“, sowohl die zustimmend gnostische Mythenbildung als auch die ablehnend christliche wie platonische Polemik, bestätigen die gegebene Interpretation des „Mythos“ und auch das daraus erhobene Autorkonzept: Der „Mythos“ ist tatsächlich sachlich in Anlehnung an und Änderung von platonischer Philosophie gebildet und tatsächlich formal in bewusst-strategisch mythisierender Gestalt geboten worden, zur Unterstützung seiner Autorität und seiner Wirkung auf das angezielte Publikum. Alle drei Reaktionen bestätigen Inhalt und Stil des „Mythos“. Dieser ist verstanden worden - es ist kein Zufall, dass sowohl Irenäus als auch Plotin die mythische Form als Ausdrucksweise nicht kritisieren - und er ist rezipiert worden, im übrigen bei Irenäus wie auch

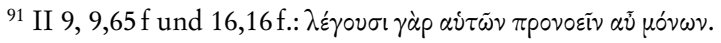


bei Plotin und darüber hinaus nicht nur kritisch, sondern auch weiterführend sachlich anregend. ${ }^{22}$

Für die Fragestellung dieses Bandes ist bedeutsam, dass für alle vier hier herangezogenen Texte, des Numenios, des gnostischen „Mythos, des Irenäus sowie des Plotin, der jeweilige reale Autor der Texte, ob diese nun anonym oder orthonym erscheinen, als Individuum unwichtig ist. Die jeweilige Autorinstanz steht, auch wenn ihr Name genannt wird, für die Sache, die sie vertritt, d. h. für die des etablierten und ausgebildeten Platonismus oder für die des erst in der Ausbildung begriffenen Christentums und seiner theologischen Begründung. ${ }^{93}$

Wir fassen mit den besprochenen Texten einen wesentlichen, bisher eher vernachlässigten Aspekt der Anfänge christlicher Theoriebildung, ${ }^{94}$ wenn man so will die Anfänge des Spezialdiskurses christliche Dogmatik. Daraus schälen sich erst die künftig wesentlichen Fragen christlicher Theologie heraus. Es wird klar, worum es gehen muss, um eine rational begründet verantwortete Antwort auf die Fragen: Wer ist Christus, wie steht er zu Gott, wie sind Schöpfung und Erlösung zu vermitteln? Die bildhafte Sprache des Neuen Testaments ist dafür zwar Kriterium, nicht aber ausgebildet durchdachtes Resultat.

${ }^{92}$ Bei Irenäus ist auf seine Rekapitulationlehre und die damit zum Ausdruck gebrachte vollständige Bedürftigkeit des Menschen vor Gott zu verweisen, die eine Haltung der sich zum Empfangen öffnenden „subiectio“ unter Gott impliziert - eine Haltung, die der grundsätzlich bedürftigen anthropologischen Konzeption der Valentinianer nicht unähnlich ist. Bei Plotin ist es natürlich schwieriger, irgendeinen positiven Lerneffekt aus seiner Beschäftigung mit der Gnosis zu konstatieren. Immerhin wiesen wir schon darauf hin, dass ihn das Problem des Abstiegs der Seele, das er auch ein „Fallen“ u. ä. nennen kann, lebenslang beschäftigt hat. Zwar bleibt der entscheidende Unterschied zu Gnosis bestehen: der Mensch kann sich aufgrund seiner Seele immer und stets zurückwenden. Aber auch Plotin weiß als Grund für dieses Fallen von einem „Über sich-herrschen-Wollen und „Sich-selbst-gehören-Wollen“ der Seele (III 7, 11,15f). Das weist auf eine gewisse Nähe in der Einsicht von der Verfasstheit des Menschen hin, und nicht zuletzt daraus rührt ja auch Plotins heftige Empörung. Um das zu demonstrieren zitiere ich hier den Anfang einer Frühschrift (V 1[10], 1,1-9) in der Übersetzung Harders: „Was hat denn eigentlich die Seelen ihres Vaters Gott vergessen lassen und bewirkt, dass sie, obgleich Teile aus jener Welt und gänzlich Jenem angehörig, ihr eigenes Wesen sowenig wie jenen mehr kennen? Nun, der Ursprung des Übels war ihr Fürwitz, das Eingehen ins Werden, die erste Andersheit, auch der Wille sich selbst zu gehören. An dieser ihrer Selbstbestimmung hatten sie, als sie denn in die Erscheinung getreten waren, Freude, sie gaben sich reichlich der Eigenbewegung hin, so liefen sie den Gegenweg und gerieten in einen weiten Abstand; und daher verlernten sie auch, dass sie selbst von dort oben stammen."

${ }^{93}$ Dennoch wird man mit Foucault nicht Beckett mit „Wen kümmert's, wer spricht?"“ zitieren können: Denn die Namen Plotin und auch Irenäus stehen für Autorität, und es „kümmert“ durchaus, „wer spricht", aber eben nicht im Sinne des individuellen Autors und seines authentischen, originalen Werkes. Vgl. den berühmten Aufsatz von M. Foucault, Was ist ein Autor?, zitiert nach der deutschen Übersetzung bei Jannidis et al. 2000, 199-229, bes. 202 und 227.

${ }^{94}$ Das versteht sich neben den parallelen Bemühungen der apologetischen Theologie. 


\section{Valentinianisches Äonenschema (nach Irenäus, Adversus Haereses 1, 1-8)}

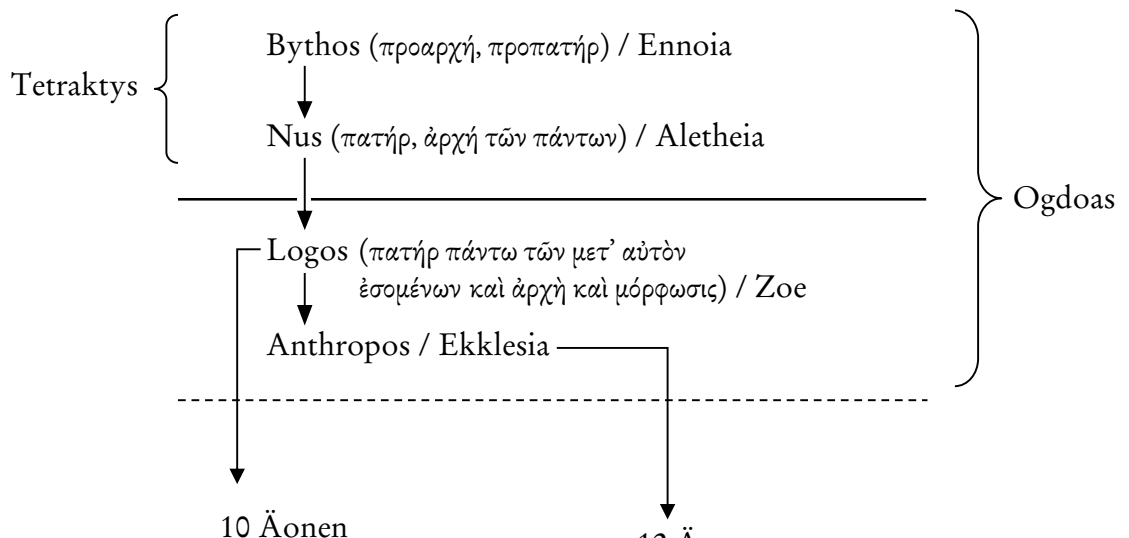

10 Äonen

(von Bythios / Mixis bis

12 Äonen

Monogenes / Makaria)

(von Parakletos / Pistis

bis Theletos / Sophia)

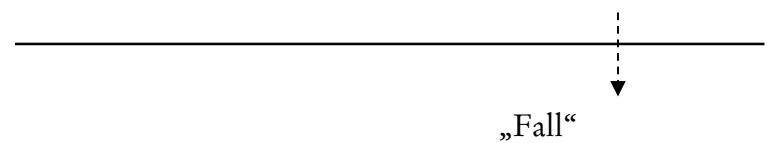

(Abtrennung der Enthymesis von der Sophia)

\section{Literaturverzeichnis}

Aland, B. (2014). Die Gnosis. Stuttgart.

Alt, K. (1990). Philosophie gegen Gnosis. Plotins Polemik in seiner Schrift II 9. Abhandlungen der Mainzer Akademie der Wissenschaften. Geistes- und Sozialwissenschaftliche Klasse. Stuttgart.

Anz, Th. (2007). Handbuch Literaturwissenschaft, Bd I: Gegenstände und Grundbegriffe. Darmstadt.

Baltes, M. (1999a). „Numenios von Apamea und der platonische Timaios,“ in: ders., $\triangle I A N O H M A T A$. Kleine Schriften zu Platon und zum Platonismus. Stuttgart/Leipzig. $1-32$.

Baltes, M. (1999b). „Was ist antiker Platonismus?“ in: Ders., $\triangle I A N O H M A T A$. Kleine Schriften zu Platon und zum Platonismus. Stuttgart und Leipzig. 223-247.

Beierwaltes, W. (1981). Plotin. Über Ewigkeit und Zeit (Enneade III 7). Übersetzt, eingeleitet und kommentiert. 3. Auflage. Frankfurt.

Burkert, W. (1984). „Mythos, Mythologie,“ in: HWPb 6. 281-283. 
Chiapparini, G. (2012). Valentino Gnostico et Platonico. Il Valentinianesimo della, grande Notizia' di Ireneo di Lione: Fra Esegesi Gnostica e Filosofia Medioplatonica. Temi metafisici e problemi del pensiero antica. Studi e testi 126. Milano.

Dörrie, H.; Baltes, M. (1987-2008). Der Platonismus in der Antike. Grundlagen - System - Entwicklung, begründet von H. Dörrie (Bd. 1), fortgeführt von M. Baltes (Bd. 2-6.2), fortgeführt von M. Baltes und Ch. Pietsch (Bd. 7.1). Stuttgart-Bad Cannstatt.

Elsas, C. (1975). Neuplatonische und gnostische Weltablehnung in der Schule Plotins. Religiongeschichtliche Versuche und Vorarbeiten 34. Berlin.

Erler, M. (2007). „Platon,“ in: Grundriss der Geschichte der Philosophie. Die Philosophie der Antike Bd. 2/2. Basel.

Erler, M. (2013). „Plato's religious voice: Socrates as godsent, in Plato and the Platonists,“ in: A. Marmodoro; J. Hill, edd., The Author's Voice in Classical and Late Antiquity. Oxford University Press. 313-339.

Foucault, M. (2000). „Was ist ein Autor?“ in: F. Janidis et al. (2000). 194-229.

Halfwassen, J. (1994). Geist und Selbstberwusstsein. Studien zu Plotin und Numenios. Abhandlungen der Mainzer Akademie der Wissenschaften. Geistes- und Sozialwissenschaftliche Klasse. Stuttgart.

Halfwassen, J. (2013). „Gnosis als Pseudomorphose des Platonismus: Plotins Gnosiskritik,“ in: C. Markschies; J. van Ort, Hgg., Zugänge zur Gnosis. Lewven. Akten zur Tagung der Patristischen Arbeitsgemeinschaft vom 02.-05.01 2011 in Berlin Spandau. Leuven. 25-42.

Heiser, A. (2012). Die Paulusinszenierung des Johannes Chrysostomus: Epitheta und ibre Vorgeschichte. Stuttgart.

Jannidis, F; Lauer, G., Martinez, M.; Winko, S. (1999). Hgg. Rückkebr des Autors. Zur Ernewerung eines umstrittenen Begriffs. Tübingen.

Jannidis, F; Lauer, G.; Martinez, M.; Winko, S. (2000). Hgg. Texte zur Theorie der Autorschaft, herausgegeben und kommentiert. Stuttgart: Reclam.

Krämer, H.J. (1967). Der Ursprung der Geistmetaphysik, Untersuchungen zur Geschichte des Platonismus zwischen Platon und Plotin, 2. Auflage. Amsterdam.

Markschies, C. (2000). „New Research on Ptolemaeus Gnosticus,“ ZAC 4 (2000): 225-254.

Markschies, C. (2011). „Individuality in Some Gnostic Authors: With a few remarks on the interpretation of Ptolemaeus, Epistula ad Floram, “ ZAC 15 (2011): 411-430.

Narbonne, J-M. (2011). „Plotinus in Dialogue with the Gnostics,“ in: R. M. Berchman; J.F. Finamore, edd., Studies in Platonism, Neoplatonism and the Platonic Tradition. 11, Leiden.

Pabst, S. (2011). Anonymität und Autorschaft. Zur Literatur- und Rechtsgeschichte der Namenlosigkeit. Studien und Texte zur Sozialgeschichte der Literatur 126. Berlin.

Pietsch, Ch. (2008). „Die philosophische Lehre des Platonismus. Theologia Platonica,“ in: H. Dörrie; M. Baltes; Ch. Pietsch, Hgg. Der Platonismus in der Antike. GrundlagenSystem - Entwicklung. Band 7.1. Stuttgart-Bad Cannstatt.

Roloff, D. (1970). Plotin. Die Großschrift III 8-V, 8-V 5-II 9. Berlin.

Rousseau, A.; Doutreleau, L. (1979). Irénée de Lyon. Contre les Hérésies. Édition critique. Tome I: Introduction, Notes Justificatives, Tables. Tome II: Texte et Traduction. Paris.

Spanu, N. (2012). Plotinus' Ennead II 9 [33] „Against the Gnostics“. A Commentary. Studia Patristica, Supplement 1. Leuven.

Tornau, Ch. (2001). Plotin. Ausgewählte Schriften. Herausgegeben, übersetzt und kommentiert. Stuttgart. 
Willand, M. (2011). „Autorfunktionen in literaturwissenschaftlicher Theorie und interpretativer Praxis. Eine Gegenüberstellung, “Journal of Literary Theory 5.2 (2011): 279-302.

Ziebritzki, H. (1994). Heiliger Geist und Weltseele. Das Problem der dritten Hypostase bei Origenes, Plotin und ibren Vorläufern. Beiträge zur historischen Theologie 84. Tübingen. 


\section{Stellenregister*}

Altes Testament/Septuaginta

1 Kön 3,9/ $3 \mathrm{Kg} \mathrm{3,9LXX} \quad 113$

Sir Prolog 27-36 21, 35

Sir 44,1-15 27

Sir 51,13-30 20f., 31

Jes 49,1-6 108, 113

Jes 52,13-53,12 114

Apuleius

Met.

229, 231

Aristides

Or. 48,55

Or. 48,47

208

208

Außerbiblische frühjüdische Texte und Quellen

Apc. Mos. 15-30 156

Apc. Mos. 17,1-2 156

Apc. Mos. 20,2; 21,6 156

1Q 22, Kol. I, $4 \quad 157$

Cassius Dio

66,4

122

Cicero

Att. 4,10,1 51

ad Q. fr. 1,3,9 51

Cat. 3,19-20 45

div. $1,60 \quad 188$

div. $2,121 \quad 188$

dom. 32-33 47

dom. 144-145 45

dom. $144 \quad 46,53$

fam. 10,3,3 $\quad 51$

fam. 10,5,3 51

fam. 10,22,1 51

fam. 12,25,1 53

fam. 16,12,1 51 fam. 14,4,1 53

har. resp. 18-19 47

leg. $\quad 50$

leg. 2,32-33 50

leg. 2,42

nat. $1,1 \quad 49$

nat. $1,6 \quad 52$

nat. $1,10 \quad 52$

nat. $1,12 \quad 50$

nat. $1,17 \quad 50$

nat. 3,95 50

Verr. 2,5,184-189 45

Epiktet

Diss. 2,6,25 ff. $\quad 111$

Diss. 1,19,8; 2,16,41; $4,7,17$

Eusebius

Hist. Eccl. 2,2,4 242

Hist. Eccl. 3,31,4 245

Hist. Eccl. 3,5,4 122

Hist. Eccl. 3,9,4 131

Hermas

PH 4,2 191

PH 7,1-4 187

PH 7,4 184, 189

$\begin{array}{ll}P H \\ 8,3 & 187\end{array}$

PH 52,3 $\quad 191$

mand. 3,10,7 192

mand. 4,1,9 $\quad 191$

mand. 6,2,1-5 193

mand.11,1 191

sim. $1 \quad 192$

sim. 3,3 191

sim. 5,1,3-5 192

sim. 5,3,2-3 192

sim. $5,3,7 \quad 192$

* in Auswahl. 


\begin{tabular}{|c|c|c|c|}
\hline $\operatorname{sim} .8$ & 190 & $A H 2,8,3$ & 277 \\
\hline sim. 8,1,6-14 & 191 & $A H 3,15,2$ & 262 \\
\hline sim. 8,9,1-4 & 192 & \multirow{3}{*}{\multicolumn{2}{|c|}{$\begin{array}{l}\text { Jesus ben Sira/Jesus Sirach/Ben Sira, } \\
\text { s.o. bei Altes Testament/Septuaginta }\end{array}$}} \\
\hline $\operatorname{sim} .8,9,3$ & 191 & & \\
\hline $\begin{array}{l}\operatorname{sim} .9 \\
\operatorname{sim} .9,5,2\end{array}$ & $\begin{array}{l}184,190 \\
191\end{array}$ & & Josephus \\
\hline $\operatorname{sim} .10$ & 184 & Ant. 1,21 & 128 \\
\hline vis. $1-v i s .4$ & 183 & Ant. 1,208-209 & 137 \\
\hline vis. $1,1,1-2$ & 189 & Ant. 1,278-284 & 137 \\
\hline vis.-mand. 12 & 183 & Ant. 1,331-334 & 137 \\
\hline vis.-mand. $12-$ sim. 8 & 183 & Ant. 1,341-342 & 137 \\
\hline vis. 2,1 & 194 & Ant. 2,10-17 & 137 \\
\hline vis. $2,4,3$ & 187 & Ant. 2,63-73 & 137 \\
\hline vis. 3 & 184,190 & Ant. 2,75-86 & 137 \\
\hline vis. $3,4,3$ & 192 & Ant. 2,171-176 & 137 \\
\hline vis. $3,6,5$ & 191 & Ant. 2,212-217 & 137 \\
\hline \multicolumn{2}{|l|}{ Hieronymus } & Ant. 4,14-66 & 132 \\
\hline Hieronymus & & Ant. 4,223 & 128 \\
\hline$P L 23,662-3$ & 122 & Ant. 5,135 & 128 \\
\hline De vir. ill. 24 & 245 & Ant. 5,215-221 & 137 \\
\hline $\begin{array}{l}\text { De vir. ill. } 40 \\
\text { De vir ill } 53\end{array}$ & $\begin{array}{l}245 \\
245\end{array}$ & Ant. 5,277-278 & 137 \\
\hline De vir. ill.53 & 245 & Ant. $5,348-350$ & 137 \\
\hline De vir. ill. 40 & 246 & Ant. 6,36 & 128 \\
\hline De vir. ill. 53 & 243 & Ant. 6,37-40 & 137 \\
\hline De vir. ill. 53,1 & 242 & Ant. 6,84 & 128 \\
\hline Hippolyt & & Ant. 6,268 & 128 \\
\hline Refutatio 6,30 & $269 \mathrm{f}$. & Ant. 7,92-93 & 137 \\
\hline Refutatio 6,31 & 269 & Ant. 7,147 & 137 \\
\hline \multicolumn{2}{|l|}{ Horaz } & Ant. 8,22-25 & 137 \\
\hline Horaz & & Ant. 8,125-129 & 137 \\
\hline C. 1,1 & 80 & Ant. 10,194-211 & 137 \\
\hline c. 2,18 & $\begin{array}{l}16 \\
76\end{array}$ & Ant. 11,111 & 128 \\
\hline c. 2,19 & $\begin{array}{l}76 \\
57\end{array}$ & Ant. $11,326-328$ & 137 \\
\hline c. 2,20 & $\begin{array}{lll}57 & & \\
57 \quad 59 \quad 70\end{array}$ & Ant. $11,333-335$ & 137 \\
\hline c. 3,30 & $57,59,70$ & Ant. 13,322 & 137 \\
\hline c. 4,3 & 78,80 & Ant. 14,91 & 128 \\
\hline Irenäus & & Ant. 18,181-2 & 87 \\
\hline \multirow[t]{2}{*}{$A H$ 1,1-8 } & $259,263-266$ & Ant. 18,257-9 & 93 \\
\hline & 268-277 & Ant. 20,229 & 128 \\
\hline$A H 1,16,3$ & 263 & Ant. 20,251 & 128 \\
\hline$A H 1,31,3$ & 263 & Apion 1,54 & 142 \\
\hline$A H$ 1,23-26 & 265 & Bell. 1,3 & 142 \\
\hline$A H 2,1,1$ & 277 & Bell. 1,9 & 90 \\
\hline$A H 2,1,3$ & 277 & Bell. 1,11 & 90 \\
\hline$A H 2,18,1-5$ & 280 & Bell. 1,13-4 & 91 \\
\hline$A H 2,2,5$ & 278 & Bell. 1,170 & 91 \\
\hline$A H 2,3,2$ & $277 \mathrm{f}$. & Bell. 2,205 & 128 \\
\hline$A H 2,6,1$ & 278 & Bell. 3,340-392 & 141 \\
\hline
\end{tabular}




\begin{tabular}{|c|c|c|c|}
\hline Bell. 3,351-354 & 137 & Nikolaos & \\
\hline Bell. 3, 399-408 & 141 & FGrH 2,90 & \\
\hline Bell. 4,319-325 & 133 & F 131-139 & 130 \\
\hline Bell. 6,110, 250, 288 & 126 & Numenius & \\
\hline Bell. 6,312-313 & 141 & Frg. 11 (Des Places) & $266 \mathrm{f}$. \\
\hline Vit. $1,1-2$ & 142 & Frg. 12 (Des Places) & $266 f$. \\
\hline Vit. 9 & 85 & Frg. 15 (Des Places) & $266 f$. \\
\hline Vit. 83 & 142 & Frg. 16 (Des Places) & $266 f$. \\
\hline Justin & & Frg. 20 & 267 \\
\hline $\begin{array}{l}2 \text { Apol. 12,1, 3,1, } \\
\text { 9,1-1-5, }\end{array}$ & & $\begin{array}{l}\text { Frg. } 21 \\
\text { Frg. } 22\end{array}$ & $\begin{array}{l}266 \mathrm{f} . \\
267 \mathrm{f} .\end{array}$ \\
\hline $14,1-15,5$ & 99 & Origenes & \\
\hline Lukian & & C. Celsum 1,16 & 131 \\
\hline Alexander & 228 & Ovid & \\
\hline De Dea Syria & $225-227,234$ & fast. $3,713-790$ & $65 \mathrm{f}$. \\
\hline $\begin{array}{l}\text { De Morte Peregrini } \\
\text { Verae Historiae }\end{array}$ & $\begin{array}{l}228 \\
229\end{array}$ & trist. 4,10 & $\begin{array}{l}58,62 \text { f., } 65,68, \\
70-73,75,78,80\end{array}$ \\
\hline $\begin{array}{l}\text { Marc Aurel } \\
\text { Med. 2,2-3 }\end{array}$ & 83 & trist. 5,3 & $\begin{array}{l}58,62 \text { f., } 65-68 \\
72-75,77 f ., 80\end{array}$ \\
\hline \multicolumn{2}{|c|}{ Nag Hammadi Codices } & Philo & \\
\hline $3,2,68,10-13$ & 262 & All. 1,18 & 84 \\
\hline $3,2,68,1-5$ & 262 & All. 1,22 & 84 \\
\hline $4,2,80,26$ & 262 & All. 1,33-4 & 84 \\
\hline $4,2,80,15-18$ & 262 & Flac. 1 & 88 \\
\hline \multirow{2}{*}{\multicolumn{2}{|c|}{ Neues Testament }} & Flac. 3 & 88 \\
\hline & & Flac. 6 & 88 \\
\hline$M t 11,27$ & 278 & Flac. 102 & 86 \\
\hline $\operatorname{Lk} 10,22$ & 278 & Flac. 109 & 86 \\
\hline$L k 22,43-44$ & 98 & Flac. 116 & 86 \\
\hline$L k 23,46$ & 98 & Flac. 125 & $\begin{array}{l}86 \\
86\end{array}$ \\
\hline Röm 1,1 & $106,108,115,117$ & Flac. 131 & $\begin{array}{l}86 \\
88\end{array}$ \\
\hline Röm 3,23 & 156 & & $\begin{array}{l}88 \\
83\end{array}$ \\
\hline Röm 7,7-25 & 156 & $\begin{array}{l}\text { Legat. } 150 \\
\text { Legat. } 172\end{array}$ & $\begin{array}{l}83 \\
93\end{array}$ \\
\hline Röm 12-15 & 117 & & $\begin{array}{l}93 \\
95\end{array}$ \\
\hline 2 Kor 3,13-18 & 157 & Legat. 180 & 95 \\
\hline $2 \operatorname{Kor} 11,14$ & 156 & Legat. 200-203 & 95 \\
\hline Phil 1,1 & $106-109,115-117$ & Legat. 333-335 & 86 \\
\hline Phil 2,3 & 107,116 & Legat. 353-363 & 97 \\
\hline Phil 2,6-11 & 107,114 f., 117 & Legat. 367 & 97 \\
\hline Pblm $8 \mathrm{ff.}$ & 112 & Legat. 370 & 93 \\
\hline Phlm 13 ff. & 112 & Lib. 93-96 & 91 \\
\hline Phlm $16 \mathrm{ff}$. & 112 & Plato & \\
\hline$A p c 1,1$ & 184 & Timaios $92 \mathrm{c} 8$ & 273 \\
\hline Apc 5,5; 7,13-17 & 155 & Plotin & \\
\hline Apc 12,1-6 & 163 & Enn. 29 & $279-286$ \\
\hline Apc 22,10 & 185 & Enn. $35,2,28-32$ & $\begin{array}{l}279-286 \\
274\end{array}$ \\
\hline
\end{tabular}


Enn. 3 7, 11,15f. 287

Hist. 2,49-51 139

Enn. 5 1,1,1-22 287

Enn. $51,1,1-9 \quad 287$

Hist. 5,13 122

Plutarch

Cat. Mai. 2,4 91

Cat. Mai. 12,4-5 91

Cat. Mai. 22,1-23,2 91

Cat. Mai. 24,1 91

Cic. 2,1-4 91

Cic. 3,1 91

Cic. 4,1-3 91

Cic. 40,1-41,1 91

Polybius

Hist. 1,1-5 90

Porphyrius

Vita Plot. $16 \quad 279 \mathrm{f}$.

Pseudo-Platon

Ep. II 314 c 3-4

Seneca

Brev. Vit. 13,2 83

ep. $113 \quad 94$

ер. 78,2-4 95

ep. 78,13 95

Ira 2,1,1-4,1 94

Ira 2,1,1-5 95

Tranquil. 9,4-5 83

Tertullian

Adv. Marc. 3,16 254

Adv. Marc. 4,11 254

Adv. Marc. 4,22,4-4 245

Adv. Val. 1,1 244

Adv. Val. 5,1 245

Apol. 1,1 253

coron. 1,1-3 249

idol. $1 \quad 246$

Mart. 1,1-2 253

nat. $1,1 \quad 248$

orat. $1 \quad 254$

pat. $1,1 \quad 242 \mathrm{f}$.

pat. 16,3 244

resurr. 59,3 251

Scap. 1,1-4 250

spect. 1,1-4 248

spect. 19,4 242

test. anim. 1,2 252

test. anim. 1,4 252

test. anim. 1,5-7 247

uxor. 11-6 250

uxor. $1,5,1 \quad 251$

uxor. 4,3 251

Thucydides

1.20-2

125

Vincentius

Comm. 18,24 (46)

(74,9-78,5 Moxon) 255

Tacitus

Hist. 1,1,1-3 


\section{Sach-, Personen- und Ortsregister*}

Aelius Aristides 7, 13, 199-219

P. Aelius Theon $210 \mathrm{f}$., $214 \mathrm{f}$.

aemulatio 3

agency 4

Alexandria 10, 21 f., 34, 83-89, 93, 96-98, 129,182

Allonymität 2

Anonymität 14f., 73, 176f., 201, 214, 261 f., 274,

Apokalypse 13, 151-180, 184-186, 189 f., 195

Aretalogie 13, 28 f., 67, 74, 200, 213, 215, 218

Arzt/doctor 13, 32, 91, 215

Asclepius 200, 202-203, 205-208, 210f., 213-215

Autor

- author as sufferer 199-219

- Autor, impliziter 165 f., 221-223, 233, 235, 274

- Autoren-Ich 31, 165, 171, 176

- Autorfunktion 106-109, 237, 260-263

- Autorinstanz 260f., 287

- Autorisierung 1f., 7, 15, 23-28, $30 \mathrm{f}$., 106, 115

- Autorkonzept 1f., 7, 9, 28-34, 223, 229f., 259-288

Bacchus 11, 57-82

Ben Sira, s. Jesus ben Sira

Biographie 26, 33, 57f., 60, 68, 74, 221, 225

- Autobiographie 13, 36, 85, 129 f., 140, 200-205

- Autobiographie, fiktional 200-205, 207, 229-232
- autobiographisch 2, 33, 36, 58, 61, 68, 121, 186, 188, 199, 201 f., 204, 207, 216, 222, 229, 242

Brief(e) 13, 40-42, 51 f., 58, 61 f., 71, 109, 117, 151, 156, 158-161, 163-164, 170, 173, 177, 184, 187

Charakterisierung/characterization 14, 45, 122, 132-135, 140, 186f., 231

Cicero 7, 11, 39-55, 130, 188, 254

Devianz 8

David 23 f., 27 f., 129, 134

Epidaurus 208, 210

Epikureismus $232 \mathrm{f}$.

Erzähler, s. Narrator

Erzähltheorie, s. Narratologie

Ethnizität 222-226, 228, 230

eusebeia 137, 140

exemplum 110, 115

Exil/Exildichtung 11, 45-47, 51, 57-82, 92

fifth evangelist 122

Gattung 2, 4, 10, 19, 28-34, 36, 40 f., 44, 46, 48, 61, $63 \mathrm{f}$., 67, 69, 71, 79, $151 \mathrm{f}$., $167,177,182,184,186,188-190,195$

Galen 206, 209, 214, 216, 221, 228

Gedankensünde 192

Genre 1f., 7f., 11, 13, 21, 34, 58, 85, 88 f., 105, 139f., 200, 205, 207, 215, 225, 228-231, 234f., 241

Glykon 231, 234

Gottesknechtslied(er) $113 \mathrm{f}$.

\footnotetext{
* in Auswahl.
} 
Herodes d. Gr. 133, 135

Horaz 11, 57-60, 68-72, 75-80

impersonation 230-233

Individuierung 14, 36, 113

Innovation 8, 10 f., 23, 34, 135, 181, 223, 233, 235

Inschrift/inscription 210f., 229

Inspiration 59, 61, 64-66, 74, 76, 142, 267

Jerusalem 10, 20-22, 24, 28-30, 33 f., 37, $85,90 \mathrm{f} ., 94 \mathrm{f} ., 97,122-124,126,129$, 132, $137 \mathrm{f} ., 140,144,161 \mathrm{f} ., 171$

- Jerusalem Temple 94f., 97, 122 f., 126, 132, 137, 140, 144

Jesus ben Sira 2, 7 f., 10, 19-38,

Jesus Sirach, s. Jesus ben Sira

Jotapata 13, 121, 123, 141, 144

Josephus 7-13, 19, 36, 83-103, 121-150 239

Julius Apellas 207-210, $214 \mathrm{f}$.

Kanon 10, 35, 69, 74, 182

Kanonisierung/Selbstkanonisierung 2, 5 f., 11, 28, 33, 35, 69 f., 78, 80

(Christus-)Konformität 12, 107, 110, 115

Krankheit/illness 13f., 32, 199-219

leadership, s. Unternehmer

Lehrhaus 20f., 29-31, $33 \mathrm{f}$.

Leser(schaft)/reader(ship) $2 \mathrm{f} ., 9,11 \mathrm{f}$., $39 f ., 42,52,57,60-62,65,67,69-71$, 73, 77-80, 83 f., 86-90, 93-96, 100, $122 \mathrm{f} ., 129,131,137,142,144,152 \mathrm{f}$., 157 f., 162, 164-166, 171 f., 194 f., 202 f., 205, 213, 221 f., 224, 229, 230, 240 f., 243-245, 247, 251 f., 255, 262

Literaturgeschichte 2,9,26, 159

medical paradoxography 200, 207, 215

metanoia $191 \mathrm{f}$.

mimesis 3

Motivgeschichte 9

Musen 11, 57-82

Mythos, gnostischer

- Begriff 259-290

- Valentinianischer Mythos 259-267, 277, 281, 283, 286
Narrator/Erzähler 3, 7 f., 12-14, 61, 64, 66, 69, 87, 89, 93, 164 f., 181, 183, 186-190, 193-195, 221-225, 229-232, 234, 241

Narratologie/Erzähltheorie 9, 221, 229-231

Neues Testament 164, 176, 182, 185, 240, 254 f., 287

Numenios 259, 265-269, 272 f., 283 f., 287

Orakel/oracle 137-139, 141, 207, 213, 227, 255

- Orakelkult 223, 231

Orthonymität $8,13 \mathrm{f}$.

paideia 34, 222-224, 226f., 234

Paulus 7, 12, 26, 36, 105-120, 156, 163-170

performative turn 230

Pergamum 207, $210 \mathrm{f}$.

persona $10 \mathrm{f} ., 19,28,30,52,57,60-63,66$, 68, 73, 78 f., 95, 203, 221-223, 229-232, 234

patients 206f., 211, $214 \mathrm{f}$.

Philosophie 48, 52, 94, 100, 128, 227, 262, 265, 274-276, 279, 281, 286

Poesie 65

Priester/priest 12, 20, 25-27, 33, 36f., 85, 90, 121, 124, 126f., 140-144, 240, 246, 285

Prosa 4f.

Prophet(en) 26-28, 34 f., 108, 113 f., 138, 154, 157, 166, 183 f., 188, 223, 230-235

Polemik 262, 277, 286

Postkolonialismus 225

Pseudepigraphie 23, 165, 167

Pseudonymität 2, 184f., 189, 262

Psychologie 192

Reden 39-46, 52, 221

Religiosität 48, 51, 53, 223, 226-228

Rezeption 1f., 4-6, 8-10, 13, 15, 21, 33, 45, 108, 114, 190, 195, 224 f., 229 f., 259, 262, 276

Rezitation 6

Rhythmisierung $4 \mathrm{f}$.

Rolle(n) 1-17, 28, 30, 34, 58, 63-68, 105-112, 114-118, 155, 195, 231 f., 234 
Salomo 10, 19, 21, 23-25, 27 f., 31, 33 f., 36 Schriftlichkeit 187, 189

Selbststilisierung/self-fashioning 2, 5, 11-13, 19, 41, 59, 79, 84 f., 90, 92f., 96, 106-110, 115-117, 234

- author-fashioning $23 \mathrm{f}$., 27, 30

Septuaginta 10, 12, 20-23, 33, 35, $111 \mathrm{f}$., 185

Sklave 12, 107, 110-112, 115-118, 189

sphragis/literarisches Siegel 57, 68-70, 72

Sozialgeschichte 9

Syrien 224, 226

Textwachstum 187

Tempel des Asclepius 207

Theophilie/Gottesnähe 58f., 65-68, 71, $74 \mathrm{f} ., 77,79$

Traum 70, 176, 188
Übersetzung $8,10,20-22,33-35,153$, $182,221,224$

Unternehmer, religiöse/religious entrepreneurs/leadership 5, 7,112,132, $134 \mathrm{f}$.

vates $3 \mathrm{f} ., 58 \mathrm{f}$., $63-65,80$

Vision 13, 73, 155, 157, 159, $163 \mathrm{f} ., 171 \mathrm{f}$., 176, 183-190, $194 \mathrm{f}$.

Visionär $184,188 \mathrm{f}$.

Weisheitslehrer 10, 19, 23, 28-31, 37

Weisheitsliteratur 21, 24f., 34, 36

Wissen, religiöses 5, 41, 186

Zweite Sophistik 222-224, 234 